Competing Economies: America, Europe, and the Pacific Rim

October 1991

OTA-ITE-498

NTIS order \#PB92-115757

\title{
Competing Economies
}

AMERICA, EUROPE, AND THE PACIFIC RIM

\section{NTS}




\section{Recommended Citation:}

U.S. Congress, Office of Technology Assessment, Competing Economies: America, Europe, and the Pacific Rim, OTA-ITE-498 (Washington, DC: U.S. Government Printing Office, October 1991).

For sale by the U.S. Government Printing office

Superintendent of Documents, Mail Stop: SSOP, Washington, DC 20402-9328

ISBN $\quad 0-16 \quad-035933-3$ 


\section{In Appreciation}

\section{H. J OHN HEINZ III \\ 1938 to 1991}

The staff of the assessment on Technology, Innovation, and U.S. Trade dedicates this report to Senator John Heinz. Committed to solving the problems of American manufacturing and workers, Senator Heinz contributed to the legislative process an enthusiasm for new ideas and optimism that solutions could be found. He was a requestor of this study and one of the first in Congress to grapple with competitiveness issues. His sense of humor delighted those privileged to work with him, his sense of seriousness made him a strong champion of American manufacturing. 


\section{Foreword}

Despite macroeconomic adjustments and a lot of discussion, U.S. manufacturing is still in trouble. A test of national competitiveness is whether standards of living improve while world market share holds steady or increases. The United States is failing on both counts. Over the past two decades, the U.S. share of world imports has increased, its share of world exports has decreased, and imports have captured an increasing share of the U.S. market. At the same time, real incomes of the large majority of all Americans have declined.

Studies of specific industries also support the claim that American manufacturing is not keeping up with the competition, the Japanese in particular. While U.S. auto manufacturers have improved in productivity and quality, the Japanese still make more reliable vehicles at lower costs. Japanese computer manufacturers have made rapid progress: even in supercomputers, one of the most advanced sectors, three Japanese firms are now threatening to overtake the U.S. leaders.

Like Japan, Korea and Taiwan have mostly succeeded in promoting development of their economies in general and several advanced industries in particular. We can learn several lessons from these examples. First, the successful governments are partners with the private sector in developing particularly risky technologies and industries. Second, they combine many different policies-including, when necessary, limitations 'on foreign companies' competition in the domestic market. Third, they patiently persevere with development strategies, often for decades. Finally, they preserve important market disciplines, making sure that domestic companies competed with their most proficient rivals.

This report examines how the economic environment of the United States can be made more conducive to improving manufacturing performance. It considers how Federal institutions, in cooperation with industry, can develop competitiveness strategies for high-tech, fast growing industries; and how trade, financial, and technology policies could be combined into a strategic competitiveness policy.

This is the final report in a series of three in OTA's assessment of Technology, Innovation, and U.S. Trade. The first two reports, Paying the Bill: Manufacturing and America's Trade Deficit and Making Things Better: Competing in Manufacturing, concluded that there are many signs of weakness in American manufacturing technology and identified policy options to improve the ability of American manufacturers to develop and diffuse technology.

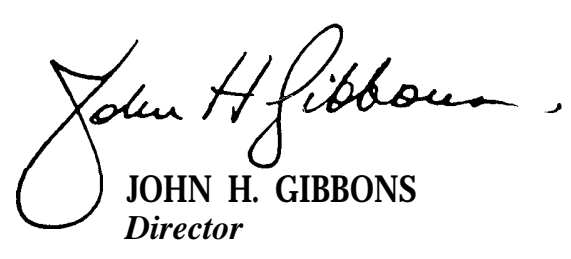




\title{
Advisory Panel-Technology, Innovation and U.S. Trade
}

\author{
Peter J. Sharfman, Chairman \\ Director of Policy Analysis \\ The MITRE Corp.
}

Alice Amsden

New School for Social Research

Economics Department

Marietta L. Baba

Professor of Anthropology and Acting Chair

Wayne State University

Wolfgang Demisch

Managing Director, Director of Research

UBS Securities

Jean-Jacques Duby

Group Director, Science and Technology

IBM - Europe

Paris LaDefense, France

Mark Eaton

Director, International and Associated Programs

Microelectronics \& Computer Technology Corp.

John T. Eby

Executive Director, Corporate Strategy

Ford Motor Co.

Larry French

Consultant

Glen S. Fukushima

Director, Public Policy and Business Development

AT\&T Japan Ltd.

Tokyo, Japan

Edward Graham

Research Fellow

Institute for International Economics

Joseph A. Greenwald

Attorney/Consultant

Howard Greis

President

Kinefac Corp.

Peter Hall

Professor of Government

Harvard University

\author{
F. William Hawley \\ Director, Governmental Relations for \\ International Affairs \\ Citicorp
}

Sanford Kane

President and CEO

PCO, Inc.

Robert Kuttner

Economics Correspondent

The New Republic

Alek A. Mikolajczak

Vice President, Technology and New Business

Rohr Industries

Susan Pharr

Professor of Government and Director, U.S.-Japan Relations Program

Harvard University

Margaret Sharp

Senior Research Fellow

Science Policy Research Unit

University of Sussex

East Sussex, England

Laura Tyson

Professor of Economics

University of California, Berkeley

John D. Warner

Vice President, Engineering

Boeing Commercial Airplane Group

Stephen Woolcock.

Fellow

Royal Institute for International Affairs

London, England

NOTE: OTA appreciates and is grateful for the valuable assistance and thoughtful critiques provided by the advisory panel members. The panel does not, however, necessarily approve, disapprove, or endorse this report. OTA assumes full responsibility for the report and the accuracy of its contents. 


\title{
OTA Project Staff-Competing Economies: America, Europe, and the Pacific Rim
}

Lionel S. Johns, Assistant Director, OTA

Energy, Materials, and International Security Division

Audrey B. Buyrn, Program Manager

Industry, Technology, and Employment Program

Julie Fox Gorte, Project Director

Katherine Gillman, Deputy Project Director

Robert Weissler, Senior Analyst

John Alic George Eberstadt Robin Gaster

Jeffrey B. Lewis Sebastian Remoy Robert Wade

Elizabeth Sheley, Editor

Administrative Staff

Carol A. Guntow, Office Administrator

Christopher N. Chuy, Office Administrator

Diane D. White, Administrative Secretary

\author{
Publishing Staff \\ Katie Boss, Publishing Officer \\ Cheryl Davis Dorinda Edmondson Denise Felix Steve Kettler ${ }^{2}$ \\ Chip Moore Christine Onrubia Susan Zimmerman
}

\section{Contractors}
Marie Anchordoguy
BSI Consulting, Inc.
Stephan Haggard
Keith Hayward
Hugo Letiche
Takashi Mashiko
Todd Watkins

James Womack and Daniel Jones

1Until June 1990.

2Until September 1991. 


\section{Contents}

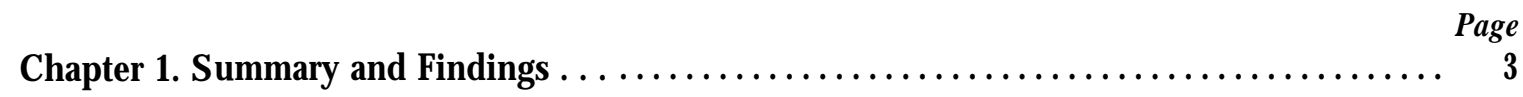

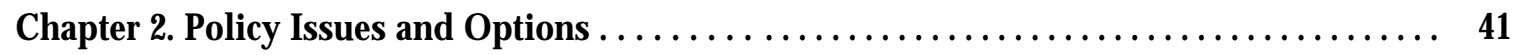

Chapter 3. American Firms, Foreign Firms: Contributions to the Nation $\ldots \ldots \ldots \ldots \ldots \ldots .85$

Chapter 4. U.S. Trade Policy ........................................ 117

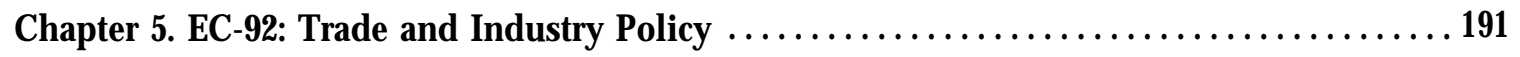

Chapter 6. Japanese Industrial Policy: The Postwar Record and the Case of Supercomputers . . 239

Chapter 7. The New Competitors: Industrial Strategies of Korea and Taiwan . . . . . . . 295

Chapter 8. Government Support of the Large Commercial Aircraft Industries of Japan, Europe, and the United States ............................. 341

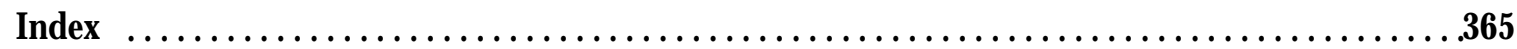


Chapter 1

Summary and Findings 


\section{CONTENTS}

THE COMPETITIVENESS PROBLEM ................................... Page

The Role of Competition: Are Free Markets Always Best? $\ldots \ldots \ldots \ldots \ldots \ldots \ldots \ldots, 3$

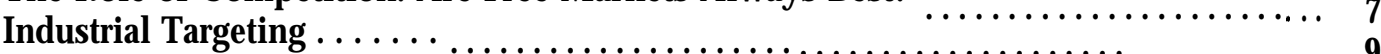

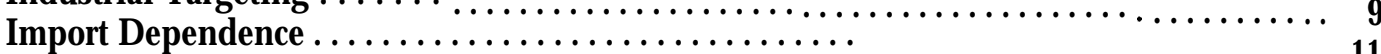

SUMMARY OF POLICY ISSUES AND OPTIONS $\ldots \ldots \ldots \ldots \ldots \ldots \ldots \ldots \ldots \ldots \ldots \ldots \ldots \ldots \ldots \ldots$

Institutions for a Strategic Competitiveness Policy $\ldots \ldots \ldots \ldots \ldots \ldots \ldots$

A Technology-Friendly Environment ..................................... 15

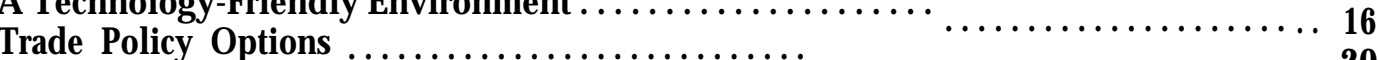

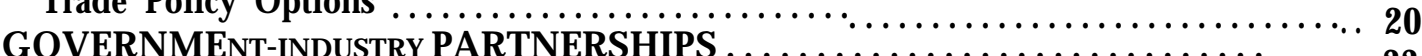

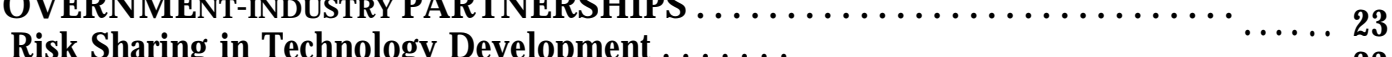

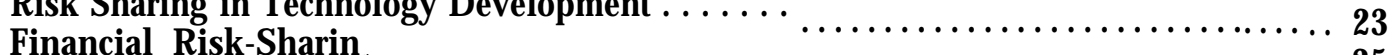

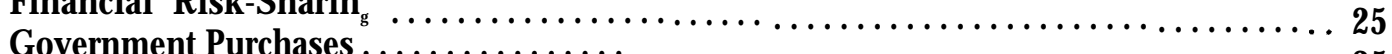

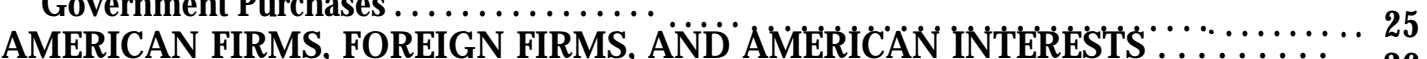

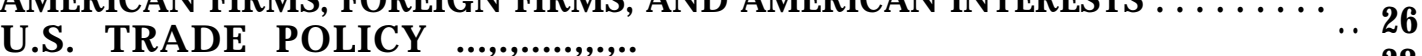

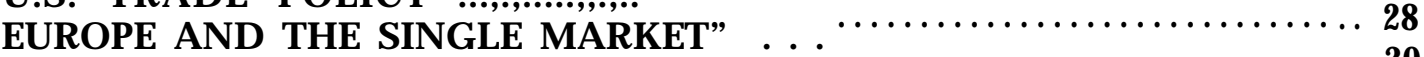

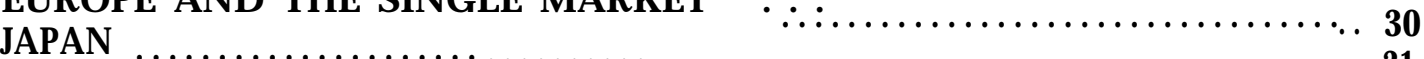

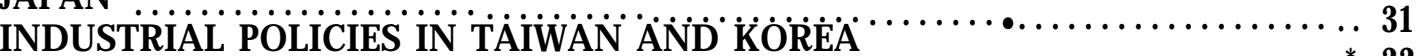

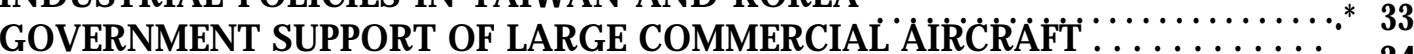

Figure

Figures

1-1. U.S. Imports as a Percent of GNP Page

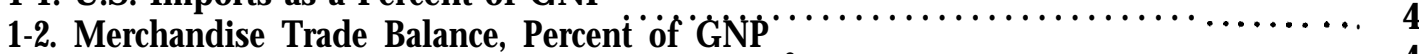

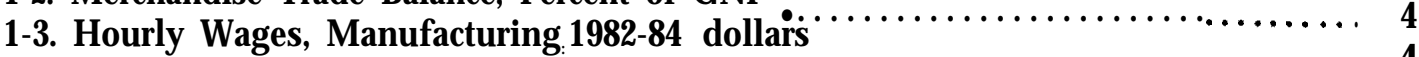

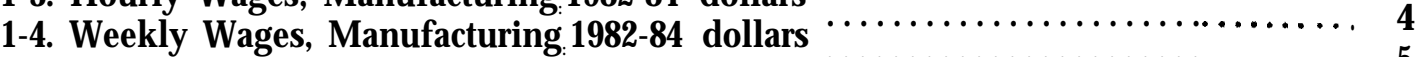

1-5. Weekly Wages and Salaries of Full-Time Employees, $1906 \dot{9}-900,1908 \dot{9}-\dot{8} \dot{4} \ldots \ldots \ldots 5$

1-6. Japanese Share of World Trade........

1-7. Imports as a Percent of GNP, Japan

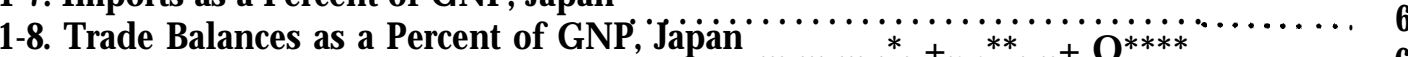

$\ldots . . . . .^{*}+.,,^{* *} \ldots+\mathrm{O}^{* * * *} \ldots \ldots \ldots, 6$

Table

Table

1-1. U.S. Share of World Imports and Exports 


\section{THE COMPETITIVENESS PROBLEM}

U.S. manufacturing is falling behind the competition. The standard of comparison is Japan; if Japanese companies were not such successful competitors in many important industries, America's competitiveness problem would be far smaller. Eventually, other East Asian nations like Korea and Taiwan probably will rival Japan as top international competitors, and the European Community is trying to improve its own competitiveness. But for now, it is Japanese industry that poses the most formidable challenge.

What is the evidence that American manufacturing has lost competitiveness? There is no widely accepted single measure of competitiveness. Analysts use many proxies: international trade balances, comparative international figures on productivity or standards of living, manufacturing's share of gross national product (GNP), and comparative studies of the performance of individual industries are common ones. However, examining U.S. performance piecemeal in a few of these areas does not give a consistent picture. So, despite growing acceptance of the notion that U.S. manufacturing is in competitive trouble, the debate persists.

A logical way to sort out the usefulness of these measures is to begin with a definition of competitiveness. One that stands out as being most useful is defined in the 1985 report of the President's Commission on Industrial Competitiveness:

Competitiveness is the degree to which a nation can, under free and fair market conditions, produce goods and services that meet the test of international markets while simultaneously maintaining or expanding the real incomes of its citizens.

There are two pertinent criteria here: meeting the test of international markets, and maintaining or expanding real incomes. Free and fair market conditions is a qualifier. We shall consider these items one by one.

The most obvious way to interpret "meeting the test of international markets" is in terms of world market share. There is no direct, single measure of U.S. manufactured goods as a share of global manufacturing output, but if we combine data on
U.S. shares of world imports and exports with figures on the proportion of U.S.-made goods in domestic consumption, the picture that emerges is unequivocal: the United States has lost world market share in merchandise. ${ }^{1}$ The U.S. share of world merchandise imports has climbed from less than 15 percent in 1968 to over 17 percent in 1988; its share of world merchandise exports has fallen from nearly 16 percent to less than 13 percent over the same period (table 1-1). ${ }^{2}$ At the same time, imports captured an increasing share of the U.S. domestic market, going from about 3 percent of GNP in 1960 to over 9 percent in 1989 (figures 1-1 and 1-2).

To be sure, it was natural and expected for the United States to lose market share as the world's developing and war-tom economies improved their performance. Sinking market share alone is not proof of failing competitiveness. Had Americans become better off in the process of producing a smaller share of world output and domestic consumption, competitiveness would not be the issue it is now.

If American manufacturing had stayed robustly competitive, we would expect to see the living standards of manufacturing workers increase. Instead, they have plummeted. Real hourly wages of manufacturing production workers peaked in 1978 at almost $\$ 9.50$ per hour; ${ }^{3}$ by 1990 , they had sunk to almost \$8.00, below the 1964 level (figure 1-3). Real weekly wages of manufacturing workers also

Table 1-1-U.S. Share of World Imports and Exports

\begin{tabular}{|c|c|}
\hline $\begin{array}{c}\text { Percent } \\
\text { of imports }\end{array}$ & $\begin{array}{l}\text { Percent } \\
\text { of exports }\end{array}$ \\
\hline $1970 \ldots \ldots$ & 13.8 \\
\hline $1973 \ldots \ldots$. . . . . . . . . . . 12.4 & 12.4 \\
\hline $1975 \ldots \ldots \ldots \ldots \ldots$ & 12.7 \\
\hline $1977 \ldots \ldots \ldots$ & 10.8 \\
\hline $1978 \ldots \ldots \ldots \ldots \ldots \ldots$ & 11.1 \\
\hline $1979 \ldots \ldots \ldots \ldots \ldots . \ldots \ldots$ & 11.1 \\
\hline $1980 \ldots \ldots \ldots \ldots$ & 11.1 \\
\hline $1981 \ldots \ldots . \ldots . \ldots$ & 11.9 \\
\hline $1982 \ldots \ldots \ldots \ldots \ldots$ & 11.6 \\
\hline 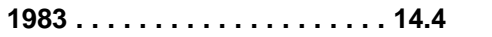 & 11.1 \\
\hline $1984 \ldots \ldots$. . . . . . . . . . 17.2 & 11.5 \\
\hline $1985 \ldots \ldots$ & 11.1 \\
\hline $1986 \ldots$. . . . . . . . . . . . . . & 10.3 \\
\hline
\end{tabular}

SOURCE: United Nations, Department of International and Social Affairs, 1985/86 Statistical Yearbook, 35th Issue (New York, NY: United Nations, 1988). 
Figure I-I —U.S. Imports as a Percent of GNP

Percent

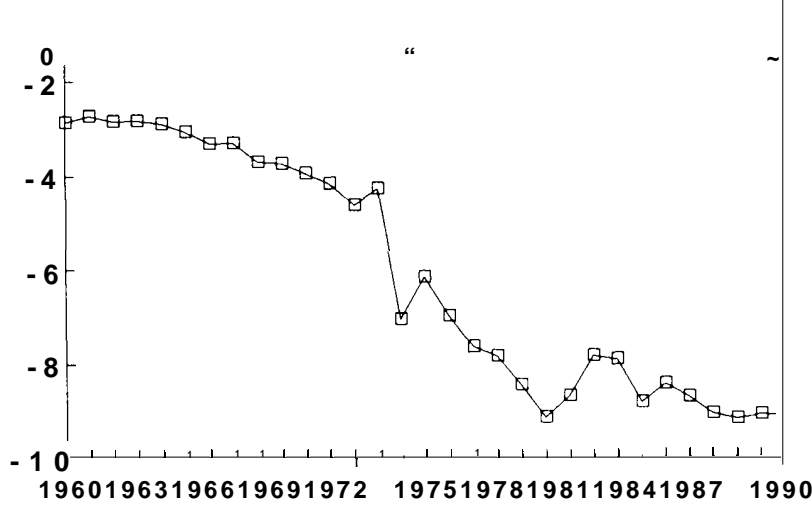

SOURCE: Economic Reporf of the President, (Washington, DC: U.S. Government Printing Office, February 1990), table C-1; and U.S. Department of Commerce, Bureau of Economic Analysis, "international Transactions," Survey of Current Business, June 1991.

Figure 1-2-Merchandise Trade Balance, Percent of GNP

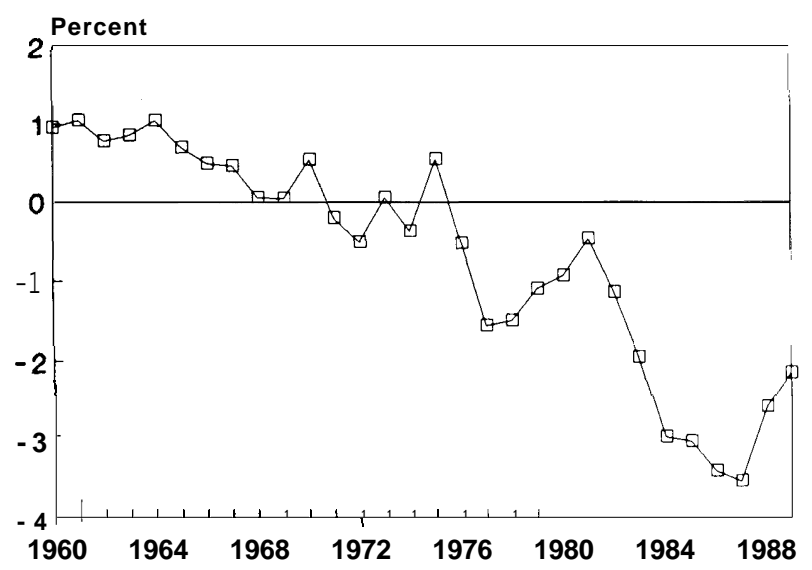

SOURCE: Economic Report of the President (Washington, DC: U.S. Government Printing Office, February 1990), table C-1; and U.S. Department of Commerce, Bureau of Economic Analysis, "International Transactions," Survey of Current Business, June 1991.

peaked in the late 1970s, but have since fallen to levels of the late sixties (figure 1-4). ${ }^{4}$ Looking more broadly at the workforce does not improve the picture. Real hourly and real weekly wages of all production and nonsupervisory workers--over 74 million people by the end of 1989, or 63 percent of the employed civilian workforce-have been sinking too. After peaking in 1972, real hourly wages dropped back to where they were in the mid-sixties, and real weekly wages declined much further. A still broader measure of living standards is wages and
Figure 1-3-Hourly Wages, Manufacturing: 1982-84 dollars

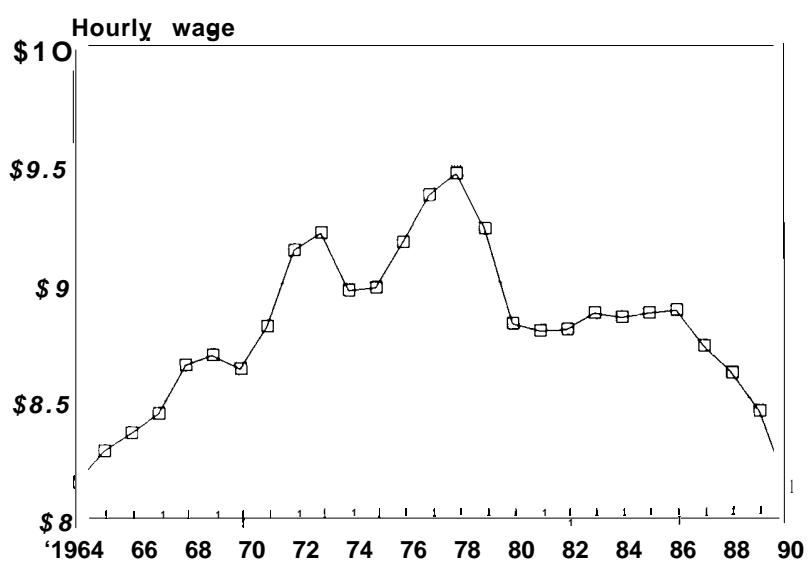

SOURCE: U.S. Department of Labor Statistics, Employment and Earnings, various issues.

salaries of all full-time workers (73 percent of the workforce). Here, too, are losses: real weekly wages were about $\$ 330$ in 1969, and below $\$ 320$ in 1990, and have been falling since 1987 (figure 1-5). In sum, the living standards of the large majority of all Americans have dropped.

So U.S. manufacturing fails the test of improving competitiveness on" two counts: decisively on meeting the test of international markets, and substantially on increasing standards of living. Have these happened under conditions of free and fair markets? Here, the evidence is not conclusive. While markets have grown more free over the postwar period in terms of the general level of tariffs and quotas, many analysts would argue that nontariff barriers have proliferated. Whether the overall effect is one of , increasing market openness, at least for a majority of our largest trading partners, is unproven.

There is another way of looking at this issue. The only explanation of U.S. losses of world market share in merchandise and losses of real income for the majority of Americans other than a drop in competitiveness would be a substantial, progressive closure of international markets. Furthermore, we would also have to make a case that abroad array of American industries needed access to other big markets (Canada, Japan, and Europe) in order to maintain competitiveness. While there are some products for which increasing returns to scale make efficient-sized enterprises too large for all but global markets, for example, large commercial aircraft and supercomputers, it is hard to argue that the U.S. 
Figure 1-4-Weekly Wages, Manufacturing: 1982-84 dollars

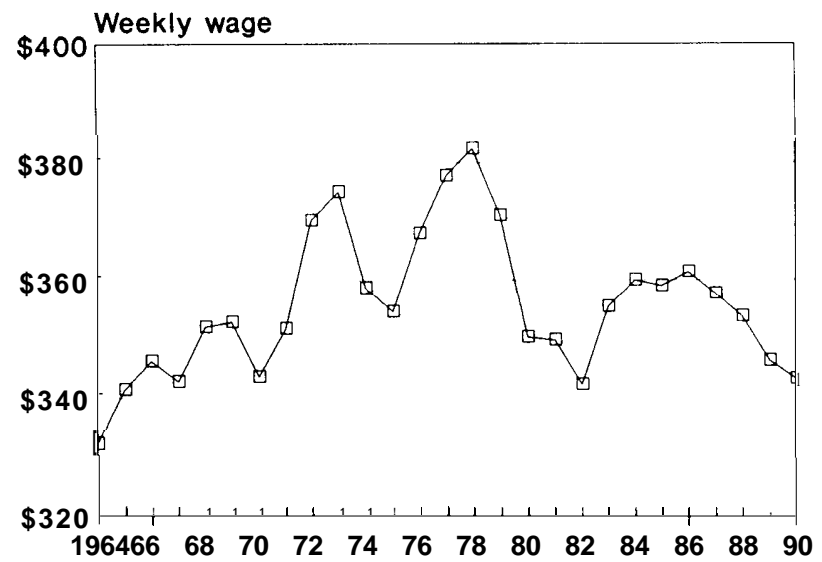

SOURCE: U.S. Department of Labor Statistics, Employment and Earnings, various issues.

Figure 1-5-Weekly Wages and Salaries of Full-Time Employees, 1969-90, 1982-84 dollars

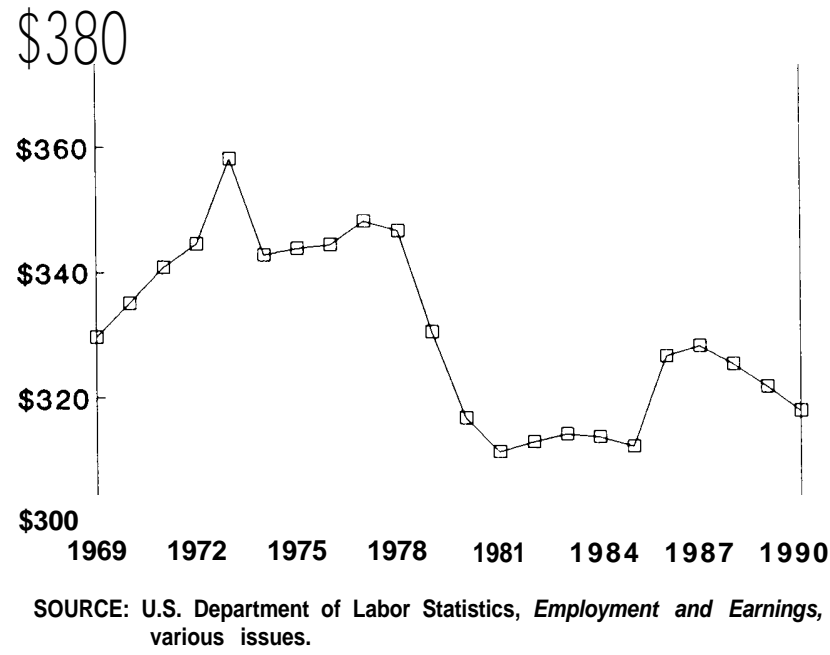

market is too small to support competitive industries in most of manufacturing. In view of what is known about decreasing formal trade barriers, the burden of proof is on anyone who would argue that market closure accounts for the drops in American world market share and standards of living since the 1970s.

This does not mean that every American industry is uncompetitive or is growing less competitive. In fact, competitiveness is best understood at the level of industries and even companies. What these figures tell us is that, at least in the most important sectors, U.S. companies are not holding their own against foreign competition. In particular, American industries are beleaguered by Japanese competitors.

Japan's record over the postwar period is in many ways a mirror image of America's. Japan's share of world exports increased 3 percent per year between 1968 and 1988, while its share of world imports increased 0.8 percent annually (figure 1-6). Japanese companies also held their own in their home market (figures 1-7 and 1-8).

At the same time, Japan has been able to sustain brisk growth in living standards compared with the rest of the developed world. Real gross domestic product (GDP) per capita rose an average of 6 percent per year between 1950 and 1989, faster than in any other developed nation (the United States averaged only 1.9 percent per year, and Western European countries between 2 and 3.5 percent). To be more accurate, Japan in the 1950s may have fit more into the category of developing than developed nation, and therefore had more potential for very rapid growth. But even after this development period, Japan's growth in real GDP per capita was higher than that of any other developed nation between 1979 and 1989 as well, averaging 3.5 percent per year, about double the rate of most European countries and the United States. ${ }^{\text {s }}$ Real earnings per employee in manufacturing increased 3.6 percent per year, on average, between 1968 and 1985 , and gross national income per capita went from 55 percent of U.S. levels in 1968 to 88 percent two decades later. ${ }^{6}$ While citizens in the United States still earn more and live better than citizens of Japan, most Americans are not becoming better off, and most Japanese are.

The complication in comparing the records of the two countries comes in the caveat "free and fair market conditions." Japan's market was anything but open in the early postwar decades. Due to a combination of business practices and government policies, it is still one of the world's most difficult markets to penetrate. Under these conditions, it is not surprising that Japan's companies did well in their domestic market, or conversely, that manufactured imports did so poorly. But while this lack of permeability kept Japan's people from consuming as much or living as well as they would have with the same income in the United States, it is also true that Japanese companies in many industries did meet the test of international competition in the more open 
Figure 1-8-Japanese Share of World Trade

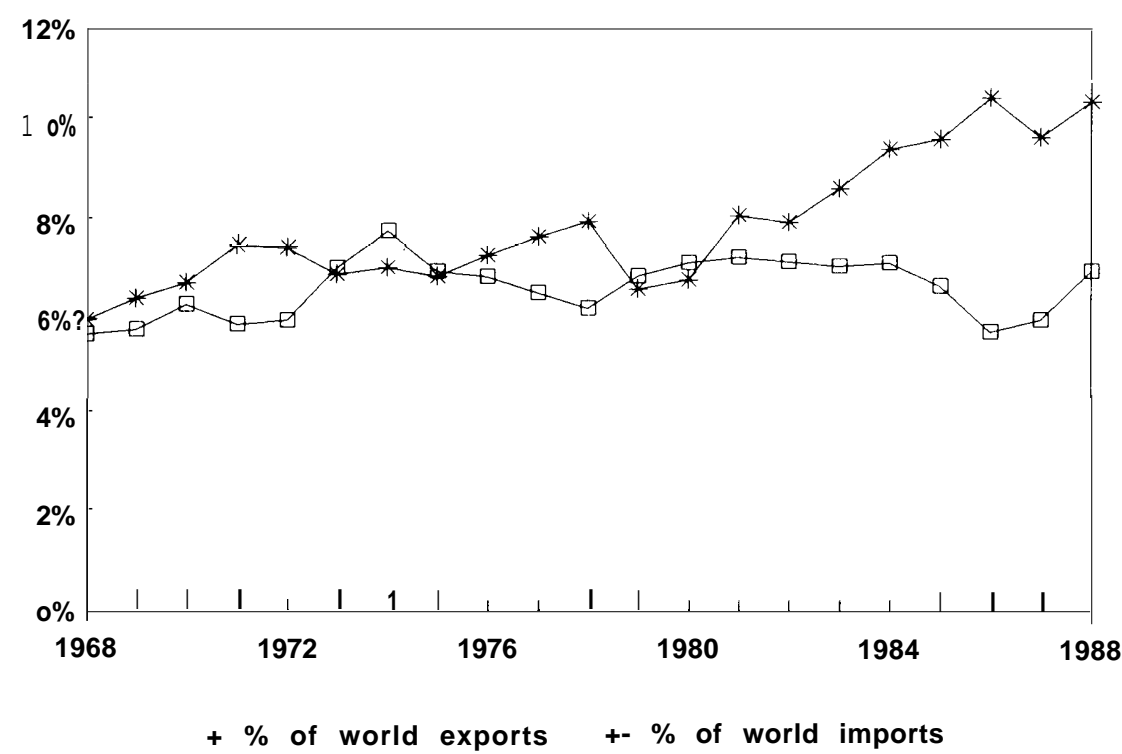

SOURCE: Economic Report of the President, (Washington, DC: U.S. Government Printing Office, February 1990), table C-1; and U.S. Department of Commerce, Bureau of E\&momic Analysis, "International Transactions," Survey of Current Business, June 1991.

Figure 1-7-imports as a Percent of GNP, Japan

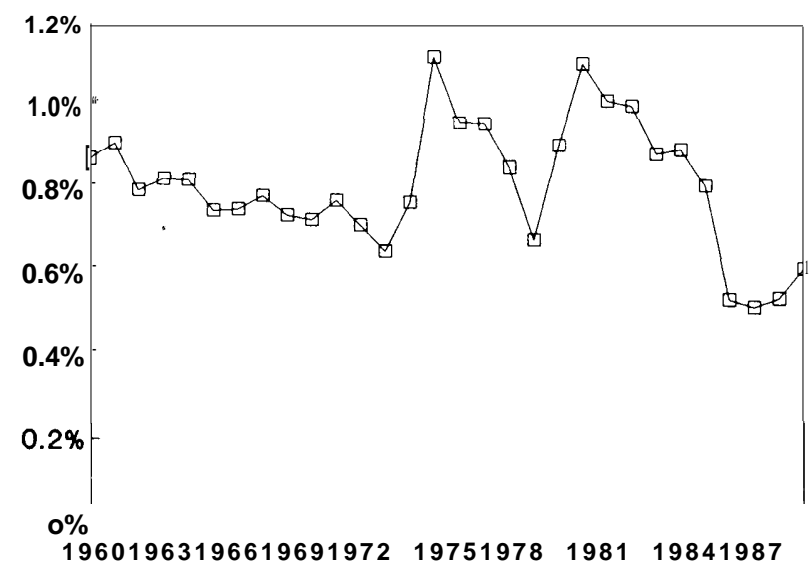

SOURCE: Organization for Economic Cooperation and Development, Department of Economics and Statistics, National Accounts, various issues.

markets of the United States, Canada, and Western Europe.

In fact, there are other conditions that affect competitive performance. Currency value is an important one. In the early 1980s, the high value of the dollar was widely held to be primarily responsible for the nation's plunge into deep trade deficits,
Figure 1-8-Trade Balance as a

Percent of GNP, Japan

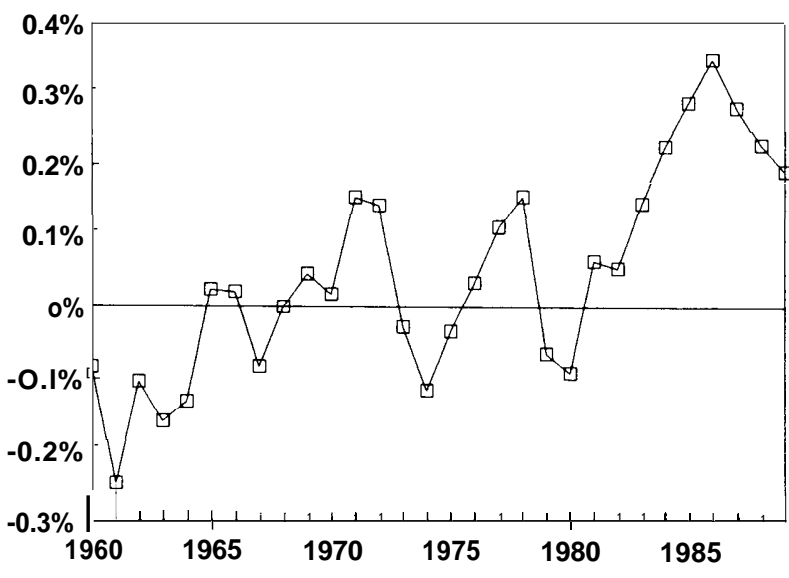

SOURCE: Organization for Economic Cooperation and Development Department of Economics and Statistics, NationalAccounts, various issues.

and conversely, the falling dollar in the late 1980s for the improvement in the trade accounts. But over the long run, adding currency value into the picture simply accentuates the difference in competitive performance of American and Japanese manufacturers; American manufactured goods have lost world market share in spite of the fact that the dollar has been on a long-term decline against a trade-weighted 
average of foreign currencies. Japan's manufacturers have increased their market shares even with a rising yen.

American manufacturers are aware of their competitiveness problems; many have made commendable efforts to improve their performance. But particularly in sectors that contribute heavily to employment, trade, knowledge, and income, there is still a gulf between Japanese and American company performance. In many cases, the gap is widening, driven by the fact that Japanese companies, flush with the profits of their market success, are investing more heavily in technological improvement and global expansion. If there are no major changes in government policies of developed nations, we expect U.S. manufacturing competitiveness to continue to sink, compared with Japan. There will be more emerging technologies in which the dominant power is Japan, not the United States, and established industries will remain behind the Japanese world leaders. This situation also faces producers in Western Europe, who are likewise behind the Japanese (and in some cases American) manufacturers in a variety of important sectors. The difference between the United States and Europe, at this point, is that European governments are taking an active role in trying to bolster their competitiveness, while the U.S. Government takes the position that the best aid to competitiveness is a free market.

\section{The Role of Competition: Are Free Markets Always Best?}

Market freedom is a relative thing. By the standards of economics, there is no free market in the world today, and there never was. There are, on the other hand, quite a number of economies whose markets are thought of as free because large segments of the economy are shaped at least as much by market forces as by policy and regulation. The United States likes to think of itself as one of the most free markets, and it probably is. That, plus the fact that the United States has been the dominant economic power of the world throughout the postwar period, is often taken as proof that the market is superior to government planning as the way to economic prosperity. The recent events in Eastern Europe, with the demonstrated failure of heavy state planning, are regarded as additional conflation.

In fact, both government and the market are, in the words of one eminent economist, instruments of social policy. They are different ways of arranging the activities of production and distribution in the economy; neither is clearly superior to the other. We do not really know what the economy would look like if markets were not limited and constrained in countless ways by government regulation, but one hypothesis is this:

The only industry that knows no bounds or rules is the illicit drug trade, where the market process resembles what Thomas Hobbes called the "Warre of Each Against. " He described life under those conditions as "Nasty, Brutish and Short. ${ }^{18}$

The miserable record of the command and control economies of Eastern Europe, compared with the record of the U.S. and Western European economies, does not imply wholesale superiority of market forces under all conditions. Most of the restraints the U.S. and other governments impose on markets exist because the market serves some interests (e.g., long-term values of society or provision of social goods like scientific knowledge, clean air, and safety) very poorly. If we examine the difference between the performance of Japan and the United States, it is appropriate to suspect that more competition is not always better.

The government of Japan has never been as sold on the tenets of neoclassical economics as the government of the United States. Japan and the fast developing East Asian economies of South Korea and Taiwan have restrained and shaped competition at various points in modern history and have benefited as a result. ${ }^{9}$ One of the most visible forms of restraint on free markets is the market protection that all three countries have used extensively to nurture infant industries and, in a few cases, to permit orderly rationalization of mature ones. ${ }^{10}$ Japan employs government intervention to harness, channel, or restrain the forces of competition. During the 1960s, the government coped with what it called "excessive competition" by organizing antirecession cartels and vigorous export campaigns, erecting barriers to foreign direct investment, and structuring the financial system to favor industrial investments (especially in targeted industries) over consumption. These measures were aimed at both restraining competition from more advanced foreign firms and restricting the cutthroat investment and price competition among Japanese firms. ${ }^{12}$ Starting in the 1980s, the government still reined in competitive forces, but with different 
measures (e.g., voluntary restraints on exports and bargains to increase foreign fins' access to the Japanese market) and for a different purpose: to soften foreign, often U. S., complaints of unfair competition. Although the forms and aims are new, the effect is still an interference with the workings of the market.

The Japanese Government has never trusted the market to achieve, by itself, large-scale investments for basic research in high technology, or to overcome the disadvantages of being behind.$^{13}$ In this, Japan is hardly alone. Few developing nations trust market signals alone to generate the investments and provide the resources necessary to improve industrial development and living standards. Korea and Taiwan, too, have altered market signals and outcomes significantly. Both share a commitment to long-term planning, industrial targeting, or strategic visions-forcing their firms to compete on world markets and nurturing them at home. Taiwan, while more open to foreign trade than Korea, and with less interventionist industrial policies, has relied more on public enterprises. Korea has been more protected from foreign competition, with the protection tied to export expansion. Both countries depend on government policies to promote an indigenous technology base. (See ch. 7 for discussion of the industrial policies of Korea and Taiwan.)

Japan, Korea, and Taiwan all developed exceptionally fast, with industrial policies that signifi cantly altered, but did not destroy, market signals. Protection of the domestic market and direct funding of $R \& D$ were forms of intervention, as were policies to steer low-cost capital, preferential access to foreign exchange, assistance in negotiations with foreign companies for access to technologies, and support of domestic technology development and implementation through a variety of fiscal incentives. At the same time, these governments were careful to maintain incentives that forced domestic firms to compete with the dominant foreigners, often in third markets or in the home markets of the foreign competitors. Market competition, in short, was viewed as having a proper place; it was superior to government planning in providing incentives to improve productivity and quality and reduce costs. But unbridled competition was not, and still is not, regarded as always yielding the best possible outcome for the nation.
The prevailing ideology in the United States is very different. We have accepted that market competition will not secure the outcome we want in some areas. For example, market incentives do not provide sufficient incentives to invest in as much $R \& D$ as would be optimal for the nation, nor do they provide incentives to preserve such public goods as clean air and water. But the United States views anything less than free trade as dangerous interference. This is consistent with the ideology of the great European powers when they were the highest value, lowest cost, most advanced producers of their day; it is nothing new for the prevailing economic view to coincide with commercial interests. 14 But the fit between the two, never perfect, is growing more uncomfortable as U.S. industries watch foreign competitors, usually Japanese, attain technological dominance in many important industries. More U.S. industries are finding themselves in the position of having to catch up, while learning that intelligent responses to market signals are insufficient to close the gap between them and the market leaders.

A case in point is capital cost. Throughout most of the postwar period, as a result of government control of financial markets, Japanese and German companies have enjoyed much lower capital costs for plant and equipment acquisition and R\&D than American fins. As a result, they have invested more in $R \& D$, plants, and equipment, and been more patient in recouping those investments. The responses have been especially strong in industries that demand high investments in R\&D and capital equipment. In Japan, special tax measures, such as accelerated depreciation, have sweetened the investment incentives in particular industries chosen by the government as strategic. As a result of these and other measures, Japanese firms invested more in technology development and adoption than American firms and have advanced faster and gained greater market shares. 15

What the Japanese Government, and more recently the Korean and Taiwanese Governments, has done is to use a combination of market signals and government planning to speed economic development and growth. At times, the interventions have backfired, but overall, the policies of the Japanese, Korean, and Taiwanese Governments have been essential to fast development. They are not the only contributors, as shown by the failure of similar government policies to lift dozens of other less 
developed countries out of poverty. What sets these East Asian nations apart?

Some of the answer, of course, is that they have relied heavily on market forces to shape the behavior and strategy of businesses. Many developing and some developed nations have erred in the direction of overprotection, and protected sectors have failed to become competitive with world leaders. The successes of the East Asian nations lie in their combination of import substitution and market protection with export promotion, which allowed domestic industries some potential for output growth and access to needed equipment and components while forcing them to compete with the best performers in the world. ${ }^{16}$ The governments were able to force or influence firms to conform with public policies through a variety of disciplinary measures. Firms that failed to improve export performance, for example, might have trouble getting the necessary permission and foreign exchange to import needed equipment.

Another part of the explanation is that the companies crafted intelligent, patient strategies for developing, producing, and marketing their products. Some of this strategic genius is attributable to government policies and some to good business strategies, but another part is sheer diligence; East Asian companies are famous for scouting and adopting the best of the strategies of other successful companies and countries. Policies and cultures that emphasized very high product quality and universal education also helped, as did ethics that valued hard work. Industrial policies were not the whole answer, but the path of development would have been slower and rockier without them.

\section{Industrial Targeting}

To Americans, industrial targeting is one of the most controversial aspects of industrial policy. The idea that some industries contribute more to national well-being and knowledge than others is not particularly contentious. It is other things in targeting that we fear. One is that government will not be rational in its choice of industries to support and that the process will end up being hijacked by special interests. Another objection is that the market is better suited than government to choose the industries that make disproportionately large contributions to national welfare.
Most developed nations and many developing ones do not share that faith in the market. The Japanese Government considers certain industries crucial to its economic health. Immediately after the war, policymakers felt that Japan should be strong in manufacturing iron and steel, ships, machinery, heavy electrical equipment, and chemicals. Later, the automobile, petrochemical, nuclear power, computer and semiconductor, and aircraft industries were added to the list. ${ }^{17}$ Though less so than in the 1950s and 1960s, Japan continues to provide particular benefits to targeted industries and the users of their outputs. ${ }^{18}$ Korea and Taiwan, too, selected industries for special support. In the 1950s, Korean industrial policy focused on import substitution in light manufacturing. In the late 1960s, emphasis shifted to steel and nonferrous metals, chemicals and petrochemicals, machinery, automobiles, and shipbuilding. Still later came emphasis on semiconductors, computers, and consumer electronics. The pattern in Taiwan was similar, emphasizing light manufacturing and import substitution in the first two postwar decades, shifting to heavy industries in the 1960s and later into more technology-intensive sectors. The tools and methods were different, but the selection of industries was similar.

Industrial targeting is not limited to developing countries. Most of the nations of the European Community (EC) have long had policies of supporting European producers of motor vehicles, telecommunications equipment, semiconductors, consumer electronics, and aircraft. While now discouraging support for national champions by individual countries, the EC's plans for the single market in 1992 and the Framework Program and EUREKA ${ }^{19}$ are aimed at developing technological and productive prowess in many of the same sectors. Electronics and telecommunications sectors receive greatest emphasis and heaviest support in European R\&D programs, while EC trade policies are being structured to cushion the European automakers' encounters with Japanese producers.

Even in the United States, which has mostly rejected the use of policies designed specifically to improve civilian industrial competitiveness, ${ }^{20}$ there are a few examples of industrial support for nonmilitary purposes. One of the most prominent is the National Aeronautics and Space Administration (NASA), which has, as part of its mission, the responsibility of improving aircraft technology .21 NASA's Aeronautics Program budget in 1991 was 
almost $\$ 920$ million; $^{22}$ in 1992 , the budget is expected to exceed $\$ 1$ billion. ${ }^{23}$ Though this is partly intended to support military technologies, NASA officials state that 90 percent of the technology developed is common to both military and civilian needs.

That industrial targeting exists is not a question. But can the U.S. Government select the right industries for support? To detractors, the idea of "picking winners" is dangerous because it opens the possibility that any industry could be selected if it had a powerful enough lobby. Another potential drawback is the argument raised by many economists, that industrial supports could skew investment incentives and create excess capacity, and thus increase vulnerability to business cycles in targeted industries. This, in turn, could make additional protective measures necessary-beginning a cycle of ever-widening support, at increasing cost to taxpayers and diminishing benefit to consumers. These are real problems and should be taken seriously, but they are not the inevitable outcome of any exercise in supporting the competitiveness of critical industries. Japan, Korea, and Taiwan have had some problems resulting from their support of targeted industries, but their overall economic performance-and, with few exceptions, the performance of the targeted sectors-has been better than that of the United States. Some argue that the success of these economies, and of targeted industries, is more coincidental with industrial policy than causally related. But after weighing the evidence, OTA concludes that the industrial policies of these East Asian countries is crucial in their economic performance.

Japanese industrial policy aimed at changing Japan's industrial structure from one characterized by labor-intensive industries immediately after the war to one dominated by capital-intensive industries in the 1950s and 1960s, and from that to one led by knowledge-intensive industries from the 1970s to the present. At each stage of policy formulation, industries selected for special support were those that made disproportionately large contributions to national well-being. ${ }^{24}$ They had high growth prospects, higher wages, and the possibility of higher profits, with more positive spillovers to other sectors in terms of contributions to technology and knowledge. In some cases, the spillovers were downstream: microelectronics and computers add to the technology intensity and productivity of industries that employ them. In the case of automobiles, primarily a consumer product, the contributions to other industries came primarily upstream, in the machinery industry.

The idea that certain sectors can be identified as incubators of larger economic change is gaining currency in the United States as well. An economy with strength in these industries will have higher wages, faster growth, and better developed processes of generating, diffusing, and using new technology than economies that do not. It is no coincidence that many of these industries-e. g., semiconductors, computers, telecommunications equipment, aircraft and spacecraft, and advanced materialsalso present formidable barriers to entry. Capital requirements for efficient production are often quite high, and the requisite knowledge of science, technology, and production is even more forbidding. If government can help potential entrants overcome entry barriers, the whole economy can be put on a path of faster growth and higher incomes.

With most of the governments of large developed economies providing some kind of support for critical industries, the market signals American firms get for these same industries often point in the opposite direction--down. In many critical, hightechnology sectors, American firms are facing competitors whose business risks are shared by their governments (and thereby, the taxpayers of their home nations). Faced with the necessity of assuming most of the risks and costs of entering or even maintaining operations under such conditions, some eventually abandon operations, as have many American manufacturers of memory chips.

Can the U.S. Government afford to be indifferent to the mix of industrial goods produced here? It would be dangerous, and in many ways unprecedented, to adopt this course. While we have let a few industries, such as consumer electronics, wither in the face of superior foreign competition, the government has stepped in many times to support industries that served various economic needs, including employment (the Chrysler bailout), technology development (aircraft in the 1920s and 1930s), and national/economic security (semiconductors). This is not meant to imply that every effort to develop or support an industry has been successful; every country that has tried industrial support has made some errors. In many developing nations, the whole enterprise of supporting industrial development has 
been disastrous; government planning cannot replace the market and the forces of competition. But the signals the market sends to American firms in the majority of high-technology, economically critical industries are not promising if we want those industries to thrive financially and technologically. It is equally dangerous to trust ad hoc, often crisis-motivated, efforts to intervene in industrial structure and performance and expect the results to make consistently positive contributions to economic well-being.

\section{Import Dependence}

One of the biggest problems in sorting out how to treat critical industries in public policy is choosing among them. All nations do not have to, and indeed, cannot, be competitive in all high-technology industries or critical sectors, if only because some, such as aircraft, will not support more than a few competitors without massive government assistance. Moreover, there are many sectors regarded as critical, and self-sufficiency in all of them may be beyond the means of any single nation, or it might spread available resources for support too thinly to have an impact. Finally, and most importantly, selfsufficiency by-passes the benefits of specialization and trade.

It should do a nation no harm to import certain critical products and export others. This is how Germany manages, and the Germans have the highest standards of living and most competitive manufacturing in Europe. Manufactured imports accounted for 14.4 percent of German GDP in 1987, and for nearly 45 percent of German manufacturing GDP. In the United States, manufactured imports were 7.3 percent of GDP and 37.8 percent of manufacturing GDP; corresponding figures for Japan (which is an outlier among both industrialized and industrializing nations) are 2.4 and 8.3 percent. ${ }^{25}$

This kind of evidence often leads some to question why the United States should care about depending on foreign manufacturers, even for key inputs. In fact, competitiveness might be improved as a result; computer manufacturers could be more competitive if they have access to low-cost foreign semiconductors than if they have to pay higher prices for domestically made ones. Certainly, after the 1986 Semiconductor Trade Agreement (STA) with Japan resulted in (though did not necessarily cause) high prices for 256K DRAMs, American computer makers suffered declines in profitability, and Japanese computer makers improved market positions and profits. ${ }^{26}$ In fact, the fallout of the STA is often used to support the argument that trade protection hurts more than it helps. Whether that is true, even in the one case of the STA, is disputed.

The STA was signed after several years of mounting disputes with Japan over the fairness of their trade in semiconductors. ${ }^{27}$ American producers alleged that Japanese semiconductors were dumped, both in the United States and in third country markets, and that American semiconductor chips were unfairly excluded from Japanese markets. After formal investigation, the International Trade Administration found that dumping charges were substantiated. The STA stipulated that both practices (dumping and exclusion) should stop. ${ }^{28}$ American officials apparently hoped for substantial cutbacks in Japanese production as a means to raise prices of Japanese semiconductors, thus ending the dumping. Shortly after the STA was signed, MITI (the Japanese Ministry of International Trade and Industry) took to issuing "forecasts" of chip production that were widely interpreted, here and in Japan, as administrative guidance to cut production. The companies, however, were initially unresponsive, and the U.S. Government announced sanctions in early 1987.

Others dispute that the STA caused Japanese producers to raise prices. 29 According to the counter argument, joint action by Japanese producers was underway for at least a year before the STA was concluded, and had begun before the STA was even a topic of discussion. The collapse of DRAM prices in 1984-85 that precipitated the withdrawal of many non-Japanese producers from the market also cost Japanese producers billions of dollars. By late 1985, the market was dominated by Japanese producers. Newspaper accounts about Japanese companies taking joint action to raise DRAM prices began to appear in 1985, as did rumors of meetings of Japanese producers aimed at addressing "the price disaster." These stories and rumors are made more believable by the many instances of coordinated Japanese industry/government management of prices and production that occurred in other industries (e.g., iron and steel) in the past.

Both sides of the story agree on one point: that MITI's forecasts and guideposts are used as targets for production and/or prices. The difference arises 
over whether the production cutbacks and price increases, which both sides agree were deliberate, were a result of the STA. Without a formal investigation, the dispute will likely remain unresolved.

Whether or not U.S. sanctions were an important cause, the fact remains that by early 1988 prices of Japanese DRAM chips rose, and production fell, a sharp break with past price behavior. While MITI denies any official guidance, its continued quarterly forecasts and their pinpoint accuracy strongly suggest to some analysts that MITI was controlling production and, possibly more significantly, investment in new facilities. Ordinarily, sustained high profits brought on by elevated prices would be expected to generate a wave of investment in new capacity, which, as of mid-1989, had not materialized, in contrast to the past and contrary to what analysts expected.

Some of the restraint in investment in new capacity was attributed to quiet guidance by MITI, and some to a new "spirit of cooperation' among the Japanese DRAM manufacturers. Both can be attributed in part to fears of reigniting trade disputes with the United States, but there was something else at work, too. The Japanese producers, probably with MITI's encouragement, had begun to act like a cartel, controlling output and prices and reaping higher profits as a result. While that was a predictable outcome of the U.S.-initiated STA and accompanying sanctions, it is one of the more ominous developments on the trade scene, and it symbolizes one of the things most feared about dependence on foreign suppliers. When suppliers act collusively to manipulate production and prices, everyone else is stuck paying higher prices. If the products of the cartels are inputs to key industries, whole economies can suffer. No nation is more aware of this than Japan, which suffered a severe economic downturn after the first oil shock in 1974.

But how much real danger is there? Cartels that can effectively manipulate supplies and prices globally are not very common. It is tempting to think that if we don't meddle with free trade we won't have a problem. But this is probably wishful thinking. Japan maintains several legal cartels, and while the number is diminishing the practice is familiar. Moreover, the historical links between the semiconductor companies and the Japanese Government mean that under ordinary circumstances they share a degree of knowledge of each other's plans and behavior that would be considered extraordinary, probably collusive, in the United States. Even without the prodding of the STA, it is conceivable that Japanese companies might have begun to exercise restraint over production and prices. Two pieces of evidence support the notion that these producers were amenable to such restraints. One is the fact that similar price rises did not occur in EPROMs (erasable programmable read-only memories), another semiconductor product covered in the STA. Unlike the situation in DRAMs, production of EPROMs was not dominated by a few Japanese companies. Another is the difference in the degree of compliance with STA in two areas: dumping and foreign companies' share of the Japanese market. Cutbacks in production resulted in price increases that eliminated dumping in fairly short order, while the share of foreign semiconductors in Japan's market has increased much more slowly than originally called for. ${ }^{30}$ It took much less time and effort to arrange production cutbacks, which resulted in higher profits for Japanese companies, than increased market share for foreign companies, which gave Japanese companies no particular benefits.

Another problem created by dependence on one or a few suppliers for critical components is access to the latest technologies. Again, under the conditions of competition envisioned in economics, a supplier of critical components would be foolish to deny the most advanced products to any customer, since a competitor is always ready to do it. For example, the world's industrial producers of textiles depend on machinery from a handful of suppliers in a few countries-Germany, Switzerland, Japan, Italy, and Sweden account for most of it. Yet textile manufacturers are routinely able to get the most advanced equipment from any supplier; textile makers in the countries that manufacture textile production equipment have no particular advantage. The story is different in electronics.

American and European systems makers, or policymakers speaking on their behalf, are concerned that it may be difficult to get the most advanced production equipment or chips from Japanese vendors. In most cases, those Japanese vendors are also systems makers, or else they have close ties through the keiretsu $u^{31}$ system with a Japanese systems maker. It is a logical, and probably not uncommon, business practice to reserve access to the latest technologies to users within the develop- 
ing firm or to special customers. According to anecdotes, when IBM and Perkin-Elmer had a special relationship, IBM got first access to new machinery developed by Perkin-Elmer. While no blame attaches to Japanese companies that give themselves or their closest customers first crack at new generations of technology, the competitive advantage it confers on Japanese firms can be significant in the fast-moving electronics industry.

Dependence on imports, particularly when those imports come from only a few suppliers, and particularly when those suppliers are also competitors, can create vulnerabilities that nations sometimes choose to avoid. Four European countries, for example, continue to provide financial support to Airbus in part because they do not wish to depend on two American companies, Boeing and McDonnell Douglas, for all large commercial jet transports. While Airbus is a financial drain on its government sponsors, it has forced the American producers to compete on price to a greater extent. Probably the foremost example of unwillingness to rely on foreign suppliers is Japan, which has a long tradition of limiting dependence on imports to a practical minimum. ${ }^{32}$ While Japan is criticized for its peculiarly strong aversion to imports, and is slowly changing, many of Japan's premier industries probably would not have developed, or would have developed far more slowly, had it permitted much greater imports and investment when Japanese industries were catching up. Now, with an increasing number of American industries in the position of latecomer, the vulnerabilities created by import dependence have assumed more importance.

\section{SUMMARY OF POLICY ISSUES AND OPTIONS}

The idea that troubled American manufacturing industries could use help from their government is gaining acceptance. Although the form such aid should take is not a settled question, the areas of agreement are widening. Agreement embraces more than the traditional areas for government action: macroeconomic policies that create stability and lower the Federal deficit, and human resource policies that produce the well-educated and welltrained workforce that American industry needs. Beyond this, a consensus is forming for more focused government policies to help industry develop and adopt technologies that can boost the competitiveness of U.S. manufacturing. Among these are policies to diffuse technologies throughout manufacturing, as with, for example, governmentfunded technology extension services.

The area of agreement is expanding to include R\&D partnerships between government and industry to develop high-risk technologies of generic commercial interest. Congress created a small program of this sort in 1988, the Advanced Technology Program in the Department of Commerce, and first funded it in 1990. The Program has now gained the backing of the Bush administration. More generally, the President's 1992 Budget endorsed government support for "generic or enabling technologies at the pre-competitive stage of R\&D." It said: "The Administration believes that appropriate Federal investments in applied civilian R\&D can result in high payoff to the economy. . . ${ }^{133}$

Helpful as all these policies can be in restoring U.S. competitiveness, in some critical cases they are not enough. Certain industries characterized by expanding markets, good jobs, increasing returns to scale, and technological spillovers to other industries are so essential to the Nation's economic growth that standards of living will suffer without them. Computers and electronic components are the clearest example. Important parts of these U.S. industries are in trouble, and it is doubtful that they can regain their competitive edge without much more substantial technology assistance than that provided by Sematech. Japanese firms are so large, so adept, and so dominant that, without trade technology, manpower, and other policy help from the U.S. Government, the U.S. electronics industry probably will continue to decline in comparison. The help from the STA was on an ad hoc basis that did not signal to the industry any sustained government commitment to the industry, and therefore it did little to encourage investment in technological improvement.

While there may be times when trade policy is a necessary complement to other policies to improve competitiveness, it is emphatically not a stand-alone fix. By itself, trade policy will do little to restore competitiveness and can have deleterious effects on downstream producers and consumers. It is much more likely that policies to encourage technology development and diffusion will be helpful, even without relief from foreign competition, than that trade policy alone will improve competitiveness. 
An approach that combines trade policy with technology assistance, and sometimes financial assistance as well, in support of critical commercial industries could be proactive and planned to avoid pitfalls. Any trade protection involved could be framed in a frank and self-respecting way as guarding important American national interests, rather than based on findings of unfair trade by others (as is now the case with most U.S. trade protection). This would skirt three problems that bedevil current U.S. trade policy. First, it is difficult and time-consuming to make charges of unfair trade stick. Second, unfair trade is often only a minor reason for a U.S. industry's decline, secondary to the ability of foreign firms (often aided by industrial policies) to lower production costs, acquire new technologies, and make genuinely superior products at a good price. Finally, whatever the mix of causes, the moralizing tone in our present trade policy is an irritant to our trading partners, and sometimes makes it harder to find reasonable solutions to trade disputes.

The difficulties of creating a coherent government strategy for supporting critical commercial industries should not be underrated. There is merit in the argument that our form of government is open to capture by special interests, so that the chances of getting rational, disinterested government decisions on industry support are slim. Experience suggests, however, that a contrary argument also has merit. The United States does employ some trade protection and does sometimes subsidize certain economic sectors (e.g., farm price supports). These departures from our free trade and free market philosophy are often politically motivated. It is possible that a coherent strategy to select a few industries for their contribution to the national good and support them with a tailored mix of technology, financial, and trade assistance would result in more rational exceptions to a general rule of free trade.

A related problem is that the U.S. Government does not have the experience or institutional capacity to operate a strategic industry and trade policy. Ideally, we would need an institution capable of identifying critical industries, analyzing their needs, and planning measures to fit the needs while taking care to keep the government support modest, make industry a full partner, and foster competition among firms within the critical industries. A tall order, and one that could only be filled over time. The rule would be to start small, gradually building expertise and a spirit of mutual trust with industry.

Another condition for a strategy in support of critical commercial industries is commitment from both Congress and the Administration, backed by wholehearted support from the American people. Congress has taken the lead in recent years toward giving some support to critical industries (e.g., in creating and funding Sematech and the Advanced Technology Program). The Administration also now supports a government role in developing generic technologies of commercial interest. It is hard to imagine, however, that Congress could unilaterally create broader industry and trade policies in support of critical industries and the institutions to carry them out. For the policies to work, both branches of government must be committed to them, and that commitment must rest on the understanding and support of the American people. There would have to be widespread comprehension that U.S. economic security is at risk, agreement that governmentindustry partnerships for improved competitiveness can pay off, and acceptance that short-term costs are worth paying in return for long-term gains in restoring excellence to U.S. manufacturing.

While the obstacles to crafting an effective strategy to support competitiveness are great, so are the payoffs. Improved competitiveness can come only from improvements in productivity and technology; these, in turn, can support higher standards of living for most Americans. This not only gives individuals more choices and comfort in their own lives, it also increases U.S. resources to do things that only rich nations are equipped to do: fight poverty and illness here and abroad, protect environmental amenities, expand the frontiers of science.

The policy issues and options discussed below include:

- building new institutions to plan and implement a government strategy in support of critical commercial industries,

- fostering a supportive environment for technology development and adoption,

- altering trade policies so they are more effective and more attuned to competitiveness needs, and

- forming government-industry partnerships for technology development and low-cost production. 


\section{Institutions for a Strategic Competitiveness Policy}

\section{Actions and Policy Tools}

A necessary first task for a government agency or commission given responsibility for industry and trade strategies is to identify the critical commercial industries that will be the focus of policy attention. This selection does not mean that other industry will be ignored; an economic and policy environment that supports industrial advance across the board is also necessary. But the concept of a critical industries policy is that some industries contribute more to continued technological advances and rising prosperity than others.

Most advanced countries do lend policy support to certain industries, and the criteria for selection are generally the same; they favor industries that are knowledge intensive (with a high proportion of technical workers and high R\&D), that have good prospects for growing markets, and that are built on versatile core technologies with spillovers to other industries. Another principle arguing for government involvement is high barriers to entry arising from exceptional capital costs, large economies of scale, and a steep learning curve, so that late entrants are at a great disadvantage. These principles usually lead to selection of much the same industries, including electronic components, computers and software, communication equipment, precision machining equipment, advanced materials, robotics, biotechnology, and aerospace.

Governmental and private bodies in several countries have made lists of emerging technologies, around which new critical industries (or advanced versions of existing industries) might coalesce. These lists too have many similarities-including the assessment that the United States will lag behind its major competitors, especially Japan, if current trends continue. ${ }^{34}$

The specific policy tools available to the agency cover trade, technology, and financial areas, and are discussed below. Its overall responsibility would be coherence and coordination. It could be given the duty not only to develop critical industry strategies but also to champion them throughout government, reminding and urging other agencies to give critical industries priority in their decisionmaking. Congress might wish to emphasize this function by requiring Federal agencies to prepare a "competi- tiveness impact evaluation" before taking major actions affecting critical industries. The extra paperwork involved could be well worth its cost if it served as a constant reminder of the potential impact of government policies on industrial competitiveness.

Finally, interaction with industry is a must. A government agency with strategic trade and industry responsibilities should have some independent knowledge and goals, but it must also work in alliance with industry-which would be expected not only to help shape the strategic plans, but also to put up at least half the funds in any venture where the government provides financial backing.

\section{Alternative Institutions}

Institutions that might develop and implement government policies to support critical commercial industries could take several forms. A certain amount of restructuring and reorganizing of current Federal functions would help. But it takes a lead agency to plan and carry out a coherent strategy in which high reward industries are selected for particular attention and in which elements of technology, trade, and financial policies are combined as needed.

Industry-specific advisory committees, established by Congress, might be one way to begin. There is a precedent for this. In the 1988 trade act, Congress created the National Advisory Committee on Semiconductors (NACS), made up of industry and Federal Government leaders, to devise a strategy for strengthening the U.S. semiconductor industry. The Committee has issued two interim reports and will publish a final one by the end of 1991, laying out a comprehensive strategy. This is just a frost step, however. No agency has responsibility for coordinating and carrying out the NACS-recommended strategy, and there is certainly no guarantee that it will do more than gather dust.

An existing agency with the potential for combining strategy development with action is the Competitiveness Policy Council, created by Congress in 1988 and launched in $1991 .{ }^{35}$ With members appointed both by the President and by leaders from both parties and both Houses of Congress, the Council is structured to take a bipartisan approach that could be effective. However, it would need broader powers and a longer life than it has now. Its present duties are only to develop recommendations for greater competitiveness, and unless continued by 
Congress, it will go out of existence in 1992. It might be turned into a commission, given at least a 5-year life, and directed explicitly to identify critical commercial industries and strategies to support them. It would also have to be given some power to implement the strategies if it is to have a real impact.

Another possibility is to lodge the responsibility for industrial strategies and trade policy in a small office in the executive branch, possibly in the Executive Office of the President. That location would be a good position from which to remind and encourage other agencies to consider effects on competitiveness in all their major decisions. This could only work, however, if the office is seen as truly competent and well-informed, with close interaction with industry and a staff of exceptional people. And it could have little effect on other government agencies unless it had strong Presidential backing. Major government reorganization is not required, but it could help. If Congress wishes to adopt a more proactive approach to trade and competitiveness issues, a reorganization could produce more focused policymaking and more direct lines of authority. In trade matters, for example, the U.S. Trade Representative (USTR) is charged with coordinating all relevant government agencies to formulate trade policy, and then with negotiating from that position. However, the USTR's own staff is thin and lacks continuity; it can do little more than concentrate on current issues. Yet responsibility for a durable, strategic approach to trade policies that guard basic American interests is lodged there. Much the same is true of policies that influence industrial competitiveness. The absence of a strong voice in government for international competitiveness just about guarantees that other objectives (e.g., foreign policy, national security) will win in a dispute.

Several bills in Congress have proposed a reorganization to focus Federal trade and competitiveness policy functions. Some would establish a Department of International Trade and Industry, assuming many of the functions of the Department of Commerce and the USTR. ${ }^{36}$ Some concentrate on trade; they would set up a department that consolidates USTR and the trade policy units from several departments and would establish a Cabinet committee to coordinate international economic policy. Others focus on technology and industry. There have been several bills to create a Department of Industry and Technology, expanding the Commerce Depart- ment's export promotion authority and creating a Civilian Technology Agency (CTA); ${ }^{37}$ some of these bills would also create an independent U.S. Trade Administration, consolidating the USTR and the Commerce Department's trade agencies.

Whatever bureaucratic arrangement is chosen matters less than the substance of the strategic policies and the commitment of both the Admin'stration and Congress. No arrangement will solve all coordination problems; there are always competing government objectives related to trade and industrial competitiveness. And no arrangement will create a U.S. equivalent of Japan's powerhouse Ministry of International Trade and Industry. What it could do is make possible a modest start in pulling together policy strands that would promote critical industries and our national economic welfare.

\section{A Technology-Friendly Environment}

Some of the most important options to help critical commercial industries perform better could also improve the competitiveness of all American industry, across the board. These are options to create a hospitable environment for the development and adoption of new technologies generally, throughout manufacturing, and they merit close consideration whether or not more targeted efforts are undertaken to nurture particular industries. OTA's earlier report, Making Things Better: Competing in Manufacturing, considered in detail options to help manufacturers improve their performance through better use of technology. Defined broadly, technology includes not only new products and advanced production machinery, but also efficient organization of work and effective use of people.

Industry and government both have parts to play in building a better technology base for U.S. manufacturing. The report defined four areas in which government could usefully contribute:

- Improving the financial environment for U.S. fins, which means taking action to reduce capital costs and relieve other pressures to show high profits every quarter.

- Upgrading the education and training of the managers, engineers, technicians, and workers needed in manufacturing.

- Diffusing technologies throughout the manufacturing sector.

- Forming a strategic technology policy to promote the development of new technologies 
with commercial promise through collaborative ventures with industry.

Options in the first three categories outlined above would benefit all U.S. manufacturing with no distinctions among industries. The fourth is for a more targeted effort, and is discussed in a later section. Most of the options summarized in this section are analyzed in greater detail in two recent OTA reports, Making Things Better and Worker Training, as well as in chapter 2 of this report.

\section{The Financial Environment}

The U.S. financial environment is not hospitable to long-term investment in new technologies and production equipment. High capital costs favor taking short-term profits rather than investing for the longer run, as do pressures from the stock market. Capital costs are affected by several factors, including interest rates, the economic depreciation of investment and its tax treatment, and other fiscal incentives for investment. Recent studies that take all these factors into account provide solid evidence that U.S. capital costs have been substantially higher than those of Japan and Germany for more than a decade, through $1988 .{ }^{38}$ Moreover, the terms on which capital is made available are more favorable to long-term investment in both Japan and Germany. An example is the stable shareholding system in Japan, in which the majority of shares in large corporations are held by either companies in the same group or by stable shareholders, and these companies do not trade their shares.

In the United States, government policy has contributed damagingly to high capital costs. The main culprit at present is the huge, accumulating Federal budget deficit, which puts upward pressure on interest rates. Also, the U.S. tax system has many fewer incentives for productivity-enhancing investment in manufacturing than those of our competitors, especially Japan. The dilemma is that some specific fiscal measures that might help firms modernize and invest in new technologies would also tend to worsen the budget deficit, because they would lower revenues, at least in the short run. The budget agreement of 1990 forbids this unless there is a compensating rise in tax revenues or decline in spending elsewhere in the same segment of the budget (nondefense domestic programs). If Congress wishes to lower capital costs through tax breaks, it will need to find something else to cut, or get agreement to raise taxes in compensation.
Ultimately, economic growth based on better competitive performance could ease budget problems, but in the short run there will be a price to pay.

Another choice is to increase savings, and thus ease pressure on interest rates. Options include a national savings campaign, with appeals to patriotism plus attractive interest rates for regular payroll savers, or perhaps a consumption tax designed to escape the severe regressive effects of a flat tax. Another option is further restrictions on deductions for home mortgages.

Tax breaks to industry, such as accelerated depreciation for investment in new equipment or a tax credit for $R \& D$, have shown positive effects in the past, though the exact size is debatable. Also, they are expensive--especially accelerated depreciation, which can cost the U.S. Treasury tens of billions per year; whatever they cost would have to be made up elsewhere.

Incentives to hold investments longer might relieve some of the pressure to focus on short-term profits. One option would be a capital gains tax that favors long-term gains and penalizes short-term turnover. It would be most effective if applied to pensions and other funds that are now tax-free, since these funds hold one-third of all stocks and probably account for half of transactions on the stock market.

\section{Human Resources}

Success in manufacturing depends on having well-trained people, comfortable with the demands of advanced technology, at every level from the manager's office to the shop floor. The failures of our public schools in turning out well-educated young people with good work habits is well-known. Unfortunately, training of adult workers in the United States is deficient compared with that in several other countries, in particular Japan and Germany.

The quickest payoff may be in improved training of the active workforce, since improvements in schooling take many years to show up on the job. An aggressive, far-reaching option, which guarantees more training without any direct cost to the government, is a payroll-based training levy. Employers would have a choice of spending a certain amount on training their workers or paying the same amount into a national training fund. Several foreign countries, including France, Germany, Ireland, and the Republic of Korea, use the system. Government 
might also offer technical assistance on training needs and best practice training methods to trade associations, labor-management groups, or industrial consortia. Restoration and improvement of formal apprenticeships is another option for government-industry partnership. And the Federal vocational education program has many useful features, including school-to-work programs, but they lack adequate funding.

Training linked with technology assistance is effective, and a few States provide it. However, technology extension services are scarce and spotty in the United States, and the link with training is scarcer still. The National Institute of Standards and Technology (NIST) is in charge of the Federal Government's modest technology extension effort; it could add a training component. The Federal Government could also take a more active hand in testing and evaluating computer-aided training technologies, including adapting and transferring instructional technologies developed for the armed forces.

Because education and training of engineers is a central competitiveness issue, the Federal Government could also be more active in this regard. While the supply of engineers seems adequate now, it could dry up in future years as the proportion of white males in the work force declines; white males predominate in engineering. This is essentially a problem to be solved in public school education; attitudes to math and science are formed early. Meanwhile Federal grants to women and minorities to encourage science and engineering careers seem to get results, and deserve support. Retraining of midcareer engineers is another way to enlarge the supply over the next few years, especially at a time when engineers are losing jobs in defense industries.

\section{Technology Diffusion}

U.S. institutions for diffusing new technologies throughout manufacturing are thin. Even large firms with the resources to develop or acquire the technologies they need often neglect to take what they could from outside the firm. Many of our 350,000 small and medium-sized manufacturing firms are worse off, with only scant exposure to new technologies.

Technology extension services funded by government could improve the manufacturing of small and medium-sized firms, but so far it is more potential than actuality. Defining industrial extension as one-on-one technical advice given to individual fins, 16 States had such programs in early 1991, and another 7 had technology demonstration or assistance centers. Spending by the 23 States for 27 centers amounted to about $\mathbf{\$ 5 0}$ million. A small Federal program was established under NIST administration in 1988; it now includes five centers, with one more planned, each with Federal funding of about $\$ 1.5$ million per year and an equal amount from State, local, and private sources. For perspective, compare these scattered programs with technology extension in Japan. Besides the nationwide system of 185 technology extension centers, funded at about $\$ 500$ million, half from the national government and half from the prefectures, many Japanese cities, wards, and other localities support industrial halls that offer similar services. These include regular workshops on common manufacturing problems, use of specialized equipment at low fees, demonstrations of new technologies, plant visits by field agents, and referral to expert consultants for advice on special problems.

If Congress wished to support a wider network of technology extension centers, it might set a minimum goal of 120 centers, serving about 24,000 small and medium-sized firms per year and costing about $\$ 120$ to $\$ 480$ million a year, depending on the level and quality of service. Some of the funds could come from State or private sources, though it may be unrealistic to demand that these sources take overall the funding within a few years (as the law provides in the case of the NIST centers). A program of this size might soon prove insufficient. It would serve about the same percentage of small and mediumsized manufacturers ( 7 percent) as is served by Georgia Tech's well-regarded industrial extension service for firms in the State of Georgia. That service does not advertise for fear of being swamped with requests.

Another promising option with at least two major advantages is a system that would allow manufacturers to lease modern production equipment, or buy it on the installment plan, at subsidized rates. The system would encourage firms to use up-to-date equipment, such as computer numerically controlled (CNC) machine tools. If the system bought U.S.made equipment, it would also benefit U.S. builders of the machinery by offering a stable assured market for part of their output. An equipment leasing system for $\mathrm{CNC}$ machine tools, for example, could start with modest government finding-probably about $\$ 3$ 
million per year. ${ }^{39}$ It could be open only to small firms, or open to all with lower rates for small firms. An option with somewhat similar effects is special tax incentives for investments in advanced manufacturing. This is one of the many inducements to modernize that the Japanese Government offers to businesses, especially small ones.

Commercialization of technology from Federal laboratories is a goal that Congress has actively pursued for more than a decade through laws and oversight. There has been progress, but the goal is far from fully realized. On the industry side, many firms fail to pursue energetically what they could get from the Federal labs. On the government side, the two main obstacles are too little money and too much red tape. With other missions taking priority, lab funding of technology transfer has been scanty. Bureaucratic hoops in the parent agency, especially delays for legal review, have many times stalled technology licensing and the conclusion of cooperative agreements between the labs and private industry.

Since Congress passed its latest (1989) law promoting technology transfer, approval of industrygovernment cost-shared cooperative $R \& D$ agreements has speeded up (it now often takes less than the 90 days allowed under the new law), and such projects are becoming more accepted. The Department of Energy (DOE) has moved to grant some of its big multiprogram National Laboratories the freedom to conclude most such agreements with industry with only a limited wait for agency review. A high level DOE group, the Technology Transfer Project, is working on easing licensing as well as cooperative $R \& D$ agreements. Problems remain, however. An umbrella agreement for an Advanced Manufacturing Initiative, negotiated between the National Center for Manufacturing Sciences (representing over 100 companies) and DOE (covering several of the national labs) was not formally launched until July 1991, nearly a year after its announcement. Moreover, funding to promote commercialization is still limited.

Congress might wish to earmark some of the labs' $R \& D$ appropriation for commercialization efforts, perhaps mandating that a few percent of the budget be set aside for the purpose. Also, continued congressional oversight seems to be necessary for getting over bureaucratic roadblocks.

Improved protection of intellectual property and modest changes in antitrust law might bolster the competitive position of some U.S. manufacturing industries. Better patent protection could start at home with speedier enforcement-patent cases that go to trial usually take $2 \frac{1}{2}$ years. Congress might consider designating special patent judges with the technical knowledge to move cases through faster (similar in principle to the tax courts). In foreign markets, the Japanese system has been a special problem. It is slower than the U.S. system in issuing and enforcing patents, and it strongly favors licensing of patents, which U.S. companies often do not wish to do. While the U.S. Government negotiates with Japan on these problems, Congress might establish a program in the Patent Office to provide U.S. firms with information on the Japanese system.

Antitrust law and enforcement have been greatly relaxed in the past decade. Changes have been made to allow cooperative endeavors that could improve U.S. competitiveness; perhaps some further moves in that direction could be considered. For example, Congress might allow the Justice Department to certify in advance that joint projects do not violate the law, or to establish 'safe harbor' market shares, so that shares below a certain percentage would not be in violation. Probably most important, Congress could recognize that joint ventures or mergers between U.S. firms are sometimes necessary to fend off foreign competition, and could instruct the courts to listen seriously to such arguments. Congress might also instruct the Justice Department and the courts to weigh carefully the long-term competitive effects of a foreign fro's taking over a U.S. firm.

Finally, information and exhortation to American manufacturers on how to make things better, given under U.S. Government auspices, have proven surprisingly effective. In 3 years, starting in 1988, the Commerce Department has given the Malcolm Baldrige National Quality Award to nine companies meeting the award's high standards. In that time, 203 companies applied for a possible 18 awards (2 each in 3 categories for each year). The award costs the taxpayers next to nothing. But it has become an excellent means of technology diffusion in several ways. Just filling out the application is instructive. Then, all applicants, win or lose, receive reports from examiners outlining their strong and weak points. Finally, the winners are obliged to share the details of what they did to win. Company representatives give hundreds of speeches a year and hold briefing sessions for executives of other companies, including their competitors. One manager who 
attended came away amazed at the level of detail"everything but the financial data.'

\section{Trade Policy Options}

Promotion of liberal trade (often termed "free trade") has been the policy of the United States since World War II. For two or three decades, this policy served national interests well enough. In the postwar world, the United States was far enough ahead of most other countries that America prospered even when trade was more liberal for imports into the United States than for U.S. exports to some other countries.

Today, with several key U.S. industries fallen to second rank, free trade is not necessarily to the country's advantage, certainly not one-way free trade. Many U.S. industries are struggling to meet foreign competitors equipped with plentiful supplies of patient capital and cutting-edge technology. The outlook is particularly bleak for small or startup firms trying to break into markets dominated by powerful multinationals. Today, most of the highreward industries-characterized by high knowledge intensity, particularly large economies of scale, positive spillovers to other industries, and well-paid jobs-are tough to survive in without government help. Indeed, except for the United States, most developed nations have some kind of government program to promote the competitiveness of hightechnology industries.

Why has the United States been so vulnerable to these foreign programs? Industry is partly to blame. Many U.S. managers have stuck far too long with outmoded technologies and management styles. But government is also to blame. Unlike its ablest competitors, the U.S. Government has not pursued domestic programs to develop its own important industries. The only way that the U.S. Government has responded to tough foreign competition is as a trade issue: it has attempted to open foreign markets, and it has at times levied extra import duties intended to compensate precisely for foreign subsidies and dumping. However, important foreign market barriers have often taken many years to remove. Similarly, U.S. law regarding subsidies and dumping has done at best a slow, incomplete job of compensating for advantages that foreign industrial policies confer, and the extra duties levied at the border are inherently inadequate to compensate for another country's domestic policies.
Rather than reacting to foreign governments' initiatives, always at least one step behind, it would be easier and more effective to improve U.S. competitiveness using domestic programs. Measures might include $R \& D$ incentives, tax breaks to encourage $R \& D$ and capital investment, increased commitment to technology diffusion, and support for education and training. Trade measures-trying to open foreign markets, and protecting the U.S. market--could be used when necessary, but in a subordinate role. Moreover, these trade measures could be used more strategically. Efforts to open markets could focus on areas of the greatest strategic importance; and protection could be based not on legalistic criteria, but on the industry's need and place in the economy.

Some say that government cannot and should not pick industries to promote, and that attempted government assistance to particular industries is likely to make them less rather than more competitive. However, there is general agreement on many of the technologies (e.g., electronic components and information technologies) that are key drivers of industrial performance, and it is not hard to identify industries that use those technologies. And while government intervention has sometimes been counterproductive, the experience of several governments provides guideposts for what approaches work best. For example, industry should take the lead in proposing joint government-industry $R \& D$ programs and should shoulder much of the cost; policies should conform with market forces as much as possible; U.S. industry must compete with the best in the world; and industry must work to improve its competitiveness and outgrow the need for assistance.

\section{Responses to Foreign Market Barriers}

Foreign market barriers often hurt U.S. industries. While GATT has reduced quotas (quantitative restrictions on imports) and tariffs (taxes on imports, also called duties), there are many other barriers to imports. These include burdensome customs procedures; discrimination in standards, regulations, and government procurement; and private agreements, tolerated or encouraged by the government, that tend to exclude foreign products.

Normally, the U.S. response, if any, is to negotiate to eliminate barriers, with negotiations led by the Office of the United States Trade Representative (USTR). The United States is hindered by lean 
USTR staffing, frequent turnover of senior government officials, and the representation of foreign interests by former key government officials. To address these problems, Congress might wish to increase USTR staffing, create more high-level career positions at the USTR and other government agencies, and prohibit senior trade officials from representing foreign interests for several years after they leave government service.

Other reasons why foreign markets can take many years to open are harder to address. Barriers take time to identify; other countries can stall negotiations; countries hedge on promises to remove barriers; and when one barrier is removed, another can take its place. And some barriers are ingrained in a country's business practices and domestic policy, making their removal difficult even if the foreign government is willing.

The United States has only limited leverage to induce foreign countries to remove barriers. GATT dispute resolution procedures, while recently improved, are still slow and uncertain. Continuing U.S. efforts in the Uruguay Round to improve these procedures might be productive. Congress might also wish to consider the ambitious task of creating a new multilateral trading system, with a much stronger commitment to and enforcement of free trade. Such a system would require a great deal of planning and commitment, and probably would have to be limited to a very small group of like-minded nations in the beginning.

The United States can also threaten to retaliate with barriers of its own to imports from the country in question. Under Section 301 and related sections of the Trade Act of 1974, as amended, ${ }^{40}$ the USTR can investigate foreign trade barriers, negotiate for their removal, and if necessary retaliate. However, even the investigation phase angers trading partners; and retaliation would most often violate GATT, could provoke counter-retaliation or GATT challenges, would not solve the problems of the U.S. industry facing the market barriers, and could cause problems for downstream U.S. industries. Therefore, Section 301 is not a very serviceable tool.

Limited U.S. leverage makes negotiations often slow and ineffective. Barriers that cause particular damage-e. g., Japanese barriers to the sale of semiconductors and supercomputers-often persist for years. While market opening is a worthwhile long-term goal, attempts to remove specific barriers often provide little or no relief in the interim, during which time the affected U.S. industry can suffer serious and irreversible damage.

U.S. policy toward market barriers could be reoriented to emphasize domestic measures to maintain competitiveness rather than negotiations to remove barriers. Normally domestic measures, such as $R \& D$ support and tax breaks, could keep an industry competitive even in the face of trade barriers. While opening foreign markets could still be pursued as a long term goal, there would be no urgency requiring measures that would anger trading partners. It would also make sense to allocate the government's limited negotiating resources according to an industry's strategic importance.

In exceptional cases, domestic measures might not be enough. This might be the case with semiconductors; limited access to Japan's market, the largest and most discriminating in the world, can be an important handicap to U.S. fins. In the rare case of an important U.S. industry facing substantial harm from foreign market barriers that domestic measures cannot alleviate, the national interest might be served by pulling out all the stops to remove the barrier: quick, aggressive negotiations led by high-ranking officials, perhaps with cabinetlevel or even Presidential involvement, followed if necessary by the threat of substantial retaliation, carried out if necessary.

\section{Use of Protection}

U.S. industries normally receive protection against imports only when they are dumped or subsidized. In this case, an extra duty can be assessed in an amount that in theory precisely counteracts the trade-distorting subsidy or dumping. However, U.S. law and practice regarding subsidies and dumping by and large fails to compensate for the advantages foreign governments create for their fins. The reasons include delay, difficulty in proving subsidies or dumping, the law's ignoring or devaluing certain subsidies, difficulty in proving the required injury, and the high expense of legal proceedings. A further problem is that the effects of government assistance can increase over time, rather than dissipating as the law assumes. To some extent, the law's limited effectiveness stems from adherence to GATT' requirements.

A more effective approach would be to assist industries beleaguered by imports primarily by 
domestic measures to promote competitiveness through cost control, productivity enhancement, and quality improvement. Where domestic measures alone might not suffice, protection could also be used, lasting only as long as strictly necessary. Criteria for awarding protection would include the industry's need, its merit (including whether the industry was making reasonable efforts on its own and showed promise of effectively competing on its own), and the importance of the industry in the U.S. economy.

Protection roughly along these lines already exists under Section 201 and the following sections of the Trade Act of 1974, as amended, which is patterned after GATT's so-called "escape clause" (GATT Article XIX). Section 201 permits the President to grant import relief for up to 8 years when the International Trade Commission (ITC) finds that increased imports 'cause or threaten serious injury' to an existing U.S. industry .41 However, Section 201 has rarely been used in recent years, and as currently written and interpreted is not very serviceable. The injury requirement usually will not be met before serious damage is done, and meeting it is especially hard for high technology industries with rapidly growing markets. While Section 201 could be amended to cover these situations, there is some question as to whether that would be consistent with GATT.

Congress could empower the President to grant protection apart from Section 201. Under GATT Article XXVIII, the United States could negotiate with other countries to accept higher U.S. tariffs on certain goods in exchange for reduced U.S. tariffs on other goods. While reduced tariffs on the other goods could adversely affect other U.S. industries, the government could possibly mitigate such effects with tax breaks or other programs. Also, continued protection ideally would depend on sufficient effort from industry to improve its competitiveness. If other countries would not agree on compensation, in rare cases as a last resort the United States might impose protection anyway and risk a GATT challenge. To some other nations, that might be interpreted as a signal that the United States was abandoning its commitment to GATT and free trade. While this is a risk, it might be preferable to the alternative of losing critical industries altogether.

\section{Promoting Exports}

Nearly all industrialized nations promote exports. Exporting is difficult, requiring firms to overcome differences of language, geography, and custom. Governments help firms to learn about markets, to identify potential customers and distributors, and to comply with administrative requirements. Such assistance seems particularly needed in the United States, whose firms must export more manufactured goods than before. However, the United States spends far less promoting manufactured exports than many of its important trading partners. In the late 1980s, low funding even led to situations such as commercial officers in U.S. embassies not having funds to return phone calls from U.S. firms. While budgets have improved somewhat in the last few years, Congress might wish to consider funding more on a par with that of other countries. Congress might wish to make a policy statement that export promotion should be a priority not only for commercial officers abroad but for the whole diplomatic staff. Cabinet-level involvement in promotion activities, such as Commerce Secretary Mossbacher's presence in Tokyo in April 1991 to kickoff the Japan Corporate Program, could also be encouraged.

Nearly all industrialized nations also assist firms with export financing. In the United States, applications for financing assistance for manufactured exports must be justified on a case-by-case basis; the need for justification increases delay and the burden on the exporter. Congress might consider adopting the approach used by Japan and many European countries, which determine in broad policy terms what exports to assist and then assist all creditworthy exports within the guidelines. Many other countries condition some of their foreign aid on purchases of capital goods, construction services, and the like from the donor country. While the United States also ties some aid to purchases, U.S. nondefense aid focuses on agriculture, nutrition, health, and education, rather than large capital projects. U.S. effort to improve international agreements limiting the use of tied aid is worth continuing. However, it is uncertain how successful that effort will be. Congress could expand the so-called War Chest for matching foreign tied aid offers to more effectively discourage foreign tied aid. The War Chest was funded at $\$ 150$ million in grants for fiscal year 1991, though as of July 1991 only $\$ 58$ million had been used. Some other countries spend many hundred million dollars annually. 
Congress could expand the Trade and Development Program (TDP), funded at \$35 million for fiscal year 1991. TDP helps to pay for feasibility studies or other plannining assistance performed by U.S. firms for capital projects in developing and middle-income countries. U.S. participation in the planning phase has often helped U.S. firms win contracts for the actual project. So far, $\$ 161$ million in program funds have led to documented U.S. sales totaling $\$ 3.2$ billion, with an estimated $\$ 18$ billion more sales expected as projects mature. 42 In expanding TDP or otherwise increasing the emphasis on capital projects, care should be taken to avoid adverse environmental and social effects, which in the 1970s turned the United States away from such projects.

As well as promoting exports, the U.S. Government at times impedes export of high-technology goods and data by its system of export controls. Export of dual-use items - those with both military and civilian use-is regulated by the Export Administration Act of 1979, as amended; ${ }^{43}$ this requires firms to obtain a license to export certain items for certain destinations. In 1990, perhaps $\$ 90$ billion worth of U.S. exports of manufactured goods required a license.

There is a genuine need for some control over exports to guard advanced technologies and products that could be used in weapons against the United States. Yet export controls have also proved an unnecessary hindrance to some manufactured exports, at times merely shifting the business from U.S. to foreign firms. For example, until mid-1990 U.S. export controls limited exports of personal computers based on Intel's 80386 processor, although they were easily available from foreign sources. While U.S. export controls are being reformed, the process is incomplete. Reform could be facilitated, as could ongoing administration of export controls, by a competitiveness policy agency. Such an agency could identify exports with strategic economic importance and help to expedite their approval when possible. While an Administration sympathetic to competitiveness concerns is essential for fully effective reform, Congress could take measures on its own to further decrease unnecessary burden on commercial competitiveness. These measures include better funding and staffing of the office that determines when foreign availability makes U.S. controls ineffective, encouraging more political appointees with technical backgrounds, encouraging more use of automatic indexing to track technological change (subject to yearly review), and court enforcement of congressionally mandated deadlines. Congress could take measures to stop abuse of the State Department's Munitions List, which is supposed to contain only items with purely military use but has been used to control some dual-use items.

An emerging area of concern is the use of so-called "foreign policy" controls, which are largely untouched by the recent reforms. Congress might wish to extend the recent reforms to foreign policy controls where feasible. For example, if the purpose of a foreign policy control is to guard technology for making chemical weapons, Congress could require that items not be controlled without multilateral agreement to control them, and that controls be removed if they are ineffective because of foreign availability.

\section{GOVERNMENT-INDUSTRY PARTNERSHIPS}

In addition to trade policy, a comprehensive strategy for greater competitiveness includes promotion of technology development and diffusion, risk-sharing between government and industry, and a generally supportive environment for adoption of new technologies.

\section{Risk Sharing in Technology Development}

The least intrusive and least expensive of several risk-sharing options is an R\&D partnership for developing new technologies of commercial interest. The main reason for government to support

such ventures is that potential benefits to society are great but the likely payoff to individual firms is too small or the possibility of failure too great to make it worth their taking the risk. In the U.S. financial environment, with its high costs and emphasis on short-term profit, government contributions to risky ventures are especially significant.

The Federal Government has in the past given some technology assistance for commercial purposes, but not on a coherent, strategic basis. By far the largest existing Federal program for precommercial technology development is NASA's aeronautical R\&D program (amounting to over $\$ 900$ million per year, including expenses for wages and salaries, $R \& D$, and facility construction), which supports military and commercial technologies. The 5-year 
Sematech program, to help the semiconductor industry develop a manufacturing process technologies for memory chips, is large ( $\$ 100$ million per year for 5 years in government funds and a matching sum from industry) and was created ad hoc in response to strong industry pressure and the argument that a competitive U.S. semiconductor industry is essential to national defense.

A small beginning for a more general $R \& D$ partnership is the Advanced Technology Program (ATP), operated by NIST in the Department of Commerce. ATP was established in the 1988 trade act, which authorized the Program to assist businesses in doing research in precompetitive, generic technologies. In fiscal year 1990, Congress provided ATP's first tiding, \$10 million, and raised funding to $\$ 36$ million in fiscal year 1991.

ATP might in time become a full-fledged civilian technology agency (CTA), although it was not created with that specific mission. Bills to establish more formally an Advanced CTA in a new Department of Industry and Technology, which would replace the Department of Commerce, were introduced in the I00th and 101st Congresses. ${ }^{45}$ These bills defined the agency's mission as contributing to U.S. competitiveness by supporting long-term, highrisk projects that are likely to yield important benefits to the Nation but lack adequate private support. A bill that passed the Senate in 1989 would have given the ATP a similar mission, and authorized funding up to $\$ 100$ million per year. ${ }^{46}$

Any CTA would have to start small, as ATP has, and grow only with experience. A mature agency might have a research budget of $\$ 300$ to $\$ 600$ million per year. This very rough estimate is based on the list of about 100 technologies developed by the private-sector Council on Competitiveness, ${ }^{47}$ each of which might merit government participatory grants of about $\$ 1$ to $\$ 2$ million per year, with enough redundancy that two or three grants might be made in each field.

Collaboration with industry in choosing technologies for support would be essential. If private companies are not interested enough in the technology to put up at least half the money and do much of the work, then the chances for commercial success are probably remote. Joint finding helps the government resist special interests or political pressure in choosing technologies for support. At the same time, a CTA would need a set of guiding principles-e. g., it should look for technologies that are knowledgeintensive and have wide applications in many products and industries.

NASA's experience underscores the importance of collaboration with industry, if the goal is competitive success. Most of NASA's R\&D is for military as well as commercial applications, and much is basic research that is quite freely available to the world and has little or no near term application to commercial production. NASA's greatest contributions to competitiveness are in two areas: its facilities, such as wind tunnels and its Numerical Aerodynamic Simulator, which are solely or preferentially available to U.S. companies; and R\&D projects in which U.S. companies are close collaborators.

So far, the U.S. Government's offers of collaborative $R \& D$ projects have been snapped up by private companies. The Advanced Technology Project's frost batch of l-year cooperative grants, amounting to $\$ 9$ million, attracted 249 applicants requesting a total of $\$ 150$ million. Eleven projects, half of them joint ventures or consortia, were chosen; they initiated $R \& D$ projects that are expected to cost $\$ 100$ million (including private funds) over 5 years.

The total dollar amounts in the government's few cooperative $R \& D$ programs are tiny compared to the $\$ 100$ billion per year that U.S. companies spend for $R \& D$. It is remarkable that such small programs have drawn so large a response, including proposals from such industrial giants as Du Pent, AT\&T Bell Laboratories, and IBM.

If Congress wishes to continue the expansion of cooperative $R \& D$ programs, with the ultimate goal of having an agency of similar size and importance as the Defense Advanced Research Projects Agency (DARPA), it may opt for another modest rise in the ATP budget for fiscal year 1992. It might also consider putting into law a more formal statement of goals for the Program.

Congress has already responded in an innovative way to the question of how to handle participation by foreign-owned firms in cooperative $R \& D$ projects. In appropriating funds for the ATP for fiscal year 1991, it set standards that apply to U.S.-owned as well as foreign fins, thus bypassing ownership as the central criterion for participation. The Secretary of Commerce is authorized to decide on a fro's eligibility based on its contributions to high-value- 
added manufacturing production and manufacturing employment within the United States. Further conditions apply to foreign firms, based on equal treatment for U.S. firms in the foreign fins' home country. These provisions provide guidance but give the Secretary of Commerce great latitude. Congress may wish to exercise substantial oversight for a time on how these provisions are carried out, and to extend these eligibility criteria for at least a few years to permit evaluation of their merit.

\section{Financial Risk-Sharing}

Strategic technology policy goes only so far. It is up to industry to make the much larger investments in product design, manufacturing equipment and tooling, worker training, and acquisition of knowhow by managers and production engineers needed for commercial production. It is normal and expected for private industry to make these investments and take the risks. Sometimes, however, in some critical sectors, private investment is inadequate from the standpoint of social benefits. U.S. investment in production equipment is meager compared to Japan 's. Japanese investment in machinery and equipment, as a share of GNP, has been twice the U.S. rate since the mid-1970s, and the discrepancy has recently widened. The discrepancy is especially damaging in critical commercial industries, such as semiconductors, that require continuing large investments for new generations of products every 3 years or so.

Government policies to share financial risks with industry can take the explicit form of loans or loan guarantees on advantageous terms, or they can take the form of tax breaks, which are implicit expenditures. Both put burdens on the Federal budget, and Congress cannot opt for either without compensation tax rises or spending cuts. Macroeconomic policies that help to lower capital costs and provide stability are probably the most important help government can provide to encourage greater investment in technology development and deployment by U.S. manufacturing companies. Specific options for financial risk-sharing are worth considering, however.

Of the two forms of risk-sharing, tax breaks are more within U.S. tradition and experience. In the past, U.S. companies have received accelerated depreciation and tax credits for capital investments. Although certain activities (e.g., real estate) have been singled out for special treatment, Congress has not in the past designed tax incentives to improve the competitiveness of particular industries. Across-theboard tax breaks for capital investment would cost the U.S. Treasury tens of billions per year, while loosening the rules for selected industries would cost less. The National Advisory Committee on Semiconductors, for example, estimated that allowing 3-year rather than 5-year depreciation for new investments in semiconductor manufacturing equipment would cost the U.S. Treasury $\$ 180$ million per year in lost revenues, and would prompt $\$ 450$ million in added capital investments by the industry. ${ }^{48}$

If Congress wishes to target tax breaks to critical commercial industries, the best way is to make these tax measures part of a comprehensive strategy that includes such things as technology support and trade policy. This presupposes the existence of an institution able to form such a policy.

Direct financial aid to commercial industries is mostly foreign to U.S. experience; the one previous effort, with the Reconstruction Finance Corporation after World War II, was not targeted to critical industries, and is generally considered an expensive failure. If Congress wishes to consider direct aid in exceptional cases, it may wish to start at a very modest scale.

\section{Government Purchases}

Government purchases have been an important factor in the birth and growth of several industries, including aircraft engines, semiconductors, and computers; the big buyer in each case was the Department of Defense (DoD). Today, defense purchases are not a very promising source of financial support for critical commercial industries. Technological spillovers from military to commercial products are probably declining (though the evidence on this is mixed). More important, laws and regulations governing DoD purchases are so restrictive and cost-inflating that it is increasingly difficult to combine military and civilian production and to take advantage of whatever spillovers may exist. Post-Cold War declines in defense spending have removed some of the potential support.

Federal, State, and local government spending for nondefense goods amounted to about $\$ 97$ billion, $\$ 10$ billion of it Federal, in 1990. Although the total is modest as a share of the GNP for goods (about 5 
percent), certain kinds of government purchases can be significant. For example, Federal purchases greatly aided the supercomputer industry's development. This role-being an assured customer for a startup product-is especially significant. Suppose the Postal Service (a quasi-public agency) decided that electric vehicles could help reduce pollution, and that their limited range and need for frequent recharging would not handicap mail runs. A substantial order might give a real boost to a U.S. producer of electric vehicles, providing it with a head start over foreign competitors. Preference for U.S. firms would be consistent with the GATT Procurement Code, which does not yet cover the Postal Service.

Internationally, procurement tells a familiar story: the U.S. market is more open than those of many major trading partners; many major trading partners use procurement as a strategic tool to develop important industries, while the Federal Government generally does not do so intentionally. Congress might wish to reorient U.S. policy to be more proactive: as well as negotiating to make procurement markets more open, the United States could take stock of opportunities to use its own procurement strategically, such as the Postal Service example. There are likely many such opportunities that are not yet prohibited by international agreements. Using procurement strategically would help U.S. competitiveness pending further market-opening agreements and would give the United States more leverage in negotiations. Awareness of strategic opportunities would make the United States a more informed negotiator. For example, if Postal Service procurement of electric cars were deemed a strategic opportunity, the United States might not agree to subject the Postal Service to the GATT Procurement Code unless other countries give up equivalent opportunities.

\section{AMERICAN FIRMS, FOREIGN FIRMS, AND AMERICAN INTERESTS}

Government involvement in efforts to boost civilian industrial competitiveness invariably raises the issue of who is eligible to participate. Three decades ago, there were only a handful of true multinationals. Today there are hundreds of firms that have a substantial interest and presence in more than one nation. The stock of direct investment abroad, on the part of firms from all nations, has increased over 10 percent per year since 1960, and by 1988 , stood at over $\$ 1.1$ trillion. ${ }^{49}$ Direct investment abroad is increasing much faster than world merchandise trade or world economic output. All developed nations must make decisions about how to treat foreign firms, and increasingly, those decisions center on foreign firms' eligibility to participate in government-sponsored projects to improve industrial competitiveness.

Foreign direct investment in the United States (FDIUS) is also on the increase-in fact, FDIUS is increasing faster than the world average. Between 1967 and 1988, the stock of FDIUS increased from $\$ 9.9$ to $\$ 328.9$ billion, or over 18 percent per annum. The world stock of direct investment abroad increased from \$105.5 billion to \$1.2 trillion over the same period, or 12.4 percent annually. The gross product of foreign affiliates in the United States accounted for 3.4 percent of GNP in 1987, nearly double their 1.8 percent in 1977. The presence of foreign direct investors is especially prominent in manufacturing. In 1987, U.S. manufacturing affiliates of foreign parents accounted for $\mathbf{1 2 . 2}$ percent of the assets of all American manufacturing, compared with 8.9 percent of the total net worth of all nonfinancial corporations. So while foreign companies are relatively small players in the U.S. economy, they control or influence a significant chunk of manufacturing.

The U.S. Government funds relatively fewer industrial-competitiveness programs that could admit foreign firms than governments in other developed nations, especially in Europe and Japan. Nevertheless, we are in the thick of the debate; foreign companies have asked for access to Sematech and the Advanced Technology Program of the Department of Commerce. How we end up dealing with foreign firms or their American affiliates depends greatly on how they behave. American firms too are held up to scrutiny in terms of their contributions to national well-being in the debate, often in caricature; some believe that the typical American firm does little manufacturing or R\&D in the United States. When we examine the contributions American firms make to the U.S. economy and living standards and compare it with foreign fins, the caricatures fall apart.

The U.S.-based parent companies of American multinationals act, on the whole, like American companies: their U.S. operations accounted for 78 
percent of the companies' total assets, 70 percent of their sales, and 74 percent of their employment in 1988 , slightly more on all three counts than in $1977 .{ }^{50}$ Contrary to the popular stereotype, there is a slight tendency for U.S. multinationals to do more of their business in the United States than formerly. American multinationals also keep good jobs and develop technology at home: the vast majority of their R\&D is done here, ${ }^{51}$ compensation per U.S. employee is 39 percent higher than compensation per employee in offshore affiliates, and assets per U.S. employee are 30 percent higher than assets per employee in offshore affiliates.

U.S. affiliates of foreign multinationals behave much like American firms in America, although there are some key differences. Affiliates do not differ significantly from American companies in terms of compensation per employee and investment in plant and equipment as a percent of sales. ${ }^{52}$ They treat their employees similarly during economic downturns, being about as likely to lay off workers as American companies. U.S. affiliates of foreign multinationals are, on the other hand, less likely to do R\&D in the United States than American companies; the $R \& D$ intensity (spending on $R \& D$ as a percent of sales) of U.S. manufacturing affiliates was about half that of American manufacturers. This is consistent with common behavior by multinationals (including American multinationals), most of whom do the bulk of their R\&D at home. Aggregate data on the hours and quality of training given in U.S. affiliate companies are not available. We do know that workers and managers in Japanese motor vehicle transplants receive substantially more training than workers and managers in American companies' auto plants. overall, however, we would expect to find little overall difference in the amount or quality of training given to workers in U.S. affiliate companies, compared with workers in American companies.

There are two sources of real difference between the behavior of affiliates and the behavior of American fins. Foreign affiliates are far more likely to import than American-owned companies, and affiliates of Japanese parents more so than affiliates of European or Canadian parents. The merchandise trade deficit associated with affiliates of foreign parents is substantial; in 1988, it was $\$ 90$ billion, three-fourths as large as the entire U.S. merchandise trade deficit. ${ }^{53}$ It is a mistake, however, to hold foreign companies primarily responsible for
America's poor trade performance. In large part, we are responsible for that: our anemic savings rate does not generate enough capital to cover our investments; our appetite for consumption is greater than our production; foreign goods are often better and/or cheaper than domestically made ones. The fast increases in foreign direct investment, and the associated trade deficit, are mainly results of these underlying weaknesses, not the causes. In other words, if we somehow prohibited American affiliates from importing, or forced them to export more (like some developing countries do), and changed nothing else, we would expect the dollar to fall to compensate.

Japanese direct investors also behave very differently in many respects than other foreign investors or American fins. Their propensity to import is higher; in 1988, affiliates of Japanese companies' imports totaled $\$ 75.9$ billion, 51 percent of total imports of affiliates. Japanese affiliates' share of U.S. sales was only 26 percent of the sales of all affiliates. Moreover, Japanese affiliates imported almost exclusively from Japan; 93 percent of their imports came from Japan. Other foreign affiliates import from home, but to a much smaller extent; European affiliates got 70 percent of their imports from Europe (although the attachment of affiliates of any nation to imports from that particular nation is less strong) and 73 percent of Canadian affiliates' imports were from Canada.

Japanese direct investment appears to be far more oriented to selling Japanese products abroad than the investment of European nations or Canada. This shows up not just in the propensity of Japanese affiliate companies to import from Japan, but in the profile of investment; Japanese firms are more likely than European firms to invest in wholesaling affiliates, particularly in motor vehicles, and their primary activity is to sell Japanese products. Possibly as a result, Japanese parents are more likely to maintain tight control over their affiliates than are European parents. American affiliates of Japanese electronics companies mostly employ Japanese managers, while American electronics affiliates in Japan mostly employ Japanese managers. This pattern of affiliates of Japanese companies having Japanese CEOs holds true in other countries as well as in the United States.

Is there a reason to be especially concerned about--or even wary of-Japanese investment? 
There are concerns that Japanese investment in high-tech firms may simply be a vehicle for fast transfer of technology to Japan, and possibly the eventual benefits (manufacturing, employment, value added) that flow from innovation. But Japanese direct investment has had many positive effects as well. Japanese direct investment in automobile manufacture has raised the standards of quality among American auto parts manufacturers that have sold to Japanese transplants. The transplants have also been largely responsible for demonstrating how efficient, high quality Japanese auto assembly works and, to some extent, transferring knowledge of how to manage such enterprises. Japanese transplants in autos have admirable records of training employees and managers. Given our inclination to consume and unwillingness to save, increased foreign investment was inevitable. It is little wonder that it should come from Japan, whose companies are richer and more competitive than any others. As to differences in Japanese affiliates' behavior and investment patterns, it is possible (though by no means universally accepted) that these stem more from the inexperience of Japanese firms in investing abroad and managing affiliates than from peculiarities of Japanese business practice, and that in time their behavior will come to resemble that of other multinationals. On the other hand, it is also possible that there are certain kinds of Japanese investment or business practice that will not contribute to American well-being. Careful monitoring over the next few years will be needed in order to determine how to treat Japanese affiliates.

In the meantime, we are still faced with the choice of including or excluding U.S. affiliates from government programs like the Advanced Technology Program. Private research consortia also receive inquiries from foreign firms and their U.S. affiliates. While such private organizations often restrict membership based on a fro's nationality, government programs (except those whose mission is national defense) often cannot. Nominally, all nations that belong to the Organization for Economic Cooperation and Development (OECD) subscribe to the principle of national treatment, which stipulates that foreign firms should be treated exactly the same as domestic firms. ${ }^{54}$ In practice, most nations of the OECD base decisions on participation in governmentsponsored competitiveness programs on other criteria. One is mirror reciprocity, meaning that affiliates of foreign firms are given the same treatment in the host country that the host country's firms are given in the foreign affiliates' countries. Another is performance standards. In Europe and the United States, affiliates or subsidiaries of foreign parents must meet certain standards, for example, establishing manufacturing and R\&D facilities in the country, or adding a certain percentage of value domestically, to be considered for participation. As of mid-1991, both reciprocity and performance standards govern participation in the Department of Commerce's Advanced Technology Program. The EC uses similar criteria, with respect to American firms at least, to govern participation in the Framework Program. (See ch. 5 for further discussion of the EC's Framework Program.)

The issue of how affiliates of foreign firms are treated in the United States is assuming greater importance as a competitiveness question, but at the moment it is of less concern than what we do to improve the competitiveness of American fins. There is increasing agreement (far from unanimous) among analysts that there are many things the government could do to assist U.S. firms to become more competitive, including many of the options noted above, in the summary of policy options.

\section{U.S. TRADE POLICY}

Since World War II, the United States' overriding objective in trade policy has been to promote free trade throughout the world, using the GATT system and, to a lesser extent, bilateral negotiations. The GATT system has reduced quantitative barriers to trade (quotas and tariffs), and as a result is often given credit for the increase in world trade.

For most of the postwar period, U.S. firms prospered under this regime. To be sure, some industries had problems, even in the 1960s when most U.S. industry was at the technological forefront of global competition. The textile and apparel industries, for instance, relied heavily on unskilled and semiskilled labor, and as a result faced competitive pressure from low-wage countries quite early; treaties limiting textile imports were signed in the 1950s. Television manufacturers came under pressure from imports in the 1960s, as a result of both high production costs and, toward the end of the decade, superior technologies (solid state circuitry) in Japanese products. Until the early 1980s, the industries that had competitive trouble were regarded as outliers, which the United States could 
probably afford to lose as it shifted into hightechnology sectors. But in the 1980s these trade troubles spread. The indisputable fact emerged that American technology development and diffusion was deficient in even the most high-technology industries.

Now, it is difficult to find an American industry that is in no competitive trouble at all, and there are a few where only fast and drastic action can preserve domestic manufacturing. Moreover, American firms are significantly behind in an increasing number of emerging technologies and industries. Trade increasingly exposes U.S. companies to competition from foreigners with superior technologies, deeper pockets, better trained workers, and governments determined to provide their indigenous firms with advantages.

Some of these advantages are nationwide-e. g., frost-rate education, encouragement of household savings, and tax breaks for $R \& D$ and capital investment. Some governments, notably in Japan, Korea, and Taiwan, have also targeted for support specific industries, such as semiconductors and computers, that seem to contribute disproportionately to a nation's wealth and economic development. Developing such industries is often a race in which the firms or nations that get ahead will likely stay ahead for some time. A company with technical advantages or greater market share can reap economies of scale or learning, which will let it capture additional market share or finance more R\&D than its competitors, enabling it to pull still further ahead.

Governments have targeted critical industries with both domestic policies and home market protection. Domestic policies include R\&D support, special tax breaks, preferential financing, and tolerance or encouragement of cartel pricing in specific industries. R\&D programs can give firms a technical advantage over competitors abroad or at home. Special tax breaks or other financial support can help domestic companies pay for their investments or charge lower prices.

Trade protection has rarely if ever been successful when used alone, but in combination with domestic policies it can be a powerful tool. A protected home market can enable domestic firms to catch up with more advanced foreign companies without having to compete with them for domestic customers. Profits in a protected home market can bankroll forays into export markets at low prices, $R \& D$, and investment in worker training and equipment. In the short term, foreign producers could probably meet these low prices; but in the long term, foreign firms not similarly supported can lose market share and the revenues to fund new investments. Of course, protection can easily go astray, leading to an industry ill-suited to international competition, but when managed properly it can aid a nation's economic development.

Other countries' domestic programs and market protection have often delivered a one-two punch to U.S. industries. For the most part, the U.S. Government does not have comparable proactive programs to promote its own industries. U.S. trade policy plays out by noticing some of the advantages foreign firms enjoy, and then trying after-the-fact to eliminate or offset them, usually after substantial delay and often incompletely. Important foreign market barriers often persist for years, despite U.S. attempts to eliminate them. While some advantages enjoyed by foreign firms are recognized by U.S. dumping and subsidies law, various problems prevent or limit redress even in deserving cases. These problems include the expense required to prepare a petition and fight a legal case, the time it takes to conduct investigations, ways by which foreign firms circumvent duty orders, the interpretation of the injury requirement so as to inhibit timely relief, and the law's failure to recognize the impact of many subsidies.

U.S. policy thus puts important industries at risk. No matter how hard U.S. firms work, under current conditions they might not be able to compete with foreign industries backed by their governments.

Other aspects of U.S. policy are also ineffective in promoting the competitiveness of U.S. industry. While many foreign governments' procurement policies are attuned to fostering national industries, U.S. procurement policy is not. The Commerce Department's export promotion programs, while useful, are small and ineffective compared with programs in other countries. Export financing by the Export-Import Bank of the United States is sometimes less attractive than that offered by other countries' export financing agencies. Finally, U.S. national security export controls unduly hinder high-technology exports; while many controls truly are necessary for national security, some are not. 


\section{EUROPE AND THE SINGLE MARKET}

The United States is not alone in facing questions of what to do about lagging industries and technologies. The nations of the European Community, individually and together, have a long record of attempts to use industrial policy, and with few real successes in past attempts, are launching a new initiative. Known as the Single Market, or, after the proposed date of its inception, Europe 1992, the initiative is really a wide variety of new policies and agreements broadly aimed at increasing European unity, improving technology, and increasing competitiveness.

Unity has been an elusive goal for Europe. The first step was taken with the Treaty of Rome in 1957, but progress toward true harmony was slow and painful. In 1985, the Commission of the European Communities (CEC) proposed a set of some 300 specific policy actions that would be needed to eliminate barriers to movement of goods, services, people, and capital throughout the 12 nations of the EC. ${ }^{55}$ For several reasons, one of the most important being determination to escape the economic stagnation that had bedeviled Europe for more than a decade, the CEC adopted the 1985 White Paper, and progress toward implementing the 300 specific resolutions began. Even though progress was immediate and rapid, the history of past disappointments led many American analysts to discount it for several years. Now, however, it is obvious that the EC will have some kind of single market in place at least by the end of 1992, although there will likely be some unfinished items still on the agenda. Significant changes in European economic activity are very possible. How significant? And what does it mean for the United States?

Nearly everyone expects that removing sources of commercial friction among the 12 EC nationsimpediments to movement of goods, people, services, and capital-will mean faster growth in the GNP of the European Community. The range of estimates of the increase in growth is wide. The closest thing to an official estimate of the EC is a report done in 1988 (known as the Cecchini report), which estimated gains at 4.3 to 6.4 percent of GDP accruing over a 6-year period, or up to 1 percent additional growth in GDP each year. Another 2.5 percent (over the 6 years) is possible if appropriate accompanying macroeconomic policies are added, according to this estimate. The Cecchini report has been hailed as an impressive technical work, but its growth estimates are also regarded as optimistic. ${ }^{56}$ In contrast, the gains in GDP from the elimination of tariffs on industrial products among Common Market countries in 1968 were on the order of 1 percent, total. $^{57}$

What this means for the United States, in the short or long run, is murky. Additional growth, even if it were substantially below the levels estimated by the Cecchini report, would ordinarily mean increased opportunities for U.S. firms to sell goods to and produce goods in Europe. The former (increased exports) would further the national interests of the United States directly; the latter only indirectly, to the extent of contributing a bit to the prosperity of firms headquartered here. But the Cecchini report also makes it clear that some of the added growth in Europe is expected to come at the expense of imports from outside the EC; the Cecchini growth forecasts assume a reduction of imports from outside the EC by 7.9 to 10.2 percent. ${ }^{58}$ Whether there will be growth in Europe due to factors not anticipated by the Cecchini team, and whether these increase the possibilities for U.S. exports, is simply not clear. Most of the fears that EC 1992 would be a "Fortress Europe" have been put to rest, but there are a few signs of increasing protectionism in Europe.

Two areas where Europe has taken specific steps that limit imports are in automobile trade and semiconductors. The former is not expected to have any significant negative impact on American exports; most U.S. autos sold in Europe are manufactured there already. The story is different for Japanese producers. The other area, semiconductors, could be more problematic for the United States. A change in the rule of origin for semiconductors ${ }^{59}$ and a stiff existing tariff on imported semiconductors favor producing in Europe to exporting. This may not have a detrimental effect on companies that already own wafer fabrication plants there, or on the large, rich Japanese producers, but smaller American producers without existing plants in Europe are faced with the painful choice of losing European markets or making expensive investments there. Certainly, the change in the rule of origin makes it more difficult for the United States to export semiconductors to Europe. 
There are also developments, such as the liberalization of European government procurement, that could open new markets to non-EC firms, although it is not likely that this will mean much in the way of increased exports. Most of the explicit liberalization of trade is intra-EC. In the short run, then, we would expect few major changes in U.S .-EC trade as a result of the single market.

But what about the long run? One of the aims of EC 1992 is to make European firms more competitive with American and Japanese fins. The single market may contribute somewhat to that by enabling European firms to achieve new economies of scale in a market that will have about the same GNP as the United States. Another contribution could come from the Framework Program and EUREKA. These two programs, the first an EC program and the second a program with 19 members (all the EC countries are members, as is the EC itself), fund R\&D intended to improve civilian industrial competitiveness on an impressive scale, by U.S. standards. The third Framework Program (1990-94) is funded at ECU 5.7 billion, and EUREKA projects announced between 1985 and 1990 came to ECU 7.4 billion. At a rough estimate, public funding of European cooperative research in both the Framework and EUREKA programs comes to about \$2 billion per year. ${ }^{60}$

The largest parts of the Framework Program, ESPRIT and RACE, are aimed at microelectronics, computer, and telecommunications technologies (including services and software as well as hardware). BRITE is a large program that funds R\&D in products and processes to improve basic manufacturing. Other programs address technology development in many areas: medicine and health, energy, advanced materials, biotechnology, agriculture, and road transport efficiency and safety.

Both the Framework Program and EUREKA projects encourage cross-border collaboration to promote unity and exchange of scientific and technological information in Europe, and the resulting enthusiasm for cross-border collaboration is due, in no small part, to this encouragement. Whether this increased international exchange and collaboration, or the money spent on developing new technologies, will contribute significantly to European competitiveness is questionable. It is probably too soon to judge most of the programs, but those that have been going for awhile, and several past efforts at cross- border collaboration in technology, have produced few unambiguously successful results.

\section{JAPAN}

Japan is the economic phoenix of the postwar period. Throughout the nearly five decades following the war, its growth of GNP and productivity have consistently been higher than in the rest of the developed world. That it should be so was by no means obvious in the frost decade after the end of the war. Japan was desperately poor, short of most raw materials, and faced labor strife. Now, one of the biggest problems Japanese bureaucrats face is how to contain the robust productive power of its premier corporations enough to avoid exacerbating trade disputes.

The Japanese Government has long used industrial policy to push its economy toward more high-value-added, knowledge-intensive industries that use more highly skilled labor and fewer natural resources. The primary tools are financial aid, government sponsorship of price, investment, and R\&D cartels, and protection of the domestic market. These policies were instrumental in improving competitiveness in industries like steel, motor vehicles, semiconductors, and computers.

A few caveats are in order. The impression is often given that Japanese policies alone are responsible for Japan's economic success, and that the record of success is unblemished. In fact, Japan's policies were creative and innovative but they would have been much less effective in a society with less well educated people that placed lower value on hard work and ceaseless pursuit of improvement. Japan's culture, with its emphasis on achieving consensus, and on the performance and interests of groups rather than individuals, played a role, although the prominence given to cultural explanations of Japan's success in the popular literature is often overdone. There are also several examples of failure in Japanese industrial policies. For instance, the longterm goal of promoting an indigenous large civilian air transport industry has remained elusive, and MITI's expectations have been scaled back considerably.

There is widespread disagreement, at least among American analysts, about the overall effect of Japanese industrial policy on Japan's national income and standards of living. Japanese consumers have long been able to live less well than American 
consumers on an equivalent amount of income, in part because of policies that sheltered many industries from foreign competition. Some of those policies, in turn, were made to foster industrial development; the inference that Japanese consumers pay for Japan's industrial policies is quite correct. But the tradeoff is not just between Japanese industry and consumers; it is also a sacrifice of short-run gratification in favor of enhanced prospects for long-run growth. Even as Japanese standards of living and wages approach those of the richest nations, there are few signs of impending stagnation, and it is likely that faster growth of Japanese living standards will continue, surpassing ours.

That does not mean that Japanese policy remains the same as always. The hand of the government in directing industrial development is considerably less heavy than it was during the high-growth period (which ended in 1974, with the first oil shock). Japan's government has liberalized financial markets and consumer credit, reduced formal, quantitative import barriers, liberalized foreign investment, and reduced the number of cartels. Some have interpreted this as proof that Japan's economy is a modem, capitalist, free-market one along the lines of America, Canada, Germany, or Great Britain. Yet Japan's trade patterns remain peculiar by the standards of other developed countries; manufactured imports are quite low, and a strong preference remains for adding as much value as possible in Japan. Japanese direct investment abroad is more oriented to exports than the direct investment of other developed nations, and it is an outlier among developed nations in that foreign direct investment plays a much smaller role in its own economy. Many in America and Japan argue that all this is simply because foreign exporters or investors are not diligent enough; their products are inferior or their knowledge of Japanese business practice is weak. Some of that is true, but it is not the whole story.

Japan's Government is still actively involved in creating an advantageous environment for Japanese business. The computer industry was targeted for development nearly three decades ago, and within the past 5 years has come of age; many Japanese computers from mainframes to laptops are now as good as or better than American models. That payoff is the result of three decades of company diligence and experimentation, combined with tax incentives (general and specific), R\&D funding in strategic areas, subsidized leasing, and market protection. ${ }^{61}$ Policies changed over time, in response to different industry needs, and even now, with competitive and technological advantage increasingly weighted on the side of the Japanese computer makers, policies to support specific segments continue. One such area is supercomputers, where Japanese Government support has continued through the 1980s and into the 1990s. Some support comes in the form of funding for research consortia. From 1981 to 1989, the Japanese Government spent 18.2 billion yen (about \$121 million) on the High Speed Computing System for Scientific and Technological Uses Project, aimed at producing a machine with a speed of 10 Gigaflops. NTT, the Japanese telephone company, also supports supercomputer technology development in its own supercomputer project, and several public and private projects are exploring parallel and massively parallel processing.

Another important element of the strategy is procurement. Until very recently, American supercomputers were superior to Japanese supercomputers, yet while U.S. machines only were bought and installed in America and Europe, they were a small share of Japanese purchases. In 1987, for example, Cray and Control Data, American supercomputer makers, accounted for 73 percent of installed supercomputers in the world; Japanese companies for 27 percent, which consisted entirely of sales within Japan. Moreover, the Japanese companies Fujitsu, NEC, and Hitachi accounted for 87 percent of all Japanese installations, and Cray for only 13 percent. In part, that could be attributed to the Japanese preference for buying goods from and doing business with other members of keiretsu, but American supercomputers had a far more difficult time in the Japanese public sector than in the private sector. A few Japanese private companies bought Cray machines because they were better and faster, and buying an inferior Japanese machine would have been a real handicap; in the public sector, however, procurement was almost exclusively of Japanese machines. The Japanese Government apparently was determined to provide Japanese companies with a secure market while they worked hard to catchup to or surpass Cray's technology.

There are many who regard such practices as unfair or underhanded. In fact, they are logical, reasonable things for governments to do; Japan is hardly alone among industrialized countries in using the power of public procurement to foster domestic 
business and competitiveness. The story is not told for the purpose of castigating Japanese policy, but to illustrate that policies designed to create competitive advantages for Japanese firms (and compensate for the advantages of foreign fins) are not relegated to Japanese history. MITI, and other Japanese Government agencies that are genkyoku (sections of the bureaucracy with primary responsibility for developing and supervising policies for an industry), may have less ability to manipulate industries and the economy than they once had, but they still wield considerable power.

Is Japan at a crossroads? Legions of writers have said so; one of the most popular themes of current writing on competitiveness is how much and how fast Japan is changing. In a sense, Japan has never stopped changing; policies that supported a particular industry or activity were shifting in the 1950s and 1960 s as well as the 1980s. But the implicit corollary to the "Japan is changing"- genre is also that it is becoming more like us in ways that will make its industrial performance more like ours. At best, this is unproven; more likely it is a delusion. Japan's government and private sector are still working, independently and together, to improve the competitive performance and market share of Japanese companies in a wide range of industries. They will probably succeed.

\section{INDUSTRIAL POLICIES IN TAIWAN AND KOREA}

Like Japan, Korea and Taiwan have used industrial policies to encourage the development of high-technology, high-wage industries. They, too, have been successful. Their successes indicate that industrial policies can contribute to industrial competitiveness under differing circumstances--in other words, that Japan's industrial policies were not mere adjuncts to a culture that provides hothouse conditions for business.

The Republic of Korea and the Republic of China (referred to throughout this chapter as Korea and Taiwan) have advanced remarkably fast, in comparison to developed and developing nations, and especially compared to what most observers expected. In 1965, Taiwan was the world's 28th largest exporter of manufactured goods; in 1986, it was 10th. Korea moved up from 33rd to 13th. In 1989, Taiwan and Korea were, respectively, the fourth and fifth largest suppliers of manufactured goods to the
U.S. market. Both nations are still poor compared with the developed world-their combined GDP is 1.5 percent of the free world's GDP-but they have done remarkably well nonetheless at moving from manufacture of light industrial products requiring large contributions from low-wage labor to compete, to high-technology industries like computers and semiconductors. Taiwan is the world's 10th largest producer of machine tools, with particular strength in low-end numerically controlled machines; Korea is the first developing country since Japan to make a strong debut in world automobile manufacture.

Korean and Taiwanese industrial policies share many similarities, but there are important differences as well. They are similar in that they rely on long-term planning--overall visions of the directions of economic growth and development-and use industrial targeting in addition to broader measures to encourage industrial activity generally. They educate their people superbly and share a cultural commitment to hard work. Finally, they both forced their companies to compete with the most proficient of world competitors, using competition abroad to provide the impetus for cost reduction and productivity improvement, while shielding them from competition at home. In Korea in particular, the protected home market was also used to make firms compete more effectively; the ability of firms to import needed inputs and machinery depended on their export performance.

The differences are also interesting. The Taiwanese market has long been more open than Korea's and the industrial structure much less concentrated. Taiwanese firms have performed well across a broader range of industries than Korean fins, reflecting the choice of market niches that rely on standardized technologies that can be purchased and used effectively by small fins. Korea has organized production into large, conglomerate firms that have very few competitors at home and have performed well in many sectors where the economies of scale that large firms can gain are advantages, such as motor vehicles, consumer electronics, semiconductors.

Both countries have had setbacks. Some attempts to develop industries or rationalize production failed, as was the case in Japan. But Japan's success has also made the world a more difficult place for Taiwan and Korea; developed countries, afraid of what could happen to their own industries if 
"another Japan" appeared, have been much less tolerant of Korean and Taiwanese policies like controlling currency values, protecting their own markets, and loose protection of intellectual property than was true for Japan. Both countries have, in response to increasing pressure from the United States and other trading partners, liberalized controls over their markets and currencies, and permitted more imports. Their own success has made it more difficult for them to pursue the policies responsible for success. Whether they can continue to develop, and raise their living standards above levels that are still only at the high end of poverty by the standards of developed nations, will probably depend as much on the performance of American and European economies as on their own. If America and the EC are successful in getting their own manufacturing back on track, by whatever standards they adopt, the world will be a more amenable place for developing countries, including Korea and Taiwan. If, on the other hand, American and European manufacturing continue to lose competitiveness, and only Japan gains, things could be different. Japan's role in promoting world development is now larger than America's, but would Japan be able to compensate for the retaliatory and self-protective policies likely to grow if American and European industries continue to lose competitiveness? It is possible, but perhaps unlikely; Japan, too, is concerned about the economic success of her neighbors, and continues to pursue industrial policies of her own in response to the challenge of these newly industrializing countries.

\section{GOVERNMENT SUPPORT OF LARGE COMMERCIAL AIRCRAFT}

More than most other civilian industries, the large commercial aircraft industry owes its existence to government policies in whatever countries it exists. The U.S. aircraft industry ${ }^{62}$ is the largest in the world, and is the largest single trade-surplus category in America's international accounts; in 1990, the United States ran a $\$ 13$ billion surplus in commercial transport aircraft and parts. ${ }^{63}$ This was not always so. For a few years in the early part of this century, European producers were more advanced technologically; without substantial support from the government, the U.S. aircraft industry might not have gotten off the ground. Today, government support is second to corporate strategy as a determinant of the strength of the industry in the United
States, and it is an extremely important contributor to the European aircraft consortium, Airbus Industrie. Although support for aircraft is regarded by some as one of the more prominent failures of Japanese industrial policy, the Japanese are hardly out of the race yet, and government supports are an important reason. Government is a major player, but its role varies widely in America, Europe, and Japan.

In the United States, most of the government support for the aircraft industry has been indirect, a byproduct of defense programs. Though their contributions have decreased considerably, military R\&D and contracts for production of military aircraft are the largest government contributions to aircraft industry competitiveness. To be sure, civilian industrial breakthroughs have also given DoD programs many boosts as well; the contributions of military and civilian developments to modern jet engines, for example, are tough to disentangle. Also, military business does not always follow the business cycle, giving aircraft and engine companies some ability to maintain expensive $R \& D$ programs and staffs through economic downturns to which this industry like so many other durable goods industries, is particularly vulnerable in recessions. On the other hand, on the occasions when government spending on defense aircraft and NASA programs declines during an economic recession, the damage to the industry is substantial.

The U.S. Government also has contributed to the civilian aircraft industry through nonmilitary programs. NASA is spending $\$ 800$ million in fiscal year 1991 on R\&D that can contribute to the civilian aircraft industry. Still, there are problems; NASA's programs are not designed to contribute most effectively to competitiveness, but instead serve a range of other purposes-understanding of basic scientific principles of aerodynamics and materials, and the like. As a result, the programs make a smaller contribution to competitiveness than they could, dollar for dollar, if they were designed to improve competitiveness. Finally, military programs have become much more burdensome, and less of a contribution to civilian industrial needs, in the last decade. Intricate and intrusive DoD procurement rules, and changes in the funding of $R \& D$, have shifted more of the burden of developing technologies for civilian aircraft to the companies' own coffers, and diminish the usefulness of military contracts. ${ }^{64}$ At the same time, military purchases are declining sharply. 
Whether government policies designed to serve other purposes could have similar beneficial effects on other industries is quite doubtful, and reliance on serendipitous externalities is not likely to be the salvation of American manufacturing. The aircraft industry is a special case in several ways. Its formidable development and R\&D costs, capital intensity, strong scale economies, and heavy reliance on accumulated experience of integrating production of millions of components make it different from most other industries. Electronics industries share some of these attributes (high development and R\&D costs, capital intensity, and in some sectors, scale economies that also make it hard for more than a very few producers to make a profit), but differs in other respects (the half-life of commercial technology is generally far shorter in electronics than in aircraft, for example). Several decades ago, the government employed policies similar to ones that it uses now in the aircraft industry to jump-start a U.S. semiconductor industry, and with similar results for U.S. competitiveness.

The governments of some European countries and Japan are less willing than the U.S. Government to leave competitive outcomes to chance in the aircraft industry. France, Germany, Great Britain, and Spain have contributed billions of dollars over more than two decades to Airbus Industrie, a consortium of four companies (Aerospatiale, Deutsche Airbus, British Aerospace, and CASA), to enable them to produce large commercial air transports that would compete directly with the products of Boeing and McDonnell Douglas. Support for Airbus is hard to pin down, since the company itself keeps no records on the amounts contributed by the governments, but the low-cost loans given to the consortium members over the years have enabled the companies to overcome the substantial barriers posed by high development and capital equipment costs and long, uncertain payback periods. While the investments made in Airbus have, according to the best estimates, not been repaid and may never be fully recompensed, there are benefits: increased competition, which forced Boeing and McDonnell Douglas to lower prices; the direct benefits of high-wage jobs and increased exports; and, indirect benefits consisting primarily of spinoffs of technology. Considering these benefits, so far the four European governments seem to believe the investment in Airbus is worth what it costs. Whether such a belief would stand up to the rigors of a standard economic benefit-cost analysis is much less certain.

Japan's Government has supported its aircraft industry for more than three decades. The industry was targeted for special support and development in MITI's planning documents since the 1970s, yet Japan has never achieved MITI's original goal for the industry: to become an independent producer of large commercial jet transports. For this reason, the aircraft industry is often used as an example of a failure of Japanese industrial policy, and occasionally as an example of the eventual fate of all attempts at industrial policy. Closer examination reveals that neither the policies nor the industry are such failures as some of the more deprecatory analyses indicate. In 1989, Japanese companies produced commercial aircraft-related products worth $\$ 1.2$ billion, ${ }^{65}$ and exported half of it. Japanese companies have become major partners in new jet engine production, and continue to progress in other segments of the business. Their accomplishments owe much to Japanese industrial policies; the fact that the aircraft industry has not moved ahead as much or as fast as many other targeted industries is not an indictment of those policies. Instead, the aircraft industry illustrates the limitations of industrial policy in the face of formidable obstacles, including Japan's unique constitutional limitations over much of the postwar period on the production or development of military aircraft.

1 We cannot be more precise than merchandise trade; figures for U.S. share of world manufactured exports and imports are not available. However, the majority of merchandise trade is in manufactured products.

2 The World Bank World Tables: 1989-90 Edition (Baltimore, MD: The Johns Hopkins University Press, 1990).

\section{1982-84 dollars.}

4 Real weekly wages have not fallen as much as real hourly wages, because hours worked per week have increased.

5 U. S. Department of Labor, Bureau of Labor Statistics, "Comparative Real Gross Domestic Product, Real GDP Per Capita, and Real GDP Per Employed Person, Fourteen Countries, 1950-1989," unpublished data, p. 8.

6 The World Bank, World Tables, op. cit., pp. 8-9 and pp. 328-329. Figures are in 1980 U.S. dollar terms.

7 Robert Heilbroner, "A' Tune-Up For the Market," The New York Times Magazine, Sept. 24, 1989, p. 61.

8 Ibid., p. 75.

9 This is OTA's conclusion based on studies of Korean, Taiwanese, and Japanese industrial policies of the postwar period (see chs. 6 and 7). Many analysts disagree that these nations' industrial policies were either effective or significantly responsible for their economic success. On the anti-industrial policy side, see, e.g., Gary Saxonhouse, "What Is All This About 'Industrial Targeting' in Japan?" The World Economy, vol. 6, No. 3, 1987, pp. 253-273; Philip Tresize, "Industrial 
Policy Is Not the Major Reason for Japan's Success," The Brookings Review 2, spring 1983, pp. 13-18; Richard Samuels, The Business of the Japanese State: Energy Markets in Comparative and Historical Perspective (Ithaca, NY: Cornell University Press, 1987). Among those who think that Japan's industrial policy had an important effect on its growth see Ira Magaziner and Thomas Hout Japanese Industrial Policy (London: Policy Studies Institute, 1980); Chalmers Johnson MITI and the Japanese Miracle: The Growth of Industrial Policy, 1925-1975 (Stanford, CA: Stanford University Press, 1982); John Zysman Governments, Markets, and Growth: Financial Systems and the Politics of Industrial Change (Ithaca, NY: Cornell University Press, 1983); M. Aoki, Information, Incentives, and Bargaining in the Japanese Economy (Cambridge: Cambridge University Press 1988); R. Lawless and T. Shaheen "Airplanes and Airports: The Subtle Skill of Japanese Protectionism" SAIS Review, fall 1987, pp. 101-120; K. Yamamura, "Caveat Emptor: The Industrial Policy of Japan" in P. Krugman Strategic Trade Policy and the New International Economics (Cambridge, MA: The MIT Press, 1986).

10 For instance, Japan recently signed a voluntary restraint agreement (VRA) with Korea, under which Korean exporters of apparel agreed to restrain their exports to Japan. See "Japan South Korea Work Out Knotty Knitwear Dispute," Japan Economic Journal, Feb. 11, 1988.

11 Daniel I. Okimoto, Between MITI and the Market: Japanese Industrial Policy for High Technology (Stanford, CA: Stanford University Press, 1989), p. 47.

12 Ibid., pp. 38-48.

13 Ibid., p. 49.

14 Guy Routh, The Origin of Economic Ideas, 2nd ed. (Dobbs Ferry, NY: Sheridan House, 1989), passim.

15 For a more complete discussion of the role of capital costs on industrial performance, see ch. 2 of this report and U.S. Office of Technology Assessment, Making Things Better: Competing in Manufacturing, OTA-ITE-443 (Washington, DC: U.S. Government Printing Office, February 1990), ch. 4 passim.

16 An eloquent explanation of how these strategies worked is in Robert Wade, Governing the Market: Economic Theory and the Role of Government in East Asian Industrialization (Princeton NJ: Princeton University Press, 1990).

17 Ryutaro Komiya, Masahiro Okuno, and Kotaro Suzumura Industrial Policy of Japan (Tokyo: Academic Press, 1988), p. 7.

18 See ch. 6 for more discussion of Japanese industrial policies.

19 The Framework Program is a set of EC-funded R\&D programs. EUREKA is a publicly coordinated and supported R\&D effort of 19 European countries, including the 12 members of the EC. See ch. 5 for discussion of the single market the Framework Program, and EUREKA.

20 Except where noted, this is the definition of industrial policy used in this study.

21 See ch. 8 and vol. II for additional discussion of the aircraft manufacturing industry in the United States, Europe, and Japan.

22 Including salaries of employees, R\&D, and construction of facilities.

23 Unpublished budget figures, NASA.

24 Marie Anchordoguy, "The Nature and Effectiveness of Japan's postwar Industrial Policy,' ' contractor report for the Office of Technology Assessment February 1990.

25 The World Bank World Tables (Washington DC: The World Bank 1989).

26 Kenneth Flamm, "Policy and Politics in the Intcrnational Semiconductor Industry," Paper Presented to the SEMI ISS Seminar, Newport Beach, CA, Jan. 16, 1989. ibid.

27 Material about the STA in this paragraph is drawn from Flamm,
28 This refers to both the formal STA and the side letter that specified that foreign shares of Japan's semiconductor market should grow.

29 The following account is drawn from Thomas Howell, Brent Bartlett, and Warren Davis, Semiconductors and Government Industrial Policy in the 1990s (Washington, DC: Dewey Ballantine, draft in progress), pp. 126-139.

30 There is some conflict on this point. MITI maintains that the foreign share is over 17 percent, while the U.S. Government and industry estimate the foreign share to be between 13 and 14 percent. The difference is that MITI counts (while U.S. Government and industry do not): 1) captive sales-i.e., in-house sales of a chip of a type that is not offered for sale to outsiders and 2) private label sales of a chip made by a Japanese firm with a U.S. firm's label.

31 Keiretsu are groups of Japanese companies that do much of their business within the group and hold significant amounts of each other's stock, See ch. 6 for additional discussion.

32 Edward J. Lincoln, Japan's Unequal Trade (Washington, DC: The Brookings Institution, 1990), pp. 62-67.

33 Budget of the United States: Fiscal Year1992, Part Two, p. 47.

34 U.S. Department of Commerce, Technology Administration Emerging Technologies: A Survey of Technical and Economic Opportunities (Washington DC: 1990); and Council on Competitiveness, Gaining New Ground (Washington, DC: 1991)

35 Not to be confused with two other groups with similar names: the non-statutory Council on Competitiveness in the office of Vice President Quayle, which is concerned with the effects of Federal regulation and a private Council on Competitiveness, composed of chief executive offices from industry, academia, and labor.

36 These bills include S. 121, as reported by the Senate Committee on Governmental Affairs in the 98th Congress; S. 1365 in the 99th Congress; H.R. 1338 and H.R. 2135 in the 100th Congress; and H.R 1274 in the 101st Congress.

37 S. 1978 in the 101st Congress; S. 1233, as reported by the Senate Committee on Governmental Affairs in the 100th Congress.

38 Robert N. McCauley and Steven A. Zimmer, "Explaining International Differences in Capital Costs," Federal Reserve Bank of New York Quarterly Review, summer 1989, pp. 7-28. See also OTA, Making Things Better, op. cit., ch. 3.

39 OTA, Making Things Better, op. cit., p. 58.

4019 U.S.C. $2411-2420$.

4119 U.S.C. $2251-2254$.

42 U.S. Trade and Development Program, 1990 Annual Report, pp. 27,29,55-61.

4350 U.S.C. App. 2401-2420. This Act's authorization lapsed as of Oct. 1, 1990, but President Bush continued its provisions in force by invoking the International Emergency Economic Powers Act 50 U.S.C. 1702. See Executive Order 12730-Continuation of Export Control Regulations, Sept. 30, 1990.

44 This option is termed strategic technology policy and described in detail in OTA Making Things Better, op. cit., pp. 71-88.

45 S. 1233 in the 100th Congress; H.R. 3838 and S. 1978 in the 10lst Congress.

46 S. 1191 in the 10lst Congress.

47 Council on Competitiveness, Gaining New Ground, op. cit.

48 National Advisory Committee on Semiconductors, Toward a National Semiconductor Strategy, Second Annual Report (Arlington, VA: 1991), p. 15.

49 John W. Rutter, "Direct Investment Update: Trends in International Direct Investment" U.S. Department of Commerce, International Tra d e Aministration September 1989. The stock of investment given here is the position of foreign direct investors, or the value of the foreign 
investors' equity in and loans to offshore affiliates. For the United States, a foreign direct investor is one that owns or controls at least 10 percent of a company's voting stock (or an equivalent amount in an unincorporated enterprise).

501988 is the latest year for which data are available.

51 The latest figures are, unfortunately, for 1982; that year, foreign affiliates of U.S. parent companies accounted for less than 9 percent of the companies' total $\mathrm{R} \& \mathrm{D}$.

52 In the late 1970s, manufacturing affiliates of foreign parents had much higher investment in plant and equipment as a percent of sales, than U.S. manufacturers; by the early 1980s, most of the difference had disappeared. U.S. affiliates of foreign multinationals also pay slightly higher compensation than American companies on average, but that is due to relatively heavy concentration of investment in high-wage industries, like banking, and not to higher wages in comparable establishments.

53 In the past, the trade surplus generated by U.S. direct investment abroad was also substantial, but it has dwindled. In 1988, U.S. parent companies were associated with a merchandise trade surplus of only about $\$ 8$ billion.

54 It is important to remember what makes a firm "foreign." Obviously, any wholly owned subsidiary of a foreign firm qualifies. In the United States, a firm is counted as an affiliate of a foreign parent if one foreign parent company controls 10 percent or more of its voting stock, or an equivalent stake in an unincorporated enterprise.

55 The 12 members are Belgium, Denmark France, Germany, Greece, Ireland, Italy, Luxembourg, The Netherlands, Portugal, Spain, and the United Kingdom.

56 See, for example, Merton J. Peck, "Industrial Organization and the Gains from Europe 1992," Vittorio Grilli, "Financial Markets and 1992," Richard N. Cooper, "Europe Without Borders," and Rudiger Dombusch, "Europe 1992: Macroeconomic Implications, " all in William C. Brainard and George L. Perry (eds.), Brookings Papers on Economic Activity 2 (Washington, DC: The Brookings Institution, 1989), pp. 277-381 passim. Peck for example, says, "It is important to emphasize this overoptimism, given the significance of the report both as a work of economic advocacy and as an impressive scientific study." Peck p. 278.

57 Peck, ibid., p. 277.

58 Dombusch, op. cit., p. 353.

59 While it is not a statutory requirement, most nations distinguish foreign from domestic goods by a rule of origin that states that the good comes from the nation where the last substantial transformation is made. The EC used this rule for semiconductors for many years, but recently changed it to state that semiconductors originated where the most substantial transformation which the EC defines as diffusion, is made.

60 The ECU 5.7 billion for the Framework Program is all public money; it is generally matched by the projects' participants, except for certain nonprofit organizations such as universities, which can receive up to 100 percent of project costs from the European Community. EUREKA is primarily funded by the private sector; less than 10 percent of its funding is public money according to the U.S. International Trade Commission. A rough calculation assuming that 10 percent of EUREKA costs are public and that both programs spend about the same amount of money each year, yields annual public funding of cooperative research amounting to ECU 1.6 billion, or about $\$ 1.9$ billion. Source of funding numbers is U.S. International Trade Commission, 1992: The Effects of Greater Economic Integration Within the European Community on the United States: Second Followup Report, USITC Pub. No 332-267 (Washington, DC: September 1990), pp. 16-6 and 16-10.

61 See, for example, Marie Anchordoguy, "Japanese Policies for the Supercomputer Industry," contract report for the Office of Technology Assessment, February 1991; Marie Anchordoguy, Computers, inc.: Japan's Challenge to IBM) (Cambridge, MA: Council on East Asian Studies, Harvard University, 1989); and Kenneth Flamm, Targeting the Computer: Government Support and International Competition (Washington DC: The Brookings Institution, 1987).

62 Throughout this assessment, the large commercial aircraft industry will be referred to as the aircraft industry. Only when specified does the term refer to all segments, including military aircraft.

63 This is unusually high; in 1990, a strike at British Aerospace delayed deliveries of some Airbus aircraft purchased by U.S. airlines. Aerospace Industries Association, "1990 Year-End Review and ForecastAn Analysis," addendum to Aerospace Facts and Figures 90-91 (Washington, DC: 1990).

64 This should not be read as an unqualifled indictment of military procurement and R\&D contracts. The changes over the past decade were made for understandable reasons--i.e., avoiding fraud and reducing costs-and this study did not look into how the changes have performed in doing what they were designed to do. For further information on that topic, see U.S. Congress, Office of Technology Assessment, Holding The Edge: Maintaining the Defense Technology Base, OTA-ISC-420 (Washington DC: U.S. Government Printing Office, April 1989).

65 The conversion rate is Y130 to $\$ 1$. 
Chapter 2

\section{Policy Issues and Options}




\section{CONTENTS}

A TECHNOLOGY Page

A TECHNOLOGY-FRIENDLY ENVIRONMENT $\ldots \ldots \ldots \ldots \ldots \ldots \ldots \ldots \ldots \ldots . . \ldots 4$

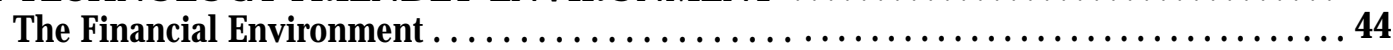

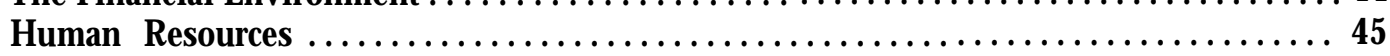

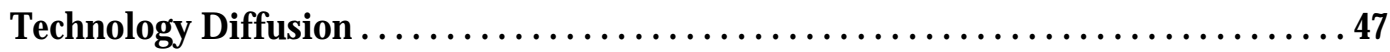

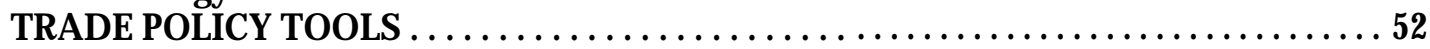

Responses to Foreign Market Barriers ............................ 53

Use of Protection .................................................. 55

Domestic Content Requirements ................................ 57

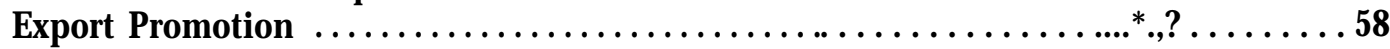

Export Controls . ..............................................59

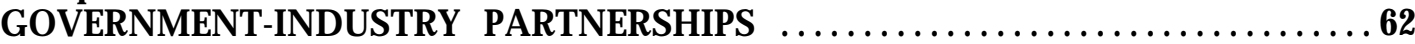

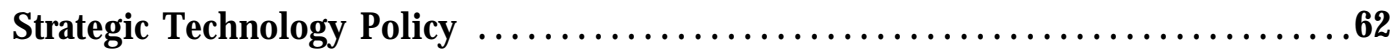

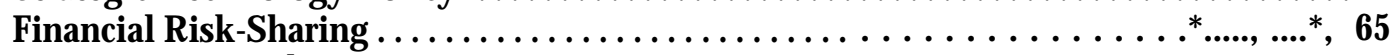

Government Purchases ........................................, 69

INSTITUTIONS FOR A STRATEGIC COMPETITIVENESS POLICY $\ldots \ldots \ldots \ldots \ldots 7$

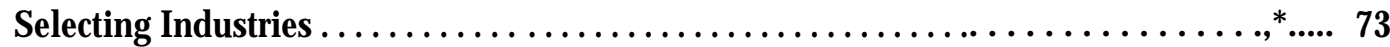

What Kind of Support? ....................................... 74

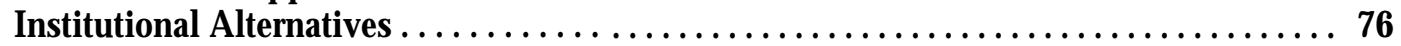

Box Page

2-A. The Baldrige National Quality Award $\ldots \ldots \ldots \ldots \ldots \ldots \ldots \ldots \ldots \ldots \ldots \ldots \ldots \ldots$

2-B. The Advanced Technology Program's F irst Round ....................... 66

2-C. National Advisory Committee on Semiconductors $\ldots \ldots \ldots \ldots \ldots \ldots \ldots \ldots$

Table

Table

2-1. Comparison of National Critical Technologies with Department of Cornmerce 
The U.S. approach to promoting particular industries has been mostly not to do it. Our underlying belief is that the national economic interest is best served by free and fair competition in the marketplace, at home and abroad. Whatever industry and trade profile results from this competition is in the national interest, and government interference is justified only when the competition is unfair or when national security is at stake. In practice, the government has intervened from time to time to support or protect certain industries. But this has been mostly ad hoc-a response to political pressures, not part of a strategy to build up competitive industries in areas of special importance.

Does this approach still make sense in a world where governments in most advanced industrial nations, including those of our most able competitors, are cooperating with private business to promote critically important industries? This study has concluded that, on the whole, free trade and vigorous competition are worthy, indeed essential goals, that must be steadily pursued. It has also found evidence from Japan, Korea, and Taiwan that selective, flexible government support of particular industries can pay off in rapid advances in technological achievement, export success, and national income. The European Community, preparing for the Single Market in 1992, is developing its own versions of support for critical industries within the Community. The core issue in this chapter is whether the United States, with its particular traditions and form of government, can combine selective promotion of strategic industries with a firm overall commitment to competition and free trade, and if so, what institutions and policy tools would be needed.

It can be argued that the U.S. form of government is open at so many places to capture by special interests that the chances of rational government decisions on aid to selected industries are slim. The good that government-industry cooperation might do in strategic fields (e.g., electronics) where we have lost competitive advantage could dissipate in expensive, useless handouts to industries whose main claim to special treatment is political clout.

This argument, however, can be stood on its head. Despite our free trade philosophy and commitment to open markets, the United States does make exceptions; it does grant some trade protection, and does sometimes subsidize favored economic sectors (e.g., price supports for farm products). Nearly always, these exceptions are motivated by politics. It is possible that a coherent strategy that first selects industries for support based on their contribution to the national good and then applies a judicious mix of supportive measures, including trade protection if needed, would result in more rational exceptions to a general regime of free trade.

Trade protection is only one part of the mix in a policy to promote strategic industries and is not by any means the dominant one. Trade protection on its own is unlikely to improve competitiveness, and in fact can have the opposite effect. If the only government action taken is to shield companies from competition, they often do not (except where there is still vigorous domestic competition) have the proper incentives to invest in technology development and diffusion, worker training, plant modernization, and other things that improve competitiveness. Another essential part of the mix is government partnership with industry in technology development, especially of high-risk technologies where the potential benefits to society are great but the prospect of returns to individual firms is too small or remote to justify a big investment. Still another part encompasses measures that spread the financial risks of adopting advanced product and process technologies to government as well as industry; such measures include indirect means, such as tax breaks that favor technology adoption.

Beyond these industry-specific strategies we broader government policies that shape the overall environment for all U.S. industries and affect their competitiveness. Taxes, spending, and the Federal budget deficit directly influence the cost of capital to firms. They wield indirect but powerful effects on our ability to compete through their influence on the growth and stability of the domestic economy and the international value of the dollar. Equally critical to industry's performance is the education of the Nation's children (a government responsibility) and the reeducation and training of adult workers (a responsibility shared by government and industry). Important as these policies are, this report cannot do 
full justice to them all. Options to improve the financial environment for industry; to upgrade the training and education of managers, engineers, and workers; and to diffuse advanced and best practice technologies throughout industry are summarized here but have been covered in greater depth in earlier OTA reports.'This chapter gives more detailed consideration to strategies that select and combine trade, technology, and fiscal or financial policies to improve the competitiveness of particular U.S. manufacturing industries. The focus is on manufacturing, not only because it dominates international trade, but also because it pays for most privately funded R\&D and provides well-paid jobs, not only in manufacturing but also in related service sectors.

The first question to ask is whether there is any need for exceptions to the Nation's free trade and free market policies. The answer starts with the strong evidence, in this report, other recent OTA reports, and elsewhere, that U.S. manufacturing is in trouble. ${ }^{2}$ Moreover, certain industries that most people regard as essential to the further technological advance of the American economy and to rising standards of living are in trouble. This is true, for example, in parts of the semiconductor and computer industries. On the other hand, the United States is not in the position Japan was 40 years ago, when that nation was behind in nearly all advanced technologies and manufacturing industries and was prepared to make sacrifices for many years to catch up. Our troubles are not those of a poor or war-ravaged country but of a rich country that has lost its edge.

All this suggests that it may make sense to offer government help to particular industries. The U.S. Government has made several starts in that direction through technology policy, most notably in the Sematech project, where the government has gone halves with industry to develop better manufacturing processes for dynamic random access memory (DRAM) semiconductor chips, at a cost to the government of $\$ 500$ million over 5 years. Yet in some critical cases, and major parts of the microelectronics complex may be among them, technology assistance is not enough. U.S. electronics companies lost their lead to Japanese competitors partly because of the Japanese fins' manufacturing excellence, but also partly because of support from the Japanese Government's trade, technology, and financial policies. Government support helped to create the large, rich, integrated Japanese electronics firms of the 1990s, whose deep pockets and command of certain critical technologies keep them a pace ahead of much of the U.S. industry. There is good reason to believe that the U.S. semiconductor industry will continue to lose ground without some trade policy help from the U.S. Government. And indeed, it has already received some trade relief as part of a broader arrangement with Japan, but while U.S. firms have gained a few percentage points' market share in Japan, mostly the results have been disappointing. ${ }^{3}$ Nevertheless, the trade agreement and Sematech were unusual, perhaps unique, attempts by the U.S. Government to strengthen a domestic industry of strategic importance.

An advantage to the strategic approach to trade policy is that it could be proactive and planned to avoid pitfalls. And it could be based on a frank appraisal of the needs and interests of the United States without casting blame on other nations. In most cases, U.S. trade policy actions are based on findings that foreign firms are competing in ways labeled unfair: that they are dumping in the United States (selling below cost or below the prices they charge in protected markets at home), or that they are taking subsidies from their governments and thus undersell U.S. fins. There often is truth in these charges. But often the whole truth is more complex, including both genuine superiority in quality and price of the foreign goods and industrial policies of foreign governments that help their firms lower production costs and acquire new technology. Dumping or subsidies may be only a part, sometimes a minor part, of the problem. To require all U.S. trade policy actions to be based on findings of unfair trade is an irritant to amity among otherwise friendly nations and is particularly galling to our trading partners when it brands their governments' industry policies as "unfair." Imposing limited, conditional, and temporary trade restrictions as part of an overall U.S. strategy to strengthen vital domestic industries is less abrasive and, under certain limited conditions, is legal under current international agreements and U.S. trade law.

If the U.S. Government should opt to develop a strategic competitiveness policy, two essential conditions would have to be met. The first is an institutional capacity to plan and carry out the policy. At present the United States lacks this capacity. Responsibility is diffuse in the executive branch even for carrying out our present policy of urging free trade and threatening sanctions for unfair 
practices. Judging by experience in the Pacific Rim and Europe, it is more effective to place the principal control over selective support for strategic industries in the hands of one or two strong agencies than to scatter it among many. Given enough interest in Congress and backing by the public, it is possible to create anew Federal agency with powers that did not exist before; witness the creation of the Environmental Protection Agency in 1970. Although an agency with power and prestige equal to that of Japan's MITI is highly improbable-and perhaps undesirable--in the American setting, it might nevertheless be possible to create an agency with the lead in competitiveness policy, a seat at the table in Cabinet meetings, and the ear of the President.

An alternative to creating a new lead agency is to use existing institutions, but assign them a much clearer mission of promoting the competitiveness of American industry. U.S. trade law already allows some leeway in pursuing this aim. What would be needed among the Federal agencies involved in trade, technology, and financial policy is a stronger understanding of which industries are critical to national economic security, better analysis of their competitive situation, closer relations with industry, and coordination of policy to support them.

This brings us to the second condition. Any strategic competitiveness policy, whether directed by a lead agency or coordinated among several lesser ones, needs wholehearted support from both Congress and the Administration. Congress can move independently in the direction of support for strategic industries. It has done so repeatedly in the past few years; for example, by creating the Sematech project via appropriations for the Defense Advanced Research Projects Agency (DARPA); by awarding DARPA funds to advance other technologies of commercial as well as military interest (e.g., flat panel displays for computers); and by setting up a purely commercial Advanced Technology program in the National Institute of Standards and Technology (NIST), under which government can take part with industry in R\&D consortia. Recently, the Bush administration has moved toward supporting a government role in developing generic technologies that could have commercial application. If Congress were so inclined, it might by resolution declare its intent to adopt policies in support of selected industries. It is harder to conceive that Congress could unilaterally create both the capacity and the will within the government to carry out competitiveness policies.

Backing for such policies by both branches of government must rest on the understanding and support of the American people. There would have to be widespread comprehension that our national economic security is at some risk, agreement that government support for critical industries could be fruitful, and acceptance that government collaboration with industry to regain excellent performance in manufacturing is not cost-free. Trade protection always costs consumers. Programs for partnership between government and industry to develop new technologies or share the financial risks of adopting them cost the taxpayer something. More basically, massive Federal budget deficits, combined with our low personal savings rate, exert a steady upward pressure on interest rates that hikes the cost of capital for all U.S. industries. And the budget deficit cannot be greatly reduced without the pain of higher taxes, cuts in favorite government programs, or both.

One explanation for the success of the Japanese government-industry partnership is the existence of a "high-growth consensus" among consumers, workers, and taxpayers as well as government and business leaders, and a willingness to make sacrifices for that purpose. ${ }^{4}$ Sacrifices of current income allowed long-term investments in technology, capital equipment, and human resources, which in turn helped to produce the large steady rises in income that Japanese citizens have enjoyed for more than 40 years. The same kind of consensus in the United States is a condition for the adoption of new government policies to restore our national competitive performance. And the same kind of future rewards-faster economic growth, increasing incomes for most citizens, healthy growth of well-paid jobs--could be expected for American citizens.

The following sections consider, first, options to foster a supportive environment for technology development and adoption. Next are options to carry out a comprehensive competitiveness policy in two areas: trade policy attuned to competitiveness needs and government-industry partnerships. Many of these options could be considered on their own merits, whether or not a more comprehensive policy is adopted. Last, there are options for new or altered institutions that would be needed to plan and implement a strategic competitiveness policy. 


\section{A TECHNOLOGY-FRIENDLY ENVIRONMENT}

OTA's earlier report, Making Things Better: Competing in Manufacturing, found that U.S. manufacturers have lost out in one industry after another to competitors who are able to make things betterto produce quality products at lower cost. And the key to this better performance is technology. Defined broadly, technology includes not only new products and advanced production machinery but also efficient organization of work and effective use of people.

Industry and government both have roles in building a better technology base for U.S. manufacturing. The report delineated four areas in which government could contribute:

- Improving the financial environment for U.S. firms, by taking action to reduce capital costs and relieve other pressures in the financial markets to show high profits every quarter. Focus on short-term profits at the expense of longer term investments in advanced equipment and new technologies has hobbled U.S. competitiveness.

- Upgrading education and training of the managers, engineers, technicians and workers needed in manufacturing. U.S. manufacturing suffers not only from the well-known defects in American public education but also from failures by managers to train workers and organize work to make best use of workers' abilities. Beyond improving public education, government can also help in the training of workers and managers and the education of manufacturing engineers.

- Diffusing technologies throughout the manufacturing sector. Many companies, especially small ones, are slow to take advantage of modern production equipment and manufacturing processes. Government technology extension services in several States and foreign countries have shown they help manufacturers select and learn to use up-to-date technologies. Other devices for technology diffusion might include a government-subsidized equipment leasing system, or easier access to technologies developed in government labs.

- Forming a strategic technology policy to promote the development of new technologies with commercial promise through collaborative ventures with industry.

Several of the options outlined above would benefit all American manufacturing, with no distinctions in kind. A hospitable environment for the generation and adoption of new technologies throughout manufacturing is needed regardless of more targeted efforts to nurture particular technologies or industries. The option for a strategic technology policy is one of those more targeted efforts, and is discussed in a later section. The discussion immediately below covers the more general options to lift the performance of U.S. manufacturing as a wholes

\section{The Financial Environment}

America's financial climate is not hospitable to long-term investments in new technology and production equipment. High U.S. capital costs favor short-term profits over long-term investments, as do pressures from the stock market. Recent studies provide solid evidence that U.S. capital costs have been substantially higher than those of Japan and Germany for more than a decade, through 1988.

Capital costs are influenced by interest rates, the economic depreciation of investment and its tax treatment, and other fiscal incentives for investment. In the United States, government policy has contributed to high interest rates, particularly in recent years. The combination of high Federal budget deficits and low personal and business savings rates has kept a relentless upward pressure on interest rates. Congress and the Administration agreed on some genuine budget discipline in late 1990, but the 1991 deficit was still projected to climb to an all-time high (declines over the next 4 years were also projected).

The dilemma is that some specific fiscal measures that might help firms to modernize and invest in new technologies would also tend to worsen the budget deficit, because they involve raising tax expenditures or lowering revenues. The budget agreement of 1990 forbids this, unless there is a compensating rise in tax revenues or decline in spending elsewhere in the same part of the budget (domestic non-defense programs). ${ }^{7}$ The serious efforts in the budget agreement to curb the deficit make sense from the standpoint of improving competitiveness since, otherwise, additional measures to reduce capital costs would probably have no more than a marginal effect. If Congress wishes to lower capital costs 
through tax breaks, the difficulty will be to find something else to cut in the nondefense budget, or get agreement to raise other taxes in compensation. Eventually, economic growth based on stronger competitive performance could help to ease the budget problems, but in the short run there would be a price to pay.

Increased savings could help to ease the upward pressure on interest rates and thus lower capital costs. A combination of carrots, sticks, and appeals to patriotism might induce greater savings. Congress could consider inaugurating a national savings campaign that rewards regular savings. For carrots, one option would be to offer government bonds at an attractive, guaranteed interest rate to people who sign up for a regular program, such as a payroll savings plan. Another option might be a tax reduction on the interest income from payroll savings.

The sticks would be policies to discourage consumption. One option is a consumption tax, crafted to escape the severe regressive effects of a flat tax either by taxing necessities lightly (or not at all) and luxury items heavily, or by granting substantial exemptions. A consumption tax might serve the dual purpose of encouraging savings while raising tax revenues. Another option would be to limit tax deductions for interest on home mortgages more strictly than the law already does. Although home equity is a form of savings for householders, these savings are tied up and unavailable for capital investments in manufacturing industries.

Tax breaks could help to lower the cost of capital to industry even if interest rates remain high. Congress could consider several options for tax inducements for technology development and capital investment. The United States has a long, but inconsistent, history of offering investment tax credits and accelerated depreciation to promote capital investment. There is evidence that these measures do have positive effects, though the magnitude is a matter of debate. They would undoubtedly be expensive; they cost tens of billions of dollars a year in lost tax revenues when they were in force. ${ }^{8}$ The tax credit for $R \& D$ is far less expensive (amounting to hundreds of millions in forgone revenue per year) but it also has less effect on competitiveness; while it rewards technology development, it has little effect on the actual adoption of new technologies in manufacturing practice. As with the investment tax credit, it is hard to pin down how much extra R\&D is due to the tax credit. Yet despite the uncertain payoffs, the arguments in favor of both kinds of programs are substantial enough that they deserve a careful hearing. It is worth repeating that under the current budget agreement (lasting through fiscal year 1994) such measures cannot be adopted unless the revenue losses they entail can be made up in some other way.

Incentives to hold investments longer might take some of the pressure off managers to focus on short-term profits. One option would be to create a capital gains tax that favors long-term gains and penalizes short-term turnover of holdings. A variable rate scheme might be adopted, with a high tax rate (say, 50 percent) for gains on assets held less than 1 year, and the rate declining through several steps to a low level (perhaps 10 or 15 percent) after 5 or 6 years. The measure would be most effective if its application were extended to pension and other funds that are now tax-free, since these funds hold one-third of the stock and probably account more than half of the transactions on the capital markets.

Stability in the economic and political environment is a great asset to business, and has been well provided in Japan and Germany, much more so than in the United States. Germany has successfully concentrated on keeping prices and exchange rates stable. In Japan, business has benefited not only from long-sustained economic growth and low inflation but also from policymakers' sensitivity to the effects on business of macroeconomic changes. For example, in the mid-1980s when the yen suddenly rose greatly against other currencies, the Japanese Government made low-interest loans easily available to firms (especially small ones) so they could ride out the period of adjustment. American manufacturers penalized by the very high value of the dollar in the early 1980s got no such help.

\section{Human Resources}

Success in manufacturing depends on having well-trained people, comfortable with the demands of advanced technology, at every level from the manager's office to the shop floor. In frost class competitive industries, production workers must sharpen reading and math skills, take more responsibility, cooperate more closely with others, and understand their own roles in the entire production system. In other words, more is being demanded of workers. At the same time, the typical American 
education leaves many young people ill-prepared for work, and training of the people already in the work force is equally deficient. Our major trade competitors (i.e., Japan and Germany) offer more and better training, both to young people preparing for work life and to active workers. The situation in the United States is likely to get worse before it gets better. About half the new entrants to the U.S. work force up to the year 2000 will be members of minority groups, and two out of five minority children grow up in poverty. Poor children drop out of school disproportionately and many never learn the skills they need for productive work.

A great deal of public policy attention is being given to the critical need for improved public schooling. But even if help arrived tomorrow, it would be many years before the results showed up in the work place. Meanwhile, another approach is government-industry programs to offer better training to those already in the work force. This would include not only financial commitments from both government and industry but also a management style that gives workers a real stake in the enterprise and real responsibilities for quality and efficiency, and organizes work to take advantage of workers' training and abilities. Some of the options for training active members of the work force are as follows:

Government encouragement to industry to train workers encompasses several possibilities. The most aggressive and far-reaching of these options, which guarantees more training without any direct cost to the government, is a payroll-based training levy. Employers would have a choice between spending a certain amount on training their workers (say 1 percent of their payroll) or paying the same amount into a national training fund. Several foreign countries (including France, Germany, Ireland, and South Korea) use the system, and four States in the United States (California, Delaware, Rhode Island, and Alaska) raise training funds through a small payroll-based levy. A less pervasive option is government technical assistance to help trade associations or joint labor-management groups identify industry-wide training needs and acquaint their members with training materials and best practice approaches. U.S. trade associations are far less active in training than their European counterparts, yet it is a low-cost way of wholesaling training information to individual firms. Cost-sharing by governments could get the activity started. A similar option is for the government to offer small grants to help firms set up training consortia. Small companies could share the costs of instruction and facilities, and large ones could use consortia to help their supplier networks develop common training appreaches. ${ }^{10}$

Training delivered to individual workers includes several existing government-funded programs that need either revitalizing or more financial support to fulfill their promise. Apprenticeship can also bean excellent way for workers to get real skills training with recognized credentials. The American apprenticeship system once served industry and a small segment of the work force well, but fell into decline in the 1980s with cuts in funding and staff for the Labor Department's Bureau of Apprenticeship and Training, and shrunken support from industry. The Federal vocational education program has many excellent features including school-to-work programs, cooperative business-labor-education training programs for active employees, and some support for apprenticeships. The problem is finding enough money to support these programs in a meaningful way. For example, a demonstration workplace literacy program has generated keen interest with hundreds of application, far more than the program could accommodate.

Training linked with technology assistance is an effective combination. Many U.S. manufacturing fins, especially small ones, have trouble adopting new technologies. One source of the trouble is inadequate training. The United States is far behind many other countries in helping individual firms learn about and use new technologies, but some States and a small Federal program are making efforts in this direction (as discussed more fully below). The best of these programs integrate training into their industrial extension efforts. The National Institute of Standards and Technology (NIST) in the Commerce Department is the agency mainly responsible for the Federal Government's modest efforts in technology diffusion. It could link training with technology in its own programs and those of other Federal agencies, and could also serve as an information clearinghouse for State agencies trying to do the same thing.

Improving the quality of worker training is, in part, a Federal responsibility. The military is the largest training institution in the United States. Besides using conventional classroom and on-the- 
job training, the armed forces have developed instructional technologies that might be adapted and transferred to civilian use. Although the law calls on the Department of Education to take on this task, no funds have been provided for it. The Department and other Federal agencies might also take a more active hand in testing and evaluating workplace training, with particular attention to computer-aided training technologies.

Education and training of engineers is a central issue for competitiveness. Although there seem to be plenty of engineers now (the United States has about as many engineers per thousand workers as Germany and Japan), the supply could dwindle a few years hence because of the demographic facts. The group most inclined to enter engineering, white males, is shrinking gas a proportion of children in the educational pipeline. In the long run, an adequate supply of engineers depends on our success in giving all our children a good education, including better math and science education starting in the early grades. Meanwhile, Federal scholarships and grants that encourage minorities and women to take up science and engineering careers seem to be getting results and deserve support. Retraining of midcareer engineers is another way to enlarge the supply over the next few years, especially as many engineers are losing jobs in defense industries, with the cutback in military spending. With government support, retraining courses might be targeted to fit the needs of commercial manufacturing.

Problems of manufacturing are generally neglected in university engineering departments. The elitism of U.S. engineers and their remoteness from the shop floor are weaknesses of American manufacturing. While this is primarily an issue for managers, government might support education and research in manufacturing engineering. One option might be to create a Manufacturing Sciences Directorate in the National Science Foundation.

\section{Technology Diffusion}

U.S. institutions for diffusing new technologies throughout manufacturing are thin. Even large firms with sufficient resources often neglect to take what they could from outside the firm. Many of our 355,000 small and medium-sized manufacturing firms are worse off, with only scant and spotty exposure to new technologies. While some small fins, such as Silicon Valley startups, are at the technological forefront, a great many others find the effort to keep informed beyond their means. The part played in U.S. competitiveness by these bread-andbutter small manufacturing firms can be critical. Large auto companies, for example, must depend on their myriad suppliers to deliver well-made parts and components on time.

Both public and private means of diffusing technology are weak in the United States. It is uncommon for large U.S. manufacturers to lend technical assistance to their suppliers, something that is everyday practice in Japan. And there is little in this country to compare with the network of free, public technology extension services for small and medium-sized manufacturers that blankets Japan. Nor do we have anything like the apprenticeship system that trains more than half the young people in Germany and Sweden and produces a high level of skills in the work forcr--a key factor in diffusing new technologies throughout manufacturing in those countries.

Throughout the past decade, Congress has taken actions aimed at transferring advanced technologies from lab to factory, bringing small and mediumsized firms up to date in best practice manufacturing technologies, and removing legal barriers that might interfere with technology advance in manufacturing. Some of these actions are well along. Others have just begun.

Congress may wish to strengthen and expand some of the more promising existing programs and consider adding others. No one program, by itself, is likely to improve U.S. manufacturing performance dramatically or rapidly. Some may fail. But given time to prove themselves, several of these measures in combination could pay off in real contributions to competitiveness.

Technology extension has the potential to improve the manufacturing performance of small and medium-sized American fins. Defining industrial extension as one-on-one technical advice given to individual fins, 16 States had real extension programs (including field agents) in early 1991, and another 7 had technology demonstration or assistance centers. At a rough guess, total spending for 27 extension or demonstration programs in 23 States amounted to about $\$ 50$ million. Most of these programs are new, although a handful, such as Georgia Tech's Industrial Extension Service, have years of solid experience. Federal industrial exten- 
sion is still smaller and newer. A program of Manufacturing Technology Centers was established in the 1988 Trade Act, and by 1991 included five centers, with another planned for 1992. Fiscal year 1991 funding was about $\$ 12$ million, with nearly \$14 million proposed for 1992. The Centers are required to get matching funds from the States or private sources and, by law, cannot receive Federal funds for more than 6 years. Because many States were in financial distress in 1991, interest in supporting new Centers had declined somewhat. ${ }^{12}$

For perspective, compare these few and scattered programs with those in Japan. Besides the nationwide system of 185 technology extension centers, funded at about $\$ 500$ million (half from the national government and half from prefectures), many Japanese cities, wards, and other localities support industrial halls that offer similar services. In addition to individual technical advice from field agents, these services include regular workshops on common manufacturing problems, use of specialized or costly equipment at low fees, demonstrations of new technologies, and referrals to expert consultants for advice on difficult problems.

There is room for expansion of both State and Federal technology extension services in the United States. States, being closer to clients, may be more in touch with local needs. On the other hand, various kinds of manufacture tend to be regionally concentrated, and Federal agencies can more easily span State lines. Moreover, while some States do an excellent job of delivering services, some are less adept. A Federal effort could help to set an acceptable, consistent quality of service.

Supposing Congress wished to support a wider network of technology extension centers, it might set a rninimum goal of providing services in some $\mathbf{1 2 0}$ centers to 24,000 small and medium-sized firms nationwide per year-i. e., about 7 percent of the nation's 355,000 manufacturing firms with fewer than 500 employees. This would cost about $\$ 120$ to $\$ 480$ million per year, depending on the level of service. Some of the funds could come from State or private sources, though it may be unrealistic to demand that these sources take over all the funding within a few years (as Federal law now provides in the case of the Manufacturing Technology Centers).

A program of this size is modest and might be overwhelmed with requests for assistance once the centers gained a good reputation. The State of
Georgia's highly regarded industrial extension service, run by Georgia-Tech, serves a similar proportion of its manufacturers; it does not advertise for fear of being swamped with requests. It is worth noting that the U.S. Agricultural Extension Service is funded at $\$ 1.2$ billion per year (with about $\$ 370$ million, or 30 percent, coming from the Federal Government), and has 9,650 county agents, 4,650 scientific and technical staff, and offices in nearly every county in $\mathbf{5 0}$ States. Agriculture accounts for 2 percent of the U.S. gross national product, manufacturing 19 percent.

Government financial aid tied to improvements in technology can be an effective means for modernizing manufacturing. It has not been much employed in the United States (except to induce investments in pollution control equipment), but has been widely and ingeniously used in Japan. One option with at least two distinct advantages is a system that would allow manufacturers to lease modern production equipment, or buy it on the installment plan, at subsidized rates. This scheme would not only encourage manufacturers to use up-to-date equipment, such as computer numerically controlled (CNC) machine tools; if the system bought U.S.-made equipment it could also benefit U.S. builders of the machinery by offering a stable, assured market for part of their output. An equipment leasing system for CNC machine tools, for example, could start with modest government funding, probably about $\$ 3$ million per year. ${ }^{13}$ It might be open only to small manufacturing fins, or could be open to all, with lower rates for small fins.

It is also possible to make government-backed financing to small manufacturing firms conditional on a technical assessment. However, that presupposes a nationwide, readily available industrial extension service, which does not yet exist in this country. Moreover; Federal programs of financial support for small business are not large enough to reach many fins. All the programs combined (including loans, loan guarantees, and investments in development corporations) amount to about $\$ 3.5$ to $\$ 4$ billion per year for every kind of small business, not just manufacturing fins. In Japan, the required technical assessment is common practice, and there it does matter. Although exact comparisons are not possible, we do know that Japanese loans and loan guarantees to small firms are at least 20 times greater than similar U.S. financial aid, and the level of subsidy is higher (some government loans for modernizing equipment are interest-free). 
As of 1988, nearly 11 percent of all outstanding loans to Japanese small businesses for plant and equipment investment were from government financial institutions, a big enough chunk to make required technical assessments significant. ${ }^{14}$

Another option is tax incentives for investments in advanced manufacturing equipment. This is another of the many inducements the Japanese Government offers to businesses, especially small ones, to modernize. For example, Japanese tax law was changed in 1984 to allow very rapid depreciation by small firms of high-technology ("mechatronic") equipment, including $\mathrm{CNC}$ machine tools. This set off a flurry of buying known as the "NC-ization period."

Commercialization of technology from Federal laboratories is a goal that Congress has pursued for more than a decade through laws and oversight. There has been progress, especially in the last year, but the goal is not yet fully realized. The U.S. Government spends about $\$ 23$ billion per year for R\&D in Federal laboratories; only a minor portion of this is of commercial interest. Much of the labs' $R \& D$ is for advanced development of weapons, and a large share is for basic research quite far from the commercial arena. However, some lab results have proven useful to civilian industry, and companies have benefited from using specialized lab facilities (e.g., the Synchrotrons Light Source at Brookhaven National Laboratory and the Combustion Research Facility of Sandia National Laboratories). Two principal ways of bridging the gap between lab research and commercial manufacturing are: 1) granting firms some exclusive rights to inventions from the labs, so it is worthwhile to invest in commercializing the technologies; and, 2) creating cooperative R\&D projects, in which industry puts up half the money and is involved in the planning from the beginning.

Two obstacles on the government side have been too little money and too much red tape. With other missions taking priority, lab funding of technology transfer has been scanty. Bureaucratic hoops in the parent agency, especially delays for legal review, have often stalled technology licensing and the conclusion of cooperative agreements between the labs and private industry for many months, sometimes a year. ${ }^{15}$

Congress has taken steps to cut the red tape and provide more funding for technology transfer from the labs. Since the passage of the National Competitiveness and Technology Transfer Act of 1989, technology commercialization has received more attention at the Department of Energy (DOE) and its labs. The high-level Technology Transfer Project Group has focused on streamlining approvals for both licensing and cooperative $R \& D$. Moreover, DOE has extended to some labs more control over patents and data rights from lab research, permitting a faster track to licensing technologies with commercial appeal. ${ }^{16}$ For its part, industry has become more aggressive at seeking out lab technology .17

The heightened "attention to commercialization has yielded some results. Cooperative $R \& D$ has increased. ${ }^{18}$ But despite the progress, funding is still limited. DOE's Defense Programs devoted only \$20 million, or 0.7 percent of its $\$ 3$ billion fiscal year 1991 R\&D budget for technology transfer. Sandia National Laboratories' direct spending on technology transfer does not exceed 0.5 percent, or \$5 million, of its $\$ 1$ billion budget, and many other labs have earmarked less or nothing at a11. ${ }^{19}$ Congress might consider designating some of the labs' R\&D appropriation for promoting commercialization, perhaps mandating that a few percent of the budget be set aside for the purpose. Activities would include identification and marketing of promising technologies, patenting when appropriate, and participating in cooperative $R \& D$ projects. Bills being drafted for the $102 \mathrm{~d}$ Congress would increase the labs' role in promoting technology commercialization. ${ }^{20}$

In addition, Congress could take action to remove some remaining barriers to commercialization. For example, the law might be changed so that software created by government employees can be copyrighted, which would sometimes make its commercialization more feasible. ${ }^{21}$ At some point, however, major responsibility for energetic technology transfer must fall to the labs, their parent agencies (especially DOE and the Department of Defense), and private companies.

Japanese technology is another lode that U.S. companies could mine if they begin to pursue new technologies from outside sources more aggressively. There are difficulties-the most obvious being the language barrier-in getting access to Japanese technologies. Also, most Japanese technology is developed by private industry and thus is less accessible to outsiders than technical knowledge 
that is freely available at universities and public institutions.

A few universities have fellowship programs that send American scientists and engineers to Japanese companies and research institutions on long-term projects, and the National Science Foundation (NSF) has recently established similar programs, largely funded by grants from the Japanese Government. The NSF-Japan programs are not yet fully subscribed, but are likely to attract more applicants as they become better known (typical of university programs). Congress may wish to monitor the progress of the NSF programs, possibly adding funding if they become oversubscribed. Another option would be to establish a congressional U. S.Japanese Fellowship Program, taking advantage of the visibility and prestige conferred by the sponsorship of Congress (perhaps especially in Japanese eyes). In addition, Congress might wish to encourage sabbaticals in Japan for researchers working in Federal labs. A longer term, more fundamental option is to promote Japanese language instruction both in the public schools and in universities, especially for scientists and engineers.

Improved protection of intellectual property and modest changes in antitrust law might bolster the competitive position of some U.S. manufacturing industries. Better intellectual property protection could start at home with speedier enforcement. Patent cases that go to trial take an average of 21/2 years before a decision. Congress might help by designating special patent judges with the technical experience to move cases through expeditiously (similar in principle to the tax courts). As for foreign markets, the Japanese patent system is a particular problem. It is slower than the U.S. system in issuing and enforcing patents, and it strongly favors licensing of patents, which U.S. companies do not always wish to do. The U.S. Government is negotiating with the Japanese on these and other problems. In addition, Congress may wish to establish a program in the Patent Office or elsewhere in the Commerce Department to provide information to U.S. companies about the Japanese patent system, which most firms do not understand.

Antitrust law and enforcement have been relaxed in the past decade, but some cooperative endeavors that could help U.S. firms may be dampened by fear of antitrust action. Changes in antitrust law and enforcement should be approached with caution; the laws have served the country well for many years in maintaining g competition. However, the laws' complexity and vagueness, together with stiff penalties, may discourage some useful cooperation. Congress amended the law in $1984^{22}$ to make joint $R \& D$ easier, chiefly by reducing the maximum penalty from treble damages to single damages for publicly registered projects. Other options might include extending the 1984 Act to cover joint manufacturing (as proposed by the Administration in the 102d Congress), and case-by-case review and advance certification by the Justice Department that particular joint projects do not violate the law. Another possibility is to establish safe harbor market shares, so that cooperating firms with combined market shares below a certain percentage would not be in violation.

Perhaps most important, Congress could instruct the Justice Department and the courts to evaluate possible mergers and joint ventures in light of a key fact of modern international competition: that foreign firms with low U.S. market share may rapidly increase that share and even become dominant, if they possess strategic technology, large world market share, sufficient financing, or other advantages. If this fact is accepted, then under standard antitrust analysis mergers or joint ventures between U.S. firms should sometimes be permitted to avoid eventual dominance by a foreign firm. Similarly, some buyouts of U.S. firms by a foreign firm would sometimes be stopped, in order to avoid eventual dominance by the foreign firm. These arguments have often been met with skepticism; Congress could urge that they be taken seriously.

Information and exhortation to American manufacturers on how to make things better, given under U.S. Government auspices, might not seem a very promising strategy. But a Department of Commerce program (the Malcolm Baldrige National Quality Award) does that very thing, and has proven astonishingly effective in just 3 years. It costs the taxpayers almost nothing. Even the administrative expenses are covered by private contributions and applications fees from companies vying for the award.

The award was created by Congress in 1987. It is given to companies or organizations that have "substantially benefited the economic and social well-being of the United States through improvements in the quality of their goods or services from 


\section{Box 2-A-The Baldrige National Quality Award}

The manager of the Baldrige Award, the National Institute of Standards and Technology (NIST) of the U.S. Department of Commerce, sets out seven major criteria that contestants must address in their applications for the award. NIST's Application Guidelines list the maximum points applicants can win in each of the categories, adding to a total potential score of 1,000 points.

Leadership: The senior executives' success in creating and sustaining a quality culture. 100 points.

Information and Analysis: The effectiveness of the company's collection and analysis of information for quality improvement and planning. 70 points. points.

Planning: The effectiveness of integration of quality requirements into the company's business plans. 60

Human Resource Utilization: The success of the company's efforts to utilize the full potential of the work force for quality. 150 points.

Quality Assurance: The effectiveness of the company's systems for assuring quality control of all operations. 140 points.

Quality Assurance Results: The company's results in quality achievement and quality improvement, demonstrated through quantitative measures. 180 points.

Customer Satisfaction: The effectiveness of the company's systems to determine customer requirements and demonstrated success in meeting them. 300 points.

Every year, six awards may be given, two each in three categories, Manufacturing, Service, and Small Business. Awards need not be given if no one qualifies. The winners are shown in the table below.

Winners of the Baldrige Award

\begin{tabular}{cll}
\hline Manufacturing & Service & Small business \\
\hline $1988 \begin{array}{l}\text { Motorola, Inc. } \\
\text { Commercial Nuclear Fuel Division, Westing- } \\
\text { house Electric Corp. }\end{array}$ & & Globe Metallurgical \\
$\begin{array}{l}\text { Merox Corp., Business Products \& Systems } \\
\text { Xeriken \& Co. }\end{array}$ & Federal Express & Wallace Co., Inc. \\
$\begin{array}{l}1990 \text { Cadillac Motor Car Division } \\
\text { IBM Rochester }\end{array}$ & & \\
\hline
\end{tabular}

Iu.s. Department of Commerce, National Institute of Standards and Technology, Malcolm Baldrige National Quality Award, pamphlet (Gaithersburg, MD: NIST, 1991).

effective practice of quality management. ${ }^{23} \mathrm{Six}$ awards may be presented each yeat--two each for manufacturing, services, and small business-but none need be given if no one qualifies. In the first 3 years of the program (1988-90), there were 203 applications and 9 awards given, 6 to manufacturing companies, 2 to small business, and 1 to a service company (see box 2-A).

The award has been an excellent means of technology diffusion. Just filling out an application, following NIST's 42-page booklet of Application Guidelines, can be an eye-opener. For example, the company must satisfactorily relate how it gives customers easy access to assistance or opportunities to comment, and how it follows up with customers to see if they are satisfied with products and services. These are just 2 of 33 detailed areas that companies must cover in their applications (50 pages for small companies, 75 pages for large ones). According to Jerry Junkins, CEO of Texas Instruments, "If you measure your-self against the criteria laid out by the Baldrige award, you have a blueprint for a better company. ${ }^{24}$ All applicants, win or lose, receive reports from examiners outlining their good and bad points, and this is enough to improve some companies' quality efforts. Some companies do not enter but use the Baldrige criteria as a company standard. One winner, Motorola, demanded that 3,600 of its 
larger suppliers prepare to compete or face being dropped. ${ }^{25}$

Winners must share with others details of what they did to win the award; company representatives give hundreds of speeches a year and hold large briefing sessions for executives of other companies, including their competitors. One manager who attended a winner's presentation came away amazed at the level of detail, which he described as "everything but the financial data." After hearing the presentation, he reckoned that his own company, considered a leader in its high-technology field, would not be able to qualify for the award for at least 6 years.

Despite a few criticisms of the Baldrige award (e.g., some consultants consider the criteria are too directive), its good effects appear to far outweigh any adverse ones. In the general area of quality standards, however, there may be room for further government action. Suppliers trying to meet formal quality requirements for large customer fins, particularly the Big Three auto assemblers, are frustrated by slightly varying requirements and separate certification. If Ford's Q-1 and GM's Mark of Excellence certifications were made consistent and interchangeable, suppliers believe they would benefit. Through oversight, Congress might encourage NIST to look into the question and work out a constructive solution.

\section{TRADE POLICY TOOLS}

Since World War II, U.S. policy has promoted free trade by keeping its own market generally open and urging other countries to do the same. For two or three decades this policy served U.S. interests well enough. U.S. manufacturing technology was so far ahead of most other countries, and the U.S. market so much larger than others, that manufacturers flourished even in cases where the free trade was mostly one way-free for U.S. imports but quite encumbered for exports. At the same time, opening American markets to foreign goods served the U.S. policy of promoting economic development in poorer countries and cementing loyalty among Cold War allies.

Today, free trade is not invariably to the United States' advantage. Advanced countries have rebuilt their war-damaged economies, several poorer countries have begun to industrialize, and the United States is no longer predominant. In some industries and technologies it has fallen to second place. This is a particular concern in key high-reward industries such as electronics, including parts of the semiconductor and computer industries. These are industries that can help make a country rich, because markets are rapidly expanding, producers can capture substantial economies of scale and learning, and the industry has technology spillover benefits for the rest of the economy.

Most of the United States' decline was selfinflicted. The U.S. Government has never formed the partnerships with industry that helped its best competitors advance. Many of its industries have stuck with outmoded management and technologies while others passed them by. Part of the trouble, however, was that foreign market barriers and export drives deprived key U.S. industries of needed revenues and experience, sapping their strength and even undermining their existence. The neardestruction of the U.S. consumer electronics industry was caused partly by closed foreign markets combined with dumping (selling at prices below fair value) of foreign goods in the U.S. market.

U.S. trade law and policy are supposed to prevent events like these. If foreign markets are closed to U.S. goods, the U.S. Government tries to get the barriers removed. If imports are subsidized by foreign governments, or if foreign subsidies or market barriers result in dumping, the U.S. Government can in some circumstances levy a duty on the imports intended to compensate for the foreign advantage. However, foreign market barriers may take years to remove. U.S. law regarding subsidies and dumping has been at best slow and incomplete in compensating for the advantages foreign firms receive from their governments. Moreover, tariffs are inherently inadequate to compensate for another country's domestic policies; when foreign governments help to give their industries a competitive edge, it takes more than trade policy for U.S. industries to catch up.

U.S. trade policy could more effectively promote U.S. competitiveness if it were part of an overall strategy. A redirected trade policy might have three operating principles. First, when a critical industry is in trouble, the primary government response would be a domestic one. Measures might include $R \& D$ support, tax breaks and incentives for $R \& D$ \& capital investment, support for technology diffusion, and support for education and training. Trade 
measures-trying to open foreign markets, and protecting the U.S. market--could be used when necessary, but in a subordinate role. Second, efforts to open markets would focus on areas of the greatest strategic importance. Third, when opting to use protection, the basis would not be legalistic criteria, but rather the industry's need and place in the economy.

The important industries are not difficult to identify. Several government and private reports in the United States, Japan, and Europe have listed high-priority technologies that drive competitive industrial performance, and their lists are similar. They include electronic components, information technologies, materials and associated processing, manufacturing process technologies, and propulsion and powertrain technologies. ${ }^{26}$ Ideally, the important industries would be identified by an institution responsible for a comprehensive government approach to trade and competitiveness policy. Otherwise, individual government agencies involved could draw up their own lists.

This leaves the question of how to fashion assistance to threatened U.S. industries. There is the danger that government assistance will be squandered on industries unable to compete, or that assistance will remove industries' incentive to improve their competitiveness. However, other countries' experiences provide significant guidepostsshowing, for example, that industry should take the lead in proposing joint government-industry R\&D programs and shoulder much of the cost; that policies should conform with market forces as much as possible; that U.S. industry must compete with the best in the world; and that industry must make its own efforts to improve its competitiveness and outgrow the need for assistance. Ideally, a government institution with overall responsibility for trade and competitiveness would coordinate strategic assistance. But in the absence of such an institution, individual agencies could act on their own according to these principles. For example, the Department of Energy, in its pilot program for cost-shared R\&Din high-temperature superconductivity, participates only in projects that industry proposes and for which industry pays about half the cost. ${ }^{27}$

Finally, these options come with an important caveat. This report is addressed to Congress, and presents options that Congress may wish to adopt. Yet there is little that Congress can do on its own. It can state goals, allocate resources, and give guidelines, but strategic policies to improve U.S. competitiveness policies require initiative and judgment by the executive branch. The sympathies and energy of the executive branch are needed to get the job done.

\section{Responses to Foreign Market Barriers}

Foreign market barriers can hurt U.S. industries. ${ }^{28}$ While GATT has reduced quotas (quantitative restrictions on imports) and tariffs (taxes on imports, also called duties), there are many other barriers to imports. These include burdensome customs procedures; preferential government procurement; discriminatory standards and regulations; and companies' agreements or practices, sometimes tolerated or encouraged by the government, not to buy foreign products.

Normally, the U.S. response, if any, is to negotiate to eliminate barriers. The Office of the United States Trade Representative (USTR) leads the negotiations, with assistance from other agencies. The USTR's lean staff can negotiate only a limited number of cases, and may be so overburdened as to affect the quality of negotiations. And the fast turnover of many senior (political level) negotiators and policymakers has sometimes hindered the United States from pressing its position consistently over the years. High ranking government officials have frequently left government to represent foreign manufacturers or their U.S. importers, giving those interests both access to top government decisionmakers and the savvy to exploit any weaknesses on the U.S. side.

Congress could address these problems in various ways. It could expand the USTR staff, enabling it to take on a wider range of foreign market barriers and match other nations, Japan in particular, in preparation and negotiating strength. Congress could also reduce the number of political appointments and add more high-level career civil service slots dealing with trade policy to the USTR, the Commerce Department, and other agencies; making long-term service more attractive would improve institutional memory and facilitate the steady pursuit of goals over the years. Finally, Congress could prohibit senior trade officials from representing foreign interests for several years after they leave government service.

Other reasons why foreign markets can take many years to open are harder to address. Barriers take 
time to identify; other countries can stall negotiations; countries hedge on promises to remove barriers; and when one barrier is removed, another can take its place. Japanese trade barriers especially are often like an onion, with layer after layer to peel away. And some hindrances are ingrained in a country's social norms and domestic policy, making their removal difficult even if the foreign government is willing.

Success often depends on the leverage the United States has over other countries. The two major sources of leverage are limited. First, when the country and subject matter are covered by GATT, the United States can invoke GATT dispute resolution procedures. This process is slow and uncertain, since the other country can veto decisions adverse to its interests. Recent developments in the GATT Uruguay Round have improved the process; further improvements may yield a more reliable means for eliminating market barriers.

Another approach would be to create a new, multilateral trading system, consisting of only those countries that are truly willing to abide by the dictates of free and open trade, and to negotiate bilateral deals with nations outside the system. ${ }^{29}$ This kind of trade management far exceeds anything we have done in the postwar period, and creating it would require much time and patience. The new trade regime probably would need a strong enforcement mechanism, perhaps along the lines of the International Trade Organization (ITO), which was originally proposed in the late 1940s but was blocked by the United States and therefore never formed. ${ }^{30}$ Congress might wish to forma task force to investigate what such a revised system could entail.

The second source of leverage is to threaten retaliation under Section 301 and related sections of the Trade Act of 1974, as amended, ${ }^{31}$ which allow the United States to impose punitive barriers to imports from another country in retaliation for that country's "unfair" trade practices. However, the U.S. Government is often reluctant to retaliate under Section 301. The retaliation could violate GATT so publicly as to make the United States vulnerable to criticism (including formal complaint and investigation under GATT rules) or further retaliation. Punitive barriers on imports would not solve the U.S. industry's problem and could create problems for downstream industries in the United States. And even the start of a Section 301 investigation angers foreign countries, for whom Section 301 is a symbol that the United States considers its national laws superior to GATT's international law. ${ }^{32}$

Because of these problems, negotiations to open foreign markets are in many cases slow and ineffective. Barriers that cause particular damage--such as Japanese barriers to the sale of semiconductors and supercomputers (chs. 4 and 6)--often persist the longest. While market opening is a worthwhile long-term goal, it often provides little or no relief in the short term, during which time the affected U.S. industry can suffer serious damage.

Accordingly, it might make sense to change the U.S. response to foreign market barriers. The response could be primarily domestic programs to aid the affected industry. Often these programs would be enough. The U.S. market, still the world's largest for many products, can often support the industry. In such cases, the United States could still negotiate to open foreign markets, but in a low-key manner, to encourage change without angering the countries involved. It would also make sense to allocate the government's limited resources according to an industry's strategic importance.

However, domestic programs might not always be enough. This might be the case with semiconductors. Even though the U.S. Government is contributing $\$ 500$ million in $R \& D$ assistance to the industry over 5 years through Sematech, that is insufficient to arrest the U.S. industry's competitive decline vis-à-vis Japan. The semiconductor industry is particularly dependent on economies of scale and learning, and without access to the Japanese marketthe largest and most discriminating in the worldthe U.S. semiconductor industry will likely keep slipping.

In such a situation-a key industry in danger if a foreign market remains closed-the United States could consider an aggressive program to open the foreign market, if necessary by a prompt threat of retaliation under Section 301. These cases could merit cabinet level or even Presidential involvement. Semiconductors apparently is a case in which aggressive action was deferred for too long. Despite negotiations begun in 1972, Japan's semiconductor market remained largely closed to U.S. products. ${ }^{33}$ The United States commenced a Section 301 investigation only in 1985, leading to an agreement in 1986 that was broken by Japan, followed by U.S. retalia- 
tion in 1987, and finally, starting in 1989, a modest increase in U.S. firms' share of the Japanese market.

While it might occasionally make sense for the United States to pull out all the stops in trying to open a foreign market, such cases must be chosen carefully. As discussed above and in chapter 4, the threat of retaliation-and execution of this threatis likely to anger foreign countries and could have other serious adverse consequences. It is thus important to rank foreign market barriers, identifying those industries that are most important and in which barriers have a pronounced effect that domestic programs cannot alleviate. In general, the USTR has not made strategic priorities. For example, in the early 1980s, the U.S. Government successfully pressured Japan to buy a certain amount of U.S.caught fish, but would not do the same with semiconductors. ${ }^{34}$ This lack of strategic planning was evident and surprising to Japan. Clyde Prestowitz, a key Japan negotiator in the Commerce Department for most of the 1980s, recalls: “Once an official of the [Japan] Economic Planning Agency asked how we created our agendas. His agency, he said, had carefully studied the competitiveness of various U.S. industries, and in his opinion there were much better issues for the U.S. to pursue than the ones on its list. ${ }^{135}$

\section{Use of Protection}

U.S. industries normally receive trade protection only when imports are dumped or subsidized. ${ }^{36}$ In this case, an extra duty can be assessed in an amount that in theory will precisely counteract the subsidy or dumping. In principle, this extra duty does not distort trade from what would occur with free trade and a free market, but rather corrects a distortion already present. The goal is to put U.S. industry back on an equal footing. Such extra duties are in principle consistent with GATT.

However, the U.S. law and practice regarding subsidies and dumping by and large fail to compensate for the advantages foreign governments create for their firms. Reasons for this include delay, difficulty in proving subsidies or dumping, the law's ignoring or devaluing certain subsidies, difficulty in proving the required injury, and the high expense of legal proceedings. A further problem is that the effects of government assistance can increase over time rather than dissipate as the law assumes. To some extent, the law's limited effectiveness stems from adherence to GATT requirements.

These U.S. laws, however imperfect, are now often the only line of defense for key industries facing stiff foreign competition; it could be harmful to weaken them further as many GATT members are seeking to do in the Uruguay Round. However, strengthening these laws might lead to a flood of cases, anger trading partners, provoke legal challenges under GATT, and result in imposing extra duties that might not be in the country's best interest.

The debate between those who would strengthen and those who would weaken the subsidy and dumping laws might be resolved by shifting the policy focus of import protection. First, for beleaguered U.S. industries, the primary response would be domestic programs to help the industry compete or rationalize. (To rationalize means to shrink, but in a planned fashion that also seeks to improve technology in potentially competitive subsectors.) This could include R\&D support, tax breaks, and other measures designed either to help an industry regain technical parity with foreign competitors or to ameliorate the shock of downsizing.

Where domestic measures alone might not suffice, protection could be used, lasting only as long as strictly necessary. Criteria for awarding protection would include the industry's need, its merit (including whether the industry was making reasonable efforts on its own and showed promise of effectively competing on its own), and the importance of the industry in the U.S. economy. While the presence of subsidies or dumping might be relevant to the decision to grant relief from imports-for example, to show that an industry is being beaten only because of the intervention of foreign governmentssubsidies or dumping would be among many factors to consider. Likely adverse effects on downstream industries would also be considered, though the government could take measures to ameliorate them (e.g., special tax breaks).

The protection component of such a reoriented policy in principle could be consistent with GATT. Such an approach could build on Section 201 and the following sections of the Trade Act of 1974, as amended, under which the government can impose temporary relief (up to 8 years) when increased imports "cause or threaten serious injury" to an existing U.S. industry .37 Section 201 follows GATT's so-called "escape clause," which permits import 
barriers in this situation but requires the payment of compensation (normally reduced tariffs on other items) to affected countries (see ch. 4). Under Section 201, the U.S. International Trade Commission (ITC) determines whether the injury requirement is satisfied and, if so, recommends relief. The final decision on relief is up to the President, who has great flexibility in choosing the nature of relief. Forms of relief include quotas, higher tariff rates, and negotiations with foreign governments "to address the underlying cause of the increase in imports or to otherwise alleviate the injury. ${ }^{1{ }^{38}}$ The President must consider the efforts that the domestic industry is making on its own to improve its performance; every 2 years thereafter, while the protection lasts, ITC must report to the President on industry's continuing efforts to improve, and the President may modify or terminate relief if he finds those efforts insufficient.

However, as currently administered, Section 201 would have limited usefulness as a vehicle for strategic use of protection. The serious injury requirement is hard to satisfy, and partly for that reason Section 201 has been little used in recent years. 39 The law contains the requirement, not specified by GATT, that the increased imports be at least as great a cause of injury as any other cause. ${ }^{40}$ The injury requirement is not often satisfied before serious damage is done. While the threat of serious injury is in principle enough to satisfy the statute, the threatened injury must be imminent, and a sufficient threat is rarely found. Also, following the language of GATT's escape clause, Section 201 by its terms can be used to protect industries already producing goods, not those still forming. ${ }^{41}$

Congress could make Section 201 more serviceable by eliminating the requirement that the increased imports be at least as great a cause of injury as any other cause. Congress could also specify that the injury test can be satisfied even when an industry is doing well, if the imports have impeded the industry's development or import and industry trends point to eventual foreign dominance. Such a provision might be consistent with GATT, although other countries could argue otherwise. ${ }^{42}$

GATT's escape clause requires that the increased imports and consequent injury be due to "unforeseen developments. " ${ }^{43}$ Section 201 does not. However, if the United States attempted to use Section 201 to protect a new (infant) industry struggling to compete against a well-established foreign industry, foreign countries could complain that imports and the consequent injury to U.S. companies were hardly "unforeseen. Uruguay Round negotiations might eliminate this requirement, which has rarely been used or invoked.

All told, Section 201 is far from an ideal tool for providing GATT-compatible protection. However, Congress could empower the President to grant protection apart from Section 201. Ideally, a government agency responsible for coordinating competitiveness strategies would recommended protection when needed. Instead of justifying protection under GATT's escape clause, the United States could justify it under GATT Article XXVIII. Under that Article, the United States could negotiate compensation, typically in the form of reduced tariffs on certain other products, in exchange for which other countries would accept increased U.S. tariffs on the products at issue. The President could be empowered to offer such compensation, as recommended by an agency with overall competitiveness responsibility. While compensation could adversely affect other U.S. industries, the government might, in some cases, be able to mitigate these effects with tax breaks or other programs that the same agency could recommend and the President could be empowered to grant, subject to a congressional override. ${ }^{44}$

If negotiations failed and other GATT-consistent means of protection could not be found, as a last resort the United States might impose protection anyway. Other countries have at times protected industries they consider crucial, regardless of GATT. Such a course might provoke a GATT dispute, and could possibly lead to a ruling requiring the United States to pay compensation. This approach would not necessarily signal U.S. abandonment of its loyalty to GATT and the free trade ideals it represents. Rather, it would mean that the United States, like other countries, can depart from free trade ideals when necessary.

Under both Section 201 and this new approach, it would be desirable to condition protection on a performance requirement or showing of progress by the industry receiving protection (which has happened to some extent under Section 201). Openended trade protection with no strings attached has been a recipe for third-rate performance for industries in many countries (e.g., the national champion computer firms in Europe-see ch. 5). On the other 
hand, the discipline Korea imposed on its developing industriest. g., requiring companies to succeed in exporting finished goods as a condition for permission to import production equipment, parts and materials-was an ingredient in the success of its export-led development, The specific policy tools Korea used are no model for the highly developed and much freer U.S. economy, but some kind of standard or gauge of serious effort on the part of the industry and progress toward competitive performance could be employed.

\section{Domestic Content Requirements}

The issue of domestic content is sure to come up if the United States protects industries against fair but damaging imports. One way of getting around protective tariffs and quotas is to build an assembly plant in the protected country; Japanese automobile production began in North America in large part to avoid current and prospective protection. The fact that foreign direct investment has grown faster than trade in the past couple of decades reflects, in part, companies' desires to avoid or avert national protection.

While foreign investment is often welcomed and occasionally sought, some nations have not been content to let foreign companies substitute domestically assembled merchandise for imported goods, because often the domestic assembly adds only a small proportion of value to what is basically an imported good. The United States has done little other than jawbone to increase the domestic content of foreign companies producing here, but many European nations and the European Community have moved more decisively. For example, the British Government eagerly pursued Japanese automobile investment but included the proviso that 60 percent of the content of the autos must be European at the time of startup and 80 percent within a few years. Such high levels of local content require that the body, the major mechanical components, and either the engine or the transmission be fully manufactured in Europe (see ch. 5); the current level is much greater than the local content of cars made by any Japanese transplant in North America, even after years of operation. Domestic content requirements are also prominent in Europe for electronics products, including office equipment, consumer electronics items, and semiconductors. Government procurement in most EC member nations strongly favors domestically made goods. Moreover, for nearly a decade, the EC has pursued vigorous antidumping measures against Japanese and other Asian firms selling electronics goods in Europe; the penalties can be lifted if the firms include substantial amounts of European-made parts and materials in their products, and many firms have relocated production to Europe in response.

Domestic content regulations, like tariffs and quotas, can benefit a nation. Almost certainly, they mean more jobs in the protected industry than otherwise, at least in the short run. But, like other forms of protection, they nearly always mean some short-term sacrifice by consumers in the form of higher prices. Whether national productivity or competitiveness improve with domestic content requirements is uncertain and may depend on whether they coincide with or are tied to measures to improve the competitiveness of the domestic firms or industries.

Experience with domestic content requirements in industrialized countries is recent and limited. There is some evidence that Japanese auto assembly transplants in North America have helped to improve the quality and productivity of U.S. suppliers; the more recent Japanese transplants in Europe are expected to do the same for European suppliers. Also, in North America the demonstration effect of the Japanese assemblers spurred the Big Three domestic automakers to improve their own and their suppliers' quality and productivity. It is not yet clear that requiring high domestic content of Japanese producers in electronics products will help the European electronics industry. It maybe improving the performance of some European suppliers, but if so that improvement has not yet spilled over into greater competitiveness of the European systems manufacturers who make computers, other office machines, and consumer electronics items; all these European companies are in trouble. It is also unclear to what degree good performance by Japaneseowned firms will contribute to an elevated level of technology and higher standards of living in the host country. It may be that the leading edge of innovation will remain in the home country of the foreign investor, but that the host country could still benefit from demonstration and direct teaching of superior manufacturing practice.

European policies reflect the ambiguities and uncertainties about benefits from foreign direct investment. The EC seems to have adopted a 
principle of tolerating or encouraging foreign investment in some critical sectors if the foreign firm agrees to a high level of local content. Yet there are contradictions. The recent EC agreement with the Japanese Government on automobiles would allow only a gradual increase in the Japanese share of the EC market, both transplant production and imports, despite the high domestic content levels that the transplants have already agreed to and are trying to achieve (see ch. 6). ${ }^{46}$ Overall, it seems that the EC Commission and the member governments are still trying to decide whether foreign direct investment is a net benefit.

Japan, on the other hand, has an unambiguous stand. Japan has often barred or severely constrained foreign direct investment, even when it was far behind other advanced industrial nations and trying to catch up. Even today, Japan remains one of the most difficult of industrialized nations in which to open a branch, partly because of the expense but also because of the red tape involved.

\section{Export Promotion}

Export promotion-helping firms take advanages of opportunities to sell abroad-is another policy tool that could help U.S. manufacturing competitiveness. To export, companies must pass many hurdles: analyzing foreign markets; identifying and contacting potential customers; learning foreign ways of doing business; creating new labels or otherwise adapting the product for foreign use; getting financing; and arranging for shipping, insurance, and customs clearance, to name a few. Even when a U.S. firm has a good, well-priced product, it can easily miss an export sale.

Government programs can provide information and contacts. They can inform U.S. firms about markets, potential customers, foreign regulations and procedures, shipping, and so on; they can inform foreign firms about U.S. firms and products; and they can arrange trade shows, interviews, and other contacts between U.S. and foreign fins. For manufactured goods, this assistance at the Federal level is provided primarily by the U.S. Foreign and Commercial Service (USFCS) of the Department of Commerce. (The Department of Agriculture provides export services for agricultural products.)

Government programs can also assist with export financing. Often credit terms play an important part in export sales, especially to developing countries.
Government help in providing easier credit terms can take the forms of:

1. insuring the exporter against the customer's default, if the exporter allows the customer deferred payment;

2. guaranteeing a bank against the customer's default, if the bank lends the customer money for the purchase; and,

3. lending money itself, either directly to the customer or indirectly through a bank.

The Export-Import Bank of the United States (Eximbank), an independent agency of the U.S. Government, provides this kind of assistance.

In both information and financing, U.S. export promotion programs are weaker than those of our major competitors, primarily because much less is spent on them (ch. 4). The difference is due in part to limits on spending by the U.S. Government, after years of enormous budget deficits. It also stems from a fundamental uncertainty among U.S. policymakers as to whether export promotion is something the government should be doing.

If Congress and the Administration decide that export promotion is a legitimate government function, there are straightforward ways to make it more effective. Congress could increase funding for USFCS to pay for additional commercial officers posted abroad. These are the people who gather information about foreign market opportunities and help U.S. firms find foreign contacts. The summer 1991 level of about 200 foreign commercial officers, ${ }^{47}$ while up somewhat from about 150 in 1980 and $1988,{ }^{48}$ is still low. For example," as of August 1990, there were only 15 commercial officers in Japan, plus 44 Japanese nationals assisting with export promotion, while 83 professional employees of the Japanese Government, all Japanese citizens, were working in the United States to promote exports. ${ }^{49}$ Congress might wish to ask the Commerce Department whether other funding increases could provide improvements in service. In the late 1980s, budgets were very tight; sometimes USFCS officers even lacked funds to return phone calls to the United States. While funding has improved somewhat, given this history and the low level of spending compared to important trading partners, it is likely that additional funding could have a healthy payoff.

The level of service depends on attitude as well as money. Congress might wish to make a policy 
statement that export promotion should be a priority not only for commercial officers abroad but for the whole diplomatic staff. Cabinet-level involvement in promotion activities, such as Commerce Secretary Mossbacher's presence in Tokyo in April 1991 to kickoff the Japan Corporate Program (ch. 4), could provide a boost.

Export promotion efforts could have a more strategic focus. While USFCS emphasizes industry sectors whose fundamental competitiveness suggests substantial export potential, it does not consider which industries are strategic to overall U.S. competitiveness. While Eximbank reports to Congress on the amount of financing meeting certain strategic priorities (such as industries with high value added, or industries that particularly benefit downstream industries), it is not clear how much Eximbank takes them into account in its decisions. Ideally, an agency with overall competitiveness responsibility would coordinate strategic priorities.

Strategic priorities for Eximbank could also help to solve the problem of excessive paperwork. Financing assistance by Eximbank must be justified on a case-by-case basis. Congress might consider adopting the approach used by Japan and many European countries, which determine in broad policy terms what exports to assist, and then assist all creditworthy exports within the guidelines.

U.S. manufacturers are at a disadvantage, compared with foreign competitors, because of tied aid. This is a scheme by which a country gives foreign aid on condition that the recipient use the money to buy products from the donor. The United States ties some of its aid, but U.S. nondefense aid focuses on agriculture, health, nutrition, and education. American farmers may reap large benefits, but manufacturers seldom do. Other countries concentrate aid much more on heavy construction projects, such as power generation and transportation, so that their tied aid involves manufactured goods, especially capital equipment.

Tied aid is often combined with export financing in a package of so-called "mixed credits." For example, the exporting country might offer to pay outright 40 percent of the cost of a power plant, and finance the other 60 percent, provided that national companies of the exporting country get the contracts for construction and equipment sales.
The U.S. effort to strengthen international agreements aimed at limiting tied aid are worth continuing. However, it is uncertain how successful that effort will be. Congress could expand the so-called War Chest for matching foreign tied aid offers to make it more effective in discouraging foreign tied aid. The War Chest was funded at $\$ 150$ million in grants for FY 1991, which would result in about $\$ 500$ million in loans, though as of July 1991 only $\$ 58$ million in grants had been used, resulting in $\$ 131$ million in loans. In contrast, Japan, France, and Germany use tied aid to make loans of billions of dollars per year.

Congress could also expand the Trade and Development Program (TDP), funded at \$31 million for FY 1990 and \$35 million for FY 1991. TDP helps to pay for feasibility studies or other planning assistance performed by. U.S. firms for capital projects. Participation in the planning phase has often helped U.S. firms win contracts for the actual project. So far, $\$ 161$ million in program funds have led to documented U.S. sales totaling $\$ 3.2$ billion, with an estimated $\$ 18$ billion more sales expected as projects mature. ${ }^{50}$ In expanding TDP or otherwise increasing the emphasis on capital projects, ${ }^{51}$ care should be taken to avoid adverse environmental and social effects, which in the 1970s turned the United States away from such projects.

\section{Export Controls}

The export of dual-use items, those having both military and civilian use, is regulated by the Export Administration Act of 1979, as amended (EAA) 2 which requires U.S. firms to get a license to export certain items to certain destinations. The intent is to deny strategically important goods and technology to potential military adversaries. In 1990, perhaps $\$ 90$ billion worth of U.S. exports of manufactured goods required a license, or about 28 percent of the $\$ 316$ billion in manufactured exports (see ch. 4).

It is generally agreed that some export controls on dual-use items are needed. However, there is an emerging consensus that export controls have unduly hindered U.S. high-technology firms in competition with foreign manufacturers. For example, U.S. controls limited exports of personal computers based on Intel's 80386 processor chip until mid1990. Yet the same computers were widely available from foreign fins. The controls merely diverted business to foreign fins. 
The U.S. export control regime has been considerably liberalized in the last few years. The political changes in Eastern Europe and the Soviet Union reduced those countries' military threat, lessening the need for controls, and in fact making desirable the export of technology to help those nations become open, economically viable societies. This changing political climate intensified the dissatisfaction of many allies with the United States' stricter position on export controls; allies brought pressure for change in the international export control regime. Finally, concern has increased over the continuing decline of U.S. manufacturing competitiveness, prompting closer scrutiny of whether the security benefits of particular controls are worth the competitiveness costs.

Reform has focused on East-West controls, traditionally the most common type, which are meant to deny militarily strategic technology to former Communist countries (see ch. 4 and box 4-C). Controls on many items have been removed or reduced, tracking a major reduction of controls at the international level, in CoCom (Coordinating Committee for Multilateral Export Controls, a group of nations cooperating in export controls). In principle, controls should be eliminated if they are not also imposed by other CoCom members, or if the item is available from unrestricted sources. In addition, delays in processing export license applications have been shortened.

However, the reform is incomplete. The reason is the tug of war that exists-and to some degree must exist-between two important governmental goals: military security, whose champion is the Department of Defense; and improved competitiveness, championed by the Department of Commerce. Although the competitiveness interest has received increasing support from the President and his closest associates, it still has not achieved equal consideration with military concerns. Congress cannot change this on its own: where possible damage to military security is at stake, the executive branch must exercise wide discretion.

If Congress were to create a new agency charged with promoting industrial competitiveness, many aspects of the export control function might reside there. It could coordinate export controls as the Commerce Department does now, but with a greater ability to serve the national interest. Other functions might include:
- evaluating the economic importance of different industries and the importance of exports to a given industry;

- expediting control reforms and license approvals in key industries;

- coordinating export policy with other policies (e.g., offering some compensating benefit to the affected industry when cumbersome export controls were deemed appropriate); and

- achieving enough prestige that its views on export control policy would carry equal weight to DoD's, within the Administration.

Without such an agency, and lacking a commitment in the Administration to advance commercial competitiveness, there are still measures that Congress could take if it wished to give competitiveness a higher priority in export control policy. However, the EAA is already a very complicated statute, and even some analysts sympathetic to competitiveness concerns believe that it contains excessive micromanagement. On the other hand, the statute leaves the the Administration an out to do what it believes is truly necessary in most cases. Where the statute leaves no flexibility, sometimes the Administration has disobeyed it. This occurred with the 1988 provision eliminating reexport controls on U.S. goods and technology that are incorporated abroad into finished products, provided the controlled U.S. content is at most 25 percent of the product's total value. ${ }^{53}$ The Bureau of Export Administration (BXA) considered that provision dangerous; for example, it would remove controls from avionics equipment incorporated abroad into airplanes. BXA implemented this clause only incompletely and almost a year late (ch. 4).

Congress could strengthen the role of the Commerce Department vis-à-vis the Defense Department and other agencies. Congress moved in this direction in the Export Enhancement Act of 1988 (1988 Act) ${ }^{54}$ for example, by limiting to 40 days the time during which the Defense Department can block a license approval recommended by the Secretary of Commerce. ${ }^{55}$ Further amendments in this direction are under consideration in S. 320, already passed by the Senate. ${ }^{56}$ For example, S. 320 would give the Commerce Department permanent representation at CoCom and direct the State Department to forward to CoCom within 7 days certain Commerce Department actions requiring CoCom approval. ${ }^{57}$ 
The Commerce Department has sometimes been bypassed when dual-use items have been put on the State Department's Munitions List, which is in principle limited to items with only military use. Items on the Munitions List face a stricter control regime, without the safeguards to protect commercial competitiveness that apply to dual-use items. Therefore, placing dual-use items on the Munitions List can reverse recent reforms and impede pending ones. Congress could discourage this practice by, for example, giving the Secretary of Commerce the right to force a quick Presidential decision regarding whether an item also has nonmilitary use. Congress could also issue a strong policy statement that the Munitions List is not to contain dual-use items.

Congress might enact additional provisions to address problems identified in chapter 4 . For example, Congress could impose stricter time limits for processing license applications, especially those requiring interagency review; mandate prompt continuing review of the Control List (list of controlled items); encourage license-free trade within CoCom countries; encourage use of industry advisory committees; and encourage the use of indexing, by which technical thresholds of what is controlled would be automatically adjusted over time unless the need to forego the adjustment were specifically justified. The 1988 Act and S. 320 address these concerns.

Other provisions in S. 320 also address competitiveness concerns. This bill contains policy statements favoring approval of exports designated for reformed Eastern European countries, or needed to aid Soviet and Eastern European economic development. Another policy statement favors temporary exports for trade shows. However, these are by necessity only guidelines, leaving final discretion with the Administration. S. 320 provides for court review to force compliance with mandated deadlines, which have often been missed..$^{58}$ The EAA already provides for court suits to enforce statutory license processing deadlines, ${ }^{59}$ this provision could be extended to cover other deadlines, such as for review of the Control List and for decontrol of items not multilaterally controlled. The review would be purely procedural; courts would not second-guess the substance of any decisions. ${ }^{60}$

There are swifter, more severe ways of enforcing deadlines. One approach is to make a missed deadline act as an acquiescence by the Administration. The 1988 Act did this for determin ations of foreign availability requested by firms; if BXA missed the deadline, foreign availability would be assumed and the item decontrolled. ${ }^{61}$ This provision was effective in speeding up those determinations. However, BXA reports that the provision strained its resources, and took effort away from other investigations of foreign availability that, while not requested, were perhaps more important to industry as a whole. BXA also states that that provision has the potential to force U.S. decontrol before it is authorized by CoCom, thereby undercutting the multilateral export control system that the United States is trying to strengthen. Another option is to make decontrol self-executing-that is, when decontrol is mandated by law (e.g., on items not controlled by other nations) the decontrol would take effect even if BXA has not published implementing regulations. Congress considered such a provision in $1990 .^{62}$ However, the absence of regulations could cause confusion, resulting in exports detrimental to national security.

One practical, nontechnical way to facilitate timely adjustment of controls would be to increase the staffing in the Commerce Department's Office of Foreign Availability (OFA). OFA determines when foreign availability of items makes U.S. controls ineffective. These determinations are crucial to minimizing the drag on competitiveness, and they require difficult fact gathering and complex technical analysis. OFA now has about two dozen people.

Another option would be to encourage political appointees with technical background. Technically knowledgeable senior BXA staff might be better able to argue their positions with other agencies.

Finally, there is an emerging problem of "NorthSouth" or "foreign policy" controls, issued under Section 6 of the EAA (see box 4-C). (The term "North-South" is a convenient shorthand to distinguish the orientation of these controls from that of East-West controls. However, the use of this term is not meant to imply that all or most developing countries give cause for concern.) Some foreign policy controls aim to prevent proliferation of weapons of mass destruction, including missiles and chemical and biological weapons. ${ }^{63}$ Other foreign policy controls, such as sanctions against countries that abuse human rights, are meant instead to make a political statement. Still other controls, such as sanctions against nations that use terrorism, appear to do both. 
The Gulf War heightened concern over proliferation, and prompted the Administration's Enhanced Proliferation Control Initiative (EPCI). Although this concern is justified, the Administration's use of foreign policy controls takes little account of competitiveness concerns. The Administration must report and just@ foreign policy controls annually to Congress, but the safeguards against unnecessary interference with commercial exports (e.g., the prohibition on controlling items with foreign availability and the prohibition on unilateral controls) do not apply to foreign policy controls. Thus, changes already adopted for export controls related to East-West national security matters (under Section 5) do not extend to controls directed to foreign policy purposes (Section 6). This made it possible for the Administration to impose unilateral controls in March 1991 on certain chemicals and manufacturing equipment that could be used to make chemical weapons. In August 1991 the Administration issued regulations that could be interpreted to require virtually all firms exporting any items to any countries to set up a monitoring and control system to guard against diversion of any products to chemical or biological weapons plants (ch. 4).

If Congress believes that competitiveness concerns should, when possible, apply in the same way to foreign policy controls, a first step might be to separate foreign policy controls with military objectives from those with political objectives. To achieve political objectives, unilateral controls or controls on items available elsewhere could be appropriate and effective. Congress could include a strongly worded statement of policy that export controls for political reasons should be issued only after careful consideration of the effect on commercial exports.

Congress might put foreign policy controls with military objectives under more or less the same discipline as national security controls. This is not a simple matter. It would not make sense, for example, to simply state that proliferation controls will henceforth be treated under Section 5 rather than Section 6, because controls under Section 5 are meant to keep items from former Communist bloc nations, and the law is written so as to coordinate controls through CoCom. However, control of the technologies for nuclear weapons, missiles, chemical weapons, and biological weapons is broader than an East-West issue. The Soviet Union and the People's Republic of China possess much of the important technology, and must join in controls for them to be effective. Similarly, to deny conventional weapons to countries sponsoring terrorism would also require the cooperation of the Soviet Union and China. Therefore, Congress might wish to treat foreign policy controls with the objective of denying military technology in a separate section of the law, which imposes discipline regarding, e.g., foreign availability, but recognizes their special international position.

\section{GOVERNMENT-INDUSTRY PARTNERSHIPS}

One thing that stands out in the story of nations that successfully use trade policy to promote the development of particular industries is that trade policy alone is not enough. Even when used aggressively, it is combined with promotion of technology development and diffusion, with risksharing between government and industry, and with support for adoption of new technologies and industrial success.

\section{Strategic Technology Policy}

The least intrusive and least expensive of several possible risk-sharing options between government and industry is what OTA has described as strategic technology policy, an R\&D partnership for developing new technologies of commercial interest. ${ }^{64}$ The potential benefits to society of such ventures are great, but the likely payoff to individual firms is too small to make it worth their taking all the risk. Therefore, the argument for industry/government risk-sharing takes on special force.

Traditionally, U.S. policy has been to limit R\&D support to basic science or else to the government's own needs-primarily, military security. There are notable exceptions: agriculture and civilian aircraft manufacture have had longtime steady support for technology development, based on a frank recognition that they were important to the nation's economic welfare. With the dawning awareness that U.S. industries really are in competitive trouble, a consensus seems to be growing for a Federal role in commercially promising R\&D.

Congress took a first step in the 1988 Trade Act, which launched a small program for R\&D partnerships, the Advanced Technology Program (ATP) located in the Commerce Department's National Institute for Standards and Technology (NIST). The Program's purpose is to help U.S. business rapidly 
commercialize new scientific discoveries and apply research results toward refining manufacturing technology. Through the ATP, NIST can assist private R\&D ventures with technical advice or can actually participate in them: it can provide start-up funding; put up a minority share of the cost; or lend equipment, facilities, and people. Congress has consistently taken the lead with ATP, providing its first funding of \$10 million in fiscal year 1990 and raising the ante to \$36 million in fiscal year 1991 .

The Administration, for its part, has moved toward support of cooperative R\&D for commercial ventures. The President's 1992 Budget proposal said: "The Administration believes that appropriate Federal investments in applied civilian R\&D can result in high payoff to the economy $\ldots .{ }^{165}$ The Budget document went on to say that the principal strategy for Federal applied civilian R\&D is to support agency mission requirements. But some of this $R \& D$ has broad applications in the private sector. In such cases, the government would support "generic or enabling technologies at the precompetitive stage of R\&D.' These terms were defined as follows:

- generic or enabling technologies have the potential to be applied to a broad range of products or processes across many fins;

- precompetitive $R \& D$ is the stage of the $R \& D$ process where the results can be shared widely within and between industrial sectors, without reducing the incentive for individual firms to develop and market commercial products and processes based on the results.

The intention of such definitions is to avoid favoring particular firms or industries, putting government money into technologies with broad applications across firms and sectors. This principle ties in with the idea that technologies with many spillovers and applications are of most potential benefit to society. It is not always possible, however, to distinguish so neatly between technologies and industries. For example, flat panel displays are a generic technology, having myriad applications from home television sets to engineering work stations to airplane cockpits. But government support for developing the technology benefits the electronics industries and firms that produce it.

Congress has already indicated its interest in an industry-government partnership for applied commercial technology development that is not neces- sarily dependent on fallout from other government missions. If this program is to take a proactive, coherent approach, rather than responding to crisis calls from industries under competitive siege or to a wave of enthusiasm for the latest technology, it would need an agency in charge and a set of guiding principles. These issues are discussed briefly below.

A Civilian Technology Agency (CTA) would be needed to guide government-industry cooperative $R \& D$ whether or not the idea of broader, integrated competitiveness policies in support of selected critical industries wins acceptance.

NIST's ATP might in time become a fill-fledged CTA, although it was not created with that explicit mission. Bills to establish more formally an Advanced Civilian Technology Agency in a new Department of Industry and Technology (which would replace the Department of Commerce) were introduced in the 100th and 101st Congresses. ${ }^{67}$ These proposals defined the agency's mission as contributing to U.S. competitiveness by supporting long-term, high-risk projects likely to yield important benefits to the Nation but that lack adequate private support. A bill that passed the Senate in 1989 would have given the ATP a similar mission and authorized substantially increased funding, up to $\$ 100$ million per year.

Any CTA would have to start small, as the ATP has, and need never grow very large. A possible model is the Defense Advanced Research Projects Agency (DARPA), a small free-wheeling Department of Defense (DoD) agency supporting risky long-term $R \& D$ that often has commercial as well as military value. DARPA has 150 employees, about half of them scientific and technical, and some \$1.5 billion a year for its research projects. Its relatively small size is one factor in a nonbureaucratic culture that gives staff members a great deal of freedom to exercise their own good judgment. At the same time, a research budget of $\$ 1$ to $\$ 2$ billion a year seems large enough to attract a critical mass of competent staff and fund a healthy portfolio of technologies.

Where in the Federal bureaucracy a CTA is placed may not matter too much. The prestigious National Science Foundation is an independent agency. DARPA is smaller than NSF and is a tiny part of the huge, hierarchical Department of Defense, but it too has won renown for its competence and dedication. If the small, experimental ATP develops into a mature CTA, the question may answer itself, since 
the Program is already started life in the Department of Commerce.

Like DARPA, a CTA might attract excellent staff by combining freedom from bureaucratic rules with great responsibility and the opportunity to serve one's country. Unlike DARPA, a CTA would not serve a defined mission and customer-the military. Instead, technologies supported by a CTA would have to prove their worth in the market. Even allowing for inevitable failures-and an agency charged with supporting high-risk technologies would not be worth its salt if it had no failures along with its successes-it is much tougher to choose technologies that can make it commercially than ones with some credible military use.

Collaboration with industry is essential in choosing technologies for support. If private companies are not interested enough to take some of the risk and do some of the work, then the chances of commercial success are probably remote. Joint funding helps the government escape pressure from special interests in selecting technologies for support, and enlists market forces in picking the best prospects.

At the same time, a CTA would need a set of guiding principles to delineate broad areas appropriate for government-industry collaboration. One obvious principle is preference for technologies with wide applications in many products and industries. Another is knowledge-intensiveness, which means not only technologies important to industries that are clearly knowledge-intensive in themselves (e.g., computers) but also projects that could deepen the knowledge-intensiveness of traditional industries (e.g., precision machining). Another principle is potentially large markets.

The importance of collaboration with industry in selecting commercially interesting projects is underscored by NASA's (National Aeronautics and Space Administration) experiences over the years. NASA's annual spending for aeronautical R\&D amounts to about $\$ 800$ million, and probably 90 percent of that is, or could be, relevant to the commercial aircraft industry, as well as to the military. This is a huge amount for the United States. Of course the military connection is a leading reason for this level of spending; even so, the research is available to commercial producers. Yet it would be mistake to think that most of NASA's R\&D, or even the major share, gives U.S. aircraft manufacturers a competi- tive advantage. Some of it is basic research, not applicable to commercial production except possibly in the very long term. Much of the advanced technology development is quite freely available to the world, and some has been used first by Airbus in Europe, not by U.S. producers (see ch. 8).

NASA's greatest contributions to competitiveness of American producers are in two areas: its facilities (e.g., wind tunnels and the Numerical Aerodynamic Simulator, a supercomputer complex), which are either preferentially or solely available to U.S. companies; and technology development projects in which the U.S. companies were close collaborators (as in the $\mathrm{E}^{3}$ program for aircraft jet engines, described in vol. 2, to improve fuel efficiency and reduce emissions and noise). Coordination between new government regulations and collaborative technology development projects to help comply with the regulations can give an extra boost to competitiveness; this was the case with Federal regulations to reduce aircraft noise.

There are at least two pluses to industry involvement in NASA's technology development projects. First, the projects are more likely to reflect genuine commercial concerns and possibilities; and second, the company engineers gain an intimate knowledge of the new technologies that outsiders cannot acquire simply by reading published research reports.

These advantages are just as valid outside NASA and the commercial aircraft industry. The few government-industry technology partnerships that already exist for manufacturing industries (apart from aircraft) follow the pattern of at least 50percent funding by industry. Sematech, the largest of these ventures, gets $\$ 100$ million per year both from the U.S. Government and from a consortium of industry members. The ATP follows a similar rule, with more than half the cost of cooperative projects paid by sponsoring firms. Although Sematech has its own facilities, the ATP-funded R\&D takes place in members' labs. There are opportunities to do more cooperative work in Federal" labs, especially in the Department of Energy's well-equipped multiprogram national labs. However, judging by NASA's experience, these ventures will be of more use to companies if they involve participation by the firms' own researchers, not just a financial contribution.

So far, the U.S. Government's offers of collaborative $R \& D$ projects have been snapped up by private 
companies. Sematech was, in fact, proposed by the semiconductor industry, which lobbied hard for it. Three small pilot projects ( $\$ 5$ to $\$ 6$ million per year total) in the national labs for commercializing high-temperature superconductivity had more willing partners from industry than the labs could fund, and the same was true of DARPA's \$30 million project for cooperative $R \& D$ on high resolution display technologies. ATP's first batch of grants for cooperative projects amounted to about $\$ 9$ million, initiating $R \& D$ programs that are expected to cost $\$ 100$ million (including private funds) over 5 years. The 11 winning grants were selected from 249 proposals requesting a total of $\$ 150$ million (box 2-B provides details).

Added together, the dollar amounts in these few cooperative programs are minute in a Federal budget of more than $\$ 1$ trillion. They are tiny compared to the more than $\$ 90$ billion per year that U.S. manufacturers spend for R\&D. It is noteworthy, however, that such very modest programs have drawn responses from so many companies, large and small. Among ATP's first 11 grantees were industry giants such as Du Pent, AT\&T Bell Laboratories, and two prominent industry consortia, the Microelectronics and Computer Technology Corp. and the National Center for Manufacturing Sciences. Although these companies and consortia have big $R \& D$ budgets of their own, each one funds a great many projects, and there are always promising but risky ones that do not make the corporate cut. However, such projects may look more attractive with cooperative funding, including government money. Furthermore, the government backing may lend a certain prestige to the undertaking. Or companies may fear missing out if their competition joins in and they do not.

So far, Congress has taken a gradual approach to expanding government partnerships with industry on commercially relevant $R \& D$. This approach makes sense, considering that the U.S. Government has little experience with industrial partnerships; that the government's institutional ability to manage R\&D partnerships is at an early stage; and that relations between government and industry in this country have traditionally been adversarial. If Congress wishes to continue this measured expansion, with the ultimate goal of having an agency about equal in size and importance to DARPA or the National Science Foundation, it may opt for a modestly increasing ATP budget for several years. It might also wish to consider writing into law a more formal statement of goals for the agency.

Participation by foreign firms in cooperative $R \& D$ programs that receive government funding is a new and somewhat unsettled question. Part of the problem is in defining just what a foreign firm is (see ch. 3). In appropriating funds for the ATP for fiscal year 1991, Congress took on the problem in an innovative way. It set standards that apply to U.S.-owned as well as foreign-owned firms, thus bypassing ownership as the central criterion for deciding whether a firm can participate in ATP projecta ${ }^{68}$ The Secretary of Commerce is authorized to decide whether firms are eligible, using the standards to determine that their participation would be "in the economic interest of the United States."

The standards applying to all firms call for investments within the United States in research, development, and manufacturing, including the manufacture of major components or subassemblies (thus insisting that investments go beyond assembly plants that add little value or knowledge-intensiveness); a significant contribution to employment in the United States; and agreement to promote U.S. manufacture of products resulting from ATPassisted technology projects. Further conditions apply to foreign-owned fins: they may participate if the Secretary finds that their home country offers U.S.-owned firms comparable opportunities to take part in joint ventures for technology development, allows U.S. companies to invest on equal terms with other countries, and affords adequate protection of the intellectual property rights of U.S. companies. ${ }^{69}$

These provisions offer guidance but also give great latitude to the Secretary of Commerce in determining the eligibility of firms, both foreign and domestic, for ATP projects. Congress may wish to exercise substantial oversight for a time on how these novel provisions are carried out.

\section{Financial Risk-Sharing}

A strategic technology policy, worthwhile as it may be, goes only so far. Government partnership in technology development stops short of commercialization. After that, it is up to industry to make the much larger investments in the product design, manufacturing equipment and tooling, worker training, and acquisition of know-how by managers and production engineers that are necessary for the commercial manufacture of new or improved prod- 


\section{Box 2-B-The Advanced Technology Program's First Round}

The U.S. Department of Commerce announced in March 1991 the first awards under the innovative Advanced Technology Program (ATP). The ATP was created by Congress in 1988 to help American business turn research results into new commercial products and improved manufacturing technologies. It established a governmentindustry partnership, in which the ATP could lend technical assistance, equipment, and people to cooperative research projects and could contribute a minority share of the funding.

Awards of about $\$ 9$ million went to 11 grantees and were first installments in R\&D programs expected to cost $\$ 100$ million over 5 years (with more than half the money coming from private industry). ${ }^{\text {T The }} 11$ winners were chosen from 249 proposals requesting $\$ 150$ million in first year grants, Several hundred volunteer reviewers from both government and industry helped to make the choices. Of the 11 grants went 5 to joint ventures or consortia-an indication, according to Commerce Department officials, that the program is fostering a greater spirit of cooperation among highly individualistic companies for precompetitive $R \& D{ }^{2}$ The program encourages joint efforts and rewards them with grant money that covers some indirect as well as direct costs.

Most of the technologies were related to microelectronics and computers, including optical recording and computer hardware. Others were in the fields of high-temperature superconductivity, machine tool control, and novel laser designs. The grantees, their projects, and the grants they requested, are described below.

\section{Printed Wiring Board Interconnect Systems}

National Center for Manufacturing Sciences, Inc. (NCMS)

Printed wiring boards are ubiquitous in electronic products, from radios to computers. The U.S. share of a $\$ 25$ billion world market has dropped from 42 to 29 percent in 3 years. Current technology is approaching fundamental limits in the materials and processes now used. Four members of the NCMS consortium, AT\&T, Texas Instruments, Digital Equipment Corp. and Hamilton Standard Interconnect will work with Sandia National Laboratories to develop new materials, better processes, and improved technical understanding.

First year request: $\$ 2,370,000$; total 5-year request: $\$ 13,783,000$; matching funds: $\$ 14,674,000$

\section{Volume Holographic Mass Storage Subsystem}

\section{Microelectronics \& Computer Technology Corp. (MCC)}

MCC proposes to build on a basic concept it has already demonstrated for a radically new form of dense, ultra-fast computer memory storage, potentially replacing slow disk drives and magnetic tape (about 100,000 times slower than the typical microprocessor). The new system would respond in microseconds, and would store data as holographic images in photorefractive crystals.

First year request: $\$ 823,000$; total 5-year request: $\$ 10,331,000$; matching funds: $\$ 12,700,000$

\section{Advanced Manufacturing Technology for Low Cost Flat Panel Displays}

\section{Advanced Display Manufacturers of America Research Consortium}

Advances are needed in testing and repair equipment, as well as in interconnection and packaging technologies, to successfully commercialize high-quality, low-cost flat panel displays. Three relatively small companies will lead a consortium in a linked series of research programs; they are Optical Imaging Systems (Troy, NY), Photonics Imaging (Norwood, OH), and Planar Systems, Inc. (Beaverton, OR). Seven other companies are participating.

First year request: $\$ 1,251,000$; total 5-year request; $\$ 7,305,000$; matching funds: $\$ 7,604,000$

Short Wavelength Sources for Optical Recording

\section{National Storage Industry Consortium}

Data storage devices are a $\$ 50$ billion-per-year industry; two-thirds of the market is now controlled by U.S. firms, one-third by Japanese. The most promising technology in the field is optical recording, as used in compact disks. The program would develop an integrated short wave length laser source, with solid state components, for $\mathrm{read} / \mathrm{write}$ heads of fast, small, rugged optical memory devices. Members of the consortium, which is not yet fully

\footnotetext{
${ }^{1}$ In some cases, part of the company contribution is in kind (e.g., laboratory equipment), so that the government grant requested may be larger that the cash outlay proposed by the company.

2“"Advanced Technology ProgramClears Another Hurdle," New Technology Week, Mar.11,1991.

${ }^{3}$ The descriptions are taken from U.S. Department of Commerce, Office of the Secretary, Commerce News, press release dated Mar. 5 , 1991 and "First Winners in the Advanced Technology Program," New Technology Week, Mar. 11, 1991.
} 
formed, include Applied Magnetics, Bernoulli Optical Systems, Eastman Kodak IBM, Maxoptix Corp., and the University of Arizona. An initial grant of $\$ 50,000$ is contingent on further development of the joint venture.

First year request: $\$ 50,000$; total 5-plus years request: $\$ 5,421,000$; matching funds: $\$ 9,200,000$

Fabrication and Testing of Precision Optics for Soft X-Ray Projection Lithography

\section{AT\&T Bell Laboratories}

$\mathrm{X}$-ray lithography is a key technology for new generations of dense microelectronic circuits. This program will attack a key problem limiting projection X-ray lithography: the manufacture, testing, and assembly of relatively large scale X-ray mirrors. It will develop technology to test, fabricate, assemble and align aspherical X-ray mirrors. Three-quarters of the grant will go to small business subcontractors.

First year request: $\$ 955,000$; total 5-plus years request: $\$ 2,000,000$; matching funds: $\$ 3,525,000$

Solid State Laser Technology for Point Source X-Ray Lithography

Hampshire Instruments, Inc. and McDonnell Douglas Electronic Systems Co.

These small companies will lead a joint venture to exploit recent advances in laser materials for use in low cost, high-performance X-ray lithography.

First year (total) request: $\$ 1,090,000$; matching funds: $\$ 1,094,000$

Nonvolatile Magnetoresistive Semiconductor Technology

Nonvolatile Electronics, Inc.

Computer memory is volatile--the data vanish when the power is shut off. This program aims to develop a fast, dense, nonvolatile memory, basing the technology on a magnetoresistive memory (MRAM) patented by Honeywell and intended for space and avionics applications. The company has licensed the technology for nonaerospace applications, and means to develop it as a competitor to conventional dynamic random access memory (DRAM) semiconductors.

First year request: $\$ 599,000$; total 3-year request: $\$ 1,738,000$; matching funds: $\$ 869,000$ New User-Interface for Computers Based on On-Line Recognition of Natural Handwriting Communication Intelligence Corp. (CIC)

CIC plans a robust natural handwriting recognition system that does not require "training" the computer to recognize each individual's handwriting (a key limitation of most current systems). Cursive handwriting input for computers could be a revolutionary advance, especially for notebook and laptop machines.

First year request: $\$ 671,000$; total 2-year request: $\$ 1,264,000$; matching funds: $\$ 912,000$ Advanced Thallium Superconductor Technology

\section{E.I. du Pent de Nemours \& Co.}

The proposal is to develop thin-film fabrication techniques for a new, proprietary high-temperature superconductor invented by Du Pent. Project includes developing fabrication techniques and creating representative superconducting electronic devices to demonstrate feasibility.

First year request: $\$ 370,000$; total 3-year request: $\$ 1,590,000$; matching funds: $\$ 784,000$

Tunable Deep UV and VUV Solid State Laser Source

\section{Light Age, Inc.}

The company will apply recent developments in laser technology to produce high-average power ultraviolet lasers that are cheaper, safer, more reliable and easier to use than current products. Potential applications are in medical and scientific instruments and materials processing. It could be particularly significant in photolithography for the semiconductor industry, challenging the dominant Japanese suppliers of semiconductor production equipment.

First year request: $\$ 627,000$; total 1.5-year request: $\$ 701,000$; matching funds: $\$ 254,000$

\section{Advanced Compensation Techniques for Enhancing Machine Tool Accuracy}

\section{Saginaw Machine Systems, Inc.}

The program seeks a general, economic solution to the problem of correcting for errors in machining caused by thermal expansion and contraction of the machine tool; thermal errors contribute to about half of the errors in machining. Working with the University of Michigan, Saginaw will develop a mathematical model of thermal errors and a sensor and computer control system that can help machine tool builders greatly improve the accuracy of their machines at reasonable cost.

First year request: $\$ 266,000$; total 2-year request: $\$ 540,000$; matching funds: $\$ 168,000$ 
ucts or the adoption of new manufacturing process technology. It is normal and expected for private industry to make these investments, take the risks and then, if all goes well, reap the rewards.

Sometimes, however, in some critical sectors, private investment is inadequate from the standpoint of social benefits. Take semiconductors. One important reason why U.S. companies have lost out to Japanese firms over the last decade is that Japanese rates of investment were higher. From 1982 until 1991, Japanese producers invested a larger share of their sales of integrated circuits in plants and equipment than did U.S. producers, and since 1984 have out invested their U.S. rivals in absolute amounts .70 This pattern holds true in all industries throughout both economies; Japanese investment in machinery and equipment as a share of gross domestic product has consistently run at double the U.S. rate since the mid- 1970s, and in the late 1980s the discrepancy widened. This bodes ill for U.S. competitiveness generally, but in the technologydependent semiconductor industry, where new generations of products are introduced every 3 years or so, the disadvantage can be crippling.

The relatively meager U.S. investments in new production equipment reflect high capital costs and a financial environment that discourages or fails to support long-term investment (see the summary discussion in ch. 1 and more detailed discussion in OTA's 1990 report, Making Things Better). Macroeconomic policies that lower interest rates and provide stability are probably the most important things government can do to encourage greater investment in technology development and deployment by U.S. manufacturing companies. There are other options as well, however.

Besides the generally unsupportive financial environment in the United States, American semiconductor companies have the added handicap of facing Japanese competitors that are much larger; are vertically integrated, from semiconductor chips through computers; make a much greater variety of end products (VCRs and compact disk players as well as computers); and have ample retained earnings for new investments. Yet formidable as they are today, Japanese companies were not always preeminent. In the 1970s, they had a catch-up job to do that was greater than the one facing U.S. companies today. They did it not only by hard work and effective management but also with government policies that gave them protected domestic markets, tight controls over foreign investment, guaranteed sales to important government customers, governmentindustry R\&D partnerships, and a variety of measures assuring plenty of low-cost capital at a time when companies' financial resources were much more limited (see ch. 6).

Government policies to share financial risks with industry can take the form of subsidies or loans on advantageous terms, or they can take the more indirect form of tax breaks (i.e., tax expenditures). Both put burdens on government resources and, under the Federal budget agreement adopted in 1990, Congress cannot opt for either without compensating tax rises or spending cuts in other domestic programs.

Of the two forms of financial risk-sharing, tax expenditures are more within U.S. traditions and experience. U.S. companies in the past have received accelerated depreciation and tax credits for capital investments, and they currently get a tax credit for R\&D (although Congress has not made this a permanent feature of the tax system but instead has renewed it from year to year). Although certain kinds of investment (e.g., real estate) have been singled out for specially favored tax treatment, Congress has not in the past designed these tax incentives to improve the competitiveness of particular industries. ${ }^{71}$ If Congress wishes to target tax breaks to selected industries because of their importance to the U.S. economy, the best way to do it is make the tax measures part of a comprehensive strategy that also includes such things as R\&D partnerships and trade policy.

Many governments have supported selected industries with more direct financial aid, in addition to tax incentives. Japan, for example, offers companies hojokin (success dependent loans) for risky enterprises in selected industries; payments can wait for a positive cash flow. Thus companies are insulated against catastrophic losses. European governments have done much the same for Airbus. The U.S. Government, by contrast, has had little experience in giving direct financial aid to selected industries for strategic competitive purposes. There have been some well-publicized government bailouts of failing individual companies, notably Lockheed and Chrysler. The Synfuels program of the late 1970s did have the purpose of energy independence; that program is generally considered a failure. The broadest U.S. 
experience with direct loans to industry (leaving aside special loan programs for small business) was the Reconstruction Finance Corp. (RFC) in the post World War II years. ${ }^{72}$ RFC was created in 1932 to shore up banks in the credit deflation of the Great Depression, and it went on to procurement of strategic materials for national defense during the war. The postwar RFC had no such clearly defined purpose. In practice, it spent most of its very ample resources (close to $\$ 1$ billion per year in 1946-47, translated into 1990 dollars) in bailing out large, prominent but floundering companies, such as the Kaiser-Fraser automobile company. The one RFC project that seemed to have any focus other than keeping a big firm afloat was a series of nine loans to the Lustron Corp., which boasted a new technology-manufactured steel-frame houses. The project failed, and accounted for RFC's biggest loss.

RFC's failure in the postwar years was surely due in large part to its lack of any strategic purpose or guidance. However, its failure also suggests some dangers inherent in government's giving large sums of money to companies that cannot get funding from private sources. This cautionary lesson has been learned so well that now even suggestions for direct financial aid from government to industry are few and far between. In its 1989 report to the President and Congress, the National Committee on Semiconductors (NACS) did propose an attenuated form of government loan guarantees to U.S. companies trying tore-enter the advanced consumer electronic business. ${ }^{73}$ The idea was that the semiconductor industry is handicapped by the lack of a U.S. consumer electronics sector, considering the remarkable convergence of technologies in consumer electronics and other electronics goods (e.g., computers). NACS proposed a private corporation, to be backed by "pledges of support' from Federal, State and local governments, that would provide low-cost patient capital to startup consumer electronics companies with U.S. ownership. The suggestion was not repeated in the second NACS report in 1991. Some committee members privately offered the explanation that members could not agree on technical details for the proposed corporation, and said that the committee may take up the issue again in its third and final report.

The likelihood of a revived consumer electronics sector in the United States under U.S. ownership is virtually nil without infant industry assistance from the government; this might include trade protection and technology partnership as well as financial aid. However, whether such a revival is necessary or important to the U.S. economy is no simple question. It includes the issue of whether foreign-owned companies producing in the United States (Sony, Philips North America, Thomson) might provide the same benefits. Moreover, reviving a consumer electronics industry is a big, expensive job, and could be quite a burden to the taxpayers even if government took only a minor share of the risk. If Congress does wish to consider direct financial aid to this or other selected industries, it may want to start with a program of very modest scale and increase it slowly. Having a large pot of money available for such ventures invites imprudence, even for an experienced institution. And the United States does not now have an institution with the experience or capacity to fit financial aid into a coordinated strategic competitiveness policy.

\section{Government Purchases}

Government procurement was a vital factor in the birth and early growth of several important U.S. industries: semiconductors, computers, aircraft, and aircraft engines. As might be inspected, the big buyer in each case was the Department of Defense (DoD). For semiconductors, for example, the amounts DoD spent in the early years were tiny compared to the sums spent today, yet the DoD then was the launch customer for a product and technology in its infancy, and bought nearly 100 percent of the industry's output. Today, the Federal Government might still be a valuable first customer for untested products that combine public benefits with the potential for competitive success. It might also be an important customer for existing products important to U.S. competitiveness.

However, the opportunities are somewhat limited. Ninety percent of Federal purchases of goods are for defense and DoD does buy large amounts of certain important products. The share of aircraft and aircraft engine production for defense is about 43 percent; for radio and TV communications equipment, 36 percent; and for electronic components, 23 percent. But much of this equipment is so highly specialized for military use that technological spillovers to the commercial side are limited; in fact, because of long lead times for developing weapons, some commercial technologies are far ahead of military applications. Technological spillovers from the military appear to be diminishing, although the evidence is 
mixed. What is certain is that restrictive laws and DoD regulations have made it increasingly difficult for companies to take advantage of whatever technological synergies may exist.

Nondefense purchases comprise less than 10 percent of the total Federal purchases of goods, only $\$ 10.3$ billion in 1990 out of $\$ 107$ billion total. The United States has no national telecommunications service, no national railway, no national airline, no national health service, and no national university system. In both Japan and Europe, government bodies of these kinds have been important buyers of such products as semiconductors, computers, telecommunications equipment, aircraft, rolling stock, and medical equipment, and have used their purchases to support domestic industries.

The Federal Government's track record in improving manufacturing competitiveness, whether as a launch customer for new products or an important customer for established products, is weak. This is partly because competitiveness is not a goal of U.S. procurement policy. Preferences for U.S. goods are not motivated by strategic economic considerations; any benefit to commercial manufacturing competitiveness is usually just a happy coincidence. In contrast, the United States' most important trading partners do use procurement to promote certain manufacturing industries.

Key U.S. trading partners have much less open procurement than does the U.S. Government. The United States has been trying to make foreign procurement markets more accessible. First, the United States is negotiating to expand the scope of the GATT Procurement Code. Under the Code, the United States and the other signatories, which include the United States' major trading partners, grant reciprocal access to each others' procurement markets for covered purchases. However, the Code currently covers only a modest amount of those purchases. ${ }^{74}$ Second, the United States has begun renegotiating several of the 19 Memoranda of Understanding (MOUs) with allies regarding defense procurement. These MOUs have substantially opened the U.S. defense procurement market but have not had the same effect on allies' defense procurement markets. Third, the United States has negotiated under Title VII of the Omnibus Trade and Competitiveness Act of $1988 .{ }^{75}$ Under Title VII, the U.S. Trade Representative is to identify cases of procurement discrimination, including important cases not yet covered by the GATT Procurement Code, and to negotiate improved market access. If negotiations are unsuccessful, the United States can retaliate by discriminating in its own procurement against goods from the country in question (see ch. 4).

The U.S. Government might try other tactics to improve access to foreign procurement markets. If some Code signatories appear more willing than other to open their procurement markets, the United States might then consider creating a kind of Gold Club Membership GATT Code with countries that agree to abide by very strict rules and enforcement procedures. Members would have broad reciprocal access to cosignatories' public contracts. There could even be a Gold Club Federal Contracts Journal in which participants advertise their procurements no later than they are announced elsewhere.

However, based on experience with other types of market barriers, a strategy based primarily on opening foreign procurement is likely to bring disappointing results. If closed foreign procurement is hurting important U.S. industries, the United States could also use domestic measures, such as R\&D support and tax breaks, to promote the industries in question.

In addition, the United States could use its own procurement strategically to develop important technologies and industries. Some measures could be taken consistent with U.S. obligations under the Current GATT Procurement Code and MOUs. For example, current U.S. law restricts defense purchases of supercomputers to U.S. machines. This has been an important help to the U.S. supercomputer industry, and a change in that policy would increase the already substantial risk that the United States will lose dominance to Japan (see ch. 6).

As another example, the GATT Procurement Code does not now cover the U.S. Postal Service. The Postal Service would be an ideal launch customer to develop an electric vehicle industry, since the limitations of electric vehicles under current technology-short range and need for frequent recharging-would not be a problem for the vehicles used to deliver local mail. Procurement of U.S.-made electric vehicles by the Postal Service could provide the United States a sharp advantage in a new industry for which the United States, Europe, and Japan are all competing to develop the technology. If the United States considered an electric 
vehicle industry worth promoting, it might want to keep the Postal Service outside the Procurement Code until the industry was well on its way. Of course, the United States might still decide to subject the Postal Service to Procurement Code discipline in exchange for concessions by other countries. The important thing is that such opportunities not be bargained away thoughtlessly.

It is not clear how many such opportunities exist. Much Federal procurement is subject to neither the GATT Procurement Code or the defense MOUs. Even the best estimates are rough. In 1990, Federal procurement of goods and services amounted to $\$ 229.6$ billion, of which $\$ 181.5$ billion was for defense. ${ }^{76}$ Of the $\$ 48.1$ billion in nondefense spending, perhaps roughly $\$ 4.6$ billion was covered by the Procurement Code, ${ }^{77}$ leaving $\$ 43.5$ billion uncovered. Of the defense procurement, probably at most $\$ 109.2$ billion was covered by MOUs and/or the Procurement Code, ${ }^{78}$ leaving at least $\$ 72.3$ billion uncovered. While some of these uncovered amounts are for services (beyond the scope of this report), probably at least $\$ 5.7$ billion in uncovered nondefense procurement is for goods, ${ }^{79}$ as might be a substantial portion (perhaps $\$ 30$ billion or more) of the uncovered defense procurement. ${ }^{80}$ Probably only a small part of the uncovered procurement could be of strategic importance. However, Congress might wish to mandate that these strategic opportunities be assessed.

Even when purchases are covered by the GATT Procurement Code or other international agreement, the U.S. Government could help industry without breaking international rules. This code does not cover $R \& D$ contracts, so the government could award such contracts to U.S. firms to enhance their position to bid on covered purchases. For example, if the Postal Service were to be covered by the Procurement Code, it could still award R\&D contracts relating to electric cars to U.S. firms before soliciting bids for a fleet.

There might also be a competitiveness bonus in standards development. The GATT Procurement Code permits countries to require national standards in government contracts; companies at the forefront in developing both standards and corresponding products would have a head start in winning the contracts. R\&D funding can be applied to develop national standards that are then included in product specifications, as with the Research and Develop- ment in Advanced Communications in Europe Program (RACE) of the European Community (see ch. 5).

In addition, all government contract specifications might be shaped to conform as closely as possible to commercial products made by U.S. industry, or to planned commercial products. For example, the specifications on a purchase of electric cars by the Postal Service might be written to make production of those vehicles a stepping stone toward U.S. fins' planned commercial production. ${ }^{81}$ Such a purchase might also be timed to fit the product cycle of U.S. fins.

With direction from Congress and the President, each agency could seek out opportunities such as these where Federal procurement and associated R\&D spending can help competitiveness. However, if one agency had overall responsibility for competitiveness, it might work with other agencies to find and coordinate such opportunities. That agency could do the same with State and local governments, advising them on how working their procurements could help U.S. competitiveness. While some State and local governments have some preferences for U.S. goods, they are not coordinated into any national policy or strategy. The agency could act as a clearinghouse to help State and local governments find U.S. suppliers.

State and local procurement could be a powerful tool for competitiveness. One reason is size. In 1990, State and local government spending on goods was $\$ 87$ billion, compared with the Federal Government's spending of $\$ 107$ billion (all but $\$ 10$ billion for defense). For certain items, State and local purchases are a significant part of the market. For example, in 1990 States and localities spent an estimated $\$ 8$ billion on cars and trucks, ${ }^{82}$ amounting to 6 percent of U.S. motor vehicle sales that year. Also, State and local governments are not now governed by the GATT Procurement Code. ${ }^{83}$ Thus, State and local governments have more freedom than the Federal Government to grant preferences for U.S. firms.

\section{INSTITUTIONS FOR A STRATEGIC COMPETITIVENESS POLICY}

In each of the policy areas discussed above, the Federal Government could take many constructive actions. Government efforts to encourage invest- 
ment and savings, enhance human resources, encourage commercial technology development and adoption, and take a more proactive stance in trade policy could help many industries become more competitive. Yet a host of individual actions, undertaken piecemeal, do not add up to a coherent strategy. At present, the Federal Government does not have an institutional structure capable of a strategic, integrated approach to competitiveness and trade policy.

As part of a more proactive approach, the Federal Government might choose to focus various government policies on assistance to critical commercial industries. One element in this strategy is development of criteria that would keep the list of eligible industries short and highly focused. Those on the short list might qualify for priority technology or financial assistance offered by Federal agencies or possibly for special consideration in U.S. trade policy.

If Congress wishes to proceed with this kind of initiative, stronger institutional capacity in the Federal Government would be needed to provide the careful analysis of trade and competitiveness issues that would lead to rational choice of strategies and industries. At the very least, the Government would need the analytic capability to identify candidate industries, to develop action-oriented strategies tailored to specific industries, and to delineate specific government actions, programs and policies. The strategy would need to be industry led, with eligible industries extensively involved in shaping feasible approaches and selecting candidate industries, and in making substantial investments in whatever government-industry partnerships are undertaken. Government decisionmakers would need to make sure that the choices are consistent with the overall goals of the program and criteria for selection.

A coordinated strategy to support critical industries might not get much attention if it were assigned to an existing line agency already saddled with numerous trade and industry responsibilities. Thus, Congress might establish a new organization in the executive branch to develop strategic competitiveness policies. The office could be small, since its role would be largely analytical and catalytic. But it would have to be well and prominently positioned (e.g., in the Executive Office of the President) to effectively leverage or influence actions of key trade and commerce agencies, and it would need Administration support to have clout.

A strategic competitiveness policy will accomplish little unless it prompts action on the part of the many Federal agencies with responsibilities in such diverse areas as foreign trade, research and development, antitrust, and taxation. Recognition is growing among Federal agencies that there are many links between policies affecting domestic industry and foreign trade. However, the two are seldom carried out in concert.

Thus, a strategic competitiveness policy would require a coordinated response by Federal agencies. A certain amount of restructuring and reorganizing of current Federal functions could help. For many years, Congress has been debating whether to rearrange the wide array of Federal trade and commercial programs into new departments or agencies. A purpose underlying most of the proposed reorganizations is to create a more coherent organizational structure for U.S. Government decisions on international trade. If Congress does establish such a department, strategic competitiveness policy could be one of its responsibilities.

At the end of this section, two organizational options are discussed in greater detail, in light of the criteria and objectives discussed immediately below. The two options are not exclusive of each other. The more modest option, establishing a "critical commercial industries office' in the executive branch to formulate and coordinate implementation of strategy in support of critical industries, could well be part of a more far reaching departmental and trade agency reorganization that has as one its goals furthering strategic competitiveness policy. Congress might also use advisory committees as a first step in identifying industries and recommending actions for subsequent adoption by the executive branch or Congress. For example, the newly launched Competitiveness Policy Council might undertake this function, ${ }^{84}$ while the National Advisory Committee on Semiconductors (see box 2-C) could serve as a model for developing strategies for specific industry sectors. Although advisory committees can be useful in identifying problems and needs, only agencies and departments have the authority to implement policies or coordinate Federal responses. Hence, legislation or additional executive action would still be required. 


\section{Box 2-C-National Advisory Committee on Semiconductors}

The National Advisory Committee on Semiconductors (NACS) is an example of a joint effort by industry and government to address the problems of a specific industry sector--in this case the troubled American semiconductor industry. Congress established the committee in the 1988 Omnibus Trade and Competitiveness Act, calling on NACS to "devise and promulgate a national semiconductor strategy." Its final report, scheduled for late 1991, is expected to lay out an overall strategy, including possible trade policy approaches. In the meantime, NACS has issued two interim reports outlining the problems of the American semiconductor industry and making specific recommendations for action by Congress and the administration.

The committee is structured to assure extensive interaction between industry and government in developing the strategy. NACS is technically an independent advisory body in the executive branch. Eight prominent industry executives serve on the committee (the president of AT\&T Bell Labs serves as chairman), as do five high-ranking government officials with key responsibilities for research and development or technology policy.'(The agencies include Defense, Commerce, the Energy Department, the National Science Foundation and the Office of Science and Technology Policy (OSTP).) A Defense Advanced Research Projects Agency official saves as Executive Director, under agreement with OSTP. The committee, which meets every other month, also has setup several working groups to address specific issues. The working groups typically include some committee members and outside experts.

NACS's first two reports, issued in late 1989 and early 1991, recommended several government actions as initial steps toward achieving a national strategy. Some of the recommendations were quite general, such as improving the education and training system, and creating a favorable business environment for all industries. Others were specific to the semiconductor industry, emphasizing, for example, research and development actions Federal agencies could take to further semiconductor technology.

It is probably premature to talk about NACS's overall impact on executive branch policy, Congress, or the industry itself, since it has yet to issue its strategy. Because Federal officials serve on NACS, its suggestions may have influenced some agency R\&D actions. It also has helped elevate visibility of semiconductor issues in the Administration. (Committee members met with President Bush's chief of staff, John Sununu, as well as Office of Management and Budget Director Richard Darman and Michael Boskin, who chairs the President's Council of Economic Advisors.) NACS's interim reports have also helped define the terms of the debate about semiconductor problem areas.

\footnotetext{
1Nonfederal committee members are appointed by the President, through the Office of Science and Technology Policy. The law states that four of the nonfederalmembers were to be selected from the semiconductor industry; the other four were to be eminent in technology, defense and economic development.
}

A proactive strategy does not mean that government would produce a blue print or plan for industry. Instead, the critical industries organization could champion competitiveness, and other domestic policies. It could encourage agencies to give priority for some forms of government assistance (e.g., technology help) to critical industries. It could also encourage agencies to take competitiveness concerns into account when making regulatory decisions that affect a critical industry.

\section{Selecting Industries}

There are many reasons why governments adopt protective stances toward specific industries, ranging from national defense, to economic security, to a desire to mitigate the impact of import competition on communities, firms, and workers. Often, the reason for protection is simply that an industry has the political leverage to gain it.

Implicit in the concept of strategic competitiveness policy is the idea that certain critical industries are important for national economic security. Doubtless, the most promising candidates would come from manufacturing industries in the technological forefront for developing new products and processes. Such industries have a high proportion of technology-oriented workers and spend proportionately more on R\&D. Examples include computers and software, electronic components, communication equipment, advanced materials, precision machining equipment, robotics, biotechnology, and aerospace.

Some critical industries would coalesce around new technologies that could in time provide dispro- 
portionate returns to the firms or countries with the largest market share. There is not much disagreement about what technologies are critical to national economic prosperity and national security. Lists developed by several U.S. Government and business organizations in 1990-91 are remarkably similar (table 2-1). ${ }^{85}$ And the conclusion is widely shared that U.S. industry's position in these technologies has weakened significantly in the past 10 years, and continues to weaken.

The benefits from commercializing these technologies could be large, as suggested by Department of Commerce's 1990 estimate that 13 emerging technologies might yield $\$ 356$ billion in annual product sales in the U.S. market alone by the year 2000. Yet if current trends continue, the United States would lag Japan in most of these technologies and the European Communities in several. ${ }^{86}$

The element of criticality suggests not only technology intensity but also the potential to provide good new jobs and make large contributions to the economy. Thus, a critical industry might be an emerging or developing high-technology industry with large potential markets. Or a critical industry might produce technology or services that enable other industries to make dramatic advances in productivity and quality. The classic examples are machine tools and semiconductors. A rationale for a Federal role in developing a U.S. high-definition television (HDTV) industry is that it could drive technologies critical for other parts of the electronics industry. Consumer demand for HDTV could be sizable. This is one of several emerging industries in which Japan is ahead.

It is important to recognize that not every industry with a claim to leading edge technologies, growing markets, good jobs, and technology spillovers could be selected for support. Public and private resources, energy, and talents are limited. The judgment of industry leaders and their willingness to put up their own money in cooperative ventures are an invaluable guide to the selection of promising industries. This implies the necessity to develop new relationships of trust and shared visions of truly national interest between government and industry.

\section{What Kind of Support?}

The range of policy tools that might be used to support a strategic competitiveness policy includes those discussed in previous sections, such as tech- nology partnerships, financial incentives, and trade policy. Some of the relevant programs already exist, or at least are on the books. To round out the array of policy tools, Congress could authorize some new ones. Options for expanding the list of these programs are touched on only briefly here, as they were discussed in more detail earlier in the chapter.

As noted above, financing long-term investment has been a particular problem for American industry, reflecting the high costs of capital and pressures to realize short-term profits. Federal policy affecting investment might be tailored to meet specific needs of a designated critical industry. For example, across-the-board loosening of depreciation rules for all American industry would be very expensive, but there might be merit to loosening the rules for specific critical industries. The public costs might still be considerable but the stimulus would at least be focused on the specific needs of industries found critical to the national interest. The National Advisory Committee on Semiconductors, for example, estimates that changing current depreciation rules for new investments in semiconductor manufacturing equipment from 5 to 3 years would cost the U.S. Treasury $\$ 180$ million in lost tax receipts, but could prompt $\$ 450$ million in capital investment each year by this industry .87

Almost by definition, technological advance will be a key factor in the competitiveness of critical industries. The creation of a CTA along the lines discussed earlier, or a major expansion of NIST's ATP, could help. While a coherent policy in support of commercially important technologies does not yet exist in this country, the Federal Government does take part in technology development that is useful to some commercial industries, notably NASA's aeronautics R\&D program and the Sematech project. Generally, however, such support has not been part of a systematic effort to further U.S. competitiveness. Sematech, for example, was created ad hoc, in response to strong industry pressure and the argument that a competitive U.S. semiconductor industry is essential to national defense.

As an organizing concept, promotion of critical industries could give direction to future government support of commercial technology. Whatever the institution, adequate funding will be critical. ATP is a tiny program in a diverse agency. The overall NIST budget is the same in real terms today as it was two decades ago. Even if NIST's budget doubles in the 
Table 2-I-Comparison of National Critical Technologies with Department of Commerce Emerging Technologies and Department of Defense Critical Technologies

\begin{tabular}{|c|c|c|}
\hline $\begin{array}{l}\text { National critical } \\
\text { technologies }\end{array}$ & $\begin{array}{c}\text { Commercial emerging } \\
\text { technologies }\end{array}$ & $\begin{array}{l}\text { Defense critical } \\
\text { technologies }\end{array}$ \\
\hline $\begin{array}{l}\text { Materials } \\
\text { - Materials synthesis and processing } \\
\text { - Electronic and photonic materials } \\
\text { - Ceramics } \\
\text { - Composites } \\
\text { - High-performance metals and alloys }\end{array}$ & $\begin{array}{l}\text { - Advanced materials } \\
\text { - Advanced semimconductor devices } \\
\text {. Superconductors } \\
\text { - Advanced materials }\end{array}$ & $\begin{array}{l}\text { - Composite materials } \\
\text { - Semimconductor materials and micro- } \\
\text { electronic circuits } \\
\text { - Composite materials }\end{array}$ \\
\hline $\begin{array}{l}\text { Manufacturing } \\
\text { - Flexible computer integrated manufac- } \\
\text { turing } \\
\text { - Intelligent processing equipment } \\
\text { - Micro- and nanofabrication } \\
\text { - Systems management technologies } \\
\end{array}$ & $\begin{array}{l}\text { - Flexible computer integrated manufac- } \\
\text { turing } \\
\text { - Artificial intelligence }\end{array}$ & - Machine intelligence and robotics \\
\hline $\begin{array}{l}\text { Information and Communications } \\
\text { - Software } \\
\text { - Microelectronics and optoelectronics } \\
\text { - High-performance computing and net- } \\
\text { working } \\
\text { - High-definition imaging and displays } \\
\text { - Sensors and signal processing } \\
\text { - Data storage and peripherals } \\
\text { - Computer simulation and modeling }\end{array}$ & $\begin{array}{l}\text { - High-performance computing } \\
\text { - Advanced semiconductor devises } \\
\text { - Optoelectronics } \\
\text { - High-performance computing } \\
\text { - Digital imaging } \\
\text { - Sensor technology } \\
\text { - High-density data storage } \\
\text { - High performance computing }\end{array}$ & $\begin{array}{l}\text { - Software producibility } \\
\text { - Semiconductor materials and micro- } \\
\text { electronic circuits } \\
\text { - Photonics } \\
\text { - Parallei computer architectures } \\
\text { - Data fusion } \\
\text { - Data fusion } \\
\text { - Signal processing } \\
\text { - Passive sensors } \\
\text { - Sensitive radars } \\
\text { - Machine intelligence and robotics } \\
\text { - Photonics } \\
\text { - Simulation and modellng } \\
\text { - Computational fluid dynamics }\end{array}$ \\
\hline $\begin{array}{l}\text { Biotechnology and Life Sciences } \\
\text { - Applied molecular biology } \\
\text { - Medical technology } \\
\end{array}$ & $\begin{array}{l}\text { - Biotechnology } \\
\text { - Medical devises and diagnostics }\end{array}$ & - Biotechnology materials and processes \\
\hline $\begin{array}{l}\text { Aeronautics and Surface Transportation } \\
\text { - Aeronautics } \\
\text { - Surface transportation technologies }\end{array}$ & & - Air-breathing propulsion \\
\hline \multicolumn{3}{|l|}{$\begin{array}{l}\text { Energy and Environment } \\
\text { Energy technologies } \\
\text { Pollution minimization, remediation, } \\
\text { and waste management } \\
\end{array}$} \\
\hline & & $\begin{array}{l}\text { - No National Critical Technoiogies coun- } \\
\text { terpart: High energy density materials, } \\
\text { Hypervelocity projectiles, Pulsed } \\
\text { power, signature control, Weapon sys- } \\
\text { tem environment }\end{array}$ \\
\hline
\end{tabular}

SOURCE: U.S. Department of Commerce, Emerging Technologies: A Survey of Technical and Economic Opportunities, Spring 1990; and U.S. Department of Defense: Critical Technologies P/an, 15 March, 1990; as cited in The National Critical Technologies Panel, Report of the National Critical Technologies Pane/ (Washington, DC: U.S. Government Printing Office, March 1991), table 2.

next 5 years, as President Bush has proposed, ATP may not get much of the increase. At its present size (\$36 million in fiscal year 1991), ATP is only a beginning. It is not yet adequate for a governmentindustry technology partnership that is big and broad enough to make a difference to the whole economy. Whether seen as an outgrowth or eventual replacement for ATP, a CTA might well begin small. But a mature program of technology support would probably need to be budgeted at $\$ 1$ billion to $\$ 2$ billion per year (see earlier discussion), though it would take time for the agency to develop the staff and experience to manage a program of that size.

If Congress wishes to authorize a critical industries program, it could also take action to give critical industries special priority in other areas of government decision making. For example, in the antitrust area, firms in a critical industry might be extended the same kind of protection for joint 
manufacturing or joint production activities that are now given to cooperative $R \& D$ activities under the National Cooperative Research and Development Act of 1984. (Special action for critical industries would not be needed if Congress decides to amend the 1984 law along these lines for all industries. Several bills to accomplish this have been proposed in recent Congresses, including $\mathbf{S . 4 7 9}$ as introduced in the $102 \mathrm{~d}$ Congress.)

In the same vein, Congress could require Federal agencies to prepare "competitiveness impact evaluations" before promulgating policies likely to have a major adverse impact on the international competitiveness of a designated critical industry. By focusing only on critical industries, the sea of paperwork that might be created by broader impact statement requirements might be avoided.

As noted, strategic competitiveness policy would allow occasional departures from the prevailing free trade philosophy. Such departures would not be frequent, but the ability to take the initiative in matters of trade policy would be a necessary part of the overall strategy. Once critical industries are identified, a special interagency group could be set up to consider trade policy actions that would promote the competitiveness of the industry; the critical industries organization would be responsible for coordinating trade policies with other strategies in support of the selected industries. As mentioned earlier, trade negotiators could be directed to give critical commercial industries top priority in dealings with other countries on fair trade and market access issues. The presence of a competitiveness champion within U.S. Government would strengthen the hand of U.S. negotiators in such dealings.

The most important job for a government body responsible for support of critical commercial industries would be to tie together the policy strands in a reasonably coherent whole. Of course, no government agency can ever establish a neat, wholly coherent policy on any broad national issue, whether it be fiscal policy, health, education, environment, or competitiveness. There will always be some messiness, conflicts and overlap between agencies, struggles between special interests and the national interest, compromise and disarray. Because the U.S. Government and the American people have relatively little experience in government-industry partnerships, it would be overoptimistic to expect the creation of a coherent strategic competitiveness policy to be easy or rapid, even assuming a consensus in support of such a strategy. A modest start and evolutionary growth is a more reasonable expectation. But the aim of coherence would nevertheless have to be steadily pursued. Otherwise, it is too easy to be sidetracked into spreading available resources too thinly, or hijacked into serving special interests.

\section{Institutional Alternatives}

Institutional arrangements for developing and implementing a critical commercial industries approach could take many forms. Two possibilities are discussed below.

\section{A Critical Industries Office}

A small office in the executive branch with an elite staff could serve as the lead agency in developing and implementing strategic competitiveness policy. The office might be placed in a department, or, in a willing Administration, the Executive Office of the President. In either case, championing critical industry strategies and serving as a catalyst for action by Federal agencies could be part of the office's mandate.

Proposals in recent Congresses to create an office of competitive analysis might be a starting point. As proposed in H.R. 1274, a trade reorganization proposal introduced but not acted on in the 101st Congress, the office would report each year on the competitive prospects of American industries, and could empanel temporary industry councils to advise on needed changes in Federal policy with respect to specific industries. Even if Congress stopped short of trade reorganization, it could direct the Administration to create a critical industries office within an existing department. The Department of Commerce, which now administers several trade and technology programs, might be a logical place.

Locating the office in the Executive Office of the President would be a good option in an Administraion that is supportive of the critical industries approach. The Executive Office can bring high visibility and government-wide perspective to issues. However, such a location is likely to be ineffective in an Administration hostile to the concept.

While private industry input would be indispensable, a critical industries office would need a strong 
staff. First, the process of identifying critical industries would demand highly competent personnel. An even more demanding task for the staff would be to encourage Federal actions and policies that make a real difference in the competitiveness of critical industries. If Congress were to direct the Administration to set up such an office, it might consider exempting the office from the normal civil service guidelines on hiring and dismissal of employees. To assure fresh thinking, Congress could direct that no more than half of the initial staff could be drawn from existing agency personnel. Congress might also make sure that the agency had the resources to actively recruit from industry, universities, and research institutions.

\section{Government Reorganization and Strategic Industry and Trade Policy}

A major change in current government organization for trade and competitiveness policy is not a prerequisite for a critical industries approach. However, the way the government organizes its functions does affect policy outcomes, and competitiveness policy is no exception. If Congress wishes to promote a more proactive approach to trade and competitiveness issues, then reorganization could produce a more focused policymaking apparatus and more direct lines of authority for carrying out the policy.

The current structure for trade decisionmaking within the Federal Government is diffuse, with dozens of agencies having roles to play and a bewildering array of interagency task forces playing coordination functions. No fewer than 10 departments, 2 independent agencies, and 4 executive office agencies take part in trade policy formulation, and the actions of many other agencies and departments can affect international trade. The Commerce, State, Treasury, and Agriculture Departments all powerfully influence trade policy, as do some independent agencies (the International Trade Commission). The U.S. Trade Representative (USTR) has statutory responsibility for trade policy coordination and negotiation, but (as noted) its staff is stretched thin by the issues of the day (e.g., securing a Uruguay Round agreement, launching negotiations for a Mexican Free Trade Agreement).

Responsibility for other government functions affecting the competitiveness of American industry is similarly diffuse. Dozens of agencies have regulatory responsibilities that, in large and small ways, can influence industrial competitiveness. Several agencies-commerce, Defense, Energy, the National Science Foundation-have $R \& D$ responsibilities relevant to industry. Efforts to coordinate functions among agencies is predictably sporadic; the White House Office of Science and Technology Policy (OSTP) in the Bush Administration, for example, has breathed life into interagency coordinating committees that a few years earlier had been all but abandoned.

Sprawling, decentralized policy structures may have adequately served the overall strategic interests of the United States throughout most of the post World War II period. Yet the absence of a powerful voice within government for the international competitiveness of American industry almost assures that other objectives (e.g., foreign policy, national security) begin with the stronger hand when disputes arise, whatever the substance of the matter. Moreover, the lack of central focus and direction, far from underpinning $g$ the U.S. Government commitment to free trade, has resulted in trade policy with quite a few contradictions and apparent exceptions.

Some in Congress have proposed government reorganization as a means to improve the focus and effectiveness of Federal trade and commercial policy functions. Some bills would establish a new Department of International Trade and Industry, assuming many functions now carried out by the Office of the USTR, the Commerce Department, and some export financing agencies. ${ }^{88}$ Other proposals have called for a Department of International Trade and Investment or Department of International Commercial Policy, consolidating USTR and the trade policy units of several existing Departments into one agency, and establishing a cabinet committee to coordinate international economic policy .89

Another set of proposals have called for creation of a Department of Industry and Technology, building on existing Commerce Department authority for export promotion and creating a Civilian Technology Agency. ${ }^{90}$ Some proposals to set up an industry and technology department would also create an independent U.S. Trade Administration, comprised of the Office of the USTR and Commerce Department agencies responsible for trade administration and international economic policy .91 (The USTR would continue to serve as a cabinet rank official). 
In the end, the specific bureaucratic arrangements outlined in these proposals are less important than the substantive goals they try to achieve. Nor should any of these arrangements be expected to eliminate coordination problems. As a practical matter, not all the Federal agency functions related to competitiveness could ever be consolidated into one department. Many key financial, trade, and technology policy functions would continue to be carried out elsewhere. Moreover, executive office coordination of these functions would still be needed. It is hard to conceive, however, that a coherent competitiveness policy can succeed without a strong agency heading up the effort.

1 Two earlier reports in OTA's assessment of Technology, Innovation and U.S. Trade consider many of these issues in detail. Paying the Bill: Manufacturing and Americans Trade Deficit, OTA-ITE390 (Springfield, VA: National Technical Information Service, 1988) discusses the place of manufacturing in international trade and the U.S. economy. Making Things Better: Competing in Manufmturing, OIYdlT!443 (Washington DC: U.S. Government Printing Office, February 1990) considers how technology can improve U.S. manufacturing competitiveness, including four possible areas for government action: the financial environment, human resources, diffusion of technology, and strategic technology policy. Other recent, closely related OTA reports are Worher Training: Competing in the New International Economy, OTA-ITE-457 (Washington, DC: U.S. Government Printing Office, September 1990) and Commercializing High Temperature Superconductivity, OTA-ITE-388 (Washington DC: U.S. Government Printing Office, August 1988).

2 U.S. Congress, Office of Technology Assessment Paying the Bill, op. cit., passim, and Making Things Better, ibid., passim; MIT Commission on Productivity, Made in America: Regaining the Productive Edge (Cambridge, MA: The MIT Press, 1989) passim.

3 The agreement was the 1986 U.S.-Japan Semiconductor trade agreement, renewed with substantial modifications in 1991. U.S. producers' access to the Japanese market (which was informally part of the agreement) has been lower than U.S. companies and negotiators deem acceptable, although U.S. companies' Japanese market shares did improve after the agreement took effect. While there is dispute about whether the agreement caused higher prices for memory chips, the price hikes that followed the STA also hurt the computer industry. For further explanation of this agreement, see ch. 4.

4 Chalmers Johnson MITI and the Japanese Miracle: The Growth of Industrial Policy, 1925-1975 (Stanford, CA: Stanford University Press, 1982).

5 The discussion below is based on options detailed in Making Things Better, op. cit., ch. 2, and Worker Training, op. cit., ch. 2.

6 From 1977 to 1988, the U.S. cost of capital for investments in machinery and equipment with a physical life of 20 years averaged 3.4 percentage points higher than similar costs in Japan and 4.9 percentage points higher for investments in a factory with a physical life of 40 years. (Robert N. McCauley and Steven A. Zimmer, 'Explaining International Differences in Capital Costs, "Federal Reserve Bank of New York Quarterly Review, summer 1989, pp. 7-28.) Although some international differences in capital costs are due to risks related to currency fluctuations, sustained differences of the magnitudes shown by McCauley and Zimmer are unlikely under free market conditions. Despite liberalization in the 1980s, the Japanese financial market is not yet as open as that in the United States. Also, tax incentives and exemptions are widely used in Japan to lower capital costs and promote investment, often in specific industries or technologies. Furthermore, the Japanese system of stable and mutual shareholding means that only a small portion of companies' shares are traded on financial markets, thus relieving pressure on management to show short-term profits. See Making Things Better, op. cit., ch. 3, for a discussion of the costs of capital and conditions of availability in Japan and the United States.

7 The 1990 budget agreement between Congress and the Administration, which partitions spending into defense, domestic nondefense, and foreign nondefense categories, lasts through three fiscal years, from 1991 through 1993. Afterwards, the three categories may again be merged so that it would be possible, say, to pay for tax expenditures in the non-defense part of the budget with spending cuts in defense.

8 The Joint Committee on Taxation estimated the cost in lost revenues of the investment tax credit at $\$ 13$ billion to $\$ 37$ billion per year in the 1980s, and $\$ 8$ billion to $\$ 64$ billion per year for the Accelerated Cost Recovery System. Both programs were ended in the tax reform law of 1986, in favor of an overall reduction in the corporate tax rate (although certain classes of assets are still granted fast depreciation).

9 These policy options for training of active workers are drawn from the OTA report Worker Training, op. cit., ch. 2.

10 A bill to setup such a program, Section 404 of S. 2114, was introduced in the 101st Congress.

11 For a detailed discussion of these options, see Making Things Better, op. cit., pp. 53-71. Descriptive and analytic material on technology diffusion in the United States and other countries is in chapters 6 and 7 of that report.

12 Fewer States applied for the Centers opening in 1991 than for those beginning 2 years earlier (20 proposals compared with 36 ). "Commerce Selects Two Manufacturing Centers," New Technology Week, Mar. 11, 1991. A smattering of other Federal programs offer some technology extension services. The largest of these is Trade Adjustment Assistance for firms, which has been funded at about $\$ 9$ million per year in recent years.

13 Making Things Better, op. cit., p. 58.

14 This is direct government loans only and does not count loan guarantees, which are about twice as great. In 1987, direct loans to small and medium enterprises from the three main government financing institutions amounted to Y3.8 trillion ( $\$ 30$ billion at Y125 to the dollar); loans guaranteed by the 52 nationwide credit associations amounted to Y7.8 trillion (\$62 billion). D. H. Whittaker, "New Technology Acquisition in Small Japanese Enterprises: Government Assistance and Private Initiative," contract report to the Office of Technology Assessment, May 1989.

15 See Making Things Better, op. cit., pp. 192-194.

16 On Mar. 1, 1991, DOE signed an agreement with Martin Marietta Energy Systems, which runs Oak Ridge National Laboratory, for a class waiver on inventions proposed by Martin Marietta for commercialization (subject to national security exceptions). Class waivers had previously been granted only to non-profit operators of DOE's national labs; this was the first such agreement with a for-profit operator. Paul Kemezis, "Oak Ridge Lab Receives Approval to Sign Deals With U.S. Industry, ” New Technology Week, Mar. 11, 1991.

17 For example, the National Center for Manufacturing Sciences organizes shopping trips to the labs on behalf of its over 100 industry members, seeking to pair lab expertise with industry needs. This complements a longer established effort from the labs' side, the Federal Laboratory Consortium, which operates a small core staff and 300 volunteers from the labs to match inquiries from firms with the appropriate lab researcher.

18 See McGraw-Hill's Tech Transfer Report, February 1991, for several recent examples.

19 Ibid.

20 Bill Loveless \& David Kramer, "Expanded Missions Eyed for DOE's National Labs,' McGraw-Hill's Tech Transfer Report, February 1991, p. 13. 
21 Software written in contractor-operated Federal labs can be copyrighted and then licensed to firms. An exclusive license is sometimes a necessary incentive for a firm to commercialize the software. However, software written in government-operated labs is written by government employees and cannot now be copyrighted, making it difficult or impossible to grant firms exclusive rights.

22 The National Cooperative Research Act of 1984 lessened the legal risks of joint R\&D. See P.L. 98-462, 15 U.S.C. 43014305.

23 Malcolm Baldrige National Quality Improvement Act of 1987, Public Law 100-107, Sec. 3.

24 Jeremy Main "How to Win the Baldrige Award, "Fortune, Apr. 23, 1990, p. 101.

\section{Ibid.}

26 These categories are drawn from the report of a private group, the Council on Competitiveness; see Gaining New Ground: Technology Priorities for Americans Future (Washington, DC: The Council, 1991). The government reports include U.S. Department of Commerce, Technology Administration, Emerging Technologies: A Survey of Technical and Economic Opportunities (Washington, DC: Department of Commerce, 1990); U.S. Department of Defense, Critical Technologies Plan, report for the Committees on Armed Services, U.S. Congress, AD-A234-900 (May 1, 1991); Government of Japan, Ministry of International Trade and Industry, Trade and Future Tusks in Industrial Technology (Sangyo Gijutsu no Doko to Kadai) (Tokyo: 1988); Commission of the European Community, First Report on the State of Science and Technology in Europe (Brussels: 1988).

27 The program began in October 1988. U.S. Congress, Office of Technology Assessment, Making Things Better, op. cit., p. 188, box 7-B.

28 Foreign market barriers, their effect on U.S. industry, and the U.S. response are discussed in more detail in ch. 4. In addition, barriers imposed by the EC, Japam Korea and Taiwan are discussed in chs. 5-7.

29 Clyde V. Prestowitz, Jr., Alan Tonelsom and Robert W. Jerome, "The Last Gasp of GATTism, ' Harvard Business Review, March-April 1991, p. 137.

30 See box 4-A. In the GATT Uruguay Round, Canada and the EC have proposed transforming GATT into an ITO; consideration of this proposal has been deferred until after the Round is completed.

3119 U.S.C. 2411-2420.

32 This is the pot calling the kettle black. Many countries consider their laws superior to GATT when they deem it necessary.

33 This case is discussed in detail inch. 4.

34 Clyde V. Prestowitz, Jr., Trading Places: How We Allowed Japan To Take The Lead (New York NY: Basic Books, 1988), pp. 283, 50-52.

35 Ibid., pp. 276-277.

36 Protection can be granted in certain other cases-for example, under Section 201, as described below. Protection has also at times been instituted by means of bilateral agreements limiting the quantity of imports of certain products from particular countries. Examples are textiles, machine tools, and automobiles. Except for textiles, in which the bilateral agreements come under an overall arrangement sanctioned by GATT these bilateral agreements at least arguably violate GATT Protection against imports is discussed in detail in ch. 4.

3719 U.S.C. 2251-2254.

3819 U.S.C. 2253(a)(3).

39 From 1980 through 1990, U.S. industry petitioned for relief under Section 20120 times. The required injury was found in seven cases (though in two only for some of the products at issue), and the U.S. industry received some protection in five (see table 4-8).

4019 U.S.C. 2252(b)(l)(B).

41 GATT's escape clause (Article XIX) requires injury "to domestic producers . . . of like or directly competitive products, ' and
U.S. law tracks this language (19 U.S.C. 2251). In contrast, GATT's provisions regarding subsidies and dumping (Article VI) permit a showing that the dumping or subsidization "retard[s] materially the establishment of a domestic industry," and U.S. law follows that language (19 U.S.C. 1671(a)(2), 1673(2)).

42 The language of GATT's escape clause is general, requiring only that the increased imports "cause or threaten serious injury to domestic producers. . . of like or directly competitive products.' There has been little interpretation of this language by GATT dispute resolution panels. Negotiations underway in the Uruguay Round could clarify the escape clause's scope. The United States seeks to restrict rather than expand this scope.

43 GATT Article XIX, par. 1(a).

44 At times protection could also be justified under GATT's national security exception (Article XXXVIII). This could be the case, for example, with protection of the domestic semiconductor industry, which furnishes the U.S. military with essential components of weapons. However, the United States and other countries have been cautious about using that exception for fear of setting precedents that would make it into an all-purpose tool to justify a great deal of protection.

45 In the time it takes to reach this point the U.S. industry's condition might improve enough so that it could get along without protection.

46 The terms of the EC proposal to the Japanese on automobiles had not been made public at this writing; this description is based on information from trade sources.

47 U.S. Commerce Department International Trade Adrministration, Office of Management personal communication, Aug. 2, 1991.

48 U.S. General Accounting Office, Export Promotion: Problems in Commerce's Programs, NSIAD-89-44 (Gaithersburg, MD: U.S. General Accounting Office, 1989), p. 17.

49 The Japanese effort included 3 officers at the Japanese embassy and 78 employees of the Japan External Trade Organization (JETRO), an agency of MITI. Those figures are from Akemi Yoshida, Attaché in Management and Coordination, Japanese Embassy, Washington DC, Aug. 21, 1991; and Hiro Sate, Director of Research JETRO (New York Office), Aug. 21, 1991. The figures for U.S. staffing in Japan are from an interview with Ed Stumpf, Director, East Asia and Pacific, USFCS, Aug. 21, 1991

50 United States Trade and Development Program, 1990 Annual Report, pp. 27, 29, 55-61.

51 H.R. 2508 and S. 1435, in conferences of August 1991, would do both.

5250 U.S.C. App. 2401-2420. This Act's authorization lapsed as of Oct. 1, 1990, but President Bush continued its provisions in force by invoking the International Emergency Economic Powers Act 50 U.S.C. 1702. See executive order 12730-Continuation of Export Control Regulations, Sept. 30, 1990.

53 Public Law 100-418, sec. 2414, codified at 50 U.S.C. App. 2504(a)(5)

54 Title II of the Omnibus Trade and Competitiveness Act of 1988, Public Law 100-418.

5550 U.S.C. App. 2409(g).

56 S. 320 passed the Senate on Feb. 20, 1991, and was referred jointly to the House Committee on Foreign Affairs and the House Committee on the Judiciary on Feb. 26, 1991. This bill resembles the conference version of H.R. 101-4653 and S. 101-2927, as passed by the House and Senate in 1990, but omits certain provisions that President Bush found objectionable in vetoing that bill. See President George Bush, Memorandum of Disapproval for the Omnibus Export Amendments Act of 1990, Nov. 16, 1990.

57 S. 320, Sec. 117.

58 A 1990 conference report on this same provision commented 
that "[s]ome provisions of the 1988 amendment to the EAA were not implemented or were implemented far beyond statutory deadlines. " H. Rept, 101-944, p. 75.

5950 U.S.C. App. 2409(j).

60 S. 320, Sec. 124.

6150 U.S.C. App. 2402(f)(3)(B).

62 This was proposed in H.R. 4653, Sec. 120, but deleted in conference. See House Conference Report 101-944 (on H. 4653), p. 75.

63 Dual-use nuclear technology comes primarily under another statute, Section 309(c) of the Nuclear Non-Proliferation Act of 1978, codified at 42 U.S.C. 2139 a(b). See Section 17(d) of the EAA, at 50 U.S.C. App. 2416(d).

64 See Making Things Better, op. cit., especially pp. 71-89.

65 Budget of the United States Government: Fiscal Year 1992, part two, p. 47.

66 For more detailed discussion see Making Things Better, op. cit., pp. 71-79.

67 One of the bills, S. 1233 in the 100th Cong., was reported out of the Senate Committee on Governmental Affairs, attached to the 1988 trade act, but was then dropped. Two similar bills, H.R. 3838 and S. 1978 were introduced in the 10lst Cong.

68 U.S.-owned companies are defined as those that have majority ownership or control by citizens of the United States.

69 U.S. Congress, House of Representatives, Conference Report [to accompany H.R. 5021] making appropriations for the Departments of Commerce, Justice and State, the Judiciary, and related agencies for the fiscal year ending Sept. 30, 1991, and for other purposes, report 101-909, Oct. 20, 1990, pp. 25-26.

70 These comparisons are for merchant producers, who sell semiconductors on the open market. Companies that produce only for their own use (captive production) are excluded; IBM the world's biggest producer, is in this category and therefore excluded. All major Japanese producers are included.

71 In practice, capital-intensive and R\&D-intensive industries tend to get more benefits than others from the tax incentives.

72 A succinct description and evaluation of the postwar RFC is in Arthur T. Denzau and Clifford M. Hardin, "A National Development Bank: Ghost of the RFC Past," formal publication number 62, Center for the Study of American Business, June 1984.

73 A Strategic Industry at Risk, a report to the President and the Congress from the National Advisory Committee on Semiconductors (Washington DC: The Committee, 1989), p. 20. See also Making Things Better, op. cit., pp. 80-89.

74 Recent data have been classified by the U.S. Government. Estimates based on detailed data are publicly available only for 1981, the Code's first year of operation. In that year, the Code was estimated to have covered only $\$ 18$ billion in U.S. procurement and $\$ 4.2$ billion in all foreign procurement combined. (For comparison in 1985 U.S. procurement, and procurement by all other Code signatories, each totaled in the range of $\$ 200$ billion.) The amount of actual trade under the Code in 1981 appeared to be much smaller+ 3.3 billion for U.S. imports and $\$ 270$ million in U.S. exports. And the amount of this trade that would not have occurred without the Code appeared to be at most $\$ 210$ million for U.S. imports and perhaps substantially less than $\$ 270$ million for U.S. exports. (See ch. 4.)

75 Public Law 100-418, Title VII.

76 U.S. Department of Commerce, Bureau of Economic Analysis. BEA breaks this down as follows: defense goods, $\$ 96.7$ billion defense services, $\$ 84.8$ billion nondefense goods, $\$ 10.3$ billion nondefense services, $\$ 37.8$ billion. (Procurement of services does not include compensation paid to employees.)

77 To get this result, proportion estimates that area few years old are applied to the 1990 figures. Based on testimony in 1989, the Code covers about 10 percent of total Federal procurement. W. Douglas Newkirk, Assistant U.S. Trade Representative for GATT Affairs, Office of the United States Trade Representative, testimony at hearings before the House Committee on Government Operations, Subcommittee on Legislation and National Security, Sept. 27, 1989, p. 6 (p. 56 of hearing print). Based on GAO testimony in 1989, describing procurement during 1985 through 1987, Code-covered procurement is split roughly 80 percent for DoD and 20 percent for other agencies. Adam Cowled, Senior Evaluator, U.S. General Accounting Office, personal communication, July 24, 1990, interpreting U.S. Congress, House Committee on Government Operations, International Procurement and Waivers of the Buy America Act: U.S. Business at a Disadvantage, H. Rept. 101-989, Nov. 29, 1990, p. 7 fn. 6, and Allan I. Mendelowitz Director, Trade, Energy and Financial Issues, United States General Accounting Office, testimony at hearings before the House Subcommittee on Legislation and National Security, Sept. 27, 1989, p. 30 of Committee print. Thus, in 1990 about 8 percent of $\$ 229.6$ billion, or $\$ 18.4$ billion, is Code-covered defense procurement, while about 2 percent of $\$ 229.6$ billion, or $\$ 4.6$ billion, is Code-covered nondefense procurement.

78 Probably roughly 50 percent of defense procurement, or $\$ 90.8$ billion, is covered by MOUs (ch. 4). Perhaps about $\$ 18,4$ billion of defense spending is covered under the Procurement Code (see previous footnote). Assuming that there is no overlap between Code and MOU coverage (which yields the highest possible figure), the combined coverage is $\$ 90.8$ billion plus $\$ 18.4$ billion, or $\$ 109.2$ billion.

79 The Procurement Code covers only goods and services "incidental" to the purchase of goods. Even if all $\$ 4,6$ billion of the Code-covered nondefense procurement is for goods, that still leaves $\$ 5.7$ billion in non-Code-covered nondefense procurement, since the total nondefense procurement of goods is $\$ 10.3$ billion (see first footnote in this paragraph).

80 Defense procurement for 1990 consisted of $\$ 96.7$ billion for goods and $\$ 84.8$ billion for services (see first footnote in this paragraph). While the $\$ 18.4$ billion of Code-covered defense procurement is likely almost all goods (see previous footnote), it is hard to tell how the $\$ 90.8$ of MOU-covered procurement is divided between goods and services. If it were divided proportionately to the total spent on defense goods versus services, $\$ 48.4$ billion would be for goods. This yields a total of at most (assuming no overlap between Code and MOU coverage) \$18.4 billion @ $\$ 48.4$ billion or $\$ 66.8$ billion in defense goods covered by the Code or MOUs, leaving at least $\$ 29.9$ billion of uncovered defense goods.

81 Other countries could argue that such actions violate the GATT Procurement Code, Article IV, which states that "Itechnical specifications. . shall not be prepared, adopted or applied with a view to creating obstacles to international trade nor have the effect of creating unnecessary obstacles to international trade." However, the point is debatable, especially if the specifications are shaped merely to be convenient for U.S. firms rather than to deliberately be inconvenient for foreign firms.

82 This estimate is based on Commerce Department data for State and local purchases of durable goods in 1990 ( $\$ 33$ billion) and the percentage of such purchases going for motor vehicles in 1982 (24 percent at that time-no more recent figure is available).

83 However, the EC has taken the position that if the Procurement Code's coverage is expanded State and local government procurements in the United States should be covered.

84 The Competitiveness Policy Council (CPC) was established by the 1988 trade act (Public Law 100-418) but did not get underway until early 1991. Its members are appointed by the President and by Senate and House leaders from both parties; it is to report annually to the President and Congress. It should not be confused with the nonstatutory Council on Competitiveness in the office of Vice President Quayle, which evaluates the impact of Federal regulation on competitiveness, or the private Council on Competitiveness. Congress will need to act if the $\mathrm{CPC}$ is to continue; the Bush Adminstration's proposed budget says that the Council will complete its work in 1991 and disband in 1992, with Vice President Quayle's competitiveness council assuming responsibil- 
ity for regulatory and "other" competitiveness issues. To date, the Vice President's council has not shown evidence of a willingness to address the broad range of issues assigned to the CPC.

85 Also broadly similar are lists of critical technologies developed by the Japanese Ministry of International Trade and Industry and the Commission of the European Community.

86 Technology Administration, U.S. Department of Commerce, Emerging Technologies: A Survey of Technical and Economic Opportunities (Washington DC: U.S. Department of Commerce, spring 1990).

87 NationaI Advisory Committee on Semiconductors, Toward A National Semiconductor Strategy, 2d annual report, N.A.C.S., Arlington, VA, February,1991, p. 15.

88 Bills to establish a Department of International Trade and Industry include, among others, S.121 as reported by the Senate Committee on Governmental Affairs in the 98th Cong.; S. 1365 as introduced in the 99th Cong.; H.R. 1338 and H.R. 2135 as introduced in the 100th Cong., and H.R. 1274 as introduced in the 101st Cong.

89 For an analysis of this approach see Stephen D. Cohen The Making of United States International Economic Policy: Principles, Problems and Proposals for Reform (New York NY: Praeger, 1988), pp. 248-271

90 See S.1978, the proposed Trade and Technology Promotion Act of 1989, as introduced in the 101st Cong. and S.1233, the proposed Economic Competitiveness, International Trade and Technology Development Act of 1987, as reported by the Senate Committee on Governmental Affairs on June 23, 1987. (Senate Report 100-82)

91 S.1233 (100th Cong.) as reported by the Senate Committee on Governmental Affairs on June 23, 1987. See S. Rept. 100-82 for discussion. 
Chapter 3

American Firms, Foreign Firms: Contributions to the Nation 


\section{CONTENTS}

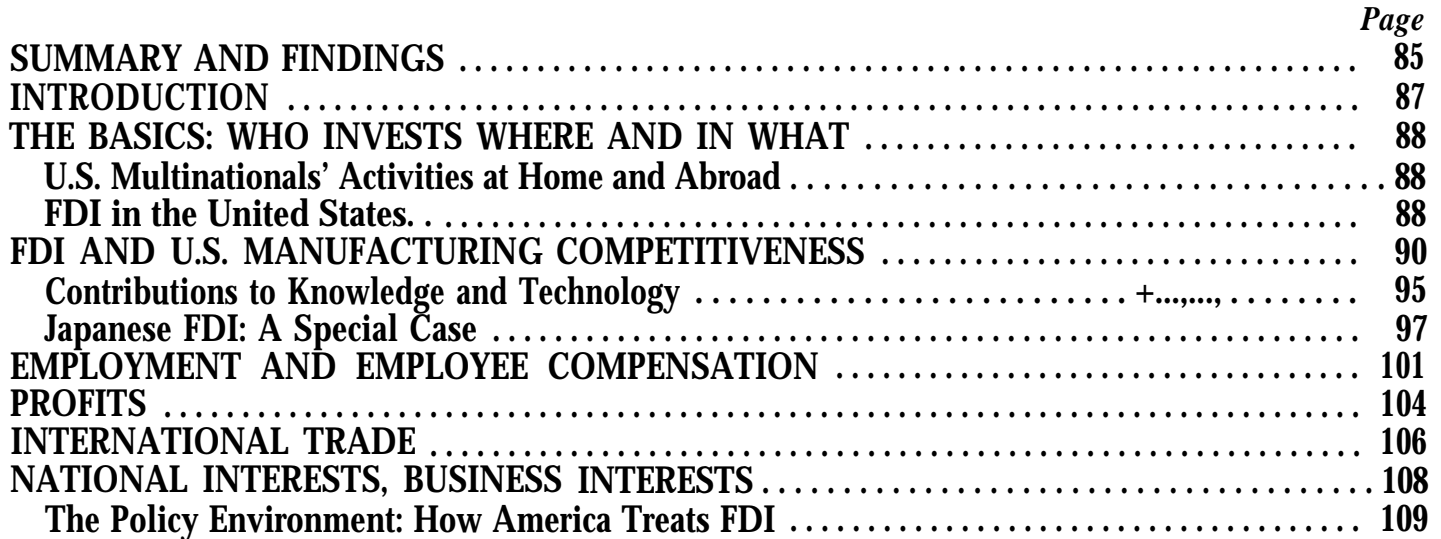

3-1. Foreign Direct Investment in the United States: Sales of Manufacturing Affiliates . . . . . . 88

3-2. Foreign Direct Investment, 1977-88: Assets of Major Investors . . . . . . . . . . . . . . 89

3-3. Foreign Direct Investment Position in the United States, $1990 \ldots \ldots \ldots \ldots \ldots \ldots \ldots \ldots \ldots . \ldots 89$

3-4. Automobile Assembly Plant Defect $\%$ 1988-89.. ........................... 94

3-5. Automobile Assembly Productivity, 1988............................ 94

3-6. R\&D Intensity, U.S. Manufacturers and U.S. Affiliates of Foreign Manufacturing

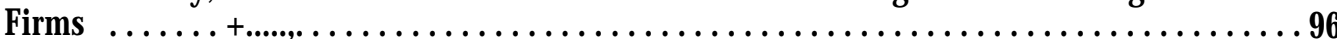

3-7. R\&D/Manufacturing Employee FDIUS and U.S, Manufacturers ............... 97

3-8. Spending for New Plant and Equipment, Foreign Manufacturing Affiiliates and U.S. Manufacturers ........................................... 97

3-9. Investment in Plant, Property and Equipment as a Percent of Sales of Manufacturing Affiliates ................................................... 98

3-10. Employment in U.S. Affiliates, 1977-88 .............................. 102

3-11. Earnings and Reinvested Earnings: Foreign Direct Investors in the United States . . . . . . . 104

3-12. Earnings and Reinvested Earnings: Japanese Direct Investors in the United States . . . . . 105

3-13. Earnings and Reinvested Earnings: European Direct Investors in the United States . . . . . 105

3-14. Earnings and Reinvested Earnings: U.S. Direct Investment Abroad ................ 106

3-15. Merchandise Trade, FDIUS Affiliates ................................... 107

\section{Tables}

Table

3-1. Foreign Direct Investment in the United States: Manufacturing Sales, 1977 and 1988 . . . . 91

3-2. Foreign Direct Investment in the United States: Assets of Manufacturing Affiliates,

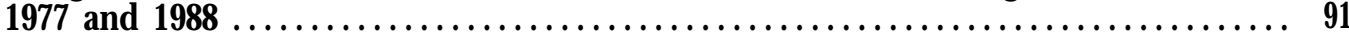

3-3. European Direct Investment in the United States Manufacturing Sales, 1977 and 1988 . . . 92

3-4. Japanese Direct Investment in the United States: Manufacturing Sales, 1977 and 1988.... 92

3-5. Canadian Direct Investment in the United States: Manufacturing Sales, 1977and1988 . . . 93

3-6. Manufacturing Research and Development Intensity: Foreign Direct Investors and

U.S. Firms, 1977-88 ........................................................ 96

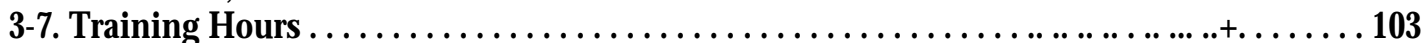




\section{American Firms, Foreign Firms: Contributions to the Nation}

\section{SUMMARY AND FINDINGS}

Both American and foreign companies are becoming more international, investing in a variety of activities outside their home counties. This is especially true of foreign companies, whose investment abroad rose at a much faster rate than that of U.S. firms in the 1980s-with a substantial share being made in the United States.

At the same time, most advanced nations are undertaking programs to promote competitiveness. Combined with the trend toward more international investment by private companies, this puts pressure on political systems to decide how or whether multinational firms can participate in competitiveness programs. Nominally, the OECD ${ }^{2}$ nations subscribe to the principle of national treatment, which means no discrimination against or in favor of any firm based on the nationality of its owners. Exceptions are routinely made for national security reasons to assure that nations retain sovereignty and the ability to command military production in times of national emergency. However, the distinctions between national security and economic competitiveness are becoming blurred, as military needs increasingly depend on industries whose primary business is in the civilian sector. Especially in advanced nations, decisionmakers are increasingly confronted with uncomfortable decisions on how to treat foreign firms and their affiliates. Less developed nations have long wrestled with policies towards foreign multinationals, but the issue was secondary for advanced nations until the last couple of decades.

The United States is a newcomer to this realm of political decisionmaking, as it is facing rapidly rising foreign assets and control for the first time in its modem history. European nations have long had higher participation by multinationals but have not yet determined how to treat foreign affiliates, especially now that Japanese multinationals, with deep pockets, advanced technologies, and outstanding records of successful market penetration, are on the European scene. Japan, the outlier among industrialized countries in the degree to which multinationals are not participants in its economy, is being pressured by many other nations to open its markets to both imports and investment.

There is some agreement among policy analysts that whatever principles govern the treatment of foreign affiliates (vis-à-vis their participation in programs to promote economic competitiveness), they should not be based narrowly on ownership. There is disagreement on what other principles should apply. One point of view is that national treatment should be the only principle, and that the standards for handling international investment should be the same as those that govern international trade in the GATT---i.e., openness and nondiscrimination based on nationality. Foreign affiliates, it is argued, behave very much like domestic fins, with only minor exceptions. Therefore, political intervention that treats foreign affiliates differently from domestic firms introduces distortions that decrease economic well-being for everyone.

Another view is that reciprocity should be the governing principle. Reciprocity means that affiliates of foreign firms are given the same treatment in the host country as the host country's firms are given in the nation they call headquarters. Reciprocity is already applied in a few instances in the United States, for example, in mineral leasing on public lands.

A current, controversial approach focuses on performance standards. Both in Europe and the United States, there is serious talk of establishing standards that any firm must meet to qualify for government-funded or government-sponsored programs. Standards generally have to do with how much production, $R \& D$, employment, and value added firms do in the host country, compared with domestic fins.

Existing data give limited insight into how foreign affiliates behave in the United States. Foreign direct investment (FDI) in the United States is on the rise, especially in manufacturing, where foreign affiliates now account for over 10 percent of the sales of all U.S. manufacturing. These affiliates contribute in various ways to the U.S. economy and, although there are some distinctions between their behavior and that of U.S.-owned fins, they are similar in some important ways. 
Foreign manufacturing affiliates are generally the equals if not the superiors of U.S. manufacturing firms in yearly investments in new plant and equipment. They do considerably less $R \& D$, as a percentage of sales, than U.S. manufacturing fins. These two measures are the most direct aggregated data we have on how foreign affiliates contribute to U.S. technology, knowledge, and productivity. They are not adequate to make complete judgments of those contributions and will not resolve the ongoing debate over whether foreign affiliates contribute to U.S. technology on balance or make net transfers of technology and other economic benefits mostly to their home countries.

In terms of employment practices, foreign affiliates are hard to distinguish from domestic companies. "In manufacturing, they pay about the same compensation as domestic firms, and more than American firms overall, but this is due more to their disproportionate investment in high-wage service industries than to any propensity to pay more than comparable American establishments. Foreign affiliates are neither more nor less reliable employers than U.S. companies; affiliates are about as likely to lay off workers during economic downturns as U.S. companies. ${ }^{3}$ Their qualitative contributions to the competence and knowledge of American employees is based on anecdotal evidence. Some foreign firms have made special contributions to American managers' and workers' knowledge and skills, as, for example, the New United Motor Manufacturing, Inc. (NUMMI) joint venture with Toyota did for General Motors' managers, engineers, and shop-floor workers. In other cases, foreign control seems to have made little difference in the behavior or attitudes of managers or workers; and in a few cases, foreign control has been a source of strife.

The most noticeable difference between foreign affiliates and U.S. firms is in their propensity to import. Firms invest abroad mainly to sell abroad; to differing degrees, that means selling products made at home. The overall trade deficit associated with foreign affiliates is sizable--a merchandise trade deficit in 1988 of $\$ 90$ billion, compared with an overall U.S. merchandise trade deficit of $\$ 120$ billion. Affiliates of U.S. firms in other countries have in the past generated substantial trade surpluses for the United States, but those surpluses are declining. In 1988, trade between U.S. parent companies and their foreign affiliates produced a merchandise trade surplus of about $\$ 8$ billion.
Japanese affiliates have by far the greatest propensity to import of any foreign affiliates, and most of what they import is made in Japan. European investors import more, per dollar of sales, than American firms or Canadian affiliates, and most of what they import is from other countries in Europe; their inclination to import from all of Europe is not as great as that of Japanese affiliates to import from Japan.

It is simplistic, however, to hold imports by foreign direct investors responsible for the high U.S. trade deficits. The fundamental causes of our poor trade performance are the Nation's anemic savings rate and declining overall competitiveness of its manufacturers, based on the ability to make highquality products at reasonable costs. ${ }^{4}$ Economic theory also argues that imports in any particular sector do not affect the overall trade balance, but rather exert their effect on the value of the dollar. Macroeconomic factors-specifically, domestic savings (including government surpluses or deficits) and domestic investment-are considered the determining factors in the overall size and direction of the current account trade balance. If foreign investors' imports persistently outweigh exports, and this makes for a greater U.S. trade deficit, then presumably the dollar will fall, which tends to promote U.S. exports and balance the current account. ${ }^{5}$ This process is costly. A persistently weak dollar can enfeeble the U.S. economy and lower the standard of living.

The furor over foreign direct investment (FDI) seems ironic to some, who point out that much of it is a natural response to nations' discriminatory trade policies. Firms invest abroad for many reasons; one is to continue to sell products abroad when exporting becomes difficult. Trade policy actions that limit Japanese exports are primary motivations for the heavy Japanese investments in the United States and Europe over the past decade or so. When the Japanese Government wished to protect Japanese firms from foreign competition in the postwar decades, it was obliged to limit both imports and direct investment (see ch. 6).

Another complication is the growth in international strategic alliances of all types, only some of which can be classed as direct investment. Crosslicensing agreements, some joint ventures, and small equity investments do not show up in statistics on direct investment, but they do affect things that 
governments care about deeply. A current debate focuses on participation of foreign companies (or their offshore affiliates) in government-funded R\&D consortia. Even when foreign firms or their affiliates are excluded, the web of technology development agreements between U.S. companies and foreign companies makes it likely that at least some of the knowledge generated in such programs will go abroad. It has never been possible for governments to control international dissemination of technology, even before firms had extensive international operations. However, with the proliferation of international activity of all types, the speed of technology diffusion is lessening and the control governments have over it are diminishing.

In the United States and Europe, ${ }^{6}$ the debate over how to treat foreign affiliates focuses heavily on Japanese affiliates. Japanese companies are the most feared, because they have reputations for manufacturing excellence and voracious appetites for technology, and also because they are perceived to behave in more nationalistic ways than firms from North America or Europe. Some anecdotal evidence bears out this perception. Besides differences in patterns and magnitude of trade, Japanese investors are more likely than other foreign investors to retain control of the operations by hiring Japanese, rather than host country, managers; more likely to equip their factories with Japanese machinery; and more likely to refer significant decisions to Japanese headquarters. These things are changing. Japanese firms in a recent MITI survey plan to give greater control and discretionary power to their foreign affiliates in the next 5 years, but the majority will still maintain control at home. The effect of Japanese management practices on the host country-good or bad-is not yet known. Nevertheless, differences in the behavior of Japanese investors, along with their formidable records in international competition, will continue to make Japanese direct investment a highly charged political focus.

\section{INTRODUCTION}

The interests of nations and firms are sometimes similar, sometimes not. Some of the things firms want-a stable business environment, productive workers, healthy profits and growth-are also attractive to governments, which is why so many governments try to improve the climate for private enterprise within their borders. But not all businesses are equally attractive to governments, and some of the things businesses want may go counter to some government interests. Nations and firms often have different stakes in the international transfer of weapons, particularly advanced weapons and the high-technology equipment needed to make them. Some enterprises contribute disproportionately to pollution and other public safety hazards; some consume large quantities of scarce natural resources. Thus, while governments at many levels may be assiduous in attracting firms from outside the country or region to locate there, they may also regulate the activities of firms in ways that discourage investment.

The fit between corporate interests and governments' objectives is growing more important to the United States. With many State and local governments actively courting foreign investment, and foreign firms and their attendant lobbies becoming more prominent players in American public policy, the Federal Government is more and more often forced to deal with issues of foreign ownership and control. The issue comes up in various ways. There is increasing concern over foreign investment in real estate and its effect on local real estate prices, especially with respect to Japan, and particularly in areas such as Los Angeles and Hawaii. ${ }^{7}$ In the late 1970s and early 1980s, for example, Middle Eastern investment caused concern, and Japanese investment in American banking and finance is a current issue. National security is also a concern; in $\mathbf{1 9 8 8}$ Congress authorized the President to suspend or prohibit any foreign acquisition of an American firm that is deemed to threaten defense production or the ability of domestic industries to meet national defense requirements. ${ }^{8}$ There is a burgeoning debate on the effect of FDI on American manufacturing competitiveness. While all of these issues are important, only the latter is of concern in this study. Before going on, however, we note that different issues may call for different definitions of what FDI is, and how concerned we are over regulating it; we will address only one of the issues in this chapter, and the discussion does not apply to all other foreign-investment issues.

Finally, we should consider whether multinational firms that are nominally American are so globalized that their interests and the Nation's interests are not likely to have much in common. This is the "Who Is Us?" question. Robert Reich, who framed the question in these terms, contrasted two hypothetical companies: one with headquarters 
in the United States but with much of its R\&D and most of its sales, assets, complex manufacturing, and jobs in foreign countries; the other, headquarters abroad but with much of its technology development and most of its jobs in the United States.

The question of what foreign direct investors contribute to U.S. technology, competitiveness, and jobs is complex, and the major subject of this chapter. Whether the typical U.S. multinational fits the hypothetical picture of a stateless, thoroughly globalized company is easier to answer. There may be a few such companies, and there maybe more in the future, but for now that is a false picture. U.S.-based multinationals do most of their business in the United States, and most of their jobs and technology development are here. Overall, they are identifiably American companies, and their competitive performance is linked to that of the Nation.

\section{THE BASICS: WHO INVESTS WHERE AND IN WHAT}

\section{U.S. Multinationals' Activities at Home and Abroad}

In 1988 (the latest year for which data are available), U.S. multinational companies had 78 percent of their total assets, 70 percent of their sales, and 74 percent of their employment in the United States. ${ }^{10}$ All these percentages were higher than in 1977 (the first year in this data series). There was no consistent trend in the 1980s toward more footloose operations by U.S. multinationals, slightly to the contrary in fact. Although direct investment abroad by U.S. multinationals increased during those years, so did their investments at home.

The data also indicate that U.S. multinationals are keeping good jobs and technology development at home. In 1988, compensation per employee in affiliated companies abroad was about 72 percent of that for employees of the parent company in the United States. Assets per employee in the affiliates were 77 percent of the figure for parent companies, which implies that the more productive jobs resided in the United States. "The same applies to R\&D. The latest government figures for the location of R\&D spending by U.S. multinationals date from 1982. ${ }^{12}$ At that time, spending for $R \& D$ by foreign affiliates was under 9 percent of the total for parents and affiliates; this compared with affiliates' share of total sales, which in 1982 was 33 percent. $R \& D$ as
Figure 3-1-Foreign Direct Investment in the United States: Sales of Manufacturing Affiliates

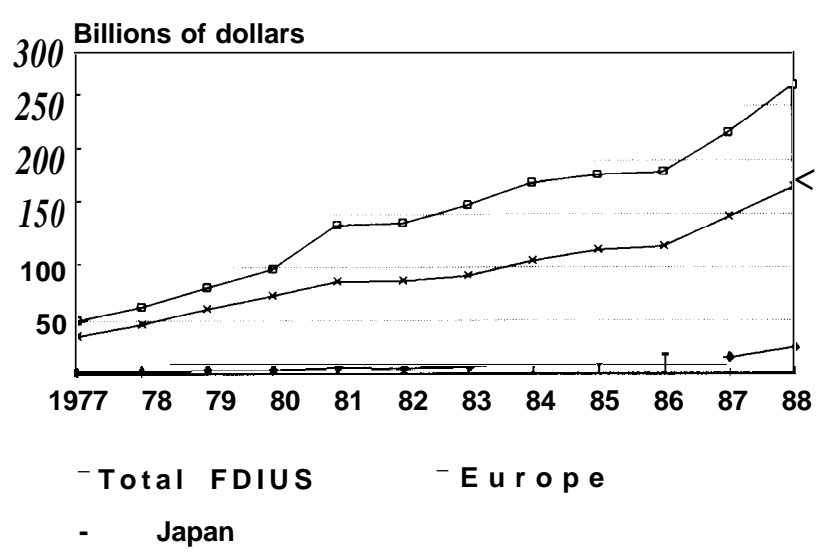

SOURCE: U.S. Department of Commerce, Bureau of Economic Analysis, Foreign Direct Investment in the United States: Operations of U.S. Affiliates, 1977-80, 1985, table E-5, and subsequent series.

a percent of sales was nearly three times higher among U.S. parent manufacturing companies than among manufacturing affiliates abroad ( 3.33 percent v. 1.15 percent).

Some U.S. multinationals have important R\&D facilities in other countries. For example, American automobile companies develop and sell unique products in Europe. It was two scientists in IBM's Zurich research laboratory who discovered hightemperature superconductivity in 1986; even so, IBM does 80 percent of its R\&Din the United States, about 12 percent in Europe, and 8 percent in Asia. ${ }^{13}$ The overall picture may change. The European Community (EC) proposes to allow companies that have filly integrated operations, that include $R \& D$, manufacturing, and sales within Europe, to participate in EC-funded R\&D programs. This may have the effect of shifting more of U.S. multinationals' $R \& D$, or more of their high value-added jobs, to Europe. As of now, however, much the greater part of these activities take place in the United States.

\section{FDI in the United States}

Direct investment in the United States rose from 16 percent of total world direct investment in $\mathbf{1 9 8 0}$ to 25 percent in 1987, while the shares of Europe, Canada, Australia, and South Africa decreased..$^{14}$ In 1990, foreign fins' total direct investments in the United States amounted to $\$ 404$ billion, compared with direct investments of $\$ 421$ billion by U.S. multinationals in foreign countries. The gross prod- 
Figure 3-2-Foreign Direct Investment, 1977-88: Assets of Major Investors

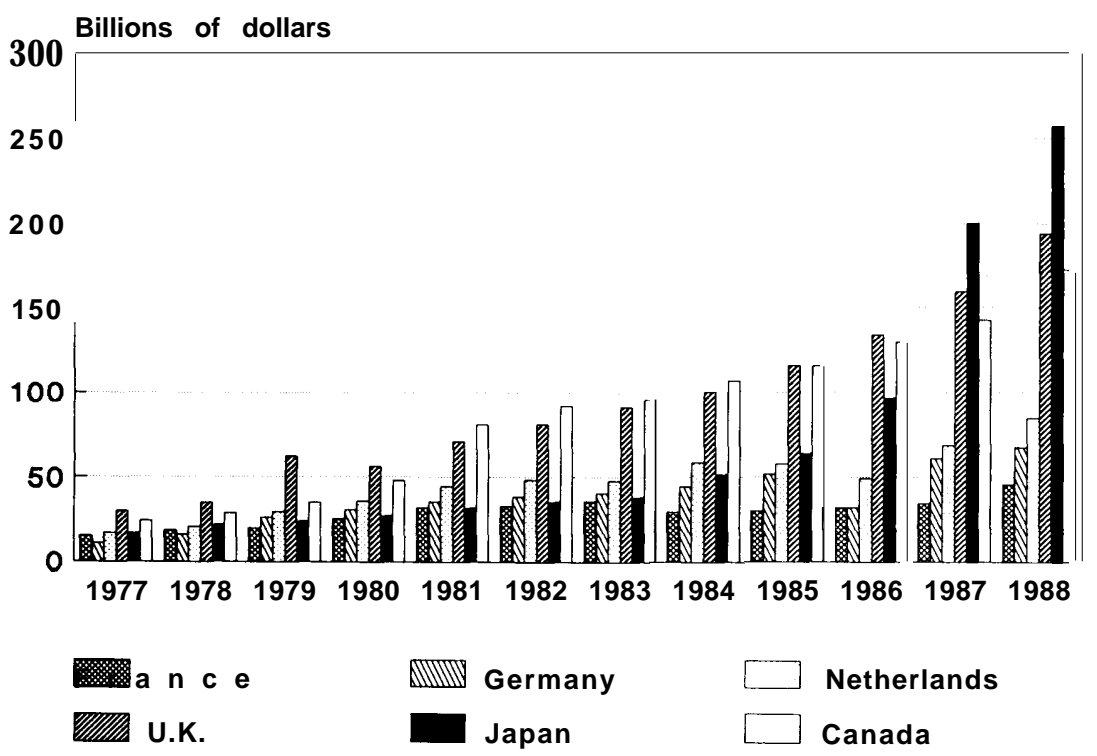

SOURCE: U.S. Department of Commerce, Bureau of Economic Analysis, Foreign Direct Investment in the United States: Operations of U.S. Affiliates, 1977-80, 1985, table B-7, and subsequent series.

uct of foreign affiliates in the United States accounted for 3.4 percent of GNP in 1987, up from 1.8 percent in $1977 .^{15}$

The rapidly increasing Japanese direct investment in manufacturing plants within the United States has made most of the news. There are three common measures of the importance of direct investment: sales, assets, and position. ${ }^{16}$ Japanese affiliates' share of the sales of all foreign manufacturing affiliates in the United States rose from 4 percent in 1977 to 9 percent in 1988 (figure 3-1). The Japanese share of the total sales of all foreign affiliates was 26 percent, the same at the beginning and the end of the period. But their investments in manufacturing during the period show up in their share of affiliates' assets, which rose from 12 to 24 percent of the total. By the late 1980s, the assets of U.S. affiliates of Japanese direct investors stood at $\$ 275$ billion, surpassing all the rest, including the United Kingdom, historically the largest foreign direct investor in the United States (figure 3-2). The total value of assets of U.K. affiliates stood at $\$ 194$ billion in 1988. ${ }^{17}$ However, the United Kingdom was still by far the leader in direct investment position, with investments valued at $\$ 108$ billion by the end of 1990 (figure 3-3). Japan was second, having passed the Netherlands in 1988; its direct investment
Figure 3-3-Foreign Direct Investment Position in the United States, 1990

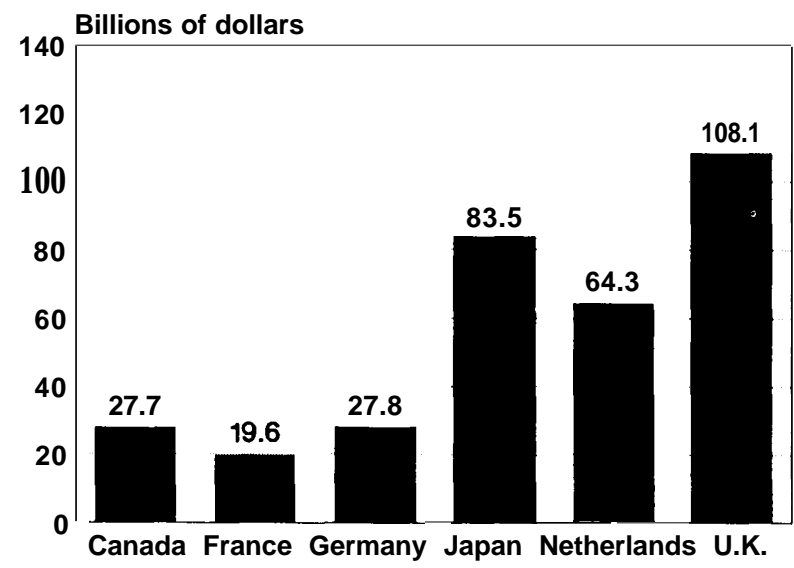

SOURCE: U.S. Department of Commerce, Bureau of Economic Analysis, Russell B. Scholl, 'The International Investment Position of the United States in 1990," Survey of Current Business, vol. 71, No. 6 , June 1991, table 7, p. 32.

position in the United States amounted to $\$ 70$ billion in 1989.

Foreign firms' participation in U.S. manufacturing is greater than their overall participation in other sectors of the economy. Foreign affiliates accounted for 12.2 percent of the assets of U.S. manufacturing in 1987 , compared with 8.9 percent of the total net worth of all nonfinancial corporations. ${ }^{18}$ Manufac- 
turing jobs were still more skewed to foreign affiliates, which accounted for 9.0 percent of U.S. manufacturing employment in 1988 but only 3.4 percent of all U.S. civilian employment. ${ }^{19}$

The picture is different for Japanese direct investment. About 15 percent of the sales of Japanese affiliates in the United States is in manufacturing, compared to 38 percent of the sales of European affiliates. ${ }^{20}$ Over 60 percent of Japanese investors' sales comes from wholesaling affiliates, ${ }^{21}$ a far higher percentage than for any other major direct investor. This implies that the Japanese interest in the American market is primarily in selling goods made in Japan. Of course, a main reason for any firm, from any nation, to invest in a foreign country is to sell more goods in that market. However, the heavy emphasis by Japanese investors on wholesaling suggests that Japanese fins, compared with those of other nations, are more interested in exporting and less interested in producing goods in the country where the goods are sold.

Trade figures for affiliates support this observation. Japanese affiliates' imports were significantly higher than those of European or Canadian affiliates throughout the period for which we have data (1977-88). In 1988, imports of Japanese affiliates in the United States were $\$ 75.9$ billion, accounting for 51 percent of the imports of all affiliates of foreign investors, and the Japanese affiliates' imports amounted to 34 percent of their sales, compared to 12 percent for European affiliates. ${ }^{22}$ Moreover, a detailed survey in 1987 showed that 93 percent of the imports of Japanese affiliates were from Japan. To be sure, all affiliates import mostly from the home country (or in the case of Europe, the home region); 70 percent of the imports of European affiliates were from Europe, and 73 percent of the imports of Canadian affiliates were from Canada. ${ }^{23}$ But the Japanese affiliates have by far the highest ratio of homecountry imports of all, as well as the highest imports relative to sales.

Direct investment in U.S. manufacturing between 1977 and 1988 shows annual increases of 16 percent in sales and almost 19 percent in assets (tables 3-1 and 3-2). The most rapid growth in manufacturing sales by foreign affiliates was in transportation equipment, where affiliates' sales increased at the rapid clip of 46.5 percent per year. Most of this was just where one would expect: in sales of motor vehicles from Japanese affiliates. If sales of motor vehicles from wholesaling affiliates are added in, the influence of Japanese affiliates is even more apparent. In 1988, the combined total of wholesale and manufacturing sales of motor vehicles, by all foreign affiliates, amounted to $\$ 80.9$ billion. Two-thirds of this ( $\$ 52.9$ billion) was from Japanese affiliates, and most of it ( $\$ 44.3$ billion) was sales from wholesaling, not manufacturing, establishments. ${ }^{24}$

Other industries with substantial manufacturing sales by foreign affiliates include chemicals and machinery (including electronic equipment); European affiliates are preeminent in both of these major sectors (table 3-3). About 29 percent of the sales of European affiliates is in chemicals and allied products, with Germany the leading foreign affiliate in the sector and the United Kingdom not far behind.

Several European countries have large sales in machinery, a category that includes machine tools and various types of production equipment used in nearly every other industry as well as semiconductors, computers, and consumer electronic goods. The United Kingdom is a leader in nonelectrical machinery, while France, Germany, and the Netherlands all have important affiliates in the United States making electronic products (Thomson, Siemens, and Philips, respectively) .25 Although there are also Japanese affiliates making or assembling electronic products in this country, most of America's huge purchases of Japanese electronic goods, from semiconductors to compact disk players, are imports. Japanese manufacturing affiliates' sales are concentrated in primary and fabricated metals (steel), electrical and electronic equipment, and transportation equipment (table 3-4).

Canada and the United States have long had substantial investment in each other's markets as a result of shared language, proximity, and similar culture and business environments. Canadian direct investment in the United States is heaviest in chemicals, ${ }^{26}$ followed by primary metals and electrical and electronic equipment (table 3-5).

\section{FDI AND U.S. MANUFACTURING COMPETITIVENESS}

The relationship between FDI and U.S. manufacturing competitiveness is anything but straightforward. In some cases, foreign investment seems to have stimulated American manufacturers to improve 
Table 3-I-Foreign Direct Investment in the United States: Manufacturing Sales, 1977 and 1988

\begin{tabular}{|c|c|c|c|}
\hline Industry & $\begin{array}{c}\text { Sales } \\
1977 \\
\text { (\$ millions) }\end{array}$ & $\begin{array}{c}\text { Sales } \\
1988 \\
\text { (\$ millions) }\end{array}$ & $\begin{array}{c}\text { Annual average } \\
\text { growth rate } \\
1977-88 \\
\text { (percent) }\end{array}$ \\
\hline Manufacturing : & $. \$ 50,489$ & $\$ 258,511$ & $16.0 \%$ \\
\hline Food and kindred products & 6,983 & 32,995 & 15.2 \\
\hline Chemicals and allied products . & 16,303 & 63,245 & 13.1 \\
\hline Primary and fabricated metals... & 6,881 & 32,806 & 15.3 \\
\hline Primary metal industries $\ldots \ldots \ldots \ldots \ldots \ldots \ldots$ & 5,545 & 20,476 & 12.6 \\
\hline Fabricated metal products ... & 1,336 & 12,330 & 22.4 \\
\hline Machinery.$\ldots \ldots \ldots \ldots \ldots$ & 9,838 & 45,933 & 15.0 \\
\hline Machinery, excluding electrical & 4,512 & 17,905 & 13.3 \\
\hline Electrical and electronic equipment. . . . . . . . & 5,326 & 28,029 & 16.3 \\
\hline \multicolumn{4}{|l|}{ Other manufacturing: } \\
\hline Textiles and apparel. & 1,072 & 3,746 & 12.0 \\
\hline Paper and allied products . & 1,803 & 8,033 & 14.5 \\
\hline Printing and publishing... & 1,741 & 12,386 & 19.5 \\
\hline Rubber and plastics products $\ldots \ldots \ldots \ldots \ldots$ & 916 & 11,295 & 25.7 \\
\hline Stone, clay and glass products. & 2,022 & 12,363 & 17.9 \\
\hline Transportation equipment . & 279 & 18,649 & 46.5 \\
\hline
\end{tabular}

NOTE: Individual industries do not add to total manufacturing.

SOURCES: U.S. Department of Commerce, Bureau of Economic Analysis, Foreign Direct Investment in the United States: Operations of U.S. Affiliates, 1977-80, 1985, table E-5, and Foreign Direct Investment $i$ n the United States, Operations of U.S. Affiliates of Foreign Companies, Preliminary 1988 Estimates, 1990table E-7.

Table 3-2-Foreign Direct Investment in United States: Assets of Manufacturing Affiliates, 1977 and 1988

\begin{tabular}{|c|c|c|c|}
\hline Industry & $\begin{array}{c}\text { Assets } \\
1977 \\
\text { (\$ millions) }\end{array}$ & $\begin{array}{c}\text { Assets } \\
1988 \\
\text { (\$ millions) }\end{array}$ & $\begin{array}{c}\text { Annual average } \\
\text { growth rate } \\
1977-88 \\
\text { (percent) }\end{array}$ \\
\hline Manufacturing & $\$ 41,759$ & $\$ 281,316$ & $18.9 \%$ \\
\hline Food and kindred products $\ldots \ldots \ldots \ldots \ldots \ldots \ldots$ & 4,373 & 30,317 & 19.2 \\
\hline Chemicals and allied products $\ldots \ldots \ldots \ldots \ldots \ldots$ & 15,258 & 80,911 & 16.4 \\
\hline Primary and fabricated metals $\ldots \ldots \ldots \ldots \ldots$ & 5,931 & 34,018 & 17.2 \\
\hline Primary metal industries $\ldots \ldots \ldots \ldots \ldots \ldots \ldots$ & 4,670 & 17,495 & 12.8 \\
\hline Fabricated metal products $\ldots \ldots \ldots \ldots \ldots \ldots$ & 1,261 & 16,523 & 26.4 \\
\hline Machinery $\ldots \ldots \ldots \ldots \ldots \ldots \ldots \ldots \ldots$ & 7,508 & 45,857 & 17.9 \\
\hline Machinery, excluding electrical . . . . . . . . . . . & 3,754 & 20,507 & 16.7 \\
\hline Electrical and electronic equipment . . . . . . . . . & 3,754 & 25,351 & 19.0 \\
\hline \multicolumn{4}{|l|}{ Other manufacturing } \\
\hline Textiles and apparel . & 726 & 4,132 & 17.1 \\
\hline Paper and allied products $\ldots \ldots \ldots \ldots \ldots$ & 1,416 & 7,015 & 15.7 \\
\hline Printing and publishing $\ldots \ldots \ldots \ldots \ldots \ldots \ldots$ & 1,361 & 15,075 & 24.4 \\
\hline Rubber and plastics products $\ldots \ldots \ldots \ldots \ldots$ & 606 & 10,164 & 29.2 \\
\hline Stone, clay and glass products $\ldots \ldots \ldots \ldots \ldots$ & 1,736 & 21,113 & 25.5 \\
\hline Transportation equipment $\ldots \ldots \ldots \ldots \ldots \ldots$ & 587 & 9.666 & 29.0 \\
\hline
\end{tabular}

NOTE: Individual industries do not add to total manufacturing.

SOURCES: U.S. Department of Commerce, Bureau of Economic Analysis, Foreign Direct Investment in the United States: Operations of U. S. Affiliates, 1977-80, 1985, tabie B-7, and Foreign Direct Investment in the United States, Operations of U.S. Affiliates of Foreign Companies, 1988, 1990, table B-5.

their competitive performance. An example comes from motor vehicles.

Japanese automakers began assembling motor vehicles in the United States in the 1980s, partly to bypass the voluntary restraint agreement that limited Japanese motor vehicle exports to the United States from 1981 to 1985 , and probably also to neutralize the effects of other forms of protection that might be imposed in the future. Honda was the pioneer. ${ }^{27}$ With several years of experience making motorcycles in the United States, it built the first Japaneseowned assembly plant in Marysville, Ohio, and began producing cars there in 1982. Honda's entry 
Table 3-3-European Direct Investment in the United States: Manufacturing Sales, 1977 and 1988

\begin{tabular}{|c|c|c|c|}
\hline Industry & $\begin{array}{c}\text { Sales } \\
1977 \\
\text { (\$ millions) }\end{array}$ & $\begin{array}{c}\text { Sales } \\
1988 \\
\text { (\$ millions) }\end{array}$ & $\begin{array}{c}\text { Percent of } \\
\text { total } \\
\text { in } 1988\end{array}$ \\
\hline Manufacturing $\ldots \ldots \ldots \ldots \ldots \ldots$ & $\$ 36,754$ & $\$ 166,608$ & \\
\hline Food and kindred products $\ldots \ldots \ldots \ldots \ldots \ldots \ldots$ & 4,594 & 25,547 & $15.3 \%$ \\
\hline Chemicals and allied products $\ldots \ldots \ldots \ldots \ldots \ldots$ & 15,330 & 47,421 & ,28.5 \\
\hline Primary and fabricated metals $\ldots \ldots \ldots \ldots \ldots \ldots$ & 3,694 & 14,148 & 8.5 \\
\hline Primary metal industries $\ldots \ldots \ldots \ldots \ldots \ldots \ldots$ & 2,886 & 6,187 & 3.7 \\
\hline Fabricated metal products . . . . . . . . . . . & 808 & 7,961 & 4.8 \\
\hline Machinery $\ldots \ldots \ldots \ldots \ldots \ldots \ldots \ldots \ldots \ldots$ & 6,701 & 28,385 & 17,0 \\
\hline Machinery, excluding electrical . . & 3,006 & 11,839 & 7.1 \\
\hline Electrical and electronic eqp. . . . . . . . . . . . & 3,695 & 17,546 & 10.5 \\
\hline \multicolumn{4}{|l|}{ Other manufacturing } \\
\hline Textiles and apparel . . . . & 780 & 2,303 & 1.4 \\
\hline Paper and allied products $\ldots \ldots \ldots \ldots \ldots \ldots$ & $\mathbf{N A}^{\mathrm{a}}$ & 5,156 & 3.1 \\
\hline Printing and publishing $\ldots \ldots \ldots \ldots \ldots \ldots \ldots$ & 481 & 6,552 & 3.9 \\
\hline Rubber and plastics products $\ldots \ldots \ldots \ldots \ldots$ & 772 & 5,112 & 3.1 \\
\hline Stone, clay and glass products $\ldots \ldots \ldots \ldots \ldots$ & 1,878 & 9,964 & 6.0 \\
\hline Transportation equipment. . . . . . . . . . & NA & 8,923 & 5.4 \\
\hline
\end{tabular}

Data suppressed to avoid disclosure of information for individual companies. NOTE: Individual industries do not add to total manufacturing.

SOURCES: U.S. Department of Commerce, Bureau of Economic Analysis, foreign Direct Investment in the United States: Operations of U.S. Affiliates, 1977-80,1985, table E-5, and Foreign Direct Investment in the United States, Operations of U.S. Affiliates of Foreign Companies, 1988, table E-8.

Table 3-4-Japanese Direct Investment in the United States: Manufacturing Sales, 1977 and 1988

\begin{tabular}{|c|c|c|}
\hline $\begin{array}{c}\text { Sales } \\
1977\end{array}$ & $\begin{array}{c}\text { Sales } \\
1988\end{array}$ & $\begin{array}{c}\text { Percent of } \\
\text { total } \\
\text { in } 1988\end{array}$ \\
\hline 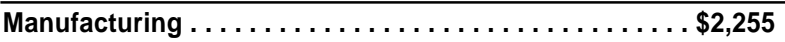 & $\$ 33,180$ & \\
\hline 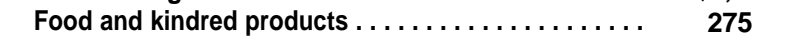 & 1,055 & $3.2 \%$ \\
\hline Chemicals and allied products $\ldots \ldots \ldots \ldots \ldots \ldots$ & 2,060 & 6.2 \\
\hline Primary and fabricated metals $\ldots \ldots \ldots \ldots \ldots$ & 5,390 & 16.2 \\
\hline Primary metal industries $\ldots \ldots \ldots \ldots \ldots \ldots \ldots$ & 3,716 & 11.2 \\
\hline Fabricated metal products . . . . . . . . . . . NA & 1,675 & 5.0 \\
\hline Machinery $\ldots \ldots \ldots \ldots \ldots \ldots \ldots \ldots \ldots \ldots$ & 8,992 & 27.1 \\
\hline Machinery, excluding electrical $\ldots \ldots \ldots \ldots \ldots$ & 3,276 & 9.9 \\
\hline Electrical and electronic equipment . . . . . . . . . & 5,716 & 17.2 \\
\hline \multicolumn{3}{|l|}{ Other manufacturing } \\
\hline Textiles and apparel . . . . . . . . . . . . . . . . . . . . 67 & 346 & 1.0 \\
\hline Paper and allied products . . . . . . . . . . . NA & 635 & 1.9 \\
\hline Printing and publishing $\ldots \ldots \ldots \ldots \ldots \ldots \ldots$ & 1,094 & 3.3 \\
\hline Rubber and plastics products . . . . . . . . . . 17 & 2,842 & 8.6 \\
\hline Stone, clay and glass products $\ldots \ldots \ldots$ NA & 1,043 & 3.1 \\
\hline Transportation equipment. . . . . . . . . . . . . . NA & 8,584 & 25.9 \\
\hline
\end{tabular}

${ }^{2}$ Data suppressed to avoid disclosure of information about particular companies.

NOTE: Individual industries do not add to total manufacturing.

SOURCES: U.S. Department of Commerce, Bureau of Economic Analysis, Foreign Direct Investment in the United States: Operations of U. S. Affiliates, 1977-80, 1985, table E-5, and Foreign Direct Investment in the United States, Operations of U.S. Affiliates of Foreign Companies, 1988, 1990, table E-8.

into U.S. motor vehicle production was followed by Nissan, Mazda, Subaru-Isuzu, Toyota, and Mitsubishi (in a joint venture with Chrysler), By 1991, the Japanese transplants (including the joint ventures) are expected to be able to produce nearly 3 million vehicles in North America. ${ }^{28}$
In the 1970s and early 1980s, the prevailing view among American automakers and their "suppliers was that the Japanese advantage in the American market stemmed mainly from low labor costs. It took firsthand demonstrations of Japanese manufacturing prowess in America to convince them that the real 
Table 3-5-Canadian Direct Investment in the United States: Manufacturing Sales, 1977 and 1988

\begin{tabular}{|c|c|c|c|}
\hline Industry & $\begin{array}{c}\text { Sales } \\
1977 \\
\text { (\$ millions) }\end{array}$ & $\begin{array}{c}\text { Sales } \\
1988 \\
\text { (\$ millions) }\end{array}$ & $\begin{array}{c}\text { Percent of } \\
\text { total } \\
\text { in } 1988\end{array}$ \\
\hline$\ldots \ldots \ldots \ldots \ldots$ & $\$ 1.1,650$ & $\$ 38,307$ & \\
\hline Food and kindred products $\ldots \ldots \ldots \ldots \ldots \ldots$ & 1,972 & 3,740 & $9.80 / 0$ \\
\hline Chemicals and allied products $\ldots \ldots \ldots \ldots \ldots \ldots$ & 649 & 11,902 & 31.1 \\
\hline Primary and fabricated metals . . . . . . . . . . & 2,068 & 5,842 & 15.3 \\
\hline Primary metal industries $\ldots \ldots \ldots \ldots \ldots \ldots \ldots$ & 1,747 & 4,644 & 12.1 \\
\hline Fabricated metal products $\ldots \ldots \ldots \ldots \ldots \ldots \ldots$ & 321 & 1,198 & 3.1 \\
\hline Machinery . . . . . . . . . . . . . & 3,108 & 5,248 & 13.7 \\
\hline Machinery, exe. electrical . & 1,489 & 1,343 & 3.5 \\
\hline Electrical and electronic equipment. . . . . . . . . & 1,619 & 3,905 & 10.2 \\
\hline \multicolumn{4}{|l|}{ Other manufacturing } \\
\hline Textiles and apparel. & $\mathrm{NA}^{\mathrm{a}}$ & 668 & 1.7 \\
\hline Paper and allied products ..... & NA & 1,990 & 5.2 \\
\hline Printing and publishing $\ldots \ldots \ldots \ldots \ldots \ldots$ & 1,171 & 3,463 & 9.0 \\
\hline Rubber and plastics products $\ldots \ldots \ldots \ldots \ldots$ & 125 & $2,024^{b}$ & 5.3 \\
\hline Stone, clay and glass products $\ldots \ldots \ldots \ldots \ldots$ & 815 & 690 & 1.8 \\
\hline Transportation equipment $\ldots \ldots \ldots \ldots \ldots \ldots \ldots$ & NA & 490 & 1.3 \\
\hline
\end{tabular}

Data supressed to avoid disclosure of information for individual companies.

Includes only information for plastics; data for rubber products was suppressed to avoid disclosure of information for an individual company.

NOTE: Individual industries do not add to total manufacturing.

SOURCES: U.S. Department of Commerce, Bureau of Economic Analysis, Foreign Direct Invesfrnenf in the United Sfates:Operations of U.S. Affiliates, 1977-80,1985, table E-5, and Foreign Direct Investment in the United states, Operations of U.S. Affiliates of Foreign Companies, 1988, 1990, table E-8.

advantage of the Japanese manufacturers was their rigorous and ceaseless attention to quality and efficiency in manufacturing. The Japanese transplants have the best quality record (in terms of defects per 100 vehicles) and average productivity (in hours per auto) of any plants in North America, and the 'worst' Japanese transplants have about the same productivity as the average for U.S. plants in North America (figures 3-4 and 3-5) ${ }^{29}$

For American auto parts makers, the lesson was more than just a demonstration. The exacting standards of quality, price, and delivery time that the Japanese auto assemblers held suppliers to in Japan were, according to the Japanese fins, beyond what most American auto parts and components makers were accustomed to providing to Detroit. In addition, business practices of the American and Japanese auto assemblers were quite different: Japanese assemblers had (and have) many fewer suppliers than the American assemblers, and those suppliers are expected to deliver whole assemblies instead of individual parts. Japanese assemblers also expected collaboration in initial design and quick turnaround on design changes, which required in-house engineering ability that American components makers were unaccustomed to providing and often did not have. ${ }^{30} \mathrm{Few}$ were able to establish relations with Japanese assemblers in North America. By 1987, researchers from the MIT International Motor Vehicle Program estimated that the local parts content of the Japanese assemblers in North America was only 30 percent; this was forecast to increase to 50 percent by $1990 .{ }^{31}$

American suppliers who were able to negotiate arrangements with Japanese transplants report difficulties in establishing the relationship, but those who succeeded also made positive changes. These include improving product quality and inventory management, increasing productivity, and expanding engineering, design, and $R \& D{ }^{32}$ Many of the same kinds of changes are increasingly required by Ford, General Motors, and Chrysler in their own attempts to compete with Japanese imports and transplants.

FDI can also enhance technology development. For example, American manufacturers have benefited from the patient capital or technology-oriented strategies of their foreign investors. When the West German chemical firm Hoechst purchased Celanese Corp., Hoechst's objective was to find a technologyintensive strategy for competing in the U.S. market. ${ }^{33}$ Rather than expand its own U.S. operation, Hoechst purchased Celanese, an existing American chemical company with well-recognized products, competent $R \& D$, and established customer relation- 
Figure 3-4-Automobile Assembly Plant Defects, 1988-89

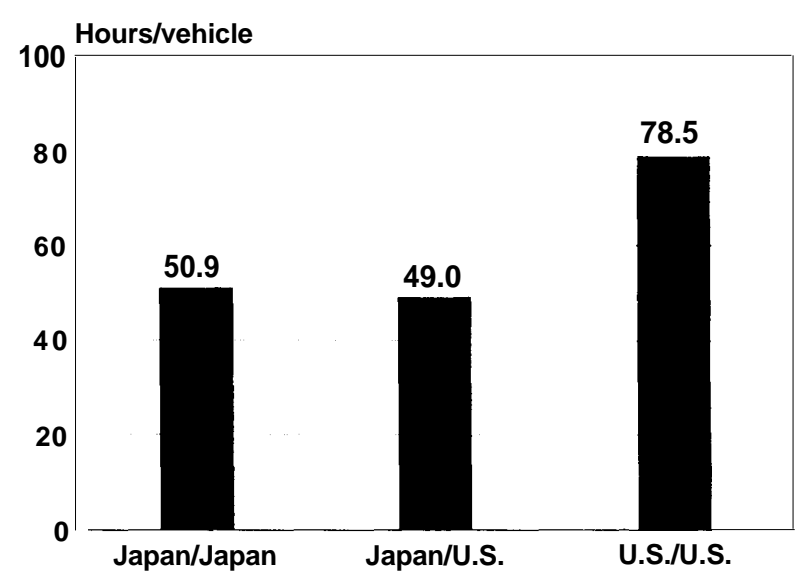

Japan/Japan = Japanese-owned Plants located in Japan

Japan/U.S. = Japanese-owned plants and joint ventures in the United States U.S./U.S. = U.S.-owned plants in the United States

SOURCE: John F. Krafcik, "Training and the Automobile Industry: international Comparisons," contractor report prepared for the Office of Technology Assessment, February 1990, pp. 8-9.

ships. Despite initial difficulties in reconciling the corporate R\&D cultures of the two firms, Celanese's $R \& D$ spending increased by 10 percent annually after the acquisition. Moreover, Hoechst was more willing to engage in long-term research than Celanese's management had been, and less reluctant to make major commitments to projects with uncertain and distant payoff.

While there are many examples of foreign investment that seem beneficial or at worst neutral in their impact on manufacturing competitiveness, there are worries as well. Most of the worry centers on Japan and several high-technology industrial sectors. In its simplest form, the fear is that Japanese investors, with their appetite for new technology, their deep pockets, and their perceived preferences for doing business with other Japanese companies, invest in American high-technology companies in order to gain access to new technologies, but that most of the benefits of such investment (jobs, economic growth, contributions to the national stock of technology) will end up in Japan. Another worry is that, since Japanese corporations investing abroad have commonly been followed by their Japanese suppliers, American businesses that could benefit from relationships with Japanese multinationals might be crowded out.

Such accusations surfaced recently, when two former executives of Ardent Computer sued Kubota
Figure 3-5-Automobile Assembly Productivity, 1988

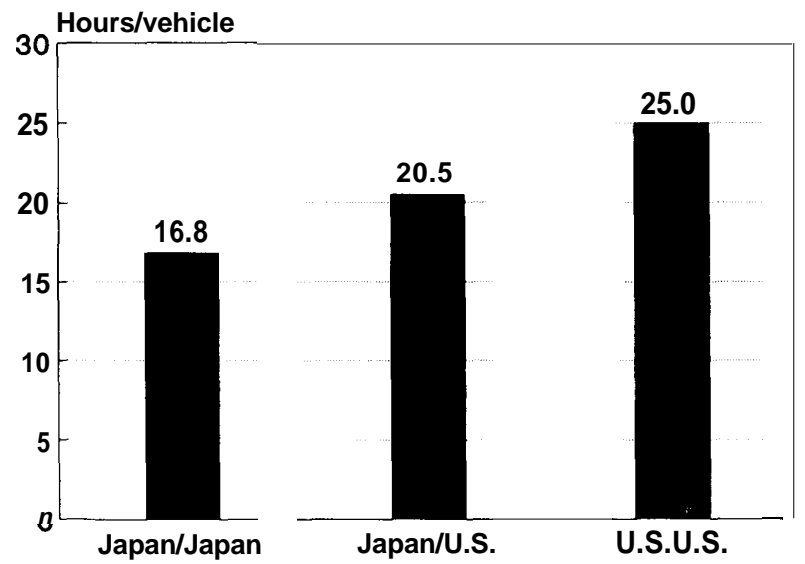

Japan/Japan = Japanese-owned plants located in Japan

Japan/U.S. = Japanese-owned plants and joint ventures in the United States U.S./U.S. = U.S.-owned plants in the United States

SOURCE: John F. Krafcik, "Training and the Automobile industry: international Comparisons," contractor report prepared for the Office of Technology Assessment, February 1990, pp. 8-9.

Ltd., a Japanese tractor company that had acquired a stake in Ardent in 1986. The two executives allege that Kubota forced Ardent to merge with Stellar Computer, and conspired to transfer the technology of the merged company (Stardent) to a Kubota subsidiary, Kubota Computers America. ${ }^{34}$ Kubota denies the claims, saying instead that the U.S. executives were failed managers who demanded money and sued after they were denied payment.

Fear of Japanese dominance also colored American reaction to the investment by some of Japan's big electronics companies in R\&D centers in the United States. ${ }^{35}$ The companies are staffing these centers by hiring leading American computer scientists from American universities and corporate labs, with offers of high salaries, excellent equipment, and plenty of R\&D money. Often, $R \& D$ investments within this country are used as a measure of the positive value of FDI. But some analysts see the hiring of America's best computer brains by powerful Japanese companies as threatening one of the last, best competitive advantages of U.S. computer companies-basic research in computer science.

These cases are part of the fear that some people have about Japanese firms. The danger, according to those who suspect Japanese investors of playing by nationalistic rules, is that American companies will end up depending on Japanese companies almost 
exclusively for key components and equipment, ${ }^{36}$ and even that the next big creative advances in technology may be locked up in patents held by Japanese companies. This dependence, they fear, will be the downfall of the American companies. What does this have to do with FDI? According to this analysis, Japanese investment is simply another way (along with exports) for Japanese companies to dominate their industries. Such fears are made more plausible by the fact that most Japanese businesses large enough to deal internationally operate in keiretsu, or groups that hold each other's stock and give preference to other group members in procuring supplies and services in ways that tend to exclude outsiders.

Fear of Japanese dominance may be rooted in xenophobia, jealousy, experience, common sense, or some combination of all of these. Many people familiar with Japanese business practices regard Japanese investors as more likely than Europeans or Canadians to direct the benefits of their investments in America to Japan. Evidence on either side of this debate is sparse. What little there is does suggest that there are good reasons to keep an eye on foreign investment in general, and Japanese investment in particular, and monitor the effects on American competitiveness.

What should we keep track of? More and more, developed nations are grappling with these issues, particularly as the strains on the postwar trade regime intensify. Most focus on the readily available measures of fins' behavior-R\&D, employment, worker compensation, value added, and the like. A common problem is that many of these measures gauge inputs, rather than the outputs that nations are interested in. It is easy to argue about the effects of FDI without proper measures of what foreign investors contribute to the nation's stock of knowledge and overall well-being, since many of the arguments on all sides depend on unsatisfactory measures and anecdotes.

In the United States, the reevaluation of policies toward international investment is a result of the tremendous growth in FDI during the past two decades. ${ }^{37}$ In large part, the European Community seems committed to making the benefits of 1992 reforms open to anyone, but there are some important questions and exceptions. In a few critical industries, principally microelectronics and motor vehicles, it appears that firms wishing to sell their products in Europe under the same conditions as European firms will need to make substantial portions of the products in Europe. As this report is written, for example, European negotiators are discussing domestic content regulations ranging up to 85 percent on motor vehicles, and a transition period of 5 years, starting in 1993, during which Japanese automakers agree to limit exports to the European Community countries. ${ }^{38}$ In electronics, the European Community has decided that the most significant part of semiconductor manufacture, diffusion in wafer fabrication, must be done in Europe for semiconductors to count as of local origin (and thus not be subject to the EC's 15 percent tariff). Some expect this decision to result in a boom in wafer fabrication in Europe, primarily on the part of American and Japanese companies. ${ }^{39}$

Clearly, one thing the European Community is interested in is jobs-hence the emphasis on local content in big-ticket trade items like semiconductors and automobiles, which account for a large share of Europe's imports. There is more to it than jobs though. Countries are concerned about the extent to which foreign investors are players in the political process, add to a nation's stock of knowledge and technology, contribute to imports and exports, pay taxes, and enhance human resource development. All of these are things that can be expected to contribute to a nation's well-being, and to the competitiveness of its fins.

\section{Contributions to Knowledge and Technology}

Firms add to nations' technical and scientific knowledge in many ways, most of which are difficult to measure. One measure that is available is the amount spent on $R \& D .^{40} R \& D$ spending is often used as a proxy for all contributions foreign firms with domestic operations make to the nation's technical knowledge. Spending on plant and equipment and reinvestment of earnings in domestic operations are also sometimes used to indicate levels of contributions to technology. It is important to keep in mind, however, that such figures are only proxies and may obscure the complexities of what goes on in the real world.

\section{The R\&D Measure}

R\&D spending is usually measured as a percentage of net sales, known as R\&D intensity. Figure 3-6 and table 3-6 show that the manufacturing affiliates of foreign direct investors lag behind U.S. manufac- 
Figure 3-6-R\&D Intensity, U.S. Manufacturers and U.S. Affiliates of Foreign Manufacturing Firms

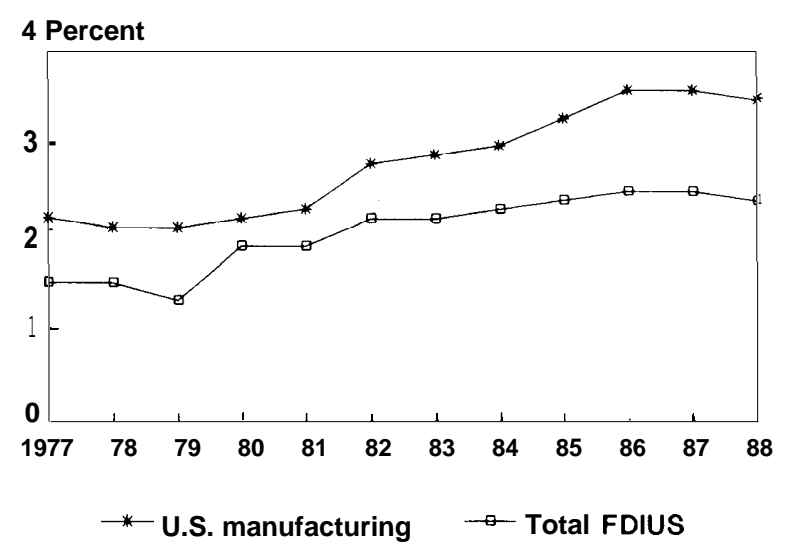

SOURCE: Economic Report of the President, 1990 (Washington, DC: U.S. Government Printing Office, February 1990), table C-90; National Science Foundation, Division of Science Resources, unpublished data; and U.S. Department of Commerce, Bureau of Economic Analysis, Foreign Direct Investment in the United States: Operations of U.S. Affiliates, 1977-80, 1985, table H-3, and subsequent series.

turers in R\&D intensity .41 This means that domestic firms perform a greater share of their $R \& D$ here than foreign firms operating here do, which is just what might be expected. As noted, U.S. multinational fins' R\&D intensity is much higher in the United States than it is in their various foreign outposts.

Data showing R\&D of foreign affiliates by country and industry exist for only one year, 1987. In that year, $R \& D$ (by manufacturing fins) as a percent of manufacturing sales of European affiliates was 2.3 percent, close to the average for all foreign affiliates. However, the R\&D intensity for Japanese manufacturing affiliates was much below average, 1.1 percent. ${ }^{42}$ It is likely that Japanese manufacturing multinationals, like U.S. multinationals, were doing most of their R\&D at home.

There is good reason for $R \& D$ intensity to be higher in the home country of multinational companies than in their foreign affiliates. $R \& D$ comprises a variety of activities, some of which are not particular to specific markets. For example, much basic and applied research done by firms is not dependent on the eccentricities of different markets, and can probably be done most efficiently at a central R\&D facility. Development and design work, on the other hand, might need to be apportioned to each of a company's major markets in order to be tailored to the tastes and specifications of local
Table 3-6-Manufacturing Research and Development Intensity: Foreign Direct Investors and U.S. Firms, 1977-88 (In percent)

\begin{tabular}{|c|c|c|c|}
\hline Year & $\begin{array}{l}\text { Total U.S. } \\
\text { manufacturers } \\
\text { (in percent) }\end{array}$ & $\begin{array}{l}\text { Company funded } \\
\text { (in percent) }\end{array}$ & $\begin{array}{l}\text { All FDIUS }{ }^{a} \\
\text { (in percent) }\end{array}$ \\
\hline $\begin{array}{l}1977 . \\
1978 \\
1979 \\
1980 \\
1981 \\
1982 \\
1983 \\
1984 \\
1985 \\
1986 \\
1987 \\
1988\end{array}$ & 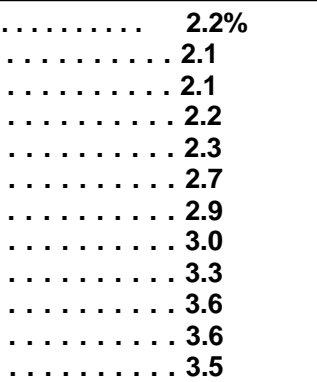 & $\begin{array}{l}\text { NA } \\
\text { NA } \\
1.470 \\
1.5 \\
1.6 \\
1.9 \\
2.0 \\
2.1 \\
2.3 \\
2.5 \\
2.4 \\
2.2\end{array}$ & $\begin{array}{l}1.570 \\
1.5 \\
1.3 \\
1.9 \\
1.9 \\
2.2 \\
2.2 \\
2.3 \\
2.4 \\
2.5 \\
2.5 \\
2.4\end{array}$ \\
\hline \multicolumn{4}{|c|}{$\begin{array}{l}\text { Manufacturing } R \& D \text { as a percent of sales by manufacturing affiliate. } \\
\text { NOTE: Total } R \& D \text { intensity includes ail funding for industrial } R \& D \text { supplied } \\
\text { by companies, the Federal Government and other sources; whereas } \\
\text { company-funded } R \& D \text { includes all funded industrial } R \& D \text { work } \\
\text { performed within company facilities from all sources except the } \\
\text { Federal Government. }\end{array}$} \\
\hline \multicolumn{4}{|c|}{$\begin{array}{l}\text { SOURCES: U.S. Department of Commerce, Bureau of Economic Analysis, } \\
\text { Foreign Direct Investment in the United States: Operations of } \\
\text { U.S. Affiliates, 1977-80, 1985, table H-3, and subsequent } \\
\text { series; and National Science Foundation, Division of Science } \\
\text { Resources Studies, unpublished data. }\end{array}$} \\
\hline
\end{tabular}

consumers. For example, all the major Japanese auto companies do design work (mainly styling) in the United States.

Another way of gauging $R \& D$ contributions is in terms of spending per employee. ${ }^{43} B y$ this measure, foreign direct investors appear quite similar to U.S. firms (figure 3-7). There are complications in comparing $R \& D$ figures across nations, since the U.S. Government and foreign governments contribute different amounts for different purposes (e.g., defense v. civilian) to industrial R\&D. All in all, however, there appears to be rough parity in $R \& D$ spending per employee between U.S. firms and foreign direct investors. Why should this be so, when $R \& D$ intensity is substantially higher for American fins? Interpretation is rather risky, since detailed knowledge of the underlying factors is lacking. However, it seems likely that affiliates or subsidiaries of foreign fins, no matter how firmly entrenched in countries outside of headquarters, are not as fully integrated to include all line and staff functions of the company as is headquarters. The affiliates may have a full production and sales staff, but are less likely to include functions such as accounting, finance, strategy, and planning in the foreign location. 
Figure 3-7-R\&D/Manufacturing Employee FDIUS and U.S. Manufacturers

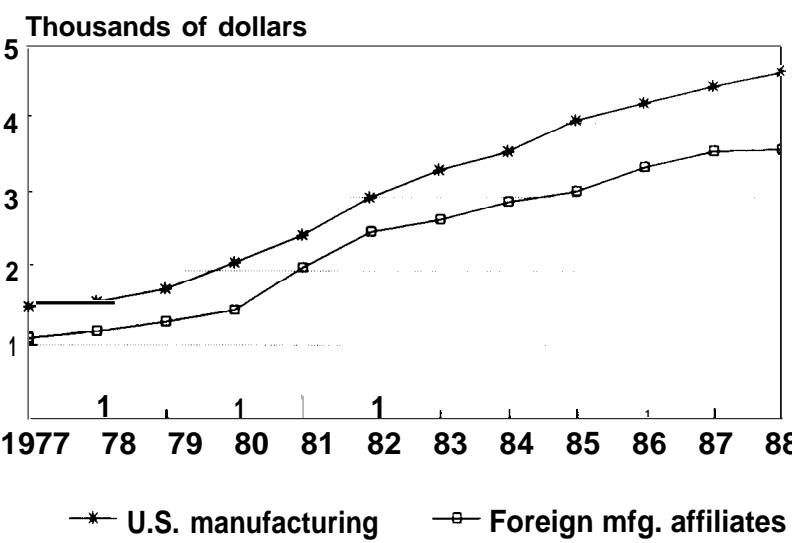

SOURCE: U.S. Department of Labor, Bureau of Labor Statistics, "Employment and Earnings, November 1988," table B-1; National Science Foundation, Division of Science Resources, unpublished data; and U.S. Department of Commerce, Bureau of Economic Analysis, Foreign Direct Investment in the United States: Operations of U.S. Affiliates, 1977-80, 1905, tables F-1 and $\mathrm{H}-3$, and subsequent series.

\section{Investment in Plant and Equipment}

Besides R\&D, another possible measure of a firm's contribution to the nation's technological proficiency is its investment in plant and equipment. While plant and equipment are not all there is to technology, they do embody and contribute to technology. Advanced equipment and welldesigned plants, together with well-trained workers, can make a significant contribution to productivity and product quality. Investment in plant and equipment may make a less direct or certain contribution to technology than $R \& D$. Investment in $R \& D$ is sometimes embodied in products or patents that can be widely diffused, while investments in plant and equipment may raise the productivity of only a few plants, and the lessons learned from such investments are difficult to transfer. Nonetheless, modern plant and equipment and intelligent use of workers and machinery do improve productivity and familiarity with modern methods of production: therefore plant and equipment investment is commonly associated with improved productivity and advancing technology.

For the period 1977-88, foreign manufacturing affiliates have been at least the equal of U.S. manufacturing firms in their yearly spending for new plant and equipment (figure 3-8). They far surpassed the American firms in the late 1970s and early
Figure3-8-Swndin for New Plant and Equipment, Foreign-Manufacturing Affiliates and U.S. Manufacturers

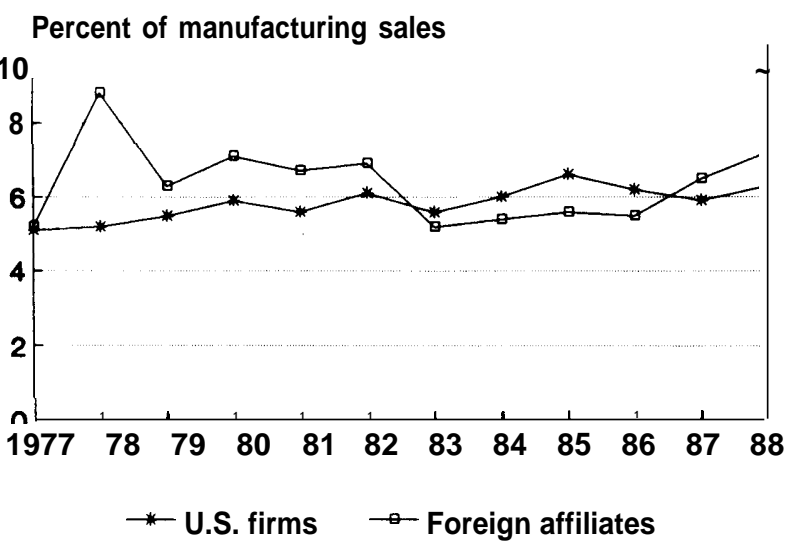

SOURCE: U.S. Department of Commerce, Bureau of Economic Analysis, Foreign Direct Investment in the United States: Operations of U.S. Affiliates, 1977-80, 1985,. tables D-29 and E-1, and subsequent series; Economic Report of the President 1990 (Washington, DC: U.S. Government Printing Office, February 1990), table C-90; and U.S. Department of Commerce, Bureau of the Census, "Plant and Equipment Expenditures and Plans," Unit@ States Department of Commerce News, Sept. 13,1990, table 4.

1980s, fell behind for a few years in the mid-1980s, ' and more recently pulled ahead.

Figures are available for 3 years (1980, 1987, and 1988) on property, plant, and equipment investment as a percentage of sales for manufacturing affiliates by country of the parent company. ${ }^{44}$ These data show that the Japanese far outstripped their European counterparts, and foreign manufacturing affiliates in general, in such investments per dollar of sales (figure 3-9). One likely reason is the Japanese propensity to invest directly in new plants rather than to acquire or buy a share in existing ones, as the European investors are more prone to do. ${ }^{45}$ Another is that the concentration of investment in capitalintensive industries--disproportionate investments in motor vehicles and electronics-means higher investment/sales ratios.

\section{Japanese FDI: A Special Case}

Japanese direct investment in the United States differs from that of other countries in more than one way. As noted, the very high proportion of sales from wholesale affiliates suggests that a dominant interest in Japanese investment is to sell goods made in Japan. This accords with the responses of firms surveyed by MITI in a recent survey. ${ }^{46}$ Over 80 percent of respondents indicated that their motive 
Figure 3-9-investment in Plant, Property and Equipment as a Percent of Sales of Manufacturing Affiliates

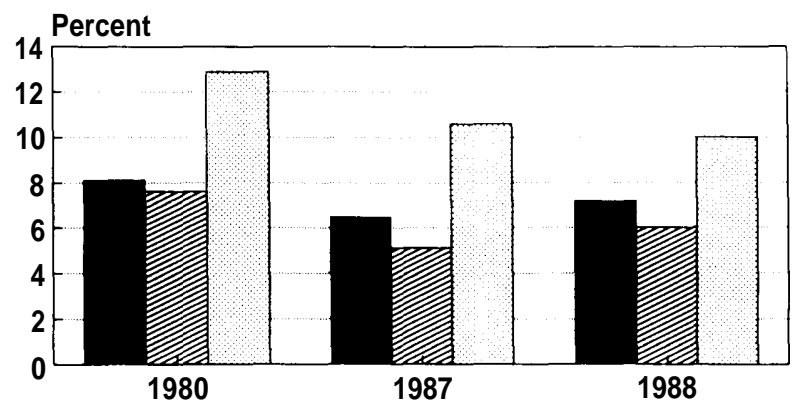

All foreign affiliates = European affiliates Japanese affiliates

SOURCE: U.S. Department of Commerce, Bureau of Economic Analysis, Foreign Direct Investment in the United States, 1980, October 1983, tables D-9 and E-1, and subsequent series.

for investing offshore was to increase sales in local markets. This motive ranked highest on the list of all reasons in all markets. ${ }^{47}$ Other motives also strongly suggest that the main reason for investing was to increase sales; nearly 50 percent of respondents said they invested in the United States because of U.S. trade regulations (implying that they were substituting local production for exports); about 25 percent invested in the United States "to obtain a good partner in the local market.' ${ }^{48}$

Another main interest (greater than that evident in other countries' investments) seems to be gaining access to advanced technologies. ${ }^{49}$ For example, contrary to the general Japanese characteristic of majority ownership in foreign affiliates, minority Japanese investments in small American hightechnology firms almost doubled from 1988 to 1989, rising from $\$ 176$ million to $\$ 320$ million. This can be seen as an effort by Japanese companies to gain access to U.S. technology and diversify into new businesses. It does not necessarily imply that Japanese firms are somehow siphoning technology from the United States, for the U.S. firms get something in return. Many find that FDI is a good entree to foreign markets, and a large Japanese partner may have distribution channels that small firms could not duplicate. ${ }^{50}$

The advantages of a tie-up between a small American company and a big Japanese firm maybe illustrated by two recent agreements signed between
Nicolet Instruments Corp. and Matsushita Communication Industrial Co. Ltd. The agreements grant Matsushita the right to sell a line of Nicolet's oscilloscopes in Japan under Matsushita's name (something Matsushita doubtless has an advantage in doing), and provide for cooperation and exchange of technical information between the two companies in the development of electronic measurement products. According to the CEO of Nicolet, the alliance greatly enhances Nicolet's market penetration for its new oscilloscope in Japan, while the technical exchanges between the two companies will allow them to develop a new line of instruments to be marketed worldwide. ${ }^{51}$ While the agreement between Nicolet and Matsushita may or may not involve direct investment, the mechanics are familiar; many Japanese investments in American hightechnology companies involve similar arrangements. ${ }^{52}$ Moreover, the different interests of the Japanese investors may prove a boon to American hightechnology companies as well. According to one source, Japanese firms are interested in one thing: long-term gain, which translates to a strong interest in R\&D. Typically, Japanese middle managers have the authority to commit significant funds to $R \& D$ or joint development programs. U.S. investors in hightechnology firms-venture capitalists-want to cash in their gains in a relatively short time (in 7 or fewer years), a constraint the Japanese investors to not impose. $^{53}$

While many American companies find alliances with (and investment from) Japanese companies beneficial, there is still worry about the long-term consequences. For -example, many observers worry that, in alliances with large Japanese fins, small American companies may end up losing control of their technologies and products. Another concern is that Japanese investment in high-technology electronics firms and their suppliers will result in U.S. semiconductor and systems makers being overly dependent on Japanese firms for critical components. That dependence, in turn, could be used as a competitive or political weapon.

For example, the recent decision of the Administration to allow the Japanese company Nippon Sanso to purchase the American firm Semi-Gas Systems, a supplier of high-quality gas equipment to semiconductor makers (and a participant in Sematech), could make the U.S. semiconductor industry vulnerable in several ways. The purchase will mean that Japanese companies will control over 40 percent of the world 
market and nearly half the U.S. market for highquality gas equipment. 54 It fight, for instance, mean that Nippon Sanso could cut off supplies to Sematech or its member companies in response to trade policy decisions like the 1989 naming of Japan as an unfair trader under the Super 301 section of U.S. trade law. Or the pressure could be more in the realm of business operations than politics: Nippon Sanso could selectively favor its Japanese customers with new products, low prices, and quick deliveries. ${ }^{55}$ Allegations of such discriminatory practices on the part of Japanese companies have surfaced in the past, but are difficult to pin down. ${ }^{56}$

The situation in semiconductor manufacturing equipment as a whole is not so stark as that in high-quality gas equipment. According to the International Trade Administration of the Department of Commerce, Japanese fins' investments accounted for 10 percent of the market in 1983, and had increased to 15 percent in 1988. VLSI Research estimated that the share would reach 26 percent in $1993 .^{57}$ These investments are a significant but not yet overwhelming share of the U.S. market, but combined with imports of semiconductor manufacturing equipment from Japan, they contribute to fears of Japanese dominance.

Whether allegations of discriminatory practices are true or not, dependency is always worrisome, particularly in technologies or industries considered critical to a nation's well-being. This category includes products for maintaining g national security and agricultural commodities in most advanced nations. Increasingly, dependence on foreign companies or countries for high-technology products has become a source of anxiety. The problem becomes acute when foreign competitors control the most advanced equipment, materials, and supplies needed to produce something as vital as semiconductor chips, especially when, as in the case of Japanese electronics companies, a few large firms are in a position to wield oligopolistic market power. Because of the particular nature of Japanese business, many fear that this control could be more costly than possible temporary disruptions in supplies or control of prices, in the end costing the United States the ability to produce advanced components and products at any price.

There is also fear that Japanese investment could mean increased economic and political influence over American business and government. This concern is typical of nearly every country facing heavy FDI. Developing nations have long maintained strict controls over foreign fins, and sometimes nationalized them, to avoid foreign economic dominance or excessive interference in domestic affairs. In this respect too, however, many nations worry that Japanese corporate investment is somehow different from investment by firms of other nationalities.

Another worry is that Japanese investment is shaped by the aims and goals of headquarters and is therefore unresponsive to local concerns. Even in developed nations, Japanese firms are unwilling to relinquish headquarters control of local operations. A symptom of this is the sparse representation of native managers in Japanese affiliates abroad. A recent report from the American Electronics Association showed that, while 71 percent of American electronics firms in Japan have Japanese CEOs, only 2 percent of Japanese electronics firms in the United States have American CEOs. ${ }^{58}$ Another report is that Japanese companies in America have difficulty recruiting qualified American management, because many U.S. executives believe that Japanese companies will keep non-Japanese staff out of important decisions, ${ }^{59}$ or force them to check with the Japanese headquarters for all decisions of consequence.

This phenomenon is not limited to the United States. A study of 62 multinational companies doing business in Australia (42 American or European and 20 Japanese) showed the same pattern. ${ }^{60}$ Most American or European operations in Australia were managed by Australians, but only one of the Japanese operations was wholly Australian-run, and even when Australian managers were used, their discretionary power was curtailed by Japanese advisors. ${ }^{61}$ Some Americans working for Japanese companies complain that they have few opportunities for advancement, and fear that Japanese companies are more likely than companies of other nationalities to keep high-paying jobs at home. ${ }^{62}$

These complaints are consistent with the responses of Japanese companies to a recent MITI survey of their international operations. As of 1989, over 93 percent of the respondents managed their international operations from Japan, either by letting each functional division (e.g., marketing, manufacturing, or administration) manage both domestic and international business, or through an international business division that controls all overseas activi- 
ties. ${ }^{63}$ Less than 6 percent of respondents have established a supervising corporation overseas to control manufacturing and sales in local markets, and less than 2 percent have overseas managing and supervising corporations that control all activities in local markets. Five years ago, however, less than 3 percent controlled any offshore operations from the local market. Nearly a third of respondents claimed that they would establish overseas managing and supervising corporations to control some or all of local operations by the mid- 1990s.

Another hallmark of Japanese investment abroad is its pattern of purchasing capital equipment from the home country. The study of multinational companies doing business in Australia reported that the American and European companies' equipment showed no national purchasing pattern; their equipment was made in America, Japan, and several European countries. Japanese companies, on the other hand, bought the overwhelming preponderance of their equipment from Japan. The study's author said:

When an American or European company buys machinery to set up a plant, they take competitive bids. But the Japanese go directly to Japan. ${ }^{64}$

Finally, for all industrialized countries, there is a fundamental asymmetry between Japanese investment abroad and foreign investment in Japan. The United States is just waking up to a reality that some nations in the industrialized world has long facedthe presence of strong foreign commercial interests in the domestic market-and is reacting to it in what is probably typical fashion. Some people welcome the foreign investors, and see the increase in FDI as a response to market forces that will benefit U.S. consumers. Some react with heightened concern, even xenophobia, and regard any foreign influence as potentially suspicious. Opinions come in every shade between these two extremes.

If Americans just awakening to these issues, Japan still slumbers. It is still the exception among industrial nations in the degree to which foreign investors are constrained from participating in its economy. While Japanese investors have aggressively stepped up investment in America, and recently in Europe, investment in Japan is still restricted. In 1985, assets of Japanese affiliates in the United States and those of U.S. affiliates in Japan were equal, both standing at $\$ 64$ billion. In the next 3 years, assets of Japanese affiliates in this country multiplied more than fourfold, rising to $\$ 275$ billion, while U.S. affiliates' assets in Japan rose only to $\$ 129$ billion. Leaving aside financial institutions, assets of Japanese affiliates in the United States rose 106 percent while U.S. affiliates' assets in Japan grew 70 percent. American companies investing in Japan, particularly in preceding decades, were often obliged to license technologies, take a Japanese firm as a partner, or promise to limit market shares in return for permission to invest there; Japanese companies, in contrast, have been relatively free to invest in America, though the ambient political atmosphere surrounding their recent investments influenced their decisions.

The asymmetry is not just bilateral. In 1986, FDI in manufacturing accounted for 10 percent of U.S. sales, 7 percent of employment, and 9 percent of assets in the manufacturing sector. Corresponding figures for major European economies are: for France, 27 percent of sales and 21 percent of employment; for Germany, 18 percent of sales, 13 percent of employment, and 17 percent of assets; and for the United Kingdom, 20 percent of sales, 14 percent of employment, and 14 percent of assets. In Japan, in stark contrast, FDI in manufacturing accounted for 1 percent of sales, employment, and assets. ${ }^{65}$ Between 1960 and 1987, direct investment in Japan increased from 0.6 percent of the world total to 0.8 percent. During the same period, inward investment in the United States increased from 9.4 percent of all inward investment in the world to 25.2 percent, and Europe's share increased from 29.8 to 37.6 percent. ${ }^{66}$ While the United States and Europe debate the merits of foreign investment and how it contributes to national well-being, the Japanese seem to have made a clear choice: domestic firms are preferred to foreign firms in Japan.

It is hard to say whether differences in Japanese investment behavior at home and abroad are a problem. Japanese firms are quite effective at selling in the markets they invest in. They are more likely than other foreign firms to build new plants and retain greater control over their affiliates (although their investment position is lower overall than those of European or Canadian investors), which could work to either the benefit or the detriment of the nation (or be neutral). For example, if Japanese affiliates invest heavily in training, $R \& D$, and capital equipment, as Japanese parent firms generally do, then America may stand to gain more from Japanese investment than from investments by firms 
of other nationalities. In at least one industry, motor vehicles, Japanese affiliates have a good record of investment in training (see the discussion below), and the few figures available on the point indicate that their manufacturing affiliates invest more in plant and equipment, per dollar of sales, than foreign affiliates generally. R\&D data by country of affiliate are even less adequate, but the scanty available figures suggest that Japanese affiliates' R\&D intensity is low. European firms fall closer to the average in all areas, but this is partly because European investment is so large that it has a greater effect on the average. In 1988, assets of European affiliates were 48 percent of the assets of all affiliates of foreign firms in the United States, while Japanese affiliates accounted for less than 24 percent. In manufacturing, where most of the R\&D spending and capital investments take place, European affiliates had 63 percent of assets, and Japanese affiliates 10 percent.

Japanese documents acknowledge that the international operations of Japanese companies have been mostly aimed at exporting, but there are indications that new strategies are emerging. As noted, MITI's survey showed that many more firms are planning to transfer significant control to foreign affiliates. Perhaps more significantly, increasing numbers of Japanese firms are also planning to spread R\&D to offshore locations. At the time of the survey, 55 percent of respondents had R\&D overseas only to provide technical support for sales and post-sale service; another 33 percent maintained foreign R\&D bases to support local manufacturing. Another 10.5 percent maintained local $R \& D$ to design products specifically for local markets, while less than 2 percent maintained foreign R\&D that was not directly in support of local market needs. ${ }^{67} \mathrm{By}$ the mid-1990s, however, 11.6 percent of the respondents planned to have foreign $R \& D$ aimed at general, rather than strictly local, corporate objectives. In addition, MITI's white paper maintains that Japanese corporations are in the first stage of global investment, and as investments mature, the expectation is that Japan's trade surplus will diminish. Such plans, if implemented, will make Japanese investment both more acceptable and more beneficial to host nations. Some American observers also expect Japan's trade surplus to dwindle as planned foreign investments are made. One member of MIT's International Motor Vehicle Program maintains that exports of Japanese automobiles will eventually be replaced largely by production in overseas markets, partly because Japanese firms are becoming more confident about their ability to manage overseas facilities and partly because overseas markets will be increasingly unwilling to sustain large auto trade deficits with Japan. ${ }^{68}$

A caution is in order, however. The plans of Japanese corporations are in line with the demands of foreign markets and governments, but it is not clear how much responsibility or R\&D will be transferred offshore without such pressure, or whether plans to replace Japanese exports with offshore production will materialize absent the increasing trade friction of recent years: Selling abroad is not, of course, the only reason for international investment, and many Japanese firms will invest abroad even without pressure from foreign governments. But if there is a lessening of trade tensions (at this point, that does not appear likely) there may also be less change in the behavior or Japan's offshore affiliates than the MITI survey suggests. Finally, it is always well to bear in mind that plans and expectations are often different from reality; unforeseen circumstances could well cause the respondents to MITI's survey to change their plans.

Perhaps the best way of viewing the issue right now is summed up in a quote:

The fears of some Americans, that the Japanese industrial presence in the United States is a mixed blessing, are not irrational. Japanese firms are not simply responding to trade friction by building an industrial presence in the U.S., but are pursuing a long-term strategy of creating an infrastructure which will enable them to sustain their market share above present levels, insulated from currency fluctuations and the vagaries of protectionist sentiment. ${ }^{69}$

\section{EMPLOYMENT AND EMPLOYEE COMPENSATION}

If it comes to a choice, most nations prefer foreign investment to imports, because foreign investment provides jobs, while the connection of imports with jobs is indirect at best. For example, one of the interests of the European Community, France and Italy in particular, in easing the adjustment to more open trade in motor vehicles is the employment they stand to lose if cars exported from Japan are allowed free access. The insistence of some in the EC on high levels of domestic content for foreign cars built in member countries. is additional evidence of the 
concern for domestic workers and jobs. The effect of this demand will be either that of guaranteeing a market to domestic firms, or of ensuring that domestic workers get some of the benefit of foreign firms' sales in the consuming country.

Affiliates of foreign parents accounted for 1.7 million manufacturing employees in the United States in 1988; this was 8.9 percent of all U.S. manufacturing employment, up from 3.5 percent in 1977. While foreign corporations are, therefore, a growing force in U.S. manufacturing employment (figure 3-10), they are not necessarily creating jobs at the same rate that their employment has grown. Not all the jobs held by workers in companies called affiliates of foreign companies are jobs that the foreign company created through investment. DuPont is a good case in point; it is a foreign affiliate because a Canadian family owns 23 percent of the stock, yet it is difficult to believe that even 23 percent of DuPont's workers in the United States owe their jobs to the Canadian investment.

On the other hand, the greenfield auto plants of the major Japanese auto companies, such as Nissan, Honda, Mazda, probably do represent net additions of jobs that would not exist otherwise. How many of the jobs these greenfield investments added is unknown; we do not know whether, in the absence of Japanese investment, other domestic producers would have made more cars, or if imports would have increased, ${ }^{70}$ or what tradeoffs between production and price would have been made. Even in the case of these wholly new investments, the number of jobs involved almost certainly exceeds the upper bound of what could reasonably be called job creation resulting from FDI. ${ }^{71}$

Although FDI does not create as many jobs as there are employees in affiliated establishments, it does affect employment in qualitative as well as quantitative ways. Where the foreign investor's influence is significant, and therefore results in different training or a different business culture and management style, there are effects. Whether they are positive or negative is another matter.

Training has been most carefully studied in Japanese-owned automobile assembly plants in the United States. They have a distinct edge over U.S.-owned assembly plants in the training they provide their employees-not only shop-floor production workers, but also supervisors and manufacturing engineers (table 3-7). For newly hired produc-
Figure 3-10-Employment in U.S. Affiliates, 1977-88

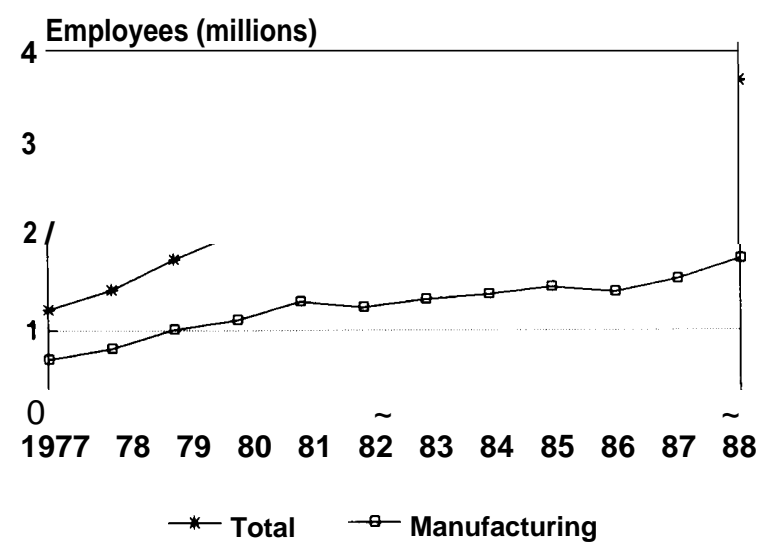

SOURCE: U.S. Department of Commerce, Bureau of Economic Analysis, Foreign Direct Investment in the United States: Operations of U.S. Affiliates, 1977-80,1985, table F-4, and subsequent series.

tion workers, the difference is enormous (279 hours v. 46 hours), but there are substantial differences in every category. Note, too, that training for most categories of employees is still greater in Japaneseowned plants in Japan than in the Japanese transplants in America.

In some cases, Americans working for foreignowned companies speak glowingly about the lessons they have learned from their foreign parents. Managers at New United Motor Manufacturing Inc. (NUMMI), a joint venture of General Motors and Toyota, attribute much of the turnaround in the plant's performance to their newly learned Japanese way of doing business. NUMMI operates from a plant in Fremont, California. The plant was formerly owned and run by General Motors and was often described as one of GM's worst plants. In 1982, it was shut down, presumably for good. It reopened 2 years later as NUMMI, with a crew of senior managers from Toyota and. a work force largely drawn from former UAW employees of the Fremont plant (80 percent of the workforce of NUMMI worked for GM Fremont). By 1986, when NUMMI was running at full capacity, its quality record matched that of Toyota's Takaoka assembly plant in Japan, while its productivity record was somewhat worse (19 assembly hours per car, compared with 16 at Takaoka). Its parts inventory averaged 2 days, compared with Takaoka's 2 hours, but this was still substantially better than GM's Framingham plant, ${ }^{72}$ where inventory averaged 2 weeks. GM says it is busy trying to pass the lessons it learned at NUMMI 
Table 3-7-Training Hours

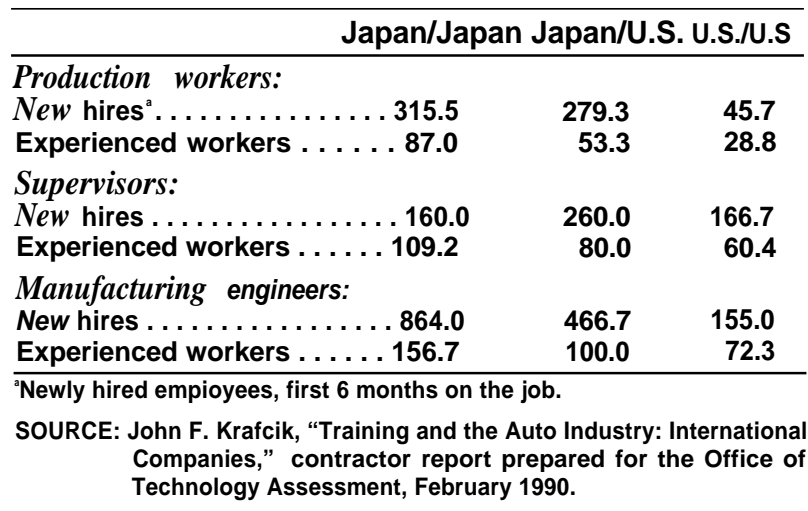

on to managers at its other plants, though this has proved difficult, for it changes the job of every worker and manager at GM.

Even at NUMMI, the employment effects are not uniformly positive. There have been complaints about the pace of work and lack of seniority benefits in work assignments, ${ }^{74}$ although no real strife has erupted. Also, it is not clear how much or how fast GM is able to transfer the knowledge the workers and managers of NUMMI have obtained from their experience with Toyota. Nevertheless, the venture's experiences have the potential of changing for the better the way some managers and workers think and work. So, too, do the other Japanese transplants.

Other experiences are more problematic. In 1984, the Japanese firm NKK bought half of National Intergroup, Inc., making National Steel Corp. a Japanese affiliate. The Japanese chairman arrived in 1986, and the company's productivity has improved 16 percent since 1984-85, but it still remains one of the least profitable in the steel industry. Despite a \$200 million annual capital improvement program, the company needs repairs for its blast furnaces, while unscheduled maintenance problems abound. The union there has one of the industry's most generous contracts, including a job security provision that restricts layoffs, but labor relations have been rocky, and the local unions have fought "efficiency-boosting job flexibility. ${ }^{175}$ Whatever lessons Japanese managers have to teach have been hard to pass on at National Steel.

Finally, as noted above, Japanese firms may be less inclined to assign discretionary responsibility to American managers than other investors; certainly, they are less likely to hire American managers in
America than U.S. firms are to hire Japanese managers in Japan.

Can American workers and managers learn more from foreign direct investors than they already have? Probably, but there are limits. In some cases, the foreign parent is more a financial than a managerial presence, and many foreign affiliates are run the same as, or only slightly different from, American companies. In other cases, foreign companies may not have much to teach. In 1988, European affiliates had nearly 3 billion dollars' worth of investment in motor vehicles and equipment in North America, but the quality and productivity records of the European auto manufacturers are worse than those of the Big Three American companies. Unlike the Japanese case, there are few lessons to be learned from European auto production management.

In terms of compensation and layoffs, foreign affiliates behave more or less like American companies. During the 1982 recession, U.S. manufacturing employment dropped 7 percent from the previous year's employment, while sales dropped 5 percent. Foreign manufacturing affiliates' employment dropped 4 percent, although sales increased 1.5 percent. Foreign affiliates' manufacturing employment also dropped in 1985, as did U.S. manufacturing employment generally. While American firms have reputations abroad as fickle employers (it has sometimes been hard for them to recruit good employees in Japan because of their reputations as unstable employers during downturns), many foreign affiliates behave in similar ways when they do business in the United States. For example, in 1985, when the semiconductor industry worldwide went into a steep slump; at least two Japanese affiliates producing chips in U.S. plants (NEC and Toshiba Semiconductor) laid off workers in much the same way as their American counterparts in Silicon Valley .77 NEC official Koichi Shimbo told the San Jose Mercury News: "When we are in the U. S., we do like the Americans. ${ }^{\prime 78}$

In terms of compensation, foreign affiliates and American firms are very little different. While foreign affiliates pay higher compensation per employee overall than U.S. fins, this is due to the relatively heavy concentration of affiliates in highwage industries like banking. Within manufacturing, foreign affiliates and American firms pay nearly the same compensation to workers. ${ }^{79}$ This is not surprising; if foreign firms failed to pay as much as 
Figure 3-n-Earnings and Reinvested Earnings: Foreign Direct Investors in the United States

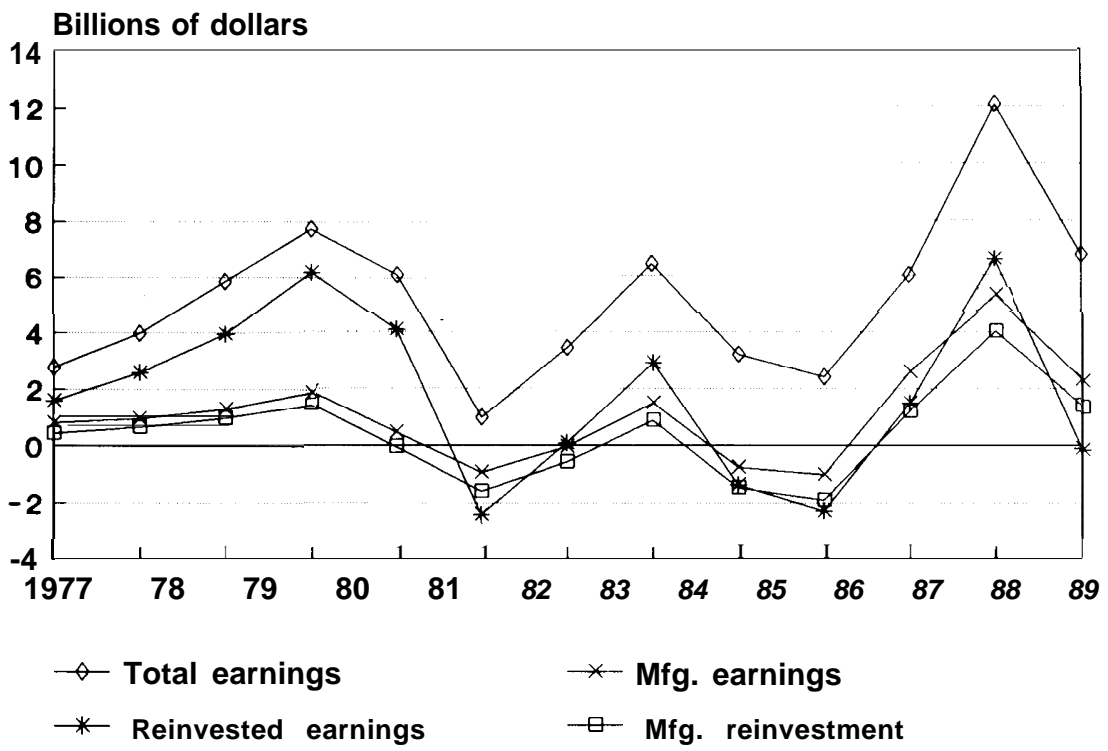

SOURCE: U.S. Department of Commerce, Bureau of Economic Analysis, "Foreign Direct Investment in the United States," Survey of Current Business, various August and October issues covering the years 1977 through 1989, table 4.

U.S. firms, they would have difficulty attracting workers. ${ }^{80}$

\section{PROFITS}

The way a multinational uses its profits also is an indicator of its commitment to foreign markets. In the 1960s, when American multinationals were investing heavily in Europe, concerns were raised about whether profits were reinvested or repatriated. Now, with FDI rising rapidly in the United States, we have come full circle, and Americans are wondering whether foreign companies use the profits made in the United States to benefit U.S. citizens, or instead send most of them back to the home country.

According to Bureau of Economic Analysis (BEA) data, reinvestment depends heavily on earnings. The amount reinvested, particularly by manufacturing affiliates, bears a very close relationship to earnings, for all foreign direct investors in general, and for European and Japanese investors in particular (figures 3-11, 3-12, and 3-13). The difference between earnings and reinvested earnings is distributed earnings, which are quite small for Japanese manufacturing affiliates and a bit larger for European affiliates. This fits with the well-known fact that Japanese manufacturing firms generally pay out very small dividends, compared with European or American manufacturers.

If we look more broadly at all FDI (not just in manufacturing), distributed earnings are increasing, although the relationship with earnings is still strong. This is particularly striking for Japanese investment, whose distributed earnings increased modestly between 1982 and 1984, and then rapidly after 1984 (figure 3-12). The increase occurred in wholesale trade and a category called "other," which includes retail trade, banking, finance, insurance, and real estate. In 1989,95 percent of Japanese affiliates' distributed earnings came from these wholesale trade and the group labeled "other,' and in 1990, 96 percent. European affiliates' distributed earnings originated differently; they came mainly from petroleum, "other," and manufacturing, with very little from wholesaling. In 1988, manufacturing accounted for the largest reported share, 32 percent. European affiliates' distributed earnings in 1988 and 1989 were reported in neither petroleum nor 'other' separately, to avoid disclosure of data of individual companies. In 1988, the two sectors combined accounted for 58 percent of all distributed earnings, and in 1989, 68 percent. 
Figure 3-12-Earnings and Reinvested Earnings: Japanese Direct Investors in the United States

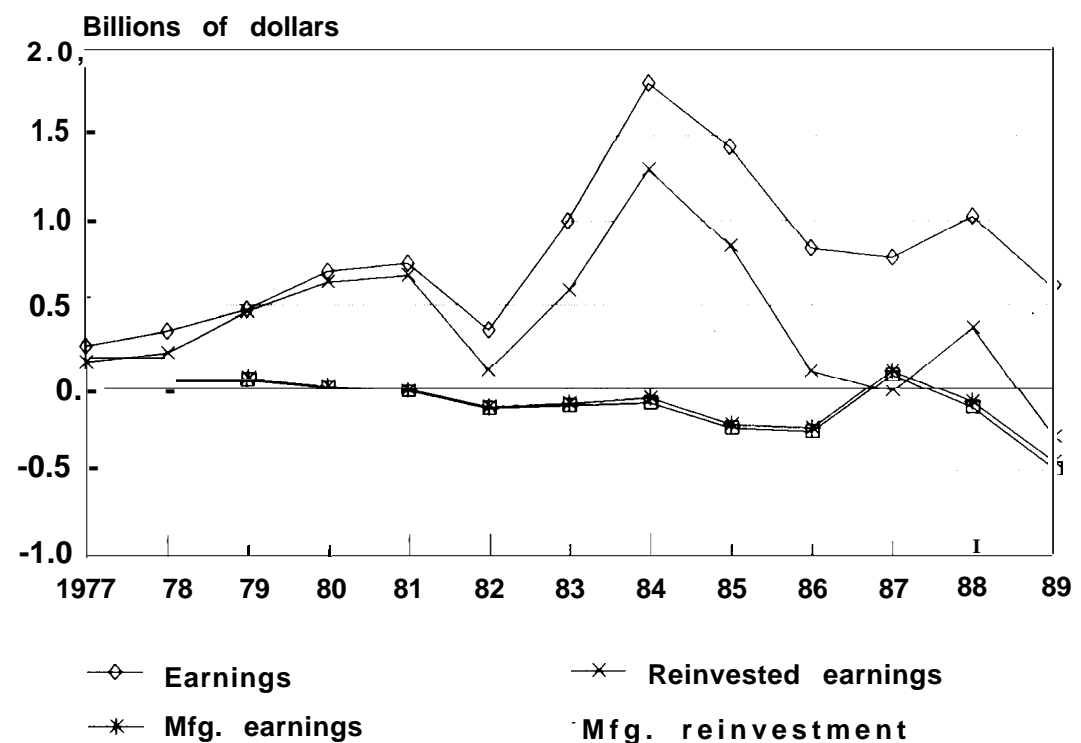

SOURCE: U.S. Department of Commerce, Bureau of Economic Analysis, "Foreign Direct Investment in the United States," Survey of Current Business, various August and October issues covering the years 1977 through 1989 , table 4.

Figure 3-13-Earnings and Reinvested Earnings: European Direct Investors in the United States

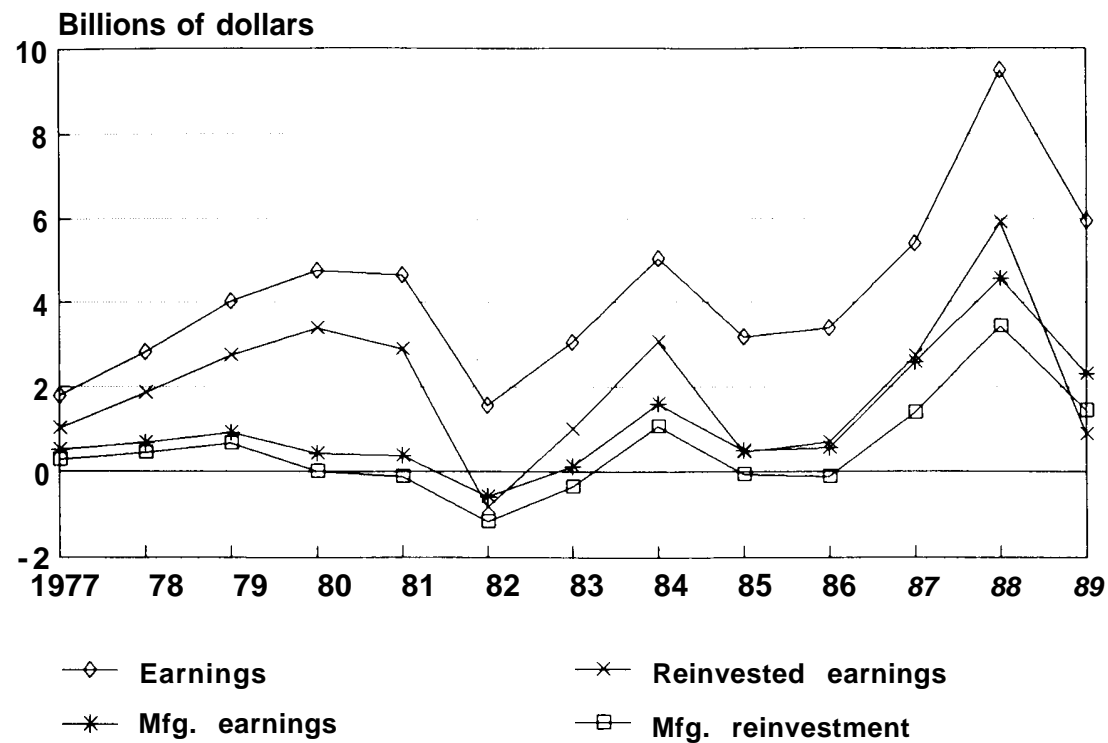

SOURCE: U.S. Department of Commerce, Bureau of Economic Analysis, "Foreign Direct Investment in the United States," Survey of Current Business, various August and October issues covering the years 1977 through 1989, table 4. 
Figure 3-14-Earnings and Reinvested Earnings: U.S. Direct Investment Abroad

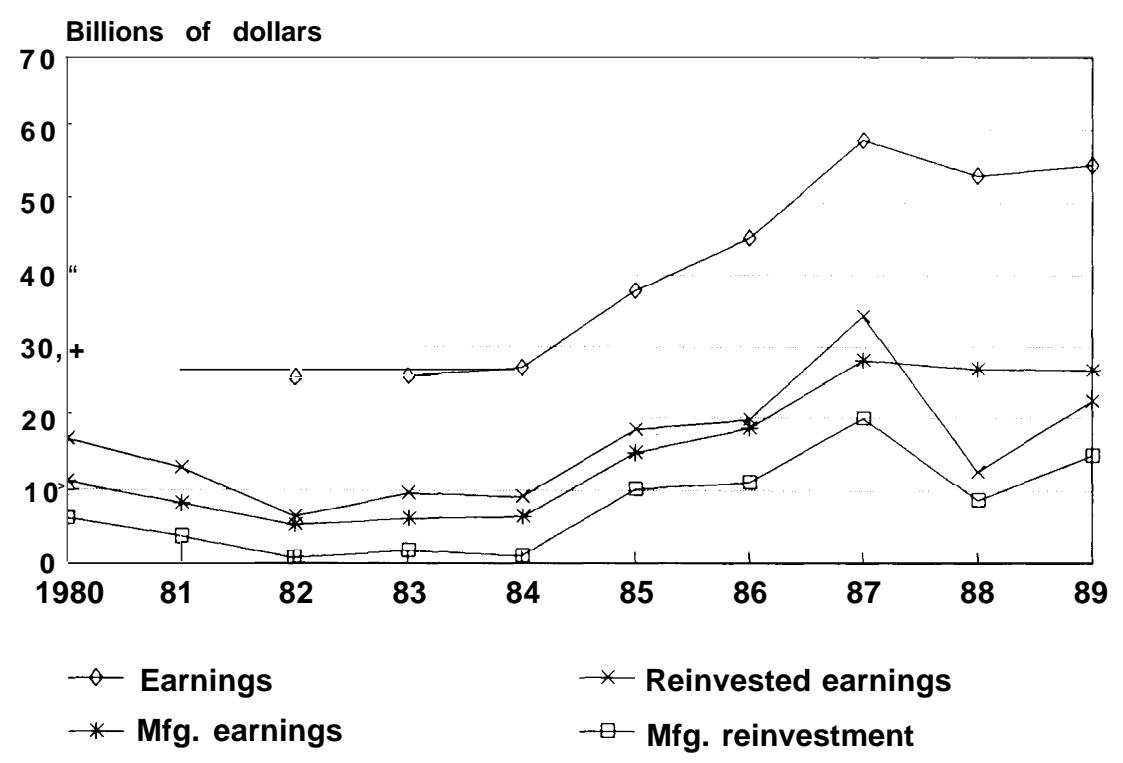

SOURCE: U.S. Department of Commerce, Bureau of Economic Analysis, "U.S. Direct Investment Abroad," Survey of Current Business, various August and October issues covering the years 1977 through 1989, table 20.

One noteworthy feature of the data, going back to 1977, is that earnings of manufacturing affiliates are often small or negative. For Japanese affiliates they are hardly ever positive; since 1980, Japanese manufacturing affiliates' earnings have been positive only once, in 1987, European manufacturing affiliates' earnings dipped into the red only once, in 1982, a recession year. This observation raises several questions about how earnings are viewed. One possibility is that foreign investors in manufacturing, and Japanese investors in particular, are here mainly to gain market share, not profit, and can afford to sustain many years of financial losses. Eventually, of course, the firms must expect to profit from the increase in market share, but perhaps not yet; substantial Japanese direct investment in manufacturing is fairly recent. Another possibility is that foreign affiliates' earnings are calculated with an eye to where the parent company would most like to pay corporate taxes and get tax breaks. Suggestions that affiliates in the United States are charged higher-thanmarket prices for both goods imported from the parent organization or for intangibles (e.g., R\&D) come up from time to time, but so far are unresolved. It is possible that earnings of foreign affiliates are understated because parent firms prefer to deal with corporate taxes at home rather than in the United States.
Whatever the resolution, Japanese affiliates in America are acting differently in making or reporting earnings and in reinvestment. American multinationals' earnings and reinvested earnings in their overseas affiliates, overall and in manufacturing, have been positive throughout the 1980s (figure 3-14). This may reflect the fact that, compared with Japanese firms, American firms are under heavier pressure to make and distribute earnings, or it may have to do with differences in corporate tax rates and incentives here and abroad.

\section{INTERNATIONAL TRADE}

Foreign affiliates have a higher propensity to import than American firms, and the overall trade deficit associated with the operations of affiliates is substantial (figure 3-15). In 1988, the deficit in merchandise trade associated with U.S. affiliates of foreign investors (about $\$ 90$ billion) was 75 percent of the total U.S. merchandise trade deficit (\$120 billion). Between 1977 and 1988, U.S. affiliates of foreign firms increased their merchandise imports 11.3 percent annually, from less than $\$ 46$ billion to nearly $\$ 150$ billion, while their merchandise exports increased from $\$ 21$ billion to $\$ 52$ billion, 8.6 percent per year. The affiliates' trade deficit accordingly increased from $\$ 21$ billion in 1977, when the United States had an overall merchandise trade deficit of 
Figure 3-15-Merchandise Trade, FDIUS Affiliates

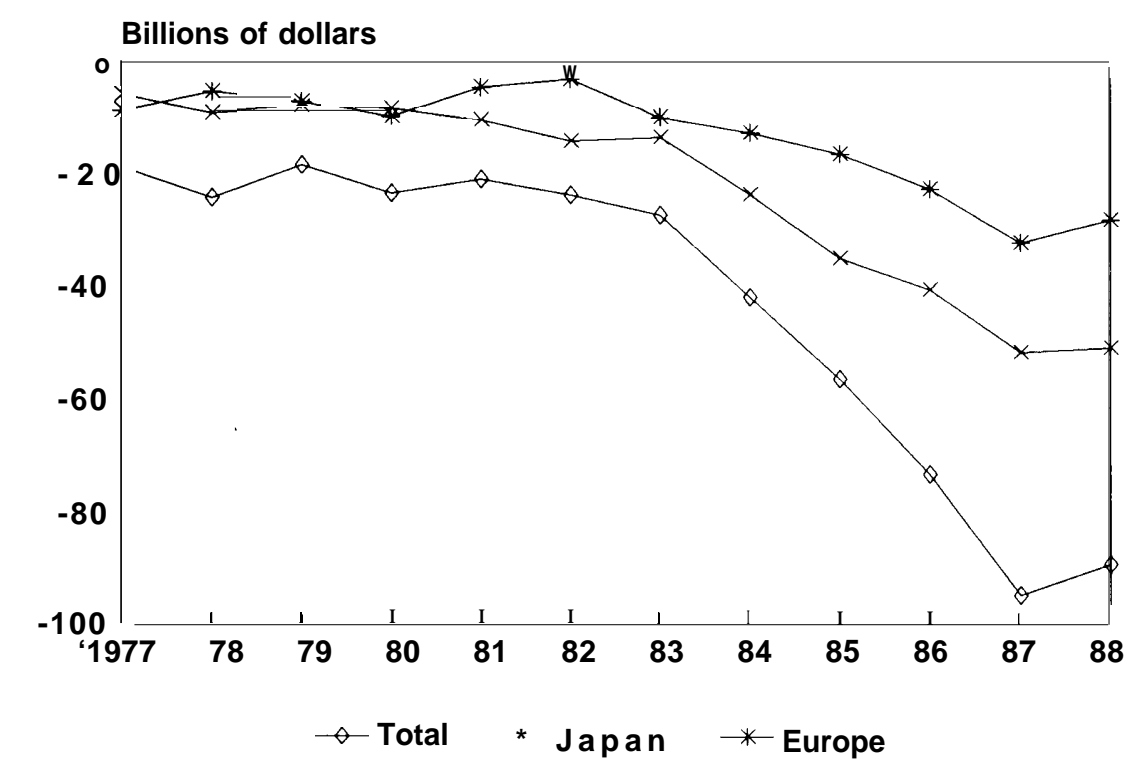

SOURCE: U.S. Department of Commerce, Bureau of Economic Analysis, Foreign Direct Investment in the United States: Operations of U.S. Affiliates, 1977-80, 1985, table H-3, and subsequent series.

$\$ 27$ billion, to nearly $\$ 90$ billion in 1988. In 1977, European affiliates accounted for 42 percent of the trade deficit associated with FDI, but their share dropped to 32 percent by 1988, while Japanese affiliates' share increased from 28 percent of the total deficit to 57 percent (figure 3-15). ${ }^{81}$

The nature of affiliates' imports varies by country. In 1988, Japanese affiliates imported mostly through their wholesale trade establishments in the United States; 93 percent of their imports came to wholesalers and only about 7 percent to manufacturers. Forty-four percent of the merchandise imports of all Japanese affiliates were motor vehicles shipped to affiliated Japanese wholesalers (\$33.4 billion of a total of $\$ 75.9$ billion). Motor vehicle imports to wholesalers dwarfed the next largest category of Japanese affiliates' imports, $\$ 12.8$ billion in imports to electrical goods wholesalers. All this supports the point made earlier, that the preponderance of Japanese FDI operations in the United States is related to selling goods made in Japan, and this shows up in trade figures as much as in sales.

While Japanese affiliates account for a substantial trade deficit in motor vehicles, there is a noteworthy countertrend. Honda, the first Japanese automaker to set up U.S. manufacturing operations, now exports cars from the United States-in fact, it expects to export 70,000 cars from the United States this year. If it does, its exports will exceed auto exports by the Big Three U.S. automakers to all nations except Canada (which has a longstanding free trade agreement with the United States in motor vehicles) .82 The U.S. content of Honda's motor vehicles was low, only 25 percent, when the company began operations here in 1982, but Honda claims it will have 75 percent North American content in its U.S. and Canadian operations by $1992 .{ }^{83}$ So while the balance of bilateral motor vehicle trade between the United States and Japan is still heavily tipped in favor of a Japanese surplus, the irony is that Japanese direct investment in the United States may end up contributing disproportionately to U.S. motor vehicle exports, too.

European affiliates' imports in 1988 also came mostly through wholesalers, but to a much smaller extent than Japan's: 54 percent of European affiliates' imports were done by wholesalers. Manufacturing affiliates accounted for 34 percent of all European affiliates' merchandise imports. Like the Japanese, European affiliates' largest single category of imports was motor vehicles imported by wholesalers, but autos were a much smaller proportion of their total merchandise imports, only 25 percent. The second largest category was imports by 
manufacturers of electric and electronic equipment (6.6 percent of total merchandise imports).

Altogether, foreign affiliates accounted for imports of motor vehicles and parts totaling $\$ 50.7$ billion in 1988 (including imports by manufacturers and wholesalers), and a motor vehicle trade deficit of $\$ 46.1$ billion. ${ }^{84}$ This compares with a total U.S. trade deficit in motor vehicles of $\$ 49.2$ billion in the same year. Manufacturing affiliates accounted for $\$ 21$ billion in merchandise exports, and $\$ 29.3$ billion in imports; wholesale trade affiliates accounted for a total of $\$ 35$ billion in exports and $\$ 109.6$ billion in imports. Clearly, the FDI deficit in auto imports by manufacturing affiliates is small compared to auto imports by wholesalers.

Firms wishing to sell in Japan cannot do it so easily by establishing a wholesaling affiliate in that country, nor would many small U.S. firms have the resources to do so even if there were no institutional barriers against it. Many of the small American high-technology firms that have formed alliances with foreign partners cite as one of the benefits their increased access to the Japanese market (see the Nicolet example above). Sometimes the arrangements are more complicated: the Japanese tractor maker, Kubota, bought a stake in the American company Cummins Engine to take advantage of Cummins' extensive European network, in preparation for European market integration in $1992 .{ }^{85}$

Although FDI is associated with a large negative effect on the U.S. trade balance, it is misleading to think of FDI as the cause of our trade deficit. The fundamental causes are our puny national savings rate (greatly exacerbated by the Federal budget deficit), and the failure of U.S. manufacturing to keep up technologically with increasingly able competitors, principally Japanese. ${ }^{86}$ According to economic theory, a nation's current account trade balance (which includes trade in services, transfer payments from governments, and income from property abroad, as well as trade in goods) is determined by the national rates of savings and investment; over time, the current account trade deficit (or surplus) is equal to the difference between domestic investment and domestic saving. If foreign investors' imports are persistently larger than their exports, this would tend to widen the U.S. current account trade deficit, but then the value of the dollar would presumably drop, making U.S. exports cheaper and returning the trade deficit to the level deter- mined by the relation between domestic savings and domestic investment. In such circumstances, weakening of the dollar might be postponed if foreigners invested enough of their savings in the United States to sustain a widening current accounts trade deficit; this is what happened during the early 1980s. Later in the decade, the dollar declined and the merchandise trade deficit and current account deficit narrowed. However, this process is costly. A lower dollar raises the price of imported goods, and in the long run, reliance on a cheap dollar to right the trade balance tends to undermine the U.S. standard of living. ${ }^{87}$ The most constructive way to get rid of the U.S. trade deficit is to produce goods that the world will buy because they are well-made and of good value.

\section{NATIONAL INTERESTS, BUSINESS INTERESTS}

What do nations want from firms, and what do firms do? Nations want things that make citizens better off: well-paid jobs, additions to knowledge and productivity, exports, investment. In some ways, foreign fins' affiliates in the United States measure up well on many counts, compared with firms whose headquarters are in the United States, and less so on others. Foreign affiliates and U.S. firms are similar in their compensation of workers. Foreign affiliates do less R\&D here per dollar of sales than do American firms, and they have a much greater propensity to import. In the latter regard, Japanese affiliates are noteworthy for their heavy importing, almost all of it from Japan. Some affiliates have made valuable contributions to workers' skills and to managers' competence, through training and object lessons; others operate in very much the same way as U.S. fins. They are about as reliable, in terms of job security, as American fins. All of this, of course, is on average. Japanese firms are particularly oriented to selling here; European fins' investments apparently represent a more diverse set of goals.

What all this means is that most of the differences in behavior between American and foreign firms are not very striking. Decisions about who ought to be allowed access to programs designed to improve competitiveness and living standards for Americans would therefore be more discriminating if they were made on the basis of individual fins' behavior and performance, rather than strictly on nationality. 
This begs the question of political influence, deliberately. Whether foreign firms or interests have undue influence in national, state or local politics, or whether their influence is exerted in ways that will harm American competitiveness and living standards or aid it, is beyond the scope of this report. Political and national security concerns are relevant to the debate over access to publicly funded programs to enhance competitiveness, and they ought to be; their absence is not a dismissal.

\section{The Policy Environment: How America Treats FDI}

The above sections suggest that there are many dimensions of foreign investment to consider if the U.S. Government wants to adopt performance criteria for deciding how to treat affiliates of foreign firms. The discussion so far has focused on what measures might be appropriate if the decision were about whether affiliates were permitted to participate in government-funded programs to promote industrial competitiveness. So far, the Federal Government has not dealt with this issue systematically. It has come up a couple of times, but not specifically as a competitiveness issue. For example, a few European firms want to participate in Sematech, just as a few American firms want to participate (and as IBM has been allowed on a limited basis) in the European semiconductor manufacturing and development consortium, JESSI. ${ }^{88}$ The decision in the United States has been to limit participation to American firms whose headquarters are in the United States and without a controlling foreign ownership position. Part of the rationale for the decision may have been national security. If that is so, then the position of the United States is either changing or is inconsistent with its stated principles and goals.

The official position of the U.S. Government on direct investment, both U.S. direct investment abroad and FDI in the United States, is that firms investing offshore should be treated no differently from domestic fins. This so called "national treatment" standard is the mirror of the official U.S. position toward international trade in the GATT, but the legal principles and policies are not so well defined in the investment arena as they are in trade. ${ }^{89}$ In a few sectors, this principle of neutrality is abridged by one of reciprocity, which stipulates that American firms must be treated abroad as foreign firms wish to be treated here. ${ }^{90}$ The United States, like most nations, makes a number of exceptions to these standards. The most prominent is for national security.

Exceptions to national treatment for national security reasons are made for two reasons: political sovereignty and military capability. Many nations have discriminated against foreign firms to keep them from gaining too great an influence over the nation's economy or political decisionmaking. The standard for what constitutes "too great' an influence is soft, and often handled case by case. Nations also seek to assure that the capacity to produce military goods and services will be at the government's disposal when needed, and that there will be no unauthorized transfers of sensitive technologies or products. ${ }^{91}$ These concerns are recognized by most nations as legitimate, and international agreements covering direct investment permit nations to make exceptions for national security purposes. ${ }^{92}$

The ability of the government to make exceptions to the national treatment standard for national security purposes was recently strengthened, at least in theory, in the Omnibus Trade and Competitiveness Act of 1988, which added section 721, often called the Exon-Florio amendment, to the Defense Production Act. This provision allows the government to block foreign mergers, acquisitions, or takeovers of U.S. firms if there is a threat to national security .93 Implementation of the provision is done by the Committee on Foreign Investment in the United States (CFIUS), whose members come from various Federal departments and agencies. ${ }^{94}$ So far, CFIUS has not ventured beyond a fairly narrow interpretation of national security. Critics argue that it should interpret national security more broadly to encompass strategic areas of the civilian economy, in the same way that Sematech received DoD funding on grounds that the ability to produce high-performance electronics products for national security depends on a competitive civilian industry.

A crucial test of CFIUS's willingness to interpret national security more broadly was its recent decision to permit a Japanese company to acquire Semi-Gas Systems Inc., the leading U.S. producer of high-purity gas systems for semiconductor manufacture. The President, acting on CFIUS recommendation, decided that the purchase of Semi-Gas by Nippon Sanso would not threaten national security, and the Justice Department decided the sale would not violate antitrust laws. Semi-Gas and Nippon Sanso are first and second in world sales of 
semiconductor gas equipment, with Semi-Gas having 21.5 percent of the world market and Nippon Sanso 17 percent. After the acquisition, Nippon Sanso will control nearly 40 percent, far ahead of the next competitor, Air Products, which has 14 percent of world sales. ${ }^{9 s}$

Although CFIUS has not yet broadened the definition of national security to include competitiveness of dual-use industries, the distinction between what is done for national security purposes and what is done to promote civilian industrial competitiveness is blurred. In some critical industries, such as electronics and telecommunications, the demarcation between the defense industrial base and overall U.S. industry is blurred; DoD must rely on technologies, people, and productive capacity that serve both civilian and military markets. If the Nation's electronics sector's competitiveness declines, so too might DoD's ability to be able to fulfil the military's production needs for either defense preparedness or for times of national emergency or war.

Moreover, the Nation's economic performance is at least equal in importance to military security, and policymakers are searching for ways in which the U.S. Government and industry can collaborate to strengthen America's competitive position. ${ }^{96} \mathrm{How}$ ever, the U.S. Government, particularly the last two Administrations, has steadfastly maintained positions in favor of free markets and against national intervention to promote economic competitiveness. This has led, some argue, to a tendency to find national security rationales for programs designed to promote economic competitiveness, including exceptions to national treatment standards for foreign firms investing in the U.S. market. The United States probably cannot continue to invoke national security for all programs to promote civilian industrial competitiveness. The United States is behind on too many fronts, and in too many high-visibility industries, not to confront the issue of economic competitiveness, and the government's proper role relative to it, for its own sake.

Anew government program with the unambiguous purpose of improving commercial technology is the Advanced Technology Program in the U.S. Department of Commerce. The law states that the program's mission is to improve "the competitive position of the United States and its business" and to "help United States businesses create and de- velop generic technologies with commercial potential. ${ }^{\prime \prime 97}$ The Program may help joint R\&D ventures with technical advice or may take part in the ventures, providing start-up funding or a minority share of the cost. Created in 1988, the Program got its frost funding (\$10 million) in fiscal year 1990; the next year Congress upped the amount to $\$ 36$ million and at the same time defined conditions under which foreign firms may participate in fiscal year 1991.

The approach is to apply performance standards to both foreign affiliates wishing to participate and U.S.-owned companies. The performance standards stipulate that participating companies shall have investments in U.S. R\&D and manufacturing (not limited to "screwdriver' assembly of imported components); a significant employment base; agreements to promote U.S. manufacture arising from any technologies developed in such ventures and to procure materials and components from the United States or Canada. The Secretary of Commerce is given the authority to find companies eligible for participation, using the performance standards as evidence that participation would be "in the economic interest of the United States. ' In addition, reciprocity provisions apply to foreign participants. They may take part if the Secretary finds that their home country offers U.S.-owned companies comparable opportunities to participate in joint ventures, allows U.S. companies to invest on equal terms with other countries, and affords adequate protection of the intellectual property rights of U.S. companies. ${ }^{98}$

For participation in government-sponsored programs such as the Advanced Technology Program, performance standards can be applied as a kind of screen, or they can be used on a case-by-case basis. While most observers seem to prefer performance requirements to discrimination based solely on ownership, ${ }^{99}$ performance requirements are controversial, too. Graham and Krugman argue that performance requirements can introduce economic distortions, just as-trade protection can, that could reduce economic well-being' and serve as a vehicle for political tampering.

The use of performance standards to govern foreign affiliates' participation in Federal programs, and other policy options, are discussed in chapter 2. While considerable information is available about the behavior and performance of foreign affiliates in the U.S. market, the kind of information that would allow an executive agency like CFIUS to discrimi- 
nate between investments that are likely to contribute to U.S. competitiveness and those that could endanger it is not always available, and some that is available is not used in today's permissive climate. The issue is very likely to heat up, however, in which case there will be increasing interest in how foreign affiliates contribute to the U.S. economy and technology. The data that exist tell us much, but they can also mask significant differences in contributions at the firm, industry, and country levels. Some of the most pressing questions, for example, about the flow of technology and value added when Japanese investors acquire control of high-technology American fins, cannot be fairly addressed with the data we have from government sources, and may require additional investigation. The behavior of foreign affiliates in general, and Japanese affiliates in particular, is similar enough to U.S. firms in many ways that it is not a simple thing to decide to exclude them on the basis of ownership alone. Neither is their behavior so similar to that of U.S. firms that national treatment standards are a matter of no consequence.

1 John W. Rutter, "Direct Investment Update: Trends in International Direct Investment" U.S. Department of Commerce, International Trade Adminstration staff report, September 1989. A U.S. affiliate of a foreign direct investor is defined as one in which an investor from another country owns or controls at least 10 percent of a domestic company's voting stock (or equivalent amount in an unincorporated enterprise). Definitions are given in U.S. Department of Commerce, Bureau of Economic Analysis, Foreign Direct Investment in the United States: 1987 Benchmark Survey, Final Results (Washington DC: U.S. Government Printing Office, 1990).

2 OECD is the Organization for Economic Cooperation and Development. Its members include Austria, Belgium, Canada Denmark France, German ${ }_{Y}$, Greece, Iceland, Ireland, Italy, Luxembourg, the Netherlands, Norway, Portugal, Spain, Sweden Switzerland, Turkey, the United Kingdom, and the United States.

3 This refers to the behavior of U.S. affiliates only; Japanese and many European countries have laws and traditions that make them much less prone to lay off workers at home.

4 For discussion of these conclusions, see U.S. Congress, Office of Technology Assessment, Paying the Bill: Manufacturing and America's Trade Deficit, OTA-ITE-390 (Washington DC: U.S. Government Printing Office, June 1988) and Mah"ng Things Better: Competing in Manufacturing, OTA-ITE443 (Washington DC: U.S. Government Printing Office, February 1990).

5 The dollar may not fall if, as in the early 1980s, interest rates are high enough and confidence in the U.S. economy great enough that foreign investment is sufficient to offset the deficit in merchandise trade and support the dollar at a high level-temporarily, at least.

6 Discussion of how the European Community treats foreign investors is in ch. 5 .

7 Edward M. Graham and Paul R. Krugman, Foreign Direct Investment in the United States (Washington DC: Institute for International Economics, 1989), pp. 21-24.

8 Public Law 100418, 100th Cong., Title V, part II, sec. 5021, which amended the Defense Production Act of 1950, adding sec. 721.

9 Robert B. Reich "Who Is Us?" Harvard Business Review,
January-February 1990.

10 Raymond J. Mataloni, Jr., "U.S. Multinational Companies: Operations in 1988," Survey of Current Business, June 1990, pp. 31-44.

11 These measures of the characteristics of jobs in U.S. parent companies versus those in their foreign affiliates were put forth by Laura Tyson in her paper, "Us, Them, and Competitiveness," The American Prospect, winter 1990-91. Tyson points out that even in developed countries, jobs in foreign affiliates are not the equal of those in the parent companies, although the discrepancies are not so great. Compensation per employee in developed country affiliates is 90 percent of that in parent companies, and assets per employee, 87 percent.

The comparative data are from Mataloni, ibid.

12 U.S. Department of Commerce, Bureau of Economic Analysis, U.S. Direct Investment Abroad: 1982 Benchmark Survey Data (Alexandria, VA: National Technical Information Service, 1985), tables III.D.1, 111.H.1, and III.Q.1. The data on R\&D spending are for majority-owned affiliates and parent companies of U.S. multinationals; other data are for "non-bank affiliates," which include foreign companies in which a U.S. investor directly owns or controls at least 10 percent of the voting stock (or an equivalent portion in unincorporated enterprises).

13 OTA interview with Jean-Jacques Duby, Group Director, Science and Technology, IBM Europe, Paris, Oct. 8, 1990.

14 Rutter, op. cit.

15 Jeffrey H. Lowe, "Gross Product of U.S. Affiiates of Foreign Companies, 1977-87," Survey of Current Business, June 1990, pp. 45-53; and Russell B. Scholl, "The International Investment Position of the United States in 1990," Survey of Current Business, June 1991, pp. 29, 32. Historical series understate the value of U.S. direct investment abroad, and in comparison overstate the value of foreign direct investment in the United States, as the value of both is measured in book value. This valuation does not capture all the appreciation of investments, and the older an investment, the more likely it is to be undervalued in the official figures. Since for many decades the United States invested more abroad than foreign companies and governments invested here, comparisons of foreign direct investment with U.S. direct investment abroad can be somewhat misleading. However, there are significant inaccuracies in attempting to measure the true value of investments as well. Historical costs are used throughout this report.

16 The investment "position" of a foreign direct investor means its total equity in and net outstanding loans to, its U.S. affiliates. In contrast, the "assets" of an affiliate are equal to the equity of all owners, domestic and foreign, in the affiliate, less all liabilities of the affiliate. "Sales" is, as implied, the sales made by the affiliate in the United States.

17 U.S. Department of Commerce, Bureau of Economic Analysis, Foreign Direct Investment in the United States: Operations of U.S. Affiliates of Foreign Companies, Preliminary 1988 Estimates (Washington, DC: U.S. Government Printing Office, 1990), table A-2.

18 Graham and Krugman, op. cit., p. 13.

19 U.S. Department of Commerce, Bureau of Economic Affairs, Foreign Direct Investment in the United States, Preliminary 1988 Estimates. op. cit., table A-1, and "The U.S. National Income and Product Accounts, Revised Estimates," Survey of Current Business, July 1989 , table $6.6 \mathrm{~B}$.

20 U.S. Department of Commerce, Bureau of Economic Analysis, Foreign Direct Investment in the United States, Preliminary 1988 Estimates, op. cit., table E-8.

21 Wholesaling affiliates handle inventories of manufactured products and their sales and distribution to retailers.

22 U.S. Department of Commerce, Bureau of Economic Analysis, Foreign Direct Investment in the United States, Preliminary 1988 Estimates, op. cit., tables G-6 and A-2.

23 U.S. Department of Commerce, Bureau of Economic Analysis, Foreign Direct Investment in the United States, 1987 Benchmark Survey, 
Final Results (Washington, DC: U.S. Government Printing Office, August 1990), p. 148

24 U.S. Department of Commerce, Bureau of Economic Analysis, Foreign Direct Investment in the United States, Preliminary 1988 Estimates (1990) op. cit., table E-8.

25 Most of these European affiliates were purchased, not built from scratch (e.g., Thomson Consumer Electronics consists of the old RCA consumer products group, which General Electric bought and then sold to Thomson SA.

26 This figure is a good illustration of the caution with which data on foreign direct investment should be treated. It is not so difficult for Americans with any knowledge of business to name a few European chemical companies, but most of us would have troublehïnking of a big Canadian company. Who are the big Canadian chemical companies investing in America? In this case, one is DuPont, the picture of an American company. A Canadian family, the Bronfman family, owns 23 percent of DuPont's stock, however, making it a foreign affiliate. Source: Michael Hodges, "The Japanese Industrial Presence in America: Same Bed, Different Dreams," Millenium, winter 1989, p. 362.

27 For good reason. Honda was considered somewhat of an outsider in Japan, both by other companies and by the Ministry of International Trade and Industry (MITI); its share of the Japanese market was relatively small, while in the United States, Honda cars were becoming the most popular imports. Honda is also very dependent on exports, and was therefore more vulnerable to protectionist moves in other countries. Exports account for 70 percent of Honda's Japanese production. James P. Womack, Daniel T. Jones, and Daniel Roos, The Machine That Changed the World (New York NY: Rawson Associates, 1990), pp. 215-216.

28 James P. Womack and Daniel Roos, "Case Study: The Automotive Industry," contract report for the Office of Technology Assessment, May 13, 1988. The 3 million figure also includes estimated production of 220,000 vehicles in a Suzuki-GM plant in Ontario.

29 John F. Krafcik and John Paul MacDuffie, "Explaining High Performance Manufacturing: The International Automotive Assembly Plant Study," paper prepared for the International Motor Vehicles Program International Policy Forum May 1989.

30 U.S. General Accounting Office, Foreign Investment: Growing Japanese Presence in the U.S. Auto Industry, GAO/NSIAD-88-111, March 1988, p. 33. This is not true of all U.S. parts makers; some are large, integrated companies like Rockwell and TRW, which have experienced engineering staffs. However, the American industry is more characterized than the Japanese or European industries by small firms with little or no ability to contribute to design and manufacturing engineering,

31 General Accounting Office, op. cit., p. 29. Another reason for sourcing major subassemblies like engines and transmissions from abroad is economies of scale, as noted in the GAO report. Because of the level of investment in assembly needed to support a facility for making engines, it maybe more cost effective to increase engine production in existing overseas facilities than to create new capacity to support new assembly transplants.

32 General Accounting Office, op. cit., p. 11.

33 All material about Hoechst's purchase of Celanese is from Robert R. Miller, "The Impact of Merger and Acquisition Activity on Research and Development in U.S.-Based Companies," contract report to the Office of Technology Assessment November 1989.

34 See, for example, Stephen Kreider Yoder, "Kubota Is Sued by Founders of U.S. Firm," Asian Wall Street Journal Weekly, July 16, 1990, p. 9; Christopher J. Chipello and Jacob M. Schlesinger, "Tractor Maker Kubota Is Plowing Funds Into U.S. High-Tech Firms," Asian Wall Street Journal Weekly, July 23, 1990, p. 6.

35 Gina Kolata, "Japanese Labs in U.S. Luring America's Computer Experts," The New York Times, Nov. 11, 1990, p. 1.

36 Kenneth Flamm argues that a small group of Japanese suppliers of dynamic random access memory (DRAM) semiconductors had enough market power in the late 1980s to limit chip production raise prices in the world market and collect extraordinary profits, rather than aggressively compete with each other on price. (It should be noted that, according to some analysts, this behavior was, in effect, sanctioned by the U.S.-Japan Semiconductor Trade Agreement of 1986. Others believe that the trade agreement had little to do with the movements of DRAM prices.) At the same time, the integrated Japanese electronics companies used their chips (for which their cost was much lower than the world price) in their own computers, and began to compete very successfully for the first time in the U.S. personal computer market. See Kenneth Flamm, "Semiconductors," in Gary Clyde Hufbauer (cd.) Europe 1992: An American Perspective (Washington DC: The Brookings Institution 1990), pp. 248-260.

37 The modem debate began in the late 1970s, when some proposed that the United States require a certain percentage of domestic content in cars assembled here.

38 Jean-Christophe de Gouville, "European Carmakers GetReady To Battle the Japanese," Japan Econonic Journal, July 28, 1990, p. 16.

39 Electronic Engineering Times, "Europeans May Miss Own Fab Boom” July 16, 1990.

40 Other measures might include the patenting and licensing activity, and citations to technical articles. Data for these measures are not available for foreign firms investing in the United States.

41 It is possible that virtually all R\&D done by foreign affiliates in the United States is done for, if not by, manufacturing affiliates. However, R\&D intensity of U.S. firms is usually presented in terms of manufacturing $R \& D$ as a percent of manufacturing sales, so the data for foreign affiliates are presented here in the same way, for consistency.

$42 \mathrm{R} \& \mathrm{D}$ intensity may have been unusually low for Japanese manufacturing affiliates in 1987; all R\&D spending, taken as a percent of sales of Japanese manufacturing affiliates, was unusually low that year-1.3 percent, compared to figures as high as 2 percent in other years. However, all R\&D spending as a percent of manufacturing sales was consistently lower for Japanese affiliates than for European affiliates throughout the period 1977-88 (data for manufacturing R\&D, by country, are available only for 1987).

43 Graham and Krugman, op. cit., pp. 58-62.

44 Data for investments in new plant and equipment are not available by country and by industry, so the more comprehensive figure for capital investments-property, plant and equipment-is used. No comparable figure for U.S. manufacturing firms is readily available.

45 Japanese investment in transportation equipment, almost all in greenfield motor vehicle plants, increased fivefold from 1985 to 1988 , rising from $\$ 715$ million (7 percent of all Japanese manufacturing assets in the United States) to $\$ 3.5$ billion (12 percent) in the 3 years. Source: U.S. Department of Commerce, Bureau of Economic Analysis, Foreign Direct Investment in the United States, op. cit., 1985, table B-7 and 1988, table B-5.

46 Tsusho-sangyosho (MITI), Tsusho Hakusho (Commerce White Paper) Heisei 2 nen (1990), 7 gatsu, p. 192.

47 The overseas markets were the United States, the EC, the newly industrializing economies (NIEs), and ASEAN nations. The percentage of respondents citing increased local sales as the main reason for investing exceeded 80 percent in all except the NIEs, where the percentage was between 70 and 75 percent.

48 Tsusho-sangyosho, op. cit., p. 192.

49 This is inferred from the pattern of investment in the United States, rather than from Japanese literature. According to a recent MITI survey of international investors, collecting technology and market information ranked eighth (out of nine) on the list of reasons for investing in the United States, cited by only about 12 percent of respondents. The same motive ranked eighth out of 10 on the list of reasons for investing in the EC (cited by about 18 percent of respondents); ninth of 9 on the list for the ASEAN nations (cited by less 
than 10 percent of respondents); and did not figure in investments in NIEs.

50 "Japanese Investments in Small U.S. High-tech Companies Grow," R\&.D Magazine, September 1990, p. 18.

51 "Nicolet Signs With Matsushita," Electronic Engineering Times, Sept. 24, 1990, p. 2.

52 For example, in a recent article the president of Meitec America, George Leslie, says, “. . .Japanese firms are ideal candidates for strategic partnerships. In fact forging a strategic alliance with a Japanese firm not only can provide an additional source of funding but also can pave the way to Japanese market entry. . ." See George Leslie, "Getting a Read on Strategic Alliances, 'Electronic Engineering Times, Sept. 3, 1990 , p. 35.

53 Ibid.

54 Letter from Senators Jeff Bingaman and Lloyd Bentsen to James F. Rill, Assistant Attorney General, Antitrust Division, U.S. Department of Justice, Sept. 27, 1990. See also Sheridan Tatsuno, "U.S Threatened by Rash of High-Tech Buyouts," New Technology Week, Monday, Aug. 6, 1990, p. 7.

55 For a short description of these arguments, see Tatsuno, ibid

56 U.S. semiconductor manufacturers allege that seven types of semiconductor equipment became available to them 2 to 3 years after delivery to semiconductor firms in Japan. Bingaman and Bentsen, op. cit. In another example, the Manufacturers' Alliance for Productivity and Innovation states in 1990 that intra-keiretsu purchasing patterns allowed Japanese investors sufficient market power to avoid competition from U.S. companies. Source: Phyllis A. Genther and Donald H. Dalton, Japanese Direct Investment in U.S. Manufacturing, International Trade Administration (Washington, DC: U.S. Department of Commerce, June 1990), p. 9.

57 Ibid., p. 17.

58 "U.S. Electronics Strengthens Foothold in Japan," New Technology Week, Monday, Jan. 8, 1990.

59 "Shadow of Suspicion," Far Eastern Economic Review, July 26, 1990.

60 Quoted study was done by Mordechai Kreinin of Michigan State University, and written up in The World Economy, a British Journal.

61 Urban C. Lehner and Alan Murray, "Japanese Buying Binge Stokes U.S. Insecurity," Asian Wall Street Journal Weekly, June 25, 1990, p. 12.

62 Ibid.

63 Tsusho-sangyosho, op. cit., p. 189.

64 Lehner and Murray, op. cit.

65 Graham and Krugman, op. cit., p. 25

66 Rutter, op. cit., p. 15.

67 Tsusho-sangyosho, op. cit., p. 188.

68 James Womack, Massachusetts Institute of Technology, personal communication with OTA staff.

69 Hodges, op. cit., p. 361

70 Throughout the 1980s, Japanese exports of automobiles to the United States have been constrained by a formal VRA and, after its expiration in 1985, an informal pledge. These agreements made it very difficult for Japanese producers to increase exports, and encouraged them to invest in North American production facilities to increase sales.

71 Supposing, for example, that production from the greenfield plants of foreign direct investors substitutes entirely for imports, rather than for output of a domestically owned and located firm. There are always some domestic jobs (e.g., in transportation, warehousing, and sales) associated with imports, so that not all the new jobs involved in making, storing, transporting, and selling the goods from the greenfield plant are net additions to the jobs that would have been associated with imports.

72 Framingham is described as the worst American-owned auto plant. Womack et al., op. cit., p. 85 .

73 Womack et al., op. cit., pp. 82-84.

74 See, for example, Mike Parker and Jane Slaughter, "Management by Stress," Technology Review, October 1988, pp. 36-44.

75 Clare Ansberry, "New Japanese Chief Seeks Turnarmmd at National Steel," Asian Wall Street Journal Weekly, Aug. 6, 1990, p. 23.

76 The high quality attained by the luxury auto manufacturers of Europe is not associated with high productivity and cost control. The mass production auto manufacturers of Europe have no better quality records and substantially worse productivity records than the American Big Three. John F. Krafcik and John Paul MacDuffie, "Explaining High Performance Manufacturing: The International Automotive Assembly Plant Study," paper prepared for the International Motor Vehicles Program International Policy Forum May 1989.

77 David Sheridan, "Worker Displacement in the California High-Tech Industry," contractor report to the Office of Technology Assessment May 1986.

78 Dedra Hauser, "Overseas Employees Favored in Cutbacks," San Jose Mercury News, Oct. 29, 1985, pp. B9-B1O, cited in Sheridan, op. cit.

79 Graham and Krugman, op. cit., pp. 56-57.

80 They are sometimes able to pay a great deal more, however. That would be unlikely in the United States, which generally has higher wages than other countries, but in developing nations, employees of foreign affiliates are sometimes the best-paid workers around.

81 U.S. Department of Commerce, Bureau of Economic Analysis, Foreign Direct Investment in the United States: Operations of U.S. Affiliates of Foreign Companies, various years.

82 John M. Kline, "Trade Competitiveness and Corporate Nationality," Columbia Journal of World Business, fall 1989, p. 29.

83 Womack et al., op. cit., p. 217. Domestic content claims, according to these authors, are "notoriously unreliable," but they judge Honda's claim is "not far off the mark."

84 U.S. Department of Commerce, Bureau of Economic Analysis, Foreign Direct Investment in the United States: Operations of U.S. Affiliates of Foreign Companies, Preliminary 1988 Estimates (Washington DC: August 1990), tables G-3 and G-6.

85 Christopher J. Chipello, "Tractor Maker Kubota Is Plowing Funds Into U.S. High-Tech Firms," Asian Wall Street Journal, July 23, 1990, p. 6.

86 Evidence and arguments for this conclusion are detailed in U.S. Congress, Office of Technology Assessment Paying the Bill: Manufacturing and America's Trade Deficit, OTA-ITE-390 (Springtleld, VA: National Technical Information Service, June 1988).

87 A falling currency dimini shes standards of living by making imports more expensive. In addition, unless all our international debts are denominated in dollars, it also obliges us to work harder to pay our debts to foreign creditors; a falling or volatile currency will also make it harder to obtain dollar-denominated loans.

88 JESSI stands for the Joint European Submicron Silicon Initiative. Ch. 5 has a more extensive discussion of JESSI.

89 Kline, op. cit., p. 30.

90 Graham and Krugman point out that foreign or foreigncontrolled companies cannot acquire gas pipeline rights-of-way or certain mineral leases on Federal land if the investor's home country denies such rights to American firms. Graham and Krugman, op. cit., p. 96.

91 Kline, op. cit., p. 27

92 These exceptions do not necessarily limit defense production solely to domestic firms, however, as the large international trade in 
military equipment attests. For example, the Department of Defense's "buy American" procurement regulations require not that the companies doing its production be American owned or controlled, but that the products involved must have at least a 50 percent U.S. content. The Department of Commerce's trade fairs permit any firm with 51 percent U.S. content in its products assembled or produced abroad to participate, and the U.S. Export-Import Bank will make loans or loan guarantees to anyone whose products have at least a 50 percent U.S. content. Source: Kline, op. cit., pp. 26-27.

93 The Defense Production Act lapsed, temporarily at least, when in the closing hours of the 101st Congress, in October 1990, the Senate failed to adopt the conference report re-authorizing the act, and did not agree to concurrent resolutions passed by the House extending the act.

94 CFIUS members include representatives of the Departments of Commerce, Defense, Justice, and State; the Office of Management and Budget the U.S. Trade Representative, and the Council of Economic
Advisers.

95 Bingaman and Bentsen, op. cit. Information in the letter was based on Dataquest, Inc. figures.

96 For a discussion of options that might be adopted to strengthen such government-industry collaboration, see U.S. Congress, Office of Technology Assessment, Making Things Better, op. cit.

97 Omnibus Trade and Competitiveness Act of 1988, Public Law 100-418, Sec. 5131.

98 U.S. Congress, House of Representatives, Conference Report 101-909 to Accompany HR. 5021, Making Appropriations for the Departments of Commerce, Justice and State, the Judiciary and Related Agencies for the Fiscal Year Ending Sept. 30, 1991, and for Other Purposes, Oct. 20, 1990.

99 See, for example, Kline, op. cit., p. 30. 
Chapter 4

\section{U.S. Trade Policy}




\section{CONTENTS}

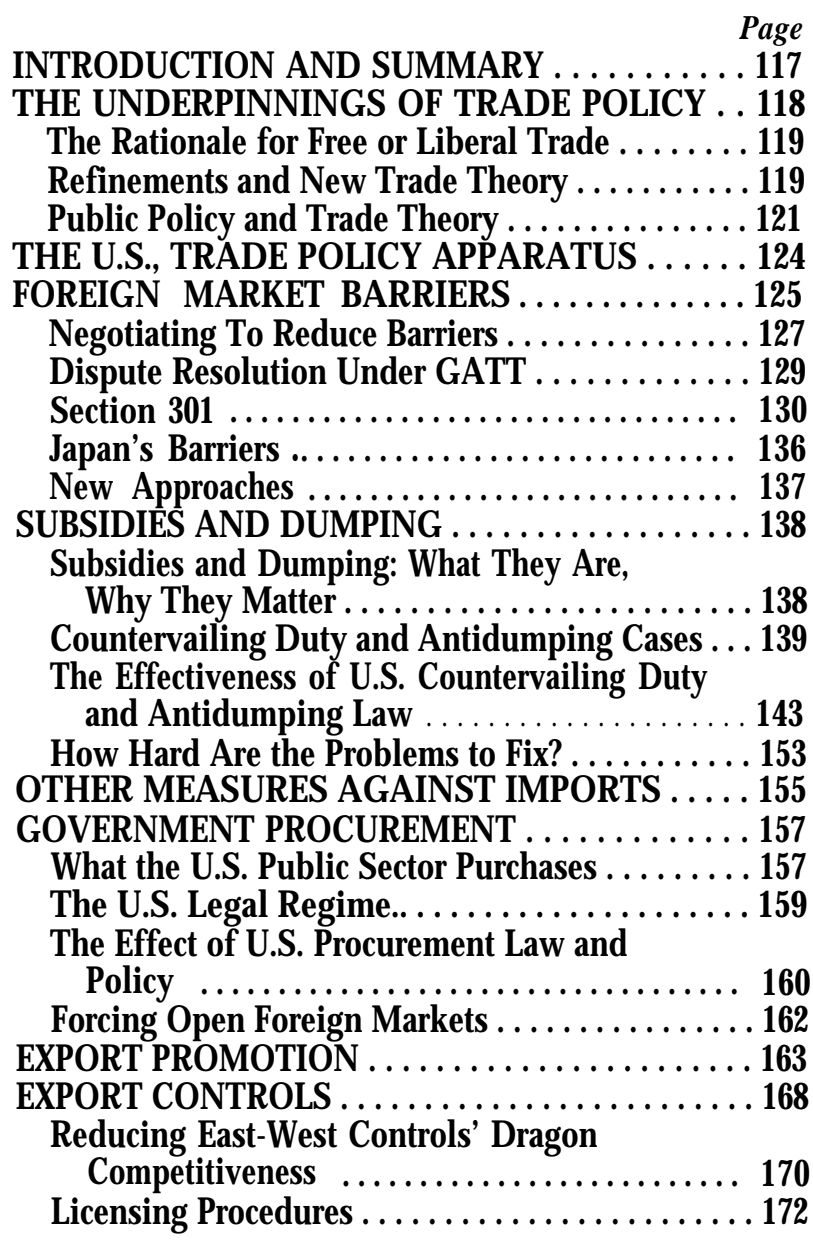

\section{Boxes}

Box Page

4-A. GAIT and the Uruguary Round . . . . . . . . 128

4-B. An Unfiled Dumping Case ............. 146

4-C. East-West and North-South Controls; Cocom and Other Multilateral Export Control Forums
Figures

Figure

4-1. Import Penetration of the Japanese Page Semiconductor Market . . . . . . . . . . . . . . 130

4-2. GATT Dispute Resolution Proceedings, 1947-86 ......................... 131

4-3. U.S. Trade Deficit With Japan and the World, 1983-1990 ...... . . . . . . . . .......*... 136

4-4. New Countervailing Duty Cases Completed, January 1987 Through June 1990 . . . . . . . . . . 140

4-5. New Antidumping Cases Completed, January 1987 Through June 1990 .. ... . . . . . . . . . . . 141

4-6. Decisions in U.S. Countervailing Duty Cases Completed January 1987 Through June $1990 \ldots \ldots \ldots \ldots \ldots \ldots \ldots \ldots \ldots \ldots \ldots . \ldots 144$

4-7.Decisions in U.S. Antidumping Cases Complete\& January 1987 Through June 1990 145

4-8. Government Purchases of All Goods and Durable Goods, 1990 ... . . . . . . . . . . . . . . 158

4-9. Defense Purchases of Durable Goods, 1990, $\$ 83.6$ Billion ................... 158

\section{Tables}

Table Page

4-1. Some International Trade Functions of Some Key Agencies ................... 125

4-2. Summary of Some U.S. Laws Regarding International Trade ................ 126

4-3. Selected Section 301 Cases ... . . . . . . . . . 132

4-4. New Countervailing Duty Cases Completed January 1, 1987 Through June 30, 1990.... . 141

4-5. New Antidumping Cases Completed Jan. 1, 1987 Through June 30, 1990 . . . . . . 142

4-6. Outstanding Measures Against Subsidies as of June $30,1990 \ldots \ldots \ldots \ldots \ldots \ldots$. . . . . . 143

4-7. Outstanding Antidumping Measures as of June $30,1990 \ldots \ldots \ldots \ldots \ldots \ldots \ldots 143$

4-8. Section 201 Cases .. .. .. .. ............... 156

4-9. Purchases of Goods by the U.S. Public Sector in 1990 ..................... 157

4-10. Spending for Export Promotion in 1987..... 164 


\section{INTRODUCTION AND SUMMARY}

Many of the United States' key trading partners, including the European Community (EC), Japan, Korea, and Taiwan, employ diverse tools to enhance manufacturing competitiveness. Tools like R\&D support, infant industry protection, and favorable financing have been used to craft comprehensive trade and industry polices. On the whole, these policies have benefited Japan, Korea, and Taiwan, while posing a competitive challenge to the United States and the EC.

The United States by and large has not imitated the proactive trade and industry policies of its trading partners. U.S. philosophy has been that manufacturing firms should make it on their own in the free market, with minimal help or interference from government. If this country were to modify its philosophy and seek ways in which government could enhance manufacturing competitiveness, two sets of policy tools could be used. The first set concerns the domestic economy. It includes improving education and training; using tax and fiscal policies to encourage long-term investment; costsharing commercially oriented R\&D with industry; and promoting diffusion of best practice technology, especially to small and medium-sized manufacturers. Application could be uniform or selective--e.g., R\&D support for certain technologies or industries. Many of these policies were discussed in Making Things Better' (also see ch. 2).

The second group of policies, examined in this chapter, deal primarily with international trade. U.S. trade policy since World War II has normally sought no advantage for U.S. businesses beyond what they would obtain in a fully open world market. Rather, policy for the most part has tried to reduce, eliminate, or counteract foreign trade practices that distort the free market. The goal has been to ensure that U.S. companies can compete on an equal footing with foreign firms-or, as is sometimes said, to "level the playing field." However, despite substantial progress in reducing quantitative restrictions on trade, this goal has not been fully met. Barriers against U.S. exports may persist for several years before the United States can get them removed. When foreign countries' domestic policies confer advantages on their firms that result in dumped or subsidized U.S. imports, the United States can levy additional duties, called countervailing or antidumping duties, against the imports. These additional duties are intended to eliminate any foreign advantage; however, most often they do not.

The failure of U.S. trade policy to meet its objectives is not so much a result of particular measures taken; the problem is that trade policy has been assigned a role that it cannot reasonably be expected to fulfill. To understand this point, it is necessary to look more closely at what other countries do. Some target their market barriers and domestic policies to promote specific industries, such as semiconductors and computers, that contribute disproportionately to a nation's wealth and economic development, and on which U.S. manufacturing competitiveness depends. Some industries yield a high reward because they have increasing returns to scale and learning and spillover benefits to other industries. Developing such industries is often a race in which whoever gets ahead will likely stay ahead. A company with technical advantages or higher market share can reap greater economies of scale or learning, which will help it capture more market share and finance more $R \& D$ than its competitors, so that it can pull still further ahead.

After World War II, the United States was the world leader in high-reward industries, and in a free and undistorted world market would likely have remained so. However, several other countries assisted their domestic firms, in part by protecting their home markets with tariffs, quotas, and other barriers. A protected home market can increase the domestic industry's market share and development while decreasing opportunities for foreign competitors. Home market protection can further enable the domestic industry to charge cartel prices, thus earning above-normal profits that can boost $R \& D$ programs. Profits in a protected home market can bankroll forays into export markets at low prices. Of course, home market protection can easily go astray, leading to an industry ill-suited for international competition; when managed properly in combination with other policies, however, it can aid a nation's economic development. 
In cases where home market protection has been successful, it has been as part of a more comprehensive strategy that included many domestic programs. This includes both society-wide programs-e. g., first-rate education, encouragement of household savings, and tax breaks for R\&D and capital investment-and industry-specific programs, such as R\&D projects, special tax breaks, preferential financing, and tolerance of cartel pricing in specific industries. By these means, some foreign governments have promoted selected industries to the point where they can earn large profits on their own, without need of government assistance (though assistance often continues).

Other countries' domestic programs and market protection have sometimes damaged U.S. industries. For the most part, U.S. trade policy plays out by noticing some of the advantages foreign firms enjoy, and then trying after-the-fact to eliminate or offset them, usually after substantial delay and often incompletely.

Export policy focuses on foreign market barriers. Where foreign markets are closed to U.S. goods, the U.S. Government can try to get the barriers removed. However, not all barriers can be addressed, and many important ones have taken years to eliminate. Removal of specific barriers is an ineffective solution at best. It takes time and effort to identify barriers; there are so many that some will be missed. And once a barrier is identified, it takes time to negotiate its removal, if it can be removed at all.

Import policy focuses on levying duties to counteract foreign subsidies and dumping. However, the law's approach of precisely compensating for observed subsidies and dumping has limited effectiveness. Identification and quantification of subsidies and dumping is a slow and laborious process. Once duties are in place, dumped or subsidized goods can come into the United States from a new country, requiring another investigation before duties can be assessed on the new goods. The formula to determine a duty that precisely neutralizes the foreign advantage does not fit the reality of modern industrial competition. Probably no formula could.

Other aspects of U.S. trade policy are also less advantageous for U.S. companies than foreign counterparts' policies. While many foreign governments' procurement policies are attuned to fostering national industries, U.S. procurement policy is not. The Commerce Department's export promotion programs, while useful, are overshadowed in funding and effectiveness by similar programs in other countries. Export financing by the Export-Import Bank of the United States is sometimes less attractive than that offered by other countries' export financing agencies. Finally, U.S. export controls for reasons of national security unduly hinder hightechnology exports; while many controls are necessary for national security, some are not.

\section{THE UNDERPINNINGS OF TRADE POLICY}

The conviction that free trade promotes social well-being is a cherished principle of economics and, not coincidentally, of postwar shapers of America's trade policy. The arguments for free trade are powerful, and the prosperity that coincided with the GATT regime, which opened more nations to trade than at any other time in modern history, is usually regarded as convincing evidence of free trade's benefits.

Yet challenges to the free-trade regime continue and are gaining force. There is growing sentiment, especially among business managers, that domestic firms are unable to compete on an equal footing with foreign firms because of the support and protection foreign producers receive from their governments. Such sentiment is found not only in America but in Western Europe as well. According to one analysis, the quest of American industries for relief from import competition through special trade protection is driven partly by recent developments such as the overvalued dollar and high unemployment of the early 1980 s. $^{2}$ In addition to temporary situations that make it difficult to export or compete with imports, companies in the United States and Europe are simply up against some very well-financed and technically sophisticated competitors from Japan and East Asia, many of which have government backing in various forms. The fear of loss of dominance--or even dissolution-is driving interest in various types of trade relief, ranging from outright protection to calls for different forms of managed trade.

Is it time for a new guiding philosophy of trade? Few argue for widespread protection, but there is deep division between those who maintain that free trade invariably yields the greatest benefits and those who believe the time has come for some degree of managed trade. (Whether "some degree' of 
managed trade is a realistic possibility is also in dispute. Critics see any management as the first step on the path to widespread protection.)

Both free trade and managed trade have potential benefits and drawbacks. Even the option of a middle course, with modification of free trade that doesn't fit the nebulous term "managed trade," would require a leap of faith, since evidence supporting any view of the philosophy of trade is equivocal. It should be stressed, as it often is not, that this is just as true of free trade as it is of other courses labeled industry policy, managed trade, and protectionism.

\section{The Rationale for Free or Liberal Trade}

Free trade is attractive for several reasons. One of the most powerful arguments in its favor is that a period of increasing prosperity has coincided withproponents would say it has been caused byinternational market opening. Many analyses attribute the twentyfold increase in trade in manufactured goods and the sevenfold increase in manufactured output to the accomplishments of the GATT.

The theoretical rationale for free trade is based on comparative advantage. Different products require differing amounts of labor, capital, or other resources to produce. Nations are endowed with these resources in different proportions. This combination of differences gives nations specific advantages in producing specific products. Nations like Canada and the United States, generously endowed with softwood forests, have advantages in producing construction lumber, plywood, and linerboard, for example. If nations specialize in producing what they make best, and there is free trade, everyone is better off than if every nation tries to produce the mix of goods it consumes by itself. This straightforward result only applies under certain conditions. These include perfect, or nearly perfect, competition, and no messy complications like barriers to entry (which make it difficult for new companies to enter a market), economies of scale or learnin g effects (which lower the costs of production as the volume of production or experience increase), and externalities (costs that producers do not take responsibility for, or benefits that are not available to them as profits).

One of the earliest and simplest theories developed to explain why nations trade and the consequences thereof was developed by Eli Heckscher and Bertil Ohlin. The Heckscher-Ohlin theory con- ceived of a simplified world with two so-called factors of production (labor and capital), two products whose production requires these factors in different proportions, and two countries with differing abundance of labor and capital. The capital-rich country would have an advantage producing the capital-intensive good, and the country in which labor was plentiful would have an advantage in producing the labor-intensive good. Although in theory it is unlikely that either country would specialize in producing one good to the exclusion of the other, ${ }^{4}$ the Heckscher-Ohlin model showed that if each exported what it was best suited to produce, the welfare of consumers in both countries would be greater than if there were no trade.

In this view, tariffs, once viewed as the classic interference with free trade, are a net loss. While producers of the protected good in the home country may benefit from a tariff and the home country gets some revenue from it, the loss to consumers more

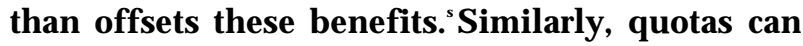
have negative results, as can the host of nontariff barriers that curtail free trade.

This is the standard beginner's guide to the economics of international trade. Like all models, it is built on a number of assumptions, all of which diverge from reality. The important question is how great a divergence exists between these assumptions and the real world. In some cases, the divergence is minor, and the result, free trade maximizing everyone's welfare, is still valid. In other cases, the divergence is significant.

\section{Refinements and New Trade Theory}

Dividing factors of production into just two or three groups is oversimplified. After work in the 1950s by Wassily Leontief showed that the United States, thought to be a relatively capital-rich nation, was exporting goods that were more labor-intensive than those it was importing, a refinement was developed. That is, labor could be segregated by skill intensity, and the U.S. advantage was in producing goods and services especially intensive of skilled labor.

Another oversimplification lay in using factor proportions as the only explanation of comparative advantage. Other factors can give a country an advantage in producing and exporting. Linder ${ }^{6}$ postulated that the size and character of the home market was an important determinant of what a 
country exported; after a product was developed for the domestic market, exports would begin when the domestic market was too saturated or too competitive to offer sufficient expansion or profit opportunities. Vernon and Wells explained trade flows through the product life cycle. The life cycle explanation argued that products would be developed and manufactured for the domestic market and later sold abroad. For the United States, products would be developed with labor-saving characteristics attractive to a relatively affluent customer. As other countries raised their standards of living, their markets would become ripe for American exports, at least until manufacturers in the foreign country learned how to make the product. Over time, as the technology matured and stabilized, countries with lower production costs (one example is lower labor costs) could master production, and the affluent country would lose its advantage and begin to import the product.

Even with these refinements, trade theory was still far from reflecting real-world conditions. By the early 1980s, dissatisfaction with the theoretical basis of America's trade policy was evident even within the economics profession. 'Outside the profession, those concerned about the adequacy of the free-trade prescription and its theoretical basis became better informed and louder. The rise of Japan as an industrial power fueled the debate, for it was manifestly not a free trader, at least during the first three decades after the war, yet its industries were becoming more competitive and its standards of living higher. While economists may never reach a verdict on whether and how Japan's trade policies and its economic prosperity are causally linked, Japan made everybody think more deeply about trade and trade theory.

Developments in trade theory in the late 1970s and 1980s, often termed the new trade theory, have been summed up by saying ". . .conventional trade theory views world trade as taking place entirely in goods like wheat; new trade theory sees it as being largely in goods like aircraft.' In other words, new trade theory permits different outcomes and policy prescriptions for different kinds of goods. So what makes aircraft different from wheat, beyond the obvious physical and utilitarian characteristics?

One of the most obvious differences is in the scale of production. While wheat farming is no longer just a matter of small family farms, there are thousands of wheat farmers, and none is large enough to exert much effect on the market. Aircraft, on the other hand, are produced by a handful of companies. There are two producers of large $(100+$ passenger seat) commercial aircraft in America and another in Europe, and three engine makers for large commercial jets. ${ }^{9}$ There is a broad consensus that the world could not support additional entrants at the level of engine or aircraft assembler. There are more firms at the subassembly levels, but many expect those numbers to shrink. Increasing returns to scale accounts for this imposing structural difference between the two industries. What this means is that compared with wheat farming, making aircraft requires a huge initial investment (typically $\$ 3$ to $\$ 5$ billion to design, develop, and certify a new model), but once it is made, producing one more airplane is relatively inexpensive (\$50 to $\$ 150$ million) .10

There are also increasing returns to scale, up to a point, in wheat farming. In all industries there is a range of increasing returns, and a point where any additional input (e.g., land, labor, capital, or knowledge, singly or in combination) begins to make the production enterprise less efficient. That point, where diminishing returns are gained as the scale of enterprise increases, is reached fairly quickly in wheat farming, so that the most economical scale of enterprise is small enough to allow many thousands of producers. Large commercial aircraft production is at the other end of the scale; increasing returns are still available to Boeing Commercial Aircraft Group, whose customer base is 60 percent of the world market and has been higher. While neither industry is typical, the patterns of world trade suggest that a greater amount of trade is in goods, like aircraft, that have increasing returns to scale over a wide range of production. If government assistance helps firms pull ahead of foreign competitors, scale economies can help keep them there.

Another quality that sets aircraft apart from commodities like wheat is knowledge intensity. All products require some knowledge, at least for efficient high-quality production. But the knowledge embodied in a 747 is far greater than the knowledge embodied in a ton of wheat, and it is much more difficult to master the technology of designing and making an airplane than the techniques for growing wheat. The product cycle approach to explaining trade flows recognized the importance of technology, but it assumed a relatively fixed cycle in which technology is eventually 
diffused from the country of origin to producers in countries with other advantages, such as labor costs. For sophisticated and expensive technology such as in airplanes, diffusion could be slow, difficult, and expensive.

Externalities complicate classic models of trade, too. Also called spillover effects, externalities are benefits or costs of a business or industry that are not captured or borne by the companies involved. Environmental pollution is a classic example of a negative externality; in most circumstances the generators of pollution have not had to bear the total damage or the entire burden of cleanup. One of the most frequently cited positive externalities is $R \& D$. $R \& D$ done by one firm or industry often generates knowledge that other firms or industries can use without paying for it. Positive externalities translate into spillover effects that can benefit the society as a whole. Policies that foster growth of industries with positive externalities can create comparative advantage and produce higher growth in standards of living.

New trade theory combines the ideas of increasing returns to scale and technological advantage, creating a virtuous circle. In industries with these increasing returns, a company with superior technology or greater market share can reap greater economies of scale or learning, which will help it capture additional market share and finance more $R \& D$ than its competitors, enabling it to pull still further ahead. In this way, a firm that starts out ahead can keep increasing its advantage, at least until other entrants that are well-funded and patient enough to weather long periods of loss and learning can make inroads as, for example, Airbus and the Japanese semiconductor producers have done.

\section{Public Policy and Trade Theory}

In industries with increasing returns to scale, significant positive externalities, and high knowledge intensity, there can be a sound economic case for departures from free trade, or protection." Economic models have postulated that it can benefit a nation's balance of trade and standard of living to protect certain kinds of industries under certain circumstances, such as infant industry protection. ${ }^{12}$

More cautious analysts suggest that policies to strengthen the research base (e.g., R\&D tax credits) and encourage pooling of resources (e.g., policies to permit or encourage strategic alliances) would be useful, but that protection or subsidies would lead to a neighbor-beggaring world of retaliation. ${ }^{13}$ This prescription may be more appropriate for technological leaders than for those facing dominant foreign competition. $R \& D$ incentives and encouragement for firms to pool resources may suffice to maintain competitiveness in a country with a well-developed technological base. However, without protection some domestic industries could face crushing competition from foreign firms whose technological superiority (perhaps attained through subsidies and protection by their own government) makes their production costs much lower.

It is hard to prescribe policy for trade in the real world. Ever since World War II, the United States has maintained a strong interest and belief in free trade. As the principal architect and (until recently, perhaps) greatest proponent of the General Agreement on Tariffs and Trade (GATT), the United States regards itself as the world's standard bearer for open markets and reasonable, unrestrained competition. While its market is still one of the world's most open, the United States' image as a staunch free trader is fading; as its industries become less competitive, the United States protects them more. The United States is only one culprit in what many regard as a watershed-some might even say a crisis-for GATT and the principle of free trade. Preeg cautions that "[t]he GATT multilateral system is. . .at the greatest risk of being overtaken by events. 14

What events? One is an increasing tendency for nations to negotiate quotas bilaterally or among trading blocs or customs unions. GATT has recorded over 200 quota arrangements that restrict industrialized countries' imports in products such as textiles and apparel, steel, motor vehicles, semiconductors, machine tools, footwear, and consumer electronics. ${ }^{15}$ These arrangements include the proliferation of voluntary restraint agreements (VRAs) that restrict trade between two nations. An example is the VRA between Japan and the United States in which Japan agreed to limit its exports of motor vehicles to the United States, from 1.76 million units in 1981 to 1.94 million units in $1985 .{ }^{16}$ Another kind of restriction is represented by the Multifiber Arrangement (MFA), by which signatories agree to quotas on trade in textile and apparel products. Different countries and regions set their own quotas, which limit how fast imports in covered areas can grow. ${ }^{17}$ Although done under GATT auspices and legal by 
GATT standards, the MFA represents an accommodation of GATT principles to reality rather than a change in GATT philosophy.

Another possible threat to the GATT is regionalism. The GATT stresses nondiscrimination -treating all trading partners the same and providing to all signatories most-favored-nation (MFN) status. ${ }^{18}$ This principle may be eroding as more nations with geographic or other ties negotiate special trading arrangements. The recent U.S. Free Trade Agreements with Canada and Israel, and Europe's Single Market Act are recent examples; more are possible, including a North American free trade agreement (FTA) and one between Australia and New Zealand. Not all these regional arrangements are inconsistent with the spirit of GATT: the U.S.-Canada FTA and the contemplated AustraliaNew Zealand FTA are viewed as building blocks for broader trade liberalization. ${ }^{19}$ The European Community is a bit more of a puzzle. While many expect unification to open the market, the murky signs now available indicate that EC policies are more likely to open opportunities for investment in Europe than for exports to it. For some products, especially motor vehicles, the effect is to restrict trade with Japan.

Finally, some analysts see industrial policies as challenges to flee trade. Nations use a variety of methods to support and nurture firms that are regarded as essential to national well-being. Nearly all use some means to assure domestic production of armaments and other goods vital to national security, and many promote the growth and development of economically strategic industries. The policies can range from outright protection for infant industries to policies whose protectionist intent is far more subtle and often unclear. For example, the laws and practices governing distribution of goods from wholesalers to retailers in Japan are often viewed as an effective form of protection against imports, as are public procurement of telecommunications equipment and services in Europe and Japan and U.S. national security requirements stipulating that some goods be purchased from domestic suppliers. Whether such policies are actually intended to protect domestic industries and companies is a topic for endless disagreement. But in fact, industrial policies often discourage imports, because nations often implement industrial policy to help their own industries catch up to the world's leaders. Even policies designed to accelerate development in new technologies, such as high-definition television (HDTV), often have overtly protectionist overtones. The fact that the United States and the EC, both behind Japan in developing HDTV systems, are debating adoption of non-Japanese HDTV standards is an indication. ${ }^{20}$

In short, no nation has an unblemished record of playing strictly by free trade rules. To the extent that the free-trade analyses of the gains from trade and penalties of protection are correct, increasing protectionism is a problem. There is a large class of goods-commodities or other unspecialized products -contributing about the average to value added, productivity, or knowledge, with relatively stable and widely available production technologies. This class probably includes most agricultural products and industrial goods such as toys, apparel and textiles, many chemicals, lumber and plywood, footwear, iron and steel, and a lot of industrial machinery. It is unlikely that significant sustained trade protection in these industries would benefit more than a narrow segment of society. This does not mean there is never a case for protection in such industries. Many nations-in fact, most industrialized nations-protect their steel, apparel, textile, and lumber industries; protection of agriculture borders on legendary.

Nations protect agriculture in part because of a deeply rooted conviction that it is unwise to depend on other nations for food, at least for the primary dietary staples. While most nations want to maintain friendly, or at least civil, relations with most others, none wants to be a hostage to the whims of another government in order to feed its citizens. This threat is remote, for little other than open aggression is likely to cause other nations to cut off food exports en masse (as most of the world has done recently to Iraq). But while a rational analysis might show that the vulnerability created by depending on imports for the bulk of one's food is not great, the penalty in the event of a worst-case incident is heavy; the popular consciousness often equates it with a loss of sovereignty.

One reason to protect mature industries such as steel and textiles is to ease adjustment. The traditional economic model says little about mobility of labor and capital, assuming that if an industry shrinks because its advantage declines then its workers and capital will migrate to industries with more advantage. Full employment is assumed, and the pain of the migration is mentioned only in 
passing, if at all. Adjustment rarely works this way, even when unemployment is low.

Several things complicate the neat economic model. Both labor and capital may be less mobile than we would wish. Displaced workers, particularly the unskilled and semiskilled, typically undergo long periods of unemployment before finding new jobs, and most take a cut in pay and benefits when they do find new employment. According to the latest information from the Bureau of Labor Statistics, over half ( 55 percent) of workers displaced from Ml-time jobs had lower incomes when they were reemployed, most because their wages were lower in new full-time employment and some because their new jobs were part-time. 21 Moreover, displacement and reemployment often involves loss of important benefits; Podgursky and Swaim report that 29.4 percent of all reemployed blue-collar workers and 20.8 percent of reemployed white-collar workers had group health insurance in their old jobs but not in their new ones. ${ }^{22}$ In the worst cases, dislocation has wider effects; downturns in industries have resulted in long-lasting economic disability for communities or regions. West Virginia's economy never recovered from the downturn in the coal industry in the 1950s, despite attempts to mitigate its poverty and unemployment.

Capital is not easily or painlessly mobile either. While it is not difficult to move money around, by shifting investments in a portfolio, for example, capital equipment may be specialized, and loss of competitiveness in an industry may result in scrapping of plant and equipment before their useful lives expire, or before they are fully depreciated. This kind of loss hardly compares to the trauma faced by workers and families confronting plant shutdowns or job losses, but it is a loss nonetheless.

If the adjustment period is long enough, and everyone accepts the need for industry downsizing, much of the pain of adjustment can be mitigated or avoided. But if it is rapid, resulting in the loss of significant capacity in only a few years, there can be considerable upheaval for workers, families, businesses, and communities. Moreover, during contraction, it is often difficult to distinguish competitive subsectors from candidates for dissolution. For example, while we think of the apparel and textile industries as sectors in which America has no particular advantage, parts of both industries are still competitive. Industrial and household textiles do not face the same competitive pressure from imports as apparel textiles, and many of these companies can continue in business profitably. But many of the firms are integrated, producing both. If part of a company's business faces collapse, it becomes difficult for the other part to obtain the capital, workers, and other resources.

While the beneficiaries of such protection are invariably many fewer than the number of people who pay, costs are limited if the protection is also limited in time and scope. Like the rationale for free trade, this often looks better on paper than in real life. In fact, governments seldom cut the lifeline that protection provides. Protection has continued for decades in textiles and apparel; there are few signs that the United States is prepared to end it, or that the industry could avoid further dislocations if all protection ended.

Political considerations aside, there is widespread agreement that industries that do not contribute disproportionately to the national storehouse of knowledge and productivity and that do not have increasing returns to scale over a wide range should receive little if any protection. There is less agreement at the other end of the industrial spectrum, but a fair economic and a powerful political case can be made for including trade policy in the toolkit of measures to promote industrial development. Such protection has been used in countries that wished to jump-start their economic development. Japan and Korea, for example, have protected many developing industries and compiled a successful record in developing industrial competitiveness and technical competence in the rarefied atmosphere of domestic protection. 23 In the United States, however, consideration of infant-industry protection has been halfhearted at best, partly because of a strong conviction of the merits of free trade, and partly because high-reward industries developed and flourished here before anywhere else. The situation is different now.

The United States retains great technological strengths, but U.S. manufacturing in general and many high-tech industries in particular are moving ahead less rapidly and surely than many of their best competitors, including Japanese and some European companies. In microelectronics, Japanese manufacturers dominate world markets and technology development in many products, starting with DRAM chips in the early 1980s. Japanese manufacturers 
have challenged the American lead in computers throughout the market, from laptop PCs to supercomputers, and few believe that they have reached their limit. After having pioneered scientific work in superconductivity (a technology that could contribute to many industrial products but is still mostly in the research stage), Americans and Europeans have watched Japanese companies take solid steps to incorporating superconducting materials in commercial products. And in high-resolution television, American companies have been mostly spectators in a game that involves European companies and governments struggling to catchup to the Japanese. Never before in modern history has the country been behind in developing high-technology industries, or more uncertain of its own ability to compete without greater government involvement.

Those who see a place for infant-industry protection believe it should be limited. A recurring allegation is that countries continue infant industry protection long past the point of true vulnerability, which hurts not only foreign competitors but also domestic consumers and downstream industries. In principle, infant industry protection puts an industry on its feet, at which point it should fend for itself. That point is undefined, however, and we know from experience that life support systems are easier to start than to stop. Another problem, in the United States, at least, is that there is no political institution capable of or charged with identifying high-reward industries that need protection to start. Congress lacks the time and depth of knowledge to make such choices, and few trust existing public-sector institutions to choose wisely. If the United States does depart from its traditional policy to open trade in all circumstances, and pursues policies that proactively support U.S. industrial competitiveness, the country will likely need new government institutions and new relationships between government and the private sector (see ch. 2 for further discussion of this point).

\section{THE U.S. TRADE POLICY APPARATUS}

No one government agency has overall responsibility for U.S. trade policy. Table 4-1 lists the major players. International negotiations on trade issues are led by the Office of the United States Trade Representative (USTR), located within the Executive Office of the President. The USTR's main mission is to achieve greater access to foreign markets for U.S. goods, services, and investment. In setting negotiating priorities, the USTR consults with other agencies, Congress, and business. The USTR negotiates bilateral and multilateral treaties and investigates alleged foreign market barriers under Section 301 (and related sections) of the Trade Act of 1974, as amended. ${ }^{24}$

The Commerce Department investigates allegations that imported goods are dumped or subsidized; conducts export promotion programs; and, with input from other agencies, interprets and enforces the export control laws. It studies competitive developments in U.S. and foreign industries. and advises the USTR and other agencies on the environment that U.S. industries need to stay competitive.

The International Trade Commission (ITC) studies the health of U.S. industries and the effect of imports on them. The ITC evaluates the injury (or threat of injury) to U.S. industries that petition for protection from dumped or subsidized imports, or from imports under Section 201 (and related sections) of the Trade Act of 1974, as amended. ${ }^{25}$

The Defense, Energy, State, and other departments advise the USTR, the Commerce Department, and other agencies about how trade policy could affect their interests. These departments assist the Commerce Department in interpreting and enforcing export controls, and the State Department leads negotiations regarding export controls. The Defense Department makes agreements with other countries regarding defense trade. The Export-Import Bank of the United States (Eximbank) helps companies get export financing.

The Agriculture Department supports agricultural trade (including export promotion and export financing), administers price support programs, studies the business condition of U.S. agriculture, and acts as agriculture's advocate within the government.

U.S. firms and industries can seek help from the government under various trade laws. Table 4-2 summarizes some of these laws, showing when they can apply, what agencies are involved, what relief can be obtained, and the usual costs to use the laws. The first law, Section 301, is concerned primarily with exports. Under Section 301, firms can complain about any "act, policy, or practice' by a foreign country that "is unreasonable or discriminatory and 
Table 4-I-Some International Trade Functions of Some Key Agencies

\begin{tabular}{|c|c|}
\hline Agency & Function \\
\hline \multirow[t]{2}{*}{$\begin{array}{l}\text { Office of the United States Trade } \\
\text { Representative (USTR), in the } \\
\text { Executive Office of the President }\end{array}$} & $\begin{array}{l}\text { Conducts most international negotiations, with assistance } \\
\text { from other agencies (negotiations usually are aimed at } \\
\text { increasing access to foreign markets). }\end{array}$ \\
\hline & $\begin{array}{l}\text { Investigates allegations of unfair foreign trade practices (most } \\
\text { often foreign trade barriers) under Section } 301 \text {. }\end{array}$ \\
\hline \multirow[t]{4}{*}{ Department of Commerce } & Investigates allegations of subsidies and dumping. \\
\hline & Conducts export promotion programs. \\
\hline & Has lead role in specifying and enforcing export controls. \\
\hline & $\begin{array}{l}\text { Studies and advises on competitiveness of particular indus- } \\
\text { tries. }\end{array}$ \\
\hline \multirow[t]{2}{*}{$\begin{array}{l}\text { U.S. International Trade Commission } \\
\text { (ITC) }\end{array}$} & $\begin{array}{l}\text { Determines whether U.S. industries are injured as required for } \\
\text { relief under the laws regarding subsidies and dumping and } \\
\text { under Section } 201 \text {. }\end{array}$ \\
\hline & $\begin{array}{l}\text { Studies and advises on the competitiveness and health of } \\
\text { particular U.S. industries, including the effect of imports. }\end{array}$ \\
\hline \multirow[t]{2}{*}{ Department of Defense } & $\begin{array}{l}\text { Assists Department of Commerce in specifying and enforcing } \\
\text { export controls. }\end{array}$ \\
\hline & $\begin{array}{l}\text { Makes agreements with other countries regarding defense } \\
\text { trade. }\end{array}$ \\
\hline Department of State & $\begin{array}{l}\text { Assists Department of Commerce in specifying and enforcing } \\
\text { export controls; leads international negotiations regarding } \\
\text { export controls. }\end{array}$ \\
\hline Department of Energy & $\begin{array}{l}\text { Assists Department of Commerce in specifying and enforcing } \\
\text { export controls. }\end{array}$ \\
\hline $\begin{array}{l}\text { Export-Import Bank of the United } \\
\text { States (Eximbank) }\end{array}$ & Helps firms to obtain financing for exports. \\
\hline \multirow[t]{5}{*}{ Department of Agriculture } & Conducts export promotion programs for agriculture. \\
\hline & $\begin{array}{l}\text { Leads many international negotiations regarding trade in } \\
\text { agriculture. }\end{array}$ \\
\hline & Collects and disseminates agricultural trade data. \\
\hline & Helps business to obtain financing for agricultural exports. \\
\hline & Administers price support programs for agriculture. \\
\hline
\end{tabular}

SOURCE: Office of Technology Assessment, 1991.

burdens or restricts United States commerce. ${ }^{126}$ Usually the complaint concerns a foreign market barrier. Under Section 301, the U.S. Government can negotiate with the country concerned to remove the barrier. If the negotiations are unsuccessful, the United States can retaliate by imposing its own barriers against goods or services from that country.

The other trade laws listed in table 4-2 concern imports. Two of these laws focus on subsidized and dumped imports. Subsidized imports are those for which the foreign producer or exporter receives a subsidy from its government. Dumped imports are those sold for less than "fair value." U.S. firms can complain to the Commerce Department and the ITC about subsidized or dumped imports. If the Commerce Department finds subsidies or dumping, and if the ITC finds that the subsidized or dumped imports have caused or threatened material injury to the U.S. industry, additional duties (called countervailing or antidumping duties, respectively) normally will be levied on the imports.

Finally, under Section 201 a U.S. industry can petition for relief from any increased imports that cause or threaten serious harm. The ITC determines whether the injury requirement is satisfied and, if so, recommends relief. However, the President ultimately decides what, if any, relief to grant.

\section{FOREIGN MARKET BARRIERS}

A major goal of U.S. trade policy is to reduce or eliminate obstacles to the sale of U.S. goods in foreign markets. However, despite U.S. efforts many barriers exist. While the United States itself limits some imports, the country is still one of the world's most open markets, and on the whole U.S. exports 
Table 4-2-Summary of Some U.S. Laws Regarding International Trade

\begin{tabular}{|c|c|c|c|c|c|}
\hline Name of law & $\begin{array}{c}\text { Sections of Title } 19 \\
\text { U.S. Code }\end{array}$ & $\begin{array}{l}\text { Agencies } \\
\text { responsible }\end{array}$ & $\begin{array}{c}\text { Action } \\
\text { complained about }\end{array}$ & $\begin{array}{l}\text { Nature of } \\
\text { relief granted }\end{array}$ & $\begin{array}{l}\text { Approximate cost to } \\
\text { petitioner in } 1988^{\mathrm{a}}\end{array}$ \\
\hline Section $301^{b}$ & $2411-2420$ & $\begin{array}{l}\text { USTR investigates and de- } \\
\text { termines any retaliation } \\
\text { subject to presidential } \\
\text { direction. }\end{array}$ & $\begin{array}{l}\text { Violations of a trade agree- } \\
\text { ment, or other unreason- } \\
\text { able foreign trade prac- } \\
\text { tices that restrain U.S. } \\
\text { commerce (usually some } \\
\text { form of foreign market } \\
\text { barrier). }\end{array}$ & $\begin{array}{l}\text { Negofiation's to get fóreign } \\
\text { practice stopped, } \\
\text { backed by threat of } \\
\text { retaliation. }\end{array}$ & $\$ 54,700-\$ 305,400$ \\
\hline $\begin{array}{l}\text { Countervailing } \\
\text { Duty Law }\end{array}$ & $\begin{array}{l}303,1671-1671 \mathrm{~h}, \\
675-1677 \mathrm{k}\end{array}$ & $\begin{array}{l}\text { Department of Commerce } \\
\text { determines subsidies. } \\
\text { ITC determines injury. }\end{array}$ & $\begin{array}{l}\text { Foreign subsidies on im- } \\
\text { ported goods, injuring } \\
\text { or threatening to injure } \\
\text { a U.S. industry. }\end{array}$ & $\begin{array}{l}\text { Countervailing duties equal } \\
\text { to the computed } \\
\text { subsidy. }\end{array}$ & $\begin{array}{l}\$ 138,100-\$ 399,400 \text { for initial in- } \\
\text { vestigation and ruling. } \\
\$ 68,300-\$ 106,700 \text { for first court } \\
\text { appeal (to Court of interna- } \\
\text { tional Trade), if taken. } \\
\$ 35,000-\$ 50,000 \text { for second court } \\
\text { appeal (to Court of Appeals for } \\
\text { the Federal Circuit), if taken. } \\
\$ 43,900-\$ 147,200 \text { for each sub- } \\
\text { sequent annual administrative } \\
\text { review, if held. }\end{array}$ \\
\hline Antidumping Law & 1673-1677k & $\begin{array}{l}\text { Department of Commerce } \\
\text { determines dumping. } \\
\text { ITC determines injury. }\end{array}$ & $\begin{array}{l}\text { Dumping of foreign goods } \\
\text { in the U.S. market, in- } \\
\text { juring or threatening to } \\
\text { injure a U.S. industry. }\end{array}$ & $\begin{array}{l}\text { Antidumping duties equal } \\
\text { to the amount by which } \\
\text { the goods are dumped. }\end{array}$ & $\begin{array}{l}\$ 151,000-\$ 553,300 \text { for initial in- } \\
\text { vestigation and ruling. } \\
\$ 50,000-\$ 83,000 \text { for first court ap- } \\
\text { peal (to Court of International } \\
\text { Trade), if taken. } \\
\$ 30,000-\$ 37,500 \text { for second court } \\
\text { appeal (to Court of Appeals for } \\
\text { the Federal Circuit), if taken. } \\
\$ 42,000-\$ 168,900 \text { for each sub- } \\
\text { sequent annual administrative } \\
\text { review, if held. }\end{array}$ \\
\hline Section $201^{\mathrm{b}}$ & 2251-2254 & $\begin{array}{l}\text { ITC determines injury and } \\
\text { recommends relief. } \\
\text { President determines } \\
\text { relief. }\end{array}$ & $\begin{array}{l}\text { Increased imports that } \\
\text { cause or threaten seri- } \\
\text { ous injury to a U.S. } \\
\text { industry. }\end{array}$ & $\begin{array}{l}\text { Protection in almost any } \\
\text { form, and/or adjust- } \\
\text { ment assistance. }\end{array}$ & $\$ 202,000-\$ 566,000$ \\
\hline
\end{tabular}
relief. ous injury to a U.S. form, and/or adjustThe cost estimates are taken from a 1988 survey by the General Accounting Office of 29 tradelawyers. U.S. Congress, GeneralAccounting Office, International Trade: Pursuit of Trade Remedies by Small Business, NSIAD-89-69BR (Gaithersburg, MD: U.S. General Accounting Office, Dec. 1, 1968), pp. 6,6-11, 13,23. Each attorney was asked to give a lower and upper bound for the cost of each type of case. Each minimum value shown in the table is the average of the minimum values given by each attorney; similarty, each maximum value in the table is the average of the attorneys' individual maximums. When an attorney in a particular instance gave an indeterminate lower or upper bound, that attorney was not included in the average. "Because most indeterminate values tended to be large values for the upper bound, [the] average cost ranges tend to understate the actual costs of pursuing the remedy." lbid., p. 6 . These cost estimates do not indude employee time devoted to the case. GAO noted (pp. 23-24) that its cost estimates were comparable to rough estimates by Professor John Jackson in "Perspectives on the Jurisprudence of International Trade: Costs and Benefits of Legal Procedures in the United States," University of Michigan Law Review, April-May 1984, pp. 1570-1587.

bof the Trade Act of 1974, Public Law 93-618, as Amended.

SOURCE: Office of Technology Assessment, 1991, and references cited. 
face more obstacles than U.S. imports. As well as immediately worsening the U.S. balance of trade, foreign market protection can help foreign industries pull permanently ahead of their U.S. counterparts, often in high-reward sectors such as semiconductors and computers. Such barriers put the United States at risk of losing industries important for its wellbeing.

\section{Negotiating To Reduce Barriers}

Traditionally, the most important obstacles to international trade have been quotas (limits imposed by a country on how much or how many of a product may be imported into that country) and tariffs (taxes on imports levied by the importing country). In general, GATT has prohibited quotas for 40 years, ${ }^{27}$ though there are some important exceptions. ${ }^{28}$ Tariffs have been greatly reduced through a series of GATT negotiating rounds, with substantial leadership from the United States (see box 4-A). The United States has pursued lowering of tariffs by other means, such as the 1989 U.S.-Canada Free Trade Agreement, which, among other things, will gradually eliminate tariffs between these two countries.

As quotas have been largely eliminated and tariffs greatly reduced, other barriers have assumed more importance. These include burdensome and slow customs procedures, limitations on the activities of foreign-owned fins, discriminatory regulations, government procurement practices that favor domestic firms, and the inclination not to buy foreign products. These barriers can be overt or hidden, and can result from government action, private action, or a combination of the two. Collectively, these obstacles are sometimes called nontariff barriers. ${ }^{29}$

Nontariff barriers are often tightly bound up with domestic policies and are therefore harder to remove than tariffs or quotas. Despite its success in reducing tariffs and removing quotas, GATT has had more difficulty in reducing nontariff barriers. Accordingly, the United States has looked beyond GATT to eliminate these impediments.

Each year the United States conducts many bilateral negotiations to eliminate particular nontariff barriers. ${ }^{30}$ The USTR sets negotiating priorities primarily based on cases' political importance, as communicated by industry, Congress, the press, and other executive departments. The USTR's negotiating priorities generally have not been based on an assessment of which industries have the most strategic importance for the nation.

These bilateral negotiations have often succeeded in reducing or eliminating market barriers. However, often many years elapse without results. One example concerns how Taiwan assessed the value of imports for the purpose of levying percentage rate tariffs. Taiwan determined the value of imported goods by administrative rulings rather than by using the invoice price. By its nature, this approach tempted government officials to set values high. In 1979, Taiwan, in an agreement with the United States, obliged itself to switch over to valuing goods based on the invoice price by January 1, 1986. However, by August 1, 1986, Taiwan had not done so. ${ }^{31}$

Another example involves semiconductors. Despite several agreements by Japan to remove market barriers to semiconductor imports, the U.S. producers' share of the Japanese market stayed at about 10 percent from 1973 to $1988 .{ }^{32}$ This happened even though U.S. chips were competitive (especially during the first half of the period), as shown by the large market shares U.S. companies had in the rest of the world.$^{33}$ In September 1986, to settle a Section 301 case brought by the Semiconductor Industry Association, Japan promised to make certain efforts to increase market access. The Japanese Government professed that it "strongly support[ed]" expanded trade, stated that Japanese firms anticipated "substantially increased' purchases of foreign semiconductors, and agreed that 'the expected improvement in access should be gradual and steady' over the agreement's 5-year term. ${ }^{34}$ During the negotiations, the United States argued that if Japan's market were truly open, non-Japanese firms would capture at least 20 percent of it. In a confidential side letter to the U.S. negotiators, the Japanese Government stated that it "understood, welcomed, and would make every effort to assist" reaching the goal of 20-percent import penetration by August 1991, when the agreement expired. ${ }^{35}$

However, in the months after the agreement, despite a falling dollar, U.S. sales rose little. On March 31, 1987, the U.S. Government found Japan's efforts to increase market access "inadequate," and on April 17 President Reagan levied punitive tariffs on certain personal computers and power hand tools from Japan..$^{37}$ In response, MITI encouraged Japanese firms to purchase more U.S. semicon- 


\section{Box 4-A-GATT and the Uruguay Round}

GATT (the General Agreement on Thrills and Trade) is both an international agreement and an international organization. Its origin traces to the 1944 Bretton Woods Conference, which launched the World Bank (International Bank for Reconstruction and Development) and the International Monetary Fund. While the conferees did not consider trade issues as such, they went on record as recognizing the need for a third international organization to deal with trade. A charter for such an organization, called the International Trade Organization (IT0), was drafted and refined, under U.N. auspices, starting in 1946, culminating in the Havana Charter in 1948. However, the U.S. Congress would not ratify the Havana Charter; as the United States was then the world's preeminent economic power, other countries declined to form an ITO without the United States.

However, the President could ratify on his own, within a previous delegation of authority by Congress, a watered down agreement called the General Agreement on Tariffs and Trade (GATT. The difference was that GATT on its surface was just an agreement; it did not explicitly call for the creation of an international organization. For example, GATT's language does not provide for a general assembly or standing committees, but merely refers to the "contracting parties" acting in concert. Originally intended as a temporary measure until the United States endorsed an ITO, GAIT has provided the legal framework for trade among nations for over 40 years. In fact, the member countries did form an organization to carry out GATT's business. However, GATT has the flavor of a loose, hastily arranged outfit, reminiscent of the Articles of Confederation that preceded the U.S. Constitution. A key weakness is GATT's set of procedures for resolving disputes under its provisions, in which any country can, in effect, veto any ruling against it.

GAIT's primary mission has been reduction of trade barriers. With some exceptions, GATT immediately prohibited quotas. ${ }^{2}$ From 1947 to 1979, GATT reduced tariffs in negotiating rounds through which countries would negotiate reciprocal lowering of tariffs. Each country, in return for concessions by others, would bind its tariffs for specified goods at certain rates. Each tariff concession granted to one country had to be granted to all member countries. Tariffs were greatly reduced by this process, leaving in 1979 an average tariff of only 4.7 percent for nonprimary products (products other than ores, timber, and the like) imported into industrial countries.

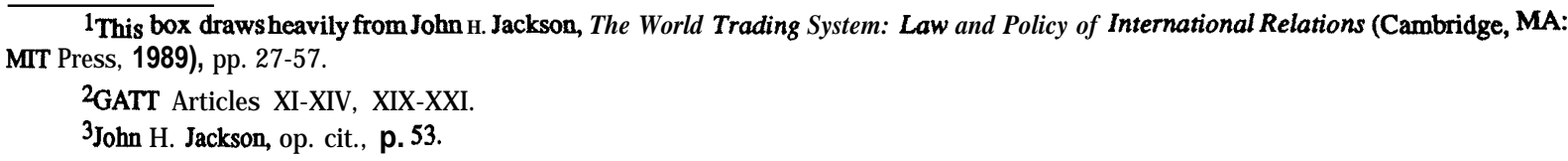

ductors and to develop long-term relationships with U.S. suppliers similar to those with Japanese suppliers. As a result, U.S. market share rose from 10.2 percent in 1988 to 11.0 percent in 1989 and 12.3 percent in 1990 (figure $4-1$ ). ${ }^{38}$ The total imports' market share was larger, 11.9 percent in 1989 and 13.2 percent in $1990 .^{39}$ The first quarter of 1991 shows no further increase. ${ }^{40}$ This was still far behind the progress envisioned by the U.S. negotiators in the 1986 agreement: steady growth to 20 percent by August 1991. A new agreement, in effect from August 1991, has set a target of 20 percent by the end of $1992 .^{41}$

Supercomputers provide yet another example. Since 1976, the Japanese Government heavily favored Japanese firms in its purchases of supercomputers, buying almost no U.S. machines even though they were generally superior. ${ }^{42}$ Cray Research, Inc., the first firm to sell supercomputers, sold the first one in 1976. The Japanese Government did not purchase supercomputers until 1983, when Japanese supercomputers were first available. Negotiations began in 1985; in August 1987 Japan agreed to make its procurement process more open to foreign firms, through, for example, improved announcement of upcoming procurements. 43 However, the Japanese Government continued to favor Japanese firms and bought very few U.S. machines. The government did this through a variety of means, such as a method of evaluating performance structured to favor Japanese machines, ${ }^{44}$ In June 1989, the USTR lauched a Section 301 investigation, with the threat of retaliation if the Japanese Government's practice did not change. In June 1990, a second agreement was reached addressing performance measures and several other procurement issues. 45 This agreement may have come too late to be of much help to the U.S. supercomputer industry (see ch. 6). 
In recent years GATT has focused on nontariff barriers, which have become more important as quotas have been eliminated and tariffs lowered To some extent, GATT addressed nontariff barriers from the beginning. For example, GATT's "national treatment" provision requires that a country's internal taxes and regulatory requirements not discriminate on the basis of whether a good is domestically produced or imported. ${ }^{4}$ This provision prohibits explicit discrimination against imports, but leaves open the crafting of laws and regulations that more subtly discourage imports. Optional supplementary agreements called GATT Codes further address nontariff barriers. A Code is effective only between two members who have both signed it. The United States and its major trading partners have signed several important Codes, including those on subsidies, dumping, and government procurement.

While GATT and its Codes have eliminated some nontariff barriers, they have not succeded to the same extent as the effort to reduce quotas and tariffs. Nontariff barriers have been an important focus of the latest GATT negotiating round, the Uruguay Round, which began in 1986 and was scheduled for completion in 1990, but has been extended through 1992. Canada and the EC have proposed replacing GATT with an ITO, but that proposal will be considered only after the Uruguay Round is completed.

The United States' priorities in the Uruguay Round negotiations have included:

1. extension of GATT to require countries to afford certain minimum levels of protection for intellectual property (patents, copyrights, and the like);

2. extension of GATT to cover investment;

3. extension of GATT to cover services;

4. a stronger dispute settlement mechanism;

5. a stronger legal regime to minimize subsidies and dumping;

6. tighter limits on exceptions to GATT's requirements granted to developing countries; and

7. strengthening of GATT's coverage of trade in agricultural products.

This last item, dealing with agriculture, is the top priority of many developing nations; progress on that item is a prerequisite for their consideration of other items.

4GATT Article III.

There are many reasons why it can take a long time to open a foreign market. First, a particular barrier must be identified and verified, and negotiations begun. Even these first steps are sigificant hurdles, given the prevalence of protection and the lean staffing of the USTR's office. Foreign countries can prolong negotiations, demand long transition periods to phase out barriers, and drag their feet on promised changes. Also, when one trade barrier is removed, another might take its place. Ultimately, success in opening foreign markets depends not only on the U.S. Government's diligence but also on its leverage with foreign countries. The United States has two main sources of leverage: dispute resolution under $\mathrm{GATT}^{46}$ and the threat of retaliation under Section 301. Neither is very effective in promptly opening foreign markets.

\section{Dispute Resolution Under GATT}

Under GATT dispute resolution procedures, an aggrieved country must first try bilateral consultations; ${ }^{47}$ if these are unsuccessful, an international panel of experts hears the case. If the panel finds a violation and the GATT Council formally adopts that decision, the offending country must either stop the practice or offer compensation (typically a lessening of barriers on other products); if it does neither, the GATT Council can authorize the aggrieved country to retaliate by erecting protection of equivalent importance against the offending country. ${ }^{48}$

This route has been well traveled. According to one tabulation, from 1947 to 1986, 233 cases came before GATT. ${ }^{49}$ Most of these cases involved industrialized countries (figure 4-2). The United States brought 77 of these cases, with 37 directed at agriculture and 11 at manufactured goods .50

It was often difficult and time-consuming to get and enforce GATT rulings, with the process typically taking a few years and some cases never being resolved. ${ }^{51}$ In the Uruguay Round, the United States has already achieved some success in reducing the time involved. An interim agreement, effective May 1989, made it possible to hear a dispute and get a 
Figure 4-1-import Penetration of the Japanese Semiconductor Market

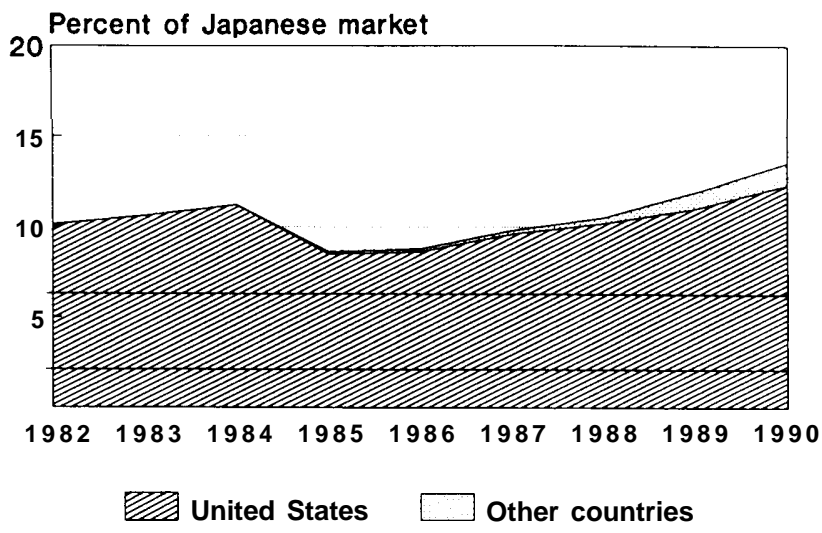

SOURCE: Telefaxed data from the Semiconductor Industry Association, May 29, 1991

decision in about 10 months from the time consultations are requested. However, any country can still block the GATT Council from adopting an adverse decision as an official ruling; the defendant thus has veto power over the tribunal. And even if the GATT Council adopts the decision, a party found in violation can refuse to change or pay compensation, and can even veto any proposed retaliation by the injured country. While the pressure of international opinion can induce a country to accept GATT rulings, it still might stall for months or years.

The United States has done its share of resisting GATT rulings, but nonetheless favors putting dispute settlement on a stronger institutional footing, so that all countries would be bound alike. However, it could well be many years before GATT dispute resolutions procedures provide for speedy, effective removal of market barriers. As long as these procedures are unreliable and while GATT's jurisdiction omits items of concern to the United States, such as services and intellectual property, there will be need for an alternative source of leverage, the threat of retaliation under Section 301.

\section{Section 301}

Section 301 (and related sections) of the Trade Act of 1974, as amended ${ }^{52}$ can address any "act, policy, or practice" by a foreign country that "is unreasonable or discriminatory and burdens or restricts United States commerce. ${ }^{153}$ In 1988, Congress clarified that Section 301 covers at least some government tolerance of private action, specifically "the toleration by a foreign government of systematic anticompetitive activities by private firms or among private firms in the foreign country that have the effect of restricting ... access of United States goods to purchasing by such firms" for reasons other than commercial considerations such as product quality, cost, and service. ${ }^{54}$

Section 301 empowers the USTR to investigate allegations of such foreign practices. If they are found, the USTR will frost negotiate to stop them. If initial negotiations fail, Section 301 requires that GATT's dispute resolution process be invoked where applicable. ${ }^{55}$ As a last resort, if all other measures fail, the USTR may retaliate. Retaliation might consist of increased tariffs or restrictions on specified goods imported from the offending country, whether or not the goods are related to the foreign practice.

From Section 301's enactment in 1974 through 1990, 83 Section 301 cases were initiated. Of these, 35 focused purely on raw and processed agricultural products; 37 in whole or in part on manufactured goods (excluding processed agricultural products and including cases concerning intellectual property); 10 on services; and 1 on investment. ${ }^{57}$

Section 301 has been an important trade tool. Its use has prompted specific reforms by other countries; more generally, the threat of Section 301 retaliation for areas not covered by GATT, such as intellectual property and services, has made other nations more receptive to expanding GATT's coverage to those areas. ${ }^{58}$

However, Section 301 generally has not achieved prompt removal of market barriers to manufactured goods. Table 4-3 lists all Section 301 cases that started in 1985 or later, concerned manufactured goods (excluding food, beverages, and tobacco), and contained a finding by the USTR that there was a foreign market barrier that needed fixing. ${ }^{60}$ Most of these cases have taken many years from the first notice of the problem to achievement of effective relief.

Part of this delay comes from the time limits of the formal Section 301 case. The USTR has 1 year to investigate the alleged practice and negotiate for its elimination (up to 18 months if needed to accommodate a GATT dispute resolution procedure ${ }^{61}$ ) and 7 months before deciding on and applying sanctions. ${ }^{62}$ The USTR often takes the full time allotted, and 
Figure 4-2-GAIT Dispute Resolution Proceedings, 1947-86

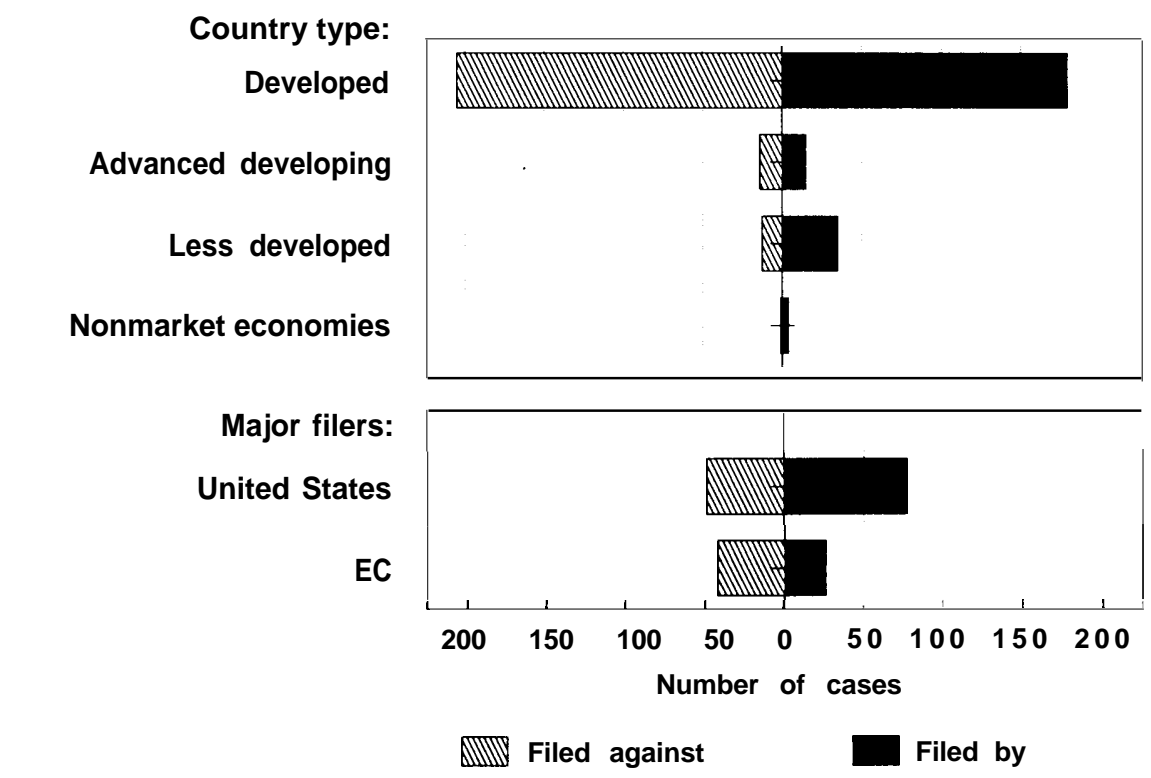

SOURCE: John Jackson, The World Trading System: Law and Polbvof/ntemationa/ Economic Relations (Cambridge, MA: MIT Press, 1989), p. 99.

foreign countries seldom make concessions unless under an imminent deadline with the threat of retaliation.

Overall, however, the longest delays are in initiating an action. Most cases start with a petition from industry for relief. ${ }^{a 3}$ It can be years before a U.S. firm or industry association is convinced that attempts to sell in a particular country are failing not because of cost or quality, but because of market barriers. Even then, a firm or industry association might balk at preparing a petition, given the expense (table 4-2), delay, and uncertain results. The USTR has initiated cases on its own, especially in recent years, ${ }^{64}$ but those actions mostly involved longstanding problems that attracted considerable congressional attention. For example, under the socalled Super 301 provision, the Administration was directed to identify the highest priority offending countries and initiate Section 301 cases on their most important practices. ${ }^{65}$ Cases 74 and 75 in table 4-3, dealing with the Japanese Government's procurement of satellites and supercomputers respectively, stemmed from this process.

Delay can occur after a case is supposedly over. Case No. 52 in table 4-3 concerned Korea's intellectual property protection. Although Korea passed remedial legislation in 1987, many problems remained into 1989.

These long delays arise because the United States is reluctant to retaliate or even start a Section 301 case. Retaliation, unless it ultimately induces the foreign country to change its practice, rarely solves the problems of the complaining U.S. industry. ${ }^{66}$ Retaliatory restrictions on the import of goods from another country would in most cases violate GATT, and the open nature of Section 301 proceedings would instantly expose this violation to the world. And while use of Section 301 does not violate GATT until retaliation occurs, starting an investigation does anger other countries, which perceive Section 301 as an assertion that U.S. law takes precedence over GATT. Such criticism might be somewhat hypocritical: if the target country maintains market barriers, overt or hidden, that could violate at least the spirit of GATT. However, this criticism is a political force to be reckoned with.

Retaliation against a foreign trade barrier would itself be a trade barrier, and could provoke counterretaliation with still more market closures. For this reason sanctions, even as retaliation, are philosophically repugnant to the USTR and the Administration, for whom free trade is a paramount goal. On a 
Table 4-3-Selected Section 301 Cases

\begin{tabular}{|c|c|c|c|c|c|c|c|}
\hline $\begin{array}{l}\text { Case } \\
\text { No. }\end{array}$ & Country & Subject & Prior history & $\begin{array}{l}\text { Date of } \\
\text { petition or } \\
\text { self-initiation }\end{array}$ & $\begin{array}{c}\text { Effective date } \\
\text { and nature } \\
\text { of relief }\end{array}$ & $\begin{array}{l}\text { Subsequent } \\
\text { history }\end{array}$ & $\begin{array}{l}\text { Wait for } \\
\text { relief }\end{array}$ \\
\hline \multirow[t]{4}{*}{48} & \multirow[t]{4}{*}{ Japan } & \multirow[t]{4}{*}{$\begin{array}{l}\text { Semiconductors: issues } \\
\text { including access to Japa- } \\
\text { nese market. }\end{array}$} & \multirow[t]{4}{*}{$\begin{array}{l}\text { Many sets of negotia- } \\
\text { tions on market access } \\
\text { since about 1972; U.S. } \\
\text { firms' market share } \\
\text { stayed roughly constant } \\
\text { at only } 10 \text { percent (far } \\
\text { below what U.S. firms } \\
\text { would have achieved in } \\
\text { an open market) despite } \\
\text { several ostensible lib- } \\
\text { eralizing moves by the } \\
\text { Japanese Government. }\end{array}$} & \multirow[t]{4}{*}{ June 14, 1985} & $\begin{array}{l}\text { July } 31,1986 \text { : Japan } \\
\text { signed an agreement ex- } \\
\text { pressing the expectation } \\
\text { of gradual, steady im } \\
\text { provement in access; in } \\
\text { a secret side letter, Japan } \\
\text { acknowledged the U.S. } \\
\text { goal that import penetra- } \\
\text { tion of Japanese market } \\
\text { would rise over } 5 \text { years } \\
\text { to } 20 \text { percent. }\end{array}$ & & \multirow[t]{4}{*}{$\begin{array}{l}\text { About } 18 \text { years for } \\
\text { some improvement } \\
\text { in market share; } \\
\text { goal of much greater } \\
\text { market share not } \\
\text { achieved after about } \\
19 \text { years. }\end{array}$} \\
\hline & & & & & $\begin{array}{l}\text { (Apr. 17, 1987: United } \\
\text { States retaliated for } \\
\text { Japan's failure to im- } \\
\text { prove market access, by } \\
\text { increasing duties on cer- } \\
\text { tain computers and } \\
\text { power hand tools from } \\
\text { Japan.) Serious Japa- } \\
\text { nese Government effort } \\
\text { to improve access com- } \\
\text { menced in 1989, lead- } \\
\text { ing to first substantial } \\
\text { increase in import share }\end{array}$ & & \\
\hline & & & & & $\begin{array}{l}\text { of Japanese market, which } \\
\text { was } 13 \text { percent in } 1990 \\
\text { (improved from } 10 \text { per- } \\
\text { cent, but much lower } \\
\text { than expected from } \\
\text { agreement). }\end{array}$ & & \\
\hline & & & & & $\begin{array}{l}\text { New agreement signed } \\
\text { June } 4,1991 \text {, effective } \\
\text { Aug. } 1,1991 \text {, with target } \\
\text { of } 20 \text {-percent import } \\
\text { penetration by the end } \\
\text { of } 1992 \text {. }\end{array}$ & & \\
\hline \multirow[t]{3}{*}{049} & \multirow[t]{3}{*}{ Brazil } & \multirow{3}{*}{$\begin{array}{l}\text { Policies toward the in- } \\
\text { formatics industry (com- } \\
\text { puter and computer- } \\
\text { related products), includ- } \\
\text { ding import restrictions and } \\
\text { inadequate intellectual } \\
\text { property protection. }\end{array}$} & \multirow[t]{3}{*}{ Negotiations since 1984.} & \multirow[t]{3}{*}{ Sept. 16, 1985} & $\begin{array}{l}\text { Oct. } 6,1986 \text { : Brazil un- } \\
\text { dertook administrative re- } \\
\text { forms designed to re- } \\
\text { duce import restrictions. }\end{array}$ & \multirow[t]{3}{*}{$\begin{array}{l}\text { substantial import } \\
\text { restrictions continued } \\
\text { into at least Febru- } \\
\text { ary } 1991 .\end{array}$} & \multirow{3}{*}{$\begin{array}{l}\text { About } 2 \text { years to start } \\
\text { removing import re- } \\
\text { strictions, with sub- } \\
\text { stantial restrictions } \\
\text { lasting at least 6-7 } \\
\text { years; about } 3 \text { years } \\
\text { to fix intellectual } \\
\text { property protection. }\end{array}$} \\
\hline & & & & & $\begin{array}{l}\text { 1987: Brazil passed } \\
\text { remedial copyright } \\
\text { legislation to protect } \\
\text { computer software. }\end{array}$ & & \\
\hline & & & & & $\begin{array}{l}\text { Negotiations still ongoing } \\
\text { as of February } 1991 .\end{array}$ & & \\
\hline
\end{tabular}


Table 4-3-Selected Section 301 Cases-Continued

\begin{tabular}{|c|c|c|c|c|c|c|c|}
\hline $\begin{array}{l}\text { Case } \\
\text { No. } \\
\end{array}$ & Country & Subject & Prior history & $\begin{array}{l}\text { Date of } \\
\text { petition or } \\
\text { self-initiation }\end{array}$ & $\begin{array}{l}\text { Effective date } \\
\text { and nature } \\
\text { of relief }\end{array}$ & $\begin{array}{l}\text { Subsequent } \\
\text { history }\end{array}$ & $\begin{array}{l}\text { Wait for } \\
\text { relief }\end{array}$ \\
\hline 052 & Korea & $\begin{array}{l}\text { Inadequate protection of } \\
\text { intellectual property } \\
\text { rights, including patent } \\
\text { protection and copyright } \\
\text { protection for software. }\end{array}$ & $\begin{array}{l}\text { Extensive bilateral nego- } \\
\text { tiations starting in March } \\
1983 \text { (patent) and in } 1984 \\
\text { (copyright). }\end{array}$ & Nov. 4, 1985 & $\begin{array}{l}\text { July 1, 1987: Korea } \\
\text { passed remedial patent } \\
\text { and copyright } \\
\text { legislation. }\end{array}$ & $\begin{array}{l}\text { Many problems re- } \\
\text { mained into } 1989 .\end{array}$ & $\begin{array}{l}\text { About 3-4 years to } \\
\text { start improving intel- } \\
\text { lectual property pro- } \\
\text { tection; many prob- } \\
\text { lems remained for } \\
\text { about 5-6 years. }\end{array}$ \\
\hline 056 & Taiwan & $\begin{array}{l}\text { Customs valuation sys- } \\
\text { tem. }\end{array}$ & $\begin{array}{l}\text { In } 1979 \text { Taiwan agreed } \\
\text { that by Jan. } 1,1986, \text { it } \\
\text { would value imports, for } \\
\text { customs purposes, based } \\
\text { on the invoice price, } \\
\text { rather than determining } \\
\text { the value by administra- } \\
\text { tive rules. By Aug. 1, } \\
1986, \text { Taiwan still had } \\
\text { not switched over. }\end{array}$ & Aug. 1, 1986 & $\begin{array}{l}\text { Oct. 1, 1986: Taiwan } \\
\text { changed its customs } \\
\text { valuation system to use } \\
\text { invoice prices. }\end{array}$ & & About 7 years. \\
\hline \multirow[t]{3}{*}{61} & Brazil & $\begin{array}{l}\text { Lack of patent protec- } \\
\text { tion for pharmaceuticals. }\end{array}$ & Negotiations since 1985. & June 11, 1987 & $\begin{array}{l}\text { (Oct. 20, 1988: United } \\
\text { States retaliated by in- } \\
\text { creasing duties on some } \\
\text { imports from Brazil.) }\end{array}$ & & $\begin{array}{l}\text { At least about } 6 \\
\text { years. }\end{array}$ \\
\hline & & & & & $\begin{array}{l}\text { June 26, 1990: Brazil's } \\
\text { President announced } \\
\text { that he would propose } \\
\text { remedial legislation to } \\
\text { Brazil's legislature by } \\
\text { Mar. 20, 1991. }\end{array}$ & & \\
\hline & & & & & $\begin{array}{l}\text { (July 2, 1990: United } \\
\text { States removed its re- } \\
\text { taliatory duties.) } \\
\text { Remedial legislation not } \\
\text { passed as of spring, } 1991 .\end{array}$ & & \\
\hline 68 & Argentina & $\begin{array}{l}\text { Pharmaceuticals: inade- } \\
\text { quate patent protection, } \\
\text { and discriminatory regis- } \\
\text { tration requirements. }\end{array}$ & Negotiations since 1985. & Aug. 10, 1988 & $\begin{array}{l}\text { Fall of 1989: Argentina } \\
\text { agreed to introduce re- } \\
\text { medial legislation by fall } \\
\text { of } 1991 \text {. The petitioner } \\
\text { then withdrew its peti- } \\
\text { tion. }\end{array}$ & $\begin{array}{l}\text { No remedial legisla- } \\
\text { tion enacted as of } \\
\text { Mar. } 5,1991 \text {. }\end{array}$ & $\begin{array}{l}\text { At least about } 6 \\
\text { years. }\end{array}$ \\
\hline
\end{tabular}


Table 4-3-Selected Section 301 Cases-Continued

\begin{tabular}{|c|c|c|c|c|c|c|c|}
\hline $\begin{array}{l}\text { Case } \\
\text { No. }\end{array}$ & Country & Subject & Prior history & $\begin{array}{l}\text { Date of } \\
\text { petition or } \\
\text { self-initiation }\end{array}$ & $\begin{array}{l}\text { Effective date } \\
\text { and nature } \\
\text { of relief }\end{array}$ & $\begin{array}{c}\text { Subsequent } \\
\text { history }\end{array}$ & $\begin{array}{c}\text { Wait for } \\
\text { relief }\end{array}$ \\
\hline 70 & EC & $\begin{array}{l}\text { Export restrictions on cop } \\
\text { per scrap, which alleg- } \\
\text { edly depressed the price } \\
\text { of scrap within the EC } \\
\text { and raised it elsewhere, } \\
\text { thereby giving an advan- } \\
\text { tage to EC brass fabrica- } \\
\text { tors. }\end{array}$ & & NOV. $14,19 \overline{8} \overline{8}$ & $\begin{array}{l}\bar{E} \bar{C} \text { agreed to remove } \\
\text { export restrictions for at } \\
\text { least } 1990 .\end{array}$ & & 1 year, 2 months \\
\hline *73 & Brazil & $\begin{array}{l}\text { Overall import licensing } \\
\text { scheme, including prohib } \\
\text { ited items, quotas, and } \\
\text { lack of transparency. }\end{array}$ & $\begin{array}{l}\text { Negotiations since } 1984 \\
\text { or earlier. }\end{array}$ & June 16, 1989 & $\begin{array}{l}\text { May 14, 1990: import } \\
\text { regulation thoroughly } \\
\text { changed, removing ob- } \\
\text { jectionable features. }\end{array}$ & & About 6 years \\
\hline 074 & Japan & $\begin{array}{l}\text { Discriminatory govern- } \\
\text { ment procurement of } \\
\text { satellites. }\end{array}$ & $\begin{array}{l}\text { In 1983, Japan published } \\
\text { its "Long Range Vision } \\
\text { on Space Development," } \\
\text { in which Japan banned } \\
\text { all public and private pur- } \\
\text { chases of foreign satel- } \\
\text { lites. The U.S. Govern- } \\
\text { ment immediately initi- } \\
\text { ated negotiations. Japan } \\
\text { agreed to remove the } \\
\text { ban on private purchases } \\
\text { but held fast to its ban } \\
\text { on public purchases. }\end{array}$ & June 16, 1989 & $\begin{array}{l}\text { June 15, 1990: Japan } \\
\text { signed an agreement for } \\
\text { open procurement prac- } \\
\text { tices, except for R\&D } \\
\text { satellites. }\end{array}$ & & About 7 years \\
\hline 075 & Japan & $\begin{array}{l}\text { Discriminatory govern- } \\
\text { ment procurement of } \\
\text { supercomputers. }\end{array}$ & $\begin{array}{l}\text { Discriminatory behavior } \\
\text { since } 1976 \text {, when U.S. } \\
\text { machines were first avail- } \\
\text { able. Negotiations since } \\
1985 \text {, including an agree- } \\
\text { ment signed in } 1987 \text {, } \\
\text { which proved to be inef- } \\
\text { fective. }\end{array}$ & June 16, 1989 & $\begin{array}{l}\text { Mar. 22, 1990: Japan } \\
\text { signed an agreement for } \\
\text { open and fair procure- } \\
\text { ment practices. }\end{array}$ & $\begin{array}{l}\text { As of May } 1991 \text {, it } \\
\text { was too early to tell if } \\
\text { this agreement would } \\
\text { stop Japan's dis- } \\
\text { crimination in pro- } \\
\text { curement. }\end{array}$ & $\begin{array}{l}\text { At least about } 5 \text { years } \\
\text { since negotiations } \\
\text { commenced; at least } \\
\text { about } 14 \text { years since } \\
\text { Japanese discrimina- } \\
\text { tion began. }\end{array}$ \\
\hline
\end{tabular}


Table 4-3-Selected Section 301 Cases-Continued

\begin{tabular}{|c|c|c|c|c|c|c|c|}
\hline $\begin{array}{l}\text { Case } \\
\text { No. }\end{array}$ & Country & Subject & Prior history & $\begin{array}{l}\text { Date of } \\
\text { petition or } \\
\text { self-initiation }\end{array}$ & $\begin{array}{c}\text { Effective date } \\
\text { and nature } \\
\text { of relief }\end{array}$ & $\begin{array}{c}\text { Subsequent } \\
\text { history }\end{array}$ & $\begin{array}{c}\text { Wait for } \\
\text { relief }\end{array}$ \\
\hline 79 & Norway & $\begin{array}{l}\text { Discriminatory govern- } \\
\text { ment procurement of } \\
\text { electronic toil collection } \\
\text { equipment. }\end{array}$ & & July 11, 1989 & $\begin{array}{l}\text { Apr. 26, 1990: Norway } \\
\text { took measures designed } \\
\text { to ensure fair consider- } \\
\text { ation of the petitioner in } \\
\text { future procurements. }\end{array}$ & & 9 months \\
\hline
\end{tabular}

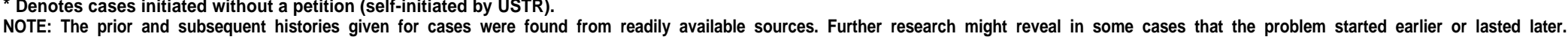
If so, the waiting times for relief in those cases would be longer than those stated.

SOURCE: This table relies almost entirely on published USTR sources: Office of the United States Trade Representative, "Section 301 Table of Cases," computer printout dated Jan. 17,1991, and Federal Register notices cited therein; Office of the United States Trade Representative, National Trade Estimate Reporf on Foreign Barriers, annual reports for 19851987, 1989-1991, Office of the United States Trade Representative, "Report to Congress on Section 301 Developments Required by Section 309(a) (3)of the Trade Act of 1974, "semiannual reports covering January 1989through June 1990, OHice of the United States Trade Respresentative, "United States, Japan Conclude SemiconduclorAgreement," press release, No. 91-21, June 4,1891 (for Case No. 46); Donald Phillips, Assistant United States Trade Representative, testimony at hearings before the House Committee on Energy and Commerce, Subcommittee on Commerce, Consumer Protection and Competitiveness, May 9, 1990, Serial No. 101-149, pp. 6-11 (for Case No. 48). Other sources were relied on for particular cases: discussion in this Chapter, and also Clyde V.Prestowitz, Jr., Trading P/aces; How WeAllowed Japan ToTake The Lead(New York, NY: Basic Books, 1988), p. 62 (Case No. 46, prior history); USTR Official, personal communication, Feb. 27,1991 (Case No. 49, subsequent history into 1991); USTR Official, personal communication, Mar. 5,1991 (Case No. 61, subsequent history); USTR Official, personal communication, Mar. 5,1991 (Case No.68, events after initiation of investigation); chapter 6 of this report (Case No. 75, showing that Japan's discriminatory procurement of supercomputers started in 1976); Jonathan Streeter, Supercomputer Industry Analyst, International Trade Administration, U.S. Department of Commerce, personal communication, May 21,1991 (Case No. 75, subsequent history). 
pragmatic level, sanctions could hurt downstream users of the affected products. For example, when Japan violated the 1986 semiconductor agreement and USTR drew up a proposed list of Japanese products on which to increase tariffs in retaliation, many U.S. firms that purchased items on the proposed list testified and lobbied against the action. ${ }^{68}$ Sanctions can also hurt U.S. firms with operations or joint venture partners in the country concerned.

\section{Japan's Barriers}

With the limited effectiveness of GATT dispute resolution procedures and Section 301, foreign market barriers often persist for years. This is especially true with Japan. In 1990, the United States had a $\$ 42$ billion bilateral trade deficit with Japan, accounting for about 40 percent of the United States total trade deficit (figure 4-3). This deficit has many causes, including often superior Japanese products, U.S. dissavings and high Japanese savings, and inadequate efforts by some U.S. firms to sell to Japan. However, one important cause is a rich network of market barriers, including official government action and regulation, unofficial advice from government to industry, government toleration or encouragement of anticompetitive activity, and a business culture in which Japanese companies maintain long-term relationships and prefer to deal with other Japanese businesses-.@

Figure 4-3-U.S. Trade Deficit With Japan and the World, 1983-1990

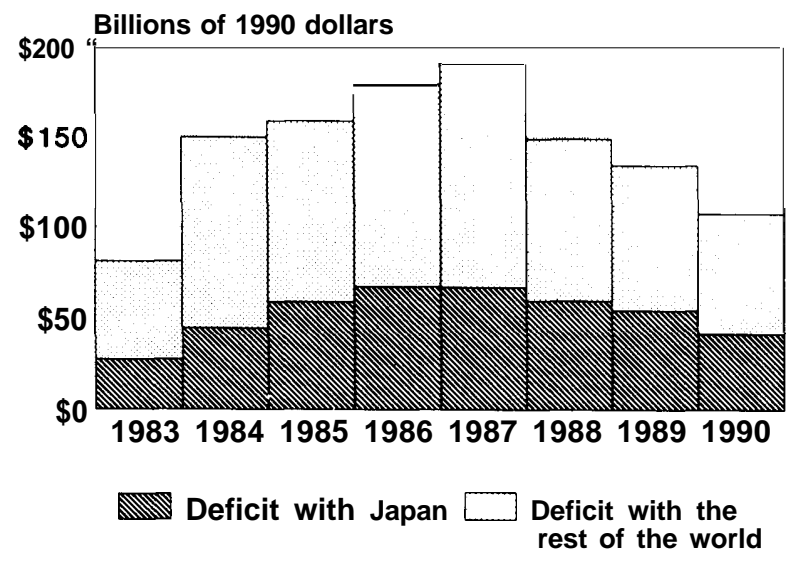

NOTE: Amounts were converted to 1990 dollars using GNP deflators from the Department of Commerce, Bureau of Economic Analysis.

SOURCE: International Monetary Fund, Direction of Trade Statistics, 1990, pp. 402-403, and U.S. Department of Commerce, Bureau of Economic Analysis, Survey of Current Business, vol. 71, No. 5 , May 1991, pp. S-16, S-17.
Some have likened Japan's trade obstacles to an onion: when one layer is peeled away, another is waiting below. This happened with semiconductors and supercomputers, as discussed above. It occurred from 1980 to 1983, when U.S. producers of aluminum bats tried to have their bats certified for use in Japan by the government-run children's baseball league. First certification was flatly denied, even though that went against an agreement signed by Japan in 1979 as part of GATT's Tokyo Round. Then certification was offered but conditioned on meeting discriminatory standards requiring an alloy seldom used in the United States and abase plug not used in U.S.-made bats. Then the standards were changed, but U.S. factories, because they were outside Japan, could not be qualified as meeting the standards, so that each lot of bats would have to be opened and inspected individually. Finally the inspection issue was resolved, but Japanese distributors refused to carry U.S.-made bats, effectively shutting U.S. producers out of the market. Each step required high-level U.S. Government involvement. ${ }^{70}$

As another example, in 1989 a well-known American manufacturer approached the USTR with a fully documented problem. Two Japanese trade journals would not run its ads because of pressure from the firm's Japanese competitors. Glen Fukushima of the USTR staff raised this case informally with a contact in MITI, and the problem was quickly resolved. Mr. Fukushima commented that,

While the outcome of this case is positive, it is troubling to realize that it required the intervention of USTR and MI'TI, potential congressional involvement, and 1 year of frustrated effort for a major, well-established, and well-endowed American company even to place an ad in two Japanese trade journals-several stages removed from actually making a sale to Japanese users. ${ }^{71}$

The difficult task of opening Japanese markets is made worse by the scant U.S. Government resources devoted to the problem. The equivalent of only about 15 full time staff at the USTR's office work on trade with Japan. ${ }^{72}$ While USTR is assisted by other agencies, U.S. negotiating teams have often been far smaller and less well prepared than Japanese teams .73 The U.S. agencies have faster staff turnover than their Japanese counterparts, especially at the most senior (political) levels. This has caused the United States to repeat mistakes and has made interagency coordination more difficult. $^{74}$ 


\section{New Approaches}

Difficulties in removing Japanese trade protection have led the U.S. Government to consider alternative approaches. In 1986, the United States tried a new approach, putting forward its expectation that the foreign share of Japan's semiconductor market would rise to 20 percent over 5 years. Rather than trying to identify every market barrier, a seemingly hopeless task, the United States in effect asked Japan to identify and remove barriers on its own as needed to reach the target import level. While the 20-percent goal has not been achieved, the 1986 U.S.-Japan semiconductor agreement, together with retaliation for Japan's breach of it, did improve U.S. market share after more than a decade of failed attempts. This results-oriented approach was endorsed in February 1989 by the top-level industry advisory group to the USTR ${ }^{75}$ but apparently has not been used in other cases.

Another approach has been to try to remove many trade barriers at once in a given sector. This approach was used in five sectors-telecommunications, electronics, forest products, medical equipment and pharmaceuticals, and autos and auto parts -in the Market-Oriented Sector-Selective (MOSS) talks, begun in 1984. Overall, the talks focused high-level attention on certain market obstacles, reduced them, and opened communication channels to resolve follow-up disputes. The talks seem to have helped U.S. firms increase their exports to Japan, though many companies reported continuing problems. The most substantial increases in exports occurred in telecommunications and in medical equipment and pharmaceuticals, for reasons including easily identifiable barriers that the Japanese Government could readily fix; strong U.S. presence already in Japan poised to take advantage of market liberalization; some industry support within Japan for market liberalization; and negotiators' ability and teamwork. Subsequent monitoring by the U.S. Government was crucial to translating the agreements into tangible trade gains ${ }^{76}$ For example, because of the MOSS talks Japan made it easier to certify U.S.-made cellular telephones for use in Japan, but follow-up U.S. Government intervention was necessary to get permission for Motorola to serve the Tokyo cellular market. $^{77}$

Yet another approach considers the whole economy. The Structural Impediments Initiative (SII), launched by President Bush and Prime Minister Uno in July 1989, sought "to identify and solve structural problems in both countries that stand as impediments to trade and to balance of payments adjustment. ${ }^{, 78}$ In a June 1990 joint report, each side resolved to modify economic practices responsible for much of the bilateral trade imbalance. Japan pledged to decrease its trade surplus, for example, by increasing spending on public works projects, liberalizing restrictions on large retail stores, and enforcing its antimonopoly laws. The United States stated that to decrease its trade deficit it would, among other things, encourage more consumer savings; reduce the budget deficit; support commercially relevant $\mathrm{R} \& \mathrm{D}$; reform various areas of Federal or State regulation, such as antitrust, product liability, and export controls; improve export promotion efforts; and improve education and work force training. ${ }^{79}$ The countries agreed to seven follow-up meetings in the next 3 years, at the level of deputy or assistant cabinet officer and vice or deputy minister, to review progress, discuss problems, and produce annual joint reports. ${ }^{80}$

The U.S. commitments stopped far short of the fundamental and wide-reaching changes necessary to reverse the competitive decline. In May 1991, the Administration noted that Japan had made "welcome progress in a number of areas" during the SII agreement's frost year, though "additional progress in all areas is necessary in order to contribute further to the goals of opening markets, reducing trade and current account imbalances, and improving the quality of life in Japan." Most observers outside the U.S. Government are less optimistic. Some commentators believe that the SII talks will not substantially open Japanese markets, and that the only approach that will work is to demand specific market shares, as was done for semiconductors. ${ }^{82}$

The U.S. Government has also used a systematic approach to deal with the EC's evolving trade and industry policies. An interagency task force, led by USTR, was formed in early 1988 to study EC-92 and help avoid a "Fortress Europe" with strong trade barriers to outsiders. The task force has 12 working groups on specific issues, such as technical standards, quantitative restrictions, investment, and rules of origin. ${ }^{83}$ It has established U.S. Government positions, developed relationships with EC officials, and negotiated to influence EC legislation before it is agreed to at the EC level. The task force has influenced EC policies in areas including standards- 
setting procedures, reciprocity provisions, and rules of origin.

\section{SUBSIDIES AND DUMPING}

\section{Subsidies and Dumping: What They Are, Why They Matter}

Governments can by domestic policies give their national industries advantages in international competition. Occasionally governments have made outright payments to firms; more commonly, benefits take a less direct form, such as R\&D support, tax breaks, loans on preferential terms, and provision of raw materials at below-market prices. Recognizing that such benefits can adversely affect industries in other countries, GATT sometimes permits those countries as a countermeasure to levy extra import duties called countervailing duties. Countervailing duties are allowed only if the benefits constitute a "subsidy" under the law. GATT does not directly define subsidies; U.S. law defines a subsidy as "any bounty or grant" paid "upon the manufacture or production or export of any article or merchandisc."

Subsidies are of two types: export and domestic. Export subsidies apply only when goods are exported. For example, in 1985 New Zealand paid its producers of carbon steel wire rod 10.5 percent of the value of the exported product. ${ }^{85}$ Other examples include preferential loans to finance exports and a reduction in corporate income tax conditioned on export performance. GATT largely prohibits export subsidies. ${ }^{86}$

Domestic subsidies are those paid whether or not goods are exported. Benefits might be in proportion to the firm's total production--e.g., the provision of a raw material at a below-market price. Or benefits might be given to the company with no clear relation to a particular product; this could occur, for example, with R\&D support or preferential loans for capital investment. Under U.S. law, domestic subsidies must be limited to "a specific enterprise or industry, or group of enterprises or industries. ${ }^{, 87}$ Broader benefits enjoyed by companies in other countries, such as abetter educated work force or easier access to long-term financing for all manufacturers, do not count as subsidies.

As acknowledged by the GATT Subsidies Code, domestic subsidies "are widely used as important instruments for the promotion of social and eco- nomic objectives. ${ }^{, 88}$ Accordingly, GATT does not prohibit domestic subsidies. However, the GAT T Subsidies Code considers that domestic subsidies, by giving one nation's businesses an advantage in international competition, "may cause or threaten to cause injury to a domestic industry" in another nation. ${ }^{89}$ In such circumstances, GATT permits the second nation to levy a countervailing duty. It is imposed in addition to any other duties normally collected and must be no more than the value of the subsidy. For example, if a foreign nation provided coal at below-market prices to steel companies, saving $\$ 10$ per ton of steel produced, then the maximurn countervailing duty allowed would be $\$ 10$ per ton.

It is not always possible to levy countervailing duties to fully capture and neutralize the benefits foreign companies receive from their governments. GATT permits an alternative countermeasure: antidumping duties, which can be imposed only when a foreign frm is "dumping." Dumping is the selling of goods in an export market at less than a benchmark 'fair value.' The benchmark is the price in the home market "in the ordinary course of trade." ${ }^{90}$ If no such home market price exists because, for example, there are no home market sales or the home market sales are not made in arm's length deals ${ }^{91}$, then the benchmark can be either the price in the ordinary course of trade in a third country, or a price constructed from "the cost of production. . . plus a reasonable addition for selling cost and profit."92

Although GATT appears to relegate costs to a subordinate role, as an option only when home market price cannot be used, the United States and other major users of antidumping duties interpret these provisions as giving costs a primary role. These countries provide that sustained home market sales at a price below the cost of production (excluding profit) will not be deemed to be in the ordinary course of trade and should be disregarded in determining the home market price. Therefore, any home market price actually used will normally be at least the cost of production excluding profit; sales below this level will be considered dumping. If all of the home market sales for a sustained period are below the cost of production excluding profit, then there will be no home market price in the ordinary course of trade, so that the benchmark used will be a constructed price consisting of costs including profit. $^{93}$ 
GATT states that dumping "is to be condemned if it causes or threatens material injury to an established industry," or "materially retards the establishment of a domestic industry," in the importing country. ${ }^{\%}$ GATT does not prohibit dumping in these circumstances. Rather, as with domestic subsidies, it allows the importing country to levy an antidumping duty, which must not be more than the amount necessary to bring the price up to the benchmark value. This amount is called the "dumping margin." Antidumping duties, like countervailing duties, are in addition to any other duties normally collected.

Sustained dumping by foreign producers is often a sign that those producers enjoy an advantage in international competition due to either government policies or societal features such as industry structure and habitual business practices, which themselves may result in part from government policies. This is true for both price-price dumping (selling in an export market for less than at home or in another export market) and price-cost dumping (selling in an export market for less than costs). With price-price dumping, the foreign producer can use its sales in the high-priced market (usually the home market) to subsidize its sales in the low-priced export market. The price difference is often due to protection in the high-priced market. ${ }^{95}$ While one way to end the foreign fins' advantage might be to remove the foreign market barriers, in practice that can be difficult. ${ }^{96}$ Sometimes the foreign producers' home government tolerates or even encourages cartel pricing; this elevates the home market price beyond what it would be with protection alone and increases the profits from home market sales that are available to subsidize low-priced exports.

Price-cost dumping indicates that the foreign supplier has a special advantage. Sustained sales below cost are normally possible only if the sales are somehow subsidized. In some cases, countervailing duty law could be used instead of antidumping law. Countervailing duty law could address subsidies provided by the government, and even those provided by related firms (e.g., in a Korean chaebol or Japanese keiretsu).sT But a fro's cross-subsidy between product lines would not come under countervailing duty law, so that only antidumping law could provide relief.

Sustained sales below cost could be part of a long-term plan to gain experience and market share in a high-reward industry, which could lead to high future profits that might more than pay back the loan with interest. ${ }^{98}$ In this case, the sales need not be subsidized, they need only be financed. For example, in the mid-to-late 1980 s, capital for industrial growth was available to Japanese firms on better terms and with less pressure for short-term profits than in the United States. This included funding from the government, banks, and related firms. Japanese dumping of DRAMs in the mid- 1980s can be viewed in this light; U.S. firms did not have the financial backing to undergo the massive losses that the larger Japanese firms swallowed, so most U.S. DRAM producers exited the field. Japanese firms emerged as the dominant producers.

When used in high-reward industries, both priceprice and price-cost dumping can enable producers to achieve economies of scale and learning. Both types of dumping can help utilize excess capacity in industries experiencing slack demand. For example, during the late 1970s and the early 1980s, there was a worldwide excess steelmaking capacity. Steel firms in the EC, Japan, and many other countries had substantial market protection at home while they dumped in the more open U.S. market. ${ }^{100}$ Since their facilities would otherwise stand idle, foreign firms could cut their losses by selling in the U.S. market for more than their variable costs, even if that was less than they charged at home, and less than their fully allocated costs. ${ }^{101}$

In the United States, it has often been said that subsidies and dumping are unfair. This label irritates foreign firms and countries accused of these practices, who often do not consider that they have done anything unfair. Rather than debating whether these practices are unfair, it is more helpful to recognize that government action, societal structure, or a combination of the two can give foreign firms a special advantage against which U.S. companies often cannot compete unaided. Countervailing and antidumping duties should be seen "not as a response to so-called unfairness, but rather as an 'interface' or buffer mechanism to ameliorate difficulties ... caused by interdependence among different economic systems. "102

\section{Countervailing Duty and Antidumping Cases}

The United States and other countries have laws to provide for investigations of subsidies and dumping and assessment of countervailing and antidump- 
ing duties. ${ }^{103}$ Figures $4-4$ and 4-5 show the countries most active in these proceedings, based on new investigations completed from January 1987 through June 1990. During this period the United States was the leading user of countervailing duty proceedings; Latin America, the Pacific Rim, and the EC were leading targets. The United States, Australia, Canada, and the EC most often used antidumping proceedings, while the Pacific Rim (especially Japan and Korea), the EC, nonmarket economies, Central and South America, and the United States were the primary targets. Antidumping cases were far more common than countervailing duty cases. Tables 4-4 and 4-5 detail who brought cases against whom and how many resulted in some final government action. ${ }^{104}$ Tables 4-6 and 4-7 list how many final actions by each country were outstanding as of June $30,1990 .^{105}$

From these figures and tables it appears that in recent years the United States has been by far the biggest user of both countervailing and antidumping duties. This does not necessarily mean, however, that the United States is more aggressive in their use. The United States has a large, relatively open market that attracts imports. Countries with more market barriers have less need to impose countervailing and antidumping duties. The United States' principal trading partners use subsidies more often, ${ }^{106}$ so the
United States has more occasion to levy countervailing duties. As for antidumping cases, the United States has not always been out in front. In the 1980s, Australia brought 30 percent of all reported cases; the United States brought 28 percent, Canada 20 percent, and the EC 19 percent. $^{107}$

GATT allows countervailing and antidumping duties only if "the effect of the dumping or subsidization ... is such as to cause or threaten material injury to an established domestic industry, or is such as to retard materially the establishment of a domestic industry." This condition is called the injury test or requirement. Under U.S. law, the injury or threat of injury must be caused by the dumped or subsidized "imports' rather than by the "dumping or subsidization" itself. ${ }^{109}$ U.S. law imposes the injury test in every antidumping case; for countervailing duty cases, however, the injury requirement applies only to countries that have signed the GATT Subsidies Code (this includes the United States' major trading partners), have "assumed obligations with respect to the United States which are substantially equivalent to obligations" under the GATT Subsidies Code, or are otherwise entitled by international agreement to application of the injury test. ${ }^{10}$

The Department of Commerce determines whether goods are subsidized or dumped and by what

Figure 4-4-New Countervailing Duty Cases Completed, January 1987 Through June 1990

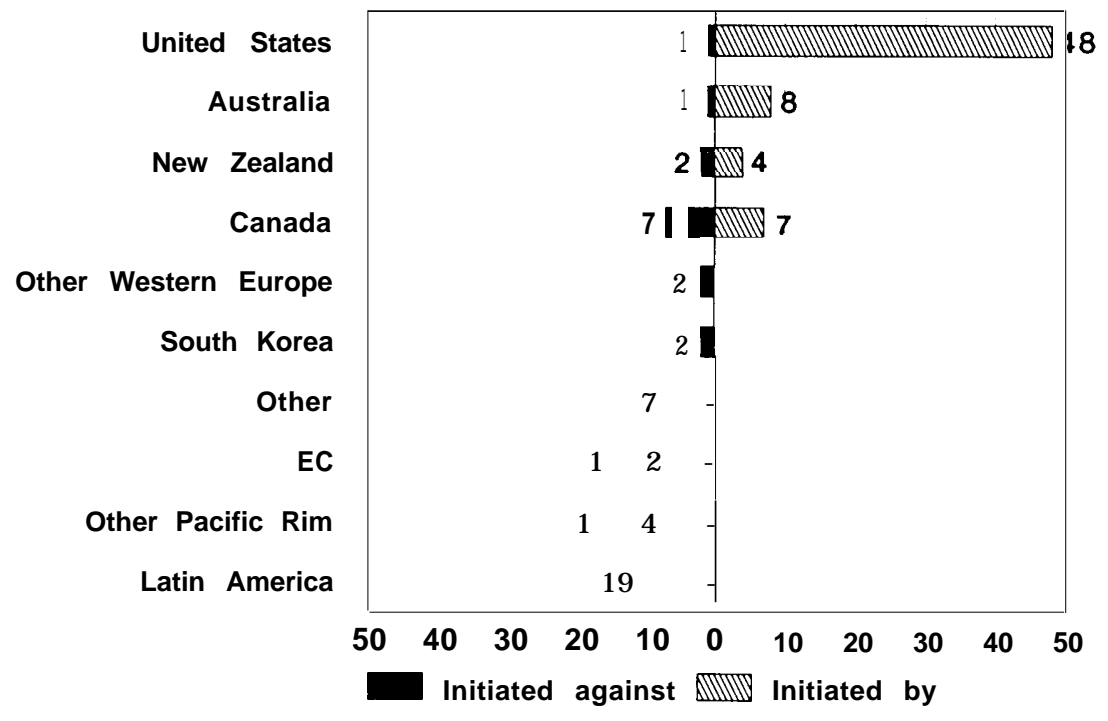

SOURCE: Semiannual filings by signatories of the GAIT Subsidies Code to the Committee of Signatories, provided by the U.S. Department of Commerce, International Trade Administration. 
Figure 4-5-New Antidumping Cases Completed, January 1987 Through June 1990

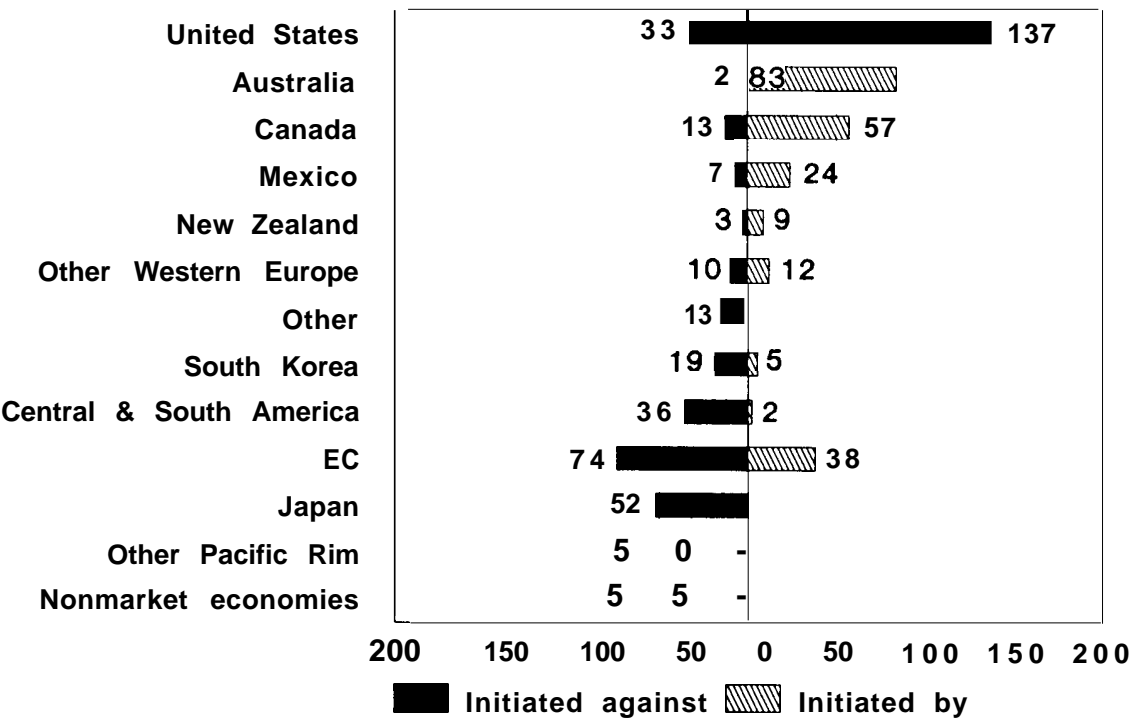

SOURCE: Semiannual filings by signatories of the GAIT Antidumping Code to the Committee on Anti-Dumping Practices, provided by the U.S. Department of Commerce, International Trade Administration.

Table 4-4-New Countervailing Duty Cases Completed January 1,1987 Through June 30, 1990

\begin{tabular}{|c|c|c|c|c|c|c|c|c|c|c|c|}
\hline & \multicolumn{11}{|c|}{ Cases filed against: } \\
\hline & $\begin{array}{l}\text { United } \\
\text { States }\end{array}$ & Australia & $\begin{array}{c}\text { New } \\
\text { Zealand }\end{array}$ & Canada & $\begin{array}{l}\text { Other } \\
\text { Western } \\
\text { Europe }\end{array}$ & $\begin{array}{l}\text { South } \\
\text { Korea }\end{array}$ & Other & EC & $\begin{array}{c}\text { Other } \\
\text { Pacific } \\
\text { Rim }\end{array}$ & $\begin{array}{l}\text { Latin } \\
\text { America }\end{array}$ & Total \\
\hline \multicolumn{12}{|l|}{ Cases filed by: } \\
\hline \multicolumn{12}{|l|}{ United States } \\
\hline Final action $\ldots \ldots \ldots \ldots \ldots \ldots$ & & & 1 & 3 & 1 & 1 & 3 & 4 & 8 & 9 & 30 \\
\hline No final action .............. & & & 0 & 3 & 1 & 1 & 3 & 2 & 5 & 3 & 18 \\
\hline \multicolumn{12}{|l|}{ Australia } \\
\hline Final action $\ldots \ldots \ldots \ldots \ldots \ldots$ & & & 1 & & & & 0 & 1 & 0 & 0 & 2 \\
\hline No final action . ............. & & & 0 & & & & 1 & 1 & 1 & 3 & 6 \\
\hline \multicolumn{12}{|l|}{ New Zealand } \\
\hline Final action $\ldots \ldots \ldots \ldots \ldots \ldots$ & & 1 & & & & & & 0 & & & 1 \\
\hline No final action .............. & & 0 & & & & & & 2 & & & 3 \\
\hline \multicolumn{12}{|l|}{ Canada } \\
\hline Final action $\ldots \ldots \ldots \ldots \ldots \ldots$ & 1 & & & & & & & 1 & & 1 & 3 \\
\hline No final action .............. & 0 & & & & & & & 1 & & 3 & 4 \\
\hline \multicolumn{12}{|l|}{ Total } \\
\hline Final action $\ldots \ldots \ldots \ldots \ldots \ldots$ & 1 & 1 & 2 & 3 & 1 & 1 & 3 & 6 & 8 & 10 & 36 \\
\hline No final action...$\ldots \ldots \ldots \ldots$ & 0 & 0 & 0 & 4 & 1 & 1 & 4 & 6 & 6 & 9 & 29 \\
\hline
\end{tabular}

Additional explanation is given in the accompanying text.

amount, and the ITC determines whether the injury test is satisfied. While the government can start an investigation on its own, that very rarely happens; usually an investigation begins only when industry petitions the government and sets out sufficient grounds for believing that subsidies or dumping have occurred and that the injury requirement is satisfied. The petition must identify any known foreign manufacturers and exporters, as well as U.S. importers, wholesalers, and retailers of the foreign 


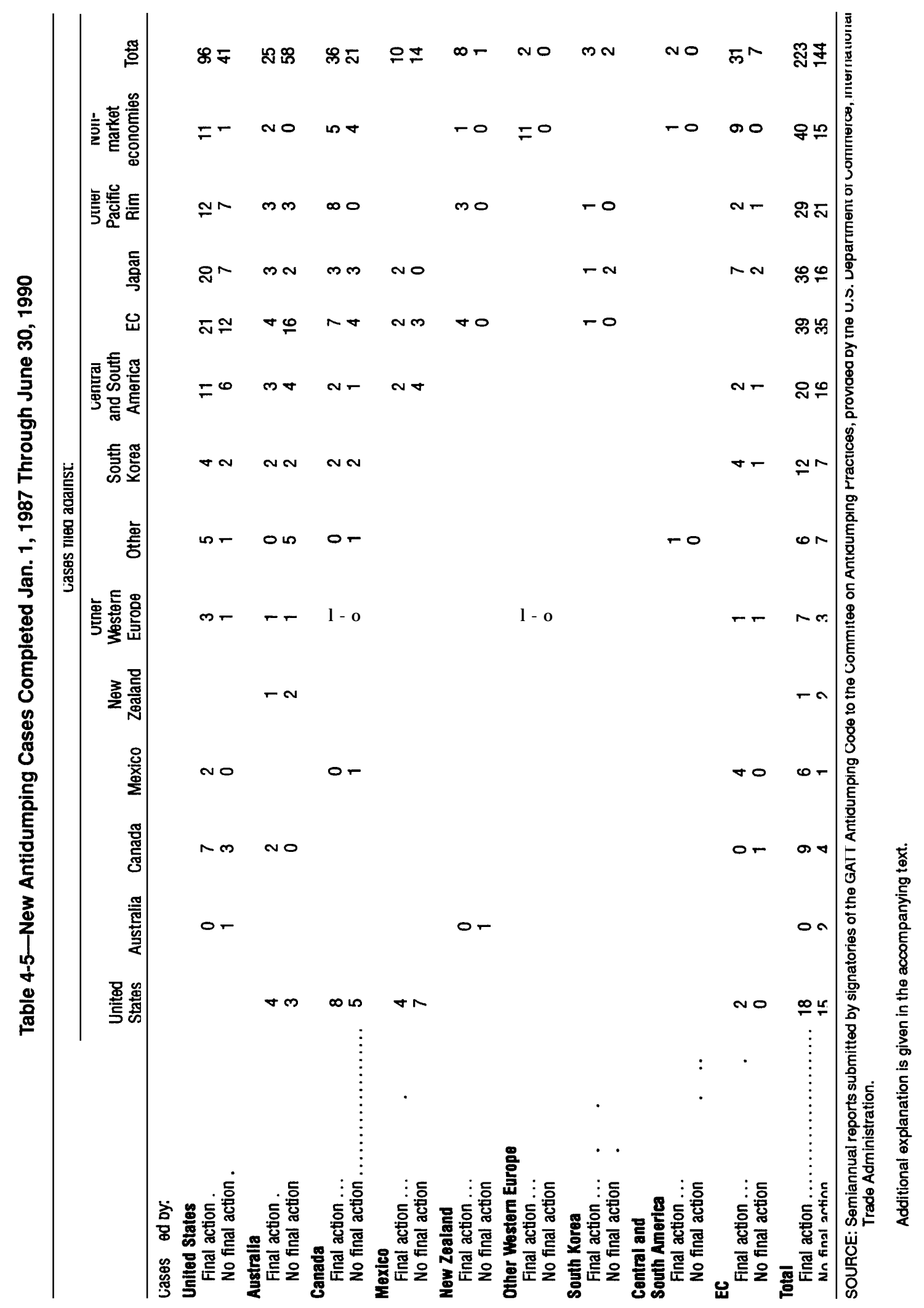


Table 4-6--Outstanding Measures Against Subsidies as of June 30,1990

\begin{tabular}{|c|c|c|}
\hline Country & $\begin{array}{l}\text { Negotiated quantity } \\
\text { restraint or } \\
\text { other agreement }\end{array}$ & Total \\
\hline 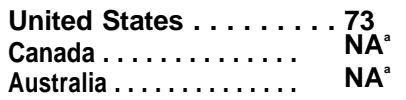 & $\begin{array}{l}13 \\
\mathbf{N A}^{\mathrm{a}} \\
\mathbf{N A}^{\mathrm{a}}\end{array}$ & $\begin{array}{r}86 \\
9 \\
1\end{array}$ \\
\hline
\end{tabular}

${ }^{2}$ NA - Not available. Canada and Australia did not describe the nature of their outstanding orders.

NOTE: All other signatories reported no outstanding orders.

SOURCE: Semiannual reports submitted by signatories of the GAIT Subsidies Code to the Committee of Signatories, provided by the U.S. Department of Commerce, International Trade Administration.

Table 4-7-Outstanding Antidumping Measures as of June 30,1990

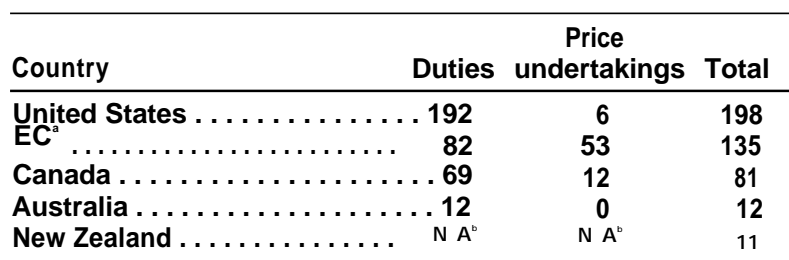

Data for the EC is as of Feb. 1, 1990. The EC filed no Semiannual report for the first half of 1990; that would normally imply that no additional action had been taken.

bA = Not applicable. New Zealand did not describe the nature of its outstanding orders.

NOTE: All other signatories reported no outstanding orders.

SOURCE: Semiannual reports submitted by the signatories of the GAIT Antidumping Code to the Committee on Anti-Dumping Practices.

goods. Those respondents are invited to participate in the investigation, along with the government of the foreign country involved.

Figures 4-6 and 4-7 show the progress of antidumping and countervailing duty cases through the Commerce Department and the ITC, along with the number of cases that have progressed through each stage for all cases completed between January 1987 and June 1990. The figures show that cases with the injury requirement progress through three stages. At each stage, the case can end with no relief; only if all three stages are passed is relief granted. First, the ITC makes a preliminary determination of whether there is reason to believe that the injury requirement could be satisfied. Second, the Commerce Department determines whether the imports at issue are subsidized or dumped, and if so by how much. Third, the ITC makes its final determination of whether the injury test is satisfied.

If subsidies or dumping are found, and if any applicable injury test is passed, the government issues an order, enforced by the Customs Service, assessing countervailing or antidumping duties in an amount equal to the subsidy value or dumping margin. In dumping cases, each subsequent shipment is assessed an antidumping duty based on how much that particular shipment is priced below the benchmark "fair value." Thus, foreign exporters can avoid paying any duty by raising prices up to the fair value, which they often do. In both subsidy and dumping cases, annual reviews are conducted on request to determine whether the amount of subsidy or the "fair value," respectively, has changed. If so, the duties already paid for that year are adjusted; the exporter then pays any additional amount due or is refunded any overpayment. The U.S. Government sometimes accepts an agreement by the foreign government or exporters to eliminate the subsidy or limit the quantity of exports to the United States, in lieu of a countervailing duty. ${ }^{111} \mathrm{Or}$, instead of levying an antidumping duty, the United States might accept an agreement by the foreign exporters to raise prices. ${ }^{112}$

\section{The Effectiveness of U.S. Countervailing Duty and Antidumping Law}

Countervailing duty and antidumping laws have helped somewhat to protect U.S. industries from advantaged foreign competition. However, the effect of these laws is limited. The reasons come in two clusters. First, the imposition of countervailing and antidumping duties is slow and uncertain. Second, even if they were promptly applied, countervailing and antidumping duties would often be inadequate to neutralize the advantage of foreign companies.

\section{Delay and Uncertainty in Imposing Duties}

The government normally will start an investigation only when an affected U.S. business files a petition. This takes considerable time and effort. The firm must suspect that subsidies or dumping are at work; it could take months or even years to piece together why certain sales were lost and conclude that there is more than just ordinary stiff competition. For example, a company might suspect dumping only after it is forced to make a series of painful price cuts in response to foreign competition. The company must be aware that a legal remedy exists; some fins, especially smaller ones, do not know that. Plus there is a certain inertia to overcome. The Torrington Co. waited until March 1988 to file petitions regarding dumping of ball bearings from 
Figure 4-6-Decisions in U.S. Countervailing Duty Cases Completed, January 1987 Through June 1990'

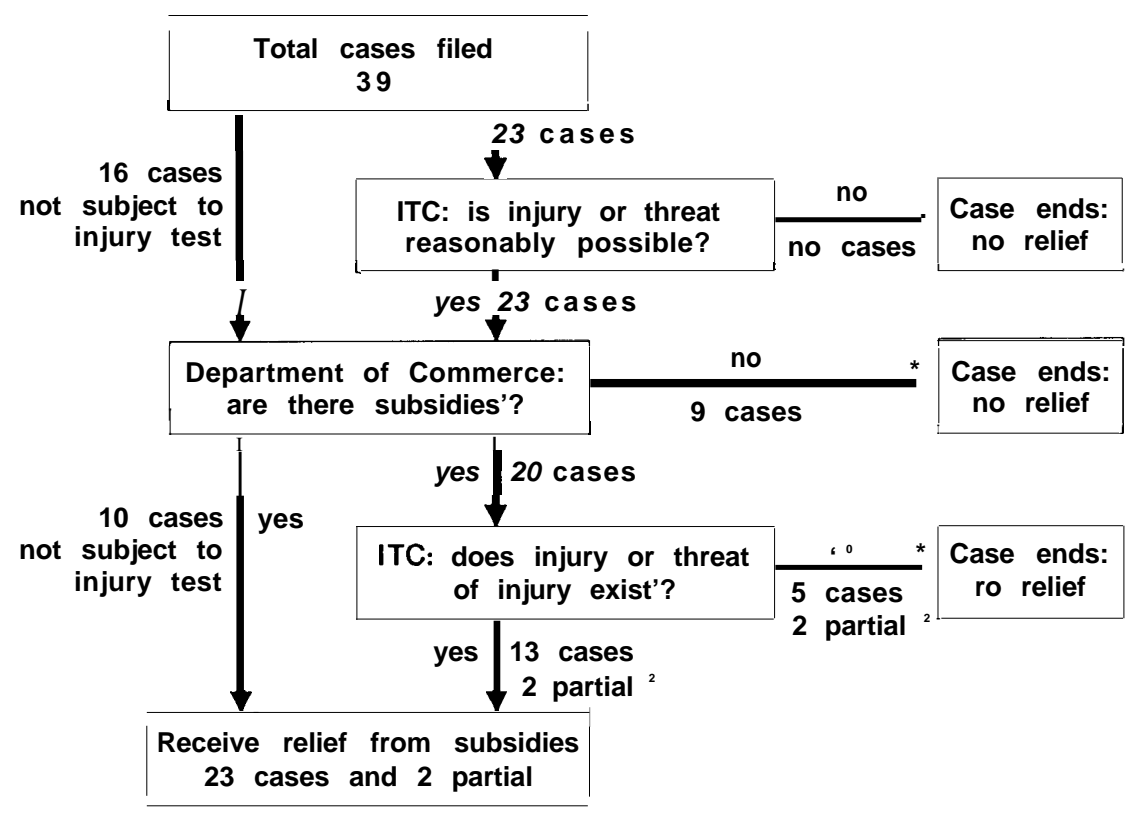

NOTES: 1 . This table does not include 7 cases that were "terminated" before a final determination was made and 5 cases for which insufficient data was provided.

2. In these cases, injury was found for some of the products at issue but not for others.

SOURCE: Unpublished data, U.S. International Trade Commission.

several countries, even though dumping and injury were apparent by early $1987 .{ }^{113}$ When asked about the delay, a Torrington official stated: "Most businessmen worry about the day-to-day order book. To start a trade action, you must sit back. "114

To file a petition, a firm must present sufficient evidence of both injury and subsidies or dumping. Regarding subsidies, the petitioner must identify particular subsidy programs before the government will investigate them, but it can be difficult for U.S. firms to learn about these programs. With dumping, the petitioner must first get evidence of the prices at which the imported goods are sold in the United States. These prices would often be known only by the foreign producer and the domestic purchaser; those parties would not want to help the petitioner because any antidumping duties would be assessed against their goods. The petitioner then would have to document the foreign manufacturer's home market price or costs of production. This too can be difficult, especially if the petitioner has no presence in that country. Evidence concerning injury can be elusive, because at issue is the state of the whole domestic industry, not just the fro(s) filing the petition. The other companies in the domestic industry might not wish to give petitioners the information they need; for example, they might be unwilling to share sensitive business information, or they might be foreign-owned, with loyalties to the respondents' Camp. ${ }^{11 \mathrm{~s}}$

Even if a firm comes up with the necessary information, other factors could dissuade it from preparing a petition and fighting the case. The frost is expense, which typically ranges in the hundreds of thousands of dollars for the initial case (table 4-2), not counting employee time. Additional expense is incurred for court appeals, which are frequently taken, and for subsequent annual reviews, which are frequently conducted. Some recent cases have been quite expensive. For example, in 1989 Bethlehem Steel filed both an antidumping and a countervailing duty petition against steel rails from Canada, which resulted in substantial duties. ${ }^{116}$ To win the case at the Commerce Department and ITC, and to defend the victory on appeal, took over $\$ 1$ million. ${ }^{117}$ When cases are filed against more than one country, the expense increases. The ball bearings cases filed by the Torrington Co. in 1988 included nine countries, 
Figure 4-7-Decisions in U.S. Antidumping Cases Completed, January 1987 Through June $1990^{i}$

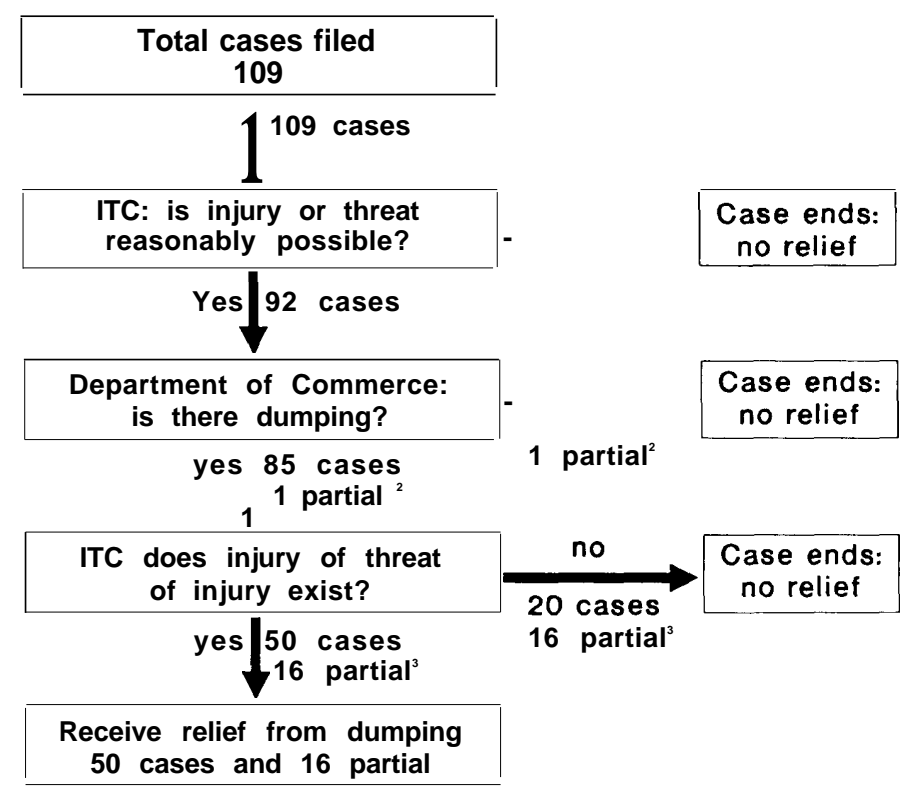

NOTES: 1 . This table does not include 10 cases that were "terminated" ( 9 cases) or "suspended" ( 1 case) before a final determination was made.

2. In this case, dumping was found for some of the products at issue but not for others.

3. In these cases, injury was found for some of the products at issue but not for others.

SOURCE: Unpublished data, international Trade Commission.

at an estimated cost of $\$ 4$ to $\$ 5$ million. ${ }^{118}$ The high costs can discourage firms, especially smaller ones, from filing petitions. ${ }^{119}$ In estimating the expense, a firm must consider the many reasons why it could lose the case and that even a successful case might not provide effective relief. The expense, uncertainty, and difficulties of gathering information dissuaded U.S. manufacturers of rock crushing machines from filing a case in the late $198 \%$ (box 4-b).

In response to the high legal and other fees as reported by the General Accounting Office (table 4-2), Congress in 1988 stepped up the role of the ITC's Trade Remedy Assistance Office (TRAO). ${ }^{120}$ TRAO can help small businesses represent themselves. TRAO gives behind-the-scenes technical and legal advice, including explaining the law and procedures, identifying relevant precedents, consulting on strategy, and reviewing draft petitions and briefs prepared by the firm. Since the 1988 legislation, TRAO has helped several companies file and pursue dumping cases. While companies have been pleased with the assistance, there are some inherent limitations to how much TRAO can help. Petitioners representing themselves have no access to confilential business information submitted by other parties; the ITC makes this information available only to outside counsel and consultants. This information is central to many cases, and lack of access puts a party at a tremendous disadvantage in formulating strategy and framing legal arguments. Further, even with TRAO's help, it requires immense effort for a firm to represent itself.

Businesses can be discouraged from filing petitions because they fear retaliation-by the accused firm or a related one that might be the prospective petitioner's supplier or customer for some products, or by the foreign government. For example, it is widely believed that the U.S. commercial airframe manufacturers, Boeing and McDonnell Douglas, for many years did not file a countervailing duty case against large subsidies received by the members of the Airbus consortium from the governments of Britain, Germany, and France, for fear that those governments would direct their national airlines to buy fewer U.S. airplanes. As another example, in the spring of 1991, a survey by the U.S. and Japanese Governments found that auto parts were priced 108 


\section{Box 4-B-An Unfiled Dumping Case}

The U.S. rock crushing machinery industry is composed of about nine companies with total annual sales of about $\$ 175$ million (including new units and spare parts). These machines are used in many public works and construction projects. The steady decline in infrastructure spending over the 1980s greatly reduced the demand for crushing equipment; 1989 sales were half those of 1979. The situation was made worse by sales lost to low-priced imports from Japan, Korea, and Taiwan that appeared in the early 1980s. After 1985, as the dollar was devalued the U.S. firms expected some relief, yet the imports' dollar price did not rise. Manufacturers lost sales in both 1987 and 1988 of some 20 to 30 machines out of 200 or 300 total sales in the United States; the west coast firms were hardest hit. Though the U.S. producers might well have been able to win a dumping case against the imports, they never filed one. The industry's attempts, and the problems it faced, show how hard it can be to use antidumping law, especially for small businesses.

One west coast producer, referred to here as Firm A, organized an ad hoc committee of manufacturers and acted as the spokesman to the government. The commerce Department's International TradeAdministration (ITA) gave Firm A the legal definition of dumping. Since they were unable to determine the Japanese firms' home market prices, the U.S. manufacturers would have to show dumping on the basis that the Japanese machines in the U.S. market were priced below the cost of production. This required an analysis of the costs of production facing the Japanese companies. The major costs of making rock crushing machines are materials and labor. Because the overwhelming material input is steel, which as a commodity would normally cost about the same anywhere in the developed world, Firm A believed that the material costs of U.S. and Japanese machines might be equal. Using this assumption, and knowing that the Japanese producers also had shipping and duty costs, Firm A was fairly sure that Japanese labor and other costs could not be low enough for the price of the imported machines to be above cost.

However, the foregoing analysis was not sufficiently rigorous to get ITA to initiate an antidumping case. The U.S. manufacturers understood this, but did not know how to proceed. ITA had sent some questionnaires whose answers would supply the necessary information, but those forms were imposing and Firm A thought they would be very difficult to complete. An analysis along the lines given below might have been sufficient to induce ITA to initiate a case. The analysis below, summarized in table $\mathrm{B}-1^{2}$, is for one representative Japanese model and its counterpart produced by Firm A. The analysis would have to have been performed for all import models at issue.

\section{List Price:}

List prices were readily available from promotional literature. List prices represent the maximum possible retail price, and most machines are sold below list. Unconfirmed reports of Japanese machines being sold at substantial discounts, some as high as 40 percent, were not uncommon. For the calculation, the list price was used initially, with discounts considered afterward.

\section{Dealer Markup:}

It was assumed that retailers of imported crushing machinery receive the same percentage markup as retailers of U.S. made machinery. U.S. machinery producers believed that the markups were similar, though they could not prove it.

Duties and Shipping Costs:

Table B-I-Estimated Cost Breakdown of Rock Crushing Machinery, Jaw Crusher Type

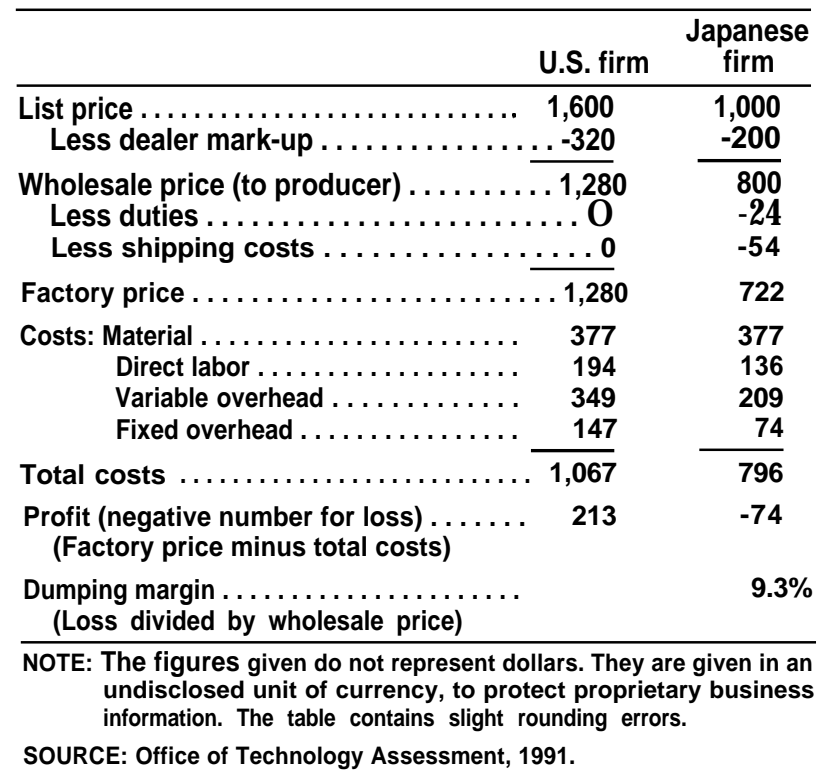

Data on shipping and duty charges were readily available and required no estimation.

\footnotetext{
${ }^{1}$ This box is based on interviews with firm executives, the trade lawyer consulted by the firms, and a former Department of Commerce official.

2The figures in table B-1 do not represent dollars. The currency unit used is not disclosed, in order to protect proprietary business information.
} 


\section{Factory Price:}

Factory price is the amount the producer receives, not counting any duties and shipping costs. To prove dumping based on below-cost sales, factory price must be less than the costs of production.

Material Costs:

The major material input was carbon steel. According to U.S. manufacturers, all other materials costs were insignificant. Carbon steel is a commodity good traded worldwide. Steel prices faced by Japanese competitors might then be assumed to be equal to those faced by U.S. firms. As the comparable machines weigh the same amount, it was assumed that the same amount of steel is used. Thus, material costs were assumed to be equal.

Direct Labor Costs:

Japanese labor costs had to be estimated. The Department of Labor does make international comparisons of wage rates, but not for specific industries. The rock crusher workers in the United States were paid more than the average industrial wage, but because no data is available on rock crusher workers in Japan, as a conservative assumption the average industrial wage in Japan was used. The labor cost estimate also assumed that Japanese labor was 10 percent more productive; that is, if it took 100 hours to build a U.S. machine, it took 90 hours to build a Japanese machine.

\section{Variable Overhead and Indirect Labor Costs:}

The estimates of Japanese variable overhead costs (e.g., energy consumption, worker benefits, and workmans' compensation) were more difficult to make than estimates of wages. Without access to hard data, variable overhead costs incurred per hour of direct labor in Japan were conservatively assumed to be two-thirds as much as the variable overhead costs incurred per hour of direct labor in the United States. (The figure in the table also reflects the assumption given above that Japanese labor was 10 percent more productive.)

Fixed Overhead:

Data on fixed overhead costs in Japan are not available. For the U.S. machine, fixed overhead was about 16 percent of the total of the other costs (material, direct labor, variable overhead). Without direct data, fixed overhead for the Japanese machine might conservatively be assumed to be about 10 percent of the total of the other costs.

As table B-1 shows, under these assumptions Japanese firms were dumping. Even with sales at list price, the dumping margin (the cost minus price, divided by price) was 9.3 percent. Moreover, both domestic and foreign rock crushers were rarely sold at list price. One reported Japanese sale was at 40 percent off list. If the wholesale price was similarly reduced by 40 percent, then, using the same cost assumptions, that sale would have a dumping margin of 89 percent.

To win a dumping case, the U.S. manufacturers would also have to prove injury. Under the law, a sizable number of sales lost to dumped goods can constitute injury if those sales were lost on the basis of price. In both 1987 and 1988, an estimated 20 to 30 imported crushers were sold in the United States, all in the west coast region, competing primarily with Firm A and one other firm. All evidence available to Firm A from its customers indicated that price was, in fact, the overriding factor. Comments such as, "we liked the way you [the domestic producers] do business but, their price was just too low" were typical. These lost sales probably constituted roughly 10 percent of the U.S. market for new machinery. Lost sales of this magnitude, if they could be proved, would stand a good chance of satisfying the injury requirement.

However, the U.S. producers did not perform the above analysis, for they did not know how. Instead, they consulted an experienced trade lawyer. The lawyer explained that, while a dumping case had a fair chance of success, it would cost about $\$ 1$ million. While this was a substantial amount to an industry with an annual profit only in the range of $\$ 5$ to $\$ 10$ million, especially since the chance of winning the case was far from certain, for the industry as a whole it probably would have been manageable. However, because the imports competed only in the west coast market, many of the companies whose sales were concentrated elsewhere did not feel injured enough to justify a large expense. The two firms bearing the brunt of the injury did not feel able to bear the bulk of the case's cost.

In principle, the firms could have filed a petition on their own, and if the Commerce Department accepted the petition then the Commerce Department and the International Trade Commission would investigate dumping and injury respectively, whether or not the U.S. producers hired a lawyer. However, this arrangement would have required considerable employee time to develop the petition. Moreover, the lack of an attorney would pose two serious practical problems. First, a petition would need to contain companies' confidential business information 


\section{Box 4-B-An Unfiled Dumping Case' Continued}

regarding sales, prices, customers, profits, and so on. They could not share this information with each other. An outside attorney could take all pertinent information from the firms in confidence, combine it as needed in the petition, and designate certain information in the petition as confidential. Without an outside attorney, the firms were stuck As the case developed, the other side (foreign manufacturers and importers) would submit confidential business information of its own as key elements of its case. While an outside attorney for the U.S. producers could have access to such information, the companies themselves could not. Thus, if they argued the case without an outside attorney, the U.S. firms would have no way of refuting key arguments of the other side, since they could not know what those arguments were. ${ }^{3}$

The Department of Commerce could initiate an investigation on its own on behalf of the U.S. industry. However, the Department of Commerce has done so only once in hundreds of cases. While the Department may have considered doing so in this case, it ultimately decided not to. The producers were forced to ride out the dumping without remedy. In this case, riding it out seems to have worked. The continued low value of the dollar and increased labor costs in Japan and other Asian countries have combined to push the price of imports up. Additionally, the continued decline in U.S. demand may have dissuaded foreign firms from buying a large market share through dumping. Domestic producers say the Japanese are still selling in the United States, but not with the same "sell at any price" fervor.

This case highlights some problems faced by small firms in trying to attain relief from dumping. The problems included difficulty in getting needed data on foreign firms' costs and prices, difficulty in collecting industry-wide data, difficulty in justifying the payment of legal fees (especially since success was uncertain), and a general lack of familiarity with the law.

${ }^{3}$ The firms would be given nonconfidential summaries of the confidential information, but those summaries would usually omit important details.

percent higher in Japan than in the United States. The Commerce Department's Auto Parts Advisory Committee, a group of 35 industry representatives, advised that the Commerce Department initiate a dumping case on its own. The Committee explained that industry would be reluctant to file antidumping petitions, partly because of the need to preserve business relationships with Japanese firms. ${ }^{121}$ Filing petitions can also anger U.S. customers who stand to be deprived of cheap imported goods.

After a petition is filed, a case takes time to yield results. Provisional duties are not imposed until the ITC first finds reason to believe the injury testis met and the Department of Commerce makes a preliminary finding of dumping or subsidies. This usually takes over 5 months for dumping cases and almost 3 months for subsidy cases. 122 The duties ordinarily apply only to goods that clear customs after the preliminary determinations are made and published, though in rare cases the Commerce Department will seek to collect duties retroactively for up to 90 days. ${ }^{123}$ The Commerce Department's preliminary determination is often based on unverified statements by the foreign manufacturers. Only after a final determination, usually another $21 / 2$ months, will the duties collected be based on verified information. ${ }^{124}$ Even these relatively modest delays could be important for products with short life cycles. Moreover, these delays must be added to the time it takes for a business to suspect subsidies or dumping and to prepare a petition.

Additional delay can occur if further proceedings, and perhaps court appeals, are necessary to get duties assessed. One example is that after a countervailing duty order is in place, subsidy levels can be increased; it will take at least a year or two before the Commerce Department determines the new subsidy level in an annual review. In while increased duties will be assessed retroactively, the underresponse to the subsidy in the interim could allow the foreign producer to capture market share.

An extreme example of delay pending review is the case of portable electric typewriters from Japan. In May 1980, Smith Corona Corp. obtained an antidumping order against these products. ${ }^{126}$ Within 2 years after this order, Japanese firms started exporting portable typewriters that included memory. In January 1987, the Commerce Department ruled that the typewriters with memory did not come under the scope of the 1980 antidumping order. ${ }^{127}$ 
Three court appeals later, in September 1990, the U.S. Court of Appeals for the Federal Circuit ruled that these typewriters did come under the $\mathbf{1 9 8 0}$ order, and ordered the collection of antidumping duties. ${ }^{128}$ However, antidumping duties could no longer be collected on typewriters imported in the intervening 8 or 9 years. ${ }^{29}$ Delays of several years can also occur because of ineffective enforcement; sometimes the duties are never collected. ${ }^{130}$

Effective relief is sometimes held up because one case after another must be filed. Each countervailing duty or antidumping case must name a specific product or group of products already entering the United States from a specific country of origin. However, after a case is won and countervailing or antidumping duties stem the flow of goods from the country named, the flow of dumped or subsidized goods can start up again from other countries. The Torrington Co. claims that this happened in the late 1980s with ball bearings, when several multinational firms switched production to facilities in other countries. ${ }^{131}$ If foreign producers can easily switch production capacity among different final products, a producer might export one product until a countervailing duty or antidumping order issues, and then switch to another product. This occurred with steel in the $1980 \mathrm{~s} .{ }^{132}$ After hundreds of cases were filed starting in 1982, in September 1984 President Reagan announced that countervailing duty and antidumping cases had been "slow, cumbersome and incomplete in remedying [the U.S. steel industry's] injuries. "133

Antidumping and countervailing duty orders are simple to circumvent for goods whose final stage assembly is easily moved across national borders. Such a move can put the goods out of the reach of a previous order; ${ }^{134}$ thus, a new pattern of subsidized or dumped imports could go unimpeded until a new case was filed and a new order obtained. In 1988, Congress added so-called 'anticircumvention' provisions so that the initial order can sometimes cover the new import patterns. However, these provisions apply only in very limited circumstances and will likely have little effect. ${ }^{1.5}$ It might not be possible to strengthen these provisions while staying consistent with GATT as it now stands. ${ }^{136}$ In the Uruguay Round, the United States and the EC have proposed that GATT should explicitly permit certain anticircumvention measures, to deal not only with cases of relocated final assembly but also with relocated parts production, as occurred with ball bearings.
Another possible impediment to relief, in the case of subsidies, is the specificity test. As discussed, a government program is counted as a subsidy only if it in fact selectively benefits a specific firm or industry, or group of firms or industries; programs granting equal benefit to a broad range of firms and industries are not counted. Foreign countries can phrase their laws so as to paint benefits as widely available, even when in practice they are not. Former U.S. Government officials representing foreign firms in trade cases could coach foreign governments on how to do this. When foreign laws appear to grant benefits to a wide range of fins, often as a practical matter the difficult task of proving that the benefits are indeed selective falls on petitioners.

In other ways as well, the Commerce Department at times does not recognize certain subsidies. For example, the Commerce Department does not count R\&D subsidies if the results are made public, but making the results public does not negate the benefits to the firm of being among the first to know and the most familiar with the new discoveries. As another example, if a foreign government disguises a long-term loan as a series of short-term loans, the Commerce Department often will count it as shortterm; this can decrease the computed subsidy if, as is most often the case, the market interest rate for long-term loans exceeds the market rate for shortterm loans.

Another important limitation on the effectiveness of countervailing duty and antidumping law is the injury test. U.S. law, implementing GATT's requirement, provides that antidumping and countervailing duties cannot be levied unless 'by reason of imports of [dumped or subsidized] merchandise or by reason of sales (or the likelihood of sales of that merchandise)" either an "industry in the United States" is "materially injured" or "threatened with material injury," or "the establishment of an industry in the United States is materially retarded." Congress has further defined 'material injury' as 'harm which is not inconsequential, immaterial, or unimportant," and has specified certain factors to be considered, such as the volume and trend of imports, whether the imports depress or suppress prices, and sales, profits, and capacity utilization in the affected industry. ${ }^{137}$ It is up to the ITC, which determines injury in U.S. cases, to evaluate and weigh the factors. The ITC has considerable discretion and the courts seldom overturn its decisions. 
As shown in figure 4-7, the injury test is the primary reason why petitioners lose antidumping cases. Well under one-tenth of the cases (6 cases, plus 1 partial case, out of 109) are lost because no dumping is found. In contrast, one-third of the cases (37 out of 109) are completely lost because no injury is found, and about half of the cases (53 out of 109) are lost completely or in part because no injury is found. Figure 4-6 shows that, while a factor, the injury test in countervailing duty cases is less important. Of 39 cases, 23 were subject to the injury test. Of those, 5 whole cases and 2 partial cases were lost because of the injury test.

The injury test adds expense. The legal fees and other expenses needed to prove injury are often greater than those needed to prove subsidies or dumping. Sometimes they are quite large. For example, in 1988 and 1989 The Torrington Co. spent a quarter of a million dollars on economic consultants merely to criticize and comment on an economic model proposed by Commission staff to analyze the injury. Torrington believed its opposition spent an equivalent sum. ${ }^{138}$ While much of this expense is unavoidable due to the complex, technical subject matter, the ITC's approach to injury determinations does add to it. The ITC determines each case on its own facts, without articulating or following rules of general applicability. One such rule could be that a drop in profit of a certain percentage of sales, if linked to the imports, normally establishes the requisite injury. Without 'safe harbor' rules such as this, petitioners are compelled to develop the facts and argue the law for all possible factors that the ITC might consider-profits, sales, capacity utilization, and so on. The ITC's case-bycase approach also makes case outcomes less predictable, which can discourage petitioners from filing complaints.

The injury test poses a particular problem for firms seeking relief in good economic times, at the beginning of a product cycle, or before much damage has been done. As the ITC has interpreted the test in some recent cases, industries that appear fairly healthy in an absolute sense and whose health has not recently declined will likely fail the injury test, even if they would have done far better if not for the subsidized or dumped imports. This happened in a case decided in January 1989 concerning digital readout (DRO) systems from Japan. The Commerce Department had found large dumping margins on DRO systems, ranging from 39 to 55 percent. ${ }^{139}$
DRO systems consist of two components: a transducer, which measures the position of equipment such as metalworking machine tools during operation, and a console, which displays the resultt in digital form. In determining injury, the International Trade Commission considered console production and transducer production to be two separate industries, and made a separate determination for each industry.

Four Commissioners, a majority of the sixmember International Trade Commission, ruled that the required injury was not present for either industry. The Commissioners never considered whether the dumped imports made the industries less successful than they otherwise would have been. ${ }^{140}$

Two Commissioners dissented. They pointed to strong economic evidence, supplemented by an admission by one of the major Japanese manufacturers, that the Japanese firms had maintained their market share only by dumping. 141 They also noted strong evidence that the dumped imports had substantially lowered the price for DRO systems in the U.S. market. ${ }^{142}$ These two Commissioners believed that injury should be considered primarily in' terms of the effect of the dumping, rather than the general health of the industry. The majority approach can make it hard for U.S. firms to win dumping cases early in a product cycle (when markets are growing) or before significant damage has been done. This can put companies in a dilemma: file a case early and risk that not enough injury will be found; or file later, when the damage is substantial and hard to reverse. ${ }^{143}$

The DRO systems case shows another hurdle in the application of the injury test. In assessing the health of the domestic industry, the Commission considered export sales together with domestic sales. Under this approach, even if subsidies or dumping severely hurts the domestic industry in its home market (the only market that U.S. countervailing or antidumping duties can address), no relief will be obtained if the U.S. industry's export sales of consoles are strong enough to make the overall industry healthy. In the DRO case, export sales were apparently much more profitable than domestic sales, which appeared to be made at a 10 ss..$^{144}$

The injury test permits the respondents to claim that the domestic industry's troubles came not because it was undersold but for other reasons. When credible alternative reasons are offered, often as a practical matter the burden of proof shifts to the 
petitioners to show that the low-priced imports were responsible for at least some of the material injury. This issue arose in a case brought in 1990 by National Label Co., a firm in Lafayette Hill, Pennsylvania. ${ }^{145}$

National Label made pressure-sensitive polyvinyl chloride covers for alkaline and some other batteries. These covers used a new technology that expands battery life. ${ }^{106}$ National Label had been making the battery covers under a 1986 patent and trade secrets license from Zweckform, a German firm, which gave National Label the exclusive right to exploit the technology in North America. Relations between the two firms soured, however, and in December 1988 Zweckform told National Label it was terminating the license, and (according to National Label) began approaching potential U.S. customers. National Label asserted that Zweckform did not have the right to terminate its exclusive license and sued Zweckform in Federal court to stop it from selling in the U.S. market. ${ }^{147}$ In January 1990, National Label also filed an antidumping petition, alleging that Zweckform was dumping battery covers in the U.S. market with the intent to drive National Label out of the business.

National Label maintained that it had been injured in at least two ways: first, that it had lowered its prices to keep from losing sales to its principal customer, Eveready; and second, that it had lost a sale to a prospective new customer, Mutec, a potentially powerful new entrant into the battery market backed by Matsushita and Kodak. Regarding its Eveready account, National Label submitted sworn statements by its president that in March 1989, Zweckform representatives visited Eveready's office in Chicago and an Eveready official present at that meeting told him later that Zweckform had solicited to sell Eveready battery covers for the U.S. market. In April 1989, according to the statement, Zweckform gave him a choice between selling his battery cover business to Zweckform or being driven out of the business through deliberate below-cost pricing by Zweckform in the U.S. market. ${ }^{148}$ However, Zweckform disputed the facts of the case, claiming that the March 1989 meeting in Chicago was to discuss the European market only, and that Zweckform had never approached Eveready regarding the U.S. market. ${ }^{149}$ Apparently Eveready told the Commission that Zweckform's version of the facts was correct. The Commission agreed with Zweckform and found that Zweckform had not offered to sell to Eveready, and therefore could not be held responsible for National Label lowering its prices to Eveready. ${ }^{150}$

Regarding the prospective Mutec account, Zweckform said that it won the sale to Mutec because National Label's samples did not meet Mutec's specifications, rather than because National Label charged more. Mutec gave testimony agreeing with Zweckform. National Label disputed this point, arguing that Mutec's rejection of the samples was a sham. National Label argued that Mutec's parent Matsushita had found National Label's samples acceptable; Eveready and other firms found National Label's cover acceptable; the rejection of National Label's samples came after Mutec had already chosen Zweckform as a supplier, with the antidumping case started or anticipated, and it was then in Mutec's interest to claim that National Label's samples were unsatisfactory; and problems found in samples can often be fixed, but here there was no chance to do so because thanks to Zweckform's low price, Mutec had decided to purchase from Zweckform before it ever tested National Label's samples. ${ }^{151}$ The commission agreed with Zweckform and found that Zweckform's low price was not what had caused National Label to lose the sale to Mutec. ${ }^{152}$

OTA does not know whose version in this case is correct. The ITC's decision was based on confidential information not available to OTA. But this case does illustrate some difficulties facing a petitioner. In both cases of alleged injury, key testimony as to the real cause of National Label's injury came from Zweckform's customer (Mutec) or potential customer (Eveready)--parties predisposed to take Zweckform's side. The details of the tests performed by Mutec on National Label's samples were considered Mutec's confidential business information. While National Label's outside counsel could see this information, National Label's president, who was a technical expert, could not. ${ }^{153}$ National Label's president believed that this handicapped his ability to challenge the rejection..$^{154}$

\section{Offsetting Foreign Advantages}

Even if antidumping and countervailing duties were applied reliably and immediately to subsidized and dumped imports, this often would not offset the advantages of foreign firms. Some practices and effects slip through the cracks; they cannot be addressed as either subsidies or dumping. Some- 
times the foreign practice can be stopped by negotiation (perhaps using Section 301 or GATT dispute resolution procedures), though such negotiations, like negotiations to remove market barriers, are likely to be slow and difficult.

Countervailing and antidumping duties affect only sales in the U.S. market. Subsidies can give foreign firms an advantage in their home and third country markets, and dumping can mean an advantage for foreign firms in third country markets. Such subsidies have been addressed in several Section 301 cases (most involved agricultural products), and third country dumping of memory chips by Japan was addressed in the simultaneous settlement of a Section 301 case and three antidumping cases. Realizing that its firms needed relief from third country dumping, the United States negotiated a special commitment by Japan not to dump in the United States or in third countries. ${ }^{155}$

Another practice that can fall through the cracks is sales in the U.S. market at very low profit margins-high enough to sustain foreign manufacturers, but low enough to squeeze U.S. manufacturers. If the same price were charged at home, such sales would not constitute dumping. Lower profit margins might be more acceptable in another country in which conditions for raising capital are different. Or the foreign firm might be crosssubsidizing its low-priced exports to the United States with profits from other product lines, as Japanese supercomputer manufacturers have begun doing. ${ }^{156}$ That cross-subsidization could not be countervailed.

Perhaps the most profound Iimitation is that subsidies are quantified in a manner that systematically understates their true value. To calculate the countervailing duty, the Commerce Department frost puts a monetary value, called the subsidy value, on the benefit conferred. For example, the subsidy value of a low interest loan would typically be the interest saved by the company compared to the interest that it would have had to pay on a commercial loan. Next, the Commerce Department allocates the subsidy value over time. For example, the subsidy value of a low-interest loan could be allocated over the life of the loan. Then, for each period used for calculating countervailing duties, the countervailing duty rate for imports is that part of the subsidy value allocated to that period, divided by the value of the goods produced (or sold) during the same period with the help of the subsidy. For several reasons, a countervailing duty computed in this manner often does not compensate for the advantage received by a foreign producer.

Sometimes the subsidy is essential in order for the foreign producer to export in the first place. Often government financing makes it possible to get crucial bank loans, without which the business might never get off the ground. In the 1960s and 1970s, the Japanese Government subsidized its computer industry by means of low-interest loans from the Japan Development Bank (JDB) to the Japan Electric Computer Co. (JECC), a joint venture of the Japanese computer manufacturers. JECC's function was to finance computer sales; JECC bought computers for cash from the manufacturers and leased them to users. The loans from JDB made it possible for JECC to acquire additional commercial loans. Without JECC's help, most of the Japanese manufacturers probably would not have been able to borrow money to finance sales of computers. These manufacturers would then have been restricted to customers who could pay cash, and as a result Japan's computer industry would have developed more slowly.

But if U.S. manufacturers had filed a countervailing duty case, what would the countervailing duty have been? As calculated by one scholar, the subsidy implicit in the JDB loans from 1961 to 1969 was 2 billion yen, while the Japanese computer fins' sales during those years were about 230 billion yen. ${ }^{158}$ Therefore the subsidy, and the countervailing duty, would have been computed as less than 1 percent of the value of the goods sold.

A similar mismatch between the countervailing duty computed and the advantage conferred on the foreign firm can occur with government support of R\&D. An example is MITI's VLSI project in the late 1970s, which concerned techniques for making denser semiconductor chips. This project was important in helping the Japanese semiconductor and computer industries catch up with their U.S. counterparts, ${ }^{159}$ and was important to the development of Japan's supercomputer industry ${ }^{160}$ But if U.S. firms were to petition for relief in 1991, what countervailing duties might be imposed? The VLSI project is relevant to producing a wide range of electronics products; those of the participating firms will probably total well over $\$ 40$ billion in $1991 .{ }^{161}$ In 
comparison, the $\$ 150$ million contributed to the VLSI project by MITI, of which little if any would be allocated to 1991, would yield a minuscule countervailing duty, far less than 1 percent of sales.

Why does the countervailing duty calculation fail to capture the full worth of the R\&D? Perhaps the most important reason is that the approach to calculating countervailing duties assumes incorrectly that benefits are static. Under the law, subsidies are used once, and then their effect is gone; the only issue is how to divide up the benefit over time and products. In fact, under the law an R\&D project in the late 1970s, such as the VLSI project, would be considered irrelevant to sales in the 1990s; the project's payback period would be considered over and its effects dissipated. In reality, however, subsidies can create new opportunities and help a business seize an advantage years later; the effect can grow, rather than diminish, with time. In high reward industries this is particularly likely.$^{162}$ The effects of Japan's VLSI project probably increase with each passing year. The same can be true, for example, with low interest loans. Under the law, preferential financing to Japanese computer companies in the 1960s is probably irrelevant to sales of supercomputers and other computers in the 1990s; but in fact, the effect of those loans is strongly felt in 1991 (see ch. 6).

Under the law, it is not possible to capture the benefit that such government action confers on industries. Legalities aside, this task is very difficult. The foreign industrial policies discussed in this report are replete with actions intended to benefit national industries. To track the effects of all actions that helped a particular industry is a hopeless task.

\section{How Hard Are the Problems to Fix?}

The ineffective response of countervailing duty and antidumping law is not easy to fix. First, the law is inherently reactive. Duties are imposed in response to specific observed foreign practices; therefore, some delay occurs before the duties are imposed. In this way the approach of U.S. trade law differs fundamentally from one in which the U.S. Government would proactively seek to create advantages for its national industries, as other governments do.

However, there are ways to improve the effectiveness of countervailing and antidumping duty law. For example, the injury test could be attuned to be more receptive to companies still doing fairly well, before serious damage is done; the Commerce Department could be directed to suspend closing out of customs entries as soon as a case is started, and, once imposed, to collect duties retroactively as far as possible; and the Commerce Department could be more aggressive in finding and evaluating subsidies. These changes might be challenged as inconsistent with GAIT's requirements. For example, an attempt to change the evaluation of subsidies to more completely capture the subsidy's full effect could run afoul of GATT's requirement that countervailing duties not exceed "the estimated bounty or subsidy determined to have been granted. ${ }^{\prime \prime 163}$ Precisely what GATT allows is not always clear; ambiguities can be resolved only by a GATT ruling on a dispute between two countries, or by amendments to clarify the rules. Some countries have maintained that current U.S. practices violate GATTe.g., the use of a minimum of 10 percent general administrative overhead and 8 percent profit when constructing a product's fair value based on foreign manufacturers' ${ }^{\prime}{ }^{1}{ }^{164}{ }^{164}$ and the practice of assuming until proven otherwise that petitions are supported by the majority of the domestic industry. This latter practice has already been found to violate the GAT Antidumping Code. ${ }^{165}$

The United States has been negotiating in the Uruguay Round to allow countervailing and antidumping cases to be more effective. Along with the EC, it has pressed to provide clear authority for certain expanded anticircumvention measures, The United States has also pressed to prohibit domestic subsidies in certain cases, just like export subsidies are now prohibited. However, the United States faces an uphill battle in GATT, with few allies and with many nations pushing to weaken countervailing duty and antidumptig law.

Several practical concerns counsel caution in trying to enhance the laws' effectiveness. Imposing countervailing and antidumping duties entails substantial administrative costs, starting with an expensive investigation. Further, the computations used to determine subsidies and dumping rely on imprecise data that may contain a fair amount of estimation. At times, duties will be levied when there really were no subsidies or dumping. The stronger the laws, the more often such mistakes will occur, throwing up misguided barriers to imports. 
This problem is magnified because countervailing duty and antidumping petitions can be filed to harass one's competitors. While cases cost petitioners, they also cost the respondents. In fact, the burden on respondent firms can be greater, because the Commerce Department and the ITC, in developing the facts of the case, often scrutinize these fins' business records. Just the threat of countervailing or antidumping duties creates uncertainty that can impede imports. And if, perhaps because of the proceedings' inherent imprecision, very small countervailing or antidumping duties are imposed, there is the threat that in subsequent annual reviews these duties will be retroactively increased.

In the case of antidumping law, the imprecision is not just in evaluating data, but also in how dumping is defined. The problem is that what is defined as dumping does not always justify a response. While dumping is often a sign that the foreign firm has a special advantage, this is not always the case. Dumping is sometimes a short-term ploy to get new customers; U.S. firms can often meet this type of competition on their own. As calculated, dumping could be found when a foreign firm prices identically at home and in the United States, if the prices in both markets fluctuate together. Or dumping could be found simply because of exchange rate fluctuations. ${ }^{166}$ But if the definition of dumping excluded these transient effects, the law would also miss, at least for a while, situations that do require a government response. Another problem with dumping calculations concerns how to compare U.S. and home market selling prices. A fair comparison requires that differences in selling costs in the two markets be taken into account to net back to ex-factory prices for sale to each market; but when the foreign exporter sells through a U.S. subsidiary it seems impossible to write rules that will always fairly compare the two selling costs. It is not always possible to separate cases that warrant antidumping duties from those that do not.

Even when foreign firms enjoy a special advantage, countervailing or antidumping duties might not be helpful. The U.S. industry might be well able to take care of itself, while important downstream industries could benefit from the cheap imports. For certain industries, the U.S. economy might be best served by the downsizing or eliminating the industry in question, with resources put to better use elsewhere. As useful as countervailing and antidumping duties are in some cases-and foreign firms and countries often target high-reward industries where the U.S. industry appears vulnerable-in other cases, they are not.

Yet another consideration is that foreign countries can use these duties against U.S. exports. These countries include traditional users of countervailing and antidumping law such as the EC and Australia and newer users such as Mexico. Imprecision in computing dumping and subsidies, and the broad reach of the "dumping" label to include some conduct not warranting a response, can comeback to bite U.S. exporters. In some cases the United States has subsidized its industries, usually in an incidental rather than planned way. For example, governmentsupported R\&D for military aircraft has helped the U.S. commercial aircraft industry (see ch. 8). ${ }^{167}$ Another example is the government's support of half a billion dollars over 5 years for Sematech, an R\&D consortium concerned with semiconductor manufacturing. If the United States decides to increase support for its industries, they could become more vulnerable to trade remedies in other countries.

Where subsidy and dumping laws are ineffective, Section 301 might apply. In 1988, Congress specified that Section 301 applies to foreign "export targeting," defined as "any government plan or scheme consisting of a combination of coordinated actions ... bestowed on a specific enterprise, industry, or group thereof," with the effect of enhancing export competitiveness. ${ }^{168}$ Section 301 would thus seem to cover a variety of foreign policy tools inadequately covered by U.S. antidumping and countervailing duty law, such as R\&D programs and preferential financing. As of August 1991, no Section 301 case had been brought based on this provision, and such use of Section 301 would pose problems. There would be the same problems of delay, angering foreign countries, and soon as when Section 301 is invoked to eliminate foreign market barriers. Other countries are particularly averse to being told how to run their domestic economies. And Section 301 cannot reach back in time: a policy discontinued years or even decades ago, such as market protection or R\&D support, can be the cause of an export surge today. 


\section{OTHER MEASURES AGAINST IMPORTS}

Restrictions on particular imports can play a role in strategies for both mature industries facing difficult adjustments and for sunrise industries that promise fast growth. The appropriateness of protection depends on a host of factors and does not hinge on the presence of any individual foreign practice such as subsidies or dumping.

To justify such protection countries sometimes invoke GATT's Article XIX, the so-called “escape clause."169 The escape clause addresses situations in

which, because of a combination of "unforeseen developments' and the country's GATT obligations, a product is imported in such "increased quantities" as to "cause or threaten serious injury" to a nation's domestic producers. Under these circumstances, a country may temporarily suspend performance of its GATT obligations "to the extent and for such time as may be necessary to prevent or remedy such injury. "170The nation may raise tariffs, or impose quotas or nontariff barriers, but must compensate the countries whose exports have been blocked. If agreement can be reached, the compensation can consist of concessions (e.g., reduced tariffs) on other items; if no agreement is reached, an affected country may impose 'substantially equivalent" barriers on imports from the nation using the escape clause. ${ }^{171}$ Typically, the affected country would raise tariffs on products of its choosing.

U.S. law implements the escape clause in Section 201 and the following sections of the Trade Act of 1974, as amended. ${ }^{172}$ While GAPP requires only that the increased imports "cause or threaten serious injury," U.S. law specifies that the increased imports be at least as great as any other cause of injury. ${ }^{173}$ The U.s. statute, reflecting $\boldsymbol{G A T T}, \boldsymbol{r e}$ quires that an existing industry be injured; the injury test cannot be met by showing that the imports are preventing the establishment of an industry. ${ }^{174}$ In these ways and perhaps others, the injury test under Section 201 is more stringent than the injury test in subsidy and dumping cases. To assess injury, U.S. law specifies factors such as idling of facilities, profit levels, and unemployment levels. ${ }^{175}$

The ITC determines injury under Section 201. A petition from industry or organized labor normally triggers an ITC investigation, ${ }^{176}$ and the ITC typically takes 4 months to decide whether the injury requirement is satisfied. ${ }^{177}$ If the injury requirement is not satisfied, the case ends with no governmental action; if the requirement is satisfied, then the ITC decides whether to recommend protection. The protection can be tariffs and/or quotas, lasting up to 8 years. ${ }^{178}$ The ITC can recommend that the President negotiate with other countries to address the underlying cause of the increased imports or ameliorate their effect (as by restraining other countries' exports), or take any other action authorized under law. ${ }^{179}$ The ITC usually submits its recommendations to the President 6 months after the petition was filed. ${ }^{180}$ The President then has 2 months to decide what trade relief, if any, to grant. ${ }^{181}$

The President is supposed to weigh the social benefits and costs, and consider "efforts being made by the domestic industry to adjust to the import competition' and the "position of the domestic industry in the United States economy. ${ }^{182}$ The President has great flexibility in selecting the form of relief; he may choose one or more measures, including tariffs, quotas, auctioning off quotas to foreign producers, assistance to the domestic industry, negotiation of agreements with foreign countries, and "any other action which may be taken by the President under authority of law." ${ }^{\prime 183}$ Relief can last up to 8 years. ${ }^{184}$ While relief is in effect, the ITC reports to the President every 2 years on industry's progress in adjusting to import competition. The President can then reduce, modify, or termin ate the relief based on changed economic circumstances or his determination that the industry "has not made adequate efforts. ' ${ }^{185}$

Table 4-8 summarizes the use of Section 201 during 1975-1990. Of 62 cases, the ITC found injury in 33 , and in 30 recommended protection. The President granted protection in 14 of the cases. Overall, a petitioner's chance of obtaining some protection was about 23 percent. Further, the President frequently reduced the level of protection recommended. ${ }^{186}$

Use of Section 201 tapered off considerably after the 1970s. The change probably occurred in part because the Trade Act of 1979 made it easier to win dumping and countervailing duty cases, so that those cases were often a more attractive route to relief. ${ }^{187}$ 
Table 4-8-Section 201 Cases

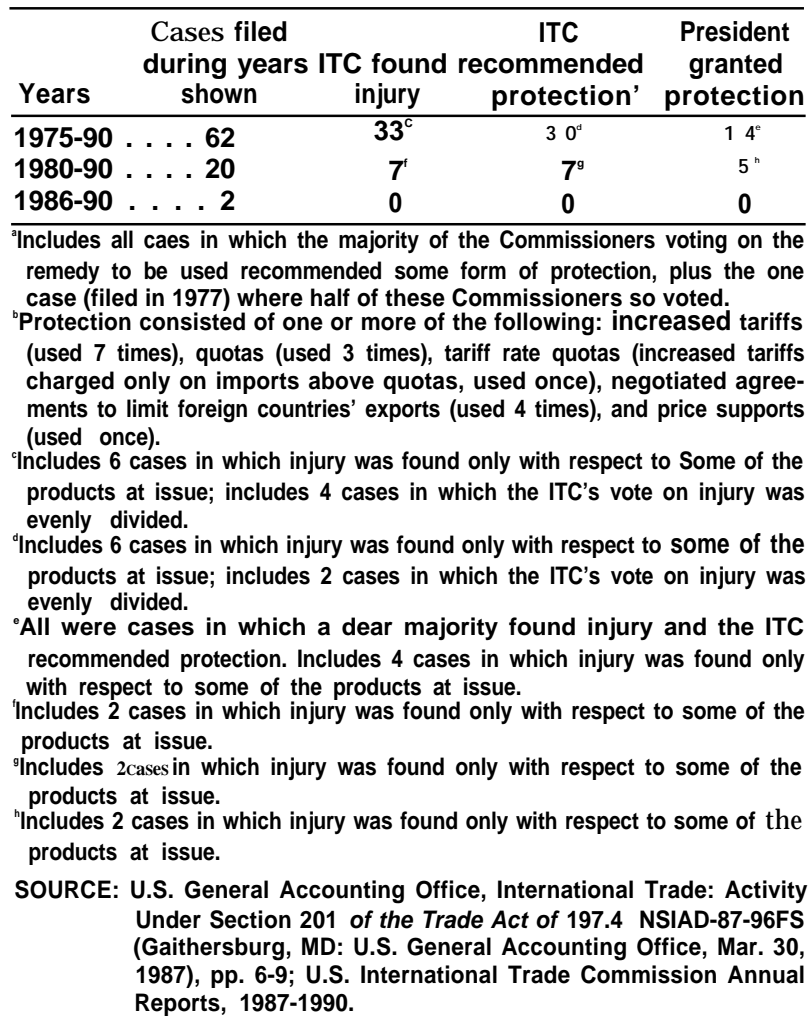

In addition, the ITC found the injury test not satisfied in a highly visible case filed in $\mathbf{1 9 8 0}$ concerning automobiles. To many, this seemed an ideal case for relief if ever there was one: an unexpected rise in oil prices suddenly made large U.S. cam an unattractive purchase compared to smaller Japanese cars. The ITC's negative decision in that case conveyed the message that the injury test under Section 201 would be very hard to meet. Although Congress in 1988 changed the statute in a way that likely would have changed the result in the autos case, ${ }_{188}^{18}$ there has not been a resurgence of interest in Section 201; in fact, only one case has been filed since.

Section 201 can be a useful trade tool. It operates within the GATT framework and therefore tends to be accepted by other countries. It has two advantages over countervailing duty and antidumping proceedings: it does not require the proof of subsidies or dumping; and it does not irritate foreign firms or countries by calling them unfair.

Section 201 has significant limitations that restrict its usefulness, especially for high-reward industries. It applies only to an already existing "domestic industry" that is "producing an article" that competes with the imported goods. ${ }^{189}$ It thus cannot be used to promote the formation of a new industry. ${ }^{190}$

The industry must be seriously injured or threatened in an absolute sense; it is not enough that the industry would have done much better without the increased imports. ${ }^{191}$ The Commission will find that a threat of serious injury exists only if "serious injury, although not yet existing, is clearly imminent if import trends continued unabated. ${ }^{\prime 192}$ These requirements make it hard to get relief at the beginning of a product cycle, when markets are growing rapidly.

Section 201 has not often been invoked on behalf of high-reward industries. One prominent highreward sector, electronics, is represented by only two cases-television receivers, filed in 1976, and CB radio transceivers, filed in 1977. The television case concerned a U.S. industry in decline, and the $C B$ radio case concerned a potential growth industry that, according to the ITC, was in deep trouble because of the Federal Communications Commission's decision to expand the citizens band from 23 to 40 channels. ${ }^{193}$ Section 201 has not been invoked for supercomputers, mainframe computers, workstations, personal computers, or semiconductors, where Japanese companies are a strong competitive threat to a U.S. industry.

Even for mature industries, the injury requirement can make it difficult to get relief before much damage has been done. For example, in July 1984 the ITC found no threat of serious injury to the nonrubber footwear industry even though imports had increased in volume from51 percent of domestic consumption in 1979 to 65 percent in $1983 .{ }^{194}$ The ITC reasoned in part that imports were predominantly at the low end and domestic production was predominantly at the high end, so that "rather than displacing domestic nonrubber footwear production, imports have served to complement it. ${ }^{\prime \prime 195}$ In value terms, the imports had increased only from 36 percent of domestic consumption in 1979 to 44 percent of domestic consumption in $1983 .{ }^{196}$ As the ITC spoke, however, the situation was changing. The industry filed another petition for relief, and in July 1985, one year after its first ruling, the ITC found a threat of serious injury. Import volume had risen to71 percent of domestic consumption in 1984, and 77 percent in the first quarter of 1985 . The 
imports had moved upscale; their value was 54 percent of domestic consumption in 1984 and 62 percent in the first quarter of $1985 .{ }^{197}$

Even if the legal hurdles are passed, relief still depends on the President. Recent Administrations have been averse to granting import relief in Section 201 cases. This results from a free trade orientation and the obligation under GATT to pay compensation.

\section{GOVERNMENT PROCUREMENT}

In market economies, governments seldom own industries, and must procure goods and services from private enterprises in order to function. Government procurement contracts cover everything from pencil sharpeners to cleaning services to supercomputers. If procurement is open and competitive, governments take bids and choose the suppliers that fulfill their needs at the cheapest prices. Often this does not happen.

Some foreign governments use public procurement to develop or maintain key industries and technologies. For example, the Japanese Government has procured Japanese supercomputers instead of faster U.S. machines to help develop its domestic industry (see ch. 6).

The United States seldom uses procurement as a tool to promote industries or technologies. Its basic policy is to conserve tax dollars and be fair to all U.S. suppliers by buying at arm's length. Accordingly, procurement law has elaborate procedures to ensure that the process is transparent, meaning that firms have adequate notice and opportunity to bid and that the selection is made according to criteria announced when bids are solicited. U.S. law allows disappointed bidders to protest; if the required procedures were not followed, a resolicitation could be required.

Another policy uses government purchases to protect domestic jobs and promote various social goals. This policy is reflected in laws giving preferences to goods manufactured in the United States-including "Buy American" laws and preferences for businesses that are small, minorityowned, or in depressed areas. National security concerns can limit purchases to U.S. goods. These laws are not meant to help commercial competitiveness, although they occasionally do--e.g., the requirement that DoD buy only domestically made supercomputers. But often these preferences do not apply, so that suppliers of foreign goods can compete on an equal footing.

Many foreign procurement markets are not so open. Standard practice in many other countries is to grant notice of procurements to, and fairly consider bids from, certain domestic firms. This imbalance of access was perpetuated by international agreements. These agreements include bilateral memoranda of understanding (MOUs) dealing with defense procurements and the GATT Procurement Code. The United States is negotiating to improve access to foreign procurements, but the negotiations are difficult and even modest improvements are not assured.

The imbalance of access and the fact that foreign governments often use procurement as a strategic tool to enhance competitiveness while the United States seldom does mean that U.S. and foreign procurement policies together have a negative effect on U.S. competitiveness.

\section{What the U.S. Public Sector Purchases}

In 1990, the U.S. public sector purchased about 9 percent of the goods produced in the United States (see table 4-9). Half of these purchases were for defense needs. ${ }^{198}$ The defense share of public purchases of durable goods was greater: 68 percent (see figure 4-8). Durable goods include computers, semiconductors, and many other important high technology products.

The effect of defense procurement on competitiveness is not clear. A large portion of defense purchases have no commercial use: military ships, missiles, military communications and electronic

Table 4-9-Purchases of Goods by the U.S. Public sector in 1990 (in billions of dollars)

\begin{tabular}{|c|c|c|c|}
\hline Durable & Nondurable & Total & $\begin{array}{c}\text { Percent of } \\
\text { GNP for good8 } \\
(\$ 2,144 \text { bn })\end{array}$ \\
\hline $\begin{array}{l}\text { Federal defense }^{a} \ldots . .83 .6 \\
\text { Federal nondefense . . } 5.7 \\
\text { State and local . . . . } 33.0\end{array}$ & $\begin{array}{r}13.1 \\
4.6 \\
53.9\end{array}$ & $\begin{array}{l}96.7 \\
10.3 \\
86.9\end{array}$ & $\begin{array}{l}4.5 \\
0.5 \\
4.1\end{array}$ \\
\hline Total $. . . \ldots \ldots \ldots, \overline{122.3}$ & 71.6 & 193.9 & $9.0^{b}$ \\
\hline
\end{tabular}

${ }^{a}$ This spending is almost all by the Department of Defense. A small amount, probably under 1 percent, is by the Department of Energy and NASA for defense-related work.

${ }^{\mathrm{b}}$ Figures do not add up because of rounding.

SOURCE: Department of Commerce, Bureau of Economic Analysis, Government Division, computer printouts, Feb. 28, 1991, and Economic Report of the President, 1991, table B-6. 
Figure 4-8-Government Purchases of All Goods and Durable Goods, 1990
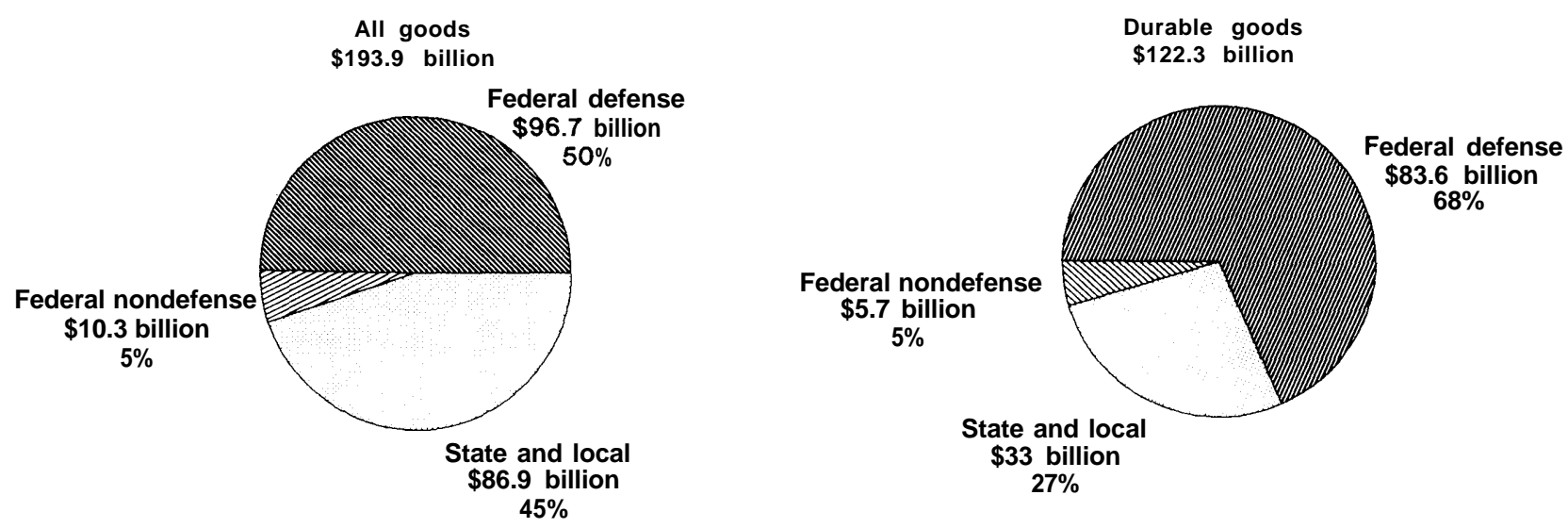

SOURCE: U.S. Department of Commerce, Bureau of Economic Analysis, unpublished data.

equipment, and combat vehicles (see figure 4-9). The largest portion (31 percent in 1990) is for aircraft. Although defense purchases of military aircraft have long generated spillover benefits to the civilian aircraft industry, these benefits are dwindling (see ch. 8, and vol. 2).

Defense procurement includes some items with commercial use, such as general purpose computers and automobiles, but their procurement represents only a tiny fraction of the U.S. market for the products. For example, defense purchases of general purpose computers in 1990 were worth $\$ 1.56$ billion, ${ }^{199}$ less than 1 percent of the estimated total U.S. market sales of $\$ 176$ billion. ${ }^{200}$ Defense purchases of noncombat motor vehicles in 1990 were worth $\$ 984$ million, ${ }^{201}$ less than 1 percent of the estimated $\$ 139$ billion in shipments of motor vehicles and car bodies made in the United States. ${ }^{202}$ These relatively small quantities limit the power of defense procurement to affect commercial industries.

On the other hand, defense needs for certain niche products have sometimes provided crucial early demand. Since its first sale in 1976, the U.S. supercomputer industry has benefited greatly from defense-related purchases by the Departments of Defense and Energy. For many years they were the major customers, and if not for early defense purchases and software generated in national laboratories, Cray Research Co., since 1976 the world's leading supplier of supercomputers, might not be in the supercomputer business today.
Figure 4-9-Defense Purchases of Durable Goods, 1990, \$83.6 Billion

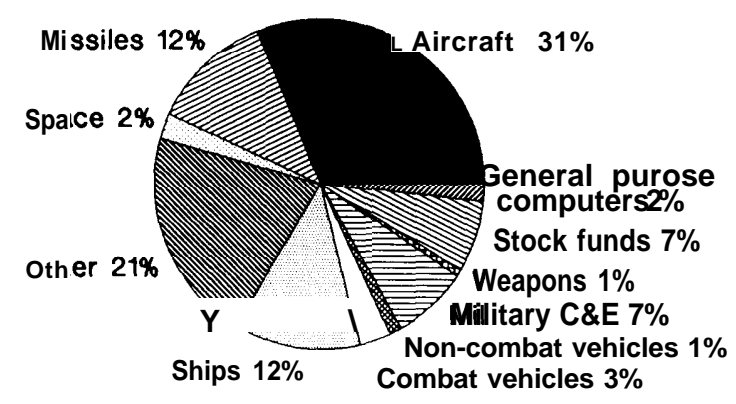

SOURCE: U.S. Department of Commerce, Bureau of Economic Analysis, unpublished data.

Federal nondefense procurements, while more oriented toward commercial products, are relatively small. In contrast to many other developed countries, the United States runs no national health service, no national railway, no national airline, no national telecommunications system, and no national university system. Therefore its public sector does not provide as large a market for medical equipment, rolling stock, aircraft, telecommunications equipment, computers, etc. For example, U.S. Government purchases of telecommunications equipment accounted for 17 percent of the domestic market in $1989 .{ }^{203}$ In contrast, up to 1988 roughly 90 percent of the equipment sold in the European Community was reportedly delivered to government entities. ${ }^{204}$

State and local governments together are more important than the Federal Government as public 
purchasers of nondefense goods in the United States. As shown in table 4-9, they purchased goods worth $\$ 87$ billion ( $\$ 33$ billion for durables) in 1990. This was 4.1 percent of the U.S. GNP for goods. Indeed, State and local governments are significant purchasers of certain products. In 1982 (the latest year for which figures are available), about 24 percent of State and local government purchases of durable goods were for motor vehicles. The same proportion spent on vehicles in 1990 equates to about $\$ 7.9$ billion in current dollars. ${ }^{205}$ This is about 6 percent of the $\$ 139$ billion in 1990 shipments of motor vehicles and car bodies made in the United States.

\section{The U.S. Legal Regime}

\section{Buy American and Other National Preferences}

" The Buy American Act was passed in 1933 as ... an unabashed protective measure, providing a barrier against goods of foreign origin in the area of Federal Government purchasing." ${ }^{206}$ This was one of many laws introduced during the depression years to use procurement to promote employment and other socioeconomic goals. ${ }^{207}$ The law has been amended several times and interpreted by regulations.

The Buy American regime applies to goods to be used within the United States. In general, domestic goods will be favored unless they are priced more than 6 percent higher than foreign goodss ${ }^{208}$ if the U.S. bidder is a small business or in a labor surplus area, the preference increases to 12 percent. ${ }^{209}$ If a product is manufactured in the United States, and if the cost of domestic components going into the product is over half the total component costs, then it is domestic; otherwise, it is foreign. ${ }^{210}$ This preference does not always apply. Two major exceptions arise under the GATT Procurement Code and bilateral defense MOUs, discussed below. Other exceptions stem from the GATT Civil Aircraft Code and the U. S-Canada and U.S.-Israel Free Trade Agreements. ${ }^{211}$

The Department of Defense $(\mathrm{DoD})$ procures under a slightly different set of rules. Products from countries that do not have special agreements with the United States can be subject to a 50 percent price preference. DoD must disadvantage foreign bids either by adding 50 percent to the value exclusive of duties, or by adding 6 percent inclusive of duties, whichever is greater. The 6 percent preference increases to 12 percent in competition with domestic bids from small businesses, or in areas of labor surplus. After this adjustment, the lowest bid wins. ${ }^{212}$

Many "Little Buy American" acts grant additional preferences to particular products such as machine tools and ball bearings. Some of these preferences are absolute, forbidding the purchase of foreign products no matter what they cost. Aside from Buy American, there are some absolute preferences for products of U.S. businesses that are small, minority-owned, or located in disadvantaged areas; in fiscal year 1990, 19.9 billion dollars' worth of contracts for goods and services were made under these preferences, out of total Federal contract actions worth $\$ 191$ billion. ${ }^{213}$

\section{Defense Procurement and Memoranda of Understanding}

The United States has negotiated defense MOUs with most major trading partners, though not Japan, Korea, or Taiwan. About half of defense procurement is open to MOU partners on an equal basis. ${ }^{214}$ Under the MOUs, the United States waives the general Buy American preference, 215 through not some of the specific Buy American preferences. ${ }^{216}$ The MOUs do not affect small business, minority business, and labor surplus area preferences; they do not apply when a U.S. or Canadian source is required to preserve the defense industrial base; and they do not apply to classified military procurements that require a U.S. source for security reasons.

The GATT Procurement Code and the Trade Agreements Act

The GATT Procurement Code $\mathrm{C}^{217}$ and the Trade Agreements Act of 1979 eliminate the general and some specific Buy American preferences. ${ }^{218}$ The Code requires signatories to give each other's goods national treatment, treating the foreign goods the same as domestic goods. The Code currently applies only to goods; it does not cover purchases by State and local governments, or military weapons or other goods necessary to maintain national security. ${ }^{219}$ Further, the Code covers only purchases worth at least 130,000 Special Drawing Rights (SDRs), equal to about $\$ 180,000$ in January $1981 . .^{20}$ Finally, the Code applies only to agencies specifically listed in a country-by-country Annex; some countries have specified other exemptions. For many countries, including the EC and the United States, agencies dealing with telecommunications, transport, energy, and water are not covered. Also, the United States 
has exempted from Code coverage purchases reserved for small or minority businesses.

The GATT Procurement Code is implemented in U.S. law by the Trade Agreements Act of 1979. ${ }^{221}$ The Code Annex lists most agencies of the U.S. Government. Some exceptions are the Department of Energy, the Department of Transportation, the Bureau of Reclamations at the Department of the Interior, the Army Corps of Engineers within DoD, and, for some products, DoD. The Act grants national treatment not only to Code co-signatories, but also to countries with whom the United States has equivalent bilateral treaties, and to many developing countries on a nonreciprocal basis. ${ }^{222}$

\section{State and Local Procurement}

Like the Federal Government, all the States have adopted the rule of competitive procurement. According to a 1987 survey, 27 States have no Buy American laws on their books; ${ }^{223}$ the other States have some Buy American laws, though sometimes they are not implemented. For example, in 1968 a California appellate court found California's Buy American law to violate the U.S. Constitution; ${ }^{224}$ the law has since been inoperative. Kansas law permits the State government to reject foreign bids, but this is not done.$^{225}$ States may offer preferences to small business, minority businesses, and in-State suppliers. ${ }^{226}$ Some local governments have preferences of their own.

\section{The Effect of U.S. Procurement Law and Policy}

U.S. procurement law and policy in international negotiations have been of limited value in advancing U.S. competitiveness. This is because the United States does not use procurement strategically, and procurements are on balance more open than foreign procurement markets.

\section{Buy American Preferences}

Buy American preferences can raise the prices the government pays for goods. It is not clear whether Buy American's benefits outweigh this and other possible costs. The 6 percent Buy American preference is intended to promote employment, but it applies with no consideration of whether additional jobs are needed ${ }^{27}$ Specific Buy American preferences, usually the result of heavy lobbying from industry associations or regional interests, have supported many industries: food, clothing, coal, paper, valves and piping, machine tools, aircraft ejection seats, supercomputers, etc. This targeting is not based on competitiveness strategy. It carries the danger that the protected industry will grow complacent and uncompetitive. The Buy American laws are complex, highly technical, and difficult for bidders and agencies alike to understand and apply. ${ }^{228}$ They add complexity, cost, and delay to an already burdened Federal procurement process. ${ }^{229}$

Occasionally, defense procurement aids competitiveness in dual-use industries. For example, the 1987 Defense Appropriations Act stipulated "that none of the funds in this Act maybe used to purchase any supercomputer which is not manufactured in the United States. "230 This restriction has probably helped the U.S. supercomputer industry, not only by assuring revenues but also by promoting the development of software for domestic machines. However, on the whole special Buy American preferences might do less good than harm (higher prices paid, inefficiencies perpetuated, and administrative burden).

While reliable data are not available, ${ }^{231}$ the effect of the general Buy American preference is likely to be modest, since defense MOUs and the GATT Procurement Code override the preference when they apply and the civilian preference is only 6 (sometimes 12) percent for nondefense goods.

Buy American preferences are a lightning rod for foreign criticism as a symbol of U.S. protectionism. ${ }^{232}$ Perhaps Buy American's best use is as a bargaining chip to open up foreign markets. Negotiations to expand the scope of the GATT Procurement Code have tended in that direction.

\section{Unequal Access}

The defense MOUs, first negotiated in the late 1970s, have perpetuated the imbalance in access to government procurements. These MOUs probably cover about half of DoD procurement. Since defense accounts for about 90 percent of government procurements of goods (table 4-9), and 80 percent of Federal procurement generally (including goods and services), ${ }^{233}$ these MOUs open a substantial part of U.S. Government procurement to foreign competition. ${ }^{234}$

These MOUs did not open foreign government procurement to U.S. competition in the same way. To begin with, defense spending is less important in other countries. While defense procurement of 
goods and services is 80 percent of government procurement in the United States, it is only an estimated 25 to 50 percent of the procurement of its allies. ${ }^{235}$

In addition, the defense MOUs were intended as defense cooperation agreements, and were not designed to open foreign procurement markets to U.S. goods. The primary goal was to secure the goodwill and cooperation of military allies. It was expected that the MOUs would reduce the U.S. surplus in defense trade, which they did. ${ }^{236}$ While 17 of the 19 MOUs in principle were supposed to grant reciprocal national treatment, ${ }^{237}$ they required national treatment only to the extent consistent with the other country's laws and regulations; ${ }^{238}$ this huge loophole allowed buy-national preferences to remain. These MOUs did not require foreign defense procurement to be transparent; in large measure it is not. Foreign procurements are often not well publicized. Also, the foreign governments' selection criteria are often less open and predictable, with U.S. bids not guaranteed full consideration. This uncertainty sometimes deters U.S. firms from preparing bids. And foreign governments have often required U.S. prime contractors to use local subcontractors, which can hurt U.S. small businesses that cannot easily export on their own. ${ }^{239}$

Reliable data on how much procurement these MOUs cover in the United States and elsewhere, and how much trade results in both directions, is not available. ${ }^{240}$ However, the lesser importance of defense procurement in foreign countries and the lack of true reciprocity suggest that the MOUs have cost U.S. firms home market share without opening export markets enough to compensate. This imbalance prompted a debate within DoD in the late 1980s about whether the MOUs are to the United States' advantage, ${ }_{i}^{24}$ it also aroused congressional concern. In 1989, the Administration began renegotiating the MOUs to achieve better access by U.S. firms to foreign defense markets. As of April 1991, MOUs had been renegotiated with France, Italy, and The Netherlands. The new terms require some procedural fairness but still do not require waivers of buy-national preferences. ${ }^{243}$

The GATT Procurement Code might have reduced the imbalance in access to government procurements. In addition to requiring national treatment, the Code requires covered purchases to be transparent. Upcoming procurements are to be announced in advance, giving firms at least 30 days to bid, and evaluation is limited to criteria specified in advance. The Code's provisions, originally written in 1979 and amended in 1986, were modeled after U.S. practice.

Recent data on procurement and trade under the Code are not publicly available because the Administration has classified it. ${ }^{244}$ Detailed data are available only for 1981, the first year during which the Code was applied. The Administration had predicted that the Code would open $\$ 20$ to $\$ 25$ billion annually in foreign procurements to U.S. competition on an equal basis. However, for 1981, the General Accounting Office found that the Code covered a total of only $\$ 4.2$ billion of purchases by all foreign signatories. In contrast, \$18 billion of U.S. procurement was covered under the Code. ${ }^{245}$ Thus, roughly 80 percent of the trade opportunities mandated by the Code were in the U.S. market, and only 20 percent in foreign markets. This roughly $80 / 20$ ratio persisted through $1987 .{ }^{246}$ This ratio contrasts sharply with the ratio of the United States' total procurement to foreign signatories' combined total procurement, which is at most about 50/50. ${ }^{247}$

While it may seem that the United States gave up more than it got with the Procurement Code, the matter is not that simple. Many of the purchases covered by the Code would have been open to foreign competition anyway. Close to 90 percent of U.S. purchases covered by the Code have been for defense ${ }^{248}$ and a substantial portion of those have been covered under MOUs. Where MOUs do not apply, if not for the Procurement Code the Buy American regime would most often govern procurement, but even under Buy American foreign goods are sometimes purchased. Thus, it is possible that the new opportunities for U.S. exports under the Code were the same or even greater than the new opportunities for foreign countries' exports to the U.S. market; there is no way to tell with the available data.

Another way of assessing the effect of the Code is to look at actual purchases made under it. While the Code does not guarantee any sales, which depend on competitive bids, the level of sales is one indication of how effectively the Code has opened a given market. In 1981, \$3.3 billion of foreign goods were purchased by the U.S. Government under the Code, but of that over $\$ 3$ billion was for fuel and related products that were sold by longstanding arrange- 
ments predating the Code. ${ }^{249}$ Only about $\$ 270$ million of nonfuel-related foreign goods were purchased, or about 1.5 percent of covered purchases. Much of that might have occurred anyway under defense MOUs. For trade in the other direction, while recognizing that data were unreliable, GAO estimated that only about $\$ 210$ million of U.S. goods were sold in 1981 to foreign governments under the Code (none of it fuel-related), or about 5 percent of the covered purchases. ${ }^{250}$ In sum, the trade volumes were low, and it is not clear whether the Code contributed more to U.S. exports or imports. Startup problems might have depressed the trade in $1981 .{ }^{251}$ Amendments effective in 1988 might have increased trade volumes in both directions.

One persistent problem is that a large part of civilian procurement in the EC and other countries is made by agencies not covered under the Procurement Code, including those responsible for telecommunications, transport, energy, and water. In these sectors, which probably account for 25 to 50 percent of the EC procurement market, ${ }^{252}$ the EC member governments favored domestic over U.S. suppliers. For example, in the last 30 years, there have been virtually no sales to the European Community of American electric utility equipment such as boilers and turbine generators, ${ }^{253}$ even though General Electric and Westinghouse were the top two world suppliers as a percent of world sales between 1955 and $1984 .{ }^{254}$ The only sales have been to countries with no production facilities of their own. EC members have favored national producers of telecommunications equipment. For example, in 1987, France, Germany, Italy, the United Kingdom, and Belgium on average satisfied 73 percent of their demand for digital switching equipment from domestic producers, despite substantially higher costs. ${ }^{255}$

In the United States these sectors are largely open. Many U.S. utilities and telecommunications companies are privately owned and procure openly and competitively as a matter of course. Governmentowned utilities have also purchased substantial shares of equipment from foreign sources. For example, from 1977 to 1981 the largest Federal purchasers of heavy electrical equipment collectively spent about 26 percent of their money abroad. ${ }^{25}$

The United States has been negotiating to bring government entities buying equipment in these sectors within the GATT Procurement Code. ${ }^{257}$ The
EC contends that if publicly held utilities in these sectors are to be covered by the Code, then privately held utilities should in many cases be subject to similar procurement requirements. The EC's position is that if: 1) there are substantial barriers to entry in the industry; and, 2) there is substantial government influence over the utility (e.g., as regulation of the utility's operation), then there is insufficient assurance that the utility would, on its own, procure as a private firm does, on the basis of quality, cost, service, etc. (Both British Telecom and the Bell operating Companies in the United States, for example, would meet these two conditions.) The EC internally is following its own precepts: effective January 1, 1993, it will regulate procurement by privately owned utilities to prevent favoring domestic goods over the goods of other EC members. ${ }^{258}$ The United States opposes this change, arguing that such utilities would, on their own, procure on the basis of cost, quality, etc., because that would maximize their profit, and that regulating such utilities would saddle them with a needless administrative burden. As of June 1991, the resolution of this issue was unclear.

The EC also wishes to include procurements by State and local governments in the new Code. However, there is some question as to the extent of the U.S. Government's legal power over State procurement. So far, the Office of the United States Trade Representative (USTR) has made inquiries as to whether States might be willing to make a voluntary commitment to follow the Code. These commitments could then be incorporated into Federal law. ${ }^{259}$ Also under negotiation is the coverage of services and rules to ensure that a fair hearing is given to unsuccessful bidders who complain that the required procedures were not followed.

\section{Forcing Open Foreign Markets}

Whether or not the GATT Procurement Code applies in a given case, the United States considers closed foreign procurement markets, like other trade barriers, unjustified. Under the Buy American Act of 1988, also known as Title VII of the Omnibus Trade and Competitiveness Act of $1988,{ }^{260}$ the USTR annually lists countries that discriminate in their procurement against U.S. products. The list is to include not only violations of the Procurement Code, but also any "significant and persistent" patterns of 
discrimination, causing "identifiable harm" to U.S. businesses, by countries "whose products or services are acquired in significant amounts' by the U.S. Government. ${ }^{261}$ When a country is listed, the USTR is to negotiate to have the practice changed; if the country does not stop, the President can retaliate by discriminating against that country in U.S. Government procurement. ${ }^{262}$

In its first report, in April 1990, the USTR described "substantial procurement problems" in several countries with markets "of particular significance,' and noted special concern over "access to the heavy electric equipment and telecommunications sectors" (currently excluded from the Procurement Code) in the EC, Germany, France, and Italy. However the USTR determined that no countries met the criteria of the statute. ${ }^{263} I t$ is difficult to understand how the examples the USTR noted for special concern fail to meet criteria for listing under Title VII. The discrimination appears to be significant and persistent, and cause considerable harm to U.S. fins; the noted countries' products and services are purchased by the U.S. Government in significant amounts. In its second report, in April 1991, the USTR listed just one country, Norway, for violating its Code obligations in its procurement of an electronic toll collection system. ${ }^{264}$ The USTR decided again, however, not to list the EC, Germany, France, and Italy for their non-Code-covered discrimination in the procurement of heavy electrical equipment and telecommunications equipment, even though this discrimination 'remain[ed] of particular concern.

Why has the Administration not used Title VII more? Partly because threatening countries with sanctions during the Procurement Code negotiations, especially for actions not inconsistent with the current Code, could antagonize them and set back the negotiations. In April 1990, the Administration believed that keeping Congress informed and promising to evaluate the progress of the negotiations in the next annual review would facilitate the negotiations in progress while keeping in reserve a prod for recalcitrant countries. ${ }^{265}$ In April 1991, the Administration reported that progress had been made in the past year in negotiations to end the cited discrimination by expanding the Code's scope and that it would continue to monitor developments.

\section{EXPORT PROMOTION}

Exporting is difficult. To export, a firm must:

- evaluate foreign markets;

- learn how business is done abroad;

- identify, contact, evaluate, and select potential customers, agents, distributors, and/or partners;

- learn about foreign customers' special needs and perhaps modify the product;

- prepare special labeling for each market and possibly special packaging as well;

- conduct an advertising campaign abroad (unless that is done by a local agent); and

- arrange for shipping, insurance, and customs clearance.

The exporter must also follow any regulatory requirements of the target country, and is sometimes disadvantaged by foreign tariffs or nontariff barriers. Frequently, special export financing must be obtained. And these efforts require the exporter to overcome separations due to geography, language, and culture.

The U.S. Government assists exporters in these efforts. The Department of Agriculture provides a full range of services for agricultural exports. But exporters of manufactured goods must go to more than one agency to get a full range of services. The Export-Import Bank of the United States (Eximbank) assists with export financing, and many other services are provided by the Commerce Department's International Trade Administration (ITA). The activities of these and other agencies are coordinated by the Trade Promotion Coordinating Committee, chaired by the Secretary of Commerce. ${ }^{266}$

Within ITA, the U.S. and Foreign Commercial Service (USFCs) is primarily responsible for gathering information on export markets and making it available to business. In summer 1991, USFCS had about 200 commercial officers and 490 foreign national employees providing export counseling in U.S. embassies abroad and a total staff of about 300 in field offices in the United States. ${ }^{267}$ USFCS emphasizes industry sectors with substantial export potential. Otherwise, USFCS does not target any particular sector for strategic or other reasons. Also within ITA, Trade Development (TD) analyzes trends by industry sector and works with industry associations to promote exports, and International Economic Policy (IEP) monitors foreign trade prac- 
tices and proposes strategies for opening foreign markets. $^{268}$

The United States spends proportionately much less on export promotion than do many other countries. An unreleased 1988 report by the Department of Commerce ${ }^{269}$ compared export promotion programs in eight nations: Belgium, Canada, France, Germany, Italy, Sweden, the United Kingdom, and the United States. The report shows that in 1987 all of the other nations spent between 2 and 25 times as great a fraction of GNP on export promotion as the United States (table 4-10). The United States ranked sixth in export promotion spending in proportion to total exports. As well as spending relatively less overall, the United States allocates funds lopsidedly for agricultural rather than industrial exports compared to other countries. The United States only spends one-eleventh as much on industrial exports as on agricultural exports, per dollar of each type of export. In contrast, France spends 29 times as much on industrial exports, the United Kingdom 5 times, Belgium 1.6 times, and Italy one-ftith as much.

The USFCS budget was particularly tight in the late 1980s, when the budget for foreign operations was not adjusted to compensate for the dollar's declining purchasing power abroad. ${ }^{270}$ Foreign posts had no money for market research contracts and often had inadequate libraries. Sometimes foreign service officers did not even have funds to return phone calls from firms in the United States. ${ }^{271}$ The USFCS budget has recently improved somewhat, from $\$ 75$ million in fiscal year 1987 to $\$ 108$ million in fiscal year $1991 .{ }^{272}$ But a policy of recovering costs horn firms using USFCS services has had some perverse effects. In the 1980s, USFCS published Basic Guide to Exporting, a step-by-step introductory manual on how to export. While the guide cost only $\$ 8.50$ per copy, the need to collect this amount made it harder for businesses to get the book; USFCS field offices could not sell it because the revenue belonged to the Government Printing Office. The need to recover publication costs similarly crippled ITA's Associate Office Program, under which local business organizations help promote ITA products, services, and activities. ${ }^{273}$

USFCS recent problems have not stopped with money matters. In January 1989, the General Accounting Office reported other weaknesses, includting a mismanaged trade show program and an inefficient information management system. ${ }^{274}$ Starting in July 1989, USFCS, with a new Director General, undertook an extensive long-term strategic review of its operations. Partly through surveys, interviews, and discussion groups, USFCS sought to determine anew what business' most important needs were, how USFCS could be most helpful, and what tasks were better left to other organizations. ${ }^{275}$

Instead of trying to be all things to all people, USFCS decided to focus on the needs of the infrequent exporter-one that exported more than once per year but less than once per week. USFCS concluded that firms exporting less needed basic information that could be disseminated most efficiently by organizations such as State governments,

Table 4-10-Spending for Export Promotion in 1987

\begin{tabular}{|c|c|c|c|c|c|c|c|c|}
\hline & Belgium & Canada & France & Germany & Italy & Sweden & $\begin{array}{l}\text { United } \\
\text { Kingdom }\end{array}$ & $\begin{array}{l}\text { United } \\
\text { States }\end{array}$ \\
\hline \multicolumn{9}{|l|}{ Central government } \\
\hline spending $\ldots \ldots \ldots$ & $\$ 45.8 \mathrm{~m}$ & $\$ 484.3 \mathrm{~m}$ & $\$ 330 . \mathrm{Im}$ & $\$ 61.5 \mathrm{~m}$ & $\$ 209.3 \mathrm{~m}$ & $\$ 10.0 \mathrm{~m}$ & $\$ 190.9 m$ & $\$ 261.6 \mathrm{~m}$ \\
\hline Total spending ${ }^{\mathrm{a}}$. & $\$ 62.9 \mathrm{~m}$ & $\$ 546.8 \mathrm{~m}$ & $\$ 340.7 m$ & $\$ 102 . I m$ & $\$ 219.3 \mathrm{~m}$ & $\$ 72.4 \mathrm{~m}$ & \$194.Im & $\$ 294.0 \mathrm{~m}$ \\
\hline On agricultural exports & $\$ 4.5 \mathrm{~m}$ & $\$ 43.7 \mathrm{~m}$ & $\$ 2.5 \mathrm{~m}$ & $\$ 5 . I m$ & $\$ 30.7 m$ & $\$ 2.2 \mathrm{~m}$ & $\$ 2.7 \mathrm{~m}$ & $\$ 173.0 \mathrm{~m}$ \\
\hline On industrial exports ........ & $\$ 58.4 \mathrm{~m}$ & $\$ 503.1 \mathrm{~m}$ & $\$ 338.2 \mathrm{~m}$ & $\$ 97.0 \mathrm{~m}$ & $\$ 188.6 \mathrm{~m}$ & $\$ 70.2 \mathrm{~m}$ & $\$ 191.4 \mathrm{~m}$ & $\$ 121.0 m$ \\
\hline \multicolumn{9}{|l|}{ Totai spending per $\$ 1,000$ of } \\
\hline ali exports $\ldots \ldots \ldots \ldots \ldots \ldots$ & $\$ 0.71$ & $\$ 6.00$ & $\$ 2.18$ & $\$ 0.35$ & $\$ 2.00$ & $\$ 1.65$ & $\$ 1.45$ & $\$ 1.16$ \\
\hline Of agricultural exports $\ldots \ldots \ldots$ & $\$ 0.46$ & NA & $\$ 0.09$ & NA & $\$ 9.30$ & NA & $\$ 0.29$ & $\$ 5.95$ \\
\hline Of industrial exports . & $\$ 0.74$ & NA & $\$ 2.61$ & NA & $\$ 1.78$ & NA & $\$ 1.53$ & $\$ 0.54$ \\
\hline \multicolumn{9}{|l|}{ Totai spending per } \\
\hline $\begin{array}{l}\$ 1,000 \mathrm{GN}^{\mathrm{b}} \ldots \ldots \ldots \ldots \ldots \ldots \\
\$ 1,000 \text { Centrai Government }\end{array}$ & $\$ 0.40$ & $\$ 1.48$ & $\$ 0.47$ & $\$ 0.11$ & $\$ 0.29$ & $\$ 0.46$ & $\$ 0.43$ & $\$ 0.06$ \\
\hline spending $\ldots \ldots \ldots \ldots \ldots \ldots$ & $\$ 1.07$ & $\$ 6.02$ & $\$ 1.95$ & $\$ 0.68$ & $\$ 0.64$ & $\$ 1.33$ & $\$ 0.98$ & $\$ 0.29$ \\
\hline Capita ................... & $\$ 6.35$ & $\$ 21.44$ & $\$ 6.19$ & $\$ 1.67$ & $\$ 3.74$ & $\$ 8.72$ & $\$ 3.42$ & $\$ 1.20$ \\
\hline
\end{tabular}

m-million

${ }^{\mathrm{a}}$ Total spending comprises not just central government spending, but spending from local governments, quasi-government agencies, and cooperating nongovernment agencies.

${ }^{\circ}$ Gross Domestic product (GDP) is used instead of Gross National Product (GNP) for Canada and Italy.

SOURCE: Unreleased Department of Commerce Report, Export Prornotion Activities of Major Competitor Nations, May 1988. 
industry associations, and chambers of commerce. USFCS considered that very experienced exporters could, for the most part, fend for themselves, although they needed help in removing foreign market barriers.

USFCS found that industry's top two priority needs were for timely, product-specific information, and for assistance in locating and dealing with overseas agents, distributors, and end users. Accordingly, it has switched the focus of its information gathering from general information about sectors to specific information about particular products, and has worked harder to help industry with foreign contacts. An example of the latter is the "Matchmaker' program, by which U.S. exporters travel abroad and interview about 10 interested local firms per day. Another example, a joint effort among USFCS, TD, and IEP, is the 5-year Japan Corporate Program, for which the Commerce Department selected 18 firms (out of about 130 applicants) that showed exceptional promise for being able to export to Japan. The companies, selected in late 1990, committed to:

- visit Japan four times per year (at least twice per year by the firm's President or CEO);

- print labeling and promotional material in Japanese;

- participate in at least one trade show each year;

- modify products as needed for the Japanese market; and

- arrange for after-sale service and maintenance.

The Commerce Department in return is providing marketing data and promotional support, which included the participation of Commerce Secretary Mosbacher in kicking off the program in Tokyo in April 1991.

USFCS has increased both its counseling regarding options and sources for financing exports, and assistance in complying with export control regulations. USFCS is also trying to improve information flow among its headquarters, domestic field officers, and overseas posts, though this effort depends largely on an automated information system whose target completion date is September 30, 1993.

The Commerce Department does not provide export financing. Often credit terms are an important part of competitiveness in export sales, especially to developing countries. All major economic powers have some governmental export credit agency (ECA) that helps to finance exports. ${ }^{276}$ In the United States, this function is carried out primarily by the Eximbank, an independent agency of the U.S. Government, and (for agricultural products) the Commodity Credit Corporation, a corporation owned by the U.S. Government and run by the Department of Agriculture.

Eximbank can fill in after private sector financing leaves off, so as to provide, when possible, export financing comparable to that available for exports from other countries. While U.S. commercial banks are often reluctant to provide export financing services because they are unfamiliar with the risks in the destination country, Eximbank's specialized knowledge of these risks enables it to provide such services. The need for Exirnbank is greater now that U.S. commercial banks, burned by bad foreign debts in the 1980s, are more cautious about foreign loans. Even when banks are willing to provide services, their interest rates and other fees may be higher than the fees for government-backed export financing abroad. Eximbank's activities have cost money; at the end of fiscal year 1990, Eximbank had an accumulated deficit of $\$ 6.5$ billion, financed by borrowing from the government. ${ }^{278}$

If an exporter grants a foreign customer time to pay, Eximbank may provide insurance against the risk of nonpayment. Similarly, if a U.S. or foreign bank lends money to the customer, Eximbank can provide the bank with a guarantee against default on the loan. Insurance and guarantees help guard against both normal commercial risk of nonpayment (bankruptcy of buyer, change in market demand for buyer's product, etc.) and political risks (war, expropriation, asset freezes, etc.). Eximbank guarantees can be crucial to obtaining private sector loans, and can help firms get these loans on better terms. Eximbank can lend money itself, though it normally does so only to match particular loans offered by foreign ECAs. ${ }^{279}$ These loans may be direct to the customer, or indirect by rediscounting bank loans (lending to a bank money that the bank in turn lends at higher interest to the customer). Eximbank also makes short-term working capital loans to exporters.

Eximbank's total outstanding commitments, including loans, guarantees, and insurance, cannot exceed $\$ 40$ billion, though the first $\$ 25$ billion of insurance and guarantees are counted only at a quarter of their value so that a total of $\$ 58.75$ billion is possible. As of September 30, 1990, actual out- 
standing commitments were $\$ 13.3$ billion in loans and $\$ 16.7$ billion in insurance and guarantees, for a total of $\$ 30$ billion. There are also ceilings set each year on new commitments. For fiscal year 1990, the ceiling was $\$ 612$ million for loans and $\$ 10.2$ billion for guarantees and insurance. The actual commitments made were $\$ 612$ million in loans (the full amount authorized) and $\$ 8.2$ billion in guarantees and insurance. These amounts are modest compared to the total U.S. exports in calendar year 1990 of about $\$ 390$ billion in goods and $\$ 133$ billion in services. Agricultural exports receive proportionately much more government financing. The Commodity Credit Corporation made commitments of $\$ 911$ million in loans and $\$ 4.5$ billion in guarantees in fiscal year $1990,{ }^{280}$ compared with about $\$ 40$ billion in agricultural exports in fiscal year $1990 .{ }^{281}$

Congress apparently envisioned that Eximbank's financing be focused on strategically selected industries. In 1983, Congress amended the Export-Import Bank Act of 1945 to require that Eximbank provide in an annual report "a detailed description of all actions which have been taken ... or ... will be taken" to:

- "maintain the competitive position of key linkage industries" [this refers primarily to industries that benefit downstream industries];

- "support industries which are engaged in the export of high value added products";

- "support industries which axe engaged in the development of new capital goods technology"; and

- "preserve and create high skilled jobs in the United States economy." ${ }^{\prime 282}$

However, it is not clear to what extent Eximbank's activities have been strategically focused. ${ }^{283}$ Further, Eximbank's effectiveness is limited in two ways.

First, Eximbank grants creditona"'needs' basis, while European and Japanese ECAs grant credit on an 'entitlement' basis. European and Japanese governments "make broad, long-term determinations about" which exports to assist and by what means, "and then provide ... sufficient resources and administrative freedom" to assist exports in all credit worthy cases within the guidelines. ${ }^{284} \mathrm{How}$ ever, in the United States, "increasing budget discipline and a strong free trade, antigovernment interventionist philosophy have combined" to require that applicants demonstrate on a case-by-case basis that they need the financing to close the deal. ${ }^{285}$ The case-by-case approach increases paperwork, which along with the uncertainty regarding approval can discourage would-be applicants.

Eximbank's effectiveness has also been limited in matching the very favorable terms of some foreign loans. The United States and its major trading partners have subscribed to an Arrangement on Guidelines for Officially Supported Export Credits. The Arrangement limits the attractiveness of ECA financing by specifying interest rate floors, minimum up-front cash payments, and maximum payback periods. ${ }^{286}$ The Arrangement has largely prevented U.S. firms from being disadvantaged by superior financing by foreign ECAs. However, the Arrangement has a big loophole that lets countries combine export loans or guarantees with grants of aid for development. The combination of export financing with aid is called mixed credits or tied aid (since the aid is tied to the purchases from the donor country).

It is difficult to assess the impact of tied aid on U.S. manufacturing competitiveness. An Eximbank study asked firms in five capital goods industries (telecommunications equipment, computers, electric power generating machinery, rail transportation products, and earth moving equipment) to estimate sales to developing countries that were lost because of foreign tied aid. The firms estimated that for the years 1985 through 1988, an average of between $\$ 400$ and $\$ 800$ million per year of sales were lost in all sectors combined. These lost sales were at least 10 percent of the combined markets of all developing countries in 8 out of 12 subsectors, and were at least 30 percent in 4 of these subsectors. However, the lost sales represented at least 10 percent of the U.S. industry's total output in only 4 subsectors ${ }^{287}$ and in no cases represented at least 30 percent.

These figures do not tell the whole story. Lost initial sales can mean lost follow-on sales, especially when compatibility is a concern. The survey responses indicated that foreign tied aid had overall decreased exports by at least 10 percent in 7 out of 12 subsectors. ${ }^{28}$ This result is open to question. To balance its case studies, Eximbank performed a macroeconomic analysis of the impact of tied aid. The analysis failed to confirm this significant negative impact. ${ }^{289}$

The United States ties a large part of foreign aid to purchases. However, since 1974, U.S. aid has 
focused on agriculture, nutrition, health, and education, rather than the large capital projects favored by some major donor countries. From 1984 through 1987, U.S. bilateral development assistance was $\$ 15.2$ billion, amounting to 34.8 percent of the aid given by the seven largest donors; but the figure drops to $\$ 1.1$ billion, or 5.3 percent of the sevencountry total, when only extractive industries, power, transport, telecommunications, and other capital goods are counted. ${ }^{290}$ Thus, tied aid programs in other donor countries offer more opportunity to manufacturing industries. This is no accident. Most other aid donors use tied aid to promote particular industries, while the United States, except for agriculture, does not. ${ }^{291}$

Japan in particular uses foreign aid to promote selected industries. Japan grants about as much nonmilitary foreign aid as the United States. ${ }^{292}$ However, 44 percent of Japanese aid goes to economic infrastructure, compared to only 4 percent of U.S. aid. ${ }^{293}$ Most of Japan's aid (about 60 percent in 1987) is in the form of subsidized loans, so a given amount of aid (subsidy) results in a greater amount of purchases; most U.S. aid (probably around 75 percent in 1987) is provided as grants.294 Japan focuses its aid on Asian countries, which represent one-third of Japan's trade with developing countries and whose relatively advanced economies have great potential to buy capital goods and services. The United States, on the other hand, gives the bulk of its aid to Central America and the Middle East, which represent less than a tenth of U.S. trade with developing countries. ${ }^{295}$

Japanese Government and business practices can magnify the competitiveness effect of aid, even if the aid in principle is not tied. Unlike the United States, Japan awards aid primarily based on proposals received. The requirements for proposals are so complex that often foreign governments need help from Japanese fins, which steer proposals in the direction of providing follow-on work for themselves or affiliated companies. Japan sometimes ties only the design and planning phase of a project. The use of a Japanese company for that phase makes use of Japanese sources for follow-on construction quite likely. ${ }^{296}$

To minimize the adverse competitive impact from other countries' use of tied aid, the United States has attempted to close or reduce the loophole that permits aid to be mixed with export credits. Effec- tive July 1988, the Arrangement was amended, at U.S. urging, so that mixed credits must have at least a 35 percent grant component ( 50 percent in the case of aid to the least developed countries). The intent was to make mixed credits so expensive that their use would decline; however, this did not occur in 1989 and $1990 .{ }^{297}$ The United States has continued attempts to limit the use of tied aid. It is negotiating for further amendments to the Arrangement, notably one to prohibit mixed credits when a project is commercially viable without a grant element. It has also gotten an informal agreement to avoid using mixed credits in Eastern Europe; as of July 1991, this agreement was working. ${ }^{298}$

To strengthen its negotiating position, the United States has matched or even overmatched some foreign mixed credit offers, to show foreign countries that they have nothing to gain by offering mixed credits. These offers have used Eximbank's war chest of grant money, which can be combined with loan funds. In fiscal year 1990, $\$ 53.8$ million in war chest grant funds were used ${ }^{29}$ supplemented by $\$ 30$ million in grant funds from the Agency for International Development (AID), resulting in \$228 million in concessionary loans. For fiscal year 1991, Eximbank had used war chest grant funds of $\$ 58.1$ million by July, yielding concessionary loans of $\$ 130.8$ million, though Eximbank reported that it might by the end of fiscal year 1991 use the entire $\$ 150$ million in grants available, for a total of about $\$ 500$ million in loans. ${ }^{300}$ While sales have been won in this manner, the war chest sums are much smaller than those available for tied aid programs in several other countries, notably Japan, France, and Germany, whose annual loans with tied aid are measured in billions of dollars. ${ }^{301}$

The U.S. Trade and Development Program (TDP) also offers tied aid. TDP started within AID but was spun off as an independent agency in 1981. This program funds feasibility studies and other project planning services by U.S. firms in developing and middle-income countries. It resembles Japan's tied aid funding for planning and design. TDP provides project planning funding only for projects that are priorities of the host country and present a good opportunity for sales of U.S. goods and services. ${ }^{302}$ TDP's budget, initially only a few million dollars, has grown in recent years. In fiscal year 1990 the \$32.2 million in funds included \$29.9 million for program activities and $\$ 2.3$ million for administrative expenses. ${ }^{303}$ Of program funds obligated in 
fiscal year 1990, 36 percent were for infrastructure, 17 percent for energy, 15 percent for manufacturing and processing, and 15 percent for communications and computer technology. In contrast to most other U.S. aid, the fast-growing Asian region received the most funding, 33 percent in fiscal year $1990 .^{304}$ TDP's fiscal year 1991 budget is \$35 million.

TDP reports that "[e]very major donor nation offers grants for feasibility studies, ' and the host country almost always

... has the option of obtaining a grant from another donor government. Typically, these grants are made to promote procurement from the donor nation, thereby virtually locking U.S. firms out of major projects at the implementation stage. ${ }^{305}$

Thus, the competition to determine who performs the feasibility study is sometimes decisive in the competition for exports. As an independent agency since 1981, TDP spent \$161.6 million through fiscal year 1990 in program funds. ${ }^{306}$ As of December 1990 , the associated projects had given rise to documented U.S. sales of $\$ 3.2$ billion ( $\$ 2.4$ billion to Asia). The sales yield to date is thus 20 times the program funds spent. The annual sales have increased rapidly in recent years, and TDP estimated that activities already funded by December 1990 will provide an additional $\$ 18$ billion of exports as projects mature.

\section{EXPORT CONTROLS}

Some items, such as computers, have both commercial and military use. The United States controls export of such dual-use items under the Export Administration Act of 1979 (EAA), as amended. ${ }^{307}$ The Act is administered by the Commerce Department's Bureau of Export Administration (BXA), in cooperation with the Defense, State, and Energy Departments, and several other Federal departments and agencies. The Control List specifies dual-use items subject to control. This list includes physical products, software, technical data, and knowhow. ${ }^{308} \mathrm{~A}$ license from BXA is necessary to export these items to some foreign countries. The license may be conditioned on assurances that the item will be used for civilian purposes; in some cases, BXA insists on the right of inspections or other constraints to guard against diversion to military use. BXA does not know precisely how much export trade is licensed, but $\$ 90$ billion seems a fair estimate for $1990{ }^{309}$ This is about 28 percent of the $\$ 316$ billion ${ }^{310}$ in total U.S. exports of manufactured goods in 1990. This percentage declined from an estimated 40 percent or more in $1985^{311}$ and is expected to decline further in 1991.

The purpose of most controls on dual-use exports is to deny militarily strategic technology to potential adversaries. This control, however, comes at a price: requiring a license can hinder commercial exports. Moreover, export controls affect primarily hightechnology industries on which U.S. manufacturing competitiveness especially depends. Some export controls on dual-use items are necessary, and some resulting drag on competitiveness is inevitable. However, there is an emerging consensus that export controls have unduly hindered competitiveness.

The export control regime came under intense scrutiny with the publication in 1987 of a report by the National Academy of Sciences. ${ }^{312}$ This scrutiny intensified for three reasons. First, political reform swept the nations of Eastern Europe and the Soviet Union. This reduced the military threat from these countries, lessening the need for controls. These nations need technology to hasten their transformation into open, economically viable societies. Sophisticated computers are needed, for example, to run a modem banking system, and fiber optics are crucial for a modem telecommunications network. If export controls prevent the transfer of such technology to these nations, they could increase the risk these nations pose. ${ }^{313}$

Second, the changing political climate intensified allies' dissatisfaction with the United States' hard line position. This led to speculation that CoCom (Coordinating Committee for Multilateral Export Controls), the multilateral forum in which the United States and its allies coordinate export controls (see box $4-\mathrm{C})$, might break apart. To avert a crisis, in June 1990 the United States agreed to a great loosening of controls. Third, concern has increased over the continuing decline in U.S. manufacturing competitiveness, prompting closer scrutiny of whether the security benefits of particular controls are worth the competitiveness costs.

Most observers agree that too many items were controlled under the EAA. Some items were not decontrolled even when advancing technology eliminated their strategic value. Some other controlled items, while still strategic, were available from unrestricted sources in third countries; the controls 


\section{Box 4-C-East-West and North-South Controls; Cocom and Other Multilateral Export Control Forums}

Traditionally, most U.S. export controls on dual-use items (items with both military and commercial use) aimed to keep militarily strategic technology from Communist countries. These controls are issued as "national security" controls under Section 5 of the Export Administration Act of 1979, as amended (EAA). ${ }^{1}$ They are sometimes referred to as "East-West" controls. East-West controls affect more than just exports to Communist or formerly Communist countries; approximately 85 percent of the individual license applications processed in 1990 were for exports to the "free world" (not Communist or formerly Communist countries). ${ }^{2}$ While individual license applications for exports to the free world are almost always granted, ${ }^{3}$ the approvals sometimes contain conditions designed to prevent possible diversion to Communist countries.

Inmost cases, the United States' militarily strategic technology is shared by other countries; to prevent transfer of such technology, cooperation from other countries is necessary. Internationally, East-West export controls have been coordinated by the Coordinating Committee for Multilateral Export Controls (CoCom), an informal, nontreaty organization with 17 member countries. CoCom consists of the NATO members except Iceland, plus Japan and Australia. ${ }^{4} \mathrm{CoC}$ com controls those dual-use items on its "Core List," a scaled down version of its old "Industrial List." Traditionally, the United States has been the most zealous CoCo member. While many CoCo members generally control items only to the extent required by $\mathrm{CoCom}$, the United States controls many items to a greater extent. Lately, the difference between the United States and other members has narrowed.

Another group of U.S. export controls is issued under Section 6 of the EAA. These "North-South" or foreign policy controls aim to prevent proliferation of weapons of mass destruction, including missiles and chemical and biological weapons, to countries that do not have them, especially those countries prone to support terrorism or other reckless use. ${ }^{6}$ Such controls are not aimed at the Communist or formerly Communist nations as a whole or the Soviet Union in particular, indeed, the Soviet Union and the People's Republic of China possess great capability in these areas. Missile and chemical weapons technology are controlled in multilateral groups other than CoCom, but these groups have limited effectiveness because they do not include the Soviet Union. No international group controls biological weapons. ${ }^{7}$ Foreign policy controls under Section 6 of the EAA can be imposed for other reasons as well, such as to sanction nations for human rights abuses. In that case the control is intended as a political statement, rather than to deny particular technology or products. In some cases-such as sanctions against nations that support terrorism the control has a mixture of military and political goals. ${ }^{8}$

\footnotetext{
150 U.S.C. app. 2404.

2“"Office of Licensing Statistics: CY 1990,” n.d. (prepared by Bureau of Export Admini istration (BXA), U.S. Commerce Department). This percentage is by number of applications, not dollar value. The figure includes all individual license applications, not just those required by East-West controls.

3In fiscal year 1990,94.2 percent of such applications were approved. BXA 1990 Annual Report, ch. 2 (in press). (This figure is based on counting the People's Republic of China as a free world nation; otherwise the approval rate would probably be slightly higher.) Only about 0.3 percent were denied; the rest were "returned without action" because of insufficient information or at the applicant's request.

4The complete membershi list is Australia, Belgium, Canada, Denmark, German $y$, France, Greece, Italy, Japan, Luxembourg, the Netherlands, Norway, Portugal, Spain, Turkey, the United Kingdom, and the United States.

5The term "North-South" is a convenient shorthand to indicate that the orientation of these controls is different from that Of East-West controls. It should not be taken to imply that all or most developing countries give cause for concern.

650 U.S.C. app. 2405. Nuclear weapons are controlled by another statute, Section 309(c) of the Nuclear Non-Proliferation Act of 1978, codified at 42 U.S.C. 2139a(b). See Section 17(d) of the EAA at 50 U.S.C. App. 2416(d).

${ }^{7}$ Multilateral coordination of North-South controls is discussed in Panel on the Future Design and Implementation of U.S. National Security Export Controls, Committee on Science, Engineering, and Public Policy, National Academy of Sciences, National Academy of Engineering, Institute of Medicine, Finding Common Ground: U.S. Export Controls in a Changed Global Environment (Washington DC: National Academy Press, 1991), pp. 83-85.

${ }^{8}$ Export controls on dual-use items can also be imposed under Section 7 of the EAA during a shortage of domestic supply.
}

did not deny technology to the target country but simply diverted business to foreign suppliers.

In principle, controlled items could still be exported, provided that an application for an export license was submitted and approved. In practice, however, the time and trouble involved discouraged some firms from applying. And even if permission to export were ultimately granted, the delay could cost the sale. Such delays have been used as a selling 
point by competing foreign manufacturers who suffered no such hindrances. In addition, export controls occasionally stopped U.S. firms from providing repairs and spare parts to items already in the field; this made U.S. suppliers appear especially unreliable. Another thorn in the side of foreign customers was reexport controls. If controlled U.S. technology or components were incorporated abroad into finished goods, sometimes permission from the U.S. Government was necessary to export those goods to a third country. As a result, many foreign manufacturers avoided using technology and components that originated in the United States. Some U.S. allies resented this extension of U.S. law onto their soil. ${ }^{314}$

In recent years this situation has improved. Reform has focused on East-West controls, traditionally the most common type, that are designed to keep technology from former Communist bloc ${ }^{315}$ countries (see box 4-C). Reform has proceeded on three interdependent tracks: multilateral negotiations, legislation by Congress, and domestic action by the Administration. In CoCom, the United States has agreed to lessen controls, and other countries therefore appear more willing to maintain not only common rules but a uniform standard of enforcement; this should reduce the advantages to foreign firms resulting from less restrictive control regimes. The Export Enhancement Act of 1988 (1988 Act) ${ }^{316}$ amended the Export Administration Act of 1979 to prod the Administration to remove unnecessary controls and streamline the license application process. Further legislation in this direction is under consideration. ${ }^{317}$ The Administration has been reducing U.S. controls to track reductions in CoCom's controls, and over time (sometimes more time than Congress allowed) has been implementing changes mandated in the 1988 Act.

Despite the reforms, export controls remain a live issue. In two sectors, computers and communications, many within industry view the Core List reductions as insufficient. Nor is it clear that procedures and attitudes have changed enough to avoid licensing delays, permit timely decontrols in the future, and facilitate increased governmentindustry cooperation. While reform proceeds on East-West controls, broad use of North-South controls could reverse some of the progress made. North-South controls are implemented for two purposes: to prevent proliferation of weapons of mass destruction; or to further other foreign policy goals, such as to show disapproval of a country's human rights abuses or support of terrorism (see box 4-C). The recent Gulf War has increased proliferation concerns, sparking the Administration's Enhanced Proliferation Control Initiative. North-South controls are largely unaffected by the recent reforms, and could lead to substantial disruption of legitimate commercial sales.

\section{Reducing East-West Controls' Drag on Competitiveness}

\section{What Is Controlled}

The United States controls exports of dual-use items bound for either former Communist bloc countries or other countries where risk of diversion to former Communist bloc countries is substantial. This second case has greater commercial impact; in 1990, 85 percent of all license applications were for exports to the free world (not former Communist bloc countries) $)^{318}$ In fiscal year 1989, computers accounted for 42 percent of the dollar value of all license applications; other electronic equipment and aircraft also accounted for large dollar values. ${ }^{319}$

These East-West controls are based largely on CoCom's Core List, which replaced the old Industrial List effective September 1, 1991. The Core List includes items in nine categories: advanced materials; material processing; electronics; computers; telecommunications and information security; sensors and lasers; navigation and avionics; marine; and, propulsion.$^{320}$ CoCom controls exports at three levels, depending on the item and the proposed destination. At the highest or "general exception" level, unanimous approval by CoCom members is necessary. At the next level, "favorable consideration," there is a presumption of approval; the export may be made if no CoCom member objects within 30 days of submission to CoCom. At the lowest level, "national discretion" (also called "administrative exception"), a member nation may approve the export on its own, but CoCom must be notified after the fact.

In May 1990, following a study of export controls, the Bush Administration found that the Industrial List contained "items not strategically critical to U.S. interests. ${ }^{1321}$ In a June 1990 CoCom meeting, the United States, responding to pressure from its allies, proposed to scrap the Industrial List and build from scratch a new, much shorter "Core List" containing only truly strategic technologies. ${ }^{322}$ As 
an interim measure, the Industrial List was trimmed in summer of 1990, especially in the computers, telecommunications, and machine tools sectors; a revised Core List was agreed upon on May 24, 1991, to take effect September 1, 1991. Controls were lifted on many important items, including satellite ground stations for television, weather, and civil communication. Machine tools were decontrolled to up to accuracies far greater than before. ${ }^{323}$ Many personal computers based on Intel's 80386 processor chip, which were available throughout the world, were no longer subject to controls as of July 1990, ${ }^{3 \mathrm{X}}$ and some more advanced versions based on Intel's 80486 chip, also available from unrestricted sources, were decontrolled in May 1991.

The significance of the reduced Core List is not only that fewer items are controlled, but also that U.S. and foreign controls will more closely resemble one another. It is widely believed that in the late 1980s many other CoCom members were chafing under controls retained only at the United States' insistence, and were sometimes enforcing controls loosely. With the U.S. agreement to eliminate or reduce most of the controls, other members appear headed toward more uniform enforcement. CoCom members have agreed on standards for an effective export control regime, and as of June 1991 BXA anticipated that these standards would be in force in all member countries by the end of $1991 .{ }^{32 .}$

Uniform enforcement standards would mean that the United States could trust the export controls of other CoCom members. Current East-West controls require licenses for some items even when shipped to CoCo destinations. The United States imposes these licenses because it does not fully trust its allies to prevent reexport in violation of CoCom rules. Those few cases in which BXA requires licenses for intra-CoCom trade tend to be cutting edge items, such as the latest computer models, which can be important for winning new customers. For years industry has wanted BXA to eliminate the license requirement for intra-CoCom trade. In the 1988 Act, Congress mandated that the Commerce Department annually take stock of which other countries have fully satisfactory export control systems, and eliminate license requirements (under the East-West controls) for exports to these countries. ${ }^{326}$ The Administration has not yet found that any countries meet the requirements. In November 1989, President Bush promised to remove intra-CoCom East-West license requirements by June 1991; ${ }^{327}$ the target date for the new enforcement standards has since been revised to the end of $1991 .{ }^{328}$

Previously, U.S. East-West export controls covered many items not controlled by CoCom, thus putting U.S. producers at a disadvantage relative to producers in many countries that rarely controlled such items. ${ }^{329}$ The 1988 Act provided that, with certain exceptions, East-West controls must not be imposed unilaterally for over 6 months. This provision led to decontrol and reduced control of many items in February 1989, 6 months after the 1988 Amendments became law. ${ }^{330}$ This should lead to greater parity between U.S. and foreign export controls.

The 1988 Act tightened provisions that items must be decontrolled to particular destination countries when they are in fact available to those countries in sufficient quality and quantity to render U.S. controls ineffective. ${ }^{331}$ The 1988 Act requires the Commerce Department to rule on alleged cases of foreign availability within 4 months and to publish its determination within 1 more month; if CoCom permission is necessary to export the item, 8 months are allowed for the ruling instead of $4 .{ }^{32}$ Under this provision, BXA completed 17 such assessments by May 15, 1991, and found foreign availability in 12 cases. In eight of those cases the item was decontrolled; in one case the item remained controlled based on by the President's finding that decontrol would be detrimental to national security, and the decision was pending in three cases. ${ }^{333}$

Another development is the effort to induce nations outside of CoCom to institute similar export controls. This will enhance the effectiveness of U.S. and CoCom controls, put U.S. exports more on a par with exports from the other countries, and permit trade with those countries under lessened controls. CoCom has approached countries for this purpose, including those of Eastern Europe. The United States has for years conducted bilateral negotiations to encourage other countries to control exports, resulting in more liberal treatment of exports to Austria, Finland, Ireland, Singapore, Sweden, Switzerland, and South Korea. Other nations, such as Taiwan, have not yet been responsive. ${ }^{334}$

A further reform is the reduction of reexport controls. The 1988 Act removed East-West controls for the reexport of items to a destination within CoCom or with similar safeguards. The Act lifted all East-West controls for the reexport of U.S. goods 
and technology incorporated abroad into foreign products, provided that either the controlled U.S. content comprises at most 25 percent of the product's total value, or CoCom controls the parts at only the national discretion level. ${ }^{335}$ The Commerce Department implemented these changes in July and October of 1989, well after the November 1988 deadline given by Congress. ${ }^{336}$ Moreover, BXA did not completely implement this provision because it believed that it would endanger national security, for example, by decontrolling sensitive avionics. BXA changed the 25 percent threshold to 10 percent for reexport to certain countries, including Iran and Libya, and did not modify an existing rule that controlled reexport of U.S. technology incorporated abroad into finished products regardless of the percentage value the technology represented.

As a result of these and other reductions in East-West export controls, the amount of licensed trade has been decreasing. The number of applications received for individual licenses dropped from 98,000 in fiscal year 1988 to 85,000 in fiscal year $1989,65,000$ in fiscal year 1990, and an annual rate of about 40,000 for the first 6 months of fiscal year 1991.337 The value of individual license applications processed dropped from $\$ 132$ billion in 1989 to $\$ 73$ billion in 1990, and the value of applications approved dropped from $\$ 123$ billion in 1989 to $\$ 63$ billion in $1990 .^{338}$ The new Core List and other recent or pending changes will further decrease the amount of licensed trade.

\section{Licensing Procedures}

In the mid- and late 1980s, acquisition of export licenses took much time and effort. For the first quarter of 1986, the Commerce Department reported an average processing time of 27 days, with some applications taking several months and a few even taking years. ${ }^{339}$ However, a survey of U.S. industry reported an average of 54 days; the difference in the averages is that industry counted time spent preparing applications, time after the applications were sent but before the Commerce Department logged them in, and time after approvals were sent but before they were received. ${ }^{330}$ The view from European firms that needed U.S. approval for purchases or reexports was particularly negative. European industry representatives reported "widespread disgust" with this system, citing: "lost applications; ... technically incompetent questions; and delays caused by the use of surface mail. "341 License turnaround times in other CoCom countries were "generally much shorter." ${ }^{342}$

When the Commerce Department wanted to approve a license but DoD did not, the interagency dispute resolution process was cumbersome. ${ }^{343}$ Both the time required and the nature of the process discouraged industry. The regulations were complex and difficult to fathom; firms seldom got advance indications from the government of the likelihood of approval and the likely delay; and companies were sometimes kept in the dark about concerns delaying license approval, making them unable to help resolve the problem. ${ }^{34}$ In one instance, it took a U.S. company almost 3 years to get a license to sell a $\$ 450,000$ nuclear magnetic resonance (NMR) spectrometer to a medical research unit in Eastern Europe; in the interim a German firm sold several similar systems to Communist bloc customers. ${ }^{345}$ The U.S. practice contrasted with that of Japan, where "company representatives work[ed] closely with their government counterparts" and " [a]s a result, export license applications [were] rarely submitted if they [were] not virtually certain to be approved. ${ }^{1346}$ Similar government-industry consultation occurred in some other CoCom countries. ${ }^{347}$ Industry was not told of likely U.S. or CoCom decisions to reduce or eliminate certain controls; advance warning could have allowed a head stint in exploring new export markets. Other CoCom members kept their industries much better informed. ${ }^{348}$

This picture has changed. Average processing times for individual licenses, as reported by the Commerce Department, have decreased from 23 days in fiscal year 1986 to 16 days in fiscal year $1990 .{ }^{349}$ This decrease is significant because during this period, with the decontrol of lower levels of technology, the applications' complexity and sensitivity increased. Applications for exports to CoCom members take the least time-an average of 3 days in calendar year 1990. Much delay comes from the need for the Department of Commerce to refer applications to other agencies and/or CoCom. In calendar year 1990, applications not requiring referral took an average of 7 days for processing; those requiring referral averaged 67 days. ${ }^{350}$

BXA has made the application process more user-friendly. BXA opened branch offices, gave many seminars to industry, and now provides extensive counseling to exporters. Urgent applications get special handling, sometimes gaining ap- 
proval in a few hours. A computerized tracking system permits instant determination of an application's status, and BXA's automated phone-in system gives status updates 24 hours per day, including authorization to ship if the license was approved with no restrictions. Exporters may submit applications by computer (accounting for 29 percent of the applications filed in fiscal year 1990); approvals for those applications are returned electronically. ${ }^{351}$ BXA consults with applicants if problems arise in interagency review and tries to work out a solution acceptable to all parties. ${ }^{352}$

\section{Remaining Concerns}

Some concerns remain despite recent progress. One issue is whether there is sufficient political will to overcome bureaucratic gridlock. Traditionally, the Defense Technology Security Administration (DTSA), the part of DoD with primary responsibility for export controls, has been hostile to liberalization. This is to be expected up to a point, since DoD's mission is military security rather than economic competitiveness. However, there is a consensus that in the mid- and late 1980s the DTSA went too far; it did not take seriously the need to avoid unnecessary drag on competitiveness and often blocked clearly justified liberalization. DTSA stalled for almost a year a 1988 Commerce Department recommendation to decontrol personal computers compatible with IBM's AT models that were based on Intel's 80286 processor. These machines, at the time midrange PCs, were available from many producers in seven non-CoCom nations (including Korea and Taiwan, which produced over 1 million units in 1988) and were in wide civilian use in Soviet bloc countries. $^{353}$

A combination of circumstances overcame DTSA's resistance in 1990, when President Bush personally backed a drastic reduction in controls. However, many in industry worry that DTSA can impede the actual implementation of promised reforms. This may have happened already. The new Core List, and the U.S. proposals for it, were supposed to be written "from scratch" ${ }^{\prime 354}$ with each item specifically justified. However, when it came time to draft the U.S. proposals in meetings of BXA's Technical Advisory Committees (TACs), industry representatives report that some DTSA representatives refused to do so and instead sought only to trim existing lists. ${ }^{355}$

With the 1988 Act, Congress strengthened the Commerce Department vis-à-vis the Defense De- partment. DoD can no longer delay license approvals indefinitely. When the Secretary of Commerce decides to approve a license, the Secretary of Defense has $\mathbf{2 0}$ days to object, and the license may be granted unless the President intervenes in another 20 days. ${ }^{356}$ However, interagency coordination below the cabinet level could still be cumbersome, taking over 100 days. ${ }^{357} \mathrm{CoCom}$ approval might require additional time. The detailed procedures are not publicly known because an Executive Order setting them out is classified.

Another possible problem in implementing reform is that dual-use items removed from the Control List might be added to the Munitions List, which is supposed to govern only purely military items. The control regime for items on the Munitions List is much stricter, without the EAA's competitiveness safeguards. While President Bush promised to remove all overlap between the lists "unless significant U.SS national security interests would be jeopardized, ${ }^{358}$ here is some danger that the Munitions List will be used to maintain or institute controls over dual-use items that could not be justified under the EAA.

Another concern is the new Core List. In two important sectors, computers and telecommunications, industry is not completely satisfied. In 1990, the computer sector accounted for 41 percent of the value of all individual license applications. ${ }^{359} \mathrm{Mod}-$ ern telecommunications systems for the Soviet Union and Eastern Europe will cost many billions of dollars. Hungary plans to spend $\$ 6.3$ billion over 10 years, Czechoslovakia \$3 billion through 1995, and Germany $\$ 4$ billion on East German upgrades in 1991 alone. ${ }^{360}$ The Core List controls computers that these nations need for economic development. In one broad performance range, the United States wanted to control the computers, but most allies did not. As a compromise, the Core List controls them at the national discretion level. Most other CoCom members will probably permit those computers to be exported with either no prior application or a very quick one; some in industry worry that they will suffer the disadvantage of long licensing delays. Current Administration policy is to process applications for items at the national discretion level within 15 days, without DoD review. ${ }^{361}$ However, even if BXA keeps to 15 days, that delay, coupled with the need to apply in the first place and the lack of certainty that the application will be approved, could cost some sales. 
The Core List controls telecommunications equipment these nations need. This includes fiber optic cable for state-of-the-art telecommunications systems, which the Core List controls at the general exceptions level. The United States pushed for that result, but many other members were quite unhappy and will seek substantial loosening of controls in 1992. Poland, Czechoslovakia, and Hungary receive favorable consideration. As long as controls affect all suppliers equally, U.S. companies will suffer no competitive disadvantage. But it is possible that foreign governments will try harder than the United States to obtain CoCom approval on behalf of their fins.

There is concern as to whether an effective mechanism exists for updating controls. Today's current list of controls can become tomorrow's obsolete list. More timely review will be easier because the U.S. list now has fewer items; it is now within the bounds of CoCom's Core List, which is much smaller than the old Industrial List. U.S. reviews will better track CoCom routine reviews, which will occur every 3 years instead of every 4 years as in the past. ${ }^{362}$ Also, industry can now better funnel information about advancing technology to the government through the TACs.

But list review requires considerable effort and expertise. The basis for decontrol is often a determination that an item is available in sufficient quantity and quality from unrestricted sources. ${ }^{363} \mathrm{~A}$ delay in this determination results in an ineffective control that hinders U.S. exports while foreign manufacturers get the business. These determinations, performed by BXA's Office of Foreign Availability (OFA), require investigating the sources, quality, and quantities of foreign goods; such information can be hard to find. Further, the technologies involved are specialized and complex. OFA's staff of about $25^{364}$-out of about 530 BXA employees ${ }^{365}$ seems too small for such an important and difficult job. The salary levels authorized for OFA--GS-13 (starting salary about $\$ 44,000$ as of Jan. 1,1991 ) for most working engineers ${ }^{366}$-make it difficult to keep top-notch people. In addition, these politically charged determinations are sometimes opposed by other agencies at high levels. One example is the case of AT personal computers already mentioned; another is semiconductor wire bonders. The Commerce Department found foreign availability of wire bonders and recommended decontrol, which was approved by the President in 1987, but was blocked into 1990 by interagency dissension. ${ }^{367}$ In 1991, a National Academy of Sciences panel found that BXA's procedure of finding foreign availability "has proven largely ineffective," and has been "costly and contentious and has rarely resulted in timely decontrol.' ${ }^{36}$

A complementary approach to avoiding outdated controls is indexing. For example, if a particular control applies to all computers above a certain processing speed, there might be a presumption, based on projected industry trends, that each year the processing speed threshold be increased by 10 percent. Each subsequent year, those opposing the adjustment would have to justify their position. As another example, there could be a presumption that personal computers (or some other type of equipment) would be decontrolled (or controlled at a lower level) after the model in question has been sold commercially for a certain number of years. Again, those who opposed a particular decontrol would have to justify their position. While Congress has encouraged indexing, ${ }^{369}$ so far the Administration has rarely used it.

Some in industry are concerned that the government does not welcome its participation and cooperation in administering export controls. In 1991 a National Academy of Sciences panel recommended increased cooperation.$^{370} \mathrm{BXA}$ did involve industry TACs in drafting and negotiating the Core List. The TACs advised on appropriate technical thresholds for control; industry representatives occasionally spotted foreign proposals that were apparently crafted to decontrol items made by foreign firms while leaving controlled similar items made by U.S. fins. It remains to be seen how BXA and industry will build on this experience. According to some analysts, BXA and industry have been in a vicious circle: BXA not taking the TACs seriously, and industry not devoting sufficient resources to them. One industry observer commented that because the industry representatives are busy corporate officers who barely have time to fly to Washington for a one-day meeting, the TACs can work well only if the Commerce Department does considerable preparatory and follow-up work: preparing memoranda setting out issues to be discussed; writing draft position papers based on the discussion at meetings; gathering facts; and soon. This observer commented that the National Academy of Sciences proceeds in this manner with its panels of experts, but the 
Commerce Department lacks the resources to do this. $^{371}$

Industry representatives have had complaints about the use of TACs. For example, a representative of one high-technology firm with experience on several TACs stated that some parts of TAC meetings are needlessly classified, preventing the representatives from reporting back to industry. ${ }^{372}$ An experienced representative on the TAC for automated manufacturing stated that DTSA representatives often will not give reasons for their positions, even in a classified session, so that industry cannot address DTSA's concerns. ${ }^{373}$ Some felt that the government used TACs to legitimate its policies: it would pose a limited set of choices, none of which appealed to industry; the industry representatives would make their choice; and then the government would claim that industry had approved that choice.

\section{Controls for Reasons of Foreign Policy}

While much progress has been made in reducing the drag from East-West export controls on commercial exports, that progress could be reversed by the use of North-South or “foreign policy' controls. Some foreign policy controls are aimed at preventing proliferation of weapons of mass destruction, missiles to carry them, and chemical and biological weapons. Other foreign policy controls, such as those in reaction to human rights abuses, and those against Libya, Syria, and Iran, are intended primarily to make a political statement rather than deny military technology. ${ }^{374}$

As explained in box 4-C, Section 5 of the EAA governs East-West controls, while Section 6 governs foreign policy controls. Section 6 controls must be justified annually, but they are not subject to the Section 5 safeguards against unnecessary interference with legitimate commercial exports. The Section 5 prohibitions against unilateral controls and against controlling items shown to have foreign availability do not apply to controls under Section 6. ${ }^{375}$ Thus, section 6 can provide an end run around the restrictions in Section 5. For example, in March 1991, BXA imposed unilateral controls for chemicals and chemical manufacturing equipment that could be used to make chemical weapons. ${ }^{376} \mathrm{As}$ another example, in June 1991, BXA removed Section 5 controls on certain equipment used to manufacture prepregs (fibers embedded in resin used to make, for example, tennis racquets and aircraft structural components), because of foreign availability. However, the equipment remained subject to foreign policy controls. ${ }^{377}$

In August 1991, BXA issued regulations under Section 6 that prohibit all exports that the exporter knows will be used to make chemical or biological weapons. ${ }^{378}$ This rule might be interpreted by BXA and the courts to imply a duty on the exporter's part to make a reasonable inquiry as to where the exports will be used; if the exports are used in making the prohibited weapons, and the exporter could have discovered that in advance with reasonable inquiry, then the exporter might be deemed in violation of the act and suffer stiff penalties. To be safe, any firm that exports virtually any goods or technology to any country might need to set up a monitoring and control system with careful communication between headquarters and marketing. ${ }^{379} \mathrm{BXA}$ can inform exporters that exports to a particular consignee require a license because of risk of diversion to a prohibited weapons plant. This gives BXA broad power to prohibit exports of any items to particular destinations. This regulation controls exports unilaterally, with no consideration of whether items have strategic importance and whether they are available from non-U.S. sources.

These rules have been fashioned within the rubric of the Administration's Enhanced Proliferation Controls Initiative (EPCI), announced December 13, $1990{ }^{380}$ Heightened concern for proliferation is natural in the wake of the Gulf War and revelations about prior exports to Iraq. However, industry is concerned that the Administration is starting an open-ended export control campaign without serious consideration of the effect on commercial trade.

1 U.S. Congress, Office of Technology Assessment, Making Things Better: Competing in Manufacturing, OTA-lTE-443 (Washington DC: U.S. Government Printing Office, February 1990), passim. Making Things Better did not consider domestic policies that affect competitiveness incidental to their main purpose--for example, environmental regulation regulation of workers' health and safety, and product liability.

2 Gary Clyde Hufbauer, Diane T. Berliner, and Kimberly Arm Elliott, Trade Protection in the United States: 31 Case Stud-es (Washington, DC: Institute for International Economics, 1986). This report uses the term "special trade protection" to mean protection under Section 201 and related sections of the Trade Act of 1974, as amended. This protection is based on GATT's so-called "escape clause," which permits countries to protect industries seriously injured by foreign competition even in the absence of any unfair trade practice.

3 Labor-Industry Coalition for International Trade, "The Uruguay Round: Will It Be a Good Deal for U.S. Manufacturing?” June 1990, p. 1.

4 Complete specialization was considered unlikely because of the 
diminishing marginal productivity of factors of production. This means that, after the point where inputs are combined optimally, any input (in this case, capital and labor) contributes in diminishing quantities to productivity the more of that input is used.

5 For a more detailed but still simple, explanation of how this works, see David B. Yoffie, International Trade and Competition: Cases and Notes in Strategy and Management (New York NY: McGraw-Hill Publishing Co., 1990), pp. 4-8.

6 The contributions of Linder, Vemon, and Wells are discussed in Yoffie, ibid.

7 Yoffie, op. cit., p. 13.

8 Paul R. Krugman, Rethinking International Trade (Cambridge, MA: The MIT Press, 1990), p. 1.

9 The two commercial aircraft makers in America are Boeing and McDonnell Douglas; the European manufacturer is Airbus, a consortium with four member companies. The engine makers are Rolls Royce of England, and GE and Pratt\& Whitney of the United States. In addition, SNECMA of France, MTU of Germany, and Mitsubishi Heavy Industries, Kawasaki Heavy Industries, and Ishikawajima-Harima Heavy Industries of Japan make major subassemblies of engines. See ch. 8 for a description of the world's large commercial jet aircraft industry.

10 W. Brian Arthur, "Positive Feedbacks in the Economy," Scientific American, February 1990, p. 93. Approximate dollar figures are OTA estimates for 1991.

11 Krugman, op. cit., p. 164.

12 Infant industry protection is defined as the protection of a fledgling group of producers from incursions of foreign firms that dominate production and have superior technology in industries with high knowledge intensity, significant positive externalities or increasing returns.

13 Arthur, op. cit., p. 98.

14 Ernest H. Preeg, The American Challenge in World Trade: U.S. Interests in the GATT Multilateral Trading System (Washington, DC: The Center for Strategic and International Studies, 1989), p. 4.

15 Ibid., p. 23.

16 Hufbauer et al., op. cit., pp. 250-251. These limits were exceeded every year of the VRA, rising from actual Japanese imports of 1.78 million units in 1981 to 2.31 million units in 1985 .

17 Occasionally limitations on imports are more stringent. In 1981, at the beginning of the negotiation of the third phase of MFA, the European Economic Community cut back the volume of imports from so-called dominant MFA suppliers (Hong Kong, Macao, Korea, and Taiwan) by nearly 7 percent. Thomas R. Howell and William A. Noellert The EEC and the Third Multifiber Arrangement: A Study Prepared for the Fiber, Fabric and Apparel Coalition for Trade (FFACT) (Washington, DC: Dewey, Ballantine, Bushby, Palmer \& Wood, 1986), p. 7.

18 This means that all GATT signatories are to be given the same favorable terms of trade as those given to the nation with the best terms, or the most-favored nation.

19 Preeg, op. cit., p. 31.

20 Some experts in both the United States and the EC argue convincingly that these countries are considering standards other than those used by Japanese producers is for technical rather than nationalistic reasons; but among policymakers, the concern is at least as much for national competitiveness as for technical superiority.

21 U.S. Department of Labor, Bureau of Labor Statistics, "BLS Reports on Worker Displacement” News Release, Dec. 9, 1988.

22 Michael Podgursky and Paul Swain, "Labor Market Adjustment and Job Displacement: Evidence from the January, 1984 Displaced Worker Survey," Final Report, Bureau of International Labor Affairs, U.S. Department of Labor, January, 1986.

23 See chs. 6 and 7, on the industrial policies of Japan Korea, and
Taiwan, for further discussion.

2419 U.S.C. $2411-2420$.

2519 U.S.C. $2251-2254$.

2619 U.S.C. 2411(b); see also 19 U.S.C. 2411(a)(1).

27 GATT Article 12, paragraph 1.

28 GATT allows agricultural quotas in many cases; it also allows quotas by countries with dangerously low foreign currency reserves and for reasons of national defense. GATT Article XI, paragraph 2; Articles XII, XXI. Quotas are also permitted under GAIT's so-called "escape clause" (Article XIX, though in this case the issuing country is obliged to pay compensation. Under GATT's Multifiber Arrangement, many bilateral agreements limit trade in textiles. Finally, sometimes two countries reach an understanding to limit bilateral trade in specified products, even though this understanding is arguably prohibited under GATT.

29 This term, as used here and often elsewhere, refers to barriers that are not tariffs and also are not quotas. Also, as used here, the term refers to both public (government-imposed) and private barriers; some use the term to mean only public barriers.

One type of barrier is the failure of foreign counties to protect intellectual property (by means of patent rights, copyrights, trademark rights, trade secret rights, etc.). If a foreign government protects intellectual property, U.S. inventors, authors, etc. will in many cases have the exclusive right to make and sell particular goods in that country. If a foreign government protects intellectual property poorly or not at all, U.S. inventors and authors can lose sales to foreign imitators. Therefore, the lack of protection can be considered a trade barrier, since it hinders sales of U.S. goods abroad. This trade barrier was discussed in U.S. Congress, Office of Technology Assessment Making Things Better, op. cit., pp. 69-71, 211-219. The justifications for protecting intellectual property are discussed in that report and in U.S. Congress, Office of Technology Assessment Intellectual Property Rights in an Age of Electronics and Information, OTA-CIT-302 (Springfield, VA: National Technical Information Service, 1986).

30 See, for example, Office of the United States Trade Representative, 1991 National Trade Estimate Report on Foreign Trade Barriers (Washington DC: U.S. Government Printing Office, Mar. 29, 1991); Office of the United States Trade Representative, "Report to Congress on Section 301 Developments Required by Section 309(a)(3) of the Trade Act of 1974 (January-June 1990)," n.d. (one of a series of semiannual reports).

31 President Ronald Reagan memorandum of Aug. 1, 1986, "Determination Under Section 301 of the Trade Act of 1974," 51 Federal Register 28219 (Aug. 6, 1986).

32 Semiconductor Industry Association "Four Years of Experience Under the U.S.-Japan Semiconductor Agreement: 'A Deal Is a Deal,' " Fourth Annual Report to the president November 1990, pp. 35-38; Clyde V. Prestowitz, Jr., Trading Places: How We Allowed Japan To Take The Lead (New York, NY: Basic Books, 1988), pp. 62-63; Donald Phillips, Assistant United States Trade Representative, testimony at hearings before the House Committee on Energy and Commerce, Subcommittee on Commerce, Consumer Protection and Competitiveness, May 9, 1990, Serial No. 101-149, pp. 8-9; Semiconductor Industry Association, "World Market Sales and Shares for 1982- 1990," n.d.

33 U.S. firms' market shares generally declined over the years. As late as 1985, U.S. firms still held 86 percent of the U.S. market, 54 percent of the European market, and 40 percent of the rest of the world market outside of Japan. Semiconductor Industry Association "World Market Sales and Shares for 1982- 1990," n.d.

34 The text of the agreement is contained in an exchange of letters on Sept. 2, 1986, between Japan's Ambassador Matsunaga and USTR Clayton Yeutter.

35 Prestowitz, Jr., op. cit., pp. 65. (The quoted language is a paraphrase by Prestowitz of the letter's contents.) 
3652 Federal Register 10275, (Mar.31, 1987).

3752 Federal Register 13412, (Apr. 17, 1987). Some other punitive tariffs were levied at the same time in retaliation for Japan's failure to stop dumping; in the September 1986 agreement, Japan's Government had also promised to stop its firms from dumping in the U.S. and third country markets.

38 Semiconductor Industry Association, "World Market Sales and Shares for 1982-1990," op. cit.

39 Ibid. The USTR gives slightly different figures for the share of imports from countries other than the United States. See Office of the United States Trade Representative, "United States, Japan Conclude Semiconductor Agreement," press release dated June 4, 1991, ref. No. 91-21, attachment entitled "Background Statistics on Semiconductor Sales to the Japanese Market."

40 Jacob M. Schlesinger, "Foreign-Chip Shine in Japan is Below Goal," The Wall Street Journal, June 17, 1991.

41 Office of the United States Trade Representative, "United States, Japan Conclude Semiconductor Agreement," press release \&ted June 4, 1991, ref. No. 91-21.

MITI claimed that the imports' market share had in fact risen to about 17percent in the first quarter of 1990 and 19 percent in the fourth quarter. MITI used a different measure of market share than the U.S. Government and industry, based on its surveys to 60 Japanese firms. The U.S. approach is based on statistics collected by the World Semiconductor Trade Statistics (WSTS) Program. The two measures differed in three ways. First, MITTs survey included only about 75 percent of the industry, while WSTS statistics were more comprehensive. Also, MITI counted, but the U.S. approach excluded, 1) captive sales-that is, in-house sales of a chip of a type that is not offered for sale to outsiders, and 2) private label sales-that is, sales of a chip made by a Japanese firm with a U.S. fro's label. The U.S. industry maintains that the Japanese industry agreed in 1986 to use the U.S. approach. In the new agreement, MITI agreed to drop using its survey and accept the use of WSTS statistics; the two countries still disagree on the other two differences in measuring approach. Under this new framework MITI claims that import penetration reached about 16 percent in 1990, compared with the U.S. figure of about 13 percent. Sources that discuss the measurement issue include Semiconductor Industry Association, Four Years of Experience, op. cit., Appendix 8; Jacob Schlesinger, op. cit.; "U.S. and Japan Sign Semiconductor Pact; Targeting 20 Percent Share, Design-Ins," Regulation, Economics and Law, June 5, 1991 (Bureau of National Affairs, Inc., Washington DC), p. A-15 (substantially the same article is in BNA's International Trade Reporter, June 5, 1991); Tsuyoshi Sunohara "Chip Pact Dispute Shifts to Market Share Calculation," Japan Economic Journal, July 14, 1990, p. 1.

42 Ch.6; U.S. Congress, General Accounting Office, U.S.-Japan Trade: Evaluation of the Market-Oriented, Sector-Selective Talks, NSIAD-88-205 (Gaithersburg, MD: U.S. General Accounting Office, July 18, 1988), p. 45; Cray Research, Inc., The Japanese Public Sector: Problems and Prospects for U.S. Supercomputer Vendors (May 1990), pp. 3-1 through 3-23,4-1 through 4-8,5-1 through 5-3.

43 Chapter 6; U.S. Congress, General Accounting Office, ibid., pp. 45-46; Cray Research Inc., ibid., p. 4-10.

44 Chapter 6; Office of the United States Trade Representative, "Report to Congress on Section 301 Developments Required by Section 309(a)(3) of the Trade Act of 1974 (January-June 1990)," n.d., pp. 5-6; Cray Research Inc., ibid., pp. 4-11 through 4-18.

45 Office of the United States Trade Representative, ibid., pp. 5-7.

46 This course of action is available only if the subject in question is covered by GATT. For example, while the United States is seeking in the Uruguay Round to have GATT require certain levels of intellectual property protection GATT does not now have any such requirement.

47 See GATT Article XXII; Article XXIII, paragraph 1.

48 This procedure is based on GATT Article XXIII, paragraph 2.
49 John Jackson, The World Trading System: Law and Policy of International Economic Relations (Cambridge, MA: MA: Press, 1989), pp. 98-100. A small number of these cases were brought under GATT's supplementary Codes, some of which provide similar dispute resolution procedures.

50 Ibid., p. 100. Of there remaining cases, 4 specifically concerned primary products (from mines, forests, and the like), while 25 had less specific product focus (such as a complaint about a country's import licensing scheme in general). 48 case were brought against the United States: 15 concerning manufactured goods, 17 concerning agriculture, 2 concerning primary products, and 14 without specific product focus.

51 Ibid., pp. 98-100.

5219 U.S.C. $2411-2420$.

5319 U.S.C. $2411(\mathrm{~b})$; see also 19 U.S.C. 2411(a)(1).

54 Omnibus Trade and Competitiveness Act of 1988, Public Law 100418, Sec. 1301, enacting new provision at 19 U.S.C. 2411(d)(3)(B)(i)(III).

55 See 19 U.S.C. 2413(a).

5619 U.S.C. $2411(\mathrm{c})(1),(3)$.

57 Office of the United States Trade Representative, "Section 301 Table of Cases," computer printout dated Jan. 17, 1991. This classification involved some judgment calls, so other analyses may give different figures.

58 As a quid pro quo for GATT coverage and effective GATT dispute resolution mechanisms, the United States would consider forgoing unilateral retaliation under Section 301.

59 Some of the cases dealt only in part with manufactured goods. Those cases are included in the table, but only those aspects of the case concerning manufactured goods are reported.

60 Normally these findings were made in the context of the Section 301 case. In Case No. 68, dealing with Argentina's patent protection for pharmaceuticals, the petition was withdrawn before such findings were made, but the USTR's annual reports, National Trade Estimate Report on Foreign Barriers, identified Argentina's inadequate patent protection for pharmaceuticals as a foreign market barrier. In Case No. 70, dealing with the EC's export restrictions on copper scrap, there were no published findings, but the U.S. Government took the case to GATT to get the foreign practice stopped.

61 Up to 1988, whenever a GATT dispute resolution mechanism was applicable, Section 301 had an open-ended time limit allowing as much time as needed for the GATT process to conclude. Under that regime, Section 301 cases during 1980-1985 covered by GATT dragged on an average of almost 4 years, compared to about 1 year for other Section 301 cases. U.S. Congress, General Accounting Office, International Trade: Combating Unfair Trade Practices, NSIAD-87-10O (Gaithersburg, MD: U.S. General Accounting Cffice, Mar. 17, 1987), pp. 18-19. In 1988, Congress imposed an 18-month limit to avoid such long delays.

6219 U.S.C. 2A14(a)(1),(2) (investigation, negotiation, and determination of sanctions), 2415(a) (application of sanctions). In certain circumstances these deadlines are shortened. For example, 3 to 6 months less time is allowed for cases involving intellectual property. 19 U.S.C. 2414(a)(3)

63 After receiving a petition, the USTR has 45 days in which to decide whether to start an investigation. 19 U.S.C. 2412(a)(2).

64 Nine out of 15 cases initiated in 1988 through 1990 were started without an industry petition. Office of the United States Trade Representative, "Section 301 Table of Cases," op. cit.

65 Omnibus Trade and Competitiveness Act of 1988, Public Law 100-418, section 1301, adding a new Section 310 to the Trade Act of 1974, codified at 19 U.S.C. 2420.

66 The retaliation itself could be of some help if it limits imports of products made by the complaining U.S. industry, or downstream products. 
67 U.S. retaliation under Section 301 has twice provoked a GAIT complaint by other countries, though no GATT panel has yet ruled on the issue.

68 Prestowitz, Jr., op. cit., pp. 67-68.

69 See, for example, ch. 6; Bela Balassa and Marcus Noland, Japan in the World Economy (Washington DC: Institute for International Economics, 1988), chapter 3; Advisory Committee [to the USTR] for Trade Policy and Negotiations, Analysis of the U.S.-Japan Trade Problem (February 1989), ch. 5; Prestowitz, Jr,, ibid., especially pp. 78-81,94-99,281-283.

These market barriers occur in the context of Japan's overall trade and industry policy, which is described in ch. 6. Other reasons for the bilateral trade deficit-including Japan's better financing for long-term investment, better education better diffusion of technology to small business, and more aggressive support for commercially oriented $R \& D$ projects--are discussed in U.S. Congress, Office of Technology Assessment Making Things Better, op. cit.

70 Prestowitz, Jr., ibid., pp. 96-99.

71 "Back to Business," Business Tokyo, July 1990, p. 40.

72 Sam Besachio, Director, Financial Management, Office of the U.S. Trade Representative, personal communication\% Aug. 7, 1991. The USTR office has 160 full-time equivalent positions authorized, but only 151 filled. The USTR estimates that roughly 10 percent of its staff effort concerns Japan. Probably at most half of this effort concerns manufactured goods.

73 Prestowitz, Jr., op. cit., pp. 276-277.

74 Ibid., pp. 257-260.

75 Report of the Advisory Committee for Trade Policy and Negotiations, op. cit., pp. xvi-xvii.

76 U.S. Congress, General Accounting Office, U.S.-Japan Trade, op. cit. passim.

77 Ibid., pp. 20-21; Ryuji Katayama et al., "Motorola's on the Line: Will Japan Pick Up?" Business Tokyo, vol. 4, September 1990, pp. 39-40.

78 Joint Report of the U.S.-Japan Working Group on the Structural Impedimenta Initiative, June 28, 1990, Introduction, second paragraph.

79 Ibid., passim.

80 Ibid., Introduction.

81 First Annual Report of the U.S.-Japan Working Group on the Structural Impediments Initiative, May 22, 1991, comments of the U.S. Delegation, pp. 1-2.

82 Rudiger Dombusch, "The SII Talks Are a Joke," The International Economy, vol. 4, February/March 1990, pp. 47-90.

83 U.S. Government Task Force on the EC Internal Market, through Office of the U.S. Trade Representative, EC 1992: An Assessment of Economic Policy issues Raised by the European Community's Single Market Program (Washington DC: U.S. Government Printing Office, May 1990), pp. 31-33; Youri Devuyst, "The United States and Europe 1992," World Competition; Law and Economics Review, vol. 13, No. 1, Sept. 1989, pp. 30-31.

8419 U.S.C. 1677(5)(A), 1303(a)(1).

85 Final Affirmative Countervailing Duty Determination and Countervailing Duty Order; Carbon Steel Wire Rod From New Zealand, 51 Federal Register 7972 (Mar. 7, 1986). The payment was in the form of a tax credit; if the credit exceeded the amount of tax due, the difference was paid to the firm.

86 GATT Article XVI; GATT Subsidies Code, Article 9. (GATT Codes are explained in box 4-A.)

8719 U.S.C. $1677(5)$.

88 GATT Subsidies Code, Article 11, paragraph 1.

89 Ibid, paragraph 2. Accordingly, the Code's signatories have agreed to "seek to avoid causing such effects through the use of subsidies.

90 GATT Article VI, paragraph 1.

91 See GATT Antidumping Code, Article 2, paragraph.

92 GATT Article VI, paragraph 1. Under U.S. law, foreign producers are assumed to have a minimum of 10 percent administrative overhead and 8 percent profit. 19 U.S.C. $1677 \mathrm{~b}(\mathrm{e})(\mathrm{l})(\mathrm{B})$.

93 Mark Koulen, "Some Problems of Interpretation and Implementation of the GATT Antidumping Code," in John Jackson and Edwin Vermulst (eds.), Antidumping Law and Practice: A Comparative Study (Ann Arbor, MI; University of Michigan Press, 1989), pp. 367-369.

\section{GATT Article VI}

95 A price difference between the two markets that is greater than shipping costs from the low-priced market to the high-priced one is not sustainable absent market barriers. If such a difference existed and no market barriers were present, third parties would buy the good in the low-priced market and resell in the high-priced market, hinging down the price there.

96 The protection could be due to a variety of factors, including explicit government regulation informal administrative guidance given to firms, and firms' own habits of doing business.

97 The law actually covers subsidies from private as well as government sources. See 19 U.S.C. 1303(a)(1).

98 For this plan to succeed, it is not necessary for the firm to drive its competitors out of business (which would constitute predatory pricing); it can be sufficient to capture substantial additional market share.

One special case of this approach is life cycle pricing, or charging a constant price throughout a product's whole life cycle so as to yield a normal profit over the cycle as a whole. This typically involves below-cost pricing at the start of the cycle, when the manufacturing costs are highest.

99 U.S. Congress, Office of Technology Assessment, Making Things Better, op. cit., ch. 3.

100 Thomas R. Howell et al., Steel and the State: Government Intervention and Steel's Structural Crisis (Boulder, CO: Westview Press, 1988), pp. 6,4145,94-98,207-215, 254-256,301-302,332-334, 347-349, 360-361 .

101 If fixed costs are particularly high the incentive to dump may be particularly strong. This might be the case, for example, in Germany and Japan where employees are not as readily laid off during slack times as in the United States.

102 Jackson, op. cit., p. 244 (emphasis in original).

103 The U.S. law is found at 19 U.S.C. 1303, $1671-1677 k$.

104 The final action is normally an order to impose antidumping or countervailing duties; but sometimes the additional duties are not imposed in exchange for an agreement by foreign exporters to raise prices or discontinue receiving subsidies, or an agreement by the foreign government to discontinue subsidies or limit quantities exported.

105 These figures and tables are based on semiannual filings that signatories to the GATT Subsidies Code and the GATT Antidumping Code are required to file. It is possible that other countries also instituted cases during this period. Also, the signatories are required to include only cases against other signatories, and some countries' filings omit cases against non-signatories. For additional analysis of global usage of autidumping cases, see U.S. Congress, General Accounting Office, International Trade: Use of the GATT Antidumping Code, NSIAD/90238FS (Gaithersburg, MD: U.S. General Accounting Office, July 25, 1990).

106 See for example Robert Ford and Wim Suyker, "Industrial Subsidies in the OECD Economies" (January 1990), table 2 (covering years 1970-88), paper No. 74 in OECD Department of Economics and Statistics Working Papers; Gary C. Hufbauer and Joanna Shelton Erb, 
Subsidies in International Trade (Washington DC: Institute for International Economics, 1984, distributed by MIT Press, Cambridge, MA), p. 3 (covering years 1952-80).

107 U.S. Congress, General Accounting Office, International Trade: Use of the GAIT Antidumping Code, op. cit., p, 4.

108 GATT Article VI, paragraph.

10919 U.S.C. $1671 \mathrm{~d}(\mathrm{~b})(1), 1673 d(b)(1)$. This difference in wording can be important. Suppose that dumped or subsidized goods caused material injury to U.S. firma but would have caused substantially the same injury if they had been sold in the U.S. market without dumping. Them at least arguably, the "dumped goods" did cause injury but the "dumping" did not.

110 See 19 U.S.C. 1303(a),(b), 1671(a),(b). In some cases, U.S. law denies the injury test to some GATT signatories that have not signed the GATT Subsidies Code. This provision of U.S. law was enacted before the GATT agreement, and is allowed under a GATT grandfather clause found in GATT's Protocol of Provisional Application paragraph (l), item (b).

$$
111 \text { See } 19 \text { U.S.C. } 1671 c(b),(c) \text {. }
$$

\section{See 19 U.S.C. $1673 c(b),(c)$.}

113 In early 1987 Torrington faced stiff price competition for every major account. The competition came from foreign firms that were slashing prices despite exchange rate shifts that should have made foreign goods much more expensive. To meet price competition, the firm took substantial losses. David Gridley, Industry Marketing Manager, The Torrington Company, personal communication, Aug. 6, 1991. The Commerce Department found large dumping margins. 54 Federal Register 20900-20910 (May 15, 1989).

114 Gridley, ibid.

115 In some cases, petitioners could purchase the required data. Some economic consulting firms specialize in collecting and analyzing data for subsidies and dumping cases.

116 United States International Trade Commission, New Steel Rails From Canada: Determination of the Commission in Investigation Nos. 701-TA-297 (Final) and 731-TA-422 (Final), USITC Pub. No. 2217, September 1989.

117 William Hoppe, General Manager, Industry Affairs, Bethlehem Steel Corp., personal communication, Aug. 29, 1991.

118 Gridley, op. cit. 13-15

119 See U.S. Congress, General Accounting Office, op. cit., pp.

120 Public Law 100-418, Sec. 1614, amending 19 U.S.C. 1339.

121 Bureau of National Affairs, "Auto Parts Industry Panel Requests Section 301 Probe of Japanese Imports," International Trade Reporter, vol. 8, No. 26, June 26, 1991, pp. 978-979.

122 The statutory time limits for the Commerce Department's preliminary determination are 160 days after the filing of the petition for dumping cases and 85 days for subsidy cases. 19 U.S.C. $1673 \mathrm{~b}(\mathrm{~b})(\mathrm{l})(\mathrm{A})$ (dumping), 1671b(b)(l)(A) (subsidies). The Commerce Department usually takes all or virtually all of the time allowed.

12319 U.S.C. 1671 b(d),(e), 1673b(d),(e).

124 The statute provides another 75 days for the final determination and another 7 days to publish an order reflecting the new subsidy value or dumping margin. 19 U.S.C. 1671d(a), 1671e(a) (subsidies), 1673d(a), 1673e(a) (dumping). While the difference between the preliminary duty and the final duty is refunded on importations during the interim if the new duty is lower, the difference is not collected if the new duty is higher. 19 U.S.C. 1671f(a) (subsidies), 1673f(a) (dumping).

125 In the 1980 s, petitioners often had to wait several years for annual reviews.

12645 Federal Register 30,618 (May 9, 1980).

12752 Federal Register 1504 (Jan. 14, 1987). This annual review, which covered imports during the period May 1981 through April 1982, was several years late. Such delays in annual reviews were common in the 1980 s, but recently the Commerce Department has worked to reduce the backlogs.

128 Smith Corona Corp. v. United States, 915 F.2d 683 (Fed. Cir. 1990). The court's opinion summarizes the history of the case.

129 The customs entries for the intervening imports had been "liquidated," meaning that it was no longer possible to collect antidumping duties retroactively. The Court of Appeals for the Federal Circuit pointed out that in February 1989, the Court of International Trade, a lower reviewing court, should have ordered liquidation suspended; had it done so, antidumping duties could have been collected retroactively to that date.

130 Statement of Senator Carl Levin before the Senate Committee on Governmental Affairs, Subcommittee on Oversight of Government Management, on Oversight and Enforcement of Antidumping and Countervailing Duties, June 13, 1991.

131 See "Request for Antidumping Monitoring Program Covering Certain Ball Bearings and Parts Thereof," submitted to the U.S. Commerce Department International Trade Adminisration,on Apr. 20, 1990, by Stewart and Stewart, Washington, DC, on behalf of the Torrington Co. In 1989, Torrington had obtained antidumping orders on ball bearings from nine countries. Torrington requested that the Commerce Department monitor imports from 14 countries not included in the 1989 orders to determine if those imports were also dumped. when the Commerce Department denied this request, Torrington filed antidumping petitions for the 14 countries. Torrington never got the chance to prove dumping, because the ITC found at a preliminary stage that there was "no reasonable indication" that the imports complained of had caused or threatened material injury to the U.S. industry. U.S. International Trade Commission, Ball Bearings, Mounted or Unmounted, and Parts Thereof from Argentina, Austria, Brazil, Canada Hong Kong, Hungary, Mexico, The People's Republic of China, Poland, The Republic of Korea, Spain, Taiwan, Turkey and Yugoslavia, USITC Pub. 2374, April 1991. (One Commissioner dissented.) Torrington has appealed this ruling, and maintains that the U.S. industry is worse off than in 1989 when the ITC did find injury. Gridley, op. cit. The 1989 antidumping orders are found at 54 Federal Register 20900-20910 (May 15, 1989).

132 Howell et al., op. cit., pp. 526-534.

133 "President's Steel Decision," pp. 1-2, attached to Office of the United States Trade Representative, "Brock Announces President's Steel Decision," Sept. 18, 1984 (press release). As requested, Congress then empowered the President to negotiate bilateral agreements to limit other countries' total steel exports to the United States.

134 A previous order concerning only the imported finished product would not apply if the parts are imported instead (although sometimes cases initially cover both a product and its components); a previous order concerning only imported parts would not apply if the finished product is imported instead; and an order applying to a product assembled in one foreign country would not apply to the end product assembled in another foreign country.

135 These provisions are found in Public Law 100-418, Sec. 1321, codified at 19 U.S.C. 1677j. As of June 1991, the Commerce Department had twice ruled on whether these provisions applied and both times decided that they did not. 56 Federal Register 9667 (Mar. 7, 1991), 55 Federal Register 52066 (Dec. 19, 1990) (color picture tubes from Canada, Japan, Korea, and Singapore); 55 Federal Register 6028 (Feb. 21, 1990), 54 Federal Register 50,260 (Dec. 5, 1989) (fork-lift trucks from Japan). The anticircumvention provisions apply only if the difference in value between the components and the end product is "small." In both cases, the Commerce Department found this require ment not satisfied; in the fork lifts case, the value added in the final assembly, including profit, was approximately 25 to 40 percent. Another limitation is that the provisions do not appear to apply when parts from one foreign country are initially assembled in another foreign country, 
as often happens today in the Pacific Rim.

The anticircumvention provisions also address cases, such as Smith Corona's electric typewriters case, in which merchandise subject to an order is slightly altered or is replaced with a later-developed product. In such cases, the previsions might be more effective.

136 A March 1990 GATT panel decision found the EC's anticircumvention provisions to violate GATT. "EEC Regulation on Imports of Parts and Components: Report by the panel," GATT Dec. L/6657, Mar. 22, 1990. While not directly relevant to the U.S. provisions, that decision does indicate that GATT will seriously scrutinize anticircumvention provisions if the matter arises.

13719 U.S.C. 1671(a)(2), 1673(2), 1677(7).

138 Gridley, op. cit.

139 "Final Determination of Sales at Less Than Fair Value: Digital Readout Systems and Subassemblies Thereof From Japan," 53 Federal Register 47,844,47,847 (Nov. 22, 1988).

140 United States International Trade Commission, Digital Readout Systems and Subassemblies Thereof From Japan: Determination of the Commission in Investigation No. 731-TA-390 (Final), Jan. 1989 (USITC Publication 2150), pp. 16-22. The Commis sioners noted various indicators of health for the two industries. Sales in both industries had declined from 1985 to 1986 , but rose in 1986, 1987, and the first three quarters of 1988. During this period, pre-tax profits as a percentage of net sales in the console industry rose steadily from 2.6 percent to 9.2 percent; in the transducer industry, pre-tax profits were 14.0 percent in 1985 , fell to 10.3 percent in 1986 , rose to 13.5 percent in 1987, and rose an amount not publicly disclosed in the first 3 quarters of 1988 as compared with the first 3 quarters of 1987. Other indicators of health considered by the Commissioners included production volume, capacity utilization, inventory levels, number of employees and hours worked, and investment in $\mathrm{R} \& \mathrm{D}$.

141 Ibid., pp. 42-53, 125-126.

142 Ibid., pp. 42-53, 126-136.

143 By statute, the injury requirement is satisfied if the ITC finds that the U.S. industry is threatened with material injury, even if the U.S. industry is not yet materially injured. However, "actual injury" must be "imminent," and a finding of a threat of material injury "may not be made on the basis of mere conjecture or supposition." 19 U.S.C. $1677(7)(F)(2)$. Thus, projecting current trends to a conclusion of future long-term injury to the U.S. industry will not normally justify finding a threat of material injury.

144 Ibid., p. 32.

145 U.S. International Trade Commission Pressure-Sensitive PVC Battery Covers from West Germany, Investigation No. 731-TA-452 (Preliminary), USITC Pub. No. 2265 (March 1990).

146 Ibid., pp. A-2, A-6, A-7.

147 Ibid., pp. 17-18.

148 Ibid., pp. A-38, A-39; Post-Conference Brief of the Petitioner, National Label Co., in the matter of Pressure-Sensitive PVC Battery Covers from West Germany, Investigation No. 731-452 (Preliminary), Feb. 13, 1990, pp. 17-21.

149 U.S. International Trade Commission op. cit., pp. A-39, A-40.

150 U.S. International Trade Commission op. cit., p. 20. Eveready's statements were confidential and not revealed by the ITC. The ITC found that "Zweck form did not bid on any Eveready purchases" at the meeting, and "the discussions between the two parties (had not] reached the point where they were in sufficient detail and scope to provide an indication of price suppression." National Label argued that, even if Zweckform had not solicited Eveready's business, Zweckform's dumped sales to other firms in the U.S. market made National Label reasonably fear that Zweckform would seek Eveready's U.S. business. Post-Conference Brief of Petitioner, National Label Co., op. cit., pp. 38-41. Therefore, according to National Label, Zweckform's dumping had in fact caused National Label to suffer injury by lowering its prices to Eveready. The Commission did not address this argument.

151 Post-Conference Brief of the Petitioner, National Label Co., op. cit., pp. 63-66; U.S. International Trade Commission op. cit., p. A-46.

152 U.S. International Trade Commission, op. cit., pp. 20-21.

153 The Commission's general practice is to permit outside attorneys and consultants to see other parties' confidential business information, but not to permit the parties' own personnel to see such information, for fear the information would be used improperly to gain business advantage.

154 James Shacklett, president, National Label Co., personal communication, Oct. 11, 1990.

155 The text of the agreement is contained in an exchange of letters on Sept. 2, 1986, between Japan's Ambassador Matsunaga and USTR Clayton Yeutter. An account of the U.S. negotiating strategy is given in Prestowitz, Jr., op. cit., p. 62.

When a foreign country sends dumped or subsidized merchandise to a third country, the United States could ask the third country to conduct its own countervailing duty or antidumping investigation and under GATT Article VI paragraph 6(b) relief could be granted if the dumping or subsidies injured the U.S. industry. Under U.S. law, firms may petition the USTR to make such a request to foreign governments. 19 U.S.C. 1677k (added in 1988, Public Law 100-418, Sec. 1317). However, this has never been tried, and there is no guarantee that the third country would honor such a request.

156 See ch. 6. Cray Research, the principal U.S. supercomputer manufacturer, lacks the size and product diversity to similarly crosssubsidize

157 Marie Anchordoguy, Computers Inc: Japan's Challenge to IBM(Cambridge, MA: Harvard University Press, 1989), pp. 72-75.

158 Ibid., pp. 68,69 (table 3, total of gross sales minus trade-ins), 228-230 (app. C).

159 Ibid., pp. 141-147.

160 See ch. 6.

161 These firms are Fujitsu, Hitachi, Mitsubishi, Toshiba, and NEC. Anchordoguy, op. cit., p. 143. The 1989 computer, electronic devices, and consumer electronics revenues of Fujitsu, Hitachi, and NEC alone were $\$ 13.7$ billion, $\$ 14.6$ billion, and $\$ 15.0$ billion for the respective fins, totaling $\$ 43.3$ billion. See tables $6-1$ and 6-3.

162 Subsidies law was designed on the premise that subsidies distort trade but do not change the underlying comparative advantage, so that discontinued subsidies have no more effect. This assumption has become increasingly mistaken. In the modem world, comparative advantage is often purchased by governments; for example, government money bought the United Kingdom a modem steel industry that could sell steel competitively in the world. Howell et al., op. cit., pp. 171-173.

163 GATT Article VI, paragraph 3.

164 Section 19 U.S.C. $1677 b(e)$. Other countries have argued that these floors are not proper and disadvantage fins, for example, in countries such as Japan where profit margins are often lower than 8 percent.

165 In July 1990, a panel of the GATT Committee on Antidumping Practices ruled that the Antidumping Code requires the investigating government to verify that an antidumping petition is supported by a majority of the domestic industry, and that the U.S. Commerce Department had not done so in an antidumping case involving stainless steel pipes and tubes from Sweden. As countries have often done with adverse GATT rulings during the Uruguay Round, the United States has said that it will bring its behavior in line with GATT norms, but only after the Uruguay Round is completed, when it is clear what the new norms will be.

166 These and other problems are discusscd in N. David Palmeter, "The Capture of Antidumping Law, "Yale Journal of International Law, vol. 14, No. 1, pp. 182-198 (reviewing Jagdish Bhagwati, 
Protectionism (Cambridge, MA: The MIT Press, 1988)).

167 In light of this, the EC accuses the United States of a double standard in complaining about government subsidies to the members of Airbus Industrie, a European consortium challenging U.S. dominance.

168 Omnibus Trade and Competitiveness Act of 1988, Public Law 100418, section 1301, enacting new provisions at 19 U.S.C.2411(d)(3)(B)(ii), 2411(d)(3)(E). This use of Section 301 is not completely new. While Section 301 has most often addressed foreign countries' barriers to sales of U.S. goods in their markets, is has sometimes included foreign subsidies as they affect sales of U.S. goods in third country markets; those subsidies could fit the definition of export targeting.

169 Normally, GATT prohibits protection with the exception that tariffs maybe imposed as agreed upon in negotiating rounds. Aside from the escape clause, GATT permits additional protection in certain other contexts, such as national defense, agriculture in some cases (this exception was made at the United States' insistence), to meet a balance of payments crisis, and in response to subsidies and dumping. Protection is also allowed when compensation is negotiated under Article XXVIII (ch. 2).

\section{GATT Article XIX.}

171 Ibid.

17219 U.S.C. 2251-2254.

17319 U.S.C. $2252(\mathrm{~b})(\mathrm{l})(\mathrm{B})$.

174 See 19 U.S.C. 2252(b)(1)(A).

17519 U.S.C. 2252 (c).

176 A petition may be filed "by any entity, including a trade association firm, certified or recognized union, or group of workers, which is representative of an industry." 19 U.S.C. 2252(a)(l). The great majority of investigations are triggered in this manner. An investigation can also be triggered by the President, the USTR, the House Ways and Means Committee, the Senate Finance Committee, or the ITC itself. 19 U.S.C. $2252(\mathrm{~b})(1)(\mathrm{A})$.

17719 U.S.C. $2252(\mathrm{~b})(2)$.

17819 U.S.C. $2252(\mathrm{e})$. The ITC can recommend protection adjustment assistance, or both. Adjustment assistance consists of: 1) payments, retraining, and/or job placement services for workers, and/or 2) financial help and/or technical assistance to firms. Even if adjustment assistance is recommended by the ITC and the recommendation is approved by the President, the petitioners must still apply for it to the Departments of Commerce and/or Labor. Generally, Section 201 petitioners desire import relief rather than adjustment assistance, for which they could apply independently without going through a Section 201 proceeding.

Recommendations for relief are made only by those Commissioners who voted to find injury.

If the vote on injury was tied, those Commissioners finding injury recommend relief; the President then has the choice of treating the Commission's vote as a vote to find no injury or a vote to find injury. 19 U.S.C. $1330(d)(1)$.

17919 U.S.C. $2252(\mathrm{e})$.

18019 U.S.C. 2252(f).

18119 U.S.C. 2253(a)(4).

18219 U.S.C. 2253(a)

18319 U.S.C. 2253(a)(3). Congress can in principle override the President's decision and reinstate the relief recommended by the ITC, but never has done so. See 19 U.S.C. 2253(c).

18419 U.S.C. 2253(e).

18519 U.S.C. $2254(\mathrm{~b})$.

186 U.S. General Accounting Office, International Trade: Activity Under Section 201 of the Trade Act of 1974, NSIAD-87-96FS (Gaithersburg, MD: U.S. General Accounting Office, Mar. 30, 1987), pp. 3, 6-9. This report lists all Section 201 cases brought during these years, except for cases TA-201-61 and 'IA-201-62, which both ended with a finding of no injury as shown in the ITC Annual Reports for 1988 and 1990. Some form of protection was granted by the President in eases No. (201 -TA-) 5, 16, 18, 19,29,35,36,37,39,43, 47,48,51, and 56. In cases $29,37,39,47$, and 56 the protection was by its terms less than that recommended (for example, lower tariffs, or shorter duration of the same tariffs). While the President sometimes granted a different type of relief that is not directly comparable with the protection recommended the President never granted protection that was by its terms greater than the relief recommended.

187 Section 201 has a higher standard of injury, and in that regard Section 201 relief is harder to get. However, before 1980, antidumping and countervailing duty cases had no time limits and no court review, and the Treasury Department, which handled those cases then, often put cases on indefinite hold. Section 201, in contrast, promised a decision within well under a year, and the required public hearing could help muster political support for relief.

188 The ITC found that the auto industry, while substantially injured by increasing imports, was injured more by a general economic recession in the country, and was thus ineligible for relief. U.S. International Trade Commission, Certain Motor Vehicles and Certain Chassis and Bodies Therefor: Report to the President on Investigation TA-201-44 under Section 201 of the Trade Act of 1974, USITC Publication 1110, December 1980, pp. 21, 67, 134, 173 (3-2 vote). In 1988, Congress specified that the ITC "may not aggregate the causes of declining demand associated with a recession or economic downturn in the United States economy into a single cause of serious injury or threat of injury." 19 U.S.C. 2252(c)(2)(A).

18919 U.S.C. 2251.

190 In theory, the government could encourage a new industry to form by other means, such as R\&D support, low-interest loans, and the promise of protection in the future if needed. When the new industry started to sell products, it would then exist and could be protected under Section 201. However, to use Section 201 in this way could violate GATT. GATT's escape clause requires that the injury be due to unforeseen increased imports. If the dominant foreign suppliers were already established when the U.S. industry started to form, it could be bard to argue that any increased imports were unforeseen. While U.S. law does not require that the increase in imports be unforeseen, an application of Section 201 to imports that were anticipated could provoke a GATT challenge, (However, the GATT provision requiring an unforeseen increase has fallen into disuse and might be eliminated in the Uruguay Round.)

191 The statute speaks in absolute, rather than relative, terms, directing Commissioners to consider, among other economic factors, "the significant idling of productive facilities in the domestic industry," "the inability of a significant number of firms to carry out domestic production operations at a reasonable level of profit," and "significant unemployment or underemployment within the domestic industry." 19 U.S.C. 2252(c). See, for example, U.S. International Trade Commission Nonrubber Footwear: Report to the President on Investigation No. TA-201-50 Under Section 201 of the Trade Act of 1974, USITC Publication No. 1545 (July 1984), pp. 11-19 (views of Chairwoman Stern, Vice Chairman Liebeler, and Commissioner Rohr).

192 U.S. International Trade Commission, ibid., p. 19 (views of Chairwoman Stem, Vice Chairman Liebeler, and Commissioner Rohr) (quoting legislative history).

193 See U.S. International Trade Commission Television Receivers, Color and Monochrome, Assembled or Not Assembled, Finished or Not Finished, and Subassemblies Thereof, Report to the President on Investigation TA-201-19, USITC Pub. 808, March 1977, pp. 13-16; U.S. International Trade Commission, Citizens Band (CB) Receivers, Report to the President on Investigation TA-201-29, USITC Pub. 862, February 1978, pp. 7, 28. These cases are also discussed in Morris Morkre and David Tarr, The Effects of Restrictions on United States Imports: Five Case Studies and Theory, Staff Report of the Bureau of Economics to the Federal Trade Commission June 1980, chs. 4, 5. 
194 U.S. International Trade Commission, Nonrubber Footwear, No. TA-201-50, op. cit., pp. 9-10,23.

195 Ibid., p. 22.

196 Ibid., pp. 9-10.

197 U.S. International Trade Commission, Nonrubber Footwear, No. 221-201-55, op. cit., pp. 11-12 (views of chairwoman stern).

198 As used in this discussion of what the U.S. public sector purchases, "defense" purchases mean purchases classified as defense in Congressional budget authorizations. To a first approximation this includes all of the Defense Department (except the civilian side of the Army Corps of Engineers), plus defense programs of the Department of Energy and NASA.

199 Department of Commerce, Bureau of Economic Analysis, Government Division Table PMB-llB, "National Defense Purchases by Subcategory in Constant Dollars,' Computer generated on Feb. 28, 1991.

200 Computer and Business Equipment Manufacturers Association

201 Department of Commerce, Table PMB-llB, op. cit.

202 U.S. Department of Commerce, International Trade Administration, 1991 U.S. Industrial Outlook, S/NO03-009-00586-8 (Washington, DC: U.S. Government Printing Office, January, 1991), pp. 37-2.

203 Eric Nelson, Director, Market Research, North American Telecommunications Association, personal Communication Apr. 1, 1990.

204 Public purchasing reportedly accounts for 90 percent of the output of telecommunications equipment, measuring equipment, and electro-medical equipment. Commission of the European Communities (CEC), Communication from the Commission on a Community Regime for Procurement in the Excluded Sectors: Water, Energy, Transport and Telecommunications, COM (88) 376 (Brussels, Belgium: CEC, Oct. 11, 1988), table 4, telefaxed from Anna Snow, Delegation of the CEC, Washington, DC, May 29, 1991.

205 U.S. Department of Commerce, Bureau of Economic Analysis, Government Transactions Methodology Papers: U.S. National Income and Product Accounts, BEA-MP-5 (Washington DC: U.S. Government Printing Office, November 1988), table III-6.

206 Robert LaucL, Library of Congress, Congressional Research Service, American Law Division, "The Buy American Act: Legislative History and 'Differential' Favoring Domestic Products,' Oct. 25, 1975, p. 2. For a recent description of Buy American legislation, see Robert Lauck, Library of Congress, Congressional Research Service, American Law Division, "Buy American Legislation," Mar. 28, 1990.

207 Other laws include the Davis-Bacon Act, the Walsh-Healy Act, and the Miller Act. See Commission on Government procurement, Report of the Commission on Government Procurement, Stock No. 5255-00002 (Washington, DC: U.S.Government Printing Office, December 1972), vol. 1, app. G, p. 167.

208 Inclusive of duty.

20948 C.F.R. 25.105.

21048 C.F.R. 25.101 (definition of "domestic end product"). Costs other than components, such as direct labor and overhead for final assembly, are not counted at all for this test. Also, the test considers only major components-' 'those articles, materials, and supplies incorporated directly into" the final product. Ibid. (definition of "components") (emphasis added). Thus, the origin of subcomponents, which are first incorporated into major components, is not considered.

21148 C.F.R. 25.104,. 105.

21248 C.F.R. 225.105.

213 U.S. General Services Admíni"stration, Federal Procurement Data Center, Federal Procurement Report, Fiscal Year 1990 through Fourth Quarter (Washington, DC: U.S. General Services Admin̈istration), pp. 74-75.
Additional detail on some of these preferences is given in U.S Department of Defense, A Report to the United States Congress by the Secretary of Defense, The Impact of Buy American Restrictions Affecting Defense Procurement (Department of Defense, July 1989), app. E, p. 13; Section 8(a) of the Small Business Act of 1953, as amended, 15 U.S.C. 637(a); and 48 CFR 13.105, 13.106 (Oct 1, 1990).

214 Alfred Volkman, Director, Foreign Contracting, Office of Deputy Assistant Secretary of Defense (Procurement), testimony at hearings before the House Committee on Government Operations, Subcommittee on Legislation and National Security, Sept. 27,1989, pp. 64, 72; see also ibid., p. 266. In this testimony, DoD said merely that "less than half" of defense procurement is opened under the MOUs. However, a DoD official clarified that the estimate was close to 50 percent. Personal communication July 19, 1991.

215 Joseph Kelly, Director, Security and International Relations Issues, U.S. General Accounting Office, testimony at hearings before the House Armed Services Committee, Subcommittee on Investigations, Apr. 30, 1991, p. 4.

216 For example, the United States does not waive restrictions on defense purchases of foreign machine tools. U.S. Congress, General Accounting Office, Defense Procurement: DoD Purchases of Foreign Made Machine Tools, GAO/NSIAD-91-70 (Gaithersburg, MD: U.S. General Accounting Office, February 1991), p. 22. Restrictions on defense purchases of supercomputers also are not waived.

217 The GATT Procurement Code took effect Jan. 1, 1981. It is described in U.S. Department of Commerce, International Trade Administration, Office of Policy, Government Procurement (July 1981) (prepared by Nancy E. Morgan) (vol. 2 of a series entitled The Tokyo Round Trade Agreements), which also gives the annexes specifying the Code's scope of application to particular countries.

218 Public Law 96-39.

219 The test here is the nature of the good rather than which agency buys it.

220 An SDR is a currency unit consisting of a basket of currencies from nations that are members of the SDR Department of the International Monetary Fund (IMF). It is also the unit of account for the IMF. In January 1991, one SDR was worth about $\$ 1.40$. Periodically the USTR publishes an updated dollar equivalent for 130,000 SDRs, to be used in assessing the Act's applicability to purchases by the U.S. Government.

221 Public Law 96-39. The Presidential authority to waive Buy American and other preferences comes from Section 301 of the Act, codified at 19 U.S.C. 2511.

222 These provisions are found in 19 U.S.C. $2511-2512$ and 48 CFR 25.40.406. Generally, for purchases covered by the Trade Agreements Act, bids from non-covered countries will not be considered at all. 19 U.S.C. 2512; 48 CFR 25.402(c). Also, under the Trade Agreements Act a good's origin is determined by where it underwent its last substantial transformation instead of by the fifty-percent-ofcomponents rule under Buy American. 48 CFR 25.401 (definition of "designated country end product").

223 Robin Zee, Purchasing Preference Practices: A 50 State Overview, Document No. C-130 (Lexington, KY: National Association of State Purchasing Officials (NASPO) and The Council of State Governments, 1989), pp. 22-24.

224 Bethlehem Steel Cop. v. Board of Commissioners of the Dept. of Water and Power of the City of Los Angeles, 276 Cal. App. 2d 211, 224,80 Cal. Rptr. 800,802 (1\%9).

225 Zee, op. cit.

226 Ibid., pp. 8-10.

227 The preference of 12 percent for goods produced in labor surplus areas raises prices paid by the government, but may save the country money by helping to reduce the costs of unemployment. Preferences for small and minority business raise prices paid by the 
government but they serve definite social goals.

228 For example, bidders and agencies sometimes mistakenly count the cost of domestic labor for final assembly, plus associated overhead and general administrative expense, as part of the cost of domestic components. U.S. Congress, General Accounting Office, Report to the Secretary of the Interior, Bureau of Reclamation: Misapplication of the Buy American Act, GAO/NSIAD-90-32 (Washington DC: U.S. General Accounting Office, November 1989); U.S Congress, General Accounting Office, Defense Procurement.' DOD Purchases of Foreign Made Machine Tools, GAO/NSIAD-91-70 (Gaithersburg, MD: U.S. General Accounting Office, February 1991), pp. 25-27.

229 See, for example, U.S. Department of Defense, Office of the Secretary of Defense, The Impact of Buy American Restrictions Affecting Defense Procurement (U.S. Department of Defense, July 1989), p. 35.

230 Public Law 100-202 (FY-1988 Department of Defense Appropriations Act), Sec. 8112. This prohibition could be waived if the Secretary of Defense certified to Congress that a foreign acquisition is required for national security. This provision is still in effect. Public Law 101-511, Sec. 8034

231 U.S. Congress, House Committee on Government Operations, International Procurement and Waivers of the Buy American Act: U.S Business at a Disadvantage, House Report No. 101-989, Nov. 29, 1990, p. 22.

232 Preferences for small business, minority-owned business, and businesses in labor surplus areas have not drawn as much criticism, probably because such programs and the underlying social goals are shared by some other nations.

233 U.S. Congress, Committee on Government Operations, op. cit., p. 7.

234 At times foreign firms were treated even better than U.S. firms when bidding for defense contracts, because foreign firms' costs were subject to less stringent audits. Ibid., pp. 13-17.

235 Allan I. Mendelowitz, Director, Trade, Energy and Financial Issues, United States General Accounting Office, testimony at hearings before the House Committee on Government Operations, Subcommittee on Legislation and National Security, Sept. 27, 1989, p. 30; and answers by the Defense Department's Office of Foreign Contracting to questions from the Subcommittee, same hearings, pp. 266-267. The Defense Department cautioned against comparisons of such data because of differing national organization and procurement systems.

Defense spending is also higher as a proportion of GDP in the United States than for U.S. allies. For example, despite roughly equal GDP, the market for defense procurement in the EC is only 40 percent of that in the United States. U.S. Congress, Office of Technology Assessment, Arming our Allies: Cooperation and Competition in Defense Technology, OTA-ISC-449 (Washington DC: U.S. Government Printing office, May 1990), pp. 47-50.

236 U.S. Congress, General Accounting Office, European Initiatives: Implications for U.S. Defense Trade and Cooperation, NSIAD-91167 (Gaithersburg, MD: U.S. General Accounting Office, Apr. 4, 1991) pp. 36, 39-42

237 The 19 are Australia (nonreciprocal), Belgium, Canada (nonreciprocal), Denmark,E gypt, Germany, France, Greece, Israel, Italy, Luxembourg, Netherlands, Norway, Portugal, Spain Sweden, Switzerland, Turkey, United Kingdom.

238 U.S. Congress, General Accounting Office, European Initiatives, op. cit., p. 37 .

239 Matthew B. Coffey, President, National Tooling and Machining Association, testimony at hearings before the House Committee on Government Operations, Subcommittee on Legislation and National Security, Sept. 27, 1989, pp. 3840.

240 U.S. Congress, House Committee on Government Operations, op. cit., p. 21, citing U.S. Congress, General Accounting Office,
Industrial Base: Adequacy of Information on the U.S. Defense Industrial Base, NSIAD-91-167 (Gaithersburg, MD: U.S. General Accounting Office, November 1989). The Defense Department estimated that the ratio of defense exports to MOU partners to imports from those partners dropped from almost 8:1 in the late 1970s and early 1980s to about 2:1 in 1987; in 1987, exports were estimated at 8 billion, imports at 4 billion. These estimates are based on unverified procurement data collected by DoD and foreign defense ministries. For that reason, and because of specific problems with the data which GAO has identified, GAO considers these estimates unreliable. Testimony at hearings before the House Committee on Government Operations, Subcommittee on Legislation and National Security, Sept. 27, 1989, p. 266 (written answers to questions included in the hearing record); U.S. Congress General Accounting Office, European Initiatives, op. cit., pp. 39-43, 61-62.

241 U.S. Congress, General Accounting Office, European Initiatives, op. cit., pp. 43-44.

242 House Committee on Government Operations, op. cit., pp. $11-13,17-21$.

243 U.S. Congress, General Accounting Office, European Initiatives, op. cit., p. 44.

244 The House Committee on Government Operations reported that the Administration had classified U.S. data derived from publicly available information and had classified data from other Code signatories after they declared the data no longer restricted. U.S. Congress, House Committee on Government Operations, op. cit., pp. 20-21.

245 U.S. Congress, U.S. General Accounting Office, The International Agreement on Government Procurement: An Assessment of its Commercial Value and U.S. Government Implementation, NSIAD-84117 (1984), pp. 11-17. As used in this chapter, Code-covered procurement means procurement that under the Code must be both transparent and nondiscriminatory.

246 Allan I. Mendelowitz, Director, Trade, Energy and Financial Issues, United States General Accounting Office, testimony at hearings before the House Subcommittee on Legislation and National Security, Sept. 27, 1989, pp. 13-14. (This testimony gave a brief, qualitative unclassified summary of the classified data.)

247 In 1985, the total central government procurement expenditures (including goods and services) of all other Code signatories combined was at least roughly equal to that of the United States. Ibid., p. 24.

248 W. Douglas Newkirk Assistant U.S. Trade Representative for GATT Affairs, testimony at hearings before the House Committee on Government Operations, Subcommittee on Legislation and National Security, Sept. 27, 1989, p. 50; U.S. Congress, General Accounting Office, The International Agreement on Government Procurement, op. cit., p. 16. Probably almost half of defense procurement is now covered under MOUs. By 1981, 11 out of 19 countries had already signed MOUs.

249 However, the Code might have made it easier in the long term for foreign suppliers to form and maintain such relationships with the U.S. Government, thus increasing U.S. imports over the years.

250 U.S. Congress, U.S. General Accounting Office, The International Agreement on Government Procurement, op. cit., pp. 15-17.

251 Ibid, pp. 13-17.

252 For the 25 percent estimate, see U.S.International Trade Commission, The Effects of Greater Economic Integration Within the European Community on the United States, USITC Publication 2204 (Washington, DC: USITC, July 1989), p. 4-14 [one page]. Some sources cite estimates as high as 50 percent, such as Aviva Freudmann, "EC Takes Giant Step to Open Public Procurement Markets," Atlantic Trade Report, vol. 2, No. 5, Mar. 1, 1990, p. 1.

253 Statement of Bernard H. Falk, president National Electrical Manufacturers Association, on the Annual Report on Foreign Discrimination Against Procurement of U.S. Goods and Services, before the 
House Committee on Government Operations, Subcommittee on Legislation and National Security, U.S. House of Representatives, May 1, 1990, p. 2.

254 Steve Thomas and Francis McGowan, The World Market for Heavy Electrical Equipment (Surrey, UK: Nuclear Engineering International Special Publications, 1990).

255 In 1987, digital switching systems in the EC reportedly cost between $\$ 225$ and $\$ 500$ per line, compared to an estimated price of around $\$ 150$ that would have resulted from competitive procurement. ('The price in the United States was around \$100.) Paolo Cecchini with Michel Catinat and Alexis Jacquemin, The European Challenge, 1992: The Benefits of the Single Market (Aldershot, UK: Gower Publishing Co., 1988), p. 22.

256 U.S. Congress, General Accounting Office, International Restraints to Competitiveness of the U.S. Heavy Electrical Equipment Industry, NSIAD-83-51 (Gaithersburg, MD: U.S. General Accounting Office, Sept. 14, 1983), p. 14. These agencies were the Army Corps of Engineers; Tennessee Valley Authority; Western Area, Southwestern, and Bonneville Power Administrations; and Bureau of Reclamation.

257 Negotiations to amend GATT's Procurement Code have been going on in parallel with the Uruguay Round negotiations to amend the basic GATT agreement

258 See U.S. International Trade Commission The Effects of Greater Economic Integration Within the European Community on the United States: Third Followup Report, USITC Publication 2368 (Washington, DC: USITC, March 1991), p. 6-4; U.S. International Trade Commission, The Effects of Greater Economic Integration Within the European Community on the United States, USITC Publication 2204 (Washington, DC: USITC, July 1989), p. 4-15.

259 Beverly Vaughan, Director of International Government Procurement Policy, Office of the United States Trade Representative, personal communication Mar., 25, 1991.

260 Public Law 100-418, Title VII.

261 Public Law 100-418, Sec. 7003, codified at 19 U.S.C. 2515 (see especially paragraph $\mathrm{d}(2)$ ).

26219 U.S.C. 2515(d),(f). For practices covered by the Procurement Code, the Code's dispute resolution procedures are to be tried for a year before the United States retaliates.

263 Office of the United States Trade Representative, Information on Certain Foreign Government Procurement Markets (Washington DC: Office of the USTR, Apr. 27, 1990).

264 Office of the United States Trade Representative, Title VII Report (Washington, DC: Office of the U.S. Trade Representative, Apr. 26, 1991)

265 Congress passed Title VII in the belief that a strategy of toughness, not patience, was more likely to open the foreign markets. This fundamental dispute--Congress advocating toughness on international trade issues while the Adminístration prefers patience-has long been a theme of U.S. trade policy.

266 The agencies represented are the Departments of Commerce, Agriculture, State, Treasury, Defense, Labor, Transportation, and Energy; the Office of Management and Budget; the Office of the U.S. Trade Representative; the Council of Economic Advisers; the Environmental Protection Agency, the Small Business Administration; the Agency for International Development the Export-Import Bank of the United States; the Overseas Private Investment Corporation; the U.S. Trade and Development Program, and the U.S. Information Agency. U.S. Department of Commerce, "Export Programs: A Busines Directory of U.S. Government Resources," May 1991.

267 U.S. Commerce Department International Trade Admintstration, Office of Financial Management, personal communication, Aug. 2, 1991.

268 Negotiations with foreign governments are led by the Office of the U.S. Trade Representative (USTR), which is within the Executive
Office of the President

269 Export Promotion Activities of Major Competitor Nations, May 1988. While the report was not released by the Commerce Department, it was provided under the Freedom of Information Act to the authors of Government Export Promotional Programs in Nine Countries: The Cornell University/XPORT Report on Government Export Promotion Programs and Policies in Canada, the United Kingdom, France, West Germany, Japan, Taiwan, Singapore, South Korea, and Brazil (Ithaca, NY: Cornell University, Johnson Graduate School of Management 1989); see page 7 of that report. The figures in the text and table 4-10 are drawn from table A on page 5 of that report, and app. I on page 54 .

270 U.S. Congress, General Accounting Office, Export Promotion: Problems in Commerce's Programs, NSIAD-89-44 (Gaithersburg, MD: U.S. General Accounting Office, Jan. 26, 1989), pp. 16-17.

271 Ibid., p. 18. Similarly, Trade Development usually lacked funds to print attractive, professional-looking brochures to advertise trade shows. Ibid., p. 41

272 U.S. Commerce Department, International Trade Admin̈istration, office of Financial Management, personal communication July $\mathbf{3 0}$ and Aug. 2, 1991. The combined budget for USFCS, TD and IEP increased from \$146 million in fiscal year 1987 to $\$ 170$ million in fiscal year 1991. The fiscal year 1987 figures are funds actually spent.

273 The program depended on ITA providing free publications. This stopped in 1981, causing program participation to wane. These two examples are taken from Ronnie L. Goldberg, BSI Consulting, Inc., "Federal programs for the Promotion of Manufactured Exports," contractor report prepared for the Office of Technology Assessment, June 1987, ch. 2, pp. 6-7.

274 U.S. Congress, General Accounting Office, Export Promotion, op. cit., passim.

275 Information about the USFCS' strategic review is taken from U.S. Department of Commerce, U.S. Foreign and Commercial Service, "Strategic and Technical Reviews Working Paper Export Assistance Needs: Working Group Recommendations SR 90-7," Mar. 1990; and interviews with USFCS staff.

276 See Organisation for Economic Co-operation and Develop ment, The Export Credit Financing Systems in OECD Member Countries (Paris, France: OECD, 1990, 4th cd.).

277 Ibid., ch. 23.

278 Eximbank 1990 Annual Report, p. 27; Organisation for Economic Cooperation and Development, op. cit., p. 229. Eximbank was capitalized in 1945 with $\$ 1$ billion from the U.S. Treasury. James Jackson, Library of Congress, Congressional Research Service, Economics Division, "Export-Import Bank Financial Issues," IB88013, July 27, 1989, p. 2.

279 The Arrangement on Guidelines for Officially Supported Export Credits requires countries to announce contemplated export loans, to permit other countries to match the terms. The Arrangement is signed by 23 countries, including the major economic powers. The text of the Arrangement is found in Organisation for Economic Cooperation and Development op. cit., ch. 25. Notification is treated in sections 14-17.

280 Chief Accountant, Commodity Credit Corporation, U.S. Department of Agriculture, personal communication, July 22, 1991.

281 This figure of $\$ 40$ billion does not include some products eligible for financing assistance, such as wood products, seafood, and leather.

282 Public Law 91-181, amending Section 9 of the Export-Import Bank Act of 1945, codified at 12 U.S.C. $635 \mathrm{~g}(\mathrm{~d})$. The amendment also directed Eximbank to report on activities "to enhance the opportunity for growth and expansion of small businesses and entrepreneurial enterprises."

283 Eximbank's 1990 Annual Report(p. 14) merely lists the dollar 
value of products exported with Eximbank's help that 1) meet the descriptions in the text (key linkage industry, high value added, etc.), or 2) are "related" to products meeting the descriptions in the text. This information by itself does not show how strategic concerns influence Eximbrmk's decisions, or what particular measures Eximbank has taken to meet the goals listed in the text.

284 Export-Import Bank of the United States, Report to the U.S. Congress on Export Credit Competition and the Export-Import Bank of the United States for the Period Jan. 1, 1989 through Dec. 31, 1989 (August 1990), p. 4.

285 Ibid.

286 Organisation for Economic Cooperation and Development op. cit., ch. 25 .

287 These were satellite earth stations, turbines, locomotives, and rail signaling equipment.

288 Export-Import Bank of the United States, Report to the U.S Congress on Tied Aid Credit Practices, Apr. 20, 1989, ch. IV. The subsectors were central office switching equipment, satellite earth stations, radio communications, boilers, turbines, rail signaling equipment, and earth moving equipment. Earth moving equipment was not divided into subsectors, so it counts both as a sector and a subsector.

289 Ibid., ch. III.

290 Export-Import Bank of the United States, Report to the U.S. Congress on TiedAid Credit Practices, op. cit., pp. 6, 14-15. The other major donors are Canada, France, Germany, Italy, Japan, and the United Kingdom.

291 Ibid., p. 16.

292 In 1988 Japan granted $\$ 9.1$ billion, the United States $\$ 9.8$ billion. Japan's share has been growing relative to the United States. U.S. Congress, General Accounting Office, Economic Assistance: Integration of Japanese Aid and Trade Policies, NSIAD-90-149 (Gaithersburg, MD: U.S. General Accounting Office, May 24, 1990), p. 6.

293 Ibid., p. 15.

294 Ibid., pp. 6-7,

295 Ibid., pp. 14-15; Export-Import Bank of the United States,

Report to the U.S. Congress on Tied Aid Credit Practices, op. cit., p. 8.

296 U.S. Congress, General Accounting Office, Economic Assistance, op. cit., pp. 11-13.

297 Export-Import Bank of the United States, "Report to the Congress under Section 15(g) of the Export-Import Bank Act of 1945, As Amended," p. 1, attached to letters from John Macomber, President ancChairman, Export-Import Bank of the United States, to the President of the Senate and the Speaker of the House, Dec. 3, 1990.

298 Export-Import Bank of the United States, "Report to the Congress under Section 15(g) of the Export-Import Bank Act of 1945 , As Amended," pp. 2-3, attached to letters from John Macomber, President and Chairman, Export-Import Bank of the United States, to the President of the Senate and the Speaker of the House, July 8, 1991.

299 These $\$ 53.8$ million counted against Eximbank's ceiling on direct loans of $\$ 612$ million for fiscal year 1990 .

300 Export-Import Bank of the United States, "Report to the Congress under Section 15(g) of the Export-Import Bank Act of 1945, As Amended," pp. 2-3, Attachment 2 (this report was attached to letters from John Macomber, President and Chairman, Export-Import Bank of the United States, to the President of the Senate and the Speaker of the House, July 8, 1991).

301 Export-Import Bank of the United States, Report to the U.S. Congress on Tied Aid Credit Practices, op. cit., ch. 11 U.S. Congress, General Accounting Office, Economic Assistance: Integration of Japanese Aid and Trade Policies, op. cit., p. 6.

302 United States Trade and Development Program Annual Report, 1990, pp. 6-7.
303 Ibid., p. 35.

304 Ibid., pp. 19,21,

305 Ibid., p. 3

306 Jonathan Raymond, Director, Congressional Affairs, U.S Trade and Development Program, personal communication, Aug. 2, 1991. TDP's total budget, which includes administrative expenses, has run 5 to 10 percent higher.

307150 U.S.C. App. 2401-2420. This Act's authorization lapsed as of Oct. 1, 1990, but President Bush continued its provisions in force by invoking the International Emergency Economic Powers Act, 50 U.S.C. 1702. See Executive Order 12730, "Continuation of Export Control Regulations," Sept. 30, 1990.

The export of purely military items is controlled by other statutes

308 The Control List is found at 15 CFR 799 (Jan. 1, 1991). Additional controls on software, technical data, and know-how are specified in a separate list found at 15 CFR 779. These lists are found within the Export Administration Regulations, 15 CFR, ch. VII, subchapter $\mathbf{C}$.

309 According to BXA statistics, in 1990 BXA granted approvals to individual license applications for $\$ 63$ billion worth of goods. However, this figure represents the amounts of goods authorized for shipment; not all amounts authorized were necessarily shipped.

Also, this figure does not include five types of special licenses covering many shipments at once. The most important of these is the distribution license, which enables exporters to ship a defiied product line for up to two years. BXA's fiscal year 1990 annual report (ch. 2, in press) gives an "informal estimate" of $\$ 17.9$ billion for products shipped in fiscal year 1990 under distribution licenses. Acknowledgeable BXA official guessed that goods shipped during calendar year 1990 under all special licenses perhaps totaled between $\$ 30$ billion and $\$ 40$ billion. Personal communication Apr. 25, 1991.

Given this uncertain information a fair estimate for calendar year 1990 might be $\$ 55$ billion for goods shipped uncles individual licenses and $\$ 35$ billion for goods shipped under special licenses. The total then would be $\$ 90$ billion for goods shipped under license in 1990.

310 U.S. Commerce Department, International Trade Administration, Office of Trade and Investment Analysis, personal communication Aug. 2, 1991.

311 NAS Z (complete citation given in the next footnote), pp. 116-117.

312 Panel on the Impact of National Security Controls on International Technology Transfer, Committee on Science, Engineering, and Public Policy, National Academy of Sciences, National Academy of Engineering, Institute of Medicine, Balancing the National Interest: U.S. National Security Export Controls and Global Economic Competition (Washington DC: National Academy Press, 1987). In 1991 the National Academy of Sciences published a second report. Panel on the Future Design and Implementation of U.S. National Security Export Controls, Committee on Science, Engineering, and Public Policy, National Academy of Sciences, National Academy of Engineering, Institute of Medicine, Finding Common Ground: U.S. Export Controls in a Changed Global Environment (Washington, DC: National Academy Press, 1991 ). These reports are sometimes called the Allen Schmitt Reports, respectively, after panel chairmen Lew Allen and Roland Schmitt. These reports will be referred to here as NAS Z and NAS II.

313 This calculus of the costs and benefits of export controls will no doubt be affected by the attempted coup in the Soviet Union, and that Union's partial disintegration, in August 1991. As this report goes to press, it is unclear where these events will lead; they have the potential to both increase the urgency of technology transfer to promote social change and increase the risk of military conflict.

314 NAS I, op. cit., pp. 187, 191; NASH, op. cit., pp. 100-101. While some allies also imposed some reexport controls, they were less intrusive.

315 This term is an imprecise shorthand. The countries at issue 
include former members of the defunct Warsaw Treaty Organization, the People's Republic of China, North Korea, and Vietnam, among others. Within these countries, CoCom for years has distinguished China as requiring less control than the Soviet Union; and recently CoCom has moved to reduce controls to Eastern European countries whose new governments represent a lesser strategic threat, provided that those countries institute export control systems of their own to keep technology from the Soviet Union and other, unreformed bloc members. So far, Czechoslovakia, Hungary, and Poland have qualified for this special treatment.

316 Title II of the Omnibus Trade and Competitiveness Act of 1988, Public Law 100-418.

317 S. 320. This bill passed the Senate on Feb. 20, 1991, and was referred jointly to the House Committee on Foreign Affairs and the House Committee on the Judiciary on Feb. 26, 1991. This bill resembles the conference version of H.R. 101-4653 and S. 101-2927, as passed by the House and Senate in 1990, but omits certain provisions that President Bush found objectionable in vetoing that bill. See President George Bush, Memorandum of Disapproval for the Omnibus Export Amendments Act of 1990, Nov. 16, 1990.

318 "Office of Licensing Statistics: CY 1990," n.d. (preparedly Bureau of Export Admitistration, U.S. Commerce Department). This percentage is by number of applications, not dollar value. (This figure includes all individual license applications, not just those required by East-West controls.)

319 Testimony of Dennis E. Kloske, Undersecretary for Export Administration, U.S. Department of Commerce, at hearings before the House Committee on Banking, Housing, and Urban Affairs, subcommittee on International Finance and Monetary Policy, Mar. 7 and 28, 1990, Serial No. 101-1030, p. 19. (The figures include all individual license applications, not just those required by East-West controls.)

320 CoCom Document CL (90) 42 (listing categories adopted on May 22, 1991 Preparatory Meeting).

321 Glennon Harrison, Library of Congress, Congressional Research Service, The Bush Administration's New Approach to Export Controls and CoCom,90-316E, June 26, 1990, p. 4.

322 Ibid., pp. 4-5.

323 Senate Committee on Banking, Housing, and Urban Affairs, Export Administration Act Amendments of 1990, Report to Accompany S. 2927, House Report No. 101-399, pp. 41-43.

324 Ibid., p. 41.

325 William Clements, Director, Office of Technology and Policy Analysis, Bureau of Export Administration U.S. Department of Commerce, personal communication, June 4, 1991.

326 Public Law 100-418, sec. 2415, codified at 50 U.S.C. App. 2404(B)(2)

327 President George Bush, Memorandum of Disapproval for the Omnibus Export Amendments Act of 1990, Nov. 16, 1990.

328 There is some question as to whether the economically less advantaged CoCom members can implement a sufficiently reliable system of controls. If not, a two-tiered CoCom system could be required, with countries in the first, more reliable, tier still controlling exports to countries in the second tier. The EC, for which trade barriers between its member states are anathema, is helping less advanced nations to establish reliable control systems so as to avoid the need for a two-tiered CoCom.

329 The Allen Panel studied the export control systems of Canada, France, Japan, the United Kingdom, and Germany and concluded that "[w]ith limited exceptions, none of the[se] countries imposed controls that extend beyond the CoCom lists." NAS I, op. cit., p. 99.

330 Thestatutoryprovision is found at 50 U.S.C. App. 2404(c)(6). The 6-month period may be extended 6 months at a time based on a finding that the item is not sufficiently available from other countries to render the U.S. control ineffective; the control may also be extended by at most 12 months to conduct negotiations to bring the item under multilateral control. An order removing East-West controls on many items 6 months after the Act is found at 54 Federal Register 8281 (Feb. 28, 1989).

33150 U.S.C. App. 2404(f). The President could maintain the controls for at most an additional 18 months if he deemed it necessary for national security, provided that he negotiated with other countries to remove the foreign availability. 2404(f).

332 Public Law 100-418, sec. 2418, codified at 50 U.S.C. App.

333 BXA, Office of Foreign Availability, "Completed Assessments (Based on claims under Trade Act-As of May 15, 1991)." Sixteen of the assessments were requested by interested firms; one was requested by a Technical Advisory Committee.

334 BXA 1989 Annual Reports, pp. 29-31, 34; William Clements, Director, Office of Technology and Policy Analysis, BXA, personal Communication Aug. 9, 1991. South Korea achieved this status only in December 1990; it and Singapore enjoy only the first of several levels of liberal treatment. Industry would like to see the level increased and to see other Southeast Asian nations brought in.

335 Public Law 100-418, section 2414, codified at50 U.S.C. App. 2404(a)(4),(5).

336 BXA 1989 Annual Report, p. 26. Congress had instructed that these changes be implemented within 90 days of the Act, or by Nov. 21, 1988.

337 BXA Annual Reports: 1990, ch. 2 (in press); 1989, p. 22; 1988, p. 22. The 1991 figure is from William Clements, Director, Office of Technology and Policy Analysis, Bureau of Export Administration, U.S. Department of Commerce, personal communication, June 4, 1991.

338 The 1989 figures are from NAS II, pp. 80, 82; the 1990 figures are from "Office of Export Licensing Statistics: CY 1990," n.d. (prepared by BXA).

339 NAS I, op. cit., p. 114.

340 Ibid., p. 113

341 Ibid., p. 191.

342 Ibid., p. 113.

343 NAS II, op. cit., pp. 98-99,

344 NASI, op. cit., pp. 114-115.

345 Ibid., p. 114, footnote.

346 Ibid., p. 214.

347 Ibid., p. 114.

348 U.S. Congress. General Accounting Office, Export Controls: Advising U.S. Business of Policy Changes, NSIAD-90-201 (Gaithersburg, MD: U.S. General Accounting Office, May 18, 1990), pp. 4-9.

349 BXA Annual Reports: 1990, ch. 2 (in press); 1989, p. 16.

350 “Office of Export Licensing Statistics: CY 1990," n.d. (prepared by BXA).

351 BXA 1990 Annual Report, ch. 2 (in press).

352 William Clements, Director, Office of Technology and Policy Analysis, personal communication, Aug. 22, 1991.

353 Alan Macmillan and Michael Andrews, BXA, Office of Foreign Availability, "Foreign Availability Assessment: ATCompatible Microcomputers" (December 1988); "AT Assessment Chronology," n.d. (prepared by BXA).

354 U.S. Department of State, "CoCom High Level Meeting: Fact Sheets," reprinted in Senate Report No. 101-399, p. 40.

355 Charlie Carter, Vice President for Technology, National Machine Tool Builders Association and industry member of the TAC for automated manufacturing, personal communication, Apr. 10, 1991; Representative of a high technology firm with representatives on several TACs, personal communication, Apr. 11, 1991. 
35650 U.S.C. App. 2409@

357 "Fact Sheet on Export Control Procedures," White House Press Release, Dec. 13, 1990.

358 President George Bush, Memorandum of Disapproval for the Omnibus Export Amendments Act of 1990, Nov. 16, 1990.

359 William Clements, Director, Office of Technology and Policy Analysis, BXA, personal communication, Aug. 9, 1991.

360 Ibid.

361 William Clements, Director, Office of Technology and Policy Analysis, BXA, personal communication, June 4, 1991.

362 To decontrol an item controlled by CoCom, CoCorn's permission is required. CoCom routinely reviews one-third of its list each year; to get CoCom to consider an item out-of-turn is possible, but requires special effort.

363 The only other basis for decontrol would be that an item is no longer strategic. Often foreign availability occurs before strategic value is lost.

364 Steven Goldman, Director, Office of Foreign Availability, personal communication, June 26, 1991.

365 This figure is for FY 1989. BXA 1989 Annual Report, p. 1.

366 Steven Goldman, op. cit.

367 NAS II, p. 98.

368 Ibid., p. 96.

36950 U.S.C. App. 2504(g)(l).

370 NAS II, pp. 194-195.

371 Personal communication Aug. 27, 1991.

372 Personal communication, Apr. 11, 1991.
373 Personal communication, Apr. 10, 1991.

374 See U.S. Department of Commerce, Bureau of Export Administration, Office of Technology and Policy Analysis, 1990 Annual Foreign Policy Report to the Congress (Jan. 21, 1990-Jan. 20, 1991), February 1990, chs. I-III.

375 Under Section 6 the President is supposed to consider foreign availability and the positions taken by other countries, and the impact of these factors on the controls' likely effectiveness, However, how these factors are weighed is up to the President's discretion. See 50 U.S.C. App. 2405(b),(h).

In addition, for many years the interagency review of license applications have been different for the two types of controls. However, in December 1990 the President directed that the procedures in place for Section 5 controls also be used for Section 6. "Fact Sheet on Export Control Procedures," White House Press Release, Dec. 13, 1990.

37656 Federal Register 10,756, 10,760 (Mar. 13, 1991).

37756 Federal Register 25053 (June 3, 1991). BXA originally found foreign availability on Sept. 25, 1989. See also "Semiannual Report to Congress-Report on the Operations of the Office of Foreign Availability: Apr. 1, 1990-Sept. 30, 1990," p. 12.

37856 Federal Register 40494-40502 (Aug. 15, 1991). The regulation will later be extended to cover use in making missiles.

379 Clements, personal communication Aug. 27, 1991, op. cit. What duty of inquiry firms will have is unclear. However, Mr. Clements has strongly urged exporters to ask their lawyers what their legal exposure might be and what precautions they should take.

380 See "Fact Sheet on Enhanced Proliferation Control Initiative," issued by the White House Dec. 13, 1990, reprinted in Bureau of National Affairs, International Trade Reporter, Dec. 19, 1990, p. 1933. 
Chapter 5

\section{EC-92: Trade and Industry Policy}




\section{CONTENTS}

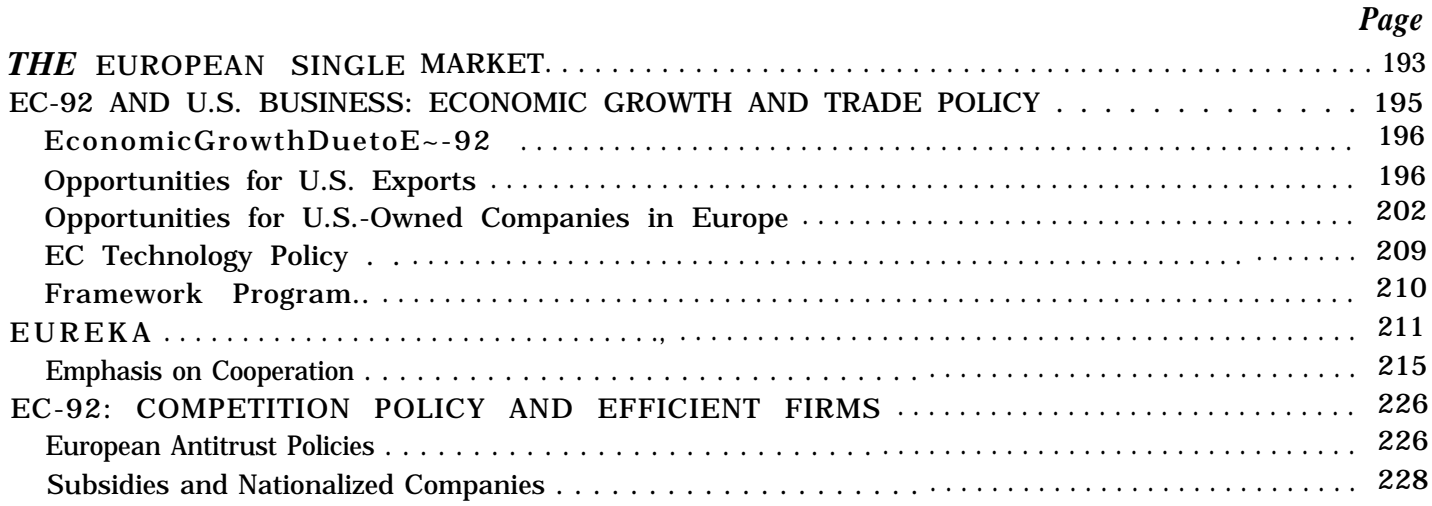

\section{Box}

Box

Page

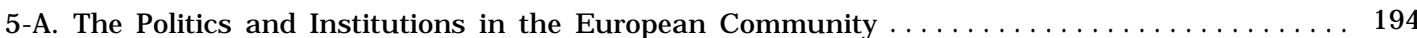

Figure

Figures

5-1. U.S. and EC Tariff Duties for Selected Commodities, $1990 \ldots \ldots \ldots \ldots \ldots \ldots \ldots \ldots \ldots \ldots \ldots .198$

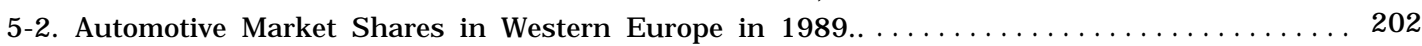

5-3. Scientists and Engineers per 10,000 Labor Force $\ldots \ldots \ldots \ldots \ldots \ldots \ldots \ldots \ldots \ldots \ldots \ldots . \ldots \ldots$

$5-4$. U.S. Patents by Nationality of Inventor $\ldots \ldots \ldots \ldots \ldots \ldots \ldots \ldots \ldots \ldots \ldots \ldots \ldots \ldots \ldots \ldots$

5-5.JESSI Program: Functional overview and Structure of the European Microelectrionic

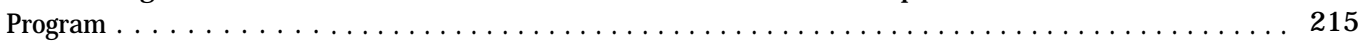

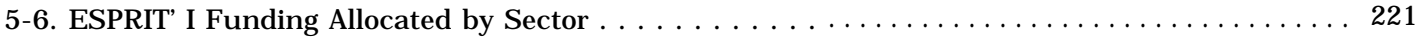

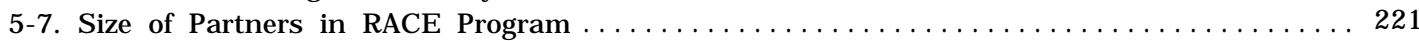

5-8. Europe's Trade Deficit in Electronics in $1987 \ldots \ldots \ldots \ldots \ldots \ldots \ldots \ldots \ldots \ldots \ldots \ldots \ldots \ldots 225$

5-9. Total Merger Activity, All National, Community, and International Mergers by

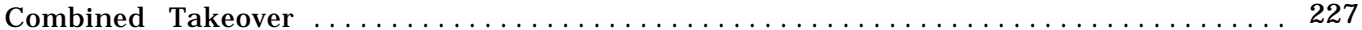

\section{Tables}

Talbe

Page

5-1. Macroeconomic Consequences of EC Market Integration for the Community, 1992-98 . . 196

5-2. U.S. Balance of Trade With the EC,1985 and $1989 \ldots \ldots \ldots \ldots \ldots \ldots \ldots \ldots \ldots \ldots \ldots \ldots . \ldots 197$

5-3. Direct Investment Outflows From Japan . . . . . . . . . . . . . . . . . . . . . . . . . . 203

5-4. Japanese Production Capacity in Europe . . . . . . . . . . . . . . . . . . . . . . . . . . 203

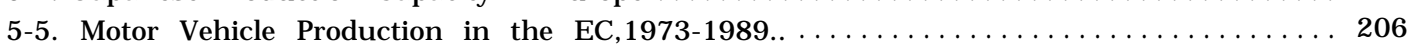

5-6. Japanese Share of the European Car Market, $1989 \ldots \ldots \ldots \ldots \ldots \ldots \ldots \ldots \ldots \ldots \ldots \ldots 206$

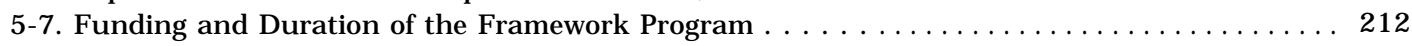

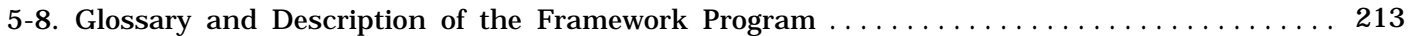

5-9. Funding of EUREKA Projects, by Area $\ldots \ldots \ldots \ldots \ldots \ldots \ldots \ldots \ldots \ldots \ldots \ldots \ldots \ldots \ldots$

5-10. EUREKA Projects: Number of projects by Funding Category . . . . . . . . . . . . . . . . . . 214

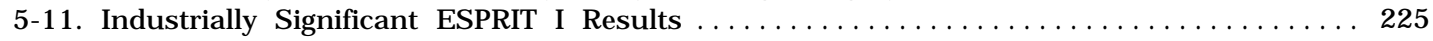

5-12. Shares of Manufacturing Industry Held by Large Firms in Japan, the United States, and the EC, $1986 \ldots \ldots \ldots \ldots \ldots \ldots \ldots \ldots \ldots \ldots \ldots \ldots \ldots \ldots \ldots \ldots \ldots \ldots \ldots \ldots$

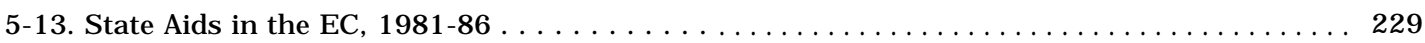


The European Community (EC) is entering a new stage in its efforts toward greater unity. Most European history for the past thousand years centered on states establishing, defending, and expanding national borders. Now the power of these states will be altered in fundamental ways. This stems from the commitment to make the EC into a single market by the end of 1992 (EC-92).

The goal of completing the internal market was first adopted in the Treaty of Rome, which established the European Economic Community in 1957. However, progress was slow until, in 1985, the Commission of the $\mathrm{EC}^{1}$ proposed a long stride forward, in the form of a White Paper that listed 300 specific policy actions, with the goal of removing barriers to the free movement of goods, services, people, and capital throughout the EC.

While EC-92 will not be completed by the end of 1992, the reforms already introduced and the growing commitments of governments, industry, and the public mean that this process is not reversible. Just what that means is debatable. According to some observers, businesses will become more efficient when the barriers to trade and cross-border operations fade and competition increases. The more optimistic forecasts estimate that growth rates could increase by 50 percent or more, while reducing inflation and unemployment. Although the size of the growth spurt is subject to debate, it is likely that the economies of the EC will get at least a temporary shot in the arm from the single market.

If EC countries are to open their markets fully to each other, it will be difficult for the individual nations to continue to create special advantages for their own firms. But that is precisely the aim of most existing national industrial policies in Europe. Thus, EC-92 could lead to either the elimination of some kinds of national industrial policies, or their control and supervision by the Commission. Some policies, such as the control of credit favored in France until the mid-1980s, could be swept away entirely, in this case by the removal of barriers blocking the flow of capital across borders. Other policies, such as controls over large mergers, will be transferred to the Commission. Many, such as subsidies policy, will remain in the hands of the member states but under the Commission's supervision.

Not all the important differences among member nations have been ironed out. Subsidies are at the heart of a significant remaining dispute. Some member nations, led by Britain, oppose government intervention to save EC-owned firms threatened by Japanese or U.S. competition. Others, with France in the lead, are determined to keep alive European companies-often their own national companiesin key industries such as electronics and motor vehicles.

Although some national industrial policies will likely be constrained under EC-92, the forces that generated them remain strong. Government intervention in cases of market failure is widely accepted in Europe. Hence, the EC is under pressure to develop an industrial policy of its own, one that does not favor industry in one EC country over that in another but seeks to improve the competitiveness of European industry.

In principle, the EC is committed to free trade. In practice, that is only partly true. While some early fears of Fortress Europe were exaggerated, the EC governments do use trade policy to protect European industry. Some defensive policies are longstanding (auto quotas dating back to the 1950s); some are new (rules of origin for semiconductors that favor manufacture within Europe); and some are now pursued more aggressively (antidumping).

Whatever the sources, current policy is not set in stone. EC officials seem to have considerable latitude in their interpretation of trade policy. And the outcome of the GATT ${ }^{2}$ Uruguay Round, expected to conclude in 1993, may change existing policies considerably; for example, the EC has put its discriminatory public procurement policies on the table. Overall, however, EC trade policy does have significant protectionist components, e.g., high tariffs, quotas, aggressive use of antidumping laws, discriminatory public procurement policies, protective rules of origin.

EC trade policy is less multilateral than it appears. It is aimed more at Japan and other Asian countries than at the United States. Key trade policies- 
notably antidumpting--have been used to dampen Japanese competition in strategic sectors, such as consumer electronics. This country-specific selectivity reappears in reciprocity clauses that extend specific benefits to trading partners only when reciprocal access is available.

EC efforts to protect European industries have encouraged importers to become local manufacturers through foreign direct investment, ${ }^{3}$ and there has recently been a large influx, especially from Japan. U.S. firms have had a major manufacturing presence in Europe for decades, and many (e.g., IBM, Ford) are now regarded as European in many respects. Other U.S. companies, however, are developing or improving their presence in Europe, not only to take advantage of the EC single market but also to expand sales into Eastern Europe. This strategy could prove tough for smaller companies.

This accelerated foreign direct investment offers a new set of challenges to the EC. For example, while the EC has used trade policy to protect its semiconductor producers, and through technology policy has spent billions of dollars trying to accomplish the same end, a strong Japanese manufacturing presence in the EC challenges both. The Commission has responded by moving toward policies that encourage specfiic kinds of investment likely to bring high wage jobs, technology transfer, work for European suppliers, and development in depressed areas.

The EC also seeks to improve the competitiveness of existing European firms through other policies. One method is technology policy aimed at supporting generic research through $R \& D$ consortia; another is support for large multinational projects like Airbus; and a third is competition policy (analogous to U.S. antitrust policy), which will discourage subsidies and state ownership. Other policies may exert indirect effects. For example, regional policy is aimed not only at redressing the inequalities of income and wealth within the EC, but also at helping failing industries and underdeveloped regions to adjust.

It is too early to assess the results of many of these policies on European competitiveness. The consequences of encouraging local production, especially in high-technology industries, remain unclear. Technology policy has been expensive and the payoffs for competitiveness remain indistinct at best, although it may have encouraged the development of an integrated European economy. Cross-border mergers that result in the formation of giant firms may improve competitiveness in some industries but not others. Progress toward deregulation of national public procurement markets could encourage EC firms to become more competitive, as could efforts to control national subsidies and limit their duration.

Trade between the EC and the United States is no small affair. Taken together, the 12 nations of the EC are the largest market for U.S. exports; in aggregate they are the biggest U.S. trading partner. Individually, 4 members of the EC (Germany, the United Kingdom, France, and Italy) are among the top 10 in volume of total trade with the United States. In 1990, the United States ran a small merchandise trade surplus with the European Community, although the range of variation with individual countries was wide; Germany's $\$ 8$ billion trade surplus with the United States in 1989 was fourth highest among all U.S. trading partners, and Italy's $\$ 4.7$ billion was eighth. Europe is also the location of the bulk of U.S. foreign direct investment.

The effects of EC-92 policies on trade between the EC and the United States and on U.S.-owned companies are not entirely clear either, but are not likely to be large. The most direct effects of EC-92 on the United States will come through trade policy, public procurement policy, and new mechanisms for setting technical standards. EC trade policy differentiates between goods produced within the EC and those imported into it, disc ruminating against the latter. The new EC public procurement policy does the same, providing large benefits for goods where at least half the content is added in the EC. And as Europe develops new procedures for setting ECwide standards to replace existing national standards, U.S. firms have worried both that they will be frozen out of the process and that EC firms will use the standards to keep out foreign-made goods.

These policies will have different effects on U.S. exporters and U.S. firms that manufacture in Europe. Many of the policies that accompany EC-92, e.g., tariffs, quotas, antidumping enforcement, rules of origin, and public procurement, will encourage exporting firms to relocate production to the EC. Firms that do not relocate could face significant trade barriers, more so in important sectors such as computers, semiconductors and telecommunications equipment. Exporters should benefit somewhat from the macroeconomic effects of EC-92, for growth 
brings increased demand that should expand U.S. exports. It is likely that any resulting boost to exports will be modest. It is too early for a conclusive judgment on U.S.-EC trade, especially as the EC has indicated that it will negotiate over many protectionist policies.

U.S. manufacturers in the EC should encounter expanded opportunities as national barriers and preferences are removed. Conversely, they may also face stiller competition from other foreign competitors into Europe (mostly Japanese firms), or from European firms themselves.

Besides its effects on U.S. exports and U. S.owned firms operating in Europe, EC-92 is interesting as a source of policy ideas and options for the United States. In many ways, EC-92 is responding to a set of issues this country is also grappling with in the face of formidable international competition. Europe's solutions may not be those we would choose, but it is a very large working laboratory for policy experiments. As its efforts take effect over the next few years, they will bear close scrutiny as to their possible relevance to the United States.

\section{THE EUROPEAN SINGLE MARKET}

The push to create a unified market in Europe began in 1957 with trade policy and the slow reduction of tariff barriers among members, which reached zero in 1968. Nonetheless, barriers remained. Even the process of crossing the border was inordinately complex and time-consuming, sometimes taking days for commercial vehicles.

In 1985, the Commission of the European Communities (CEC) introduced a package of radical reforms in a White Paper. ${ }^{6}$ This ambitious program aimed to remove barriers blocking the free flow of people, goods, services, and capital among EC countries. The package boiled down to 287 specific actions, each of which had to be negotiated in detail with the 12 member governments, affected interest groups, the European Parliament, and even third parties like the United States. This would have been impossible without a key institutional change, the Single European Act (SEA), which allows most agreements to be pushed through by modified majority vote among the member countries; a single country can no longer block adoption. These changes take place in the institutional and political context described in box 5-A.

Progress in removing barriers among EC nations is substantial but incomplete. The process of approving and implementing measures is complex and time-cons uming. Most measures have been agreed on in principle, but as of mid-1991, only about one-third had been finalized, and only a handful have been adopted as law throughout the Community. Serious obstacles remain, such as harmonization of monetary policy. Yet there is little doubt that the process is irreversible. Member states have made too many crucial commitments and central reforms have already been implemented.

For goods, the hundreds of documents needed to cross borders have been reduced to one, and the Commission aims to remove all border formalities in the next few years. Quantitative restrictions are formally illegal among members, and the EC is working to resolve some signicant exceptions (e.g., autos). ${ }^{7}$ Taxes are being reformed so that indirect taxes do not discriminate against imported items. ${ }^{8}$ The free flow of goods can still be restricted on health and safety grounds, but the European Court is interpreting this loophole very narrowly.

For capital, three directives remove national controls on deals in stock and mutual shares:

1. long-term commercial credits and securities not traded on exchanges;

2. admission of securities to capital markets; and

3. investments in short-term securities, current and deposit accounts, and loans.

Once the three directives are fully irnplemented, ${ }^{9}$ there will be no barriers to the free movement of capital within the EC.

Services have always been tightly regulated in Europe; even the right to establish a business has been limited. That will now change, as companies operating in any EC country will have increasing access to services markets in all the other EC countries. Banks, for example, will operate under the key principles of the single banking license, mutual recognition, and home country control. These will create a single market for banking services, regulated by the authorities of the bank's home country. This also sets off a race toward deregulation, as banks will tend to setup shop in the country with the least restrictive regulatory regime. ${ }^{10}$ 


\section{Box 5-A-The Politics and Institutions in the European Community ${ }^{1}$}

Institutions-There are four institutional power centers in the EC: the Council of Ministers, the Commission of the European Communities (Commission), the European Parliament, and the European Court of Justice (European Court).

The Council of Ministers represents national political power within the EC and is the strongest of the four centers. European Council meetings, ${ }^{2}$ are attended by heads of government for the 12 countries. More specialized topics are discussed by Councils of particular ministries-e. g., the EC's Science and Technology Framework Program is considered by Ministers of Science, Technology, or Research. The Foreign Ministers' Council is the most important of the specialized Councils.

Until 1985, legislation considered by the Council of Ministers had to be passed unanimously, so that even the smallest state held an absolute veto over the affairs of the EC. In 1985, the EC passed the Single European Act (SEA), which applied majority voting to all decisions affecting the implementation of the single internal market, except fiscal decisions and those relating to the free movement of people and workers' rights. The decisions needed to implement the single market will be taken largely by qualified majority voting. The Council is chaired by the President of the EC, an office that rotates biannually among the member states, in alphabetical order.

The Commission is the executive branch of the EC and has the sole right to make proposals to the Council of Ministers. Under its current President, Jacques Delors of France, the Commission has been a dynamic force pushing member states to give up sovereignty on the way to the single market, and then economic and even political union.

The Commission is divided into 24 Directorates General (DGs), the equivalent of Ministries. Each is led by a Commissioner, of which there are 17 (the President included), one nominated by each small member state and two by each large one. ${ }^{4}$ There are powerful tensions between DGs and Commissioners who strongly support free market

\footnotetext{
1This material is drawn from various CEC documents and Alberta Sbragia, "The European Community and Institutional Development: Politics, Money, and Law," Brookings Institution forthcoming.

2 Sometimes called EC summit meetings.

${ }^{3}$ Votes in the Council are weighted roughly by population: the United Kingdom, France, Germany, and Italy hold 10 votes each; Spain 8; Belgium, Greece, the Netherlands, and Portugal 5 each; Denmark snd Ireland 3; and Luxembourg 2. Proposals pass underqualified majority voting when they receive at least 54 out of the 76 total votes. Hence a blocking veto requires at least two major countries plus one medium sized one. Britain has been the country most consistently opposed to decisions but overruled under the SEA.

${ }^{4}$ The member states with tWO Comissioners are France, Germany, Italy, Spain, and the United Kingdom.
}

Article 48 of the Treaty gives workers the right to move freely within the EC to take up offers of employment. ${ }^{11}$ This right has been expanded so that workers can now also seek work and bring family and some dependents. ${ }^{12}$ There are still difficulties, such as the mutual recognition of professional qualifications, but EC citizens are now in essence free to work anywhere in the EC. Going further, France, Germany, the Benelux countries, and Italy have recently signed the Schengen agreement, which will eliminate all border checks on people. Spain and Portugal also intend to participate.

Other aspects of EC policy are not as settled. Disagreements remain, especially over the issue of subsidies and trade protection for firms whose ultimate owners are mainly European. This rift among member countries was highlighted in disputes over how to treat companies in the electronics sector. Britain's conservative government, sticking to its free market principles, allowed the Japanese electronics giant Fujitsu to buy the premier British computer firm, ICL, in 1990. At the opposite pole, the French Government announced in April 1991 that it would provide $\$ 1.5$ billion in subsidies to its two state-owned electronics companies-the computer manufacturer Groupe Bull SA and the defense and consumer electronics group Thomson SA, both of which experienced large losses in 1990. The justification, given by French Minister of Industry Roger Fauroux, was that "the future competitiveness of entire sectors of European industry" depended on the survival of European electronics firms. ${ }^{13}$ The EC Commission, which has supervisory power over industry subsidies, was reported to be divided over whether to approve the French subsidy.

It would be a mistake to view the progress toward EC-92 as a flood propelling all before it in one direction. In tone and even intent, various EC 
principles (notably Leon Brittan of the United Kingdom) and those who support a more interventionist industrial policy (notably Pandolfi of Italy and Delors).

Until recently, the Parliament has been relatively weak essentially a talking shop. Direct elections strengthened the Parliament; its role was also enhanced by the SEA. It can now delay but not block proposals. The powers of the Parliament will be extended.

The European Court acts somewhat like the U.S. Supreme Court. The Commission occasionally uses the Court to define its own rights and to interpret the key legal statutes of the EC. The Treaty of Rome and subsequent amendments, notably the SEA, provide the written constitution on which the Court bases its decisions. The Court may become increasingly important, as the EC seems to be moving away from a governmental system based on administrative discretion toward a more rule-driven model of government.

Politics-Industrial policy in Europe has attracted political backing from three key points on the political spectrum. While the left has abandoned a fully socialist economy in favor of a mixed model after World War II, it seeks to mitigate market outcomes and prevent market failures. The mix varies, as do the mechanisms chosen.

Christian Democratic parties have developed corporatist ideas based on notions of reciprocal rights and obligations between the state and the major social groups. These parties usually have tight relations with major producer groups-both employers and unions-and see negotiation with these groups as the basis for economic and industrial policies.

Nationalist tendencies springing from the right also support industrial policies. Gaullism stresses the importance of strategic industries and national independence, for national security reasons. That implies national control of the technology base. Together, these three philosophies have given industrial policy the respectability that it lacks in the United States.

Still, industrial policy is not universally viewed in Europe as either successful or appropriate. The tide of political opinion in Europe turned against it following the election of Margaret Thatcher as British Prime Minister in 1979. Thatcherites view industrial policies as expensive, inefficient, and corrupt. They replaced nationalization with privatization. EC-92 itself in many respects rejects traditional European industrial policy; it is committed to make markets work and reduce the role of the government in the economy.

\footnotetext{
5For a good example of moderate left thinkin gin the post-War period, see Anthony Crosland, The Future of Socialism (Westport, CT: Greenwood Press, 1977).

6Even in Sweden, the Social Democratic party has recently been forced into a mainstream agenda influenced by Thatcherism.
}

directives are at loggerheads with others, reflecting the differing views of the members on how close government-industry cooperation ought to be. Even where several policies converge toward one result, they are not entirely consistent and probably were not designed to be so. Rather, they evolved in that direction.

\section{EC-92 AND U.S. BUSINESS: ECONOMIC GROWTH AND TRADE POLICY}

EC-92 will affect U.S. companies in three ways:

. a growth effect, in which an expanded EC market will offer greater sales opportunities to both European and American fins;

- a near-term protectionist effect, as some EC policies governing trade, public procurement, and standards give EC-made goods an advantage over U.S. exports; and

. a longer term competitiveness effect, in which EC support of technology advances and collaboration among European firms might improve their performance compared with U.S. fins.

Nearly everyone expects a boost in economic growth from EC-92. The questions are how great it will be and whether it will outweigh any losses U.S. firms may suffer. EC-92 policies will affect U.S. exports and sales by U.S. firms located in Europe differently. The distinction is important from the standpoint of U.S. national interests. Success in exports tends to strengthen the national economy and raise standards of living. Success by U.S.-owned firms operating in foreign countries is not so closely tied to the Nation's interests, though it may be indirectly supportive if profits from the foreign 
Table 5-I-Macroeconomic Consequences of EC Market Integration for the Community, 1992-98

\begin{tabular}{|c|c|c|c|c|}
\hline $\begin{array}{l}\text { Trade } \\
\text { barriers }\end{array}$ & $\begin{array}{c}\text { Public } \\
\text { procurement }\end{array}$ & $\begin{array}{l}\text { Financial } \\
\text { services }\end{array}$ & $\begin{array}{l}\text { supply } \\
\text { effects }\end{array}$ & $\begin{array}{l}\text { Total } \\
\text { value }\end{array}$ \\
\hline Change & & ercent) & & \\
\hline $\begin{array}{l}\text { GDP } \ldots \ldots \ldots \ldots \ldots \ldots \ldots \ldots \ldots \ldots \ldots \\
\text { Consumer prices } \ldots \ldots \ldots \ldots \ldots \ldots \ldots \ldots\end{array}$ & $\begin{array}{r}0.5 \\
-1.4\end{array}$ & $\begin{array}{r}1.5 \\
-1.4\end{array}$ & $\begin{array}{r}2.1 \\
-2.3\end{array}$ & $\begin{array}{r}4.5 \\
-6.1\end{array}$ \\
\hline
\end{tabular}

ventures come back to enrich American citizens or enhance domestic investment.

\section{Economic Growth Due to EC-92}

EC-92 is still in early stages of implementation, so its effects on growth are not yet discernible. However, most analysts expect EC-92 to increase the EC's productivity by removing intra-European trade barriers, encouraging restructuring, promoting competition, and boosting investment. All this is expected to result in faster economic growth.

The original estimates on the medium-term (199298) growth effects of EC-92 were produced by Paolo Cecchini for the Commission. Relying extensively on macroeconomic analysis, Cecchini used OECD and EC economic models to produce a set of estimates for the medium-term impact of EC-92 on the European economy over 6 years, as described in table 5-1.

This estimate from the Commission strongly influenced European policymakers. It suggested that there was a specific policy route available that would increase the rate of economic growth by around 50 percent every year for 6 years, with further effects later on (the Cecchini estimate of 4.5 percent extra growth over 6 years is the average of a range of estimates, from 3.2 to 5.7 percent). According to the report, still more growth might result with changes in macroeconomic policy, such as increased public investment and reduced income taxes. In that case, gross domestic product (GDP) gains might be as high as 7 percent over the 6 years, and employment gains could rise from about 1.8 million new jobs to 5 million, at the cost of a smaller reduction in consumer prices (4.5 instead of 6.1 percent).

The Cecchini report has not been accepted unchallenged. While Richard Baldwin sees dynamic gains from EC-92 that dwarf the estimates made by Cecchini, ${ }^{14}$ most other American (and several Euro- pean) economists regard the Cecchini estimates as optimistic. Merton Peck, for example, concludes that 1.5 to 2.5 percent additional growth in GDP is a more justified figure, although he concedes that his estimate is itself only a guess based on previous experience of GDP gains with removal of trade barriers, and that his work excludes the dynamic gains stressed by Baldwin. ${ }^{15}$

Keynes long ago pointed out that a primary determin ant of economic activity was the "animal spirits" of entrepreneurs, and EC-92 already has been a shot of adrenalin for Europe. "Europhoria" may be no more appropriate than 'Europessimism,' but it does have the benefit of making the business community more optimistic and more likely to invest, hence improving chances for the economy to grow faster. How much faster is, for now, an unanswerable question.

\section{Opportunities for U.S. Exports}

If EC-92 is successful in making European firms more competitive, both imports and exports would be likely to increase. This growth in trade, added to the growth of the EC market, could help U.S. exports, assuming they are able to take advantage of the growth.

An obstacle to increased U.S. exports could lie in the EC's trade and procurement policies. Since most European countries already have some protectionist trade and procurement policies, only EC policies that move in the direction of greater protection will make it harder for U.S. exporters to sell in Europe. But the early fears that EC-92, while dissolving trade barriers within the Community, would erect a Fortress Europe against outsiders have abated. An overall move toward more protectionism against non-EC traders now appears unlikely. However, there are important exceptions affecting specific industries. One of these is the electronics complex, including computers, semiconductors, and telecom- 
munications equipment. This is the largest and most important category of U.S. exports to the EC.

Table 5-2 shows exports and trade balances for the industries accounting for most U.S. manufacturing exports to the EC in 1989 (the last full year for which detailed trade figures are available). It seems that changes in trade and procurement policy will make little difference to two of the three industries that are our biggest exporters to Europe--chemicals and aircraft. The electronics situation is murkier. Without question, EC trade, procurement, and technology policies are all targeted toward helping European firms compete more vigorously in the computer, semiconductor, and telecommunications industries. Although this effort is unlikely to cripple U.S. exports, it could dampen them.

U.S.-EC trade in chemicals is large and two-way; the $\$ 9.9$ billion in U.S. exports to the EC was almost matched by U.S. imports from the EC. This reflects the fact that both the United States and the EC are home to strong, competitive chemicals industries (though EC companies are larger and have a bigger share of world sales ${ }^{16}$ ). There are no new departures in EC-92 trade or procurement policy likely to hinder expanded U.S. chemicals exports to the EC as that market grows. The new, more unified system of standards and testing could make it easier for U.S. firms to export to the EC, because their products will have to pass only 1 set of tests and requirements, not 12; however, it is unclear whether U.S. exports could be tested in the United States or would have to be tested in Europe (see the discussion of standards below). Firms just beginning to export to the EC may find it more difficult, because competition within the EC market will be keen. ${ }^{17}$

The U.S. aircraft industry is not only a big exporter but also a big generator of trade surpluses for the United States, in both EC and world trade. It is getting increasingly tough competition from Airbus, however. The large, sustained subsidies to Airbus from European governments are no small part of its success (see ch. 8), but those subsidies have nothing to do with new policies under EC-92.

Table 5-2-U.S. Balance of Trade With the EC, 1985 and 1989

\begin{tabular}{|c|c|c|c|c|c|c|}
\hline \multirow[b]{2}{*}{ Product category } & \multicolumn{2}{|c|}{$\begin{array}{c}1985 \\
\text { (billion dollars) }\end{array}$} & \multicolumn{3}{|c|}{$\begin{array}{c}1989 \\
\text { (billion dollars) }\end{array}$} & \multirow{2}{*}{$\begin{array}{l}\text { Share of } \\
\text { U.S. exports } \\
\text { (in percent) }\end{array}$} \\
\hline & $\begin{array}{l}\text { Us. } \\
\text { imports }\end{array}$ & Balance & $\begin{array}{l}\text { Us. } \\
\text { exports }\end{array}$ & $\begin{array}{l}\text { Us. } \\
\text { imports }\end{array}$ & Balance & \\
\hline 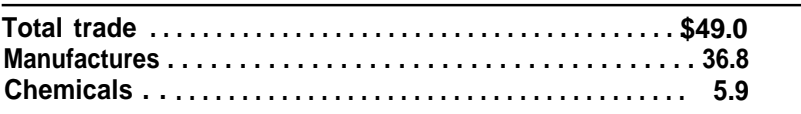 & $\begin{array}{r}\$ 67.8 \\
56.8 \\
6.2\end{array}$ & $\begin{array}{r}\$-18.8 \\
-20.0 \\
-0.3\end{array}$ & $\begin{array}{r}\$ 86.6 \\
71.7 \\
9.9\end{array}$ & $\begin{array}{r}\$ 85.1 \\
75.5 \\
9.1\end{array}$ & $\begin{array}{c}\$ 1.5 \\
-3.8 \\
0.8\end{array}$ & $\begin{array}{l}\overline{24} \% \\
26 \\
27\end{array}$ \\
\hline 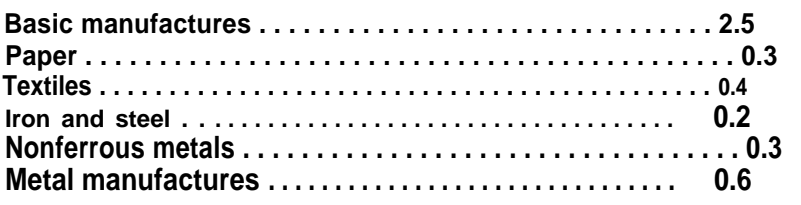 & $\begin{array}{r}10.8 \\
0.6 \\
1.4 \\
3.0 \\
1.3 \\
1.2\end{array}$ & $\begin{array}{l}-8.3 \\
-0.3 \\
-1.0 \\
-2.8 \\
-1.0 \\
-0.6\end{array}$ & $\begin{array}{l}5.4 \\
0.7 \\
1.0 \\
0.4 \\
0.7 \\
1.0\end{array}$ & $\begin{array}{r}13.4 \\
0.8 \\
1.7 \\
3.1 \\
1.3 \\
1.7\end{array}$ & $\begin{array}{l}-8.0 \\
-0.1 \\
-0.7 \\
-2.7 \\
-0.6 \\
-0.7\end{array}$ & $\begin{array}{l}19 \\
16 \\
25 \\
12 \\
15 \\
21\end{array}$ \\
\hline 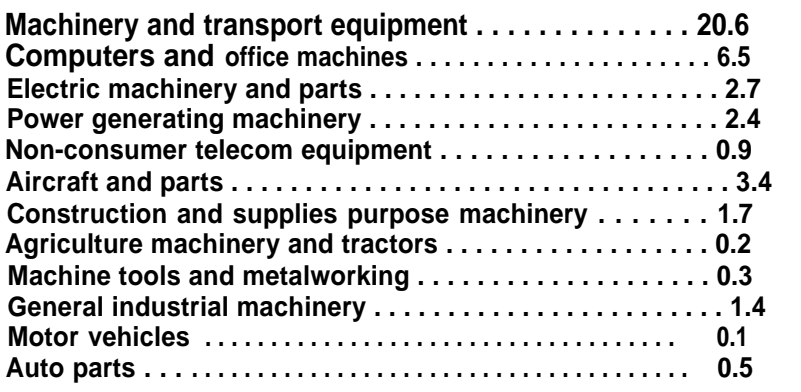 & $\begin{array}{r}27.1 \\
1.8 \\
2.6 \\
3.2 \\
0.3 \\
2.0 \\
2.7 \\
0.9 \\
0.8 \\
2.7 \\
7.9 \\
1.5\end{array}$ & $\begin{array}{r}-6.5 \\
4.7 \\
0.1 \\
-0.8 \\
0.6 \\
1.4 \\
-1.0 \\
-0.7 \\
-0.5 \\
-1.3 \\
-7.8 \\
-1.0\end{array}$ & $\begin{array}{r}42.7 \\
11.2 \\
5.5 \\
5.4 \\
1.7 \\
9.4 \\
2.6 \\
0.6 \\
0.7 \\
2.9 \\
1.0 \\
1.0\end{array}$ & $\begin{array}{r}36.2 \\
2.7 \\
4.3 \\
4.6 \\
0.6 \\
3.5 \\
4.8 \\
0.9 \\
1.1 \\
4.5 \\
6.7 \\
2.5\end{array}$ & $\begin{array}{r}6.5 \\
8.5 \\
1.2 \\
0.8 \\
1.1 \\
5.9 \\
-2.2 \\
-0.3 \\
-0.4 \\
-1.6 \\
-5.7 \\
1.5\end{array}$ & $\begin{array}{r}27 \\
44 \\
21 \\
37 \\
23 \\
39 \\
23 \\
25 \\
26 \\
22 \\
10 \\
8\end{array}$ \\
\hline 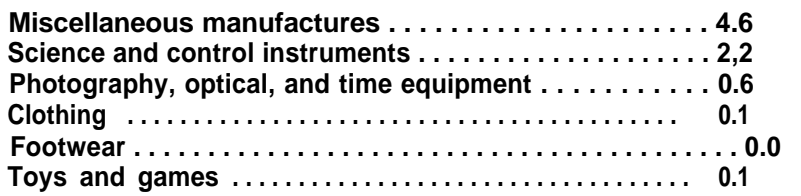 & $\begin{array}{l}9.7 \\
1.1 \\
0.9 \\
1.8 \\
1.1 \\
0.3\end{array}$ & $\begin{array}{r}-5.1 \\
1.1 \\
-0.3 \\
-1.7 \\
-1.1 \\
-0.2\end{array}$ & $\begin{array}{c}11.0 \\
4.1 \\
1.4 \\
0.3 \\
0.1 \\
0.4\end{array}$ & $\begin{array}{r}13.2 \\
2.0 \\
1.4 \\
1.7 \\
1.3 \\
0.4\end{array}$ & $\begin{array}{r}-2.2 \\
2.1 \\
0.0 \\
-1.4 \\
-1.2 \\
0.0\end{array}$ & $\begin{array}{l}31 \\
36 \\
40 \\
14 \\
24 \\
25\end{array}$ \\
\hline
\end{tabular}

1985 data includes Spain and Portugal.

SOURCE: National Association of Manufacturers, from Department of Commerce data. 
None of the EC-92 trade and public procurement policies should change the prospects for sales of U.S. aircraft in Europe very much; developments in the competition among Airbus, Boeing, and McDonnell Douglas are likely to affect U.S.-EC trade in aircraft much more than EC-1992 (see ch. 8). ${ }^{18}$

\section{EC Trade and Public Procurement Policies}

New EC-92 trade and procurement policies do affect U.S. electronics exports directly. Europe is the leading destination for computer and electronics exports from the United States, and an important market for these industries. As shown in table 5-2, computers and office machines alone accounted for $\$ 11.2$ billion of U.S. exports to the EC in 1989, generating an $\$ 8.5$ billion surplus for the United States. Electrical machinery and parts-mostly semiconductors-added another $\$ 5.5$ billion in exports and nonconsumer telecommunications equipment $\$ 1.7$ billion; together, these two sectors generated a $\$ 2.3$ billion trade surplus.

As shown in figure 5-1, EC tariffs on computers and telecommunications equipment are the same as or a little lower than U.S. tariffs on the same items-around 5 to 8 percent. The largest tariff in the group is on semiconductors, at 14 percent; the United States has had no tariff on semiconductors since the early 1980s. The EC semiconductor tariff has not stopped U.S. exports. In fact, the Commission can waive the tariff when a certain chip is needed by an EC producer and is not made there or is in short supply. According to one estimate, about 20 to 30 percent of semiconductor imports faced no tariff in $1988 .{ }^{10}$

What is new is the EC's rule of origin for semiconductors, introduced in February 1989. Under this rule, the country of origin is defined not by the testing and assembly of chips, as had been the case, but by the location of wafer fabrication (where the diffusion process occurs) .20 Wafer fabrication is the most important and technically demanding part of semiconductor manufacture. The final step, testing and assembly, adds only 10 to 15 percent of the chip's total value; wafer fabrication constitutes about 60 percent. ${ }^{21}$ Semiconductors that do not qualify as EC-made (i.e., are not fabricated in Europe) face the 14-percent tariff. But more important is the combination of the semiconductor rule of origin with strong preferences for EC-made goods in public procurements and the settlement of antidumping actions.

EC directives allow public purchasers in four sectors-water, energy, transport, and telecommunications-to reject bids that have less than half EC content by value. (These sectors are excluded from GATT rules that govern public procurement,

Figure 5-I —U.S. and EC Tariff Duties for Selected Commodities, 1990

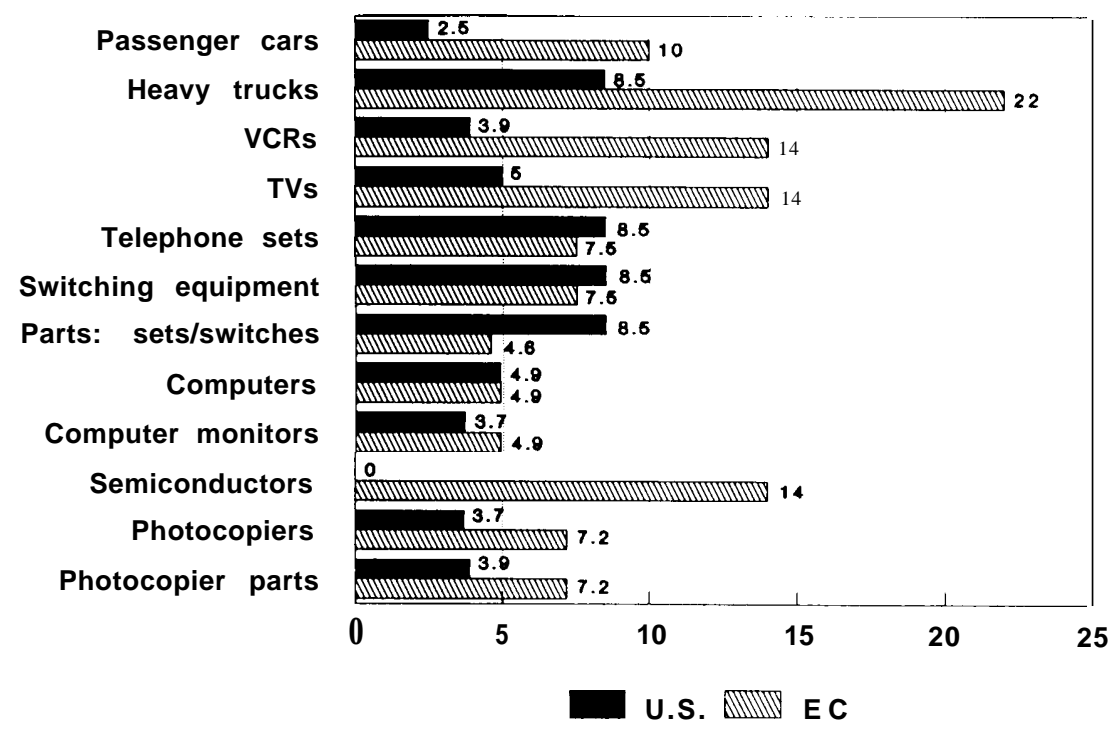

NOTE: Japan had no tariffs for these products.

SOURCE: Office Of Technology Assessment, 1991, derived from published tariff schedules for the United States, EC, and Japan. 
and therefore are designated the excluded sectors.) Even if the purchasers choose to consider non-EC bids, they are required to give a 3-percent price advantage to goods and services of EC origin. The four sectors account for at least one-quarter of all public procurement in the $\mathrm{EC}^{22}$ (some estimates are as high as one-half $\mathrm{f}^{23}$ ) and for many high-technology purchases. Public procurement, as defined by the EC, covers not only governments but also firms that benefit from exclusive geographical rights or barriers to entry in their industry and businesses that governments control through the granting of licenses. This means, for instance, that British Telecom, a private firm licensed by the British Government, follows the public procurement rules. The U.S. International Trade Commission reckons that public sector purchases account for as much as $\mathbf{9 0}$ percent of U.S. companies' telecommunications equipment sales in the EC, and up to one-third of EC sales by computer companies. ${ }^{24}$ Semiconductors are essential components of the computers and telecommunications equipment covered by the public procurement rules.

On the other hand, U.S. exporters could benefit from some changes in public procurement under EC-92, especially as they apply to purchases outside the excluded sectors. The new rules require greater openness and less discrimination in public purchases. Assuming tough enforcement, this could break the hold that many national companies now enjoy as favored suppliers-an important EC goal, for favoritism is costly. One of the main sources of the economic growth and reduced prices expected in EC-92 is lowered costs arising from competition in public procurement. The Commission has a measure of control over the national governments in this regard. Public purchasers must disclose annual projected procurement figures and report on contracts awarded in the past year. ${ }^{25}$ So far, however, the Commission's enforcement powers are weak. For example, when the Danish Government specified that only Danish labor and materials could be used in building a bridge, the EC stopped short of taking court action to halt the project and reopen bids. Instead, it agreed to an out-of-court settlement in which Denmark promised to change its ways in the future and allow the excluded bidders on the bridge project to sue for compensation. Nevertheless, even this much is progress.

The excluded sectors also fall under new nondiscrimination rules, but with more exceptions and looser criteria for openness. The preference for EC suppliers in these sectors remains one of the biggest worries for U.S. exporters facing EC-92. GE, for example, noted that it was hard to justify spending upwards of $\$ 200,000$ on bids to provide power plant equipment when the bids need not even be considered. Other U.S. firms have made the same point, emphasizing that the EC rules differ from the U.S. Government's Buy American preferences, which give U.S.-based bids a price advantage of 6 percent (12 percent for small businesses), but then require that all bids be considered on an equal basis. The uncertainty under the EC rules may be enough to deter bids from any company that cannot confidently claim 50-percent EC content.

Some U.S. producers of semiconductors are fearful that the restrictions on public sector purchases could spill over into the private sector (or public purchases outside the excluded sector). A firm selling computers, say, in more than one market might not want to make different product lines for each, and so would have reason to buy chips from EC sources to help satisfy the 50-percent requirement. Thus the public procurement rule could set the standard for the whole market.

These fears may be exaggerated. U.S. firms have done quite well exporting semiconductors, computers, and telecommunication equipment to the $\mathrm{EC}$, despite the European tradition of making public purchases from national champion firms ${ }^{26}$ U.S. exporters stand to benefit from the new rules for greater openness to all bidders. Furthermore, there is a possibility that even in the excluded sectors, U.S. exports may eventually win the same treatment as EC goods. In the Uruguay Round of GATT negotiations, the EC has shown interest in an expanded GATT Government Procurement Code, which would extend to signatories equal treatment in all public procurement (except defense). Meanwhile, however, the combination of new rules of origin and discrimin atory public procurement is pushing foreign firms to manufacture in Europe rather than export to Europe goods formerly made at home. While that may be good news for U.S. multinationals, it could be bad news for exporters, especially small ones without the scale of operations to justify locating in Europe.

Another EC trade policy that affects U.S. exports, especially in electronics, is its recent aggressive pursuit of antidumping actions. From 1985 through 
1990, the EC initiated 209 antidumping actions, concluded 190, imposed penalties in 67 , and made agreements to remedy the injury to EC producers in 51 , often by shifting high-value-added production to the EC. ${ }^{27}$ The most significant actions were against Japanese, other Asian, and Eastern European companies; hardly any were directed against U.S. firms. ${ }^{28}$ But aggressive antidumping actions and penalties add much weight to the factors that encourage foreign firms to locate and manufacture in Europe, and that has consequences for U.S. exports.

The EC has often settled cases against Japanese producers with agreements that, in the future, the goods in question can avoid antidumping penalties (i.e., additional duties) by including at least 40 percent non-Japanese content. This doesn't necessarily mean EC content, according to the Commission. However, there are reports that some manufacturers of machines using semiconductors assume that it does mean EC content, or at least it might, and to be on the safe side they design in EC-made chips rather than U.S.-made chips. ${ }^{29}$

In the well-known Ricoh case, the EC did go after photocopiers made in the United States. In November 1988, Ricoh copiers, made in Japan, were found to be dumped. The EC assessed 20-percent antidumping duties (the regular EC duty is 7.2 percent). Three months later, the Commission charged that Ricoh had increased production in California, where it was simply an assembly operation, and that the real manufacture was occurring in Japan. Therefore, the EC ruled, the California-assembled copiers should face the same duty as if they were allJapanese. Moreover, an EC rule adopted in July 1989 extended new rules of origin to copiers. It stated that the country of origin would be determined by where "technically sophisticated components, such as the various printed circuit boards, lenses, various motors and high-voltage generators" were manufactured. ${ }^{30}$ Nowhere is it explicitly stated that these high-technology components would have to be made in the EC in order for a photocopier to escape penalties in an antidumping case, or perhaps to be considered for public procurement. But again, that may well be the practical effect.

\section{EC Standards, Testing, and Certification}

A central part of EC-92 is the creation of a unified standards and testing system in Europe. This means that goods that pass muster in 1 of the 12 member nations should be accepted in all of them. Pan-
European acceptability should be a boon for European as well as foreign firms, since it relieves them of the need to meet varying standards in different countries. For many U.S. companies that positive effect will outweigh any negative ones.

Still, there are worries about negative effects. One has to do with the content of the standards and another with the means of testing them. Initially, U.S. companies were concerned that the new EC standards were being written behind closed doors, and that they might be designed so restrictively as to handicap all but European firms. This fear has receded somewhat as EC standards-making bodies have allowed U.S. companies a more substantial voice in the process, for example, by letting them comment on proposed standards at an early stage, before it is too late to make any difference. Concern about the content of the standards has not vanished, however. U.S. firms find that they must push their own interests quite aggressively in the standardsetting process. Even for large, well-organized companies this requires a great deal of vigilance, and for smaller ones it maybe impossible. For many U.S. exporting firms, however, the biggest remaining worry is not so much the content of the EC standards as how their products will be tested to make sure they conform to the standards.

A new testing system is part of EC's new unified approach to standards. Before EC-92, all 12 nations had to agree before any European standard could be adopted. The process was glacially slow and produced standards that were sometimes immediately obsolete. EC-92's new approach is based on a two-pronged strategy. First, the EC has taken direct jurisdiction over "regulated products' that involve health and safety risks to consumers and the environment. The Commission writes broad essential requirements for these products into directives, which then become EC law. Nonregulated products will follow national standards, but with the crucial proviso of mutual recognition; that is, any good that can be legally sold, manufactured, and marketed in one member nation should be equally salable in another. ${ }^{32}$

For regulated products, manufacturers can meet the essential requirements by submitting their products to testing by an independent laboratory, which is itself licensed as a "notfiled body" by a member government. ${ }^{33}$ Another route to meeting the requirements is known as self-certification. The EC's 
standard-setting bodies, CEN, CENELEC, and ETSI, ${ }^{34}$ are writing detailed standards that will meet the requirements for regulated products. Manufacturers may choose to follow these detailed standards. This involves testing their products themselves for the various characteristics required (or getting an outside lab to do so), following approved quality assurance methods, and keeping documentation; they can then put the official CE stamp of approval on their own products. Self-certification is something of an honor system. It can be challenged by rival producers, in which case the self-certifying company would have to show proof of its claims. And the EC may decide to limit self-certification to products in which environmental and safety risks are not great.

There are advantages to the other route for approval of regulated products-submission to testing-since it allows innovative departures from the detailed standards set by CEN, CENELEC, and ETSI so long as the EC's broad essential requirements are met. However, the problem for U.S. firms (as for other non-EC companies) is to get their products tested in their home territory. Considering that parts and components, as well as final products, may require testing, shipping these overseas could be totally impractical, especially for small companies. U.S. industries and government agencies are pushing the EC to license U.S. test laboratories as notified bodies, or else allow EC notified bodies to subcontract testing to U.S. labs. ${ }^{35}$ Such devices have precedents. For example, Canada accredits U.S. labs that have passed the inspection of a Canadian official.

As of mid-1991, the EC had initially refused to accredit U.S. labs and was taking a narrow view of possible subcontracting; for example, it appeared that quality assurance audits could not be conducted by outsiders. Possibly, testing may be done in affiliated labs that EC notified bodies set up in the United States. There is already a move in this direction, and while it might solve manufacturers' testing problems, it could also put some U.S. labs out of business. ${ }^{36}$ Mutual international recognition of standards is also possible, but here there are difficulties, too. The EC will deal only with a national authority, and the U.S. system is highly decentralized. Standards for various products are set by hundreds of public and private bodies at the National, State, and sometimes regional levels. Testing and certification matters were far from settled in 1991; all were under negotiation.

Discussions were held in June 1991 between U.S. Secretary of Commerce Robert Mosbacher and EC Commission Vice-President Martin Bangemann. These yielded promising prospects for conformity assessment facilities in the United States to receive EC notified body status, allowing them to carry out "the full range of required conformity assessment procedures under the EC directives.' This would be conditional on the successful conclusion of a mutual recognition agreement allowing, in return, EC bodies to have full participation in U.S. conformity assessment systems. ${ }^{37}$ The Commission, however, has not yet received a mandate from the Council to negotiate such agreements, and it is still not clear what the terms of such an agreement would be, except that third country governments would have to ensure the technical competence of the facilities concerned. Both sides also renewed their commitments to the promotion of international standards.

Standards for nonregulated products are relatively unaffected by EC-92. Although the EC standardssetting bodies are working on harmonizing detailed standards for these products too, that is a long-range task. Meanwhile, the mutual recognition rule still applies to these products, as it has since 1979; no EC member nation can exclude a product that meets another member's standards, solely on the grounds of having a different standard.

Finally, if the EC gains wide adoption of its standards throughout the world, U.S. exports could lose some luster. The EC has already announced its intention to give Eastern Europe a special place at the standards-setting table, and to give technical assistance on standards to non-European countries in the Mediterranean, South America, India, and Southeast Asia. ${ }^{38}$ Some of the EC's draft policies on standards go further in this direction. For example, some standards include patented technologies. Standard-setting bodies in most countries, including the United States, require that the owner of the patent must license it, on fair and equal terms, to anyone wishing to produce to the standard and sell in that country's market. However, one draft EC policy would require the patent holder to license it equitably only to EC producers, or to producers in countries that adopt the EC standards. ${ }^{39}$ This would not only exclude firms in the United States and Japan from the required licensing and equitable treatment 
(since these countries are not necessarily going to adopt the EC standards for their own markets), but would be an incentive for other countries to sign on to the EC standards.

Quite possibly, this last draft policy will not be adopted. Certainly, U.S. exporting firms oppose it. It does illustrate the fact that American and other foreign firms must carefully watch out for their interests in the standard-setting process and express their concerns forcefully. overall, it appears that U.S. exporters will gain from the unified EC-92 standards and testing regime, and the problems it raises can be manageable, though not without effort.

\section{Opportunities for U.S.-Owned Companies in Europe}

EC-92 could confer some special benefits on American-owned companies already established in Europe, at least in the short run. Ford opened its frost auto plant in Europe 80 years ago, and both Ford and General Motors have been operating as European firms for decades. They have plants in several European countries, along with widespread sales and service networks, and they are leading sellers in European markets (figure 5-2). IBM dominates the European computer market. Other U.S. firms have longstanding alliances with European firms, e.g., GE Aircraft Engines with the French firm SNECMA. Many of the U.S.-based multinationals have strong ties with local suppliers, and some have world-class R\&D labs in their host countries (e.g., hightemperature superconductivity was discovered in IBM's R\&D facility in Berne, Switzerland). Such companies will have no trouble qualifying their products as EC-made goods, and thus will escape tariffs and quotas. Many EC-92 reforms are specifically designed to disrupt cozy relationships between national governments and national champion fins; in some areas of public procurement, U.S. multinationals will be able to compete on a more equal footing with EC-owned companies.

The advantage some U.S. firm have in already being there will not last forever. Japanese firms are latecomers as foreign direct investors in Europe (as they are in the United States), but that is changing fast (table 5-3). In 1989, for example, there was just 1 Japanese-owned semiconductor wafer fabrication plant in Europe (there were 12 U.S.-owned), ${ }^{40}$ but at least 3 more were under construction in $1991 .^{41}$ Three Japanese auto plants in EC countries were
Figure 5-2-Automotive Market Shares in Western Europe in 1989 (bn=billion)

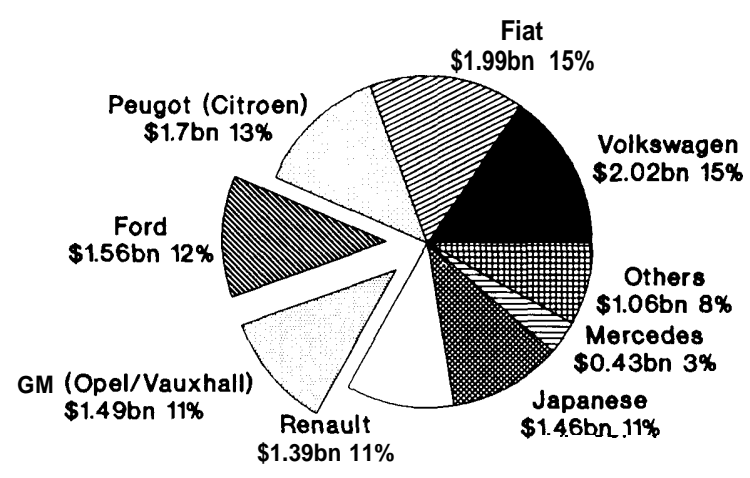

SOURCE: Kevin Done, "W Europe Car Sales Continue Rising: Volkswagen Group Keeps Place at Top of League," Financial Times, Jan. 22, 1990, p. 3.

turning out 295,000 cars per year in 1990, but 6 new Japanese plants will be up and running by 1994, producing 934,000 units a year (table 5-4). Tariffs, quotas, anti-dumping actions, and public procurement policies are driving Japanese firms to establish branches in Europe, with the prospect of a growing market under EC-92 as the reward.

\section{Foreign Direct Investment in Electronics} in the EC

EC policies that favor goods made in Europe are most prominent in the electronics sector, covering everything from semiconductors to computer printers to compact disk players. Many of these policies are longstanding, predating the passage of the Single European Act of 1985 and the decision to push forward with EC-92; some are national policies of member states. Notably, European computer firms have long enjoyed favored status in government purchases; public sector purchases make up about 15 percent of the European computer market, and most of that goes to each nation's own champion firms. Groupe Bull in France and Siemens-Nixdorf in Germany each make about one-third of their domestic sales to their own governments. ${ }^{42}$ The stateowned Bull has received about 7 billion francs (more than $\$ 1$ billion) in subsidies since $1983,{ }^{43}$ and the French Government proposed to give it still more in 1991.44

The EC is committed to ending member states' support for national champion companies, a support that never achieved its purpose. The heavily subsi- 
Table 5-3--Direct Investment Outflows From Japan

\begin{tabular}{|c|c|c|c|}
\hline & $\begin{array}{c}\text { Total } \\
\text { (billion dollars) }\end{array}$ & $\begin{array}{c}\text { Europe } \\
\text {, (percent of total) }\end{array}$ & $\begin{array}{l}\text { North America } \\
\text { (percent of total) }\end{array}$ \\
\hline $1980 \ldots \ldots \ldots \ldots \ldots$ & $\$ 4.7$ & $12.3 \%$ & $34.0 \%$ \\
\hline $1985 \ldots \ldots \ldots \ldots \ldots$ & 12.2 & 15.8 & 45.0 \\
\hline $1986 \ldots \ldots \ldots \ldots \ldots$ & 22.3 & 11.5 & 46.8 \\
\hline $1987 \ldots \ldots \ldots \ldots \ldots$ & 33.4 & 19.7 & 46.0 \\
\hline $1988 \ldots \ldots \ldots \ldots \ldots \ldots$ & 47.0 & 19.4 & 47.5 \\
\hline $1989 \ldots \ldots \ldots \ldots \ldots$ & 67.5 & 21.9 & 50.2 \\
\hline
\end{tabular}

NOTE: Fiscal year from April to March.

SOURCE: Organization for Economic Cooperation and Development (OECD), OECD Economic Surveys 1989/1990: Japan (Paris, France: 1990), table 14, p. 52.

Table 5-4-Japanese Production Capacity in Europe ${ }^{a}$ (000s of units)

\begin{tabular}{|c|c|}
\hline 1990 & 1994 \\
\hline 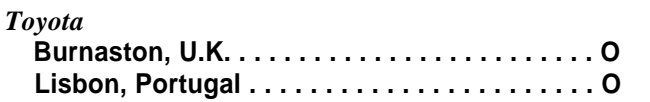 & $\begin{array}{r}200 \\
15\end{array}$ \\
\hline $\begin{array}{l}\text { Honda } \\
\quad \text { Swindon, U.K.................... }\end{array}$ & 200 \\
\hline $\begin{array}{l}\text { Nissan } \\
\quad \text { Washington, U. K. } \ldots \ldots \ldots \ldots \ldots \ldots \ldots \ldots 200 \\
\quad \text { Barcelona, Spain } \ldots \ldots \ldots \ldots \ldots \ldots \ldots \ldots\end{array}$ & $\begin{array}{r}200 \\
74\end{array}$ \\
\hline $\begin{array}{l}\text { Mitsubishi }{ }^{b} \\
\quad \text { Boom, Netherlands . . . . . . . . . . . . . o }\end{array}$ & 100 \\
\hline $\begin{array}{l}\text { Suzuki } \\
\quad \text { Linares, Spain } \ldots \ldots \ldots \ldots \ldots \ldots \ldots \ldots \ldots \ldots \\
\quad \text { Esztergom, Hungary } \ldots \ldots \ldots \ldots \ldots\end{array}$ & $\begin{array}{l}50 \\
50\end{array}$ \\
\hline $\begin{array}{l}\text { IBC (Isuzu-GM) } \\
\quad \text { Luton, U. K. } \ldots \ldots \ldots \ldots \ldots \ldots \ldots \ldots \ldots \ldots \ldots \ldots \ldots \ldots \ldots \ldots \ldots \\
\quad \text { Total } \ldots \ldots \ldots \ldots \ldots \ldots \ldots \ldots \ldots\end{array}$ & $\begin{array}{r}45 \\
934\end{array}$ \\
\hline
\end{tabular}

${ }^{2}$ The capacity figures given are incremental capacity beyond that currently existing. The Barcelona, Linares, Boom, and Lutton plants are facilities already being operated on a smaller scale by European or American companies. They will continue to produce European designs exclusively for their European or American joint-venture partners while adding the capacity shown in the table to produce Japanese designs to be sold by both partners.

'No final announcement of Mitsubishi's plans has been made. Negotiations are understood to be held up over the Dutch Government's asking price for its ownership stake in Volvo's Dutch subsidiary. Mitsubishi would take this stake to form a joint venture with Volvo to produce and market a Mitsubishi designed car.

SOURCE: James P. Womack and Daniel T. Jones, "European Automotive Policy: Past, Present, and Future," contractor report prepared for the Office of Technology Assessment, July 5, 1991.

dized national computer companies have not done well in world markets. ${ }^{45}$ Nor have European semiconductor producers achieved international success, despite trade protection and government assistance. Their share of the world market declined from about 25 percent in the early 1970 s to around 10 to 12 percent in the late 1980s, and today their chips are sold largely in Europe. The weakness of the European computer industry has meant limited demand for high-performance, leading-edge integrated circuits. ${ }^{46}$ In the electronic sector overall, the EC's trade deficit was about $\$ 35$ billion in $1990 .^{47}$
While disavowing support for national champions, the EC nevertheless has policies that strongly favor EC-made electronics goods. The hefty EC tariff of 14 percent applies not only to semiconductors (see figure 5-1) but to several consumer electronics items (e.g., color TVs). And protection has increased in the 1980s. The EC tariff was raised from 9.5 to 19.5 percent for compact disk players in 1983, and from 8 to 14 percent for VCRs in 1985. As discussed above, public procurement in the excluded sectors under EC-92 will give European goods strong advantages. Perhaps most forceful of all has been the EC's aggressive pursuit of antidumping actions in the electronics sector. ${ }^{48}$ As we shall see, all these EC policies favoring locally made electronics goods have powerfully encouraged foreign firms to locate more of their production in Europe.

Several EC antidumping actions in recent years have been directed against the Japanese and other East Asian electronics producers. Of 149 actions initiated in the 4 years 1987 to 1990, 16 were against Japan, 18 against Korea, 6 against Hong Kong, and 6 against Taiwan. ${ }^{49}$ Most of these actions concerned electronics products, including both office equipment and consumer products: typewriters, photocopiers, computer printers, video cassette recorders and tapes, audio cassettes and tapes, compact disk players, and small color TVs. ${ }^{50}$ There were 63 antidumping actions against China (16), Turkey (14), Yugoslavia (11), and other Eastern European countries (22 in all), but these mostly involved low-technology products such as building materials, textiles, and apparel. Only three actions were taken against U.S. firms (two in 1987, one in 1990). ${ }^{51}$

During the 1980s, European electronics firms protested strongly against what they saw as aggressive Japanese pricing. Many Japanese companies employ product cycle pricing, in which early models of a product are priced as high as the current cost of 
producing them would warrant but lower in relation to the average production cost over the expected product cycle-which would include the period after economies of scale and learning have been achieved. Japanese firms are also known for their commitment to building market share over short term profittaking. These strategies led to accusations that Japanese firms were dumping, for which there are remedies under GATT if it causes injury to the recipient country's industry.

The EC tightened its antidumping enforcement so aggressively as to be accused in some quarters of protectionism. The EC has interpreted its antidumping regulation so as to make the finding of dumping and the proof of injury to EC producers much more likely, and the size of the injury greater. ${ }^{52} \mathrm{EC}$ mechanisms for determinimg the dumping margin tend to exaggerate the "fair" value of a product; higher "fair" prices help to ensure both that dumping is found and that the margin between the "fair' and dumped price is large. The EC also tends to assume that there is a causal link between dumping and injury to home producers, rather than having to prove the link; for example, even low market shares captured by imports have been used as evidence of injury. ${ }^{54}$ Other practices also put exportiers accused of dumping at a disadvantage. The Commission itself verifies complaints; limits access to the case file; holds informal hearings in accordance with Continental law practice, which allows ex parte communications and does not require a written record; and grants no automatic right of review.

Most important, the EC does not set antidumping duties individually for each importer. Rather, one rate is imposed on all imports from the country as a whole, affecting dumped and non-dumped imports alike. In principle, importers can get their own antidumping duties reduced or eliminated by showing that they did not dump or dumped by a lesser amount, but the procedures to do this are slow, uncertain, and burdensome.

The EC forgoes duties in some cases in return for undertakings by foreign exporters to charge higher prices. This was the case in the EC semiconductor agreements with Japanese producers in 1989 (for DRAMs) and 1990 (for Erasable Programmable Read-Only Memories, or EPROMs). Like the U. S.Japan semiconductor agreement of 1986, these agreements set price floors, with the goal of encouraging European producers to invest in production facilities without fear of cutthroat below-cost competition from the Japanese. ${ }^{56}$

Foreign exporters on whom antidumping duties have been imposed have also avoided paying these duties by shifting the last part of their production offshore, usually to the EC. An order directed to imports of finished goods from the exporter's home country would then no longer apply. Very often, only the final assembly was shifted. The EC responded with an anticircumvention, or "screwdriver assembly,' rule. Under this rule, the Commission has the authority to levy the same duty as before on the finished goods if the parts and materials used come at least 60 percent (in total value) from the country or countries subject to the previous order. To avoid this provision, firms have decided to use over 40 percent EC-origin parts and materials, even though, according to the letter of the EC rule, those components and materials could be produced in third countries. ${ }^{57}$ Japan, the target of many important EC antidumping actions, took the EC rule as it applied to Japanese plants in Europe to GATT, where it was found by a GATT panel to be illegal. ${ }^{58}$ The EC did not abjure its anticircumvention rule, but after the GATT ruling in March 1990, antidumping actions came to a temporary standstill; however, a new action on components of disposable lighters is reported to be under way.

The antidumping rules, the new rule of origin for semiconductors, and the preference for EC-made goods in public procurement all add up to powerful incentives for foreign electronics firms to locate production facilities in the EC, which they did. By 1988, Japanese manufacturers of photocopiers, electronic typewriters, and printers had 10 subsidiaries in Britain, 6 in Germany, and 4 in France. ${ }^{59}$ But these did not suffice. They were labeled screwdriver plants. To comply with the EC's anticircumvention rule the companies then had to scramble to find European parts suppliers-not always with great success since the components sector, especially in the United Kingdom, was weak. According to a Japanese source, "Japanese manufacturers looking to procure parts locally had to start by training and helping parts makers themselves." ${ }^{\prime 60}$

Similarly, when Japanese companies started making audio cassettes in Europe, they were hit with an antidumping action that imposed duties on the magnetic film going into the cassettes. The Japanese response was to shift production of the film into the 
EC. ${ }^{61}$ As for semiconductors, the indispensable electronic guts of all these products, the EC's 1989 rule of origin is forcing still more inward investment. Fujitsu, Mitsubishi Electric, Hitachi, and Sony have started to build or have announced plans for new wafer fabrication plants (fabs) in Europe; NEC is already there. ${ }^{62}$

It is putting it too strongly to say that the EC now has a coherent, unambiguous policy of forcing inward investment, even in the electronics sector, where the forces are most powerful. For example, when Fujitsu bought out the British computer company ICL in 1990, the company was promptly expelled from the industry's most influential lobbying group and was partially excluded from JESSI, the semiconductor research consortium heavily supported by the EC. This suggests that it could take more than local investment for a Japanese company to be treated like a European company. All the same, many EC leaders are strongly and explicitly committed to encouraging inward investment in forms that promise to create well-paid knowledge-intensive jobs and to transfer valuable technology to local supply fins.

For U.S.-owned companies already well established in Europe, ${ }^{63}$ the new Japanese presence could mean greatly intensified competition in the European market. For U.S. companies that export to Europe but have no wafer fab there, the rule of origin for semiconductors could cause problems, especially for smaller companies that can hardly afford the $\$ 200$ to $\$ 300$ million investment in a European plant. Intel (not a small company but not a giant either) was one of those faced with the alternative of laying out hundreds of millions for an EC plant or losing EC sales. At congressional hearings in early 1989 , an Intel representative protested against the EC's "domestic content policy," saying that it forced U.S. companies to transfer jobs, technology, and investments to Europe regardless of competitive considerations. ${ }^{64}$ In October 1989, however, Intel announced a decision to build a $\$ 425$ million wafer fab in Ireland, with substantial investment aids (i.e., subsidies) from the Irish Government.

\section{Foreign Direct Investment in Autos in the EC}

If there is some ambiguity in the EC's policy of encouraging foreign inward investment in electronics, there is more in motor vehicles. Longstanding quotas and informal arrangements that restricted Japanese auto imports, combined with newer local content requirements, spurred Japanese investment in auto plants in the EC in the late 1980s. However, in April 1991, the European Commission proposed a scheme that, reportedly, would allow only a small increase in the Japanese share of the EC market through 1998, Counting imports and transplant production as the Japanese share. At the end of July 1991, the Japanese Government reached an agreement with the CEC on auto exports and possibly production in the EC through the end of 1999. Although all the details were unclear as of August 1991, the pact apparently caps the Japanese producers' shares of the overall market at 16 percent (about half imports and half domestic production) by the end of $1999 .{ }^{65}$ Though this is a higher share than they now hold, the agreement apparently permits no growth (or a slight decline) in Japanese exports, compared to 1990, with little additional production in Europe above that already announced and under construction.

Until quite recently, many policymakers in Europe considered their motor vehicle industry to be a competitive success. European automotive trade showed a positive balance through 1989 , and for a remarkable 6-year period, from 1984 through 1989, European motor vehicle sales were extraordinarily robust, far higher than analysts had forecast (table 5-5). This prosperous period followed one of stagnation, in which the number of car companies shrank and employment greatly declined, but the result was a high level of capacity utilization and profits for every surviving company. ${ }^{66}$

This seeming strength was deceptive. First, national auto champions have been protected and encouraged through a panoply of industrial policy measures in European countries throughout this century. Quotas have quite effectively controlled Japanese imports into the major auto-producing countries, as is evident by comparing their imports with those of European countries with no domestically owned motor industry (table 5-6). Italy and Japan agreed in the 1950 s on a limit of 2,000 imported Japanese cars annually, and the limit stood until the July agreement, which will permit Japan to export 138,000 cars to Italy by the end of 1999. France imposed a 3-percent market share limitation in 1977; Britain and Japan reached an informal agreement in 1975 limiting Japanese imports to 11 percent of the U.K. market. Germany has no formal agreements with Japan on market share limitations. However, in 1981, when the U.S. voluntary restraint 
Table 5-5-Motor Vehicle Production in the EC, 1973-1989 (millions of units)

\begin{tabular}{|c|c|c|c|c|c|c|c|c|}
\hline Year & FRG & U.K. & Spain & Italy & France & Belgium & Holland & Total \\
\hline $\begin{array}{l}1973 \\
1978\end{array}$ & $\begin{array}{l} \\
\ldots \ldots \ldots \ldots \ldots 3,949 \\
\ldots \ldots \ldots \ldots \ldots . .64,186\end{array}$ & $\begin{array}{l}2,164 \\
1,607\end{array}$ & $\begin{array}{r}822 \\
1,144\end{array}$ & $\begin{array}{l}1,958 \\
1,656\end{array}$ & $\begin{array}{l}3,569 \\
3,508\end{array}$ & $\begin{array}{l}299 \\
303\end{array}$ & $\begin{array}{r}107 \\
85\end{array}$ & $\begin{array}{l}12,868 \\
12,489\end{array}$ \\
\hline 1981 & $.3,897$ & 1,184 & 987 & 1,434 & 3,019 & 237 & 101 & 10,859 \\
\hline 1982 & $.4,062$ & 1,156 & 1,070 & 1,453 & 3,149 & 278 & 109 & 11,277 \\
\hline 1983 & $.4,154$ & 1,289 & 1,288 & 1,575 & 3,336 & 285 & 122 & 12,049 \\
\hline 1984 & $\ldots 4,045$ & 1,134 & 1,309 & 1,601 & 3,062 & 249 & 129 & 11,529 \\
\hline 1985 & .. $\quad \ldots \ldots \ldots \ldots, 4,445$ & 1,311 & 1,418 & 1,573 & 3,016 & 267 & 128 & 12,158 \\
\hline 1986 & $. .4,578$ & 1,203 & 1,307 & 1,913 & 3,195 & 295 & 142 & 12,633 \\
\hline 1987 & $. .4,634$ & 1,389 & 1,704 & 1,913 & 3,493 & 352 & 152 & 13,637 \\
\hline 1988 & .. $\quad \ldots \ldots \ldots . . .$. & 1,545 & 1,866 & 2,111 & 3,678 & 398 & 149 & 14,372 \\
\hline 1989 & .. $\quad \ldots \ldots \ldots \ldots \ldots, 4,852$ & 1,626 & 2,046 & 2,221 & 3,920 & 389 & $149^{\prime}$ & 15.203 \\
\hline
\end{tabular}

NOTE: Spanish production is included although Spain was not amember ofthe ECuntil 1985.

Because the European motor vehicle production system is highly integrated but as yet has no integrated production totals available, it is necessary to estimate production for the whole of the EC by totaling production country by country. This method may leadto some double counting, in particular of French and German vehicles assembled in Belgium and French vehicles assembled in Spain.

SOURCE: Forallcountries except Holland: Automotive News, Market Data Book, 1990 edition, p. 3. For Holland: Motor Vehicle Manufacturers Association of the United States, Wodd Vehicle Data, various years.

Table 5-6-Japanese Share of the European Car Market, 1989 (in percent)

\begin{tabular}{|c|c|}
\hline 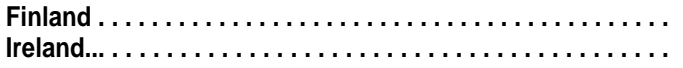 & $\begin{array}{l}39.6 \% \\
39.4\end{array}$ \\
\hline$\ldots \ldots \ldots \ldots \ldots \ldots \ldots \ldots \ldots \ldots \ldots \ldots \ldots \ldots$ & 37.8 \\
\hline & \\
\hline & 30 \\
\hline & \\
\hline & \\
\hline ds ..... & 2 \\
\hline & 24 \\
\hline & 19 \\
\hline & 14.8 \\
\hline$\ldots \ldots \ldots \ldots \ldots$ & 11.3 \\
\hline 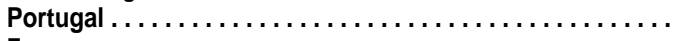 & 6.1 \\
\hline 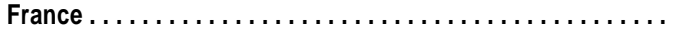 & 2.9 \\
\hline & 1.6 \\
\hline Spain & 1.1 \\
\hline
\end{tabular}

NOTE: Sweden is an exception in having a large domestically owned motor industry and a high level of Japanese imports. However, the Japanese imports are almost entirely in the smaller size classes where no Swedish products are offered. For comparison purposes, the Japanese share of the U.S. car market was 27.4 percent in 1989.

SOURCE: Financial Times, Feb. 5, 1990. For the United States, Earl Kreher, Motor Vehicle Manufacturers Association, personal communication, Aug. 7, 1991.

agreement covering imports of Japanese autos was announced, it was widely reported that the Japanese Government gave these assurances to the German Government: exports would not be diverted to Germany, and Japanese companies would not increase their sales in the German market by more than 10 percent per year (about 1 percentage point of market share). ${ }^{67}$

While the high level of trade protection and its long duration might not be proof of fundamental weakness in European auto manufacture, there is more direct evidence. The first independent global survey of auto company performance in plants, $R \& D$ operations, and supply chain management indicates that European companies, both the mass producers (Volkswagen, Fiat, Renault, and PSA) and the high-priced specialists (Mercedes, BMW, Volvo, Jaguar, and Rover), lag behind Japanese and even U.S. performance significantly. ${ }^{68}$ They score worse in productivity, product quality,@ and responsiveness to changing demand.

Finally, by the end of 1990, the European market had run out of steam; sales were falling in all markets but Germany. Exports to the United States had already dropped with the decline of the dollar, and firms with the heaviest dependence on the U.S. market (Jaguar, Saab, and Volvo) had been forced to find buyers or joint venture partners. At the same time, Japanese firms were making major investments in new production capacity within Europe, gearing up to produce 935,000 units per year by 1994 and as much as 1.2 million units in 1998. Thus it began to occur to European policymakers that the European motor industry might face in the 1990s what the Americans faced in the 1980s-a catastrophic loss of market share at the hands of the Japanese. This prospect is probably much exaggerated because of the protective measures the EC has taken for its auto companies. Even so, European auto producers face an unaccustomed challenge, as do the well-entrenched U.S. auto makers in Europe.

The frost mitigating factor is the extension of quotas on Japanese imports, under the aegis of the 
EC. Originally, the EC Commission intended to remove all member states' quotas, beginning in January 1991 and completing the process by January $1993 .{ }^{70}$ But this idea was conceived when the European auto boom was at its height. As the industry's sales weakened, leaders of the German industry abandoned the free-trade camp they had traditionally occupied, joining the French and Italians to urge Europe-wide share limits on Japanese imports along with a transition period for dropping individual country restrictions.

Terms of the agreement made with the Japanese by the EC in April 1991 were not all public, but trade sources reported that they would allow Japanese companies to increase their sales of passenger cars in the EC-including both imports and transplant production-horn about 1.2 million in 1990 to 2.3 million in 1999, or from about 10 percent to somewhere around 16 percent of the EC market. ${ }^{71}$ EC estimates of additional production from the Japanese transplants by 1998 range from 900,000 to 1.4 million cars per year, which implies that virtually all of the growth in Japanese car sales would come from transplants, and that imports would stay flat. Also, these numbers imply sizable growth in the EC market-over 2.5 percent per year. ${ }^{72}$ The EC scheme also states that the very restrictive formal national quotas on Japanese imports in France, Italy, Spain, and Portugal will be abolished at the end of 1992, but that the Japanese will "voluntarily" limit imports into those markets under EC and Japanese supervision, to account for "unexpected circumstances [that] might arise after January 1, 1993.' After 1998, the EC market would be open to the Japanese, according to the proposal.

There are still parts of the agreement that are not entirely transparent. In particular, it is unclear how long the Japanese will be willing to abide by informal limitations on transplant production in the EC. "We can't accept this," said Moriharu Shizume, Paris representative of the Japan Automobile Manufacturers Association. "They set up local content rules-60 percent, 70 percent, then 80 percent. Now that we've got almost 80 percent, they still don't accept it. ' ${ }^{\prime 73}$

Domestic content requirements for Japanese cars were set first in Britain, which was in the vanguard for Japanese auto transplants in Europe. In negotiating terms with the Japanese companies, the British Government demanded high levels of European content, both as a condition for investment aids provided by the national and local governments and in order not to count the transplant vehicles against Britain's 11 percent quota on Japanese imports. ${ }^{74}$ The result was a commitment for 60 percent European content in the initial production runs at the three largest Japanese transplants (Nissan, Toyota, and Honda, all in the United Kingdom). What is more, these facilities are committed to 80 -percent European content by 2 to 3 years after startup, a level not currently contemplated by any North American transplant even after several years of production. ${ }^{75}$ This level of local content requires that the body, most major mechanical components, and either the engine or the transmission be fully manufactured in Europe.

The local content requirements have probably slowed the rate of Japanese assembly plant investment in Europe. Also, under EC urging, the British have ceased offering investment aids to the transplants, and that, too, may have slowed the rate. This does not mean that the Japanese have no further designs on producing in Europe.

Another important but often overlooked reason for slow growth, both of Japanese imports into Europe and of Japanese transplant production, is the European distribution system for motor vehicles. It differs greatly from the U.S. system. The United States has always been a large market without internal barriers where similar vehicles are sold for the same price in every region. Moreover, since the late 1940s, U.S. antitrust laws have forbidden assembler firms from requiring that their dealers sell only one brand from a single site.

By contrast, EC rules allow the established European auto assemblers to limit the freedom of the dealer and the customer, to their own distinct advantage. The assemblers are able to sell the same car for vastly different amounts in different countries, both in Europe and elsewhere. Their usual approach is to price very low in their own home market to establish a volume base and keep others (e.g., Japanese imports) out, and to sell at much higher prices in other markets. At the same time, European (and Europe-based American) assemblers forbid their dealers to "dual," that is, to take on Japanese brands at established dealerships. It was precisely the aggressive use of dualing that allowed the Europeans (in the late 1950s) and then the Japanese (in the early 1970s) to rapidly build 
distribution networks in the United States with practically no investment.

For all these reasons-an EC-wide quota at least for Japanese imports (and possibly an unwritten agreement governing transplant production as well), high local content requirements for transplant vehicles, and the existing distribution system-a surge in Japanese share of the European auto market is not likely over the next few years. The current EC rules allowing selective pricing and exclusive selling come up for renewal in 1995, and the result may well be rules more like those in the United States. Even so, EC-wide quotas and local content requirements would continue to provide very substantial protection for European producers. The gradual relinquishment of voluntary national quotas could cause problems for the French, Italian, and Spanish industries, but the Japanese firms have practically no distribution and service networks in any of these countries and cannot build them overnight.

The likely prospect is for only a gradual increase in competitive pressure on European automakers from Japanese imports and Japanese transplants combined. ${ }^{76}$ That goes for U.S.-owned auto firms in Europe as well. Whatever pressure they feel will not compare to the hammer blows suffered by the Big Three in the United States in the 1980s. In just the 5 years from 1985 to 1990, cars made by Japanese companies (imports and transplants) rose from 22 to 33.5 percent of a shrinkithg U.S. market (overall sales declined from $\mathbf{1 1 . 0}$ million to $\mathbf{9 . 3}$ million units); in the same 5 years, the market share of Big Three cars sank from 72 to 59 percent.

There may even be an opportunity for some modest increase in U.S. auto exports to Europe in the 1990s, in all likelihood coming from the Japanese transplants in this country, not the U.S. Big Three. ${ }^{77}$ Later in the decade, this eastward flow across the Atlantic might be balanced by exports to the United States and Canada from Japanese transplants in Europe. Each Japanese company might decide to produce certain kinds of vehicles at only one site in its global production system, in Europe or North America, for high-volume sales in the region of production and for exports in lower volumes to fill market niches in other regions. ${ }^{78}$

A final note: The pressure of Japanese competition, mitigated though it may be, has finally made bedfellows of European auto producers and the American-owned firms in Europe. For 80 years, since Ford established an assembly plant in Britain in 1911, American companies have been treated as outsiders by the Europeans. For example, the organization formed in the 1970s to promote the interests of European motor vehicle fins, the Committee of Common Market Motor Vehicle Constructors (CCMC), resisted all efforts of the Americans to join. However, in the debate about how to deal with the Japanese in 1992, tensions in the CCMC became so great that 11 of the 12 members resigned in December 1990. Left behind was Jacques Calvet, PSA chairman, who was intransigent in demanding curbs on Japanese imports and transplant production. A new organization is being formed that will include the Europeans and the Americans, but will exclude the Japanese.

Thus the course of events has strengthened the perception that the two American firms, with their top-to-bottom production systems spread across the continent, are now European, after 80 years on probation. It seems most unlikely that the EC will apply anything like the import or investment barriers on these fins, or their U.S. parents, that are contemplated for Japanese firms, even if the European market should prove disappointingly flat.

\section{EC-92 and the United States: Conclusions}

If EC-92 does substantially increase the growth of the Community's GNP, as many Europeans believe it will, that should also increase demand for the products of U.S. companies. As internal trade barriers are cleared away, U.S. firms should find it easier to sell and distribute their products to customers throughout the EC. Market growth could help some American exporters to Europe, especially in industries whose base of operations already is global, such as the chemical industry. On the other hand, some of the EC's most effective protection is focused on computers and electronics, the biggest and arguably most important of U.S. exports to Europe.

Even if demand for U.S. products does grow, EC trade and public procurement policies in some sectors will encourage U.S. firms to supply the demand from a production base in Europe. No one policy alone might force a U.S. firm to manufacture in Europe. But companies will judge their effects in the context of other factors: the new opportunities to be found in both Eastern and Western Europe; the shift of competitors, especially the Japanese, into Europe; advantages for manufacturers in getting 
closer to suppliers and customers in a bigger, richer, more unified market; and uncertainties about more forceful protection in the future. These factors, combined with steady pressures of protectionism, especially in electronics, seem to be encouraging a wave of foreign direct investment, which implies some shift in the manufacturing base into the EC.

Thus from the U.S. perspective, the message of EC-92 is mixed for exports to the EC but more positive for those planning or able to produce there. For businesses that would profit from locating production in Europe, not all are equally well-placed to make the shift. EC-92 could create problems for small U.S. exporting firms, although there has been no flood of complaints so far, according to the Small Business Administration. ${ }^{79}$ It might also have ill effects on small firms that are not now exporters. As some large U.S. firms shift production into the EC, they may not make an effort to bring their traditional suppliers with them, and many of the suppliers are themselves simply too small to follow.

\section{EC Technology Policy}

European firms face a difficult time competitively. In several industries, years of protection and government support have sapped firms' competitiveness. Now those firms are newly vulnerable, as the national policies that formerly pampered and protected them give way to EC policies that forbid subsidizing one member nation's firms at the expense of another's. Another form of competitive pressure is the trend in EC policies to treat foreignowned firms operating in Europe much like locally owned fins. As we have seen, the trend is by no means complete or universal (witness the continued EC favoritism toward European auto companies), but it is strong enough that many foreign fins, especially the Japanese, are shifting production into the EC to evade trade restrictions.

A particular worry is the new challenge from Japan, a more serious matter than the longstanding American dominance of European computer and semiconductor markets. Europeans viewed with alarm Japanese companies' incursions into U.S. markets where, in some industries, they wiped out the domestic competitors altogether. Europe was the next target. This new competitive pressure on European firms, and the increased intensity of international competition generally, especially in high-technology fields, spurred the Community to develop policies meant to improve the competitive performance of EC-owned firms.

First, the EC is vigorously attacking the entrenched structure of European industry through a reinvigorated competition policy (more on this below). Second, it is trying to develop mechanisms to close what it sees as a crucial technology gap between Europe and both the United States and Japan. The new technology policy is an ambitious attempt to use R\&D consortia, partly funded by the $\mathrm{EC}$, as a means of reaching the technical frontier in some strategic sectors, notably information technology, telecommunications, and energy. Another major goal is to create a supranational, European orientation among EC fins.

Technology is key to improved competitiveness, in everything from product innovation and design to manufacturing quality and efficiency. Even before the 1980s, European efforts to improve technology were afoot. In 1979, the EC Commissioner for Industry, Etienne Davignon, created a task force to study the long-term needs of the telematics sector (telecommunications and information technologies) and to draft a strategy for the EC as a whole to revitalize high-technology electronics industries. ${ }^{80}$ Eventually, this effort spawned two new European technology development and implementation programs, ESPRIT (the European Strategic Programme for Research and Development in Information Technology), begun in 1984, and a few years later, RACE (Research in Advanced Communications for $\mathrm{Eu}-$ rope). By the end of the decade, several other EC $R \& D$ programs, brought together under an umbrella called the Framework Program, had begun: BRITE, or Basic Research in Industrial Technologies for Europe; EURAM (European Research in Advanced Materials), which was merged with BRITE in its second phase; several biotechnology programs; and a host of small programs aimed at promoting research and development, science, and cooperation across the borders of the EC nations. In addition, 19 countries (the $\mathbf{1 2}$ of the EC plus Austria, Finland, Iceland, Norway, Sweden, Switzerland, and Turkey) participate in a project called EUREKA (European Research Coordination Agency).

The total effort represented by the Framework Program and EUREKA is prodigious. The Third Framework Program (1990-94) is funded at ECU 5.7 billion, and EUREKA projects announced between 1985 and 1990 came to ECU 7.4 billion. As the 
Second and Third Framework Programs overlap, exact annual finding is hard to estimate, but at a rough estimate, public funding of European cooperative research in both the Framework and EUREKA programs comes to about ECU 1.6 billion (\$1.9 billion) per year.

There is a new spirit of optimism in Europe now, and the technology programs begun in the 1980s are apart of it. But will the programs have a real effect in changing the European technological landscape? This is not answerable now, because many of the initiatives launched in the 1980 s are too new to evaluate fairly; the oldest have been going less than a decade. Many of Japan's more impressive technical accomplishments, such as the birth and development of microelectronics manufacturing, required far more than a decade to yield conclusive results (though when Japan began its industrial targeting and technology initiatives it was technically much further behind than Europe). But there is enough information to make tentative conclusions about the likely performance of Europe's new technology efforts. So far, the programs have achieved some things-a greater degree of transborder and multiinstitutional cooperation, a greater sharing of technical and scientific information, and generally positive reviews on the part of participants about the contri- bution to technology-but they have not yet made much difference in competitiveness.

\section{Framework Program}

The broad purpose of the Framework Program is to improve living standards, which in turn means boosting European industrial competitiveness and technology .82 It was apparent to European companies and governments in the 1980s that many of the more important technological developments of the past decades had skipped Europe. Several indicators show Europe's failure to keep up. A 1988 EC study disclosed that Europe was the world leader in only 2 of 37 technologies identified as economically important. (The same study concluded that 31 were dominated by the United States and 9 by Japan. ${ }^{83}$ Europe was also behind the United States and Japan in the concentration of $R \& D$ workers in the labor force (figure 5-3), and Japanese inventors streaked past Europeans in obtaining U.S. patents (figure 5-4). Moreover, the areas in which Japanese and European patents were granted tell the story of European decline in electronics, communications, and information technology in particular. The Japanese patents were heavily concentrated in electronics, while Germany's were mostly in chemicals and materials, and France's were a diverse list, promi-

Figure 5-3-Scientists and Engineers per 10,000 Labor Force

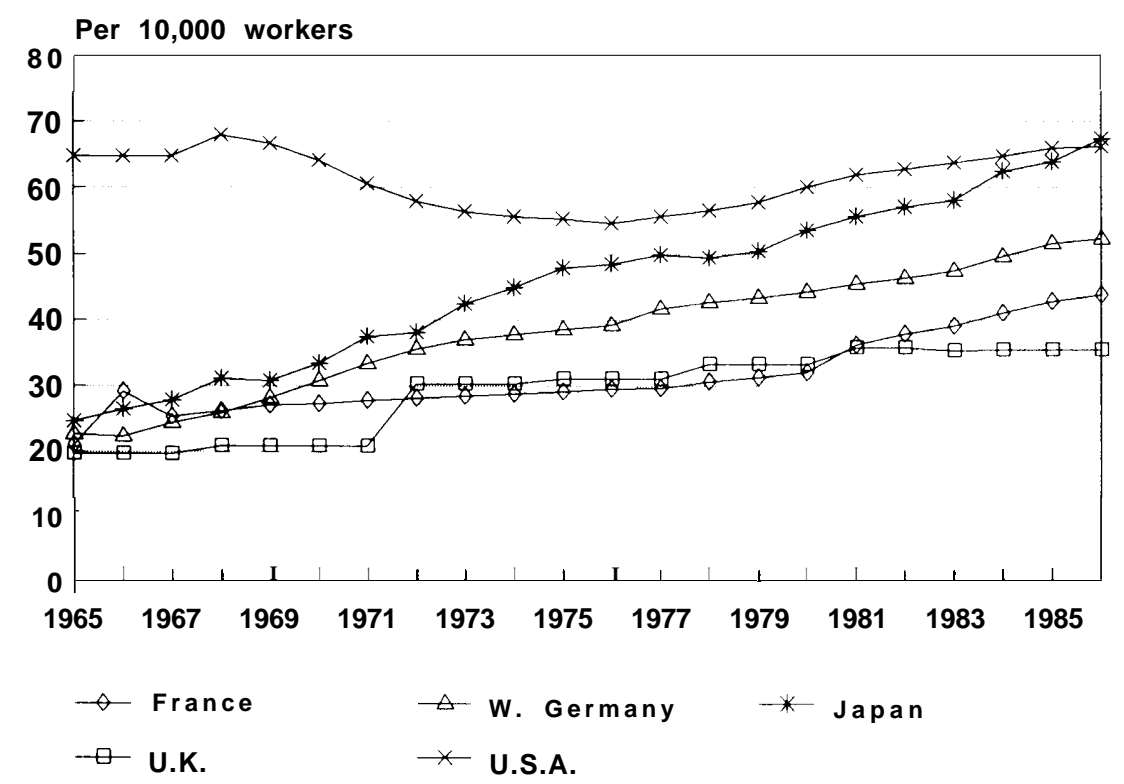

SOURCE: National Science Board, National Science and Engineering Indicators, NSB 69-1 (Washington, DC: U.S. Government Printing Office, 1989), p. 262. 
Figure 5-4-U.S. Patents by Nationality of Inventor

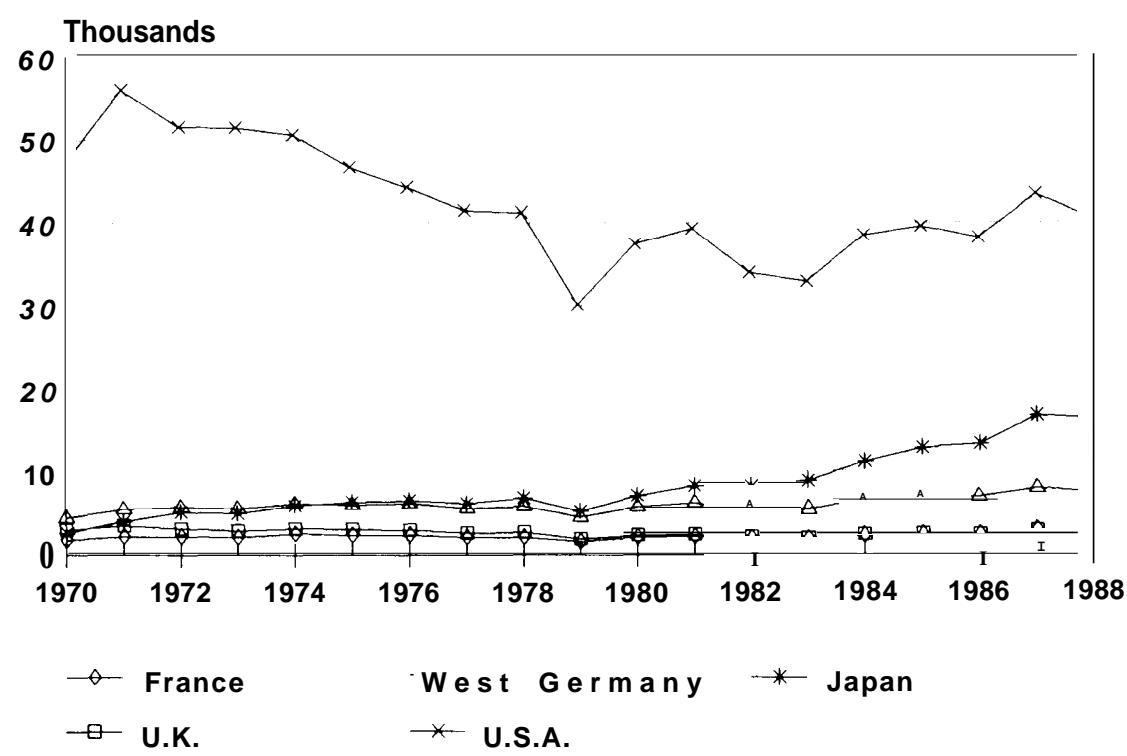

SOURCE: National Science Board, National Science and Engineering Indicators, NSB 89-1 (Washington, DC: U.S. Government Printing Office, 1989), p. 365.

nently including nuclear energy and industrial machinery. ${ }^{84}$

The Framework Program was set up to overcome the European weaknesses. European industry remains strong in some high-technology fieldschemistry, certain energy technologies, and aeronautics-but is weaker in electronics and most information technologies (hardware and software), motor vehicles, and biotechnology. The biggest program, ESPRIT, tackles information technologies. RACE aims at improvement in telecommunications hardware and service and manufacturing technologies. BRITE/EURAM's research includes, in descending order of funding: new materials; reliability, wear, and deterioration; CAD/CAM and mathematical modeling; new production technologies for textile products; new testing methods; laser and joining technologies; membranes; and new testing methods. ${ }^{85}$

High-technology sectors are a particular focus, probably for the same reason that they are a focus of industrial policy elsewhere: they are viewed as making disproportionate contributions to wellbeing. They are knowledge intensive, often have application in many other sectors, and contribute disproportionately to value added. In some cases, such as telecommunications, they are also a key part of the infrastructure of developed nations. The lion's share of the ECU 5.7 billion in funding for the Framework program goes for projects designed to improve European competitiveness in hightechnology industries and services. ${ }^{86}$ The combined finding for medicine and health, information and communication technologies, biotechnology, and nuclear fusion is ECU 2.7 billion, more than half the total. ${ }^{87}$ ESPRIT II (European Strategic Programme for Research and development in Information Technologies), the biggest program, is funded at ECU 1.6 billion from 1988 through 1992. Tables 5-7 and 5-8 show the funding, purpose, and duration of the individual programs within Framework. ${ }^{88}$

Another characteristic of the Framework Program is that it is designed to do precompetitive research. The definition of precompetitive is comfortably loose (the CEC defines it as being at a stage prior to industrial development) yet it still exerts a real effect on projects, making officials wary of approving those that seem too close to the market. Further, all Framework projects are collaborative, not just among companies but across national borders. Only projects that have participants from more than one country can be considered.

\section{EUREKA}

EUREKA, the European Research Cooperation Agency, was begun in 1985 at the initiative of 
Table 5-7-Funding and Duration of the Framework Program

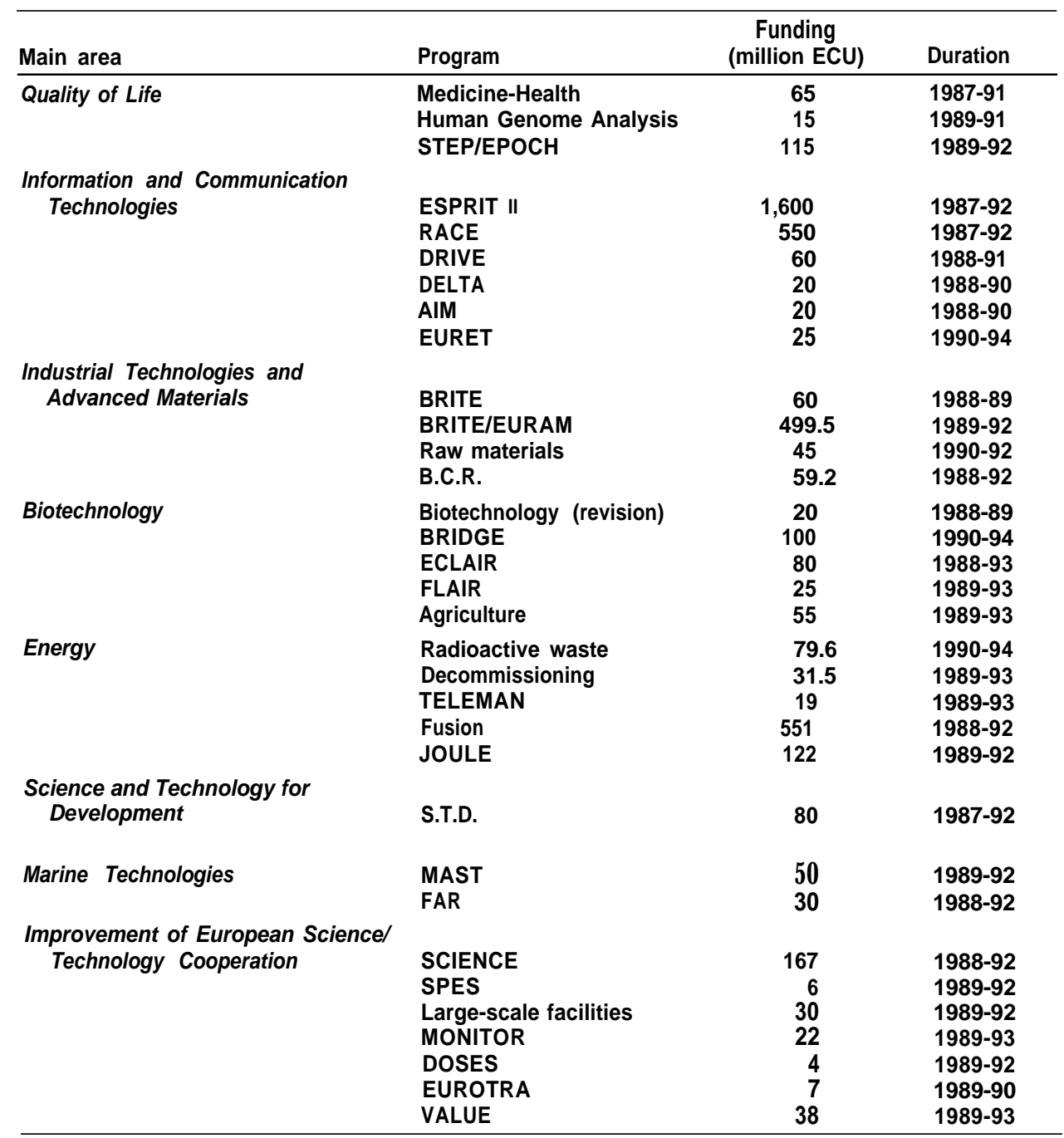

SOURCE: Commission of the European Communities, EC Research Funding: A Guido for Applicants (Brussels, Belgium: January 1990), p. 117.

France and West Germany. Although it is not an EC project, the EC countries and the CEC itself are members, along with the European Free Trade Association (EFTA) nations and Turkey. Its aims are similar to those of the Framework Program-to promote cross-border collaboration in research and technology and to improve competitiveness. As a result, there is overlap between EUREKA projects and parts of the Framework Program in scope and funding. However, the programs do differ, principally in sources of funding. For EUREKA projects, funding is mostly private. National governments (and the EC) can fix their own contributions at any level they desire up to 35 percent of total project costs, so public funding is generally low compared with the Framework Program. According to one source, of the ECU 7.4 billion allocated to 388 EUREKA projects between November 1985 and June 1990, less than 10 percent was public funding.

EUREKA does not limit projects to precompetitive R\&D. EUREKA projects can be closer to the market than projects done under the Framework Program, although not as close as some participants might wish. While some EUREKA projects involve basic research, most are on topics of immediate commercial interest. ${ }^{90}$ Large companies involved in both Framework projects and EUREKA sometimes prefer EUREKA as a result. 
Table 5-8-Glossary and Description of the Framework Program

1. Quality of Life

Medicine/health: Coordinates and improves efficiency of medical and health research

Genome analysis: Studies use and improvement of biotechnology in the study of the human genome

Radiation protection: Improves knowledge of human exposure to radiation and effects of radiation on humans and their environment

STEP/EPOCH(Sclence and Technology for Environmental Protection European Programme On Climatology and natural Hazards): Provides scientific and technical support for environmental policies of the EC

ESPRIT ii (European Strategic Programme for Research and development in information Technologies): Develops basic technologies for European information technology industries

RACE (Research and development in Advanced Communications technologies for Europe): Contributes to introduction of Integrated Broadband Communication taking into account Integrated Services Digital Network

DRIVE (Dedicated Road infrastructure for Vehicle safety in Europe): Develops information technologies to improve road transportation efficiency and safety

DELTA (Development of European Learning through Technological Advance): Applies advanced information technology to education and develops tools to support (long) distance learning

AIM (Advanced Informatics in Medicine): Develops information technologies for improving health care services at reasonable cost

EURET (REcherche clans le Transport en Europe, or Research on Transportation in Europe): Develops a Community transport system to respond to increases in demand for all types of transport necessitated by the single market

2. Industrial Technologies and Advanced Materials

BRITE/EURAM (Basic Research in industrial Technology for Europe, and European Research in Advanced Materials): intended to strengthen the competitiveness of European manufacturing industry (including particularly small and mediumsized enterprises) in world markets

Raw materials (Raw materials and recycling): Enhances the competitiveness of the Community's industries involved with raw materials and recycling

B.C.R. (Bureau Communautaire de Reference): improves the reliability of chemical analysis and physical measurements to achieve agreement among member states

3. Biotechnology

BRIDGE (Biotechnology Research for innovation, Development and Growth in Europe): Promotes cross-border research to speed up the production of biological data, materials and processes needed for the optimal use of natural organisms

ECLAIR (European Collaborative Linkage of Agriculture and industry through Research): Promotes application of new developments in life sciences and biotechnology to products for industrial agricultural use

FLAIR (Food Linked Agro-industrial Research programmed): Contributes to the competitiveness, safety, and quality of Europe's food industry

Agriculture (Competitiveness of agriculture and management of agricultural resources): Helps farmers adapt to situations created by overproduction and restrictive price and market policies

\section{Energy}

Radioactive waste (Management and storage of radioactive waste): Perfects and demonstrates a system for managing and sorting radioactive waste

Decommissioning (Decommissioning of nuclear installations): Develops a system to manage decommissioned nuclear installations and radioactive wastes

TELEMAN (TELEMANipulation dan les environments nucleaires dangereux et perturbes; or Remote handling in hazardous or disordered nuclear environments): Develops advanced remote operated equipment for the nuclear industry, and a scientific and technological basis for remote operating systems

Fusion (Controlled nuclear fusion): Establishes physical and technological basis necessary for planning of NET (Next European Torus)

JOULE (Non-nuclear energies and rational use of energy): Develops energy technologies that take account of new and renewable energy sources and increases security of supply of energy

5. S.T.D. (Science and Technology for Development): Promotes scientific cooperation between the EC and developing countries

6. Marine Technologies

MAST (MArine Science and Technology): improves knowledge of the marine environment and promotes new expiration technologies

FAR (Fisheries and Aquaculture Research): Promotes rational and scientific research on resources; develops aquaculture

\section{7. /improvement of European Science/'Technology} Cooperation

SCIENCE (Stimulation des Cooperation internationales et des Echanges Necessaires aux Chercheurs en Europe; Scientific and Technical Cooperation): improves general quality of scientific R\&D, promotes training through research; enhances mobility of researchers

SPES (Stimulation Programme for Economic Sciences): Establishes cooperation and interchange between European economists

Large-scale facilities (Large -scale scientific facilities and installations): Optimizes use of large-scale scientific facilities and installations

MONITOR (Strategic analysis, forecasting and evacuation): identifies new directions and priorities for Community research and technological development policy; improves evacuation of $R \& D$ program

DOSES (Development Of Statistical Expert Systems): Promotes use of advanced statistical techniques; in particular, application of expert systems

EUROTRA (Programme EUROpean de TRAduction automatique de conception avancee; machine transition): Develops a machine transition system capable of dealing with all official EC languages

VALUE (Valorization and Utilisation for Europe; Dissemination of results): Promotes dissemination and utilization of the results of scientific and technical research, with special consideration of the needs of small and medium sized enterprises

SOURCE: Commission of the European Communities, EC Research Funding: A Guide for Applicants, op. cit., p. 117. 
EUREKA is like Framework in putting special emphasis on high-technology areas. Its heaviest funding goes to robotics and production automation, closely followed by information technology and communications. Other fields with strong support are medical and biotechnology, transport, new materials, lasers, energy, and the environment (see tables 5-9 and 5-10). ${ }^{91}$

One of the most important EUREKA projects is JESSI, the Joint European Submicron Silicon Initiative. Begun as a 1-year feasibility study in December 1986 and going through another 18 months of project definition and participant acceptance, the project started work in mid-1989 toward its goal: to produce static and dynamic random access memories (SRAMS and DRAMs) and logic chips using 0.3 micron feature sizes by $1995 .{ }^{92}$ Major cooperators in JESSI include Philips and Siemens, who had a relationship as a result of their Megabit (Mega) project, an earlier effort aimed at producing 4megabit DRAMs (Siemens) and l-megabit SRAMS

Table 5-9-Funding of EUREKA Projects, by Area

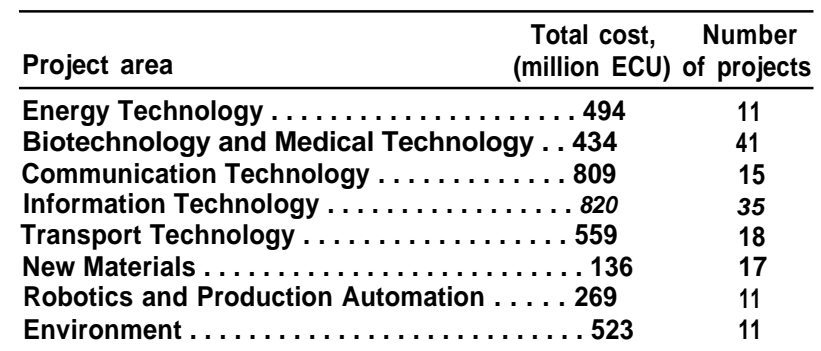

SOURCE: EUREKA Secretariat, EUREKA: Together for the Future (Brussels, Belgium: 1989), passim.
(Philips). The Mega project, begun in 1983-84, was supported by the German and Dutch Governments to the tune of DM 320 million and DM 160 million, respectively; Siemens paid DM 1.4 billion and Philips DM 1.5 billion for production facilities. In the end, Siemens acquired production technology and know-how to make 4M DRAMs, and had an operation actually making IM DRAMs in Regensberg, West Germany. The Mega project and other development work at Siemens no doubt contributed to this success, but so did Siemens' licensing of Toshiba's IM miniaturization technology in $1985 .^{93}$

However the success of the Mega project maybe judged, European microelectronics companies were still behind the world leaders at its conclusion and were facing escalating competitive pressure, particularly from the Japanese, whose market share in Europe was increasing steadily. Philips and Siemens together initiated the first discussions of JESSI, which other companies later joined. By 1988, a JESSI planning group included 29 companies and institutes from six countries. They put together a multiyear ECU 3.8 billion research effort with four subprograms: technologies for chip production, chipmaking equipment and materials, applications of microelectronics, and basic research (figure 5-5). The overall objective is "to secure the availability of world-competitive microelectronics for the European industry. ${ }^{\prime \prime 4}$ Recently, however, Philips withdrew from its leadership of the SRAM project of JESSI, probably reflecting a severe downturn in Philips' financial performance and large cutbacks in operations generally. Philips will probably abandon

Table 5-10-EUREKA Projects: Number of Projects by Funding Category

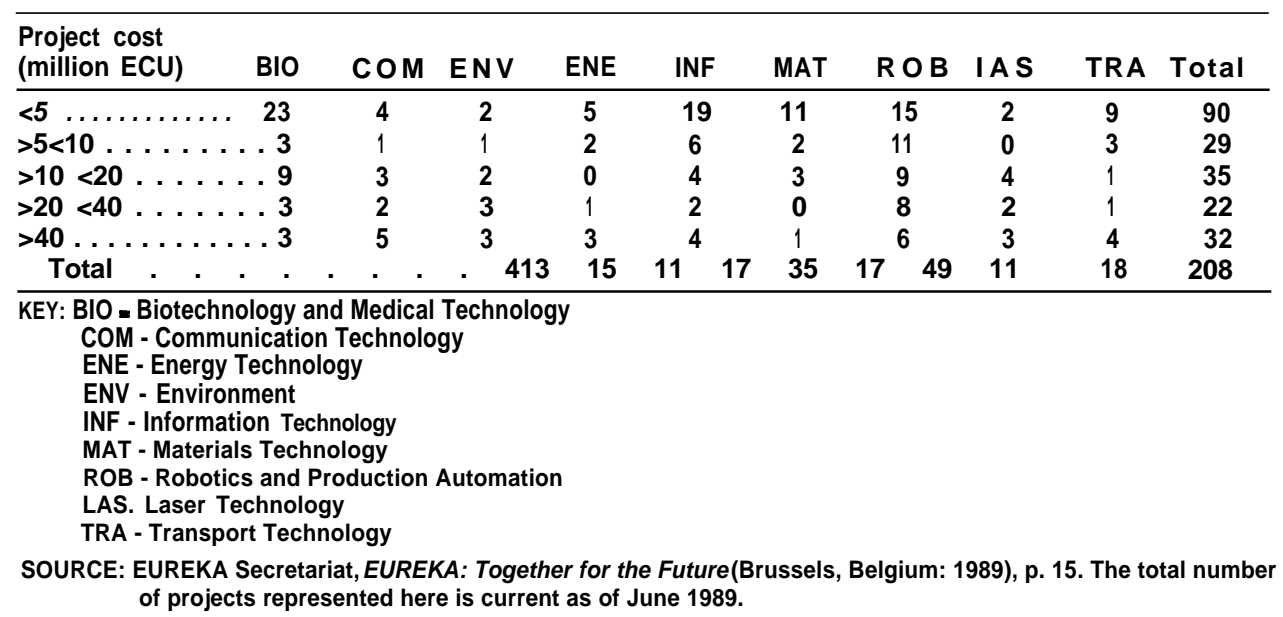


Figure 5-5-JESSI Program: Functional Overview and Structure of the European Microelectronic Program

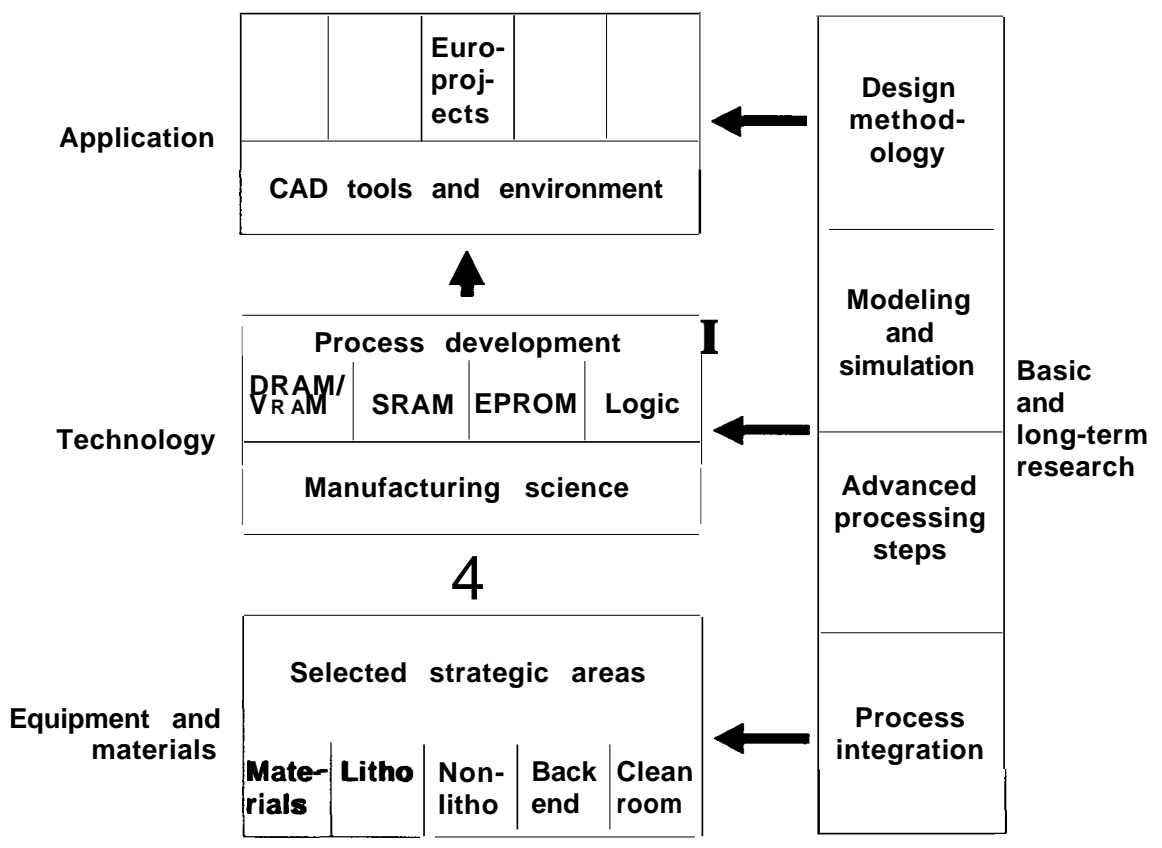

SOURCE: JESSI Planning Group.

the memory business altogether. While this is not by itself a crippling blow to JESSI, the fact that other participants are also in trouble is not a good omen for JESSI's eventual outcome.

JESSI is very much a commercial undertaking. It is principally a EUREKA project but has some funding from ESPRIT as well. ESPRIT funding goes into the basic research subprogram, which accounts for only 14 percent of JESSI cost and 22 percent of the manpower. Nevertheless, the contribution to JESSI accounts for 30 percent of the funding in ESPRIT's microelectronics program; some expect the overlap between the ESPRIT microelectronics program and JESSI to be nearly complete within a few years.

Some of the impetus for the Mega project, JESSI, and Framework's ESPRIT programs probably arose from European concern that competing with Japan in electronics would be a different ballgame from competing with U.S. companies. According to one analysis:

Because Japanese chip producers were part of larger systems houses, foreign competitors began to suspect that systems divisions of the same Japanese companies were getting access to leading edge products before their foreign competitors. This may have been perfectly natural . . . but it put foreign systems houses at a competitive disadvantage in getting timely access to the new parts. The resurgence of European support for semiconductors in the mid-1980s, in frameworks like the Mega project and the ESPRIT program, in some measure reflected these mounting concerns. ... Back in the late 1970s, reliance by European systems houses on U.S. semiconductor companies for supplies of advanced chips, though far from welcome, did not pose a strategic problem for European industry. The U.S. merchant chip manufacturers were not, for the most part, vertically integrated into downstream systems. All competitors enjoyed roughly equal access to state-of-the-art components."

\section{Emphasis on Cooperation}

Cooperation across institutions and borders, and among customers, competitors, and suppliers, is valued by Europeans both as a means to improved competitiveness and as a contributor to European political and economic integration. Different kinds of cooperation serve different purposes. Cooperation across borders is a frequently mentioned goal, based on the underlying assumption that Europe's competitive problems stemmed in large part from both fragmentation of markets, which deprived compa- 
nies and industries of economies of scale and scope, and fragmented research efforts, which resulted in overlapping but underfunded research and development projects.

Claire Shearman points to European market fragmentation as an important cause of Europe's weakness in electronics and information technology, and observes that the effect may have been aggravated by the protection of most national markets, which led European companies to focus more on domestic than on international markets. ${ }^{96}$ Undoubtedly, the ability to achieve economies of scale is important in some parts of the electronics industry. The cost of investment in new plant and equipment; the difficulties and costs of acquiring engineering, design, and production expertise; and the efficient scale of operation are all quite high compared with most other industries. For example, a new wafer fabrication plant and its equipment can require an investment of half a billion dollars.

However, with a few important exceptions, such as electronics products, telecommunications equipment and service, and large jet aircraft, limitations imposed by markets the size of most EC members are probably minor. For example, it is unlikely that national markets in Europe were too small to have allowed producers of textiles, many types of machinery, paper, and some chemicals and pharmaceuticals to produce at an efficient scale. Moreover, while the European market was far from unified and cross-border movement of goods was not without trouble, 60 percent of European trade in the late 1980s was with other European countries, indicating that European companies were already focused on European, rather than strictly national, markets. ${ }^{97}$

In telecommunications, the fragmentation was real, but not strictly a function of market size. Telecommunications services in EC nations are provided by governments, through ministries of posts, telegraph, and telephone (PTTs); usually equipment is procured from one or two companies, frequently national champions. Because PITs retained monopolies over provision of services and tight control over procurement of equipment, different countries introduced new technologies (hardware and services) at different rates. The rates were mostly slower than in the United States, where because of deregulation private companies could offer many new services to American consumers. ${ }^{98}$ In addition, there was no coordination of the different national services, making equipment and software incompatible from one country to the next. This made international telephone service inconvenient at best. According to one account,

To establish a private line between Italy and the Netherlands in the early 1980s, a user had to deal with every PIT in between, frequently making it a nightmare to trace and correct breakdowns. ... Tariff differentials were striking. A 500-kilometer leased line could cost ECU 840 per month in Britain, and ECU 2,230 per month in France. European businesses reported tremendous difficulties in establishing reliable, modern, efficient telecommunications links across Europe.

Fragmentation of research and development efforts, public and private, is also seen as a handicap. According to the CEC, the fact that each of the large members and several smaller ones had mounted their own research efforts in high-technology sectors resulted in many small research efforts, most with inadequate resources. Coordination among them was inadequate, information was diffused poorly, and there was duplication of effort. ${ }^{100}$

In response to the problems they see as arising from fragmentation, EC policymakers encourage cooperation of all kinds. This includes cooperation across borders, between customers and suppliers, between industry and academia, between large and small companies, and among competitors.

\section{Cooperation Across Borders}

International collaboration is not strictly a European development. For the past decade or so, multinational firms have expanded their cooperative relationships with firms in other countries through a variety of arrangements: joint ventures, licensing, marketing agreements and exchanges, direct and indirect investments, mergers and acquisitions, and R\&D collaborations. ${ }^{101}$ In many high-technology sectors, the firm that can best integrate its technical expertise with that of other firms is better equipped than one that relies more on in-house developments. Japanese fins, in particular, have shown how much can be accomplished by integrating technological developments from around the globe with their own strengths in manufacturing and design and close collaborations with customers and suppliers in Japan.

The multinational enterprises responsible for the swell of technical collaborative arrangements around 
the world are mostly Japanese, European, or American. The EC, in promoting international collaboration in technology, encouraged a trend that already had a head of steam, but there is little doubt that the encouragement was real; many of the resulting collaborations would not have happened without the Framework program as an enticement. For example, a senior manager in Plessey Research ventured the opinion that Plessey and Thomson, as competitors in gallium arsenide research, would ordinarily not work together, but they are doing so on an ESPRIT project (Advanced GaInAs-based Devices for High Speed Integrated Circuits) ${ }^{102}$ because "you have to collaborate in order to get funding. "103

Even where the programs do not stimulate wholly new alliances, they strengthen existing ones. An evaluation of BRITE found that it was an excellent catalyst' of transborder collaboration. Although three-quarters of the bilateral relationships formed in the program already existed, BRITE strengthened the relationships, according to the evaluators, and helped turn bilateral relationships into multilateral ones. ${ }^{104}$ The assessment was not all favorable; evaluators found that BRITE was not particularly effective at helping potential participants in isolated places find partners.

Preexisting relationships may be the norm in other parts of the Framework Program besides BRITE. One executive of Siemens, the largest single recipient of ESPRIT funds, states that the company wants to work only with partners it has worked with previously, and does not use the Framework Program as a dating service. Bad experiences with strangers account for this policy. ${ }^{105}$

Evidence from several quarters indicates that both Framework and EUREKA have succeeded in engendering cross-border collaboration. European evaluators seem confident that the Framework Program has done so. EUREKA has linked more than 800 organizations in more than 200 projects. The CEC notes that the Framework Program has many more applicant consortia than the available funds can support. ${ }^{106}$ Part of this success is due to the Framework Program's requirement that funded projects must have participation from different countries. ${ }^{107}$ Part is undoubtedly driven by the new optimism for market integration in Europe and the stimulation of European technology and science initiatives generally. The threat from a strong outsider (in this case, Japanese and American technology companies) may also have played a role, especially in industries where the time and money needed for a critical mass of R\&D are difficult for companies to bear individually.

\section{Customer-Supplier Cooperation}

The success of Japanese firms is due in part to their development of links upstream to suppliers and downstream to customers. These links allow the joint development of technologies, standards, and quality controls. The days when arm's-length relationships with customers and suppliers were regarded as the best business practice are ending, especially when development costs of new products and techniques are high.

Development of large jet aircraft is an example. The cost of developing the Boeing 777 is likely to be in the neighborhood of $\$ 5$ billion, not counting the engine, and Pratt \& Whitney estimates the cost of developing a new high-thrust engine at $\$ 2$ billion (see ch. 8). High development costs are nothing new in this industry; in the late 1970s, the cost of launching the 757 and 767 exceeded the net worth of the Boeing Co., and the development cost of the DC-10 was over three ties the capitalized value of the Douglas Co. Still, aircraft development costs are rising exponentially, with the result that all the major aircraft manufacturers are asking first-tier contractors to shoulder more of the development costs.

Cooperation is also becoming more important in electronics. Producers of computers, telecommunications equipment, and consumer electronics can no longer rely on off-the-shelf commodity chips as the primary building blocks of new products. Integrated circuits are now much more often application specific, and even entire systems can be integrated onto a single chip. This means that systems makers must transfer design information, including proprietary design information, to semiconductor producers, who could at least in theory convey that information to the competitors of the systems producers. ${ }^{108}$

These technical changes make vertical integration-production of components as well as final products within a single fro-an increasingly attractive strategy, and reliance on a vertically integrated competitor for semiconductors an increasingly risky one. 109 All the big Japanese systems companies are vertically integrated. Few American or European systems makers are, and even those that 
are still have to depend on outside suppliers for key components. During the 1980s, the outsiders in question were more and more often Japanese, for the vertically integrated, well funded, and technologically proficient Japanese firms had seized the competitive high ground in semiconductors and were steadily capturing world market share. Systems companies in America and Europe became uneasy about relying on their powerful competitors for components. This unease spawned efforts to improve coordination between semiconductor equipment producers and semiconductor makers, and between semiconductor producers and systems makers, in both the United States and Europe. Cooperation between customers and suppliers in electronics became a survival tactic. In its evaluation of ESPRIT, the CEC made this point emphatically:

The belief that all the industries which are becoming dependent on embedded microelectronics can develop competitively by purchasing standard components from remote and competing nations is fallacious. Close working relationships between major semiconductor users and suppliers are essential. $^{110}$

The idea of fostering vertical linkages is not confined to high-technology industries. There are advantages to coordination and cooperation even in less technology intensive industries such as textiles and apparel. For example, increasing coordination all the way along the chain from apparel design through fiber and textile production, sewing, wholesaling, and retailing is the objective of the Quick Response program of leaders in the U.S. fiber, textile, and apparel industries.

The sparse information available on the subject suggests that the Framework Program has had some effect in generating links between customers and suppliers. Many of the BRITE projects involved small and medium-sized firms making capital goods (e.g., machinery and equipment) for industrial customers; here, the diffusion of technology that BRITE achieved was in the interest of all participants." As the evaluation of the BRITE program stated:

Projects which unite customers and suppliers are usually successful because there is a community of interests. ${ }^{112}$

JESSI explicitly emphasizes customer/supplier links. Like Sematech, JESSI recognizes the advantage of Japanese vertical integration, and one goal is to help overcome this advantage by forging stronger bonds between customers and suppliers. Its planning report states:

What is lacking-above all-in Europe is the spirit of togetherness which is typical for Japan Incorporated. Japanese companies compete strongly amongst each other, but not before having shared in the effort to conquer a new market for Japan. Many semiconductor manufacturers, especially in [the] far east, are integrated into vertically structured system houses. Therefore, careful attention must be paid to defining user/producer interfaces in order to guarantee protection of the users' know-how.llq

User/supplier links are less prominently stated in RACE documents, but the goal is there nonetheless. Closer relations among industrial suppliers of equipment and telecommunications service providers (the PTTs) is one of the aims of RACE, where such linkage is regarded as necessary to accomplish RACE's other goals of making Integrated Broadband Communications and other innovative services available across Europe and setting common standards for European telecommunications services. ${ }^{114}$ There is evidence that such linkages may be happening. RACE mostly aims to provide services, but participation is heavily tilted toward telecommunications equipment manufacturers. With 395 participations in RACE, equipment makers have a larger share of total participations than any other group. It can be inferred from this heavy participation, plus the positive evaluations of RACE by participants, that both suppliers (the equipment manufacturers) and users (the PTTs) find it beneficial to work together in RACE projects. ${ }^{115}$

There are a few hints that achieving cooperative relationships between users and suppliers could be improved. The CEC's evaluation of ESPRIT acknowledged that more inputs from major software system suppliers would be valuable in the Software Technology part of ESPRIT.. The program has made technical progress in software technology, but is not yet exploited commercially, and the time when all commercial programmers use standard techniques, and all universities teach them, is still far off. ${ }^{116}$ The ESPRIT evaluators made similar comments on the Computer Integrated Manufacturing (CIM) projects. Computer integrated manufacturing requires an understanding not only of electronic equipment, but also of mechanical equipment; the evaluators noted that the absence of so-called mechatronic projects in ESPRIT, which united mechanical and electronic skills, was regrettable. The recommendation was to 
pay more attention to user attitudes and understanding, which, more than a shortage of technology, delay wider adoption of CIM in Europe. ${ }^{117}$

\section{Cooperation Between Competitors}

This is one of the most difficult of all forms of cooperation. Competition and cooperation are not mutually exclusive, but neither are they broadly compatible. Competition, and the benefits that it brings to companies and economies, often falls apart if cooperation extends to collusion. In Japan, industrial interests and bureaucrats usually manage to balance promotion of competition-assuring that no one firm attains too great a market share within Japan-with encouragement of cooperative arrangements in R\&D (and in some circumstances, production). ${ }^{118}$ But even in Japan, with its long tradition of industrial cooperation and a deeply rooted perception of the need for national cohesion, cooperative research is difficult to manage. It took several years of "administrative massaging" by the director of Japan's VLSI (Very Large Scale Integration) Project to overcome the suspicion and fears of the participants from five companies and MITI's Electrotechnical Laboratories before real research couldbegin.119 In Europe and America, where cooperation without collusion is less well established, the problem is greater.

Evaluators of the BRITE program are unequivocal on this point.

Projects which bring together competitors are unlikely to succeed. The Commission. . . hoped that cooperation in research might lead to such links. But these industrialists are often engaged in stern competition and their research forms the core of their business. When they do join together for research, it is usually for research that is on the periphery of their true concerns and therefore of doubtful industrial value; otherwise, disagreement soon arises. European culture is not the same as Japanese culture, and the only way any cooperation of this sort can succeed is if it is imposed at the highest level in the company. In reality, a number of projects in this category have patently failed, and the Commission must stop them. $I^{\mathrm{N}}$

The evaluators of ESPRIT came to a somewhat different conclusion. They note that early work plans for ESPRIT, though put together substantially by the "Big Twelve" European information technology companies, ${ }^{121}$ "did not address the core business needs of the principal protagonists and concentrated on activities where competitors could actually agree to collaborate in a 'precompetitive' way." ${ }^{122}$ Unlike the BRITE evaluators, however, the ESPRIT review board did not regard this as reason for stopping projects; rather, the problem was treated as minor.

\section{Cooperation Between Academia and Industry}

European universities have long been viewed as aloof from the concerns of industry, compared with those in the United States and Japan. ${ }^{123}$ One goal of the Framework Program is to reinforce a growing trend toward stronger relationships between academia and industry. ESPRIT and BRITE, for example, have specifically encouraged university and industrial researchers to unite in certain research projects. ${ }^{124}$ In ESPRIT, 75 percent of the collaborations include firms and academic research units. ${ }^{125}$

Although the overall impression is that industryacademic cooperation is good for both and should be encouraged, there are a few caveats. These partnerships will help bring academic research out of the ivory tower and into the real world. But the CEC warns that universities should not let industry's R\&D funding lure them into abandoning inquiries of a fundamental or scientific nature and concentrating too heavily on short-term problems of companies. While noting that some shift of emphasis was exactly what was needed, the CEC is concerned that the pendulum could swing too far. University participants in BRITE had the same concern; several academics indicated to the BRITE evaluation review team that the industrial participants' emphasis on empiricism was excessive and could undermine the value of the results. ${ }^{126}$ Further, exclusive relationships with industry could restrict the availability of research reports from universities, a problem already emerging in the United States. ${ }^{127}$

These caveats are relatively minor. Most collaborative projects involving academia are viewed by ESPRIT participants as working either adequately (45 percent of respondents) or well (over 20 percent). ${ }^{128}$ In BRITE, three-quarters of the contractors viewed collaboration between industries and universities as enhancing the projects' chances of success. ${ }^{129}$ However, this kind of cooperation is not sufficient to promote competitiveness in Europe without managerial know-how and skilled people to exploit market opportunities. 


\section{Precompetitive Projects}

As noted, the Community is trying to find a way to balance competition and cooperation and obtain the best from both. One way to strike a compromise is to limit projects to precompetitive R\&D. According to the CEC, this means limiting projects to "a stage prior to industrial development, or not yet 'market ready.' This is to ensure that EC research does not lead to any distortion of competition, which would be in breach of the EC Treaty regulations. ${ }^{130}$

This is not a precise definition. There is some understandable puzzlement over what is precompetitive, and some frustration with precompetitiveness as a requirement for acceptance. The BRITE evaluation team said it best:

The panel remains puzzled by the incorporation of the concept of pre-competitivity in a research programme whose primary goal is to enhance the competitiveness of European industry. This is a major contradiction that the Commission cannot escape. Some excellent projects were not funded because they were considered too "competitive" by the selection team. Concern about the idea of pre-competitivity has also had the effect of pushing some projects upstream so that their industrial interest diminished. The panel fully realizes that there were good legal reasons for this criterion to be written into BRITE. But the law should be the servant of the Community, not its master. ${ }^{131}$

This concern is echoed by some participants. For example, one member of the Industrial Research and Development Advisory Committee (IRDAC) to the EC expressed frustration that no one knows what "precompetitive' means, and stated that efforts to keep JESSI precompetitive were making it uncompetitive.$^{132} \mathrm{~A}$ participant in JESSI from Siemens disagrees with the perception of JESSI as precompetitive, and believes that the consortium is successfully developing complex integrated circuits that can be integrated into systems; ESPRIT, according to this researcher, had failed in this respect. ${ }^{133}$ Another observer notes a strong conflict between precompetitive research and the process of developing a specific product ${ }^{134}$ The limitations imposed by the requirement that the research be precompetitive tend to show up often in comparisons of ESPRIT and EUREKA, which is not required to be as far from the market as the Framework Program.

The EC will probably continue to stress precompetitivity, partly because the law constrains it to, and partly because many people still think that it is an appropriate guiding principle. ${ }^{135}$ But certain adjustments can be made. In the second phase of ESPRIT, work continues to be precompetitive but more emphasis is placed on projects of clear benefit to industry. Among the goals of ESPRIT II are providing a sustainable capability to design and produce application-specific intergrated circuits (ASICs), developing technologies needed for next-generation information processing systems, and enhancing the ability of European industry to integrate nextgeneration processing into complete application systems. $^{136}$

\section{Small Business}

The Framework Program emphasizes participation by small business. In Europe, as in Japan and the United States, most R\&D is carried out by large organizations, with a few notable exceptions such as Silicon Valley microelectronics startup firms. Small businesses often lack staff and money to keep abreast of technological change and are often left behind as technology advances. To compensate, many developed nations have various types of extension and training services for small businesses; Japan's is particularly well funded and extensive. ${ }^{137}$

The EC's emphasis on including small and medium-sized enterprises (SMEs) ${ }^{138}$ in the Framework Program is intended to improve their technological competence and ability to innovate. Both are important goals, though the former is explicit and the latter most often implied.

Some programs are naturals for SMEs, and others are not. ESPRIT, whose designers were the Big Twelve European information technology companies, is not. Much of the R\&D for information technology (IT) involves too great expense for most small firms to handle. While there is a natural place for small, specialized firms in supplying the large IT companies with specialty materials and chemicals, production equipment, and other niche products, even these are difficult markets to enter because of high capital requirements and the increasing domination of Japanese fins, many of which are conglomerates and operate on a global scale. Even so, ESPRIT evaluators feel that the program has been successful in attracting and funding projects for SMEs. The Big Twelve participated in 70 percent of the ESPRIT projects and received 50 percent of the funding; SMEs participated in 65 percent of the projects and received 14 percent of the funding 
(figure 5-6). SMEs' share of the program has increased and that of the Big Twelve has fallen. ${ }^{139}$

RACE is another project that does not invite easy participation by SMEs. RACE's design, like ESPRIT's, relies heavily on large organizations-in this case, the large PTTs that provide telecommunications service in EC countries, and telematics equipment producers. RACE evaluations are nearly mute on the topic of SME participation. The management audit of RACE in 1989 discloses that just over two-fifths of RACE partners were SMEs, but there is no mention of their share of funding (figure 5-7) $\cdot{ }^{140} \mathrm{By}$ size class, the largest number of participants had more than 5,000 employees.

BRITE, on the other hand, was built for small enterprises; not entirely, to be sure, but substantial participation of SMEs was intended and desired in BRITE in a way that was never true of ESPRIT and RACE. The exact share of SMEs in BRITE funding is unknown; the evaluation team found that the reported figure of 31 percent is misleading because some of the companies placed in the category of SME are part of larger enterprises. ${ }^{141}$ But it is also very likely true that a larger share of BRITE's funding goes to SMEs than is the case for RACE or ESPRIT

The CEC seems generally satisfied that it is meeting its goals in attracting and funding proposals horn SMEs, at least in the big Framework programs.

Figure 5-6-ESPRIT I Funding Allocated by Sector

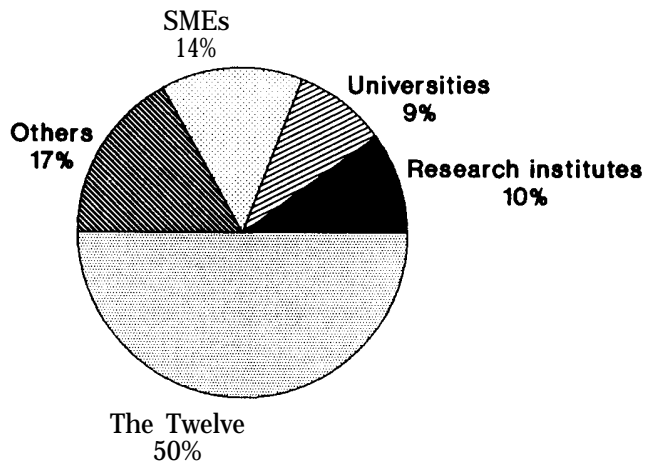

SOURCE: Commission of the European Communities, Communication from the Commission to the Council and the Parliament Concerning the Performance and Results of the Programme ESPRIT, SEC(89) 1348 final (Brussels, Belgium: Sept. 7, 1989), p. 12.
Figure 5-7-Size of Partners in RACE Program

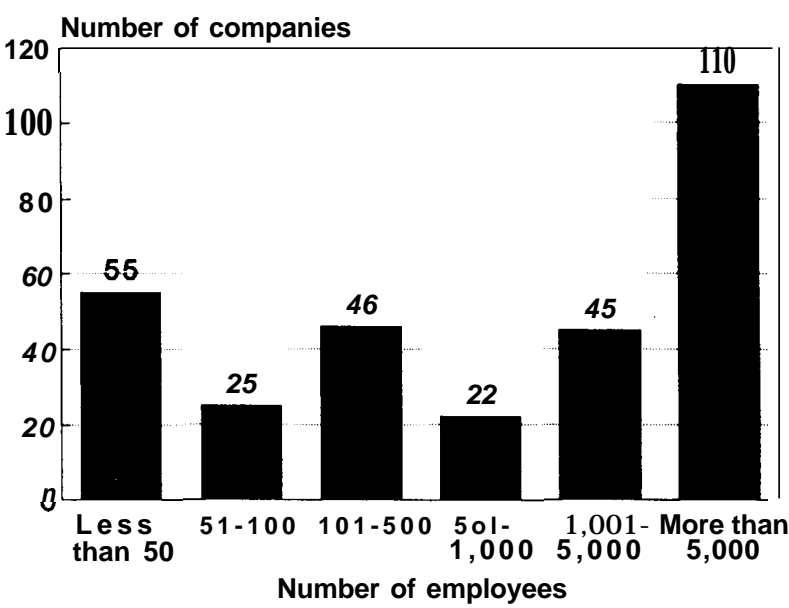

SOURCE: Commission of the European Communities, RACE 'W, (Brussels, Belgium: 1990), p. 93.

Whether or how much SME participation is contributing to the overall aims of Framework is less clear. Large organizations do the bulk of R\&D for a good reason: $R \& D$ is generally an expensive proposition, requiring specialized equipment and people, a longer term outlook, and stable financing; many small enterprises are unable to mount such efforts and most do not need to. There is merit in small organizations' having the technological expertise to keep up with the larger organizations that they supply, and in that sense bringing them into $R \& D$ consortia is helpful. But the most pressing technological issue for SMEs is usually not how to do more R\&D, but how to apply what is known, as the BRITE evaluators said:

The challenge facing traditional S.M.E.'s-like many other firms-is not in fact the need to adopt new technology, but rather to integrate into their production methods technologies that already exist on the market. Such an objective, which is crucial to the future of European industry, does not fall within the scope of BRITE ... [T] he Commission should discuss the possibility of launching a much larger and more ambitious programme than the current SPRINT ${ }^{12}$ programme, with suitable procedures for promoting the dissemination of technologies within the industrial fabric, and in particular for small and medium-sized firms. ${ }^{13}$

Another salient finding of the BRITE evaluators is that SMEs benefit from contacts with larger organizations (companies and universities), in part because those larger organizations have easier access to information and can make it available to 
smaller companies. Whether large firms benefit in equal measure from their participation in consortia with small ones is less clear (see the section on Sleeping Partners).

\section{International Participation in the Framework Program}

The Framework Program was designed to improve the competitiveness of European firms vis-àvis American and Japanese firms. Naturally, this makes U.S. and Japanese efforts to join Framework Program consortia a thorny issue.

Up to now, American firms that want to participate have been given access, but not always as much as they would like. For example, IBM was allowed to participate in JESSI, which receives some funds from ESPRIT, but is not permitted to take part in working groups or committees that make management decisions about projects. RACE, on the other hand, has allowed IBM to function as a prime contractor, and EUREKA projects let IBM participate as the only computer company in a given consortium. In contrast, ESPRIT projects require IBM to have a European computer company as a watchdog. ${ }^{144}$ Although participation by IBM is becoming more accepted, this does not end all the problems, either for IBM or for Europe. IBM would like unconstrained access, especially since it has substantial manufacturing and R\&D in Europe (IBM conducts 12 percent of its R\&Din Europe, 8 percent in Japan, and the rest in the United States). One reason for IBM's restricted access to JESSI and the Framework Program is that European companies do not have equal access to Sematech, which Europeans view as a comparable program.

More to the point, Europeans are still uneasy about access of foreign companies. While a few American companies besides IBM (and many companies from EFTA countries) have been able to participate in Framework and EUREKA projects, the question of who should get in is unsettled and controversial. An official of the Dutch consumer electronics firm, Philips, maintains that while the frost goal of the Framework Program is the integration of Europe, the second goal (especially of the telematics programs) is to break the domination of AT\&T and IBM. ${ }^{145}$ This statement is no doubt an exaggeration, but if there is any truth in it, uneasiness about even limited participation on the part of IBM and AT\&T could be expected. Nevertheless, it could be self-defeating to exclude IBM from proj- ects such as JESSI, which is supposed to foster tighter links between supplier and customer fins. As one IBM official put it: "We have to be in JESSI; all the key players--our suppliers and users-are there. IBM is the largest buyer and supplier of chips in Europe." The same goes for IBM's participation in RACE, Prometheus (a EUREKA project that links modern information and automotive technologies to improve transportation efficiency and safety), and other projects: 3 years ago, IBM was involved in only 3 projects; now it is in $20 .{ }^{146}$

Still more problematic is the question of Japanese participation, for Japanese firms are a greater competitive threat than most American firms, especially in information technology. Two things concern Europeans facing dependency on Japanese suppliers. For one, the big Japanese firms not only supply components, they also compete directly with systems integrators. Depending on a competitor for key supplies is risky at best. In addition, many fear that the Japanese firms will act nationalistically, or in keeping with long-established intercompany ties, serving the needs of their Japanese customers before foreign customers. Until 1990, the issue of Japanese participation in the Framework Program was avoidable. Then Fujitsu, a longstanding supplier of products (both components and systems) to the British computer firm ICL, bought 80 percent of ICL. ICL was one of the original Big Twelve information technology companies in Europe and a participant in many ESPRIT projects. Although ICL met and still meets the EC's criteria for participation in the Framework Program-an integrated presence in Europe, including $\mathrm{R} \& \mathrm{D}$, sales, and manufacturing ${ }^{147}$ - the prospect of one of the Japanese giants having immediate access to and decisionmaking power in ESPRIT' projects is forcing a reevaluation. As of spring 1991, ICL had been removed from the working committee that manages JESSI and was invited out of three of five projects.

So far, beyond the Fujitsu-ICL imbroglio, Japanese firms have not participated in Framework projects. Whether this is because they have been uninterested, reached a polite understanding that they were unwelcome, or been formally deterred, is unknown. ${ }^{148}$ But the participation of Japanese companies is likely to be a bigger issue in the future, for they are beginning to knock on the Commission's door, as one participant put it, to ask for admission to the programs. ${ }^{149}$ 


\section{Sleeping Partners}

The Framework Program is required to contribute to the nations that fund it, though not in exact proportion to the funding. The contributions from the large economies--Germany, France, Great Britain, and Italy-are much greater than those of the smaller countries, particularly ones like Portugal and Greece that lack well-developed high-technology sectors. While every project need not scrupulously include participation from every member nation, and participation does not have to match exactly relative funding levels, there is some pressure to include participants from tie smaller and weaker economies.

Sometimes this is a minor problem. A few representatives from strong system companies mention that a drawback of Framework projects is that they were pressed to include unwanted organizations that contribute little to the project; these are variously termed sleeping partners or alibi partners. In response to questionnaires, participants in BRITE, RACE, and ESPRIT have all indicated that they are generally satisfied with the alliances formed within the programs, but not universally. Some of the disenchantment is undoubtedly due to the necessary coupling of strong and weak enterprises; this factor is also sometimes viewed as a weakness in the American high-technology consortium, Microelectronics and Computer Consortium. However, the inconvenience may be balanced, in part, by the benefits gained by weaker enterprises and nations. ${ }^{150}$

\section{Performance of Framework and}

\section{EUREKA Programs}

Europeans are excited about the Framework Program and EUREKA. Most are happy with the significant increase in transborder cooperation, new linkages forged between companies and academic institutions, and alliances between small and large enterprises. The programs have also contributed to standard-setting in Europe. They claim to be eliminating wasteful duplication within national programs, as well as fragmented and unconnected national programs themselves. And they have produced some commercially exploitable results.

What the technology programs have not yet done is make much of a dent in the basic problem: Europe's slipping competitiveness in high technology. It may be too soon for the programs to have made such a difference; the oldest of the programs have been in operation for less than a decade. Moreover, Framework and EUREKA are only part of Europe's new economy, and many of the more sweeping changes planned for the single market have not yet been implemented.

Accomplishments-In some ways, the programs have much to show for the short time they have been in operation, most notably an increase in cooperation. International cooperative agreements were on the upswing before Framework and EUREKA got into gear, but observers inside and outside Europe agree that the programs have increased European firms' and research organizations' knowledge of each other, helped to arrange collaborations that would have been difficult before, and set the stage for future alliances. They have helped producers and users to hook up, and sometimes have become indispensable for that purpose. There is still room for improvement; RACE and ESPRIT have been criticized for not including enough user input, and concentrating too much on the agenda of the Big Twelve. But for the most part, policymakers, participants, and Europe in general seem pleased with the progress in linking up users and suppliers.

An often-cited contribution of the technology programs is in standard-setting. The programs help in two ways: greater communication among companies working in the same business helps to build consensus on harmonizing varying standards; and the cooperation of the 12 nations helps to make Europe more of a force in world standard-setting.

All EUREKA communications projects at least touch on aspects of standardization, and five aim directly at developing standards, including, for example, a project to develop high-definition television production and broadcasting standards and equipment for producing and receiving nextgeneration television broadcasts. ${ }^{151}$ RACE is particularly interested in developing standards for integrated broadband communications (IBC) across the EC by 1995, which in turn will require common standards for telecommunications equipment and service. These and other such projects may lead to EC-wide standards and possibly to worldwide standards. That is both a significant accomplishment of European technology programs and a source of international friction. Foreign companies fear that by being excluded or accorded second-class status (e.g., being left out of the critical process of making decisions) in technology programs they will be at a 
competitive disadvantage with regard to standards, for it is unlikely that their own product standards would be considered for the European Community. ${ }^{152}$

The Framework Program has also helped to solve one of Europe's particular problems: knitting together 12 separate, sovereign nations. The EC does not intend to become one unified economy and political entity-a United States of Europe-but one major aim of unification is to reduce the fragmentation and division that characterize the 12 members now. The Framework program, along with the 279 directives of the Single Market Act, will help to lower technical barriers among these nations, and to reduce the fragmentation caused by the traditions of different European institutions. If the evaluations of Framework programs are any indication, ${ }^{153}$ Europeans are confident that the Framework programs have, in the words of the ESPRIT evaluators, "influenced several thousand of scientists and engineers in information technology fields to think European and to do so in a positive way. "154

Another contribution of the programs is helping to avoid duplication of effort. This is a benefit claimed for most R\&D consortia, but in Europe's case may be well-founded because of prior national support for duplicative efforts. Several participants mentioned the efficiencies of learning from others. Officials of Siemens, speaking of the company's participation in the Eurolaser project, indicated that one of the benefits was the ability to go to the labs of another company and possibly do investigations there. This, according to Siemens, helps a company to do its technical work more economically. ${ }^{155}$

Duplication, or redundancy, is another issue that cannot be neatly resolved. The benefits of avoiding wasteful duplication are obvious, but there is also a danger of eliminating all overlap. Von Hipple points out that the best climate for innovation is one in which many organizations are involved in independent efforts to solve the same problem. There is perhaps a danger that too much cooperation could focus innovation efforts too narrowly. However, that danger probably is minuscule for Europe now, especially in view of the fact that some EUREKA projects are similar to but independent of EC programs. ${ }^{156}$

Competitiveness-The Framework program and EUREKA have not yet made a big difference in the competitiveness of European industry. Whether they are on track to do so is an open question.

EC evaluations tend to avoid the issue of competitiveness. This is understandable; it is difficult to measure. More importantly, the EC seems determined to give the programs plenty of time to work-a necessary part of competitiveness programs, particularly in programs designed to catch up with the leaders. Still, some attempts have been made to assess the programs in terms of market outcomes.

A few ESPRIT projects have already yielded commercial results, or are on the verge of doing so. For example, ASM Lithography B.V., a Dutch company, has the lead role in an ESPRIT project to develop a deep ultraviolet wafer stepper for semiconductor production. It recently announced that its deep UV stepper was being tested in several locations throughout the world. The stepper is capable of etching lines less than 0.3 microns wide, and if the tests go as expected the company stands to gain significant market share. The Japanese companies Canon and Nikon already have deep $W$ wafer steppers, but at the end of 1990 they were not yet available outside Japan. ${ }^{157}$

Another ESPRIT project that helped produce a commercial product was the Supernode project. ${ }^{158} \mathrm{It}$ ran 3 years, and produced a modular, reconfigurable computer than can link a few to many processors together. Since the end of Supemode in 1988, both Telemat of France and Parsys of the United Kingdom have made and marketed Supernode computers, and by April of 1990 they had sold more than 200 of the machines. ${ }^{159}$

Stories of commercial exploitation of products resulting from Framework or EUREKA projects are beginning to appear, but are not yet plentiful. Participants in the first phase of ESPRIT reported that 143 of the 227 projects resulted in "industrially significant" results (table 5-11), but only about 12 percent of the projects of ESPRIT I resulted in a commercial product by the time of the evaluation. Concern is surfacing over the issue; a recent news item reported that several influential officials of the CEC criticized ESPRIT for producing little commercially useful technology, and were concerned that European electronics companies were still overly dependent on EC subsidies and trade protection. ${ }^{160}$ 
Table 5-1 I-industrially Significant ESPRIT I Results

\begin{tabular}{|c|}
\hline .27 \\
\hline $\begin{array}{l}\text { Contributed directly to products and services developed } \\
\text { for the market but not yet commercially available .......44 }\end{array}$ \\
\hline $\begin{array}{l}\text { Used outside the ESPRIT project, either within the } \\
\text { company concerned or in another company } \ldots \ldots \ldots \ldots\end{array}$ \\
\hline $\begin{array}{l}\text { Contributed to standardization, either adopted as } \\
\text { an international standard or being elaborated by } \\
\text { an international standards organization } \ldots \ldots \ldots \ldots \ldots 28\end{array}$ \\
\hline $\begin{array}{l}\text { OURCE: J.F. Blackburn, London Representative of the Commerce } \\
\text { Department for Industrial Assessment in Computer Sciences } \\
\text { and Telecommunications, "Overview of European Strategic } \\
\text { Technology in Computers, Telecommunications, and Electron- } \\
\text { ics," ESN Information Bulletin, ESNIB 90-40, p. 12. }\end{array}$ \\
\hline
\end{tabular}

Results of BRITE are more promising. Fifty-nine percent of BRITE participants reported that they expected commercial benefits from their projects within 5 years. The evaluation team regarded this expectation as somewhat optimistic, but found it encouraging. ${ }^{161}$

JESSI got off to a slow start-according to one participant, work only began in 1990 after an 18-month startup phase ${ }^{162}$--and Philips recently announced it was pulling out of the JESSI SRAM development project. Another indication of trouble is that funding from the national governments has not materialized, and the EC is far behind schedule in its funding. However, several of the project's participants, as well as the ESPRIT evaluation team, indicated that its strategic direction is sound. Another comment on its significance is the news that JESSI and Sematech just initiated their first cooperative venture (others are expected). ${ }^{163}$

Overall, the assessment of commercial output from the Framework Program and EUREKA projects is mixed. Even if they come up with commercial products or services, that is not the same as competitive success, which means raising market share while maintaining or increasing standards of living. That, in turn, means helping to eliminate Europe's trade deficit in high-technology products. On these points, the evidence is clearer. So far, the projects have not made much difference. For example, in 1975, the EC had a trade surplus in information technology products, but by the beginning of ESPRIT I, it was becoming steadily more dependent on imports. The trade deficit in IT products reached $\$ 5$ billion by 1980 , and increased to nearly $\$ 22$ billion by 1987 (figure $5-8$ ). The largest deficits were in such products as integrated circuits, consumer electronics, and computers. That year, the EC accounted for 28 percent of world consumption of computer systems but supplied only 13 percent, and consumed 17 percent of the world's microelectronics while producing 11 percent. The Commission praised European computer companies for giving good service and keeping upmarket share, but also noted that some "European vendors have kept their turnover up by adopting the role of system integrator or product distributor which results in a reduction in value added. "For example, Siemens' supercomputers are made for it by Fujitsu and its laptops are made by Matsushita.

Another problem is getting off the dole. It is hard to call a company or an industry truly successful if it needs continuing subsidies or protection to survive. One reason why Japanese electronics companies are judged successful is that they continue to flourish while formal and informal trade protection is disappearing (albeit slowly and sometimes grudgingly). Few European companies have managed this. The Airbus consortium, for example, is widely cited in Europe as a successful venture, yet it has received over $\$ 5$ billion in success-dependent loans, which have yet to be repaid, and continues to receive substantial development loans from the governments of Germany, France, England, and Spain. Another example is a company called ES2 (European Silicon Structures). In 1985, the company was formed as a joint venture of major electronics firms from nine European countries to produce ASICs. In

\section{Figure 5-8-Europe's Trade Deficit in Electronics in $1987(21.9 \mathrm{bn})$}

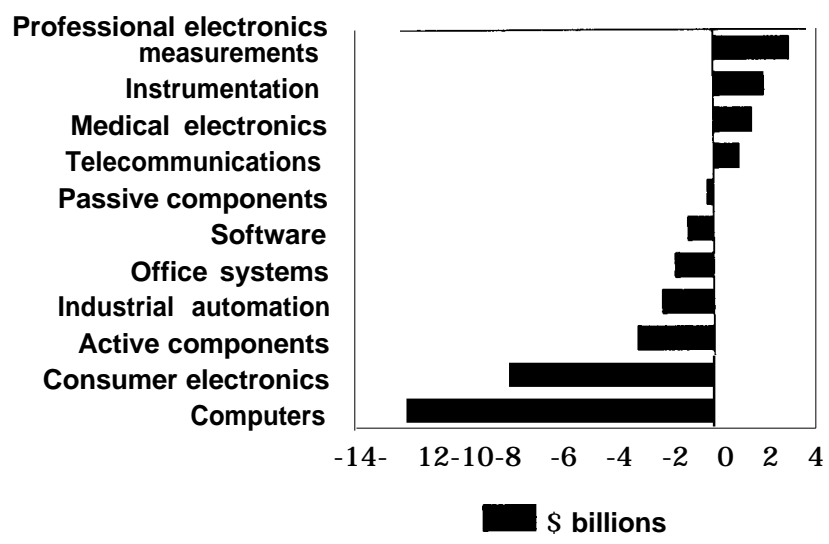

SOURCE: Information from the Commission of the European Communities, Communication From the Commission to the Council and the Parliament Concerning the Performance and Results of the Programme ESPRIT, SEC(89) 1348 final (Brussels, Belgium: Sept. 7, 1969), p. 6, who cite EIC as their source. 
1989, it posted revenues of $\$ 19.3$ million, 45 percent higher than in the previous year. No other company of the same size participated in so many European technology programs; it was a player in ESPRIT and JESSI. A success? The company had not yet managed to break even, much less turn a profit, by the end of 1989, and its revenues were considerably below the prediction of its founders, who announced in 1985 that its sales would break $\$ 100$ million in 5 years. ${ }^{165}$

Even the evaluations, which are generally positive in tone and outlook, sound a few warnings. For example, ESPRIT evaluators noted that too much of the technological advance was in niche areas with limited market potential; that work in the software technology portion of the program had produced valuable inhouse developments but had yet to result in commercial exploitation; and the work in the office systems portion of the program were disappointing overall. The major success of the program was the increase in trans-European cooperation made possible by EC funding, but even that was judged possibly not robust enough to survive substantial funding reduction. ${ }^{166}$

European policymakers and many experts point out that it is too soon to bring the jury back on Framework and EUREKA, and they are right. The programs have achieved some notable results, and it is laudable that those in charge have resisted the temptation to make snap judgments. But at this point they have little to teach others about new ways to improve competitiveness.

\section{EC-92: COMPETITION POLICY AND EFFICIENT FIRMS}

EC-92's removal of trade, financial, and technology barriers within Europe will create big enough markets to satisfy the needs of any European industry that may have been handicapped by a national market too small to allow economies of scale. The Commission wants to encourage the formation of firms large enough to take advantage of the bigger market, but at the same time to foster competition. EC competition policy has two distinct aims. One, similar to the U.S. antitrust tradition, is oriented toward the regulation of restrictive practices and cartels in the private sector. The other is aimed at removing member countries' favoritism toward their national companies in a wide range of industries and sectors, including telecommunica- tions, passenger air transportation, energy, autos, chemicals, and an array of service industries. The goal of these policies is to help create stronger, more competitive, possibly pan-European firms.

\section{European Antitrust Policies}

Competition policy governs mergers, acquisitions, and formal linkages such as joint ventures (merger policy) and corporate practices that limit competition in a market (restrictive practices). Until recently, antitrust policies in the EC have been run at the national level. In general, European countries are less sympathetic to antitrust actions than the United States. Some, like France and Germany, evaluate mergers and restrictive practices case by case, and allow firms a great deal of market power when they believe that consumers or the national interest gain thereby. France and Italy have also used antitrust law to favor national champions involved in mergers and takeovers. Britain, while in principle opposing restrictive practices by companies, is more relaxed in practice than the United States. Britain, France, and Germany all use balance of benefits arguments to determine whether business arrangements are appropriate, and their responses to unacceptable practices rarely involve structural change in the market.

In 1990, the EC took control of very large mergers in Europe. EC policy will probably remove the controls imposed by national governments, keep a close eye on firms' restrictive practices that tight distort competition among European countries, and at the same time encourage the creation of larger firms, including cross-border mergers. 167 Many EC officials believe that European firms in many industries are simply too small to compete effectively, and that a new single market can offer economies of scale that larger companies can exploit. However, some voices in the EC have warned against a simple view that bigger is better. In particular, Sir Leon Brittan, the EC Commissioner for competition policy, has argued that she alone does not create world beaters, and that the EC needs more competition in home markets. ${ }^{168}$ As table 5-12 shows, European manufacturing firms are somewhat smaller than U.S. firms. They are closer in size to Japanese firms, but this maybe deceptive since most leading Japanese manufacturing companies belong to industry groups (keiretsu) that in effect expand their size. 
Table 5-12-Shares of Manufacturing Industry Held by Large Firms in Japan, the United States, and the EC, 1986

\begin{tabular}{|c|c|c|c|c|}
\hline \multirow[b]{2}{*}{ Largest } & \multicolumn{4}{|c|}{$\begin{array}{l}\text { Share of largest firms in } \\
\text { total sales of industry }\end{array}$} \\
\hline & 5 & 10 & 20 & 40 \\
\hline $\begin{array}{l}\text { EC } \\
\text { United States } \ldots \ldots \ldots \ldots \\
\text { Japan } \ldots \ldots \ldots \ldots\end{array}$ & $\begin{array}{r}6.8 \\
3.0\end{array}$ & $\begin{array}{r}\text { (pe } \\
10.8 \\
3.5 \\
12.6\end{array}$ & $\begin{array}{l}\text { ent) } \\
16.9 \\
.626 \\
17.5\end{array}$ & $\begin{array}{r}23.0 \\
34.6 \\
23.7\end{array}$ \\
\hline
\end{tabular}
the EC," European Economy, No. 40, May 1989, table 5-1.

The EC's mergers directive (put in effect Sept. 21, 1990) layers an EC merger-control office on top of the national offices, to deal with mega-mergers with a substantial European dimension. The EC office now has the power to veto all mergers, and those joint ventures in which one company is established in the EC, with worldwide revenues of at least ECU 5 billion and EC revenues of at least ECU250 million. ${ }^{169}$ (However, the directive allows national merger authorities to intervene when they believe that a "legitimate interest" is at stake. ${ }^{170}$ ) The Commission can compel firms to disclose intentions, as well as block mergers and fine violators. ${ }^{171}$ It also has extraterritorial powers over mergers between two foreign-based firms doing business in the EC: competition rules govern all business arrangements that operate witiin the EC, even firms that have no registered home office there.

In principle, the EC will approve business arrangements (including both mergers and interfirm links) when they do not impede competition within the Community. The directive offers a safe haven for mergers that will not result in one firm controlling 25 percent or more of a relevant market; there are also block exemptions, covering certain classes of business activity; and firms can seek a letter of comfort from the EC giving tentative approval to a proposed arrangement in advance. All restrictive practices are illegal unless they in some way benefit the interests of the Community.

The directive allows the Commission to take into account social and economic factors when considering mergers. ${ }^{172}$ It is not yet clear exactly how the Commission will interpret this mandate, but an indication comes from the Commission's decision not to intervene in the merger between Siemens and Nixdorf, on the grounds that competition from other EC and non-EC firms will provide effective competition despite the increase in concentration. ${ }^{173} \mathrm{An}$ approach consistent with this decision was earlier outlined in a paper by three senior officials in DG-11. ${ }^{174}$ The authors analyzed mergers against two kinds of measures:

1. the danger of reduced competition, in which the key variables are the degree of market power concentration, the speed with which demand is growing (making entry more or less attractive), and the extent of import penetration; and

2. the potential for efficiency gains, focusing on the technology content of the industry and the existence of economies of scale.

These criteria suggest how the Commission may try to mesh the aims of encouraging mergers into larger firms with traditional antitrust policy.

Such an EC policy would bless and possibly accelerate a process already under way. Merger activity in the EC has taken off as firms jockey for position in the new single market (figure 5-9). The number of significant deals more than tripled between 1982 and $1987,,^{175}$ and by 1989 cross-border mergers rose to 1,267 deals with an estimated value of ECU60 billion. ${ }^{176}$ Some national policies have also changed. French restrictions on foreign ownership appeared to be declining, as France was the second largest target country in late 1989 and the largest in the first quarter of $1990 .{ }^{177}$ The Commission has specifically encouraged much of this activity, as the assertion of market forces over government regulation. ${ }^{178}$

\section{Figure 5-9-Total Merger Activity, All National, Community, and International Mergers by Combined Takeover}

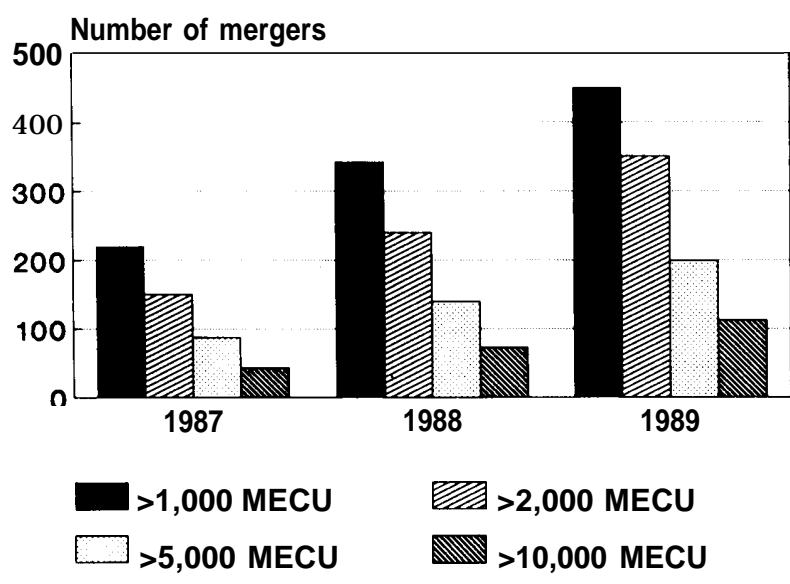

SOURCE: EC Competition Reports [July]. 
Though it seems to be accepted wisdom among some in the EC that bigger firms mean better competitive performance in general, that belief is open to question. In some industries, to be sure, large size seems a distinct advantage. For example, the competitiveness of Japan's giant electronics firms is often given as a leading reason for their great success in the 1980s. But in other industries, the advantages of very large size are not so overwhelming. A famous misstep of Japan's illustrious MITI was its abortive attempt in the 1960 s to reduce the auto industry to three firms, under the conviction that the industry could not support any more. The industry resisted, MITI abandoned the attempt, and there are still 11 Japanese auto producers, most of them doing very well. Likewise, MITI tried to rationalize the machine tool industry, and got no further. Today, Japanese machine tool builders, which are still very numerous, lead the world. Obviously, many factors contribute to success in manufacturing and in some industries size is one of them, but even in those, it may be quite far down the list in importance.

\section{Subsidies and Nationalized Companies}

Peter Sutherland, the former Commissioner in charge of competition, put the Commission's position on favoritism to national companies in these terms:

If you remove national trade barriers, and if you also leave the capacity of governments to interfere with trade by supporting unfairly one industry against another, to allow companies to carve up markets and fix distribution, you would have the same effect of destroying 1992 as if the barriers were left untouched. ${ }^{179}$

The question is not only one of fairness and removal of intra-EC barriers. Protection and pampering can also sap firms' competitiveness.

Subsidies for both national champions and lame ducks are a prominent feature of the economic landscape in Europe. Moreover, nationalized industries have always had special relations with governments and their treasuries. Both are under challenge from the EC.

Subsidies--Subsidies have long been a central component of European industrial policies. ${ }^{180} \mathrm{E} \mathrm{C}$ member states provide much greater industrial subsidies (known as "state aids") than either Japan or the United States. In the EC, state aids average around 3 percent of GDP, compared to 1 percent in
Japan and 0.5 percent in the United States. ${ }^{181}$ Table 5-13 shows the major subsidies provided by the largest EC member states.

There are many different, sometimes subtle, ways in which governments can help out industries. Simple cash grants are one possibility. Tax relief can be specially tailored. Debt can be written off. Different countries tend to provide subsidies in different ways: Germany uses tax concessions (58 percent of total aid); France provides 26 percent through equity and less than 20 percent through tax concessions; France and the Netherlands provide subsidized energy. Most national subsidies are sector-specific, with relatively little being spent on either R\&D or support for small and medium-sized enterprises ( 5 and 2.6 percent respectively of national subsidies for the period 1981-86) ${ }^{182}$ Steel subsidies, for example, amount, on average, to more than 50 percent of the sector's value added in Ireland, Italy, France, and Britain, while annual coal subsidies are about ECU44,000 per job in France, and more than ECU26,000 in Germany. ${ }^{183}$ There have also been heavy subsidies for sunrise industries such as Airbus and microelectronics.

In the early 1980s, there was some falloff in European subsidies; state aid to manufacturing declined in real terms in 6 of 10 EC counties between 1981 and $1985 .{ }^{184}$ The practice is far from vanishing, however. EC member states must notify the Commission of all proposed state aid, and notifications jumped from 162 in 1984 to 376 in 1988. ${ }^{185}$ With the EC, subsidy patterns diverged during the 1980s, declining in Britain with the election and long duration of Mrs. Thatcher's conservative government, remaining stable in France, increasing slightly in Germany, and rising greatly in Italy. As of 1986, Italy was offering eight times as much state aid in absolute terms as Britain.

Within several member nations, subsidies have become hotly fought political issues, especially in the case of declining industries. The huge British coal strike of the mid-1980s was precisely about state subsidies for pits that lost money, while strikes and violence met French attempts to cut subsidies for steel and coal. There has also been some dawning realization that, even in sunrise industries, pumping money into national champions might not work.

With EC-92, problems with national subsidies multiply. They distort trade among EC countries, in effect working to export unemployment (which is 
Table 5-13-State Aids in the EC, 1981-86

\begin{tabular}{|c|c|c|c|c|}
\hline Overall state aid & Italy & Germany & France & U.K. \\
\hline 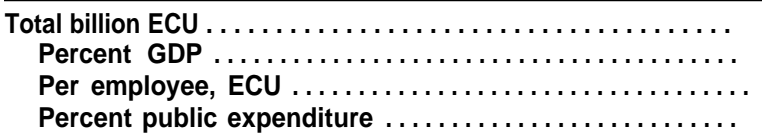 & $\begin{array}{r}27.7 \\
5.7 \\
1,357.0 \\
15.0\end{array}$ & $\begin{array}{r}19.1 \\
2.5 \\
761.0 \\
10.0\end{array}$ & $\begin{array}{r}16.7 \\
2.7 \\
792.0 \\
11.0\end{array}$ & $\begin{array}{r}9.4 \\
1.8 \\
396.0 \\
5.0\end{array}$ \\
\hline 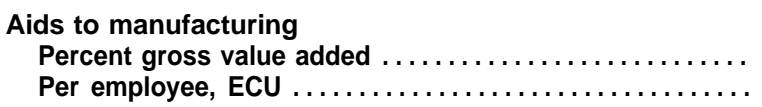 & $\begin{array}{r}16.7 \\
6,226.0\end{array}$ & $\begin{array}{r}3.0 \\
982.0\end{array}$ & $\begin{array}{c}4.9 \\
1,649.0\end{array}$ & $\begin{array}{r}3.8 \\
971.0\end{array}$ \\
\hline $\begin{array}{l}\text { Excluding steel and ship-building } \\
\quad \text { Percent gross value added } \ldots \ldots \ldots \ldots \ldots \ldots \ldots \ldots \ldots \ldots \ldots \ldots \ldots \ldots \ldots \ldots\end{array}$ & $\begin{array}{r}15.8 \\
5,951.0\end{array}$ & $\begin{array}{r}2.9 \\
940.0\end{array}$ & $\begin{array}{r}3.6 \\
1,223.0\end{array}$ & $\begin{array}{r}2.9 \\
757.0\end{array}$ \\
\hline $\begin{array}{l}\text { Aid to steel and ship-building } \\
\text { Steel, percent value added } \ldots \ldots \ldots \ldots \ldots \ldots \ldots \ldots \ldots \ldots \ldots \ldots \ldots \\
\text { Ships, percent value added } \ldots \ldots \ldots \ldots \ldots \ldots \ldots \ldots \ldots\end{array}$ & $\begin{array}{l}71.4 \\
34.2\end{array}$ & $\begin{array}{r}8.6 \\
12.3\end{array}$ & $\begin{array}{l}58.3 \\
56.6\end{array}$ & $\begin{array}{l}57.6 \\
21.6\end{array}$ \\
\hline 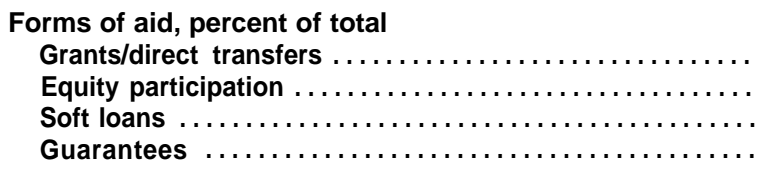 & $\begin{array}{r}79.0 \\
18.0 \\
3.0 \\
0.0\end{array}$ & $\begin{array}{r}95.0 \\
0.0 \\
0.0 \\
5.0\end{array}$ & $\begin{array}{r}24.0 \\
26.0 \\
45.0 \\
5.0\end{array}$ & $\begin{array}{r}71.0 \\
18.0 \\
8.0 \\
1.0\end{array}$ \\
\hline 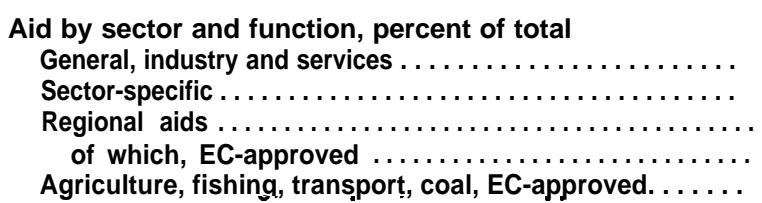 & $\begin{array}{r}32.0 \\
16.0 \\
21.0 \\
5.0 \\
30.0\end{array}$ & $\begin{array}{r}13.0 \\
5.0 \\
18.0 \\
18.0 \\
64.0\end{array}$ & $\begin{array}{c}20.0 \\
20.0 \\
15.0 \\
0.0 \\
56.0\end{array}$ & $\begin{array}{r}16.0 \\
17.0 \\
13.0 \\
11.0 \\
44.0\end{array}$ \\
\hline
\end{tabular}

contrary to the Treaty). And in practice the subsidies can simply cancel each other out, creating distortions between subsidized and nonsubsidized industries without offsetting increases in economic activity. ${ }^{186}$

The fairness doctrine makes subsidies a priority target for EC action. The Treaty empowers the commission to act against subsidies without the need for approval by the Council of Ministers, and Commission decisions are subject to review only by the European Court of Justice. ${ }^{187}$ New subsidies must be reported to the Commission for prior approval, and the Commission is empowered to demand changes in existing aid schemes and to force companies to repay aid that it deems unacceptable..$^{188}$

None of this means that European subsidies are at an end. The EC's own policies accept subsidies for important trans-Europe projects (e.g., Airbus), regional development, economic stabilization, and "such other categories of aid as may be specified by decision of Council acting by a qualified majority on a proposal from the Commission. ", ${ }^{189}$ These exceptions add up to very large loopholes.
It is not yet clear how vigorously the Commission will act to end national subsidies. Enforcement so far has not been strong and countries are still approving various kinds of subsidy; France, for example, recently announced a large new program to build a high-speed train system, which it wishes to subsidize ${ }^{190}$ However, EC action against subsidies has picked up somewhat in recent years. The Commission has acted in two celebrated cases. Renault was forced to return some FF6 billion in subsidies to the French Government and to cut production of cars by 15 percent and trucks by 30 percent. ${ }^{191}$ And in Britain, the Thatcher Government was forced to revoke about half the subsidies given to British Aerospace when it bought the failing Rover auto company. ${ }^{192}$ On the other hand, the Commission has approved subsidies for some $R \& D$ projects that are or might become quite close to the market, such as Dutch support for high definition television (HDTV). ${ }^{193}$ Also, European subsidies are quite a different matter from national ones; they are much more likely to get EC approval. Nor have the large and long-continued subsidies from the four national governments supporting Airbus excited any opposition from the Commission. 
So long as subsidized private companies have to face real competition (as Airbus does from two U.S. firms, Boeing primarily and McDonnell Douglas secondarily) and the subsidies are intelligently applied, state aid may boost a company's competitiveness. (See ch. 8 for an analysis of Airbus subsidies.) However, the lengthy history of European subsidies to national champions, together with protection from outside competitors, strongly suggests that this combination does not work. EC efforts to control national subsidies and limit their duration holds some promise for making European companies tougher competitors in the long run.

State Ownership--Public ownership of manufacturing firms in Europe dates back to the 1930s. Countries first nationalized natural monopolies like electricity or gas. Later, some firms were nationalized because they were seen as strategic, e.g., steel, coal, shipbuilding, and electronics. The British and French both favored this approach. But governments have also nationalized failing firms that they could not politically allow to collapse. Industries that dominate a geographical region have been prime candidates (e.g., French steel). ${ }^{194}$ The state sector is so large in some countries (still, even after a decade of privatization) that any significant improvement in the performance of the sector will have an effect on national competitiveness as a whole.

State ownership in Europe has created few internationally successful fins. It usually implied a domestic monopoly, as state ownership is hard to justify where there are other private domestic companies in the same sector (although there were exceptions like British Airways). Monopoly status and access to the national treasury tended to promote inefficiency.

The conservative governments that came to power in European countries in the past decade or so privatized dozens of companies. But there are limits. Thatcherite ideas about privatizing the British National Health Service have come to nothing. The French Government seems determined to maintain ownership over a number of important manufacturing firms, ${ }^{195}$ although state-owned firms like Pechiney and Rhone-Poulenc have had such serious capital needs that partial privatizations have since become quite common. ${ }^{196}$ Were a deep recession to occur, some form of lemon socialism could return.

While the Treaty specifically states that the EC must be neutral between public and private owner- ship, state aid for government-owned companies is now under attack as it can give these companies an unfair advantage over private sector competitors. ${ }^{197}$ The EC is digging into the behavior of state-owned firms to root out "unfair" practices. For example, the EC's telecommunications directive ends national PTT monopolies over end-user telecommunications equipment, provides for above-board, nondiscriminatory treatment (transparency) in procurement, and requires that PTTs separate their regulatory and commercial roles. This should loosen tight national government control over telecommunications, which has been used to favor domestic suppliers.

The Commission is trying to establish the principle that state-owned companies should behave as commercial companies normally do, by investing on the basis of risks and probable returns and purchasing on the basis of cost and quality. Yet much of the point of state ownership in Europe is to encourage behavior that is not commercial, keeping certain plants open and operating in some ways as a public service. Government subsidies are required to make that possible. The Commission is now seriously questioning some subsidies to nationally owned companies (e.g., the subsidy France proposed for Groupe Bull for 1991).

Perhaps the logic of liberalization and equal treatment under the Treaty means fundamental changes in the long run for public sector companies; it is even possible their raison d'etre will disappear. That time has not yet come. Meanwhile, European state-owned firms have some advantages in that they are subsidized, but the disadvantages of insulation from genuine competition in the commercial world is a handicap of considerably greater weight.

1 The Commission is the executive arm and civil service of the European Community.

2 General Agreement on Tariffs and Trade.

3 Not necessarily in the EC. The EC and the European Free Trade Association (EFTA) countries have a free trade arrangement under which tariffs are set at zero and there are no quotas. EFTA's members are Austria Finland, Iceland, Liechtenstein, Norway, Sweden, and Switzerland.

4 The problem of standards seems to have been reduced over the past 2 years, although it remains high among the concerns of U.S. manufacturers.

5 Paulo Cecchini, with Michel Catinat and Alexis Jacquemin, The European Challenge: 1992: The Benefits of a Single Market (Aldershot, UK: Wildwood House Press, 1988), p. 27.

6 Commission of the European Communities, Completing the Internal Market: White Paper from the Commission to the European Council, COM (85) 310 final (Brussels, Belgium: 1985). 
7 Article 30 prohibits "quantitative restrictions on imports and all measures having equivalent effects."

8 In Denmark, for example, there are luxury taxes on autos that range from 100 percent of the value upwards.

9 France, Italy, and the other Mediterranean countries have been given a transition period for implementation, although all will have to comply before 1993.

10 Stephen Woolcock, Michael Hodges, and Kristin Schreiber, Britain, Germany, and 1992, the Limits of Deregulation (New York, NY: The Royal Institute of International Affairs/The Council on Foreign Relations, 1991), ch. 6.

11 See also Commission Regulation @EC) 1612/68 Article 1.

12 For at least for 3 months, citizens may reside in another EC country while looking for work.

13 William Drozdiak, "As Europe '92 Nears, Rift on Aid Widens," The Washington Post, Apr. 21, 1991, p. H1. At the same time, however, another Japanese electronics giant, NEC, was reported to be angling for a 5 or 10 percent share of Groupe Bull, and the French Government was considering the proposal. Fujitsu began its buyout of ICL with a similar minority share. Alan Cane, William Dawkins, and Stefan Wagstyl, "NEC in Talks on Groupe Bull Stake," Financial Times, Apr. 24, 1991, p. 1.

14 Richard Baldwin, "The Growth Effects of 1992," Economic Policy, October 1989, pp. 248-281. Baldwin estimates that EC-92 might add between 0.2 and 0.9 percentage points to the EC's long-term growth rate, rather than simply conferring a one-time rise.

15 Merton J. Peck, "Industrial Organization and the Gain from Europe 1992," in William C. Brainard and George L. Perry (eds.) Brookings Papers on Economic Activity 2 (Washington, DC: The Brookings Institution 1989).

16 Six of the world's top 10 chemical companies (ranked by chemical sales) are EC fins, 1 is Swiss, and 3 are American. Chemical sales by EC firms in 1989 were $\$ 312$ billion, and by U.S. firms, $\$ 274$ billion. U.S. International Trade Commission, The Effects of Greater Economic Integration Within the European Community on the United States: Second Follow-Up Report, US ITC Publication 2318 (Washingto\% DC: September, 1990), pp. 22-23 ff.

17 Ibid., pp. 22-27.

18 There are some complicating factors; for example, deregulation, which EC-92 favors, could create tough price competition among European airlines and cause them to postpone purchases of new aircraft (which occurred with deregulation in the United States).

19 Kenneth Flamm, "Semiconductors," in Gary C. Hufbauer(ed.) Europe 1992: An American Perspective (Washington, DC: The Brookings Institution 1990), p. 244,

20 Commission Regulation (EEC) 288/89, February 1989.

21 Michael Borrus, director, Berkeley Roundtable on International Economics, personal communication.

22 U.S. International Trade Commission, The Effects of Greater Economic Integration Within the European Community on the United States, US ITC Publication 2204 (Washington, DC: The Commission July 1989), pp. 4-14.

23 Aviva Friedman, "EC Takes Giant Step to Open Public Procurement Markets," Atlantic Trade Reporter, Mar. 1, 1990, p. 1.

24 Ibid., pp. 4-7. These estimates apply to all U.S. firms, whether exporters or located in the EC.

25 U.S. International Trade Commission, op. cit. (July 1989), pp. 4-12; CEC, Public Procurement and Construction-Toward an Integrated Market, CB-PP-88-002-EN-C (Luxembourg: Office for Official Publications of the European Communities, 1989), p. 15.

26 A major thrust of EC-92 is to open up these public purchases to all EC fins, not just national champions.
27 EC Commission, Eighth Annual Report on the Community's Anti-Dumping and Anti-Subsidy Activities (Brussels: The Commission 1989), Table 1; EC Commission, Ninth Annual Report on the Community's Anti-Dumping and Anti-Subsidy Activities (Brussels: The Commis sion, 1990), Table 1.

28 Of 149 actions initiated in the 4 years 1987-90, 46wereagainst Japan, Korea, Hong Kong, and Taiwan; 3 were against the United States. (Ibid., annexes.)

29 Statement of Michael C. Maibach to Subcommittee of the House Committee on Foreign Affairs, Mar. 23, 1989, cited in U.S. International Trade Commission, 1992: The Effects of Greater Economic Integration within the European Community on the United States: First Follow-up Report (Washington DC: March 1990), pp. 14-18, and Michael C. Maibach, personal communication. See also Kenneth Flamm, op. cit., p. 276, footnote 77.

30 coremission Regulation (EEC) 2071/89 of July 11, 1989.

31 For example, the essential requirements contained in the l'by Safety Directive state that toys "must not jeopardize the safety or health of the user, they must not strangle or suffocate children, they must not be highly inflammable, they may not contain excessive quantities of dangerous chemicals or radioactive elements, they must be properly insulated against electric shock and they should ensure sufficient hygiene and cleanliness to prevent conlamination, infection, and sickness. " Diane Good, "The Implications of 1992 for U.S. Manufacturers: Products (product Standards and Product Liability) and Environmental Law," International Quarterly, vol. 2, July 1990, p. 109.

32 This principle comes from the historic Cassis de Dijon case decided by the European Court of Justice in 1979; the decision stated that French cassis could not be barred from sale in West Germany merely because it was manufactured to non-German specifications. CEC, Europe Without Frontiers - Completing the Internal Market, Periodical 3/1988 (Luxembourg: Office for Official Publications of the European Communities, 1988).

33 Under EN 45000 standards for lab practices conforming to international standards (which the United States accepts).

34 The European Committee for Standardization (CEN), the European Committee for Electrotechnical Standardization (CENELEC), and the European Telecommunications Standards Institute (ETSI). CEN and CENELEC are private umbrella organizations, comprising standards oranizations of the various members. ETSI membership is made up of manufacturers, administrators, and users.

35 U.S. International Trade Commission, op. cit. (September 1990), pp. 4-21 to 4-14; U.S. International Trade $\mathrm{Co}_{\text {mmission, 1992: }}$ The Effects of Greater Economic Integration within the European Community on the United States: Third Follow-up Report (Washington, DC: March 1991), pp. 4-11 to 4-14.

36 Ibid.

37 EC Office of Press and Public Affairs, "U.S.-EC Joint Communique Resulting from their Meeting on Standards and Conformity Assessment, June 21, 1991." No. 20/91, June 24, 1991.

38 U.S. International Trade Commission, op. cit. (March 1991), citing EC Commission, Green Paper on the Development of European Standardization: Action for Faster Technological Integration in Europe, COM (90) 456 final, Oct. 8, 1990, pp. 31, 33.

39 This was a draft policy in ETSI, governing telecommunications standards, in the spring of 1991 .

40 Flamm, op. cit., p. 268, table 5-4.

41 By Fujitsu, Mitsubishi, and Hitachi. "The Last Hurrah for European High Tech?' Business Week, Apr. 29, 1991, p. 44.

42 "Spare the Rod and Spoil the Child," The Economist, Apr. 20, 1991.

43 Ibid.

44 See Drozdiak, op. cit. 
45 For example, the EC trade deficit with the United States in computers and office machines was $\$ 8.5$ billion in 1989 (table 5-2). For a concise history and analysis of government support of the computer industry in the United States, Europe, and Japan, see Kenneth Flamm, Targeting the Computer: Government Support and International Competition (Washington, DC: The Brookings Institution, 1987). Trade protection and government procurement were even more prominent in Japan than in Europe for three decades, beginning in the 1960s, but the Japanese were far more insistent on maintaining competition among domestic firms; see ch. 6 .

46 Flamm, "Semiconductors," op. cit., p. 232.

47 "National Champions Become Laggards," Financial Times, Apr. 29, 1991.

48 This does not exhaust the list of actions taken against foreign, especially Japanese, electronics producers. France (acting for itself, not the EC) imposed the ingenious requirement in 1982 that all imported VCRs should go through customs at a small, lightly staffed office in Poitiers, located in the middle of the country; this tactic made processing quite time-consuming. EC-wide import restrictions were adopted in 1983, when the Japanese Government promised voluntary export restraints on VCRs for 3 years.

49 Commission of the European Communities, Eighth Annual Report and Ninth Annual Report, op. cit. (1990 and 1991), table Annex $\mathrm{F}$ and $\mathrm{G}$, respectively.

50 Organized EC action against Japanese producers of office equipment began in 1984, when the Commuoity set up a committee to investigate electronic typewriters; committees for photocopiers and printers followed in 1985 and 1987. Dumping levies were fixed for typewriters in 1985, for copiers in 1987 and for printers in 1988. The Long-Term Credit Bank of Japan, Ltd., 1992 and Euro-Japanese Economic Relations (Tokyo: The Bank, 1990), pp. 7-10.

51 Ibid. and Commission of the European Communities, Eighth Annual Report and Ninth Annual Report, op. cit., several annexes.

52 This pattern is described in Ivo Van Bael, "EECAnti-Dumping Law and Procedure Revisited," Journal of World Trade, April 1990, pp. 5-10.

53 The dumping margin is the difference between the price charged by the importer and some "fair" price, either that charged by the importer in some other market or a price calculated by trade authorities. The margin can be exaggerated in several ways, including the attribution of artificially high selling, administration, and general expenses to "normal" imports, and the addition of an unrealistic profit margin.

54 Van Bael, op. cit.; also, Brian Hindley, "Dumping and the Far East Trade of the European Community," World Economy, vol. 11, No. 4,1988, pp. 445 ff.; Christopher Norall, "New Trends in Anti-Dumping Practice in Brussels," World Economy, vol. 9, No. 1, 1986, pp. 97 ff.

55 Jean-Francois Bellis, "The EC Antidumping System," in John Jackson and Edwin Vermulst (eds.), Antidumping Law and Practice: A Comparative Study (Ann Arbor, Ml: University of Michigan Press, 1989), pp. 60-61,63-64.

56 Flamm, op. cit., p. 279.

57 The basic EC antidumping provisions are in Regulation $2423 / 88$.

58 The ruling was on narrow grounds, holding that antidumping duties levied on parts and materials at the point of sale within Europe amounted to an internal tax, not a duty, and therefore violated GATT's national treatment provisions. GATT Document L/6657, Mar. 22, 1990.

59 Long-Term Credit Bank, op. cit.

60 Ibid., p. 9.

61 The Economist, Jan. 14, 1990. "Turn of the Screw," The Economist, vol. 318, No. 7690, Jan. 19, 1991.

62 "Four Manufacturers Starting Pattern Printing Line in 1992," Nikkei Microdevices, July 1990, pp. 44-54. Translated in JPRS Report:
Science and Technology Japan, "Rush to Secure EC Market," Mar. 8, 1991.

63 Analog Devices, AT\& Digital Equipment, Hughes, IBM, IT\&T, LSI Logic, Motorola, and Texas Instruments all had wafer fabrication plants inEC countries in 1989. - op. cit. (1990), p. 268.

64 Maibach, op. cit. (1989).

65 See "Statement by Mr. Nakao, Minister of International Trade and Industry," mimeo, Tokyo, July 31, 1991; "Statement by Mr. Andriessen," Vice-President of the CEC, mimeo, Brussels, July 31, 1991; and Martin DuBois and Mark M. Nelson, "Tokyo, EC Reach Agreement on Sales of Japanese Cars," The Asian Wall Street Journal Weekly, Aug. 5, 1991, p. 8.

66 Much of the material in the section on the auto industry is drown directly from James P. Womack and Daniel T. Jones, "European Automotive Policy: Past, Present, and Future," contractor report to the Office of Technology Assessment, February 1991. Additional sources include Alastair Smith and Anthony J. Venables, "Automobiles," in Hufbauer, op. cit.; the Commission of the European Community, A Single Community Motor Vehicle Market, December 1989; U.S. International Trade Commission, op. cit. (July 1989 and July 1990); James P. Womack, Daniel T. Jones, and Daniel Roos, The Machine that Changed the World (New York, NY: Rawson Associates/Mac 1990); OTA interviews with representatives of the motor vehicle industry in the United States and Europe.

67 According to Womack, Jones, and Roos, the “. . . 'free trade' countries, led by Germany and Sweden, have periodically indicated that their continued support of an open market for Japanese cars is predicated on 'appropriate' behavior by the Japanese firms, meaning in practice that their market share should only grow very slowly and without serious threat to the home country producers." Ibid., p. 288.

68 Womack, Jones, and Roos, op. cit.

69 Defined as the number of manufacturing defects in cars reaching customers, not as durability or luxury.

70 U. S. International Trade Commission, op. cit., March 1990, pp. 11-15.

71 DuBois and Nelson, op. cit.

72 EC sales of Japanese cars were about 12 million in 1990. The EC-Japan agreement is based on estimated sales in 1999 of 15.1 million units, meaning growth of nearly 2.6 percent per year. Japanese sales of 2.4 million in 1999 would amount to 16 percent of that market.

73 Richard Johnson, "EC Limit on Japanese Transplants," Automotive News, May 6, 1991; and DuBois and Nelson, op. cit.

74 The official explanation given for the British local content requirements was that other European nations with Japanese quotas (notably Italy and France) would count British assembled vehicles against their own Japanese import quotas unless the vehicles had a high level of European content. Another likely motive was to protect British components manufacturers. Womack and Jones, op. cit. (1991).

75 The figure for local content in Japanese cars made in America is uncertain but is probably about 50 percent, according to James P. Womack, automotive industry consultant and former research director of MIT's International Motor Vehicles Program.

76 These figures include passenger cars only, not trucks. Japanese light trucks were also gaining in U.S. market share until 1987, when the U.S. tariff on light trucks was hiked to 25 percent (passenger cars carry a 2.5 percent tariff). Data provided by James P. Womack, based on Ward's Automotive Reports, various issues.

77 Honda has already announced plans to export about 6,000 Accord station wagons from Ohio to Europe. "U.S. Honda To Ship Wagons to Japan," The New York Times, Jan. 8, 1991, p. D4.

78 Womack and Jones, op. cit., p. 34.

79 Deborah Smith, International Trade Officer (EC), Small Business Admínilitration, personal communication Jan. 13, 1990. 
80 Wayne Sandholtz, "New Europe, New Telecommunications," paper presented at the annual meeting of the American Political Science Association, San Francisco, CA, Aug. 30-Sept. 2, 1990.

81 An ECU, European Currency Unit, is now worth about $\$ 1.18$. The ECU 5.7 billion for Framework programs is all public money; it is generally matched by the projects' participants, except for certain nonprofit organizations such as universities, which can receive up to 100 percent of project costs from the European Community. EUREKA is primarily funded by the private sector, less than 10 percent of its funding is public money. A rough calculation, assuming that 10 percent of EUREKA costs are public and that both programs spend about the same amount of money each year, yields annual public funding of cooperative research amounting to ECU 1.6 billion, or about $\$ 1.9$ billion. Source of funding numbers is U.S. International Trade Commission, 1992: The Effects of Greater Economic Integration Within the European Community on the United States: Second Followup Report, US ITC Publication No 332-267 (Washington, DC: U.S. International Trade Commission, September 1990) pp. 16-6 and 16-10.

82 For example, the Commission states ". . the [European] Community's influence has grown to such an extent that it affects almost all areas of business and society, so that it is now obliged to grapple with the problems of securing and maintaining our living conditions. Viewed against this background, science and research have taken on a key role which the Community cannot ignore. . . . The main aim is to maintain the international competitiveness of European industry in high technology sectors, in the face of competition in global markets, above all from the USA and Japan" (emphasis added). See Commission on the European Communities, EC Research Funding: A Guide for Applicants (Brussels, Belgium: 1990), p. 3.

83 Office for Official Publications of the European Communities, Research and Technological Development Policy, Luxembourg, 1988, p. 8. Some technologies are dominated by two countries together, which accounts for the figures adding to more than the total. This was cited in U.S. International Trade Commission, op. cit. (September 1990), pp. 16-23.

84 Japanese patents were most likely to be granted (in descending order of importance) in photocopying, dynamic information storage or retrieval, dynamic magnetic information storage or retrieval, photography, radiation imagery chemistry, recorders, typewriting machines, static information storage and retrieval, pictorial communication and television, and motor vehicles. Germany's patents were mainly in chemistry, materials, and printing; they included fertilizers, organic compounds of different types, ammunition and explosives, solid material comminution or disintegration, plastic article or earthenware shaping or treating, synthetic resins or natural rubbers, and, finally, brakes. France's list is more diverse: induced nuclear reactions, systems, and elements; clutches and power-stop control; ammunition and explosives; pulse or digital communications; rotary kinetic fluid motors or pumps; brakes; pipe joints or couplings; organic compounds; aeronautics; and electricity, electrical systems, and devices. National Science Foundation Science and Engineering Indicators-1989 (Washington, DC: U.S.Government Printing Office, 1989), pp. 358-360.

85 Commission of the European Communities, Evaluation of the First BRITE Programme [1985-1988], EUR 11782 EN (Brussels, Belgium: July 1988), p. 15.

86 With the ECU worth about $\$ 1.18$, Framework funding was worth about $\$ 6.7$ billion over the period 1987-91.

87 This does not count projects like DRIVE (Dedicated Road Infrastructure for Vehicle Safety in Europe) and BRITE/EURAM (BRITE is Basic Research in Industrial Technologies for Europe, and EURAM is European Research in Advanced Materials), which fund several high-technology projects. It also does not count projects aimed mostly at improving science or learning.

88 Tables 5-2 and 5-8 show the breakdown of funding and project descriptions of the Second Framework Program, scheduled to last from 1987 to 1991. Some of the preexisting projects from the first Framework carried over, and the Third Framework Program, approved in April 1990 and lasting through 1994, overlaps the second program. The third program was approved while the second was still in effect because rapid changes in technology necessitated an increase in funding (ECU 400 million) and a shift of priorities. The tables show programs of the Second Framework program rather than the third because more detail on individual projects is available for the second program. The third program has three areas of emphasis (which encompass the eight of the second program) and reallocation of funds to emphasize new areas such as microelectronics and networks connecting information systems. Source: U.S. International Trade Commission op. cit., pp. 16-18.

89 U.S. International Trade Commission, 1992: The Effects of Greater Economic Integration Within the European Community on the United States: Second Followup Report, USITC Publication 2318 (Washington DC: U.S. Government Printing Office, September 1990), pp. 16-10.

90 Commission of the European Communities, EC Research Funding, op. cit., p. 20.

91 EUREKA Secretariat, EUREKA: Together for the Future (Brussels, Belgium: EUREKA Secretariat, 1989), passim.

92 J.F. Blackburn, " Overview of European Technology in Computers, Telecommunications, and Electronics," ESN Information Bulletin, ESNIB 90-04, 1990, p. 24.

93 Siemens' decision to license Toshiba's technology initially concerned both Philips and the German Government. Philips would have preferred developing the technology in Europe even if that meant delaying a successful completion of the project, while the West German technology minister was reportedly so angry with Siemens that he considered withdrawing government backing of the Mega project. Robert S. Williams, "JESSI," Harvard Business School Case 9-389135, Rev. May 9, 1989.

94 Planungsgruppe JESSI, "JESSI Program: An Initiative of European Institutions and Companies, Results of the Planning Phase," Itzehoe, Feb. 1, 1989.

95 Flamm, "Semiconductors," op. cit., pp. 247, 262. The Mega project was a cooperative project of Philips and Siemens, along with the governments of the Netherlands and West Germany, to improve semiconductor manufacturing technology. The Mega project aimed at developing technologies to manufacture 4-megabit D RAMs (Siemens) and 1-megabit SRAMs (Philips). Flamm's statement also accords with the experience of Siemens A.G. An executive of the company stated that Europe must be competitive in wafer steppers and lithography technology, which he regarded as strategic technologies, because the Japanese do not sell the latest technology or the first machines to Europeans. Hartwig Bierhenke, Corporate Research and Development Siemens A.G., interview with OTA staff, Oct. 10, 1990.

96 Claire Shearman, "Science and Technology in Europe," mimeo, pp. 3-21.

97 OECD figures quoted in The Economist, "European Community: A Power in Its Own Right," July 7, 1990, p. 6.

98 Wayne Sandholtz, "New Europe, New Telecommunications," paper prepared for the Annual Meeting of the American Political Science Association, San Francisco, CA, Aug. 30-Sept. 2, 1990.

99 Ibid., p. 12.

100 Commission of the European Communities, Research and Technological Development for Europe (Brussels, Belgium: December 1987), p. 3.

101 See, for example, Sylvia Ostry, "Beyond the Border: The New International Policy Arena," paper presented at the OECD Forum for the Future, Paris, France, Oct. 30, 1990, and Shearman, op. cit., p. 5-1.

102 Gallium-Indium-Arsenide, project 2035.

103 Interview with Fred A. Meyers, Senior Manager, GaAs IC Research Department, Plessey Research Carswell Ltd., with Todd Watkins, Harvard University: interview no. 4, pp. 3-4. 
104 "III-Evaluation of the BRITE Programmed," mimeo, p. 17.

105 Jens Moritz, Corporate R\&D, Joint R\&D-Projects and Research Funding, Siemens A.G., interview with OTA staff, Oct. 10, 1990.

106 Commission of the European Communities, First Report on the State of Science and Technology in Europe, mimeo, no date.

107 Commission of the European Communities, EC Research Funding, op. cit., p. 40. There are 10 criteria for selection of Framework projects listed in this document; one is "cross-border character." The others are compliance with the aims of the program, scientific and technical quality and originality, innovative potential, industrial relevance and influence on competitiveness, feasibility of implementation, scientific qualifications of the applicant, pre-competitive character, amount of EC funding, and composition of the partnership.

108 According to Flamm, “[A]s entire proprietary designs for electronic systems are transferred onto a single chip, retaining control over that design becomes increasingly intertwined with finding chip suppliers who will not appropriate key elements and use them to manufacture competitive product of their own. Access to a state-of-theart chip supply, which combines leading-edge manufacturing technology with reasonable security for key elements of proprietary systems designs, has become a strategic issue throughout the global electronics industry. " Flamm, "Semiconductors," op. cit., p. 229.

109 Ibid., pp. 228-229.

110 Commission of the European Communities, "Communication From the Commission to the Council and the Parliament Concerning a Review To Assess the Performance and Results of the Programme ESPRIT," Brussels, Belgium, Sept. 7, 1989 (mimeo), p. 13.

111 Ibid., p. 22.

112 III-Evaluation of The BRITE Programme, op. cit., p. 17.

113 JESSI Program, An Initiative of European Institutions and Companies: Results of the Planning Phase," Itzehoe, Feb. 1,1989, p. 22.

114 Commission of the European Communities, RACE' 90 : Research and Development in Advanced Communications Technologies in Europe, op. cit., p. 1.

115 Commission on the European Communities, Programme Management Audit of RACE, DRIVE, DELTA, and AIM: Report of an External Audit Team (Brussels, Belgium: October 1989). On page A3-2, the team reports that 'RACE participants are mostly content; their main concerns are the monthly reporting and the concertation meetings.' Results of this audit should be used very cautiously, however, because it is based on a survey whose response rate was low. The audit team sent out 1,650 questionnaires to participants in RACE, DRIVE, DELTA, and AIM, and based its assessment of the management of these programs on 348 returned questionnaires - a 21-percent response rate. The management audit document does not say what procedures were used to obtain responses, or if they were all entirely voluntary. If the latter, then it is possible that these response were atypical.

116 Comrnissionofthe EuropeanCommunities, "Communication from the Commission," op. cit., p. 14 .

117 Ibid., p. 16.

118 See, for example, Martinfransman, The Market and Beyond: Cooperation and Competition in Information Technology Development in the Japanese System (Cambridge, U.K.: Cambridge University Press, 1990).

119 Daniel I. Okimoto, Between MITI and the Market: Japanese Industrial Policy for High Technology (Stanford, CA: Stanford University Press, 1989), p. 71.

120 III-Evaluation of the BRITE Programme, op. cit., pp. 21-22.

121 AEG, Bull, CGE, GEC, ICL, Nixdorf, Olivetti, Philips, Plessey, Siemens, STET, Thomson.

122 Commission of the European Communities, "Communication from the Commission," op. cit., p. 11.
123 Many European writers view U.S. universities as making material contributions to the nation's technology base, as well as to basic science; and they view Japanese universities as effective training grounds for professionals.

124 Commission of the European Communities, First Report on the State of Science and Technology in Europe (Brussels, Belgium: mimeo, no date), pp. 92-93.

125 Mary Tyszkiewicz, "Research Collaboration in the European Community: The Lessons for the United States," mimeo, April 1990.

126 Commission of the European Communities, Evaluation of the First BRITE Programme, op. cit., p. 25.

127 Commission of the European Communities, First Report, op. cit., pp. 91,93.

128 Commission of the European Communities, "Communication from the Commission," op. cit., p. 20.

129 Commission of the European Communities, Evaluation of the First BRTEE Programme, op. cit., p. 25.

130 Commission on the European Communities, EC Research Funding, op. cit., p. 25.

131 Commission of European Communities, Evaluation of the First BRITE Programme, op. cit., p. 12.

132 Harry Beckers, Shell, Group Research Coordinator, and Chairman, IRDAC, interview with OTA staff, Oct. 2, 1990.

133 Hartwig Bierhenke, Corporate Research and Development Siemens AG, interview with OTA staff, Oct. 10, 1990. There may not be as much of an inconsistency in the perceptions of Bierhenke and Becker as it appears. JESSI is a EUREKA project, and EUREKA is not an EC program and therefore not constrained by precompetitivity. However, through ESPRIT, the EC is putting money into JESSI; 30 percent of the funding of the microelectronics portion of IESSI comes from ESPRIT The applications people in JESSI are not very satisfied with ESPRIT, so while the overlap between the two programs is growing, so is the tension. See Henk G. Boddendijk, ManagingDirector, Philips International B.V., interview with OTA staff, Oct. 12, 1990.

134 J.J. Kaptein, Former President, Oce, and member of the EUREKA advisory board to the Minister of Economic Affairs of the Netherlands, interview with Todd Watkins, Harvard University, summer 1990.

135 For example, Jens Moritz of Siemensbelieves that Framework projects should go no closer to the market than they are. Jens Moritz, Corporate R\&D, Siemens AG, interview with OTA staff, Oct. 10, 1990.

136 J.F. Blackburn, "Overview of European Technology in Computers, Telecommunications, and Electronics," ESN Information Bulletin, April 1990, p. 12.

137 U.S. Congress, Office of Technology Assessment, Making Things Better: Competing in Manufacturing, OTA-ITE-443 (Washington, DC: U.S. Government Printing Office, February 1990), pp. 161-167.

138 An SME is anenterprise thatemploys 5000rfewerpeople, has an annual net turnover of less than ECU 38 million, and has not more than a third of its ownership held by a parent organization or a financial institution. CEC, EC Research Funding, op. cit., p. 14.

139 Commission of the European Communities, "Communication From the Commission," op. cit., p. 12. The report also notes that the share of the Big Twelve dropped when Spain and Portugal joined the community.

140 Commission of the European Communities, Research and Development in Advance Communications Technologies in Europe: RACE '90 (Brussels, Belgium: March 1990), p. 93.

141 Commission of the European Communities, Evaluation of the First BRITE Programme, op. cit., pp. 22-23.

142 SPRINT is the Strategic Programme for Innovation and 
Technology Transfer. Its funding in the Second Framework Program was ECU 90 million, and its mission is to promote the dissemination of innovation and new technology. Commission of the European Communities, EC Research Funding, op. cit., p. 138.

143 Ibid., p. 24.

144 Jean-Jacques Duby, Group Director, Science and Technology, IBM Europe; interviews with OTA staff, Oct. 8, 1990.

145 W.A. Ledeboer, European Affairs Coordination Manager, Corporate Product Development Coordination Philips, interview with OTA staff, Oct. 12, 1990.

146 Jean-Jacques Duby, interviews with OTA staff, Oct. 8, 1990 and Nov. 2, 1990.

147 One participant from a prominent American company with substantial presence in Europe added another caveat to these-a low profile.

148 One source states that Japanese firms have been rigorously excluded. See Charles Smith and Tony Major, 'The Stakes Rise,' Far Eastern Economic Review, Aug. 12, 1990, pp. 46-47.

149 Jean-Jacques Duby, interview with OTA staff, Nov. 2, 1990.

150 Mary Tyszkiewicz, op. cit., p. 16.

151 Other projects related to standards include an effort to setup a network of public and private research centers across Europe using open systems interconnection (0S1, which is not based on the characteristics of the products of a single manufacturer) as a basis for communication and a project that studies the feasibility of digital audio broadcasting. EUREKA: Together for the Future, 1989 Progress Report, p. 8.

152 See the discussion of standards earlier in this chapter.

153 It is worth bearing in mind that existing evaluations are not robust. Both the RACE and BRITE evaluations are based on limited sampling. The evaluation for RACE, DRIVE, DELTA, and AIM programs together was based on results of 348 questionnaires returned by participants, out of a total of about 1,650 sent, for a 21-percent response rate. BRITE was evaluated on the basis of 177 questionnaires out of 450 sent, 9 plenary meetings, and over 100 interviews with senior officials of national ministries, industrial managers, leaders of projects not selected for inclusion in BRITE, and academics. Among some of the statistical problems of the BRITE survey are the following: the criteria for selecting interviewees were not explicitly identified; the mail survey had no way to know which of the 174 projects were represented in the survey response; there was no analysis of nonresponse bias; the attributes of the sample were not compared with those of the population; and industrial organizations were underrepresented and academic and research institutions overrepresented. The ESPRIT evaluation was based on 949 questionnairee responses and meetings that included input from 210 participant organizations-a significantly higher number than R4CE or BRITE, but there is no indication in the evaluation document of what the response rate was. This caveat is in no way intended to question the sincerity of the evaluators or of the EC in conducting the evaluations, but without more attention to the design of the evaluation surveys it is hard to know what biases are included in the survey. OTA staff noticed that, with the partial exception of the BRITE evaluation, all the evaluations mentioned above are more positive in tone and contain fewer criticisms of the programs than did staff interviews with representatives of companies and organizations participating in them. OTA interviews have no statistical validity; but there was no attempt to select interviewees based on their opinions of Framework projects.

154 Commission of the European Communities, "Communication from the Commission," op. cit., p. 20.

155 Outfried Voigt, Executive Director, and Wolfram Rath, Siemens AG, Power Generation Group, interview with Todd Watkins, Harvard Business School.

156 Shearman, op. cit., p. 9-6.

157 Roger Woolnough, "Breakthrough in Esprit's Deep UV
Project," Electronic Engineering Times, Dec. 3, 1990, p. 24.

158 Project P 1085, "Development and Application of Low Cost High Performance Multiprocessor Machine."

159 Blackburn, op. cit., p. 13.

160 Guy de Jonquieres, "ESPRIT, JESSI Come Under Attack," New Technology Week, Nov. 5, 1990.

161 Commission of the European Communities, "Evaluation of the First BRITE Programme," op. cit.

162 Boddendijk, op. cit.

163 "JESSI, Sematech Forge First Link," Electronic Engineering Times, Dec. 3, 1990, p. 2. This first project is an assessment of how European and American integrated circuit manufacturing stacks up against world standards; the two projects are expected to sign a cooperative agreement on development of semiconductor production equipment in the near future.

164 Commission of the European Communities, "Communication from the Commission" op. cit., pp. 7-9.

165 Roger Woolnough, "ES2: Still a Unique ASIC Player," Electronic Engineering Times, Sept. 10, 1990.

166 Commission of the European Communities, "Communication From the Commission," op. cit., pp. 14, 15,21,31.

167 For some insight on the direction EC competition policy may take, see Alexis Jacquemin, Pierre Buigues, and Fabienne Ilzkovits, "Horizontal Mergers and Competition Policy in the European Community," European Economy, No. 40, May 1989.

168 Sir Leon Brittan, "1992: Priorities in Competition Policy," European Access, Apr. 2, 1989, p. 20.

169 In principle all proposed ties between competitors must be reported to the EC, including joint ventures and strategic alliances. In practice, the Coremission cannot possibly handle that much information and will probably limit its demands.

170 See WoodPulp case, December 1988, described in Douglas E. Rosenthal, "Competition Policy," Gary Clyde Hufbauer, op. cit., p. 325 .

171 Guy de Jonquieres, "EC To Exert New Powers," Financial Times, Oct. 18, 1990.

172 Ibid.

173 Reported inEurope 1992 Law andStrategy, vol.1, No. 6, June 1990, p. 7.

174 Jacquemin et al., op. cit.

175 Ibid., p. 42 ,

176 Translink International, European Deal Review, Fourth Quarter, 1989 , p. 5 .

177 Purchases in France were 6.3 billion pounds, compared to 6.1 billion pounds in the more traditionally liberal United Kingdom.

178 CEC, quoted in Michael R.Calabrese, "Merger Law Develops," Europe 1992: Law and Strategy, vol.1, No.6, June 1990, p. 3.

179 Quoted in Nicholas Colchester and David Buchan, Europower (London: Economist Books, Random House, 1990), pp. 145-146.

180 RobertFord and Wim Suyker, "Industrial Subsidies in OECD Economies," OECD department of Economics and Statistics, Working Paper No. 74. OECD Paris, January 1990; CEC, First and Second. Brussels, 1989 and 1990

181 The ECarguesthatmost U.S. support for industry is concealed within the defense budget, making the comparison unequal.

182 Commission of the European Communities, First Report on State Aids, Luxembourg, 1989.

183 Commission of the European Communities, Survey, op. cit., p. 17.

184 EC, Subsidies, op. cit., table IVA, p. 14. 
185 Niall O'Neill, J.M. Didier \& Associates, "StateAids: TheLast Frontier?" 1992: The External Impact of European Unification, vol. 2, No. 10, Aug. 10, 1990 p. 9.

186 Commission of the European Communities, Survey, op. cit., p. 2.

187 Articles 92-94.

188 For a concise description, see David A. Deacon, "Current State Aid Policy in the EC and the Implication of 1992," in Ronald Gerritse (cd.), Producer Subsidies (London: Pinter, 1990).

189 Treaty of Rome, Article 93 (3)d.

190 France plans to spend about $\$ 33.5$ billion on 2,175 miles of high speed network. Atlantic Trade Reporter, June 21, 1990, p. 7. As noted earlier, France has also proposed large new subsidies for its state-owned computer company, Groupe Bull.

191 "France, EC Reach Compromise on Renault Subsidies," 1992: The External Impact of European Unification, vol. 2, No. 5, June 1, 1990, p. 2; Europe 1992 Law and Strategy, vol. 1, No. 6, June 1990, p. 5. The CEC compromised from its original position which demanded FF12 billion, but France also promised to provide no further subsidies in 1990, and to implement its promise to remove Renault's regie (state-owned) status, which effectively protected it from takeover.

192 Colchester and Buchan, op. cit., p. 151.

193 The Dutch support, ECU23.6 million for Philips, was specifically approved under this exception. Europe 1992: Law and Strategy, vol. 1, No. 6, June 1990, p. 5.
194 Politically, the pressure to nationalize came in Britain mainly from the Labour Party and trade unions. In France, it came partly as workers coerced the government through crippling strikes and violence. In Italy, there was pressure from trade unions and the Communist Party (as in France), but the dominant Christian Democratic Party also benefited from the enormous possibilities for political patronage that nationalization offered. Even Germany has a surprisingly large nationalized sector. By the time nationalization peaked, governments owned large manufacturing concerns in every major European country.

195 Mitterrand formalized this approach in his 1988 election manifesto, calling for a policy stance of neither more nationalization nor more privatization.

196 George Graham, "Companies Learn to Live Within Bounds," Financial Times, Sept. 6, 1990. From September 1988 to September 1990, public sector firms had received FF183.4 billion in fresh capital: FF13.8 billion in cash from the state, FF21.1 billion in state write-offs, FF34.4 billion from the financial markets, and FF85.7 billion from reinvested profits.

197 Sir Leon Brittan, the EC Commissioner for Competition Policy, argues that state-owned firms should be funded on commercial terms, not dipping into government coffers through soft loans or subsidies. See "State Aid Policy and the Publicly Owned Companies: Are There Limits to What The State Can Do?" address to the Conseil de la Concurrence, Mar. 9, 1990; "Developments in EC policy towards public companies," address to the Confindustria Conference, Sept. 22, 1990. 
Chapter 6

\section{Japanese Industrial Pol i cy: The Postwar Record and the Case of Supercomputers}




\section{CONTENTS}

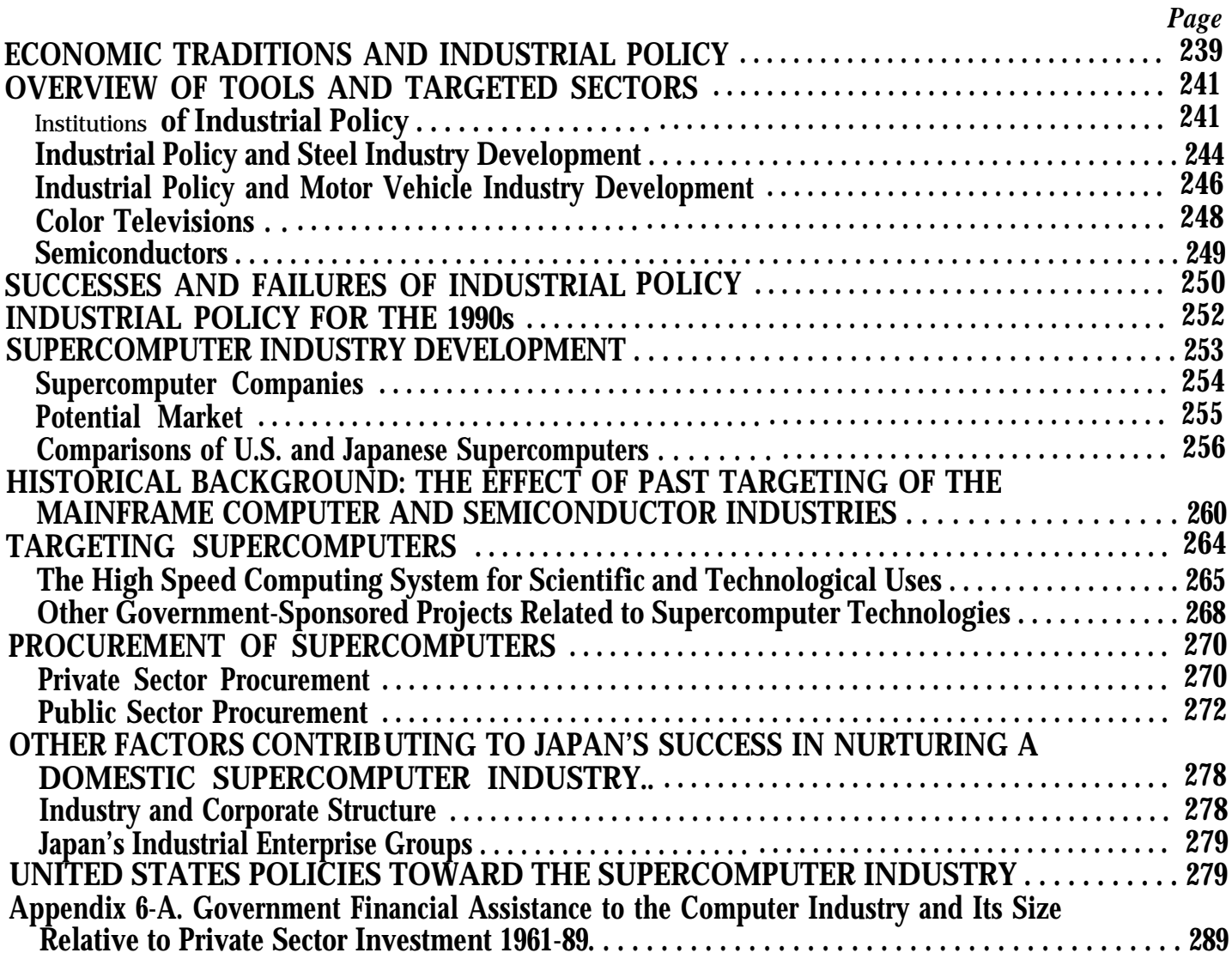

\section{Figures}

Figure

6-1. Actual v. Peak Supercomputer Performance $\ldots \ldots \ldots \ldots \ldots \ldots \ldots \ldots \ldots \ldots \ldots \ldots \ldots \ldots \ldots$

6-2. Performance/Price Data ............................................. 259

6-3. Schedule of Research and Development for High Speed Computing System for Scientific

and Technological Uses Project ..................................... 265

6-4. organization of the Supercomputer Project, 1981-89. . ..................... 266

\section{Tables}

Table

6-1. Comparison of Cray Research, Fujitsu, Hitachi, and NEC Revenues, R\&D Expenditures,

and Profits, 1981, 1982, 1988, 1989 ................................. 254

6-2. Cray Researches Revenues, R\&D Expenditures, and Profits .................. 255

6-3. Divisions of U.S. and Japanese Supercomputers Firms, 1989 . . . . . . . . . . . . . . 255

6-4. Value of Worldwide Supercomputer Shipments . . . . . . . . . . . . . . . . . . . . 256

6-5. Number of New Installations in Japanese Supercomputer Market ................ 257

6-6. Japanese Procurement of Supercomputers, 1980-90 . . . . . . . . . . . . . . . . 260

6-7. Government Subsidies for Computer-Related Government-SponsoredR\&D Projects . . . . 263

6-8. U.S. and Japanese Supercomputer Companies' Share of the World Market ............ 270

6-9. U.S. and Japanese Supercomputer Companies' Share of the European Market, 1989 . . . . 270

6-10. U.S. and Japanese Supercomputer Companies' Share of the Japanese Market, Installed Base . . 271

6-11. Purchases by Firms with Keiretsu Ties to Japanese Supercomputer Makers, 1980-90.......271

6-12. List Purchase and Rental Prices of Japanese Supercomputers ................... 276 


\section{Japanese Industrial Policy: The Postwar Record and the Case of Supercomputers}

Japan is the world's most successful practitioner of industrial policy. Japan's industrial policies are largely, though not solely, responsible for its economic recovery from World War II and its increasing preeminence in high-technology industries. Other factors influencing these successes are intelligent corporate strategies, an emphasis on saving and investment rather than consumption, and social ethics that place premium value on hard work and good education.

The Japanese Government has used industrial policies throughout the postwar period-and indeed did so for decades before the war-to guide the economy in the direction of higher value added and greater knowledge intensity, and away from heavy reliance on unskilled labor and natural resources. While there is no consensus on the impact of Japanese industrial policy on national income, research suggests that by reducing the costs and risks for domestic firms to invest in a given industry, and by helping firms to advance technologically, industrial policies and targeting have contributed to Japan's international competitiveness in many industries, including steel, motor vehicles, semiconductors, and computers. Considering the impact that competitive companies in these industries have on other industries both upstream and downstream, the effect is profound.

American analysts are divided in their assessments of Japanese industrial policy. All acknowledge that the Japanese bureaucracy has tried to create competitive advantages both in specific industries and for business in general. There is less agreement about the results. It is rare in economics or political science to encounter a bona fide control group; lacking one, it is difficult to know what would have happened in a particular nation if some historical circumstance had been different. We cannot be certain what Japan's economic development would have been without industrial policy; this leaves ample room for disagreement. At one end of the spectrum are analysts who view industrial policy as the major explanation of Japan's success. Analysts at the other end hold the view that Japan's industrial policies have had a marginal impact at best. OTA's conclusion is that industrial policy has been a key ingredient, along with several other attributes of Japanese society, policy, and business tradition. ${ }^{2}$

The debate over the effectiveness of Japan's industrial policies has been fierce for reasons other than the wide latitude for interpretation of historical events. Accepting that Japan's approach has been successful is close to admitting that perhaps our own policies and ideology might need rethinking, a difficult and painful process for any nation. But the admission of Japan's success does not mean a makeover of America in Japan's image. Other nations can learn from Japan's success, as Japan did from nations more advanced; most of the world's developed nations or regions are in the process of strengthening their commitments to industrial policies, in part because of Japan's economic performance. This does not mean that other nations or regions are blindly copying Japanese policies of the past or present.

As most Western writers on the subject have noted, Japan is changing, and has been throughout the postwar period. The speed and character of the changes in Japan are another part of the vigorous debate over Japanese policy. Some argue that Japan is becoming more like the West, in terms of both economic performance and government policy. In some ways, it is; yet the Japanese industrial policy tradition and bureaucracy are still powerful, and continue to operate in very different ways than the United States. Moreover, Japan's Government and economic system continue to support development of industries and products at the high-technology frontier, although the intervention is less heavy handed than it was a couple of decades ago.

\section{ECONOMIC TRADITIONS AND INDUSTRIAL POLICY}

From very early in its history, the Japanese Government took the initiative in industrialization and economic development. Threatened by foreign powers and lagging behind economically and technologically, the Meiji Government, together with the top merchant families, took the lead in the 1870s 
in establishing and promoting Japan's basic infrastructure and industries. ${ }^{3}$ By the turn of the century, the policies devised by the Meiji Government to promote industrial development were paying off: iron and steel production doubled between 1875 and 1895 , machinery production rose sevenfold, and textile production increased eightfold. Japan was developing military power as well, and was strong enough to renegotiate a few treaties that had rankled for some time.

Successful experience with a strong bureaucracy and close relations between business and government gives modem Japan a view of competition and the appropriate role of the state that is quite different from the laissez-faire traditions of the United States or Great Britain. Active government intervention in the economy is considered natural and indispensible in the Japanese bureaucracies, and unfettered price and investment competition is viewed with reservation, at best. Many of the practices of business and government that are considered perfectly normal means of promoting industrial health and development in Japan are considered unfair in America. According to one analyst:

The American criticism of Japan. . . stem[s] from the conviction that in many cases market outcomes are shaped by Japanese business practices considered unfair-predatory pricing, patent infringement, industrial espionage, and explicit or implicit protection of Japanese markets from import competition ... the basis on which the problem must rest [is that] Japanese success in blocking imports into their own country or in penetrating U.S. markets comes, at least in part, from anticompetitive behavior rather than from competitive ability.

Scholars differ not only on whether Japanese industrial policy has succeeded but also on the criteria they use to measure success. Some studies focus on the contribution of industrial policies (including targeting) to the development of the targeted industry, ${ }^{6}$ others on consumer welfare or national return on investment, ${ }^{7}$ and still others on how policies affect both specific industries and the nation's long-term technological trajectory. ${ }^{8}$

Analysts at one end of the spectrum believe that Japan's active state bureaucracy, close governmentbusiness relationships, the stable political rule of the Liberal Democratic Party, the weak Diet (legislature), and strong industrial policy are key ingredients of Japan's success. According to this school, Japan is a mercantilist country that focuses primarily on national economic goals and self-sufficiency. With the decline of U.S. hegemony, analysts of this stripe are particularly concerned about what they see as Japan's hesitation to take on a fair share of the economic and political burden of supporting the world economic order. They argue that Japan is benefiting tremendously from the open trading system, exploiting the openness of other nations. They acknowledge that fierce market competition has been another key ingredient of Japan's success, but suggest that market forces have been shaped by state industrial and trade policies and other institutional guidelines in ways that often benefit Japanese businesses at the expense of both foreign businesses and Japanese consumers. They identify institutions like MITI (the Ministry of International Trade and Industry), the keiretsu, the government's Japan Development Bank, and the quasi-governmental telecommunications giant, NIT, as hindering foreign access to the Japanese market. While they acknowledge that MITI's power has waned in recent years and that Japan's economy is more open now than it was a decade ago, they believe that MITI still plays an important role in nurturing industries and technologies, and that Japan's market is still more closed to imports than those of most other developed nations.

There are a variety of views within this school of thought. Some see the bureaucracy as having been the most important actor guiding development, some see big business as having the upper hand in the government-business relationship, and some believe that no one group in the ruling elite is really in charge.

At the other end of the spectrum are those who see Japan's industrial policy as having had, at best, a marginal effect on Japan's success. These analysts argue that high rates of savings and investment operating in a free market, a good educational system, and willingness to quickly adopt foreign technologies are the key sources of Japan's success. This group sees Japan as being very similar to the United States and Western capitalist democracies in having policies that both support the free trade regime and focus on maximizing consumer welfare. Some argue that Japan has developed in spite of industrial policy, others that industrial policy has only compensated for Japan's underdeveloped stock and venture capital markets and small supply of scientists, and still others that industrial policy has 
helped at the margin in some industries..$^{10}$ Overall, they believe that the role of Japan's industrial policy has been greatly exaggerated and point out that some targeted industries, such as petrochemicals, have not been successful, while many competitive industries, such as consumer electronics, have not been actively targeted. Proponents of this view argued for a long time that the U.S. trade deficit with Japan had little to do with Japan's industrial and trade policies and was instead primarily the result of an overvalued dollar. The failure of the sharp plunge of the dollar since 1985 to correct the U.S.-Japan trade imbalance has led several of these analysts to change their views. ${ }^{11}$

In addition to the stubborn trade deficit with Japan, another development is reconciling some of the differences between the views described above. In the past decade or so, a group of economists often referred to as "the new international economists," using accepted economic methods, have given new life to an old idea: that there are industries that add more to national income and well-being than others, and that governments can raise national income by promoting such industries. These sectors are characterized by significant barriers to entry (in terms of both knowledge and resources), increasing returns to scale, a steep learning curve, high value added, and significant positive spillovers to other sectors of the economy. Some of these analysts suggest that the Japanese Government, by using strategic industrial and trade policies, has been able to increase national income in some cases by targeting such sectors. ${ }^{12}$

As new evidence becomes available, it seems increasingly clear that Japan's industrial policy has contributed significantly to the development of several specific industries, and has created a climate conducive to development in many more; its role has been particularly significant in high-risk, high-cost, and innovative industries.

\section{OVERVIEW OF TOOLS AND TARGETED SECTORS}

There have been four main periods of industrial policy since World War II. The earliest, 1945 to 1952, included the creation or rebuilding of many of the industrial-policy institutions to help Japan's economy get back on its feet. From the mid- 1950s to the mid-1960s, the government began to allocate scarce funds to specific industries, including steel, automobiles, and electronics. The following decade was the peak of Japan's so-called high-growth period, and represented to many Japan's last chance to gain a foothold in high-technology industries before the inevitable pressure to open up its markets began. Government still wielded powerful tools, though with less heavy handed policies than in the 1950s.

The current period began in the mid-1970s, following the first energy shock. Starting in the early 1970s, the state, besieged by the oil crisis and various pollution and quality-of-life problems, began to shift its support away from energy-intensive industries, such as steel, towards more knowledgeintensive, high value-added industries, such as computers, semiconductors, and biotechnology. In this period, and particularly in the 1980s, many Japanese companies became very strong, and thus less dependent on government for protection and subsidies. In response to increased trade friction, industrial and trade policies became less visible and formal, and tariffs and quotas were eliminated or substantially reduced. At the end of the decade, legal hindrances to foreign investment were removed as well. Despite this liberalization, Japan's market remains one of the most difficult to enter, especially among advanced capitalist countries; most of the current barriers are business practices and institutions, many of which evolved to serve other purposes as well as protection.

\section{Institutions of Industrial Policy}

The Japanese bureaucracy, fortified by new tools instituted during the Occupation, used industrial policy to try to change Japan's industrial structure from labor-intensive industries during and before the war to capital-intensive industries in the two decades following the war, and to knowledge-intensive industries beginning in the 1970s. In the first few years following the war, Japanese and Occupation leaders set up many of the institutions and laws that would provide a foundation for postwar industrial policy. MITI, the central and most powerful of those institutions, was created in 1949 (before that, it was the Ministry of Commerce and Industry, or MCI). In 1950, the Japan Export Bank (later called the Export-Import Bank) was established to promote exports by providing financing. The government's Japan Development Bank (JDB) was established in 1951 to help supply low interest loans to designated industries for investment in plant and equipment. JDB went on to be an important bellwether for 
commercial bank lending, as well as being a lender itself. $^{13}$

Several laws, such as the Foreign Exchange Control Law of 1933, the Foreign Exchange and Foreign Trade Control Law of 1949, and the Foreign Investment Law of 1950, gave the Japanese Government control over the flow of foreign exchange, investment, and goods. Though necessary in the early years to deal with balance-of-payment problems, these laws also provided the government with an effective tool with which to protect Japanese industries from foreign competition. MITI's control over the foreign exchange budget "played a large role in protecting and fostering domestic industry," states Professor Nakamura Takafusa of Tokyo University .14

Numerous studies show how these laws prohibited or controlled the entry of foreign products and investment and promoted production-oriented rather than consumer products-oriented industries. ${ }^{15}$ For example, the threat to fledgling Japanese producers from foreign firms that wished to sell cars or invest in automobile production in Japan was substantial in the early 1950s. The Japanese Government remembered that, in the 1930s, vehicles manufactured in Japan by General Motors and Ford came to dominate the market, inhibiting the development of Japanese auto companies. By 1934, vehicles made in Japan by American companies held almost 90 percent of the Japanese market, and the large volume of imported parts threatened to leave Japan with a chronic trade deficit. ${ }^{16}$ So, when several European and one American automobile firm began to explore possibilities for building assembly plants in Japan in the early 1950s, MITI took several steps. One was to issue its "Basic Policy for the Introduction of Foreign Investment into Japan's Passenger Car Industry," supplementing the Foreign Exchange Law, which stated that repatriation of earnings from foreign investment in marketing facilities was not guaranteed, and earnings repatriation from production facilities would be guaranteed only if those facilities "contributed significantly to the development of domestic industry." ${ }^{17}$ In effect, this gave MITI the authority to determine on a case-by-case basis whose earnings could be repatriated, and effectively barred marketing. Moreover, MITI stated that foreign firms would be allowed to enter the Japanese market only through technical tie-ups with domestic fins. It announced four provisions for inclusion in the contracts:
1. small European cars were more suitable than large American cars;

2. the use of foreign currency allocated for cars should be used for importing parts instead, and MITI could only allocate enough for production of 1,200 cars per company;

3. the Japanese company should try to obtain the right to sell the cars in Southeast Asia; and

4. domestically made parts should eventually substitute for imported parts.

Using these tough criteria, MITI rejected all but 4 of 11 proposed tie-ups. ${ }^{18}$

Access to foreign technology was preferred over both foreign direct investment and imports. Foreign technology was seen as an important source of profit, and access to it was tilted mostly towards basic industries..$^{19}$ The automobile case was perhaps the most notable exception; and even there, one of the primary reasons for promoting automobile production was to support the metalworking and machinery industries that auto production demanded. MITI (which was MCI before 1949, but which is referred to as MITI throughout this report, for convenience) emphasized that automobile production was closely connected with parts and machinery industries and established an automobile section in January $1946 .^{20}$ Later, in the 1950s, MITI used the same argument more strongly, again in support of its then uncompetitive automobile industry, promoting passenger car development as "the pinnacle of the modem machinery industry in our country where there is no aircraft industry. ${ }^{21}$ Making cars would raise technology and quality in both machinery and steel industries, as well as create markets.

Though originally enacted to deal with immediate postwar problems, the laws controlling foreign investment and foreign exchange were retained far longer than the Occupation forces intended; in many cases, they were not revised until the late 1970s and 1980s, and many of the revisions were cosmetic. On the other hand, the antitrust law was weakened 1 year after the Occupation ended; this enabled the government to restrict competition and promote economies of scale, authorized anti-recession and rationalization cartels, sanctioned retail price maintenance, and relaxed restrictions on cooperative arrangements such as cross-shareholding, interlocking directorates, and mergers. In the late 1950s and 1960s, the Japanese Government exempted from the 
law certain sectors such as the machinery and electronics industries. ${ }^{22}$

The weakening of the antitrust laws was also a part of the government's strategy to encourage the rebuilding of the industrial groups after the Occupation. Industrial groups, or keiretsu, were also a prominent part of the Japanese economic scene before the war, but in somewhat different forms; the pre-war zaibatsu were family controlled enterprises, in many cases of quite grand proportions. While the Japanese authorities initially cooperated with the Occupation forces in dismantling the zaibatsu after the war, they had little commitment to a less concentrated economic structure overall. ${ }^{23}$ The reemergence of these groups as looser, bank-centered alliances had two benefits: the government could more easily influence the behavior of firms through centralized control over funds and banking, and the close relations of buyers and suppliers (including cross-shareholding) within groups helped keep imports and foreign investment down. The cohesiveness of the industrial groups became even more important in the late 1950s and early 1960s, when foreign pressure to liberalize Japan's market stepped up. Japan also joined the Organization for Economic Cooperation and Development (OECD) and in 1964 agreed to accept the obligations of a developed country under Article 11 in the General Agreement on Tariffs and Trade (GATT), which meant working to eliminate quantitative restrictions on trade. ${ }^{24}$

Another institutional innovation that provided key financial support for industrial policies is the Fiscal Investment and Loan Program (FILP), a huge discretionary "second budget" separate from the general account budget. ${ }^{25}$ First established in 1953 when the Ministry of Finance (MOF) pooled the postal savings accounts, national pensions, and various other accounts, this budget is made annually by MITI and MOF bureaucrats with little input from elected officials and other constituents. It is enormous; it has been from one-third to one-half the size of the General Account Budget and has ranged from a low of 3.3 percent of GNP in 1956 to a high of 6.3 percent in 1972. ${ }^{26}$ In 1990, the FILP was in the neighborhood of 34.6 trillion yen, or about $\$ 250$ billion (at an exchange rate of Y135 per dollar) .27 The postal savings system, which contributes nearly a quarter of the money in the total FILP budget, has deposits of over V134 trillion (about \$1 trillion), making it the largest financial institution in the world. ${ }^{28}$ The system was able to attract savings from citizens by allowing a lower tax rate on interest to depositors and allowing the post offices to offer higher interest rates than banks, although these "higher" rates are still low by American standards. In 1988, they increased to what was then a high of 1.68 percent, and recently went up to 3.48 percent. ${ }^{29}$ By paying low interest rates to depositors, the FILP system has been able to subsidize producers with low interest loans. ${ }^{30}$

FILP money goes directly to finance government policies; it is still an important instrument of MITI influence. ${ }^{31}$ In the 1950 s especially, FILP was indispensable for implementing government policies; in the early part of that decade, it accounted for nearly 30 percent of the capital available to industry. In the 1980s, in contrast, FILP's contribution fell to less than 10 percent. Japan's companies now have many sources of capital and far less need for publicly funded capital investments or indicative loans to encourage private sector lending. ${ }^{32}$

Targeting was also supported indirectly by a broader financial system that favors producers over consumers. Indeed, by not allowing instruments of consumer credit to develop until recently, Japan has made it imperative that its citizens save a large part of their income for any major expenditures. The lack of adequate provisions for retirement also made saving for old age a must. By limiting the development of viable alternatives to savings deposits and limiting interest rates on those deposits, the government gave citizens little choice but to put their savings in bank or post office accounts at very low interest rates, while Japanese financial institutions were able to invest those savings abroad at interest rates often exceeding 10 percent.

MITI thus controlled a large source of money that was unaffected by political maneuvering or lobbying, foreign exchange and investment, and trade. Also in the toolkit of policies to promote industrial development were policies to gain cheap access to foreign technology, tax measures to encourage specific types of investment, the ability to organize cartels, and a limited ability to affect industrial concentration (the number and size of firms in an industry). Through a process of constant consensus building with industry representatives, MITI bureaucrats could bring many specific measures into play as needed for the industries it wished to promote, as illustrated by the case studies below. 


\section{Industrial Policy and Steel Industry Development}

The steel industry is a key example of Japan building up a competitive industry in an area in which it clearly had no comparative advantage. The steel industry was badly damaged during the war, leaving only about 25 to 30 percent of plant capacity functional as late as $1949 .{ }^{33}$ Japanese producers also had tremendous cost disadvantages, largely due to the high price of imported raw materials and poor labor productivity resulting from inefficient equipment. ${ }^{34}$ To help the industry become competitive, the government protected it from foreign competition, gave it financial aid for investment in new technologies and improved plants, created various mechanisms to manage domestic price and investment competition, and encouraged mergers to help the firms gain greater economies of scale.

Initially the steel industry was protected by high tariffs. Japan imported very little steel during the 1950s, even though domestic steel cost more than U.S. steel. Except during the 1957 recession, steel imports never exceeded 2.7 percent of internal demand..$^{35}$ Imports of raw materials and equipment necessary to produce steel were generally exempt from import duties.

Financial assistance in the form of grants, low interest loans, and tax breaks were given to the industry, especially in the 1950s and early 1960s. Much of the aid came from Japanese coffers, but in the 1957 to 1958 recession, MITI arranged for the World Bank to funnel loans to the steel industry through the Japan Development Bank. The JDB guaranteed the loans and also got the World Bank to loosen its regulations on the percent of equity and liquidity required for a firm receiving World Bank loans. ${ }^{36}$ As in other industries, financial aid had strings attached: it went only to the firms MITI felt were strongest and most capable of using the money effectively, and it was given for investment in specific types of equipment, especially to larger, modern factories using efficient technologies.

MITI's control over access to foreign exchange enabled it to play a key role in the introduction and diffusion of basic oxygen furnace (BOF) technolofg. ${ }^{37}$ In 1955, two Japanese steel makers asked to license BOF technology from an Austrian firm. Mill, concerned that competition between the two for technology would result in a higher price, selected one to be the general licensee and required that it give the other steel makers equal access to the technology as sublicensees. ${ }^{38}$ This kept the Austrian patent holder from playing the Japanese companies off against each other to get a higher license fee, a strategy MITI would use again in gaining access to foreign technology, notably in semiconductors and computers. A complex agreement was worked out by which all firms using the BOF technology contributed to the $\$ 1.2$ million license fee. As a result, the technology was cheap: during the 14-year period of the license, it cost Japanese steel makers 0.36 cents per ton, compared with the 15 to 25 cents per ton that North American firms paid in royalties. ${ }^{39}$ In addition, MITI's action helped diffuse the technology quickly. ${ }^{40}$ The competition, then, quickly shifted from who could gain access to the technology to who could apply it rapidly and efficiently. MITI did not pick BOF technology as a winner; the two firms discovered it themselves. But by making it available at a reasonable rate and on terms that promoted rapid diffusion, MITI helped upgrade Japan's steel industry faster and more cheaply than market forces would likely have done.

MITI also helped stabilize prices, production, and investment through cartels. A major problem in capital-intensive, high-freed-cost industries like steel, which make relatively undifferentiated producer goods, is that their boom-bust cycle can often lead to severe investment and price competition. During boom times, the firms expand capacity to cut costs through economies of scale; during recessions they cut prices to minimize losses inherent in businesses that have high freed costs. Many studies have concluded that these investment and price cartels helped provide the industry with stability of supply and prices, especially during recessions. ${ }^{42}$ Japan's companies were particularly vulnerable to economic downturns because of lifetime employment, high debt-to-equity ratios, and especially intense domestic competition. Because of these, it was much harder for Japan's companies than for their foreign competitors to lay off workers, cut back on production and investment, and operate at low capacity utilization. While these rigidities are partially offset by other institutions such as widespread use of temporary workers, subcontracting, close relationships with banks, deep pockets and ready availability of capital, recessions still pose a special problem. ${ }^{43}$ Of course, this also means that part of the problem of over-investment and excessive price 
competition is a result of government industrial policy; some studies argue that MITI's cartels, by sharply reducing risks, encouraged firms to overinvest in plant and equipment, which in turn exacerbated the problems of recession vulnerability. ${ }^{44}$ While Japan's steel makers have had excess capacity problems, particularly right after the first oil shock in 1974, their capacity utilization has almost always been higher than that of their U.S. and European counterparts, ${ }^{45}$ perhaps enabled by the very fast growth of the Japanese economy, the emphasis on exports, or both. And Japan's big integrated mills did contribute to Japan's becoming the world's lowest cost producer of steel.

MITI's original plan for the steel industry encouraged cooperation in order to stabilize investment, prices, and output. Later, it encouraged mergers to increase the size of firms, hoping to strengthen the steel companies to compete with foreign firms. ${ }^{46} \mathrm{In}$ the 1960s, as Japan was beginning to liberalize its markets to conform with GATT and OECD requirements, MITI pushed for mergers in many industries to strengthen them and thus prevent U.S. firms from dominating Japanese producers. ${ }^{47}$ Yawata and Fuji Steel, Japan's two largest steel fins, were one firm--a nationalized steel company-until it was broken up and privatized by the U.S. Occupation. With MITI pressure and financial assistance, the two companies merged to form New Japan Steel in March 1970, creating the world's largest steel maker. MITI's goals were to create a dominant firm that could provide stable leadership in price, technology, and production volume, and to decrease costs. ${ }^{48}$ The merger attained these goals, and the higher steel prices that Japanese scholars feared would result never materialized. Imai Kenichi, a scholar who was particularly concerned that the new company's size and domination of the market would have a negative impact on market performance, admits that:

within only 2 years after the merger, the Nippon (Japan) Steel Corp. developed its international competitiveness beyond a necessary level to the point where Japanese-U.S. relations maybe brought to another crisis similar to that which developed over textiles. ...49

In short, the merger was so successful it caused trade friction.

Other policies promoted development of the steel industry. Special depreciation allowances promote investment in rationalization (a term that covers many things having to do with achieving the proper size of industry and enterprises, including downsizing to eliminate excess capacity, advancement of technology, improvement of quality, reduction of costs, and improvement of efficiency), acquisition of experimental equipment, and exports. During the 1950s, the steel and automobile industries received exceptionally large benefits from special depreciation schemes, and between 1962 and 1973, the steel industry ratio of special depreciation allowances to total depreciation was, at 15 percent, almost twice the industry average of 8 Percent. ${ }^{\text {so }}$ By another estimate, a revision of the depreciation schedule in 1961 reduced the statutory life (depreciation period) of industrial equipment by 20 percent; another revision 3 years later reduced it an additional 15 Percent. $^{51}$

Early in the 1950s, the steel industry was also an object of special attention from the Japan Development Bank. JDB provided up to 15 percent of the funds to implement MITI's first rationalization plan for the industry from 1951 to $1953 .{ }^{52}$ Until the late 1960s, the iron and steel industries were protected from imports by measures equivalent to a 30-percent tariff. By 1973, the effective rate of protection had fallen to 17 percent, but it shot backup to over 50 percent in 1975 (Japan's severe post-oil-shock recession), and fell again to below 20 percent by $1978 .^{53}$ The steel industry got approval to import needed industrial equipment without paying the tariff on it. Finally, the industry was encouraged to export through the use of a tax deduction in the early years; this provision disappeared in 1963.

Without industrial policy it is extremely unlikely that such a competitive industry would have emerged so rapidly after the devastation of the war. While Japan's steel industry has had some problemsespecially excess capacity after the oil shock in the mid-1970s--it has been able to scale back its operations and shift into specialty steel. Some scholars nonetheless argue that steel may be "the success that never was" because it had a relatively low return on investment compared with other industries in Japan; ${ }^{54}$ they assert that the resources poured into the steel industry could have been allocated more efficiently in other industries to gain a higher return. Targeting steel, they maintain, "probably reduced Japanese national income." ${ }^{55}$ 
Japan's steel industry did have a relatively low return on investment. But this was not the concern of the Japanese Government, nor the firms or their shareholders. Their goal was to gain greater world market share and to provide the foundation for industries that use steel, such as automobiles, machine tools, and shipbuilding. Low return on investment in an industry that provides key inputs into other industries does not necessarily lead to a net loss for the economy.

Indeed, evaluating the effectiveness of industrial policy on the basis of return on investment often leads to the conclusion that Japan is largely a failure. Many of Japan's top firms today have returns on investment that are unacceptable by U.S. standards, made possible by, for example, cross-shareholding and stable shareholding, low capital costs, and a general preference for increasing market share over increasing share prices. ${ }^{56}$ But while many Japanese firms and industries may be inefficient by U.S. financial standards, they are effective in consistently winning market share in many key industries. Also, the low returns on steel may well have been compensated by higher returns in industries that use steel, including automobiles and machinery. Steel had other benefits for Japan; by 1960 it was the country's largest earner of precious foreign exchange. ${ }^{57}$ More generally, it provided the industrial infrastructure necessary for an advanced, industrialized nation, including a large pool of skilled workers with high-paying jobs.

\section{Industrial Policy and Motor Vehicle Industry Development}

Policies towards nurturing an internationally competitive automobile industry followed a pattern similar to those of the steel industry: heavy protection and subsidization, incentives for investment in technology, and increased concentration in the industry.

Efforts to support Japan's fledgling auto industry began before the war. ${ }^{58}$ Early car producers were true entrepreneurs, but without support they might well have withered on the vine. The Japanese military became interested in motor vehicles as early as 1906; by 1918 the government had passed the Military Vehicle Subsidy Law to provide manufacturing, maintenance, and purchasing subsidies to producers and buyers of qualifiedd vehicles (buses and trucks). To qualied for the subsidies, a producer had to show that over half the capital and voting rights of the company were held by Japanese nationals, and most parts had to be made in Japan. This was an important stimulus to the domestic industry, but not enough to protect it. Ford and General Motors, watching their sales take off after the Great Kanto Earthquake of 1923 damaged all of Japan's domestic auto producers, rushed to set up their own offices in 1924 and 1925, and quickly came to dominate the market. It became apparent to the government that imports and foreign direct investment could cripple the technologically backward domestic industry, which could in turn contribute a chronic deficit to the trade accounts and be a drain on Japan's scarce foreign exchange. The Automobile Manufacturing Enterprise Law of 1936, through various regulations, forced Ford and GM to terminate their successful operations in Japan and enabled Toyota and Nissan to use the U.S. companies' dealer networks to build their own distribution systems. This law also gave the army control over policies affecting the automobile industry, and turned domestic producers' attention almost exclusively to making trucks and buses.

After a few chaotic postwar years during which Japanese automobile producers had trouble getting permission from the Occupation forces to produce cars or obtain the raw materials and parts needed to do so, responsibility for promoting the auto industry was transferred to MITI. The Ministry pushed automobile industry targeting because, it argued, the auto industry would provide the source of demand needed for Japan to modernize related industries, including machinery. 59 This decision was controversial-the governor of the Bank of Japan, for example, initially argued that:

... since Japan should develop its foreign trade on the basis of the international division of labor, efforts to develop the auto industry will be futile... As we can get inexpensive motor vehicles of excellent quality from the United States, why don't we rely upon them?

\section{MITI prevailed.}

The first 5-year plan for promotion of the auto industry came from MITI in 1948, and it featured the use of imported technology and financial assistance provided by the Reconstruction Finance Bank to help obtain capital, raw materials, electricity, and labor. The Asian market was the main export target, and controls on prices and distribution were put in 
place for an interim period, to be lifted when appropriate. ${ }^{61}$ Recession caused by economic policies known as the Dodge Line (after Joseph Dodge, the Detroit banker who drafted and implemented Japan's deflationary program) forced abandonment of the plan and threw the automobile companies into chaos. Nissan laid off over 1,800 employees in October 1949 and cut wages 10 percent, Diesel Motors abolished its agreement with its union and laid off nearly a quarter of its workers, and Toyota almost collapsed (although its founder refused to lay off anyone and was eventually forced out of the company as layoffs were implemented). Rescue came in the form of the Korean War. Japan, as the best source of emergency supplies, received many orders for special procurements by the U.S.-led U.N. forces, enough to end the recession and save the struggling automobile industry. ${ }^{62}$

The hiatus in government promotion of the automobile industry brought by the Dodge Line was brief. After the recovery, many new policies were implemented to support the industry. They included an ambitious road construction program; protection from imports and direct investment; imports of foreign technology under favorable terms; and direct financial assistance. ${ }^{63}$ Protection consisted of high tariffs ( 35 to 40 percent on cars until 1969, falling to zero by 1978), commodity taxes that favored domestic automobiles, foreign exchange allocation that restricted imports, and foreign exchange controls on direct investment. Excise taxes that favored small cars over large, luxury vehicles effectively kept out American cars, but after a surge in imported small cars from Europe, additional measures were implemented. Among them were allocation of foreign exchange to buy European cars only for taxi companies and the media, and prohibition of resale for 3 years. ${ }^{64}$

Other measures were similar to those used in steel: low interest government loans, subsidies, special depreciation allowances, exemption of necessary equipment from import duties, and approval of foreign exchange essential for foreign technology imports. ${ }^{65}$ In 1956, the Law on Temporary Measures for Promoting the Machinery Industries added auto parts and automobiles, and research suggests that this promotion was particularly effective. ${ }^{66}$ For example, financial aid along with efforts to encourage standardization and increase concentration of the auto parts industry contributed to a 56-percent cut in the cost of producing a passenger car between 1961 and 1965.

Even with all these supports and the outstanding performance of the Japanese motor vehicle producers, the auto industry is frequently pointed to as a failure of Japan's industrial policy because of MITI's repeated failures to consolidate the industry into one or two firms or groups. In 1955, for example, MITI tried to promote production of an exportable subcompact by a single company, an idea the firms rejected strongly. In 1961, MITI tried to consolidate the industry into three groups to develop three types of cars. This plan was rejected, too. Had it been adopted, it would by widespread agreement have damaged the industry's long-term competitiveness. It is important to realize, however, that what would clearly have been a mistake did not, in fact, occur. Indeed, there have been very few large blunders of industrial policy, such as would have occurred if MITI had succeeded in merging the auto companies, because there is a system of checks and balances among the firms and government officials; policies are made through a process of negotiation and compromise, and in cases where the firms believe that a government policy goes sharply. . against their long-term interest, they reject it. The auto case is not the sole example of MITI unsuccessfully attempting to merge firms; in the late 1960s and early 1970 s the ministry also tried to get the six major computer firms to merge into two or three companies, and the firms refused. A compromise was reached whereby the six firms formed three different groups for cooperative research and development. Despite this failed MITI attempt to consolidate the computer industry, even the most skeptical analysts acknowledge that industrial policy contributed to the development of the computer industry. ${ }^{68}$

Protection from imports and foreign investment, along with financial assistance, help in importing needed inputs, and special access to foreign technology were necessary though not sufficient conditions for Japan to develop comparative and competitive advantage in the automobile industry. The government did not create the automobile industry in Japan, nor did it create other successful industries such as electronics. Clearly, the companies' willingness to invest in new technologies, their persistence in finding new and better ways to use technologies, their continual improvement, and intelligent strategies for penetrating foreign markets played a vital role, as did Japan's well-educated and disciplined 
workers and overall financial policies that encouraged savings and discouraged consumption.

\section{Color Televisions}

Many proponents of the market explanation of Japan's economic development point to consumer electronics as an industry that succeeded without government promotion. In fact, they argue that the industry boomed in spite of a blunder by MITI: that of delaying Sony's acquisition of transistor technology by restricting Sony's use of foreign exchange. ${ }^{69}$ In 1953, MITI refused Sony permission to acquire transistor technology from the United States because MITI did not want to use scarce foreign exchange for the technology; it also felt that a small, recent start-up such as Sony would not be able to use a brand new technology successfully .70 While the frequently cited American account of this refusa $1^{71}$ says that MITI delayed Sony's access for 3 years, Akio Morita of Sony says it took 6 months to persuade MITI to give them the needed foreign exchange. ${ }^{72}$ Nonetheless, this mistake stands out as one of MITI's more serious errors.

The argument that the industry succeeded without government help is less powerful when the evidence is analyzed. The producers of televisions did not enjoy the number of tailor-made policies and degree of support given to targeted industries like automobiles, steel, semiconductors, and computers. But the television industry, like many others in Japan, benefited from government policies that lowered capital costs, protected against imports and foreign investment, promoted exports, and tolerated behavior that, in the United States, would have run afoul of antitrust laws. ${ }^{73}$ MITI's policies made it possible for the color television industry to keep prices high at home and low abroad-in fact, Japanese producers were found guilty of dumping in the U.S. and European markets. For over a decade, Japanese makers sold televisions in the United States for about one-third to one-half the price of the same sets in Japan; this export price was also below cost. ${ }^{74}$ High prices at home could only work under certain conditions: that is, if all major manufacturers agreed not to undercut one another's prices (collusive behavior, by U.S. standards), and if the market were effectively closed to imports. Both occurred. To fix export and domestic prices, the managers of the major manufacturers met regularly in groups such as the Okura Group and the Palace Group, named after the hotels in which the meetings took place. ${ }^{75}$ And in the first half of the 1960s, the tariff on television imports was 40 percent. $^{76}$

While Japanese firms needed to charge low prices to win U.S. market share, they avoided undue price competition with each other. Domestic firms set minimum export prices, ${ }^{77}$ which MITI monitored. Another safeguard was the so-called "five company rule,' which required that each Japanese exporter specify five U.S. dealers as its only and exclusive customers. This kept large U.S. retailers such as Sears from playing the Japanese suppliers against each other to lower prices. An export association managed the formal registration of these buyersupplier relationships; firms reported to that association each specific shipment of color televisions to the United -States, stating the buyers and suppliers involved, and the type, quantity, and price of the televisions. $^{78}$

When the United States started to complain about this dumping in the late 1960s, Japanese consumers became aware of the discrepancy and boycotted Japanese televisions. MITI immediately gave guidance to the industry to reduce domestic prices, and the firm complied, though export prices were still much lower. ${ }^{79}$ The secret meetings among the firms and control of distributors were allowed to continue. $^{80}$

Japanese firms raised prices in the United States in 1974 in response to growing allegations of dumping and antitrust violations. This price change reduced but did not eliminate the gap between high domestic and lower export prices. Moreover, Japanese television manufacturers reportedly began to give kickbacks to U.S. retailers, making the actual prices much lower than those reported in accounting records, customs forms, and invoices. ${ }^{81}$

Collusion and dumping were not the only reasons for the success of the Japanese television makers. Japanese manufacturers worked hard to reduce their costs by introducing new technologies; in particular, they converted their TV production to solid-state integrated circuits early on. Japanese televisions gained a reputation for reliability in America, and made it possible for televisions to be repaired by large retail establishments rather than repair shops. As in every other successful Japanese industry, success came from a combination of intelligent company strategy and diligence, good workers, and government policies. None of these factors alone would have resulted in the same record of success. 


\section{Semiconductors}

While there is a range of views about how important industrial and trade policies have been to some industries (consumer electronics particularly), there is much less skepticism when it comes to the semiconductor industry, and still less for the computer industry. There is no question that in a free market, U.S. companies would have dominated the Japanese semiconductor industry. Texas Instruments (TI) applied for 14 patents in Japan in 1960 and for permission to establish a wholly owned subsidiary there in 1964. These applications threatened to disrupt the development of a domestic semiconductor industry, an area that business and government leaders had decided was strategic to Japan's long-term economic growth. By refusing to act on either application, the bureaucracy allowed the Japanese companies to copy TI's technology for years without paying for it. ${ }^{82}$ TI did finally win approval of some of its patents in 1977, and combined the others into one application, pursuing them until it was granted its final patent in October 1989. ${ }^{83}$ This was an exceptional case, even by Japanese standards, where it commonly takes 6 to 7 years to process a patent application (compared with 18 months in the United States).

TI threatened that any Japanese exports using its technology would be met with an immediate lawsuit based on TI's patents in the destination country, and this began to pose a problem for Japanese consumer electronics makers in the late 1960s. ${ }^{84}$ Something needed to be done to appease TI. MITI had to agree with TI's request for a wholly owned subsidiary because it needed [a license under] TI's patents [to export]," explained a former MITI official closely involved in the negotiations. ${ }^{85}$ But granting TI permission to operate a wholly owned subsidiary in Japan also posed serious problems.

Fairchild and Motorola both had wholly owned subsidiaries in Okinawa. The Japanese Government was then negotiating with the U.S. Government for the return of Okinawa. Had TI been allowed to open a subsidiary in Japan proper, it would have been difficult to keep Motorola and Fairchild from retaining theirs in Okinawa when that island came back into the Japanese fold. To avoid the precedent, MITI pressured TI to make a nominal joint venture with Sony "on paper, ' one that would last only 3 years, after which Sony would sell its shares to TI. ${ }^{86}$
MITI's strategy worked. When the United States returned Okinawa to Japan, the Okinawan subsidiaries of Fairchild and Motorola were forced to enter 50-50 joint ventures with Japanese partners. ${ }^{87}$ In addition, it was difficult for these American companies to form ventures with any of Japan's major electronics companies, because MITI favored pure blooded (junketsu) Japanese firms over mixed breed (konketsu) joint ventures. ${ }^{88}$ MITI ultimately found them relatively small, inexperienced partners. ${ }^{89}$

Japanese firms only began to produce sophisticated chips in the 1960s; in 1966, a couple of years after beginning production, Japanese firms were selling one type of IC (integrated circuit) for over $\mathrm{Y} 1,000$, some three times the price of a similar one sold in the United States. The higher Japanese costs reflected lower yields, which were about 10 percent in the mid-1960s, compared with 25 percent in the United States on average. ${ }^{90}$ As late as 1972 , the semiconductor divisions of all the major Japanese producers were in the red; ${ }^{91}$ in 1971, Japanese makers had to sell at more than 20 percent below cost to compete with U.S. manufacturers. ${ }^{92}$

Protection is only part of the story. Government financial assistance, such as low interest loans, accelerated depreciation, and other measures that lowered capital costs, enabled Japanese companies to continue investing heavily despite years of large losses. Another major theme of the Japanese approach to a home grown semiconductor industry was technology development and acquisition. U.S. firms that wanted to make joint ventures in Japan were obliged to transfer technologies as part of the deal. ${ }^{93}$ The government also sponsored several cooperative R\&D projects that helped domestic firms gain the technological expertise necessary to compete with U.S. companies over the long term. To help the six major companies get an early jump on integrated circuit R\&D, MITI organized a 2-year cooperative R\&D project from 1964 to 1966. Tarui Yasuo, a member of MITI's Electrotechnical Lab who participated in this project and later led MITI's well-known VLSI project (1976-1979), said that a major goal of the government was to "reduce duplication of effort" by dividing up the labor; another purpose was "frankly to avoid patents that cover procedures developed in the U. S.A.' ${ }^{\prime 94}$ Government-sponsored programs continue through the present.

Some of the most famous projects were the VLSI project, which accelerated the rate at which Japanese 
producers caught up with American memory technology; a software and peripheral development program from 1979 to 1983; the optoelectronic IC (OEIC) project lasting from 1981 to 1986; and a project in the mid-1980s to develop super-highspeed device technologies. ${ }^{95}$ By the mid- 1980s, the Japanese companies had come to dominate several semiconductor markets, had made inroads into all of them, and were poised to advance in almost every area of computer technology.

\section{SUCCESSES AND FAILURES OF INDUSTRIAL POLICY}

So far, this chapter has focused on successes of Japanese industrial policy. It probably bears repeating at this point that a number of the cases that some observers regard as failures-such as MITI's failure to reduce the number of firms in the automobile industry-ended up as very successful industries. There is a big difference between mistakes, or unsuitable proposals, and failures of industrial policy. Not every proposal MITI advances is a winner, but even so, its interventions have helped targeted industries and Japanese industry on the whole become more competitive. MITI and other ministries reduce the likelihood of mistakes by extensive consultation with the private sector.

A few targeted industries have not improved their competitiveness. Industrial policies towards petrochemicals, oil, and coal are often pointed to as failures. ${ }^{96}$ For example, the petrochemical industry, completely dependent on imported oil, was left with huge excess capacity when the oil shock hit Japan in the early 1970s. It had to be scaled back dramatically in a process that was costly to the government and the firms. The huge subsidies that have supported Japan's uncompetitive agricultural sector are also sometimes identified as industrial-policy failures. Overall, the fact that the Japanese Government spends more on declining industries than on ascending ones is also cited as proof that industrial policy is a waste of government resources.

It is important, however, to evaluate the success of policies based on their goals. Japan has never entertained the idea of developing an internationally competitive energy sector, which would obviously be impossible given the nation's lack of energy resources; policies toward oil and coal have been aimed at providing Japan with a stable and predictable energy supply and at keeping as much domestic control over energy as possible. Such a policy makes sense considering Japan's vulnerability to disruptions in energy supply and price; it took fully 5 years for Japanese manufacturing production to exceed 1973 levels after the oil-shock-induced recession of 1974-75.9 $9^{7}$ Similarly, Japan has never aspired to having an internationally competitive agricultural sector; rather, the industry has been protected and subsidized for political and social reasonsprimarily to assure farming communities' strong support for the pro-business Liberal Democratic Party.

To a skeptic, the heavy support for Japanese agriculture is proof of the proposition that government intervention in the economy is prone to become the servant of political power and special interests. Yet most nations do not wish to depend on imports for food, particularly for dietary staples. As a result, all developed nations support their agricultural sectors (some more than others). In Japan, it is not easy to find other industries as heavily subsidized as agriculture with as little economic payoff; for the most part, the separation between Japan's legislature (Diet) and bureaucracy hinders special interests from getting MITI support unless there is good economic sense behind their appeals.

For MITI to spend more on declining than on sunrise industries is not unreasonable. Supporting so-called 'structurally depressed' industries, which are not expected to recover from recessions or exceed past output records, is an inherently expensive activity. Industrial adjustment-contracting the size of an industry and shifting workers, managers, and capital from one industry to another-is difficult, time-consuming, and expensive in any Country. Countries differ in the extent to which those costs are borne by workers and owners of enterprises, as opposed to the public sector. Japan's government takes more responsibility for adjustment, and bears more of the cost, than do most developed nations. One reason is the value Japan places on employment security. Culturally and economically, Japan depends on steady employment; the option of laying off workers without making some provision for their future employment is abhorrent to the Japanese Government and employers alike. While not all Japanese employees are covered by so-called lifetime employment, most Japanese employers are reluctant to lay people off. It is even more important in Japan than in the United States that downsizing be orderly. As a result, the government has frequently 
organized cartels among producers to promote steady contraction and paid for some of the worker adjustment costs. While the money the government spends on declining industries does not contribute to increasing the competitiveness of a sunrise sector (a goal that some American analysts think is the only supportable objective of government targeting), it is not wasted. It contributes to a stable business environment, prevents cutthroat competition and large-scale, chaotic layoffs, and helps keep Japan's unemployment rate extraordinarily low.

A few efforts have disappointed MITI's expectations. Promotion of software development in the 1970s and 1980s has not been very effective; projects were scattered and inadequately funded and money was generally given to software houses to develop products approved by the Information Promotion Agency (IPA), a MITI-related association, rather than responding to the software needs of the users. By neglecting to tie its aid to the market, the government ended up with mostly unused software.

An even clearer example of disappointed expectations is the aircraft industry. Commercial aircraft was targeted in MITI's visions for the 1970s and 1980s, yet Japanese industry has never become a successful assembler of large commercial aircraft, as MITI hoped. But even here, calling MITI's policies a failure is inaccurate. With MITI support, Japan's aircraft industry has become a major supplier of parts, generating $\$ 1.2$ billion worth of commercial aircraft products in 1989; over half were exported. Japanese companies had a 15-percent share in developing Boeing's 767, making most of the fuselage and underwing fairing; they have taken a 20-percent workshare as a risk-sharing partner in the development of the new 777 (see ch. 8, or volume 2). Moreover, Japan's aircraft industry faced unusually formidable obstacles to development; for example, after World War II the country was barred from aviation-related activities while the rest of the world moved into the jet age.

While there have been failures as well as successes in Japan's efforts to promote certain industries, Japan has a good batting average in targeting industries for international competitiveness. Several factors distinguish the Japanese experience from those of less successful nations. Most critical perhaps is that on the whole, policies have been structured to preserve the forces of competition.
While that may sound strange to say about a nation that protected its developing industries as assiduously as Japan did, still the government almost always promoted several firms in an industry. $R \& D$ projects usually had two or more companies work together on a topic, each of which could bring the new technology to the market. Moreover, firms were strongly encouraged to export-often to America, where they had to compete with then-dominant fins. In a few instances, MITI has given a company a monopoly position in an industry or an R\&D project; generally these have been failures. ${ }^{98}$ In Europe, attempts to nurture domestic computer industries by promoting national champions also failed, in part due to their lack of domestic competition (see ch. 5). The lesson from Japan is that if a state protects the domestic market from foreign competition, it is imperative to at least keep domestic competition intact. Another lesson is that firms must compete somewhere (in Japan's case, in export markets) with the best producers.

Business input into the policymaking process has contributed to the success of Japan's industrial policies. Government officials consult closely and extensively with industry. This consultation is necessary because industry representatives know more about their products, technologies, and business environment than bureaucrats do, and often can tell better what will or will not work. Business functions as a check on government policies, and, in turn, the state counterbalances business demands. For example, the automobile industry resisted MITI's plans to merge the firms, which likely would have hurt the industry; but MITI did increase specialization in the industry. The private sector's role in policymaking increases business' commitment to make the policies succeed.

Another' attribute of Japan's industrial policy structure is stability. A stable institution, partially insulated from day-to-day interest group demands, is essential for consistent, long-term guidance. Even when an administration changes, Japanese companies can be assured that MITI's basic policies will not, and that there will not be a sudden turnover of ministry officials. The relative impartiality and lack of corruption of MITI officials is also critical: industrial policy can only work in an environment of trust in which high-quality career bureaucrats work in the national interest. 
Tying government aid to performance and requiring firms to Commit" some of their own funds to R\&D projects have helped to increase the success of Japanese policies. Japan's market is another factor; the domestic market is relatively large, enabling domestic firm to gain economies of scale at home before entering foreign markets. Of course, having access to the world's biggest market-the United States-was also key.

The importance of the comprehensive approach to nurturing an industry cannot be overstated. MITI has promoted not just products, but the entire industries, including the needed parts and infrastructure. For example, Japanese policy frost encouraged development of semiconductors and computer parts, then the hardware of small computers, large computers, and finally software and supercomputers.

As stated before, all of Japan's targeting policies were boosted to a large degree by economy-wide policies and cultural factors. Without government's provision for a large pool of savings-and many other measures designed to transfer capital from consumers to producers-Japan would not have been able to finance its targeting policies. Japan's industrial policies and targeting have cost consumers a great deal in terms of current consumption (while the resulting increases in productivity allow them to improve their living standards in the long run), and the contribution of this deferred gratification on the part of millions of ordinary Japanese citizens should not be underestimated. A first-rate education system, and a culture that reinforces even for small children the importance of educational performance, is another factor. A long history of adopting and modifying for Japanese use successful policies and practices (including technology) from other countries was helpful, as was sheer diligence. It is worth remembering that in most cases where an infant, technologically backward industry was protected in Japan, that industry was working toward world leadership in technology application and development. Most of them got there.

\section{INDUSTRIAL POLICY FOR THE 1990s}

Japan's star is on the rise. Its people are growing richer faster than any others among the developed countries; its fins-at least, its international firmsare cash-rich and outstripping their American and European competitors in advancing and applying technology. In foreign policy, Japan is, with caution, taking a more independent path. In business, Japanese firms are increasingly independent of their government and their banks. Some have suggested that MITI's power and Japan's industrial policy are artifacts of the past.

But a look at MITI policy today indicates that while targeting policies are less important than they once were, the role of MITI and its sister ministries is far from marginal. Indeed, while Japanese companies have money, they may still need encouragement to invest much in technologies that are unlikely to bring about a profit for a decade or more; competing firms also need more encouragement to cooperate with one another than in the past, when cooperation was considered necessary for survival. In many industries, a Japanese fro's fiercest competition comes from other Japanese firms. Finally, Japan's era of cheap capital may be over; in the past year, Japanese interest rates and capital costs have increased rapidly as the bubble burst in the Nikkei stock market. ${ }^{99}$ For these reasons, MITI's role in providing seed money and in coordinating cooperative $R \& D$ remains important.

MITI is funding more R\&D directly, in absolute amounts, than previously. This may seem ironic considering the wealth of many Japanese firms, but they have also moved from being technological followers to positions of leadership, which means the payoffs of R\&D are less certain. For example, one new large-scale MITI project focuses on developing micromachines that combine sensing devices with microprocessors and motors (a technology that originated in the United States) for uses such as surgery without incisions and inspection of cooling pipes in nuclear plants (see app. 6-A). ${ }^{100}$ MITI will plow some \$200 million into this 10-year project beginning in autumn of 1991. Another project focuses on electronic lasers. Eight companiesMitsubishi Electric, Toshiba, Hitachi, NEC, Sumitomo Denki Kogyo, Kobe Steel, Kansai Electric Power, and Nisshin Electric-have created a cooperative $R \& D$ association for the project. Each firm will put in 4 percent of the Y10 billion ( $\$ 78$ million) project, and government will provide the remaining 68 Percent. ${ }^{101}$ The aim is to catchup with the United States in an area that Japan sees as important for applications such as medical equipment, space communications, energy transmission, semiconductors, uranium enrichment, and nuclear fusion. ${ }^{102}$ 
As the content of these two projects suggests, MITI is increasingly supporting basic technologies that, while not close to the market, will have a broad impact on many areas. This strategy makes it easier for competing firms to cooperate and minimizes foreign criticism. Other targeted technologies include new materials, biotechnology, superconductivity, hypersonic flight, high-definition television, biocomputers, parallel processing, and optoelectronics.

Japan's long history of outright trade protection and the fact that her market is still especially difficult to penetrate, in combination with the spectacular successes of many Japanese industries in international competition, have led to increasingly sharp trade conflicts with major trading partners. If the conflicts were only with the United States, it might be possible to attribute them to jealousy. But trade friction is growing rougher with Europe, too, and there are reports of growing wariness toward Japanese investment and imports in Australia. MITI has assumed much of the responsibility for oiling these troubled waters, helping to ease trade fiction through negotiations and encouragement of Japanese firms to use foreign products. ${ }^{103}$ For example, MITI loans companies roughly $\$ 1$ billion to promote aircraft imports. To escape being even larger targets for those who urge retaliatory protection or reciprocity, Japanese firms might need some powerful agency to mediate, intervene, and palliate.

A nation with little or no formal trade protection and a huge market should not need such an agency; Japan's market should be a magnet for foreign goods and companies, as is America's. But MITI's role as ombudsman for the interests of foreign governments and enterprises arises from the Japanese Government's still-powerful ability to govern the activities of foreign firms (be they investors or traders) in Japan. Government procurement practices, customs clearances, inspection standards, approvals on foreign investment, antimonopoly law enforcement, and administrative guidance on issues such as price and production cartels are done largely at government's direction, rather than according to strict legal criteria. There are few clear rules for foreign firms to follow and there are few open, transparent systems for dispute resolution. This discretionary system enables the Japanese Government to use relatively subtle, informal tactics that, according to the weight of anecdotes of those who do business there, still can impede (or assist) the efforts of foreign firms in the Japanese market.

\section{SUPERCOMPUTER INDUSTRY DEVELOPMENT}

A supercomputer is a general purpose computer that is faster than commercial competitors and that has sufficient central memory to compute problem sets of general scientific interest. ${ }^{104} \mathrm{~A}$ supercomputer can do in 1 minute what it takes a mainframe computer 3 hours to do, a workstation 15 hours and a personal computer 96 hours. ${ }^{105}$ These very fast machines enable researchers to analyze a wide range of physical phenomena. They are used, for example, to predict and analyze weather, to design airplanes and automobiles to reduce air turbulence, to discover pharmaceutical compounds with desired effects, and to design semiconductor chips.

A healthy supercomputer industry is considered important because it is a technology driver. "Supercomputers are the testing ground for Japanese logic and memory chips and new types of technology [which can then also be used in mainframes and other products]," explains Raul Mendez, a U.S. supercomputer expert, who after working at the U.S. Office of Naval Research in Tokyo is now the Director of the Institute of Supercomputing Research in that city. ${ }^{106}$ Sekimoto Tadahiro, President of NEC, one of Japan's major supercomputer companies, agrees: "Japanese supercomputer makers can use their technological improvements [related to supercomputers] in their mainframe computers; in that sense we are in a more advantageous position than the U.S. firms that specialize in supercomputers." ${ }^{107}$ Uenohara Michiyuki, executive adviser to NEC and formerly the VP in charge of NEC's research division, explains: “The reason Japanese companies are going into the supercomputer business is for the same reason that auto companies get into race cars; even though it's a small market, it drives the technology. ${ }^{1108} I B M$, which had not been a supercomputer producer since 1970 , reentered the field in 1985 with a vector version of the IBM 3090 that performed in the supercomputer class at the low end; ${ }^{109}$ moreover, IBM is providing financial support to Supercomputing Systems, Inc. (SSI), a new company that expects to produce a new supercomputer in the early 1990s. This suggests that IBM came to the same conclusions about the importance of supercomputer technology as the Japanese companies. 
Supercomputers are important tools for other industries. Increasingly, designs of automobiles and aircraft, pharmaceutical products, and new materials all rely on supercomputers. For example, supercomputers allow simulation of automobile crashes, which in turn can reduce time and expense involved in developing new products. Proposed designs can be tested by computer, without the need to build a model. The computer simulation gives much more precise results than some actual experiments, such as slow-motion blow-up movies of critical parts. Real test crashes can be reduced in number and designed precisely to confirm that a design will work. Similarly, NASA uses a supercomputer to simulate airflow inside aircraft engines, allowing designers to observe things that could not be seen directly in a wind tunnel. To have the benefits of supercomputers in applications, however, it may not be necessary to have a domestic industry.

There are two major types of supercomputers: traditional supercomputers and massively parallel processing supercomputers. Traditional supercomputers - with one or a small number of processors (currently up to eight)--are the major focus of this study. (A processor, sometimes called a central processing unit or $\mathrm{CPU}$, is the heart of a computer.
A processor manipulates data. Other parts of a computer are memory, which stores data, and input-output devices, which transfer data between the computer and the outside world.) Massively parallel processing machines, which have from about 64 to thousands of processors, may be the trend for supercomputing in the next century; their prospects will be discussed as well. ${ }^{110}$

\section{Supercomputer Companies}

There are four major companies in the world supercomputer industry today: Cray Research of the United States, and Fujitsu, Hitachi, and NEC of Japan. Two other companies are also working to bring out their first supercomputers, Cray Computer and SSI (Supercomputer Systems, Inc.). Cray Computer, Seymour Cray's firm that broke off from Cray Research in 1989, has just sold and (as of mid-1991) plans to deliver the first unit of its new supercomputer, the Cray-3, to the Lawrence Livermore National Laboratory before the end of 1991. SSI, a firm started by Stephen Chen after he left Cray Research in 1987, is backed by IBM. Chen's new supercomputer, a 48 to 64 processor machine, is not expected until 1992 or 1993. ETA, a subsidiary of

Table 6-I-Comparison of Cray Research, Fujitsu, Hitachi, and NEC Revenues, R\&D Expenditures, and Profits, 1981,1982, 1988, 1989

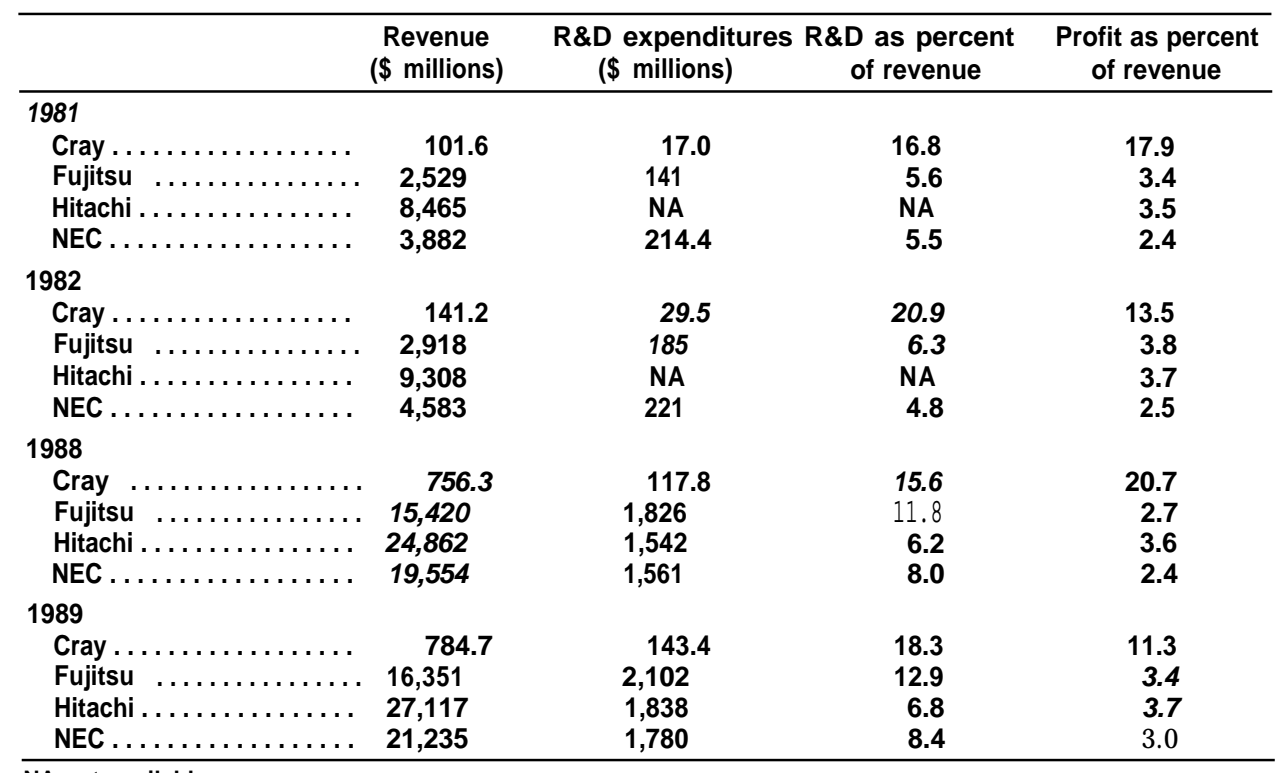

NA-not available.

NOTE: Japanese yen converted at 230/\$ in 1981 and 1982, 130/\$ in 1988 and 1989. The Japanese year ends on Mar. 31. Thus Japanese data are for years ending Mar. 31, 1982, 1983, 1989, 1980.

SOURCE: Company financial reports. 
Table 6-2-Cray Research's Revenues, R\&D Expenditures, and Profits

\begin{tabular}{|c|c|c|c|c|c|}
\hline Year & & $\begin{array}{c}\text { Revenues } \\
\text { (\$ millions) }\end{array}$ & $\begin{array}{c}\text { R\&D } \\
\text { expenditures } \\
(\$ \text { millions }) \\
\end{array}$ & $\begin{array}{l}\text { R\&D as percent } \\
\text { of revenues }\end{array}$ & $\begin{array}{c}\text { Profit as } \\
\text { percent } \\
\text { of revenues } \\
\end{array}$ \\
\hline 1977 & & 11.39 & 1.90 & 16.7 & 17.8 \\
\hline 1978 & $\ldots$ & 17.18 & 2.53 & 14.7 & 20.4 \\
\hline 1979 & $\cdots$ & 42.72 & 6.42 & 15.0 & 18.3 \\
\hline 1980 & $\ldots$ & 60.75 & 9.55 & 15.7 & 17.9 \\
\hline 1981 & & 101.64 & 17.04 & 16.8 & 17.9 \\
\hline 1982 & $\ldots \ldots \ldots \ldots \ldots \ldots \ldots \ldots \ldots$ & 141.15 & 29.51 & 20.9 & 13.5 \\
\hline 1983 & & 169.69 & 25.54 & 15.1 & 15.4 \\
\hline 1984 & & 228.75 & 37.54 & 16.4 & 19.8 \\
\hline 1985 & 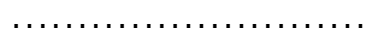 & 380.16 & 49.17 & 12.9 & 19.9 \\
\hline 1986. & $\ldots \ldots \ldots \ldots \ldots \ldots \ldots \ldots$ & 596.69 & 87.68 & 14.7 & 20.9 \\
\hline 1987. & $\ldots \ldots \ldots, \ldots, \ldots, \ldots$, & 687.34 & 108.83 & 15.8 & 21.4 \\
\hline 1988. & & 756.31 & 117.76 & 15.6 & 20.7 \\
\hline 1989 & 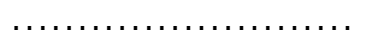 & 784.70 & 143.35 & 18.3 & 11.3 \\
\hline
\end{tabular}

SOURCE: Cray Research annual financial reports.

Table 6-3-Divisions of U.S. and Japanese Supercomputers Firms, 1989 (by percent of sales)

\begin{tabular}{|c|c|c|c|c|c|c|}
\hline & Computers & $\begin{array}{c}\text { Telecom- } \\
\text { munications }\end{array}$ & $\begin{array}{l}\text { Electronic } \\
\text { devices }\end{array}$ & $\begin{array}{l}\text { Consumer } \\
\text { electronics }\end{array}$ & $\begin{array}{c}\text { Heavy } \\
\text { electric } \\
\text { equipment }\end{array}$ & Other \\
\hline Cray Research .... & 100 & - & - & - & - & - \\
\hline Fujitsu $\ldots \ldots \ldots \ldots$ & 70.5 & 16.3 & 13.2 & - & - & - \\
\hline NEC $\ldots \ldots \ldots \ldots$ & 47.0 & 29.4 & 20.1 & 3.5 & - & - \\
\hline Hitachi $^{\mathrm{a}} \ldots \ldots \ldots \ldots$ & 30.0 & 5.0 & 10.2 & 13.7 & 21.4 & 19.7 \\
\hline
\end{tabular}

Control Data Corp. (CDC), was a major player until it withdrew from the market in 1989.

The sales, $R \& D$, and profit data of the four major firms are given in tables 6-1 and 6-2. It is hard to make direct comparisons between Cray Research and the Japanese firms because Cray makes one product line-super-computers-whereas the Japanese firms are both vertically integrated and diversified into various related electronics industries (table 6-3). What is clear from the numbers is that Cray Research is very small compared with its chief competitors: in 1989 its sales were 4.8 percent those of Fujitsu, 2.9 percent those of Hitachi, and 3.7 percent those of NEC. Cray spends a much higher percentage of revenues on $R \& D$ than its Japanese counterparts, 18 percent in 1989 compared to 7 to 13 percent for the Japanese makers. ${ }^{111}$ The data also show that healthy Japanese companies have profit rates (profits as a percentage of revenues) of only some 2 to 4 percent per year, a level that would put a U.S. firm in serious trouble; Cray's profit as a percent of revenues has ranged from a high of 20.7 percent in 1988 to 11.3 percent in 1989 (table 6-2).

\section{Potential Market}

The world supercomputer market is over $\$ 1.1$ billion today. Its annual growth rates in the 1980s ranged from a high of 84.3 percent in 1981 to a low of 4.5 percent in 1989, with an average of 30 percent (table 6-4). The Japanese market has been growing much faster although it has slowed suddenly in the past year: the growth in the number of supercomputers sold has ranged from a high of $\mathbf{1 4 5 . 5}$ percent in 1986 to a negative growth rate in 1990 of about -47 percent (table 6-5). One reason for the sharp decline in $\mathbf{1 9 9 0}$ is that higher prices charged to the Japanese Government (resulting from the 1990 U.S.-Japan supercomputer agreement, which limits Japanese companies' discounts) have not been matched by equally high government budgets, inevitably leading to fewer procurements. Public and private sector purchases of upgraded models have also declined because users are waiting for new, more sophisticated models expected out in 1991.

The drive for ever faster computers pushes the technology in two directions: making faster proces- 
Table 6-4-Value of Worldwide Supercomputer Shipments

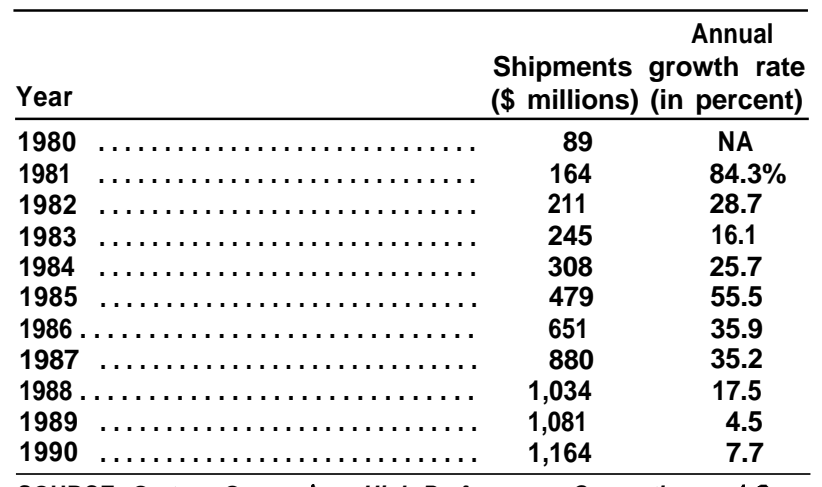

SOURCE: Gartner Group, Inc., High Performance Computing and Communications: Investment in American Competitiveness, Mar. .15, 1991, p. 73.

sors (a processor is the part of the computer that does arithmetic calculations), and using many processors at once. The latter is becoming more important. Traditional supercomputers rely heavily on having fast processors, but manufacturers have been increasing the number of processors to gain extra speed. Cray Research's top-of-the-line machine today has 8 processors; both Cray Research and Cray Computer have announced that they are developing 16-processor machines that they expect to debut in the next few years. Cray Research, along with other companies, is working on machines with 64 processors. The world market for traditional supercomputers is expected to continue healthy growth for the rest of the 1990s, but some analysts expect massively parallel machines to begin taking some of the market from traditional supercomputers.

In the future, the greatest speeds will be achieved by having a large number of processors, even if each processor is only moderately fast. The market for massively parallel supercomputers, which have from 64 processors to many thousand, could prove to be much greater than for traditional supercomputers in the future. To use so many processors to advantage, it is necessary to divide the problem into many independent parts that individual central processing units (CPUs) can work on in parallel. It is difficult to write software to break down problems in this way and even harder to write the software so that all of the CPUs are able to communicate with one another. "There are daunting software problems in massively parallel processing machines, " explained an expert at Lawrence Livermore National Laboratory. ${ }^{112}$ Even if writing software were simpler, there is still a much larger existing stock of software for traditional supercomputers; it will take some time before a comparable library is available for massively parallel machines. The software that has been written was designed to handle special problems, such as pattern recognition. Writing software to make a massively parallel machine into a general purpose machine is much harder.

Scientists and supercomputer users give varying predictions of the future market for massively parallel processing computers, ranging from pessimistic predictions that such machines will never be general purpose machines to optimistic views that they will became more important than traditional supercomputers within the next 5 to 10 years. ${ }^{113}$ Several companies-including Thinking Machines, Alliant, Intel, BBN, Ncube, MasPar, and Cray-are betting on the latter. Most supercomputer experts and supercomputer users agree that the software problem may take a decade to solve, and some analysts see the massively parallel machines as remaining niche machines for the foreseeable future. ${ }^{114}$

\section{Comparisons of U.S. and Japanese Supercomputers}

Japanese manufacturers have faster components, which, all other things equal, would mean faster machines. However, Cray appears to have three compensating advantages. First, Cray excels in packaging and connectors, which also affect machine speed. Second, Cray's processors appear to have a "more balanced" design, meaning that its different elements work together more smoothly, with fewer bottlenecks. ${ }^{115}$ (A bottleneck could occur, for example, if the processor's arithmetic unit-that part of the processor that actually adds, multiplies, etc.-has to stand idle waiting for data to be fetched from memory.) Third, some of Cray's supercomputers gain speed by using more than one processor; no Japanese machines with more than one processor have yet been sold. While using more than one processor is an advantage, it is often tricky to keep all processors busy at once, just as it is tricky to keep different parts of one processor busy at once. Cray's multiprocessor machines tend to work best when doing many problems at once, so that each processor can be assigned its own problem to work on by itself; this reduces the need for inter-processor coordination. Thus, these machines perform better in timesharing systems, running many applications at 
Table 6-5--Number of New Installations in Japanese Supercomputer Market

\begin{tabular}{|c|c|c|c|c|c|c|c|c|c|c|}
\hline 1980 & 1981 & 1982 & 1983 & 1984 & 1985 & 1986 & 1987 & 1988 & 1989 & 1990 \\
\hline $\begin{array}{l}\text { Total (number of } \\
\text { supercomputers) } \ldots \ldots 2 \\
\text { Annual growth rate } \ldots \ldots 2\end{array}$ & $\begin{array}{l}0 \\
\cdot\end{array}$ & $\frac{0}{-1}$ & $\begin{array}{c}4 \\
400 \%\end{array}$ & $\begin{array}{l}6 \\
50 \%\end{array}$ & $\begin{array}{l}11 \\
83.3^{\prime} \% .\end{array}$ & $\begin{array}{l}27 \\
145.5 \%\end{array}$ & $\begin{array}{c}36 \\
33.3 \%\end{array}$ & $\begin{array}{l}37 \\
2.8 \%\end{array}$ & $\begin{array}{c}32 \\
13.5 \%\end{array}$ & $\begin{array}{l}17 \\
46.9 \%\end{array}$ \\
\hline $\begin{array}{l}\text { Sales to public sector: } \\
\text { Total } \ldots \ldots \ldots \ldots \\
\text { By foreign firms } \ldots \ldots \ldots- \\
\text { By Japanese firms } \ldots \ldots- \\
\text { Percent of public } \\
\text { procurement of } \\
\text { foreign machines } \ldots \ldots-\end{array}$ & $\bar{z}$ & E & $\begin{array}{l}2 \\
0 \\
2\end{array}$ & $\begin{array}{l}4 \\
1 \\
3\end{array}$ & $\begin{array}{l}4 \\
0 \\
4\end{array}$ & $\begin{array}{c}12 \\
0 \\
12\end{array}$ & $\begin{array}{c}11 \\
0 \\
11\end{array}$ & $\begin{array}{l}8 \\
2 \\
6\end{array}$ & $\begin{array}{l}4 \\
1 \\
3\end{array}$ & $\begin{array}{l}6 \\
1 \\
5\end{array}$ \\
\hline $\begin{array}{l}\text { Sales to private sector: } 2 \\
\text { Total } \ldots \ldots \ldots \ldots \ldots \ldots\end{array}$ & - & - & 2 & 2 & 7 & 15 & 25 & 29 & 28 & 11 \\
\hline $\begin{array}{l}\text { By foreign firms } \ldots \ldots 2 \\
\text { By Japanese firms } \ldots .0\end{array}$ & - & - & $\begin{array}{l}0 \\
2\end{array}$ & $\begin{array}{l}0 \\
2\end{array}$ & $\begin{array}{l}1 \\
6\end{array}$ & $\begin{array}{c}2 \\
13\end{array}$ & $\begin{array}{c}2 \\
23\end{array}$ & $\begin{array}{c}6 \\
23\end{array}$ & $\begin{array}{l}8 \\
20\end{array}$ & $\begin{array}{l}2 \\
9\end{array}$ \\
\hline $\begin{array}{l}\text { Percent of private } \\
\text { sector procurement } \\
\text { of foreign machines . . 100\% } \\
\text { Foreign share of all }\end{array}$ & & - & $0 \%$ & $0 \%$ & $14.3 \%$ & $13.3 \%$ & $8.0 \%$ & $20.7 \%$ & $28.6 \%$ & $18.2 \%$ \\
\hline $\begin{array}{l}\text { new procurements } \ldots 100 \% \\
\text { Japanese share of all } \\
\text { new procurements } \ldots .\end{array}$ & - & - & $0 \%$ & $16.7 \%$ & $9.1 \%$ & $7.4 \%$ & $5.6 \%$ & 21.670 & $28.1 \%$ & $\begin{array}{l}17.6 \% \\
82.4 \%\end{array}$ \\
\hline
\end{tabular}

NA=Not applicable.

SOURCE: Nlkkel Uotcha, IBM-Ban, Apr. 30, 1990, pp. 21-24.

once, than when dedicated to solve one very large problem.

As these last two factors suggest, measuring a supercomputer's speed is not a cut-and-dried affair. Each machine has what is called a theoretical or peak speed-the speed at which the hardware in principle can do raw calculations. However, on real problems the speed is usually much less-typically between one-half and one-tenth of the peak speed. How much less depends on the hardware design (issues of balance within a processor and coordination among processors), the software (which might be more or less clever at breaking up the problem to keep the whole machine busy at once), and the particular problem (which may, for example, require a great deal of multiplication and division but relatively little fetching and storing of data to and from memory, or vice versa).

One way of comparing the performance of different supercomputers is by benchmarking-running certain problems on each, and comparing the speeds. While benchmarking results depend on which problems are chosen and what software is used, all comparative analyses of supercomputers use benchmark tests as at least one important indicator of performance. Benchmark tests have been done on U.S. and Japanese supercomputers by various universities and labs. Cray Research reported as of May,
1990, that its machines always came out on top (figure 6-1). ${ }^{116}$

In the next generation, however, the gap will narrow; if current rates of progress do not change, Japanese makers will exceed Cray in the peak speeds of multiprocessor machines and likely the actual performance of hardware in the next decade. Japanese supercomputers are rapidly catching up in speed. In recent tests run by Jack J. Dongarra, a computer scientist at the Oak Ridge National Laboratory and a specialist on supercomputer speeds, the one processor SX-3 ran nearly three times as fast as a single processor Cray Y-MP, though not quite as fast as the eight processor Y-MP. ${ }^{117}$ Hideo Yoshihara, a former Boeing specialist in the use of supercomputers for computational fluid dynamics, estimates that the four processor NEC SX-3, which is expected out in late 1991, will have an actual speed of some 7 gigaflops, higher than current Cray machines (1.5 gigaflops), and that the Cray Research C-90 (which will be released as the Y-MP16), also expected in late 1991, will have a similar speed-7 to 8 gigaflops. Cray disputes this, predicting that its C-90 will be considerably faster than NEC's fourprocessor SX-3. Yoshihara estimates that Cray Computer's Cray-3 will have an actual speed of 7 to 8 gigflops, $^{118}$ and another estimate agrees ${ }^{119}$ that all three new machines will have similar speeds. ${ }^{120}$ Fujitsu is said to be working on an eight CPU 
Figure 6-I-Actual v. Peak Supercomputer Performance (megaflops)

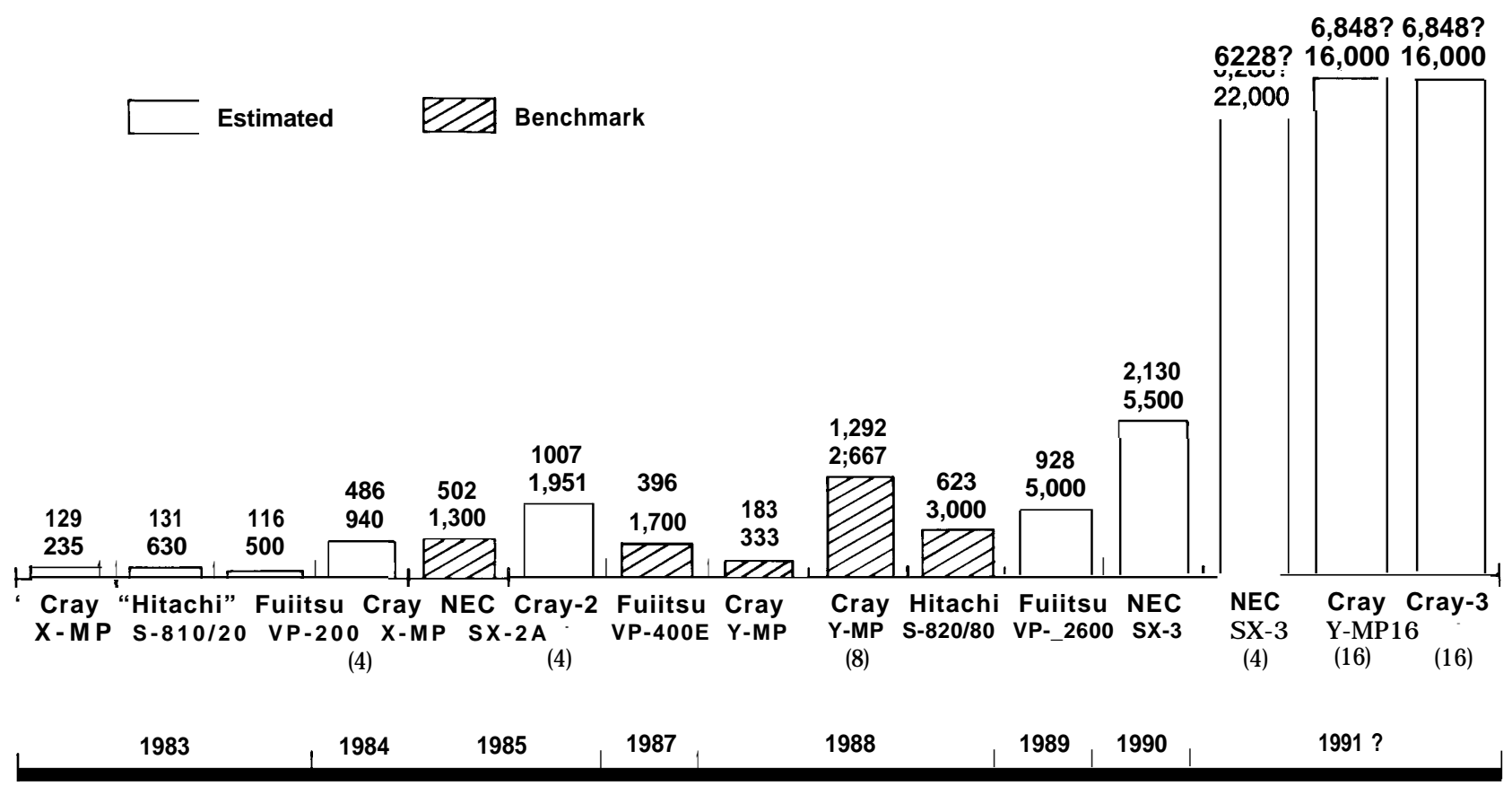

NOTES: Bars show actual or estimated performance on Navier/Stokes benchmark. Numbers show actual or estimated benchmark performance (top) and peak performance (bottom). All systems have only one processor, except where a different number is indicated in parentheses.

SOURCE: Gartner Group, Inc., High Performance Computing and Communications: Investment in American Competitiveness, report prepared for U.S. Department of Energy and Los Alarms National Laboratory, Mar. 15, 1991, p. 205.

machine, ${ }^{121}$ and to have a four CPU machine likely to be introduced in 1992, but no estimates have been made of their speeds.

In short, while Japanese supercomputers currently in use are slower than their U.S. counterparts, and their actual speeds have been substantially slower than their advertised peak speeds, they are still fast and closing the gap. In price/performance ratio, Japanese supercomputers are less competitive than Crays even when the Japanese machines are discounted by 50 percent, according to data from Cray (figure 6-2). According to a different source (and using peak rather than actual performance data) Japanese machines do better in price/performance, and will maintain this edge over traditional U.S. supercomputers, though the United States could beat Japan with massively parallel supercomputers. ${ }^{122}$ In reliability, Japanese machines excel; Japanese machines have been running at more than 5,000 hours mean time between failures (MTBF), compared with Cray's record of less than 1,000 for the Cray X-MP series. While the Y-MP machines are much better in MTBF than the X-MPs, they are not as good as the Japanese machines. ${ }^{123}$
While Japanese manufacturers are closing the gap with Cray in speed and are ahead in reliability, they still suffer from a relative lack of applications software. When NEC announced the SX-3, in April 1989 , with the claim that it was the world's fastest supercomputer:

... people in America were amazed, but Japanese users were not nearly as impressed; they understand that even if it is potentially very fast, it is worthless unless NEC provides [applications] software to use that Speed. ${ }^{24}$

Indeed, NEC has only sold seven supercomputers in Japan to firms outside of the government and its own industrial group (table 6-6).

In massively parallel machines, the United States holds the clear lead. There are no commercialized massively parallel processing machines in Japan. Matsushita, together with Kyoto University, has been developing a parallel processing minisupercomputer, the Adena 256. This machine has 256 processors and a speed of 1.6 gigaflops, and will sell for about Y150 million ( $\$ 1.15$ million). They are also working on a 25-gigaflop machine that they 
Figure 6-2-Performance/Price Data
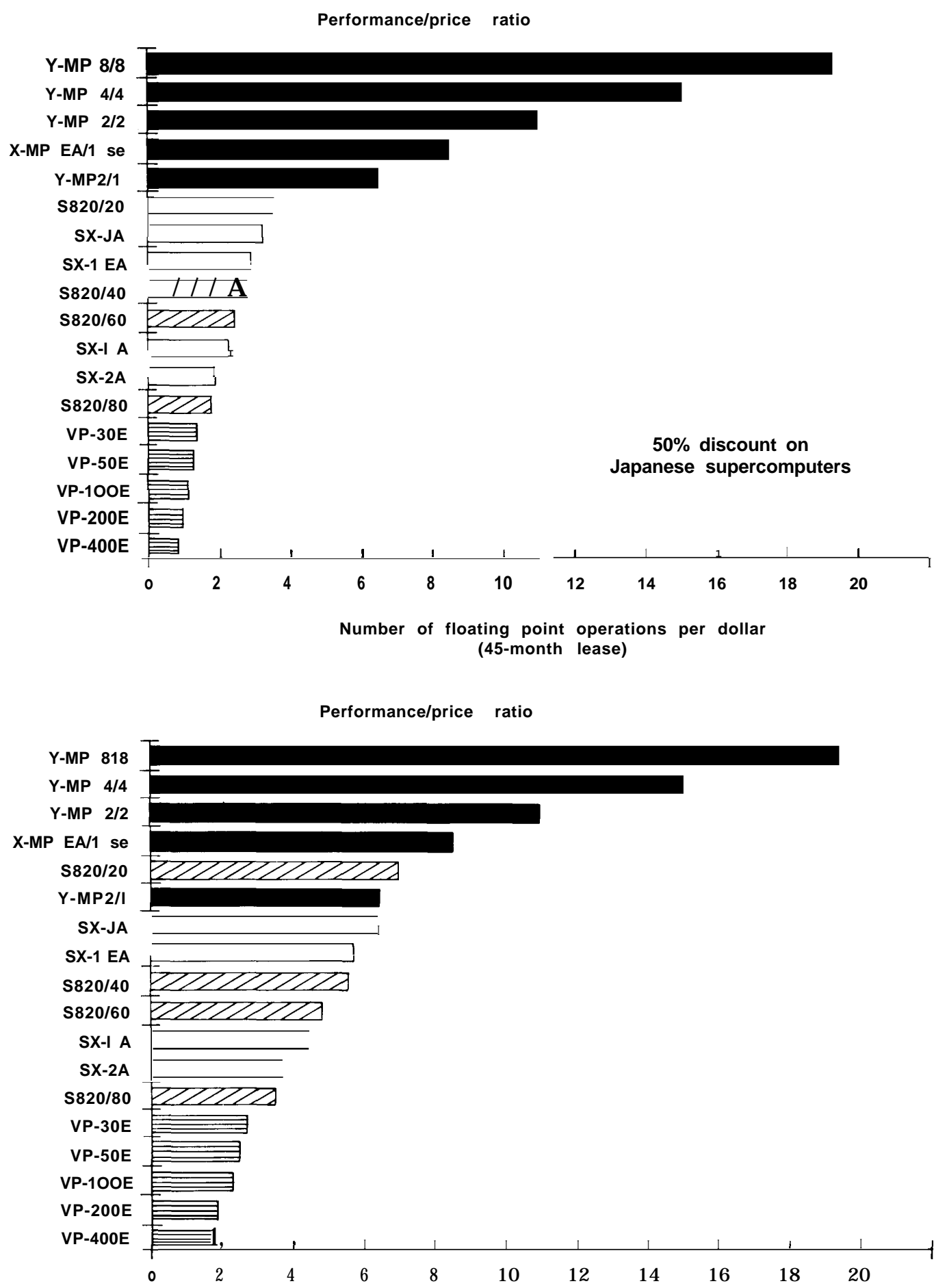

Number of floating point operations per dollar (45-month lease)

NOTE: Performance/Price ratio is calculated from published list prices on all supercomputers shown as of Sept. 30, 1989. A 45-month lease is assumed. It is also assumed that the code run on the computer is 70 to 80 percent vectorized.

SOURCE: Cray Research, Inc. 
Table 6-6-Japanese Procurement of Supercomputers, 1980-90

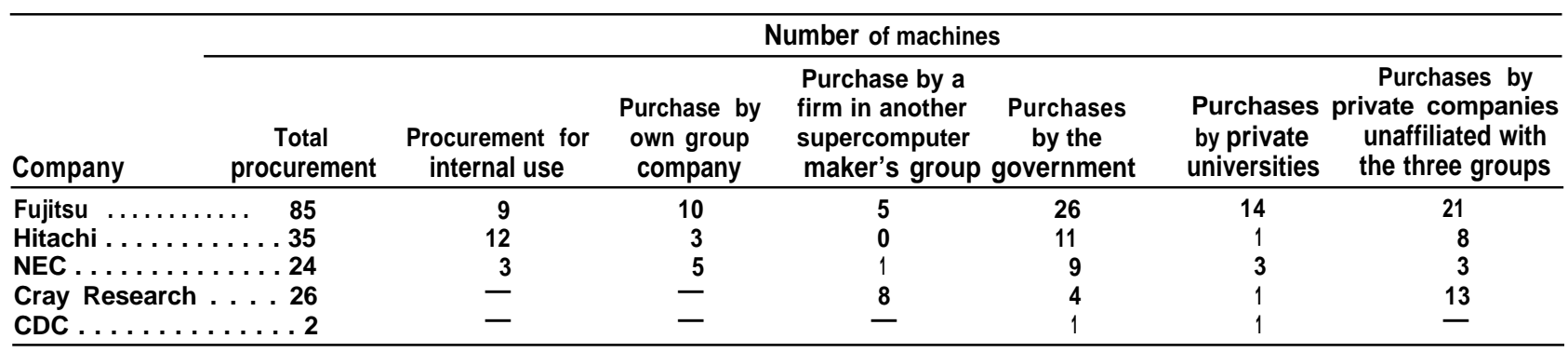

SOURCES: Nikkei Uotcha, IBM-Ban, Apr. 30, 1990, pp. 21-24; Kigyo Keiretsu Soran, 1991.

hope to finish by 1992 and a 100-gigaflop machine by $1995-96 .{ }^{125}$ U.S. and Japanese scientists do not see these efforts as a real threat to U.S. dominance in this area in the near future, but the Japanese are beginning to invest heavily in this technology..$^{126}$

\section{HISTORICAL BACKGROUND: THE EFFECT OF PAST TARGETING OF THE MAINFRAME COMPUTER AND SEMICONDUCTOR INDUSTRIES}

Japan's three supercomputer firms-Fujitsu, Hitachi, and NEC--are also its major producers of mainframe computers, and three of its major producers of semiconductor devices. These firms' experience with computers and semiconductors was crucial in preparing them to make supercomputers. Their rise in the supercomputer industry today depended on previous Japanese Government policies that helped these companies acquire the necessary technological knowledge and skills.

In the late 1950s, Japanese Government officials and businessmen decided to nurture a domestic computer industry. Their main concern at the time was not whether computers alone would become a profitable business, although they hoped it would be. Instead, the primary interest was in the positive contributions of computers to other industries, such as telecommunications, automation, and aerospace, and to the economy's overall productivity. "It was clear to both the government and the telecommunications and heavy electric equipment makers that to survive they had to go into computers," explained Yoshioka Tadashi, who was a MITI official closely involved in nurturing computers in the 1950s and 1960s and more recently the Director and adviser of the Japan Electronics Industry Development Association (JEIDA). ${ }^{127}$ The first step, in 1957, was to pass the Extraordinary Measures Law for Promotion of the Electronics Industry, targeting electronics in general and computers in particular. This law and its later extensions provided various subsidies and tax benefits for the industry; it also exempted the industry from antitrust law and encouraged firms to cooperate on price, production, investment, and $R \& D$ to gain the economies of scale necessary to compete with IBM. Japan did not want to depend on foreign firms for something as critical as computers. ${ }^{128}$

There were four key types of policies that the Japanese Government used to nurture a competitive computer industry: protection, a computer rental company, substantial financial aid, and governmentsponsored R\&D projects. In the 1960s and early 1970s protection was heavy against both imports and foreign investment. While IBM had a sales office in Japan since 1925, MITI repeatedly rejected IBM's efforts to transfer the technology and capital necessary to produce in Japan. ${ }^{129}$ In the late 1950s, according to a former MITI official, IBM started warning the Japanese electronics firms and the government about their infringement of IBM's patents. ${ }^{130}$ MITI realized that the industry would not be able to get off the ground without licenses under IBM's basic patents ${ }^{131}$ and thus negotiated with IBM. IBM agreed to license its basic patents in exchange for permission to set up a wholly owned subsidiary to produce computers in Japan. ${ }^{132} \mathrm{By}$ negotiating with IBM on the behalf of the firms, MITI was able to get licenses at lower rates than if IBM had been permitted to negotiate with each firm alone. MITI also controlled which models IBM could produce and sell in Japan, quantities of each model, and how much and which specific parts IBM could import for its production. ${ }^{133}$ It also decided how much IBM had to export ${ }^{134}$ (indeed, IBM was one of Japan's largest earners of foreign exchange at the time) and limited the profit IBM's Japanese 
subsidiary could repatriate to its parent company. ${ }^{135}$ Finally, it delayed the start of IBM's production by 2 years after the agreement had been made. ${ }^{136}$

Even with all MITI's controls, IBM was lucky. By reestablishing itself in Japan in 1949 (after receiving back its assets that had been confiscated during the war), IBM Japan avoided being forced by the Foreign Investment Law of 1950 to make a joint venture with a Japanese firm. ${ }^{137}$ When Sperry Rand (UNIVAC computers) wanted to sell computers in Japan in the late 1950s, MITI used this law to require it to make a joint venture with Japanese companies and to give the Japanese partners a majority of the shares; MITI felt it could more easily control a firm with majority Japanese ownership. ${ }^{136}$ When Sperry Rand decided in the early 1960 s that it wanted to produce computers in Japan, MITI insisted that it make another joint venture, this time with Oki Electric, to create Oki UNIVAC; Oki was required to hold 51 percent of the shares. Similarly, MITI allowed Hewlett Packard into Japan only on the condition that it make a joint venture with Yokogawa Electric, with the latter holding 51 percent of the shares. ${ }^{139}$

In addition to controlling the actions of U.S. manufacturers, the state also had a "Buy Japan' policy. In the 1960s and early 1970s the government procured some 25 percent of all Japanese computers; in the last half of the 1970s and early 1980s, this increased by up to 5 percentage points. ${ }^{10} \mathrm{In}$ both 1984 and 1989,90 percent of the computers used by the government were Japanese machines while only 59 percent of the machines used by the private sector were domestic. ${ }^{141}$ "Protectionism was one of the most important policies [to promote the computer industry]. The government created the computer market, first by making government labs buy domestic machines, then having national universities purchase them,' explained Takeuchi Hiroshi, Managing Director of the Long Term Credit Bank of Japan. ${ }^{142}$

While not a formal government policy, the tendency of Japanese firms to purchase computers made by their group (keiretsu) computer company also serves to protect the market; in 1968, for example, about half the computers being used by firms in the major industrial groups were machines made by their own group's computer firm. ${ }^{143}$ As of the late 1980s, 45.7 percent of the Sumitomo group machines were of NEC origin and 54.3 percent of foreign origin (the Sumitomo group did not use machines of other Japanese computer makers); 70.6 percent of machines being used by Daiichi-Kangyo group companies were of their group members Fujitsu and Hitachi, 28 percent were of foreign origin, and a mere 1.4 percent were machines of other Japanese makers. ${ }^{14}$ This pattern, with Japanese firms in each group buying computers either from their own group or from foreign fins, suggests that the fins' in-group purchases are made at least partly because of group loyalty rather than the machines' worth. This loyalty handicaps foreign firms operating in Japan. The foreign share of the Japanese installed computer base plunged from 93 percent in 1958 to 48 percent by 1965 and 42.5 percent by $1969 .{ }^{145}$ In 1989 , the foreign share stood at about 37 Percent. ${ }^{146}$

While early protection gave the computer firms a safe harbor within which to develop, it was clear that the government would ultimately have to open up its markets; the firms had to become competitive in order to survive over the long term. A major problem they faced was that of renting their machines. Most Japanese computer users did not have the huge amounts of money needed to purchase computers; rapid technological advances deterred those that did from purchasing machines that would inevitably become obsolete within a year or two. IBM was renting its machines, so domestic companies needed to be able to rent to compete. But domestic firms did not have the funds necessary to finance a rental system, nor were banks willing to lend them the money. ${ }^{147}$ To enable the firms to offer rentals, MITI helped them establish the Japan Electronic Computer Co. (JECC), a joint venture among the major computer makers, in 1961. JECC's role was to finance the rental of mainframe computers; by the 1980s it would also become the major renter of supercomputers. Between 1961 and 1989, the government channeled over $\$ 6$ billion in loans into JECC to help the company buy computers from member firms and rent them to users for low monthly fees. ${ }^{148}$

When a user wanted to rent a computer, it notified JECC, and JECC purchased it from the maker and rented it to the user. The effect of purchasing the machines was to give the makers their return on investment up front-similar in effect to an interest free loan. ${ }^{199}$ Since the firms themselves put capital into $\mathrm{JECC}_{1}{ }^{150}$ to some extent the firms were lending money to themselves. However, between 1961 and 
1989 JECC also received low interest loans from the Japan Development Bank with an implicit subsidy value of $\$ 461$ million. ${ }^{151}$ "JECC had a very big effect in reducing our need for capital; if there had not been a JECC in the 1960s and 1970s, we [Fujitsu] could not have expanded our scale of production; in that sense JECC played a very big role,' explained Tajiri Yasushi, a manager at Fujitsu. ${ }^{152}$

By enabling Japanese computer companies to rent their machines at low monthly fees, JECC stimulated both the supply and demand for domestic computers. ${ }^{153}$ JECC also managed a price cartel for the industry and did not allow any discounting. By limiting price competition, JECC assured firms that profits would not evaporate in cutthroat price wars and shifted the competition to cost, technology, and quality.

JECC and domestic protection severely limited foreign computer fins' market share in the Japanese market, but they were not enough to improve Japanese electronics companies' competitiveness to match that of IBM or Cray Research. In the early 1970s, the Japanese computer makers' scale of production was, on any given model, 1 to 2 percent that of $\mathrm{IBM}^{154}$ and the technology was far inferior. They needed financial help. One estimate is that government financial assistance-subsidies, loans, and tax benefits-to the industry amounted to some $\$ 14.3$ billion from 1961 to $1989 .{ }^{155}$ According to this estimate, in the $1960 \mathrm{~s}$, government aid was some 188 percent of what the firms themselves were investing in $R \& D$ and plant and equipment; from 1970 to 1975 , it was 168 percent; from 1975 to 1981 ,

92 percent, and from 1982 to 1989,26 percent. As a percent of sales, government aid was 53 percent from 1961 to 1969 ; 40 percent from 1970 to 1975 ; 14 percent from 1976 to 1981 and 5 percent from 1982 to $1989 .{ }^{15} 6$ OTA has reestimated the total government financial assistance as $\$ 12.6$ billion (see app. 6-A). Under OTA's reestimated, government aid as a percentage of investment in these four time periods, from earliest to latest, was $87,148,84$, and 23 percent; as a fraction of sales it was $24,35,13$, and 4 percent respectively.

This does not include the tremendous benefit the firms received from the Japan Telegraph and Telephone Co. (NIT'), which was a government-owned company until April 1, 1985, when the Ministry of Finance started to sell some of its shares to the public (the government intends to keep one-third of NTT's shares permanently, and the company remains under the supervision of the Ministry of Post and Telecommunications). NTT has long been referred to as the doru bako (dollar box) helping the computer companies by purchasing their products (according to some, at artificially high prices) ${ }^{157}$ Tajiri Yasushi, a manager in Fujitsu's marketing department, stated in 1987 that:

NIT has probably been the greatest help to Fujitsu's business. Because of the profitability of doing business with NIT, it was more important [than MITI] for private industry. Our business with NTT has always been based on NTT purchasing the product, and we have always made a profit on business with NTT. ${ }^{158}$

Indeed, Fujitsu, NEC, and Hitachi got the bulk of NTT's computer procurement, which totaled some $\$ 13.3$ billion from 1965 to $1975^{159}$ and $\$ 13.6$ billion from 1980 to $1986 .{ }^{160}$

The government also used cooperative $R \& D$ projects to nurture a competitive computer industry. These were aimed at helping the firms reduce their technological gap with U.S. computer companies by reducing duplicative research and accelerating technological advances. Numerous projects were undertaken from the early 1960s through the 1980s and early 1990s (table 6-7). Several have been particularly important in enabling Japanese firma to develop the technologies and skills necessary to produce supercomputers in the 1980s. Early projects, such as the 1966 Super High-Performance Computer Project, helped the firms gain a foothold in the supercomputer industry both in design and in integrated circuits.

The "New Series" Project, from 1972 to 1976, was critical in getting Fujitsu and Hitachi to standardize their architectures and go the IBM compatible route ${ }^{161}$ Standardizing their architectures meant that with minor modifications, software created for a Fujitsu machine could also run on a Hitachi and vice versa, and that the two machines could be used with each other. This assured potential users that if one of the two companies withdrew from the computer business, machines and software purchased from the defunct supplier could be kept and used with machines and software from the remaining firm. Possibly, these decisions also helped Japanese companies to compensate for weakness in software development and small libraries of 
Table 6-7-Government Subsidies for Computer-Related Government-Sponsored R\&D Projects

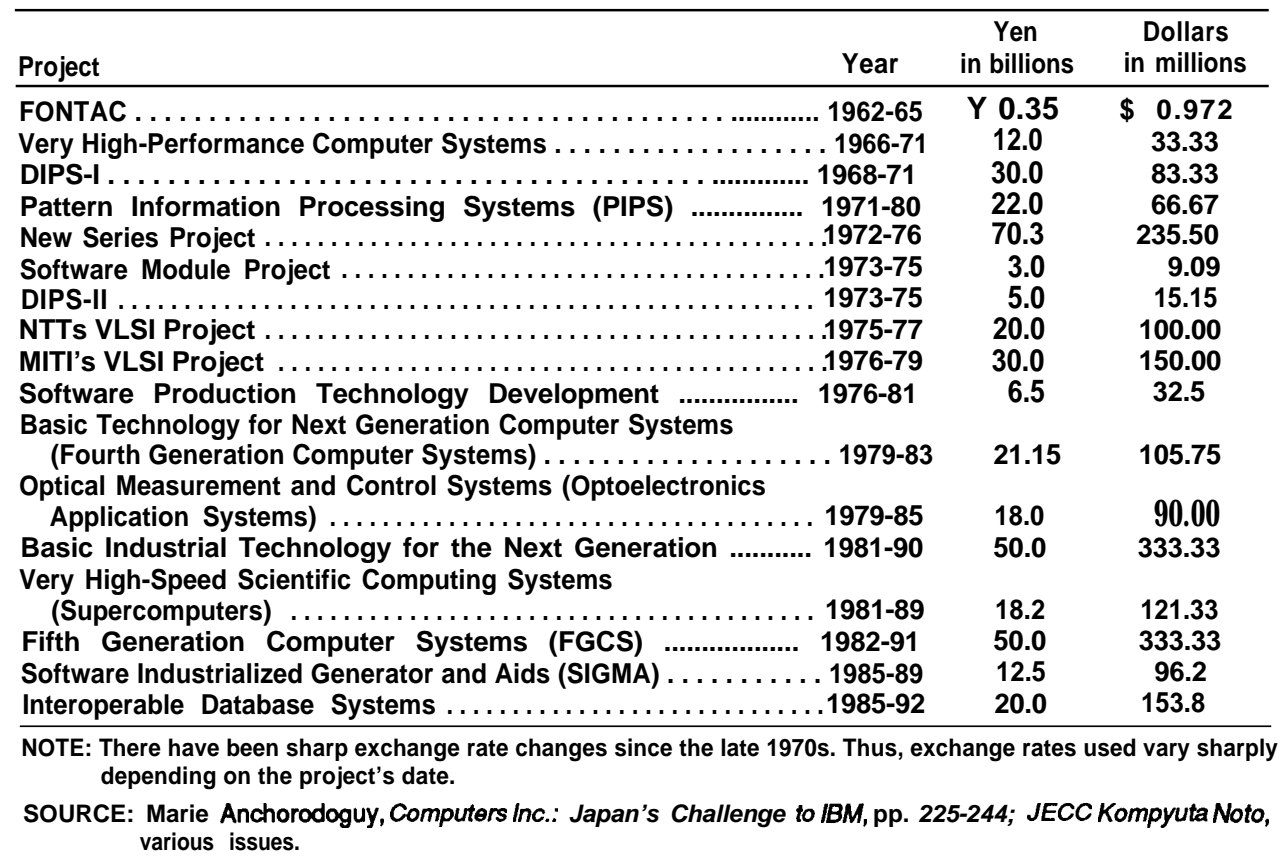

software (an area of strength for IBM). At any rate, Fujitsu and Hitachi cooperated just long enough to "unravel the secrets" of the architecture of IBM computers. ${ }^{163}$ In explaining to his employees Fujitsu's decision to cooperate with Hitachi in this project, Kiyomiya Hire, Fujitsu's Vice President, said:

Frankly speaking, if we do not do this, we cannot confront our American competitors. If Japanese makers in the domestic market did not cooperate and only competed, before we knew it, we would be taken over by the American firms; there is a danger that every maker would be dealt a fatal blow. On the other hand, if we only cooperate and do not compete at all, we will all slide into stagnant waters, which also would be bad. The British and French computer industries are examples of this. Thus, using cooperative relations during the early stages of development as a base, we will then compete on commercializing the product; as a whole, we must oppose the threat posed by foreign capital. Thus we will cooperate on R\&D, but in sales and production we will compete fiercely as we have in the past.... Finally, I would like to add that in the background of this move is the earnest guidance of MITI and the deep understanding of NTT. In regards to the big problems created by the decision to liberalize the computer industry in three years, both NTT and MITI have been serious and forward-looking in considering what form our computer industry should take in order to oppose the giant power of American capital. ${ }^{164}$
The architecture of the M-series computers Fujitsu and Hitachi developed during this project is the basis of their mainframe and supercomputer architecture today; Fujitsu's M-380 mainframe and Hitachi's $\mathrm{M}-280 \mathrm{H}$ mainframe were used as the starting point for the development of their Fujitsu VP series of supercomputers and Hitachi S-81O supercomputers respectively. ${ }^{165}$ When Fujitsu Chairman, Kobayashi Taiyu, was asked how the Japanese were able to survive during this volatile period in the early 1970s even though RCA and GE withdrew from the computer industry at this time, he replied: “[B]ecause MITI started providing research grants and made different companies get together for cooperative development of new machines; for the first time, Japanese makers were ready for battle.

NIT's and MITI's VLSI (very large scale integrated circuit) projects, from 1975 to 1977 and 1976 to 1980 respectively, were also key in helping the Japanese companies catch up in device technology. This was a necessary step to their becoming competitive in supercomputers today. NTT provided Y20 billion ( $\$ 100$ million) to work with Fujitsu, Hitachi, and NEC on 64K RAMs (random access memories with 64 kilobits, or 64 thousand bits, of memory), something immediately commercializable. ${ }^{167}$ While the NTT project formally lasted only 3 years, NTT, 
which does no production of its own, continued to work closely with these firms on advanced chips after the project ended. These efforts led to many advances in developing 64K RAMs in the last half of the $1970 \mathrm{~s}^{168}$ and a $256 \mathrm{~K}$ RAM in early 1980. "NTT played a great role in the development of VLSI technology," according to Sakai Yoshio, senior researcher at Hitachi's Central Research Laboratory. ${ }^{169}$

MITI's VLSI project targeted the development of the production equipment necessary for very large scale integration. Denser packing of integrated circuits, which increases speed and decreases cost, would be key to advances in electronics in general and computers in particular. The problem was how to develop equipment to draw narrower lines on wafers and thereby squeeze more circuits onto a wafer. To study these topics, MITI divided up the five firms involved in the project-Fujitsu, Hitachi, Mitsubishi, NEC, and Toshiba-into three groups and had them take seven different approaches to the same problem. The rationale was that there are always failures in R\&D; if several firms approach a problem differently and agree to share their results, the time and money it takes to develop a successful technology can be cut substantially. The 4 year project cost Y72 billion (\$360 million), of which Y30 billion was funded by the government. ${ }^{170}$ "The timing of the project was critical," explained Shimizu Sakae, Senior Managing Director of Toshiba, "there was no electron beam [for drawing very fine lines] and we needed a breakthrough to get ahead. The firms did not have any of the equipment for producing VLSIs, such as the electron beam or testing equipment. "171 The firms would not have done research on such advanced chips at that time if not for the project. ${ }^{172}$ Indeed, the project was too risky for firms to do without the government sharing costs and risks. As one maker put it:

Because of the limited resources of a private firm, we domestic makers cannot allow a failure; we cannot deny that this [participation in MITI's VLSI project] was taking a big hedge against risk. ${ }^{173}$

Without MITI's VLSI Project, explained Matsukara Yasuo, General Manager of NEC's VLSI development division, each company would have had to spend five times as much on $R \& D$ to develop electron-beam technology. ${ }^{174}$

Several specialists point to the VLSI project results as being a critical ingredient in Japan's ability to enter the supercomputer market in the early 1980s. ${ }^{175}$ Indeed, the speed of Japan's supercomputers today is largely the result of very advanced semiconductors. While Japanese companies' private efforts account for most of the advances in devices used in supercomputers, the VLSI project did allow them to get a foothold in this field at a critical time.

Japanese policies supporting the development of the computer and semiconductor industries were characterized by flexibility-making fast responses to new developments and supporting the firms that seemed strongest at various points in time-and strategic use of market signals to provide firms incentives to improve technology. For example, JECC only bought domestic computers that users specifically asked to rent. There was a direct tie to the market; if no one asked to rent a particular computer, JECC did not buy it. Those firms with the best machines got the most orders from customers and thus the most benefit from JECC. By managing prices, JECC helped the firms avoid destructive competition, but prices were set at levels competitive with IBM. Price cooperation pressured the firms to compete on other dimensions key to developing competitiveness-like cost, quality, and technology. R\&D subsidies were important but the firms often had to match R\&D grants and always had to contribute their engineers. This assured some degree of commitment from the companies, as well as direct transfer of technologies to the private sector. And subsidized R\&D was tied to performance. If a company did not commercialize the results of a project, or in general became uncompetitive, it could expect to be left out of the next project. This happened to Oki Electric-it was left out of the VLSI project due to its failure to commercialize the results of the research it did in MITI's earlier 'New Series" project. ${ }^{176}$ Finally, cooperation on R\&D a step before the commercialization stage helped the firms but still left substantial room for competition, which provided incentives for rapid development and manufacturing efficiency.

\section{TARGETING SUPERCOMPUTERS}

As the earlier analysis of U.S. and Japanese supercomputers suggests, Japanese companies have almost caught up with (and maybe poised to move ahead of) their U.S. competitor (Cray Research) in the hardware for traditional supercomputers, though they lag in software (especially applications software) and in developing massively parallel process- 
ing machines. Government policies have been an important ingredient enabling them to rapidly close the technological gap with American companies.

\section{The High Speed Computing System for Scientific and Technological Uses}

The major R\&D effort targeting supercomputers was the High Speed Computing System for Scientific and Technological Uses Project, 1981 to 1989. ${ }^{177}$ It was clear to MITI and the computer companies that both high speed devices (components) and architectures (overall designs) that permitted many calculations to be done in parallel would be necessary to make better computers, and that these computers would have important applications.

For nuclear fusion, nuclear power, energy exploration, weather and earthquake forecasting, and defense-areas related to national security-it is necessary to have a high speed computer [such as that to be developed in this project],

according to a MITI statement on the project. ${ }^{178}$ MITI also knew that the R\&D needed to make better computers would be useful in other industries as well:

Completing the High Speed Computer System for Scientific and Technological Uses will have broad spillovers sharply raising the scientific and technological level of every industry. . . thereby contributing to our aim of establishing our nation as a leader in technology. ${ }^{179}$

The primary goal of the project was to help the firms acquire the technological building blocks for making their own supercomputers, but the formal goal was to develop a prototype; 180 in order to get money from the Ministry of Finance for projects, MITI needs to be able to show them something specific at the end. ${ }^{181}$ The project was fully funded by the government; the initial budget was Y23 billion but in the end the government spent only Y18.2 billion (\$121.33 men). $1^{82}$ It called for development of a 10-gigaflops parallel processing supercomputer, a speed that at that time seemed like a dream. ${ }^{183}$ The six major vertically integrated computer/semiconductor companies-Hitachi, Fujitsu, NEC, Mitsubishi, Oki, and Toshiba-participated in the project (figures 6-3 and 6-4). Matsushita and Sony wanted to join the project but were not allowed in. ${ }^{184}$

The project focused on high-speed devices and parrallel architectures. The research on high-speed devices was divided up among the six participating firms: NEC, Toshiba, Hitachi, and Mitsubishi researched gallium arsenide chips; 185 Fujitsu, Hitachi, and NEC, Josephson junctions; and Fujitsu and Oki, HEMT (high electronic mobility transistor) de-

Figure 6-3-Schedule of Research and Development for High Speed Computing System for Scientific and Technological Uses Project

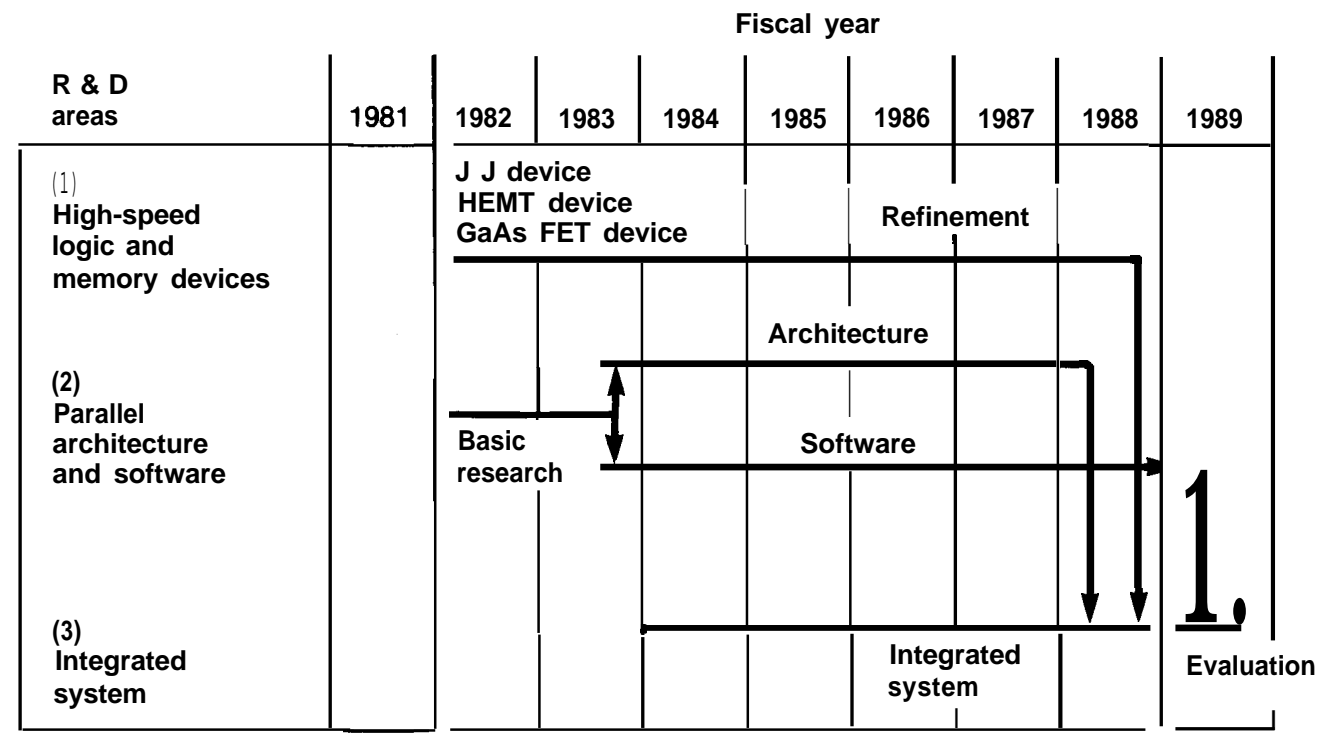

SOURCE: MITI. 
Figure 6-4-Organization of the Supercomputer Project, 1981-89

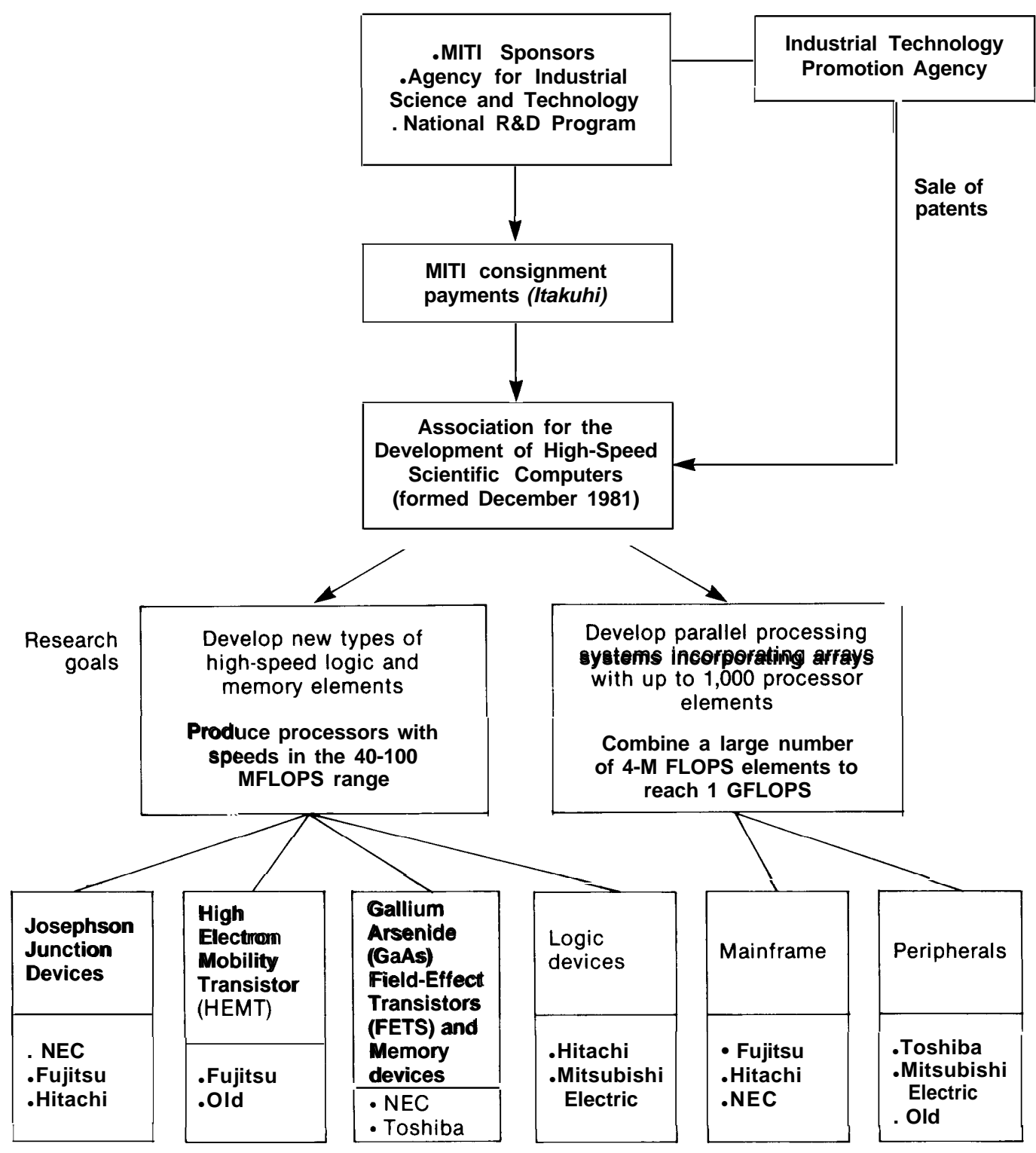

SOURCE: Dataquest, Inc.

vices. ${ }^{186}$ Both U.S. and Japanese researchers agree that this project helped the Japanese firms gain proficiency in these technologies. ${ }^{187}$

The research on parallel processing was divided into three subgroups: the high-speed parallel subproject; the sigma-1 dataflow subproject; and the satellite image processing subproject. The high-speed parallel subproject was the most important. Aimed at quickly developing a four CPU machine, the subproject combined into one machine four of Fujitsu's already successful single processor ma- chines, ${ }_{1}^{188}$ which had an architecture based on that developed in an earlier MITT project. ${ }^{189}$ Fujitsu focused on developing the software needed to get the four processors to operate in parallel. The prototype high-speed parallel system ran at over 10 gigaflops. The system was designed to accommodate up to 16 processors, but because of budget constraints only 4 were used. ${ }^{190}$

The second architectural subproject--Sigma-1 Dataflow subproject-focused on developing a machine with 128 processors, a precursor to one 
with 1,024 processors. ${ }^{191}$ Dataflow machines were tried in the United States and were not very successful; thus most U.S. scientists do not expect this subproject to have a big impact on Japanese supercomputers. ${ }^{192}$ The subpl-eject also had software problems, according to a U.S. researcher who visited the ETL (MITI's Electrotechnical Laboratory) in both 1989 and 1990 and saw little progress made on the software necessary to run the machine. ${ }^{193}$ Nonetheless, the research group's successful completion of a 128-processor machine adds to the participants' understanding of massively parallel architectures.

The third subproject was the satellite image data processing system, ${ }^{194}$ mother way of exploring parallel architectures; this system can be used for data processing of images and visualization. Three types of architecture were explored: Toshiba focused on a high-speed three-dimensional display processor using 16 very fast VLSI processors; Mitsubishi worked on a simpler machine aimed at processing image data obtained from satellites; and Oki worked on a two-dimensional display using 8 processors for use in global data processing networks. ${ }^{195}$ These results will help these firms make parallel processing machines for voice and pattern recognition and visualization, areas considered increasingly important in the 1990s.

As early as the mid-1980s, people from the firms involved said that the project was helping them significantly; ${ }^{196}$ but the big results of the project have yet to be incorporated into the firms' machines. The final prototype, completed in early 1990, demonstrates how the main technologies developed in the project work together, primarily the device technologies and the results of the high speed parallel subproject. ${ }^{197}$ It is not, however, a prototype of a machine that could be directly commercialized. While Fujitsu was the main contractor for the prototype of a 10-gigaflop machine, doing the computing system and integration of all the parts, Hitachi did the operating system, and NEC the high-speed, large-capacity storage system. ${ }^{198}$ Many concrete results were achieved: in the final prototype, gallium arsenide devices were used, though not as extensively as initially envisioned; Josephson junction devices were not used at all in the final prototype, although the project advances in Josephson junctions put Japan in the lead in this area, which is considered to have good prospects in the late 1990s and after ${ }^{199}$ Fujitsu used these results to develop a recently announced hybrid Josephson junction-VLSI device, which it plans to use in its next generation supercomputers, scheduled for the mid-1990s. ${ }^{200}$ All in all, some 602 patents resulted from the project. ${ }^{201}$ Licenses are available to all participating companies for a nominal fee and other companies for a higher though still reasonable fee.

Another contribution of the project was that it got Japanese computer makers to focus on supercomputers. The companies were not initially interested in the project because they thought there was not a large enough market for supercomputers. ${ }^{202}$ When the project was started, there were few supercomputers in use worldwide, so we thought there was not enough demand. I do not think that one company would have made such a big effort in supercomputers [as the project has], " explained Oketani Kisaburo, section chief of Fujitsu's Market Planning Departrnent. ${ }^{203}$ When asked why Fujitsu does not refuse to join MITI projects it is not interested in, Tajiri Yasushi of Fujitsu explained: " If we ever said, 'forget about Fujitsu [for a given project] and do it with someone else,' we would never be invited to join a government project again, ${ }^{\prime 204}$ a consequence Fujitsu was not willing to accept.

The government offered to fund the entire project and the firms went along. Supercomputer development might have happened eventually, but the project started things moving sooner, and, through cooperation, probably got the job done faster and more efficiently than if any one firm had worked on its own. "The Japanese industry and R\&D institutes are very cooperative and often go on 'division-oflabor' arrangements. This gives us a considerable edge over IBM, which has to do everything on its own,' " stated Fujitsu Chairman Kobayashi Taiyu. ${ }^{205}$

The companies supplemented the project with their own research. A Japanese expert closely involved in the project said the three Japanese supercomputer makers are each spending three to four times the project budget on supercomputer research themselves, ${ }^{206}$ suggesting spending of some $\$ 360$ to 490 million investment by each of the three fins. This investment, along with the $\$ 121.33$ million provided by this government project, pays part of the development of new generation supercomputers. Cray forecast that it would spend $\$ 100$ million in development costs for its C-90 machine due out in late $1991{ }^{207}$ Cray's spending should not be compared directly with the Japanese companies' 
spending during the High Speed Computing System project, for that project spans more than one generation of product development; moreover, it is not clear how many years Cray's $\$ 100$ million expenditure on the C-90 covers. Nevertheless, the very rough comparison is instructive. The Japanese firms can outgun Cray in $R \& D$, in part because of help from their government.

NTT has its own supercomputer project, which involves Fujitsu, NEC, and Hitachi. ${ }^{208}$ In early 1985, the NTT lab successfully developed a 1K lead-based Josephson memory chip, which ranks as one of the fastest in the world, and also a pace-setting $4 \mathrm{~K}$ gallium arsenide memory. ${ }^{209}$ Unfortunately, it is impossible to get any further information on NTT's supercomputer project.

\section{Other Government-Sponsored Projects Related to Supercomputer Technologies}

Several other projects have contributed to Japan's ability to produce parallel processing machines. Indeed, there are over 70 projects exploring parallel and massively parallel processing in Japan's public and private sectors; about 25 percent focus on high speed supercomputing, 25 percent on artificial intelligence, and the remaining 50 percent on areas such as image processing, computer graphics, computer aided design (CAD), and databases. ${ }^{210}$.

The largest is the Fifth Generation Computer Project, 1981 to 1991, a Y100 billion project, which the government is supporting with Y50 billion (\$333.33 million). This project focused on developing parallel processing for artificial intelligence (as opposed to numerical computing applications). The goal was for a machine able to infer knowledge based on data stored in its memory, for example, a computer able to write its own software for new applications and able to process and understand a variety of symbols, including kanji (the Chinese characters that are part of the Japanese written language) and photographs. The initial expectation was that the fifth generation machine would be able to "reason" at an elementary level, and thus help managers, doctors, and others who analyze problems through complex sequences of inferences.

Eight companies (Fujitsu, Hitachi, NEC, Mitsubishi, Toshiba, Oki, Matsushita, and Sharp), along with NTT, have sent engineers to ICOT (Institute for New Generation Computer Technology), a central laboratory established in $\mathbf{1 9 8 2}$ to conduct the re- search. (NTT also has its own fifth generation computer project, which it invited NEC, Hitachi, and Fujitsu to join. ${ }^{211}$ ) At ICOT, researchers from the different companies work side by side, something unusual in MITI projects. ICOT also distributes work among five other laboratories.

The Fifth Generation Project worked on both software and hardware. The Japanese companies originally did not want to join the cooperative effort because they believed that the goals were far too vague; they were particularly concerned that the project did not target an IBM-compatible machine. ${ }^{212}$ But the government agreed to put up money to get the project started, and the firms went along and ultimately matched the government funding.

It is too early to assess the project's impact. It is generally believed that the project fell far short of its ambitious goal of creating a prototype "thinking machine." Some U.S. scientists in particular criticize the project's focus on logic programming and the fact that it has not produced any fundamental advances. ${ }^{213}$ Even so, the project probably is not a dead loss. Speaking of one of the project's interim results-Mitsubishi's uniprocessor and 16-processor parallel inference machines, which were demonstrated at Argonne National Lab in Illinois-an Argonne scientist said:

They are learning a lot about parallel processing. By working in this project, the companies have gotten their brightest people exposed to many issues in parallel processing and to the international scientific community. Now that the project is ending, these people will go back to their firms with this knowledge. The project has not been a total success but I expect a favorable long-term effect. ${ }^{214}$

Computer makers expect some spin-offs from technology researched in the project, according to Shimizu Sakae, Toshiba's Senior Managing Director; ${ }^{215}$ some spin-offs have already been commercialized.

The project has played a role in pushing the industry to explore new technologies, especially non-IBM compatible machines. The industry was rattled in mid-1982 when IBM cooperated with the FBI in a sting to catch Hitachi and Mitsubishi stealing IBM's technological secrets. The Japanese firms have been forced to make licensing agreements with IBM involving large sums. Hitachi, for instance, reportedly paid IBM Y1O billion ( $\$ 45.45$ 
million) for the cost of a lawsuit and for past use of software similar to IBM's, and in the mid to late 1980 s was paying some Y8 to Y12 billion $\mathbf{\$ 6 0 - 9 0}$ million) a year for its use; IBM also received the right to inspect new Hitachi machines to confirm that Hitachi is keeping the agreement. ${ }^{216}$ Japanese companies felt that, to survive over the long term, they would have to develop their own operating system standard. "We have to make a complete break from the IBM standard in order to survive," said Yamamoto Kinko, the Managing Director of the Japan Information Processing Development Center (JIPDEC). ${ }^{217}$ "We've got to find another standard," agrees Tomioka Susumu, manager of Fujitsu's software division. ${ }^{218}$ If Japanese companies do develop their own standard, and it is widely accepted, this could have serious consequences for IBM, as well as other U.S. systems and component producers.

Finally, the technologies investigated in the project will help Japanese companies to move towards massively parallel machines. In the interim stage of the Fifth Generation Project, Mitsubishi completed a prototype of a 64-processor parallel inference machine. The project is concluding with three prototypes: a full version 1000 VLSI processing unit made by Fujitsu, one with about 256 processors made by Mitsubishi, and a smaller version made by a third company. ${ }^{219}$ It is too early to know how good these machines will be; but even though they are unlikely to be commercial successes, the firms and their researchers will have gained experience.

As a successor to the Fifth Generation Project, MITI is exploring a New Information Processing Technology Project (NIPT). This so-called "Sixth Generation Computer Project" is expected to focus on basic principles of massively parallel processing, three dimensional information, and visual and auditory recognition, aimed at developing a reliable computer with a million or more processors. ${ }^{220}$ The project will continue the Fifth Generation project's focus on a"thinking" computer, one that performs tasks such as pattern recognition and intuitive information processing better than conventional computers. The goal is to be able to deal with ambiguous or incomplete information. ${ }^{221}$ Though in July 1991 the project was still in the planning stage and had not yet been given the official go-ahead, it was expected to be approved, to be of the same scale as the Fifth Generation Project, and to follow an organizational structure such as that used by ICOT. ${ }^{222}$ Two U.S. computer scientists familiar with this proposal argue that while there will be difficult problems in designing and building the proposed sixth-generation computer, it will likely serve as a magnet attracting Japan's top research minds. ${ }^{23}$ The project would require a major software effort and further R\&D on massively parallel processing architectures, areas where Japanese companies lag American companies.

Finally, there have been a few government projects to help Japanese companies develop software for supercomputers, another area of comparative weakness. One small national project run by the Fluid Dynamics Analysis System Research Association aims to develop fluid dynamics software for supercomputers. Started in March 1988, five companies, seven major users, and one software house are participating in this 4-year project; members include Asahi Kasei, Takenaka Komuten, Tokyo Electric Power, Toshiba, NICK, NEC, Hitachi, Fujitsu, Matsushita Denko, Marubeni, and Mitsubishi Heavy Industries. Some experts see the involvement of users in software $R \& D$ projects as a promising approach to ensure that the project will be commercially useful. The group has received Y1 billion (\$7.7 million) from the government for the 4-year period from March 1988 to March 1992. ${ }^{2 x}$ Member companies are charged Y60 million each, and supporting members (which they hope to increase to some 200-300 fins) Y4.8 million. ${ }^{225}$ Another smallscale software project that will have an impact on supercomputers is MITI's New Software Structuring Project, which aims to make it easier to maintain large software systems such as online systems for banks, companies, and government agencies. This project is expected to begin in 1991 with actual research starting in 1992; it will last 8 years and will be funded at about $\mathrm{Y} 5$ billion (about $\$ 35$ million). ${ }^{226}$

The Japanese Government is playing a critical role in providing the seed money and the coordination necessary to get Japan's government labs, major companies, and universities to cooperate in developing very future-oriented supercomputer technologies, work that they would not be doing otherwise. When asked in the late 1980s whether government projects such as the Fifth Generation and supercomputer projects have any significance given that Japanese firms have become very strong in their own right, Kuwahara Yutaka, head of R\&D Administra- 
Table 6-8-U.S. and Japanese Supercomputer Companies' Share of the World Market

\begin{tabular}{|c|c|c|c|c|c|c|}
\hline \multirow[b]{2}{*}{ Company } & \multicolumn{6}{|c|}{$\begin{array}{l}\text { Market share in percent } \\
\text { (number of installations) }\end{array}$} \\
\hline & 1980 & 1985 & 1986 & 1987 & 1988 & 1989 \\
\hline 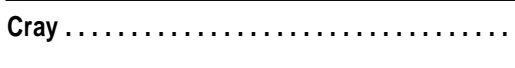 & $90 \%$ & $56 \%$ & $\begin{array}{l}60.7 \% \\
(148)\end{array}$ & $67 \%$ & $64 \%$ & $\begin{array}{l}53.1 \% \\
(219)\end{array}$ \\
\hline Fujitsu $\ldots \ldots \ldots \ldots$ & $00 / 0$ & & $\begin{array}{l}15.5 \% \\
(38)\end{array}$ & 1770 & $12 \%$ & $\begin{array}{l}21.6 \% \\
(89)\end{array}$ \\
\hline NEC . . . . & $0 \%$ & $24 \%$ & $\begin{array}{l}2.5^{\circ} 10 \\
(6)\end{array}$ & $6 \%$ & $4 \%$ & $\begin{array}{l}6.3 \% \\
(26)\end{array}$ \\
\hline Hitachi ... & $0 \%$ & & $\begin{array}{l}4.5 \% \\
(11)\end{array}$ & $4 \%$ & $4 \%$ & $\begin{array}{l}7.8 \% \\
(32)\end{array}$ \\
\hline CDC/ETA $\ldots \ldots \ldots \ldots \ldots \ldots \ldots \ldots$ & $10 \%$ & $20 \%$ I & $\begin{array}{l}16.8 \% \\
(41)\end{array}$ & $6 \%$ & $16 \%$ & $\begin{array}{l}11.2 \% \\
(46)\end{array}$ \\
\hline Total ........................ & $\ldots 100 \%$ & $100 \%$ & $\begin{array}{l}100 \% \\
(244)\end{array}$ & $100 \%$ & $\begin{array}{l}100 \% \\
(340)\end{array}$ & $\begin{array}{l}100 \% \\
(412)\end{array}$ \\
\hline
\end{tabular}

SOURCES: Kompyutopia, December 1989, p. 76; Nikkei Sangyo Shimbun, Apr. 19, 1989, p. 3; Los Angeles Times, Sept. 4, 1987; High Performance Computing and Communications: Investment in American Competitiveness, Gartner Group, Inc., p. 69.

tion at Hitachi's Central Research Laboratory, replied:

Government projects are significant because there are many things for us to challenge in the future, many of which can be better done in a government project than a private one.... When profit decreases. . due to the recession, the increasingly higher yen, and trade friction, we, in our [corporate] $\mathrm{lab}$, are pressured to cut costs and to be more product-oriented. It is very difficult to propose a future-oriented technology because we will be asked, 'Is it necessary? How profitable will the results be?' So we believe that national projects are very very important when they are future-oriented-when they focus on very risky $R \& D$ that is very difficult for the private sector to challenge alone.

JECC also provides implicit subsidies to Japanese supercomputer makers. A third of Fujitsu's supercomputers are rented through JECC, and "A substantial amount of our supercomputer business comes from JECC," stated Watanabe Tadashi of $\mathrm{NEC}{ }^{228}$

\section{PROCUREMENT OF SUPERCOMPUTERS}

A major aspect of targeting supercomputers has been the procurement of domestic machines by the government and the private sector. While companies in the United States and Europe bought American machines (which, until recently, performed much better and still have more software than Japanese machines), the Japanese Government and private sector bought Japanese machines (tables 6-8 through 6-10).
Table 6-9-U.S. and Japanese Supercomputer Companies' Share of the European Market, 1989

\begin{tabular}{|c|c|}
\hline & $\begin{array}{l}\text { Market share in percent } \\
\text { (number of installations) }\end{array}$ \\
\hline Cray & $\begin{array}{ll}\cdots & 84 \% \\
& (73)\end{array}$ \\
\hline Fujitsu & $\begin{array}{ll}9 & 9 \% \\
& (8)\end{array}$ \\
\hline $\mathrm{CDC} / \mathrm{ET} /$ & $\begin{array}{l}6 \% \\
(5)\end{array}$ \\
\hline NEC . . & $\ldots$ \\
\hline & $\begin{array}{ll}0 \% \\
(0)\end{array}$ \\
\hline Total & $\begin{array}{c}100 \% \\
(87)\end{array}$ \\
\hline
\end{tabular}

SOURCE: Cray Research.

\section{Private Sector Procurement}

Analysis of private sector procurement of supercomputers in Japan shows that a significant amount are purchases of a group member's machine. Of $\mathbf{1 2}$ machines owned by Fujitsu group companies, 10 are Fujitsus and 2 are foreign machines; of 11 machines owned by NEC group companies, 5 are NECs, 3 are Fujitsus, and 3 are foreign machines; and of 9 machines owned by Hitachi group companies, 3 are Hitachis, 3 are machines of other Japanese supercomputer makers, and 3 are foreign machines (table 6-11). (These figures do not include machines used internally by Fujitsu, Hitachi, and NEC.)

Keiretsu feelings are strong, and firms only go against them when they feel their survival is at stake. "We would like ideally to purchase the supercomputer of the maker in our group, but if we try to save the face of each firm in our group, we'd be defeated 
Table 6-10-U.S. and Japanese Supercomputer Companies' Share of the Japanese Market, Installed Base

\begin{tabular}{|c|c|c|c|c|}
\hline \multirow[b]{2}{*}{ Company } & \multicolumn{4}{|c|}{$\begin{array}{l}\text { Market share in percent } \\
\text { (number of installations) }\end{array}$} \\
\hline & 1987 & 1988 & 1989 & $1990(3 / 90)$ \\
\hline Cray & $\begin{array}{l}13.0 \% \\
(7)\end{array}$ & $\begin{array}{c}11.5 \% \\
(13)\end{array}$ & $\begin{array}{c}10.1 \% \\
(14)\end{array}$ & $\begin{array}{c}15.6 \% \\
(23)\end{array}$ \\
\hline Fujitsu & (30) & $\begin{array}{l}54.0 \% \\
(61)\end{array}$ & $\begin{array}{l}49.6 \% \\
(69)\end{array}$ & $\begin{array}{l}49.0 \% \\
(72)\end{array}$ \\
\hline NEC & $\begin{array}{c}13.0 \% \\
(7)\end{array}$ & $\begin{array}{l}15.9^{\prime} Y O \\
(18)\end{array}$ & $\begin{array}{c}16.6 Y 0 \\
(23)\end{array}$ & $\begin{array}{l}14.3 \% \\
(21)\end{array}$ \\
\hline & $\begin{array}{l}18.5 \% \\
\text { (lo) }\end{array}$ & $\begin{array}{c}17.770 \\
(20)\end{array}$ & $\begin{array}{c}23.0 \% \\
(32)\end{array}$ & $\begin{array}{l}19.7 \% \\
(29)\end{array}$ \\
\hline CDC/ETA & & $\begin{array}{l}0.9 \% \\
(1)\end{array}$ & $\begin{array}{c}0.7 \% \\
(1)\end{array}$ & $\begin{array}{l}1.4 \% \\
(2)\end{array}$ \\
\hline Total & $\begin{array}{c}100.0 \% \\
(54)\end{array}$ & $\begin{array}{c}110.0 \% \\
(113)\end{array}$ & $\begin{array}{c}100.0 \% \\
(139)\end{array}$ & $\begin{array}{c}100.0 \% \\
(147)\end{array}$ \\
\hline
\end{tabular}

Table 6-n-Purchases by Firms with Keiretsu Ties to Japanese Supercomputer Makers, $1980-90$

\begin{tabular}{|c|c|c|c|c|}
\hline \multirow[b]{2}{*}{ Company group } & \multicolumn{4}{|c|}{ Number of machines } \\
\hline & $\begin{array}{c}\text { Total } \\
\text { purchases by } \\
\text { group members }\end{array}$ & $\begin{array}{l}\text { Purchases from } \\
\text { affiliated makers }\end{array}$ & $\begin{array}{c}\text { Purchases } \\
\text { from other } \\
\text { Japanese makers }\end{array}$ & $\begin{array}{c}\text { Purchases } \\
\text { of foreign } \\
\text { supercomputers }\end{array}$ \\
\hline & 10 & 0 & 2 \\
\hline \multicolumn{2}{|c|}{$\begin{array}{lr}\text { Fujltsu s group } \ldots \ldots \ldots \\
\text { Hitachi's group . . . . . . . }\end{array}$} & 3 & 3 & 3 \\
\hline \multicolumn{2}{|c|}{ NEC'S group . . . . . . . . 11} & 5 & 3 & 3 \\
\hline \multicolumn{2}{|c|}{ Total . . . . . . . . . . . 32} & 18 & 6 & 8 \\
\hline
\end{tabular}

SOURCE: Nikkei Uotcha, IBM-Ban, Apr. 30, 1990, pp. 21-24; KigyoKeiretsu Soran, 1991.

in the severe competition we face, and we cannot afford to do that," explained one auto maker. ${ }^{229}$ Many argue that supercomputers are driving the competition in automobile design today; for example, Toyota's purchase of a Cray after it learned that Nissan had made many key product development advances using a Cray supports this notion. Toyota had been using a Fujitsu, and the switch only serves to underline the superiority of Cray machines and their software (at that time) for auto industry applications. $^{230}$

Mazda, which is heavily indebted to the Sumitomo group for bailing it out when it was threatened with bankruptcy, solved its obligation by a compromise; it bought an NEC machine to save face with the Sumitomo group and a Cray for its applications software ${ }^{231}$ Sumitomo Chemical did not make such a compromise; it completely went against NEC (its group computer maker) when, in September 1989, it bought a Cray because of Cray's better software. ${ }^{232}$

Nissan, which has a long relationship with Hitachi, bought two Cray supercomputers. But
Nissan's first purchase of a Cray in 1986 only came after U.S. pressure. According to some reports, Nissan engineers leaked to the U.S. Embassy in Tokyo and to Cray's office there that they wanted a Cray but that top company executives had decided to purchase a Hitachi due to their "relationship." The leak had its intended effect; the United States Trade Representative (USTR) and Department of Commerce officials discussed the issue with MITI, which in turn pressured Nissan to purchase a Cray. ${ }^{233}$ Since then, Nissan officials have frequently stated that Cray's simulations software and its UNIX-based operating system are the deciding factors in its purchase of Cray machines. ${ }^{234}$ "For our needs, Cray performed the best," explained a Nissan manager. ${ }^{235}$

Automobile companies are the clearest example of a Japanese industry in which all the major actors have Cray machines. Of Cray's 26 Japanese installations, $\mathbf{1 0}$ are in the auto industry, which purchased the Cray machines primarily for their performance, especially the crash simulations applications software. Of less significance, Japanese auto companies 
are aware that purchasing foreign machines helps to balance their huge exports of autos to the United States, potentially reducing trade friction. ${ }^{236}$

While Cray has been able to attract some customers from the groups of Japan's supercomputer makers, its biggest Japanese market is firms that are not part of the groups to which NEC, Fujitsu, and Hitachi belong. Of all supercomputer purchases in Japan, 26 percent ( 46 of 172 ) have been by private companies unaffiliated with the groups of Japan's three supercomputer makers; 50 percent of the purchases of Cray machines were by such companies (13 of 26), compared to 25 percent for Fujitsu (21 of 85),23 percent for Hitachi (8 of 35), and 13 percent for NEC (3 of 24) (table 6-6). Toshiba is one such example. In 1989 it bought a Cray Y-MP8/4128 for its applications software and the fact that it worked on UNIX, which was compatible with Toshiba's engineering work stations. 237 That many such companies have purchased Cray machines supports the notion that Cray is very competitive.

The fact that Japanese firms are vertically integrated and can use their own supercomputers in their semiconductor divisions also explains a chunk of private sector procurement. Of Hitachi's total sales of 35 supercomputers, 12 are used internally; of NEC's 24 supercomputers, 3 are used internally; of Fujitsu's 85 supercomputers, 9 are used internally (table 6-6). Finally, strong societal pressure to buy Japanese probably also tilts the market in domestic firms' favor.

It is very difficult to estimate how many foreign supercomputers would have been purchased in an open market. There are two issues: quality and price. On quality, most U.S. observers would say that at least through 1989 U.S. machines were superior. A more conservative approach is to say that, on the basis of quality alone, U.S. firms would have won all sales to the private sector through 1986, all sales to Japanese auto manufacturers through 1989, and the three additional keiretsu-related sales during 19871989. This amounts to 20 supercomputers. The U.S. machines would have cost substantially more, and it is impossible to know how many Japanese users would have paid to obtain a better foreign machine if the market had been fully open. However, on the somewhat tenuous assumption that the customers would have been willing and able to pay higher prices for foreign machines, Cray and ETA would have sold 20 more supercomputers. If three later upgrades of those machines are counted, the total lost sales amount to 23 machines. ${ }^{238}$

\section{Public Sector Procurement}

While Cray and CDC have faced keiretsu ties in their efforts to sell to Japan's private sector, public sector sales have been even harder to win. Of 51 government procurements of supercomputers, 5 have been of foreign machines (see tables 6-5 and 6-6). ${ }^{239}$ This record ultimately led to two agreements between the United States and Japan over supercomputer procurement, one in 1987 and another in 1990.

The Japanese Government did not purchase any supercomputers until 1983, the year Japanese firms introduced their first models; the Cray-1 had been out since 1976 and Japan's private sector had purchased two foreign machines as early as $\mathbf{1 9 8 0}$ (table 6-5). When Japan's public sector did start buying supercomputers, the U.S. Government and supercomputer makers realized that the public procurement process was not transparent-U.S. firms were never notified when a procurement would occur-and the Japanese firms gave deep discounts, which the U.S. Government and supercomputer makers maintained were some 80 to 90 percent off list prices.

The Japanese Government budget is a primary cause of the heavy discounts on supercomputers sold in public sector markets; the Ministry of Finance does not give the Ministry of Education a large enough budget to allow the public universities and laboratories to purchase supercomputers at or near list prices. A high level Ministry of Education official says that the Ministry has a responsibility to use taxpayer money with as much care as possible and thus to have universities purchase supercomputers as cheaply as Possible. ${ }^{240}$ These discounts have the effect of decreasing net government aid to the supercomputer makers, though in ways that help them win sales in important markets.

Indeed, discounting to universities can make good business sense. IBM long ago began giving universities big discounts on its mainframes, and university users often develop software, which increases the demand for a machine. Also, when students accustomed to using a certain machine graduate and enter a company, they tend to want to continue with the same type of machine. A discount sale can also help to secure future business. Once a computer maker installs its machine, it has a very high probability of 
continued sales (though if the customer is a university, probably at discounts) in the future because of compatibility.

Small public sector budgets encourage Japanese makers to offer heavy discounts to universities and government laboratories or forego the business altogether. Discounts of 80 percent or more are considered natural. 'It's not that we like to give such discounts. If only the government would give [public institutions] a sufficient budget, then this would not have to happen, ' explained one mid-level Fujitsu manager. ${ }^{241}$ But the benefits to Japanese makers still outweigh the costs: "When they use our new machine, it helps us improve upon the product in the future," explained a Hitachi manager; "When a university uses our machine. .. it improves our image,' adds an NEC manager; "We want to give assistance to Japan's researchers; not just in supercomputers, but in other products too; it [the heavy discounting of supercomputers] is the price of that business,' explains a Fujitsu manager. ${ }^{242}$ Discounts also oblige university professors, who are closely involved in recommending their top graduates to recruiting firms, to give their best graduates to firms giving big discounts. ${ }^{243}$ Aware of their weakness in software, firms see universities as helping them improve their software. ${ }^{244}$ "Actually it would be fine to give it to them for free, but that becomes a gift and causes tax problems; that's why we take the approach of just giving them a big discount," explained a manager of a Japanese supercomputer firm.

By late 1985 and early 1986, the United States started to express more forcefully its dissatisfaction with the lack of transparency and the lack of public procurement of foreign supercomputers. By 1986, the Japanese Government had purchased 22 supercomputers, only 1 of which was foreign, even though U.S. machines were far superior at the time. In response to U.S. complaints, Prime Minister Nakasone Yasuhiro assured the United States that NTT would buy another Cray supercomputer to improve the trade balance. ${ }^{246}$ (The Ministry of Finance owned 100 percent of NTT's stock until April 1985; MOF has since sold some of its NIT shares but the company is still mostly government-owned.) According to Japanese documents, Nakasone's decision to have NTT buy another foreign supercomputer came at a time when NTT was at pains to increase purchases from the United States. Soon after, NTT President Shinto made a deal with the head of the Recruit Corp., a Japanese real estate/jobreferral firm, to have Recruit repurchase the supercomputer NTT planned to buy from Cray. ${ }^{247}$

By late 1986, it was clear that no big changes in public procurement were forthcoming; discounting of up to 80 to 90 percent off list prices continued. After various negotiations among the USTR, Commerce Department, and State Department, the Administration decided to conduct an inquiry into Japanese procurement under section 305 of the 1974 Trade Act and to negotiate with Japan in the framework of the MOSS (Market-Oriented, Sector Selective) talks. From the beginning the U.S. Government made it clear that it wanted an open market, not a few token procurements.

Negotiations did not get off to a good start. In early 1987, talks with MITI vice-minister Kuroda Makoto were abruptly adjourned after a lunch meeting in which Kuroda allegedly stated that the United States would have to nationalize Cray or merge it with larger U.S. firms in order for it to survive in today's world of large vertically integrated fins, and that no matter how much the United States tried, it would not be able to sell supercomputers in Japan. ${ }^{248} \mathrm{~A}$ month later, on March 26, 1987, the Washington Post printed a copy of a U.S. Embassy cable regarding this alleged Kuroda statement, which Kuroda immediately denied. ${ }^{249}$ Whether or not Kuroda really said this, the sentiment is echoed in Japanese language documents that talk of Cray's dependence on Japan for memory chips and suggest that Cray will be overwhelmed by Japanese competition in the next few years. ${ }^{250}$

Japan responded immediately to the publication of the alleged Kuroda statement by announcing that NTT would purchase another Cray supercomputer. NTT, which was mostly government-owned, was reported to have said that the government pressured it to make this purchase to ease U.S.-Japan trade friction. ${ }^{251}$ This supercomputer, like the one NTT had purchased in 1986, was resold to Recruit. ${ }^{252}$ The two Crays that NIT purchased and sold to Recruit were token purchases; they did not signal a move towards more open public markets. ${ }^{253}$ Ministry of Posts and Telecommunications (MPT) Minister Nakayama reportedly explained in a Diet committee that NTT's purchase and resale of a Cray to Recruit "was at a time when, as a policy to help U.S.-Japan 
trade friction, we were searching for someplace [that would take the supercomputer off our hands]. ${ }^{\prime 254}$

At the same time as this NTT announcement, the Japanese Government was hurrying to get approval of an emergency budget to provide bigger budgets for the universities. ${ }^{255}$ Even before the alleged Kuroda statement hit the newspapers, Japanese Government officials knew the United States was upset not just over supercomputers but also about semiconductors-semiconductor trade friction would lead President Reagan to impose tariffs on some Japanese personal computers, power hand tools, and televisions in April 1987. In March 1987, MITI Minister Tamura told Prime Minister Nakasone that if Japan bought a couple of the Cray-2s, it would be very useful in alleviating trade friction. ${ }^{256} \mathrm{~A}$ former U.S. Government official closely involved in negotiations on both semiconductors and supercomputers said that he received several calls from Japanese officials asking him if the United States would back off retaliation over semiconductor trade if Japan bought more supercomputers. ${ }^{257}$

In October 1987, after the emergency budget was approved, MITI's Agency of Industrial Science and Technology (AIST) and the Tokyo Institute of Technology (TIT), a public institution, announced that they would each buy an American supercomputer. The Japanese Government decided to have them purchase one Cray Research machine and one ETA, the latter because they felt CDC, the parent of ETA, might complain if only Cray machines were purchased. ${ }^{258}$ The bidding was formally open but there was no chance for Japanese companies to win these bids because the emergency budget had been approved to alleviate U.S.-Japan trade friction. ${ }^{259} \mathrm{~A}$ MITI official acknowledged that TIT's directed purchase of an ETA machine was contradictory to the principle of open competition that the U.S.-Japan agreement was to provide. ${ }^{260}$

With these two purchases the Japanese Government felt it had fulfilled its promise to procure supercomputers. ${ }^{261}$ U.S. officials, however, saw two token purchases rather than a free competitive bid process. CDC's late delivery of its supercomputer, along with the machine's failure to operate at the speed promised, hurt the U.S. case. ${ }^{262 /}$ 'The Americans never looked so foolish,' said one Japanese expert. ${ }^{263}$ To this day TIT researchers vent their frustration at this $\mathrm{CDC}$ machine; $\mathrm{CDC}^{\prime} \mathrm{s}$ withdrawal from the supercomputer business in 1989 only exacerbated their problem.

TIT researchers' complaints were not the only ones. Researchers in Japanese public sector labs voiced concern that purchasing more expensive foreign supercomputers would cut sharply into the rest of their research budget. ${ }^{264}$ There was also concern about foreign supercomputers' compatibility with existing mainframes and peripherals, especially since Japanese supercomputer firms also made mainframes and peripherals while Cray Research did not. ${ }^{265}$

A formal agreement between the two countries was finalized in summer 1987 requiring that government institutions give full public notice of their intentions to procure a machine. The agreement did not deal with discounting; U.S. Government officials involved in the negotiations say that the U.S. administration believed that by charging discounted prices, the Japanese firms would only be hurting themselves. The United States also knew that it would be difficult to criticize Japanese supercomputer makers for discounting when IBM was actively discounting its mainframes for Japanese universities. There was also concern that European countries would object if the United States tried to limit discounting on sales to third countries.

The agreement was not effective. Since Japan's market was now formally open and U.S. makers were notified when public procurements would be made, they had to make bids (a costly process) or else look like they were not trying. But these bids were useless because the Japanese makers were still using very heavy discounts, selection did not have to be based on actual performance, and the Japanese universities preferred Japanese machines because of longstanding ties with companies.

The 1987 agreement did accomplish one thing: it hushed U.S. criticism for a time. ${ }^{266}$ This allowed Japanese supercomputer companies additional time to improve their competitiveness. Other than the two emergency budget procurements completed before the agreement, there were no more purchases of U.S. machines until the start of new negotiations on supercomputer procurement in 1989.

The first public sector procurement after the 1987 agreement-Tohoku University's Large-Scale Corm puting Center's decision to purchase a supercomputer-is a good example of how the heavy discounts 
work. The bid was for a machine to replace the Center's NEC SX-1 model, so it was expected that NEC would win the bid; Cray nonetheless made a bid since the market was now officially open. NEC bid the SX-2 and Cray the Y-MP-832. The first bid was made in June 1988, with NEC offering a monthly price of Y48 million against Cray's bid of Y74.739 million. NEC appeared to have an unbeatable advantage, but instead of awarding NEC the contract, the university asked for a second round of bids trying to get a better discount. NEC cut its bid to Y40.1 million and Cray cut its slightly to Y74.73 million. When the university asked for a third round, Cray dropped out. The university did not give NEC the contract until the eighth round of bids. The final price was V14.6 million, a 70-percent cut from NEC's original bid and a 90-percent discount from the original list price. ${ }^{267}$ The person in charge of the university's procurement said "to have to rebid is natural not just for computers; even making eight bids is not necessarily too many. ${ }^{\prime 268}$ These low prices are possible for Japanese companies because of government aid to the industry and because the firms can funnel mainframe and semiconductor profits to support their supercomputer business. But to Cray, these are "market-shattering" prices, explained Jonathan Streeter of the Department of Commerce ${ }^{269}$ In numerous interviews with Japanese Government officials and industry people, all agreed that Japan's supercomputer makers are losing money on their supercomputers but that they are going for long-term market share rather than immediate profits. "We don't need to make a profit on our line of supercomputers,' admits Watanabe Tadashi, the major architect of NEC supercomputers; "whatever is spun off from our supercomputer $R \& D$ helps in other information-technology fields. ' ${ }^{270}$

The Tohoku University case is not an exception. In 1988, Hitachi won a bid to Hokkaido University's Large-Scale Computing Center but only after five rebids, for a monthly rental price of Y15.75 million; the list price was Y89 million a month; including the peripherals and application software, the discount was between 80 and 90 percent. ${ }^{271} \mathrm{~A}$ similar case was the Japan Railways Technical Research Institute (RTRI) purchase of an NEC supercomputer in 1988. Cray was interested in the procurement but "withdrew when RTRI demanded an 80 percent discount," explained Yoshikazu Hori, President of Cray Research's subsidiary in Japan. ${ }^{272}$
By early 1989 the United States, realizing that the agreement was not having its intended effect, started to consider targeting supercomputers under Super 301 of the 1988 Omnibus Trade and Competitiveness Act. This Act required the USTR to identify the highest priority offenders among countries that unfairly restrict the sales of U.S. goods and services, to investigate the practices involved, and to negotiate to eliminate the market barriers. If the barriers were not removed, sanctions could be applied (see ch. 4).

Trade friction between the United States and Japan worsened when in April 1989 NEC announced that Japan's frost 4 CPU machine, the SX-3, would be coming out soon. That machine had a theoretical peak speed of 22 gigaflops, far faster than any other. ${ }^{273}$ Soon thereafter, CDC withdrew from the supercomputer business, and the United States' competitive position deteriorated. MITI reportedly scolded NEC, saying "Why are you irritating the United States by announcing a new advanced series of supercomputers] at a time when they are thinking about invoking Super 301 against Japan?' ${ }^{227}$ NEC then announced that it had decided to increase its use of U.S.-made semiconductors in its SX-3 series of supercomputers to help alleviate U.S.-Japan fiction over supercomputers. ${ }^{275}$ It didn't work.

In late May 1989, the U.S. Government listed Japan under Super 301; in June it started investigating Japanese practices regarding supercomputers, wood products, and satellites. In this second set of supercomputer negotiations, the United States made it clear that it wanted to deal with the heavy discounting of supercomputers. Right after the U.S. announcement, MITI reportedly advised computer makers to keep their supercomputer discounts under 50 percent, although bigger discounts on mainframes were okay. ${ }^{276}$

The first Japanese public sector supercomputer procurement after these negotiations began (but before they were concluded) was the purchase of a Fujitsu machine by the National Astronomical Laboratory to replace its existing Fujitsu. The only bidder was Fujitsu, which offered a 60-percent discount off the list price for a system of $\mathbf{1 3 4}$ machines, including 3 mainframes, engineering workstations, and other equipment. Fujitsu was careful, however, to keep the discount on the supercomputer within the 50-percent limit and to give the entire product a 60 -percent discount by 
discounting the mainframe parts of the system more heavily. ${ }^{277}$

Soon after, in early December 1989, Fujitsu won a bid for the Japan Atomic Energy Research Institute with a 25-percent discount off list price, a level that the government suggested would allow the firms to escape U.S. displeasure. ${ }^{278}$ But this and subsequent "smaller" discounts were the result of Japanese companies cutting their list prices in order to make their discounts appear smaller (table 6-12). For example, in October 1989 NEC dropped the list price of its new SX-3 series machines by 35 percent, ${ }^{279}$ Fujitsu and Hitachi had already lowered their list prices by 20 to 35 Percent. ${ }^{200}$ When Fujitsu won the Japan Atomic Energy Research Institute procurement after lowering its list prices to give a lower discount, MITI Minister Matsunaga said that "Fujitsu's drop in list price is the result of the operation of competitive market forces." ${ }^{281} \mathrm{Th}$ is 25-percent discount was a 53-percent discount over the previous list price: the two Fujitsu VP260O-10 supercomputers purchased had an original list price of Y80 million a month each, but had been dropped to Y50 million a month; the final bid was Y37.389 million a month. ${ }^{282}$ The United States complained that dropping the list prices just made it look like a smaller discount and was in no way a solution to the problem, ${ }^{283}$ but no further changes have been made.
Before the 1990 agreement was finalized, Tohoku University decided to buy a Cray machine for its Fluid Dynamics Research Lab. Formally, this was a first installation for the lab, but the researchers had been using the university Computing Center's NEC machine, so everyone expected NEC to win the bid. But NEC suddenly withdrew, citing government pressure aimed at easing U.S.-Japan trade problems. ${ }^{284}$

This strategy worked. A draft of the agreement was finalized in late March, and the U.S. administration did not target Japan for a second year under Super 301. The agreement was formally signed on June 15, 1990, a day before USTR would have been required to make a recommendation regarding sanctions.

There was a consensus among the Japanese ministries to do the agreement to protect the U. S.Japan relationship. SII [the Structural Impediments Initiative Talks] did not go well. Trade figures were bad. It was crisis management. The United States threatened retaliation under Super 301; without that threat, many ministries would not have gone along,

explained an official of the Ministry of Foreign Affairs involved in the negotiations. ${ }^{285}$

The primary difference between the 1987 and 1990 agreements is that the latter requires real performance criteria, not just theoretical peak performance data, to be used and that discounts be

Table 6-12-List Purchase and Rental Prices of Japanese Supercomputers

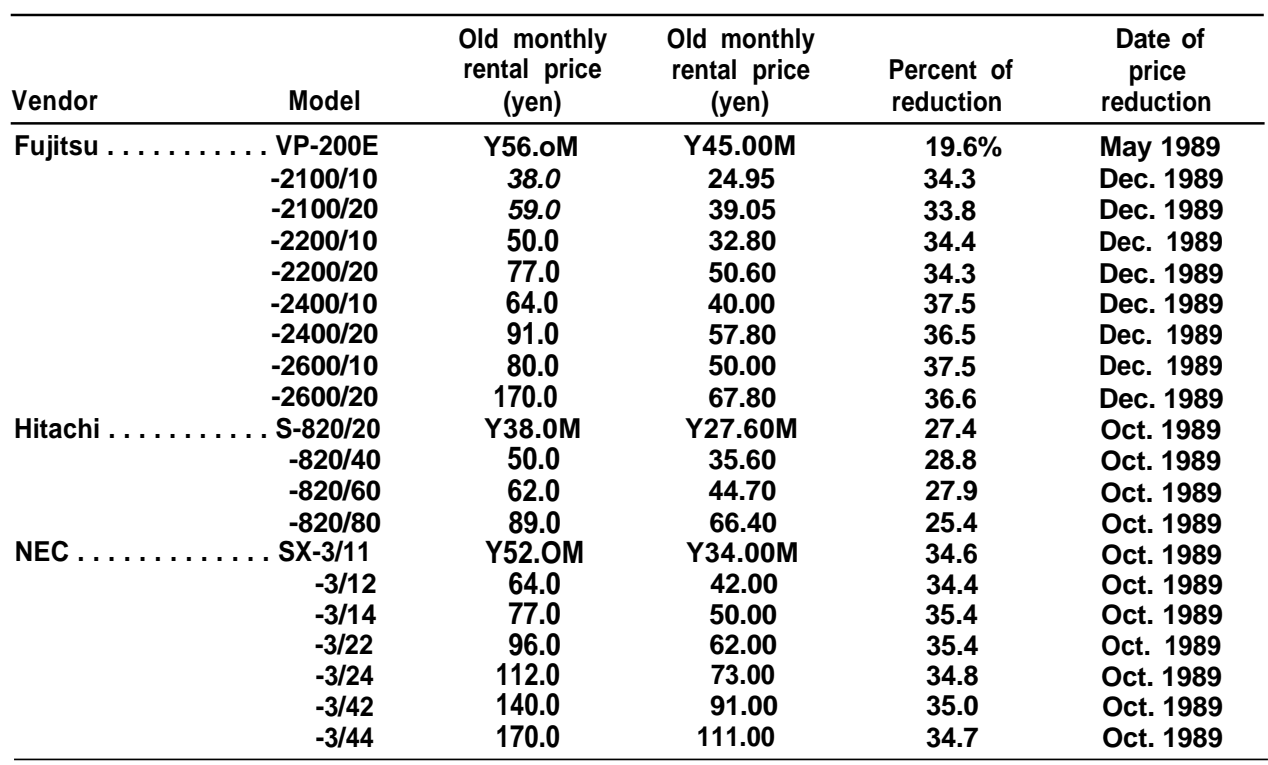

SOURCE: Nikkei Computer, Mar. 26, 1990, p. 97. 
limited. In this regard, the agreement is an improvement. But virtually everyone agrees that the second agreement, like the first, is deeply flawed. First, the agreement may very well strengthen the Japanese supercomputer makers. MITI and the firms are happy with the agreement because it is better for the firms not to have to discount their machines so much. "Because discounts are only 20 to 30 percent now, the firms make more money,' stated a Ministry of Foreign Affairs official closely involved in the negotiations. ${ }^{286}$ Before the agreement was signed, a spokesman for a maker said, "there would be nothing better for us than to be able to sell our supercomputers at list price. ${ }^{1287}$

Another problem with the agreement concerns reciprocity. As a strictly legal matter, reciprocity is not an issue. The agreement was intended to remedy Japan's violation of the GATT Procurement Code; Japan has not complained of any U.S. violation, so there is no need for the United States to change its procurement practices. While the United States has refused to buy Japanese supercomputers for defense purposes (e.g., for defense research at the national laboratories and in defense applications at NASA facilities), that does not violate the Code, which exempts defense purchases.

However, most U.S. Government supercomputer procurement is for defense purposes, and Japan could ask on grounds of fairness that the United States open that market for Japanese machines. Watanabe Tadashi, the chief architect of NEC's supercomputers, says, “The U.S. Government hasn't bought a single Japanese supercomputer; now you tell me who's being unfair. ${ }^{\prime 288}$ Fujitsu chairman Yamamoto Takuma agrees that the United States is unfair in calling on the Japanese Government to buy U.S. supercomputers when the U.S. Government does not buy Japanese machines: "We do not intend to crush them under our feet; nothing can be gained by doing that. That is why Fujitsu has always tied up with a $\sim$. S.] partner, and we will continue this strategy in the future."

The Japanese not only see the lack of reciprocity as a problem, they also see the United States as having a double standard on discounts. Japan argues that the United States is complaining about Japanese dumping of supercomputers because Cray Research, a relatively small one-product company, cannot afford to sell its machines at such low prices. ${ }^{290}$
Even if the agreement were perfect, however, it would be hard to overcome the effects of past preferential procurements. Public institutions with Japanese supercomputers in place would normally wish to replace their machines with an upgraded model from the same maker. "The most significant part of the agreement is for frost installations. Japanese first-time buyers will be able to choose the best company,' explained Jonathan Streeter of the U.S. Department of Commerce. ${ }^{291}$

The agreement's usefulness to U.S. manufacturers is also limited by university budgets; with higher prices, probably fewer machines will be bought. Total budgets for universities rise at only 10 percent a year (or less); thus, sharp increases in expenditures on supercomputers would require cutting another part of the budget. The fact that six public sector labs, four of which are universities, have delayed supercomputer procurements originally planned for $1990^{292}$ suggests that the kind of government funding the U.S. Government and Cray Research are hoping for will not be forthcoming in the near future. Indeed, Japanese public procurement has plunged from 12 and 11 machines in 1986 and 1987, respectively, to 8,4, and 6 in 1988, 1989, and 1990.

The Japanese and U.S. Governments are publicly calling the 1990 agreement a success. "The Tohoku University procurement is the first application of the 1990 agreement. It is an example of the success of the talks. Cray's success is not artificial, rather Cray's machine fits the needs of Tohoku University," stated Kawamura Yasuhisa, a Ministry of Foreign Affairs official involved in the negotiations. ${ }^{293} \mathrm{~A}$ few days after Tohoku University decided on a Cray, Kyoto University decided on a Fujitsu for a replacement machine of the same brand. "After the 1987 agreement there were no Cray purchases in the public market, and after the 1990 agreement there have been two purchases, one of which was a Cray. Cray has a 50-percent market share of purchases made after the agreement,' explained this same official. ${ }^{294}$

It has cost Cray Research a total of $\$ 158.1$ million to develop the Cray-1, Cray-2, and Cray X-MP and Y-MP models; the company estimates that the C90 machine currently being developed will cost $\$ 100$ million. ${ }^{295}$ Had Japan's market been open, Cray might have afforded more R\&D. As discussed, it seems reasonable to assume that the 20 Japanese machines sold to the private sector were inferior to 
available U.S. machines. This is also true for the 21 Japanese machines sold to the public sector through 1986. Thus, had supercomputers been selected on quality alone, the U.S. firms would have made 41 additional sales. But price is also a factor. The U.S. machines would have been much more expensive to public sector customers. Again, assuming the customers would have paid the higher prices, Cray and ETA would have sold 41 more machines. With subsequent upgrades, the total would be 56 . Based on historical market share ${ }^{296}$ about 52 of these sales would have gone to Cray, the remainder to ETA. Cray's X-MP series available at the time was priced between $\$ 7$ and $\$ 20$ million, with the higher priced models selling the most. If the 56 machines cost an average of $\$ 13$ million each (a conservative estimate), this would have meant $\$ 676$ million in revenue for Cray. Cray invests about 15 percent of revenues in $R \& D$ each year, so this would have meant $\$ 100$ million in extra $R \& D$, which could have helped fund a whole new generation of supercomputers. ${ }^{297}$

\section{OTHER FACTORS CONTRIBUTING TO JAPAN'S SUCCESS IN NURTURING A DOMESTIC SUPERCOMPUTER INDUSTRY}

\section{Industry and Corporate Structure}

Japan's targeting and procurement policies helped Hitachi, Fujitsu, and NEC to build their supercomputer business, but the policies were not solely responsible for the companies' successes. In part, their success is related to the ways in which Japanese corporations are organized and run. ${ }^{298}$ Japan also created apolitical and economic environment that fostered corporate arrangements giving Japanese companies advantages in international competition. The state's encouragement of interfirm cooperation on dimensions such as price, production, and $R \& D$; government encouragement of the reemergence of industrial groups after World War II; and its centralized control over financial capital have led to the emergence of large, vertically integrated firms making supercomputers. All of them are miembers of Japan's large industrial groups. ${ }^{299}$

In targeting specific industries, the Japanese Government has usually given priority to such fins. In mainframe computers and in telecommunica- tions, MITI and NTT have consistently favored Fujitsu, Hitachi, and NEC. "MITI promotes the larger, more stable, more promising fins, " stated Takashi Harumi, Director of International Research Exchange at MITI. ${ }^{300}$

Vertical integration gives Japanese firms making supercomputers several advantages. It allows them to cross-subsidize among divisions, using profits from healthy divisions to fund new areas such as supercomputers, and to keep divisions such as semiconductors alive despite their sharp boom-bust cycles. Second, it provides them with a relatively stable internal market, which affords greater ability to experiment with high speed integrated circuits that they can use in-house. Third, it provides an assured supply of components. For example, in 1988 and 1989, when semiconductor prices increased rapidly, U.S. computer and systems makers were scrambling to obtain enough memory chips that only Japanese firms produce in volume; Japanese makers were not similarly vulnerable. Finally, making production equipment in-house allows the Japanese firms to tailor-make production processes for their specific products, giving them a competitive edge. ${ }^{301}$

Japan's institutional environment encourages Japanese managers to view industries as belonging to an interdependent chain with valuable skill and knowledge spillovers for one another. Unlike their U.S. counterparts, Japanese companies do not necessarily stop making a product or bail out of a given industry solely because it does not provide as high a profit as investment of those same resources in another industry would. DRAMS are an example. Japanese companies regard the skills involved in producing DRAMS as important for other electronics components and systems; even if DRAMS are not in themselves highly profitable, they make a critical contribution to the bottom line in other ways that are less visible, though no less important. "The U.S. is going backwards in developing the components needed to make supercomputers. We want to make money and there is not a lot of money in those components, says Sidney Fernbach, a U.S. supercomputer expert. $^{302}$

The view of many Japanese businesses of the interdependence of the different electronics industries is reflected in a statement by Ota Hideo of Mitsubishi: "We are not thinking of loss or profit just for computers, but for the whole company. And we use computers in all our businesses. When we 
cannot follow computer technology, we will be in trouble all over. "303

There are heavy costs associated with this vertical integration and diversification; these high costs are part of the reason why several U.S. electronics firms that were vertically integrated and diversified in the 1960s and 1970s, such as Motorola, General Electric, and RCA, narrowed their focus to a few divisions and products. But Japanese firms are better able to bear these costs because of an environment that encourages long-term investment.

\section{Japanese Industrial Enterprise Groups}

Deep pockets are also the result of other institutional arrangements that help buffer Japanese firms making supercomputers from international competition and short-term market fluctuations. In particular, the fact that Fujitsu, NEC, and Hitachi are all members of or allied with keiretsu is an advantage. The U.S. Occupation had partially dismantled these groups, but by the late 1950s, the groups were rebuilding with government encouragement. A key motivation of both the firms and the government was that the groups would help keep out foreign products and investments at a time when Japan was under increasing pressure to liberalize its markets.

There are several advantages to membership in a keiretsu. These groups hold shares in other companies that are group members and agree not to sell them. This practice is known as mutual shareholding. In addition, large Japanese firms have stable shareholders, non-group firms who hold a company's stock and do not trade it. This combination of stable and mutual shareholding means that about 60 to 80 percent of member fins' stocks are never traded. ${ }^{304}$ Thus managers do not have to worry about takeovers or short-term fluctuations in their stock prices; they have more latitude than U.S. managers to focus on long-term goals.

Second, these groups provide their members with somewhat of an assured market. This is particularly important when a fro's products are not yet competitive. As mentioned earlier, as of 1968 about half of the mainframe computers being used by firms in the industrial groups were made by their keiretsu computer firm. ${ }^{303}$ Among firms with keiretsu ties to supercomputer makers, 56 percent of purchases (18 of 32, see table 6-11) were from the affiliate. Many argue that these groups are the most potent force protecting the Japanese market today. Their control over a significant share of Japanese business ${ }^{306}$ raises barriers to entry-in many cases bars entryto foreign firm in many major industries.

Third, these groups are centered around main banks, which helps group members get relatively easy access to capital; until recently, that also meant low-cost capital. Banks help out member companies during hard times. ${ }^{307}$ The close ties between Japanese companies and their main banks are less important today, when so many Japanese companies are enjoying unprecedented success and market power, but it was very important in the 1960s and 1970s and is still important for firms involved in risky ventures such as supercomputers.

\section{UNITED STATES POLICIES TOWARD THE SUPERCOMPUTER INDUSTRY}

Consistent with their concern for the decline in U.S. competitiveness in supercomputers, most computer scientists and industry people, and many policymakers believe that the U.S. Government should support the industry more thoroughly. The U.S. Government had and still has an important role in the development and competitiveness of the supercomputer industry in America, though that role is far smaller than that of the Japanese government past and present. The primary forms of support the U.S. Government offers are procurement and the contributions of national laboratories and NASA in developing software. Procurement, in particular, is likely to diminish in value. While defense-related supercomputer purchases have been and will probably remain closed to foreign firms, other Federal procurements are open to foreign competition. As of mid-1991 Japanese supercomputer makers had not won any sales. However, as the Japanese firms catch up in performance and software, they are more likely to do SO.

The U.S. Government funnels some $\$ 500$ million into advanced computing each year through the National Science Foundation (NSF), NASA, the Department of Defense, and the Department of Energy. ${ }^{\text {sa }}$ But there is growing agreement among supercomputer experts that it is not doing enough. "It could be too late unless we act and act forcefully; our infrastructure is going fast and the rest will go down with it," argued one supercomputer analyst. $^{309}$ 
One proposal for increased government support is the Federal High Performance Computing Program, presented to Congress in 1989, which called for an additional \$1.917 billion in U.S. Government financing of research related to advanced computing technologies over a 5 -year period. ${ }^{310}$ The program has four parts. The first, high-performance computing systems, would provide Federal support for basic research in high-performance computer technology (including massively parallel systems) and its transfer to industry; in addition, this part of the program calls for the Department of Energy, NASA, and the Defense Advanced Research Projects Agency (DARPA), to continue to acquire the first production models of new high-performance computers. The second part, advanced software technology and algorithms, would encourage joint research (government, industry, and university) to improve the basic tools, languages, algorithms and associated theory for solving very complex, large-scale problems in science and technology, or the so-called Grand Challenges. The Office of Science and Technology Policy (OSTP) listed the following as examples of Grand Challenges:

- prediction of weather, climate, and global change;

- challenges in materials science (including semiconductor materials);

- semiconductor design;

- superconductivity;

- structural biology, including the structure and function of biologically important molecules;

- design of drugs;

- human genome mapping;

- quantum chromodynamics;

- astronomy, including manipulation of data gathered by Very Large Array or Very Long Baseline Array radiotelescopes;

- challenges in transportation, including modeling of airflows around aircraft, inside engines, and around ship hulls;

- reduction of vehicle signatures for low detection military vehicles;

- vehicle dynamics;

- nuclear fusion;

- efficiency of combustion systems;

- enhanced oil and gas recovery;

- computational ocean sciences, including development of a global ocean prediction model incorporating temperature, chemical composi- tion, circulation and coupling to the atmosphere;

- speech as a communications interface with computers;

- machine vision; and

- undersea surveillance for anti-submarine warfare.

The third part of the High Performance Computing Program is the national research and education network, providing distributed computing that links the governmental research, industry, and higher education communities. The network, using fiberoptic trunks now being installed by communications carriers, will incorporate new switching systems and network protocols to support interactive graphics, nationwide data files, and high-definition displays. The fourth part is for basic research and human resources, supporting basic research in computer science and improved computational science education in universities. ${ }^{311}$ For fiscal year 1991, the program received $\$ 489$ million and was carried out by eight agencies, ${ }^{312}$ with 71 percent coming from DARPA and NSF. In fiscal year 1992, the proposed budget is $\$ 638$ million, with 69 percent from DARPA and NSF. ${ }^{313}$

Many computer scientists, industry executives, independent analysts, and policymakers argue that the U.S. Government needs to support more than this project if it is to stem the erosion of U.S. competitiveness in supercomputers and other hightechnology areas, and that the focus needs to be on supporting commercial applications. Only in this way, they suggest, can supercomputer companies compete with Japanese companies and avoid dependence on Japanese suppliers in the long term. In the past several years, some U.S. high-technology companies have reported delays of supplies of either components or machinery from their Japanese sources. Complaints have become so numerous that the General Accounting Office has recently started exploring them. ${ }^{314}$ While these U.S. companies tend to believe that delaying or withholding parts is unfair, it makes good sense for a company to supply itself and its related companies first, then its best domestic customers, and finally its overseas ones; it is neither unwise nor unfair to delay delivery of strategic components or machinery to competitors.

Because Crays are widely regarded in the United States as superior, and have a much larger library of software, there have been few procurements of 
Japanese machines in the private sector; Fujitsu has sold two machines to the U.S. subsidiary of France's Schlumberger, but other than that the only procurement of a Japanese supercomputer was that of an NEC machine by the Houston Area Research Center in 1986, a center closely connected to NEC's U.S. supercomputer subsidiary, HNSX. More Japanese machines will undoubtedly sell in the private sector, for they are getting faster and already are very reliable. The financial resources of the Japanese companies leave little doubt as to their staying power in the industry; there is more doubt among U.S. supercomputer experts as to Cray's ability to stand up to this kind of competition in the long run (it should be noted that officials of Cray do not regard their company as endangered). As a result, public procurement in the United States is still an important issue.

Most experts agree that the U.S. Government's supercomputer procurement has been a key factor encouraging the growth of the supercomputer industry here, and the government remains a key customer. In the beginning, only U.S. companies made supercomputers, and developments in highperformance computing were tied to the needs of researchers in government labs. Most government purchases are still by institutions that use the machines for military purposes at least part of the time (national laboratories and NASA, for example), and it is consistent with the GATT Procurement Code for any Government to maintain an absolute preference for domestic goods in such purchases. In addition, many scientists in institutions that use the supercomputers feel that their support is necessary to keep Cray Research alive; although many would prefer that there were additional U.S. competitors, they do not want the field narrowed only to Japanese companies.

This opinion is not universally shared. Some U.S. supercomputer specialists argue that the U.S. Governrnent should not protect U.S. supercomputer makers; rather it should protect the right of researchers to have access to the latest and most technologically sophisticated research tools. ${ }^{315}$ User access to supercomputers is more important than the supercomputer industry itself; it is more important that U.S. petroleum, aerospace, and automobile firms have access to the best tools [supercomputers] than that Cray Research continues to exist. ${ }^{\prime{ }^{316}}$ Larry Smarr, director of the National Center for Supercomputing Applications, adds that using national secu- rity considerations as a reason for barring Japanese competitors is contradictory and self-defeating. "Just count the number of Crays and IBM vector machines the Japanese manufacturers can study in Japan compared to the number of their supercomputers that we have access to in the United States. If the Japanese firms are truly our competitors, it would benefit us greatly to know everything we can about their design capabilities. The oldest rule in the book is to 'Know your enemy. ' "317 Whether reliance solely on Japanese companies would eventually cost U.S. supercomputer users their ability to get first crack at the fastest, newest machines is a matter of disagreement among specialists.

Export control policy is another issue. Getting a license for exports of high-performance computers is often time consuming and difficult, and that can put Japanese companies at an advantage in selling in foreign markets. For small (relative to Hitachi, Fujitsu, and NEC) U.S. companies like Cray Research, streamlithing the export licensing process as much as possible, consistent with national security, would be a big help. Since the first installation is particularly important in the case of selling supercomputers, speed in making changes to export control policy is also important to Cray. Thirdcountry markets are growing fast and if U.S. makers miss out on these markets today, it could diminish their income stream far into the future.

1 This chapter is drawn extensively from two contractor reports: Marie Anchordoguy, "The Nature and Effectiveness of Japan's Postwar Industrial Policy," contractor report for the Office of "Technology Assessment, February 1991; and Marie Anchordoguy, "Japanese Policies for the Supercomputer Industry," contractor report for the Office of Technology Assessment, February 1991.

2 These include hard work, good and universal education, financial policies that enabled Japanese firms to invest heavily and patiently in technology acquisition development and diffusion, and vigorous, if not free and open, competition.

3 The top merchant families were later to become the zaibatsu, some of which persist today in the form of keiretsu, or industrial groups.

4 Tessa Morris-Suzuki, A History of Japanese Economic Thought (London: Nissan Institute for Japanese Studies, 1989), p. 62.

5 Edward J. Lincoln, Japan's Unequal Trade (Washington, DC: The Brookings Institution, 1990), pp. 5-6.

6 See for example, Marie Anchordoguy, Computers Inc: Japan's Challenge to IBM (Cambridge, MA: Harvard University Press, 1989); and Phyllis A. Genther, "A History of Japan's Government-Business Relationship: The Passenger Car Industry," Michigan Papers in Japanese Studies No.20 (Ann Arbor, MI: Center for Japanese Studies, University of Michigan, 1990).

7 See, for example, Paul R. Krugman, "Targeted Industrial Policies: Theory and Evidence,' The New Protectionist Threat to World Welfare, Dominick Salvatore (cd.) (New York, NY: North Holland Press, 1987), pp. 266-296. 
8 See, for example, Giovanni Dosi, Laura D'Andrea Tyson, and John Zysman, "Trade, Technologies, and Development: A Framework for Discussing Japan," Politics and Productivity: How Japan's Development Strategy Works, Chalmers Johnson, Laura D'Andrea Tyson, and John Zysman (eds.) (Cambridge, MA: Ballinger, 1989), pp. 3-38.

9 A representative sampling of these three views is the following three sources: Chalmers Johnson, MITI and the Japanese Miracle (Stanford, CA: Stanford University Press, 1987); Richard Samuels, The Business of the Japanese State (Ithaca, NY: Cornell University Press, 1987); and Karel Van Wolferen, The Enigma of Japanese Power (New York, NY: Alfred Knopf, 1989).

10 See, for example, Charles Schultz, "Industrial Policy: A Dissent," The Brookings Review, fall 1983, and "Industrial Policy: A Solution in Search of a Problem," California Management Review, summer 1983; Komiya Ryutaro and Kazutomo Irie, "The U.S.-Japan Trade Problem: An Economic Analysis from a Japanese Viewpoint," Japan' sEconomic Structure: Should it Change?, Kozo Yamamura (cd.) (Seattle, WA: Society for Japanese Studies, 1990) pp. 65-104; Gary Saxonhouse, "Why Japan is Winning," Issues in Science and Technology, spring 1986, pp. 72-80; and Hugh Patrick, "Japanese High Technology Industrial Policy in Comparative Context," Japan's High Technology Industries, Hugh Patrick (cd.) (Seattle, WA: University of Washington Press, 1986), pp. 3-33.

11 See, for example, Robert Z. Lawrence, "Imports in Japan: Closed Markets or Minds?," Brookings Papers on Economic Activity, No. 2,1987, pp. 5 17-548; Rudiger Dombusch, "Give Japana Target and Say 'Import! '," The New York Times, Sept. 24, 1989; "Misguided Efforts Won't Open Japan's Market," The Japan Economic Journal, Dee. 16, 1989, p. 9; and Mordechai E. Kreinin, "How Closed is Japan's Market? Additional Evidence," The World Economy, vol. 11, no. 4, December 1988, pp. 529-542.

12 See Paul R. Krugman, "Introduction: New Thinking About Trade Policy," and James A. Brander, "Rationales for Strategic Trade and Industrial Policy," Paul R. Krugman (cd.), Strategic Trade Policy and the New International Economics (Cambridge, MA: The MIT Press, 1986), pp. 1-46.

13 Robert J. Ballon and Iwao Tomita, The Financial Behavior of Japanese Corporations (Tokyo: Kodansha International, 1988), p. 37.

14 Nakamura Takafusa, The Postwar Japanese Economy, Its Development and Structure, Jacqueline Kaminski, translator (Tokyo: Tokyo University Press, 1981), p. 44.

15 See, for example, Johnson, op. cit.; and Anchordoguy, Computers Inc.: Japan's Challenge to IBM, op. cit.

16 Genther, op. cit., p. 23.

17 Genther, op. cit., p. 80.

18 Genther, op. cit., pp. 81-82.

19 Merton J. Peck and Shuji Tamura, “Technology," in Asia's New Giant, Hugh Patrick and Henry Rosovsky (eds.) (Washington DC: The Brookings Institution 1976), p. 152.

20 Genther, op. cit., p. 47.

21 Genther, op. cit., p. 70.

22 This was done in the Extraordinary Measures Laws for the Promotion of the Machinery and Electronics Industries of 1956 and 1957 and their subsequent extensions.

23 Johnson, op. cit., p, 174.

24 Japan also accepted obligations under Article 14 of GATT, which specified no subsidies of exports. See Johnson, op. cit., p. 263.

25 Johnson, op. cit., p. 210.

26 Johnson, op. cit., p. 211.

27 Nomura Research Institute, NIR Review, February 1991. The 1990 figure was a projection the 1989 figure was 32.3 trillion yen.
28 "Postal Savings Deposits Set Monthly Record," The Japan Times, Jan. 10,1990, p. 9; and Ministry of Finance, The Budget in Brief, 1988, Budget Bureau, 1989, p. 66.

29 Marcus W. Brauchli, "BanksFeudwithP ostal Service in Japan over Citicorp Proposal," The Wall Street Journal, Sept. 22, 1988, p. 35; and personal communication Marie Anchordoguy with local post office in Japan, January 1991.

30 Koichi Hamada and Akiyoshi Horiuchi, "The Political Economy of the Financial Market," in Kozo Yamamura and Yasukich Yasuba (eds.), The PoliticalEconomy ofJapan, Volume 1: The Domestic Transformation (Stanford, CA: Stanford University Press, 1987), pp. 223-260.

31 Daniel I. Okimoto, Between MITI and the Market: Japanese Industrial Policy for High Technology (Stanford, CA: Stanford University Press, 1989), p. 150.

32 Ibid., p. 77.

33 Leonard Lynn, How Japan Innovates: A Comparison with the U.S. in the Case of Oxygen Steelmaking (Boulder, CO: Westview Press, 1982), p. 145

34 Ibid., pp. 4546.

35 Yamawaki Hideki, "Tekko Gyo," (The Steel Industry), in Nihon no Sangyo Seisaku, Komiya Ryutaro, Okuno Masatatsu, and Suzumura Kotaro (eds.) (Tokyo: Tokyo University Press, 1984), pp. 258,263 .

36 Nihon Kaihatsu Ginko 25 Nenshi (Twenty-five Year History of the Japan Development Bank) (Tokyo: Japan Development Bank, 1976), p. 537.

37 BOF technology was pioneered in Austria in the early 1950s, and in the succeeding three decades came to account for the majority of the world's mass-produced carbon steel. Its advantages over the open hearth technology that preceded it were that it offered economies of scale in integrated steel mills, had lower energy costs, took much less time to heat the iron, and was generally more cost-effective. See Luc Kiers, The American Steel Industry: Problems, Challenges, Perspectives (Boulder, CO: Westview Press, 1980), pp. 19-20; and Bela Gold, Gerhard Rosegger and Myles G. Boylan, Jr., Evaluating Technological Innovations (Lexington, MA: Lexington Books, 1980), pp. 120121.

38 Lynn, op. cit., p. 83.

39 Lynn, op. cit., pp. 84-85.

40 Peck and Tamura, op. cit., pp. 556-558.

41 In such industries, firms lose less money by cutting prices than by idling mills, since fixed costs accrue whether or not production occurs.

42 See, for example, Patricia A. O'Brien, "Coordinating Market Forces: The Anatomy of Investment Decisions in the Japanese Steel Industry, 1945 -1975," dissertation from the Harvard Business School, 1986, p. 268.

43 Okimoto, op. cit., p. 37.

44 See, for example, Okimoto, op. cit., pp. 38-48; Imai Kenichi, "Iron and Steel: Industrial Organization" in Japanese Economic Studies (White Plains, NY: International Arts and Sciences Press, Inc., winter 1974-75); and Yamawaki, op. Cit.

45 Walter Adams, "The Steel Industry," in The Structure of American Industry, Walter Adams (cd.) (New York, NY: Macmilhn Publishing Company, 1977, fifth edition), p. 117; and Tekko Jukyo no Ugoki (Trends in the Supply of and Demand for Steel) (Tokyo: Kozai Kurabu) quarterly report, various issues.

46 Yamawaki, op. cit., p. 281.

47 Tsuruta Toshimasa, Sengo Nihon no Sangyo Seisaku (Industrial Policy in Post-War Japan) (Tokyo: Nihon Keizai Shimbunsha, 1982), p. 49.

48 The Long Term Credit Bank of Japan, Shuyo Sangyo Sengo 25 
Nenshi (Twenty-five Year History of Major Industries in the Postwar Period) (Tokyo: Kurihara Shigeo, 1972), pp. 361-364.

49 Imai, op. cit., pp. 52-53.

50 Seiritsu Ogura and Naoyuki Yoshino, "The Tax System and the Fiscal Investment and Loan Program," in Ryutaro Komiya, Masahiro Okuno, and Kotaro S uzumura (eds.), Industrial Policy of Japan (Tokyo: Academic Press, Inc, 1988), pp. 127-132.

51 Yamawaki, op. cit., p. 286.

52 Yamawaki, op. cit., p. 136.

53 Motoshige Itoh and Kazuharu Kiyono, "Foreign Trade and Direct Investment" in Komiya et al. (eds.), op. cit., p. 161.

54 Paul R. Krugman, "Targeted Industrial Policies: Theory and Evidence,' op. cit., pp. 283-288.

55 Ibid., p. 289.

56 Hitachi, Fujitsu, and NEC are among the world's most successful and competitive corporations, yet they have profits as a percent of sales in the 2-4 percent range.

57 Kiyoshi Kawahito, The Japanese Steel Industry (New York, NY: Praeger Publishers, 1972), p. 48.

58 The following summary of prewar motor vehicle industrial promotion is drawn from Genther, op. cit., pp. 15-39 passim.

59 Hiroya Ueno and Hiromichi Muto, "Japan's Automobile Industry," in Japanese Economic Studies (White Plains, NY: International Arts and Sciences Press, Inc., fall 1974), pp. 12-13.

60 See ibid., p. 12; and C.S. Chang, The Japanese Auto Industry and the U.S. Market (New York, NY: Praeger Publishers, 1981), p. 47.

61 Genther, op. cit., pp. 52-55.

62 Genther, op. cit., pp. 55-64.

63 Hiromichi Muto, "The Automotive Industry," in Komiya, et. al. (eds.) op. cit., pp. 310-313.

64 Muto, op. cit., p. 313.

65 Muto, op. cit., pp. 314-315.

66 See, for example, Eugene Kaplan, Japan: The GovernmentBusiness Relationship (Washington DC: U.S.Government Printing Office, 1972); Tenkanki no Jidosha Sangyo (Turning Point in the Auto Industry), MITI Kikai Joho Sangyokyoku Jidoshaka (cd.) (Tokyo: Nikkan Kogyo Shimbunsha, 1976), pp. 89-91; Nihon no Jidosha Kogyo (Japan's Auto Industry), MITI Jukogyokyoku Jidoshaka (ed.) (Tokyo: MITI Kenkyukai, 1959), pp. 46-62; Ueno and Hiromichi, op. cit., pp. 3-90; Hiromichi, "Jidosha" (Autos), in Nihon no Sangyo Seisaku, op. cit.

67 Nihon Choki Shinyo Ginko Sangyo Kenkyukai, Shin Jidai ni Chosen suru Nihon no Sangyo (Japan's Industries Challenging the New Era) (Tokyo:Mainichi Shimbunsha, 1968), p. 48.

68 Saxonhouse, op. cit., pp. 72-80.

69 Philip H. Tresize and Yukio Suzuki, "Politics, Government, and Economic Growth in Japan," in Asia's New Giant, Hugh Patrick and Henry Rosovsky (eds.) (Washington, DC: The Brookings Institution, 1976), pp. 798-799.

70 Akio Morita, Made in Japan (New York, NY: E.P. Dutton, 1986), pp. 65-66

71 Tresize and Suzuki, op. cit.

72 Morita, op. cit., pp. 65-66.

73 This overview of the color television case draws heavily on Kozo Yamamura and Jan Vandenberg, "Japan's Rapid-Growth Policy on Trial: The Television Case, " in Gary Saxonhouse and Kozo Yamamura (eds.), Law and Trade Issues of the Japanese Economy (Seattle, WA: University of Washington Press, 1986), pp. 238-283.

74 Yamamura and Vandenberg, op. cit. pp. 256-257.

75 Komiya Ryutaro, Takeuchi Hiroshi, and Kitahara Masao,
"Kaden Denki" (The Consumer Electric Goods Industry) in Nihon no Sangyo Soshiki Ron vol. I, Kumagai Hisao (cd.) (Tokyo: Chuo Koron Sha, 1973), p. 28.

76 Komiya et al.(eds.), Industrial Policy ofJapan, op. cit., p. 162.

77 Denshi Kogyo Nenkan, 1973, p. 752.

78 Yamamura and Vandenburg, op. cit., p. 259.

79 Toyokeizai, Jan. 23, 1971, p. 12; Komiya et al., "Kaden Denki," op. cit., pp. 66-67.

80 Yamamura and Vandenberg, op. cit., p. 257.

81 Yamamura and Vandenberg, op. cit., p. 261; Toyokeizai, Jan. 26, 1980, p. 84; Time, June 13, 1977, p. 63.

82 Asahi Shimbun, Apr. 27, 1\%7, p. 7; and Toyokeizai, July 27, $1 \% 8$, pp. $42-43$.

83 Andy Zipser, Stephen Kreider Yoder, and Jacob M. Schlesinger, "Texas Instruments Obtains Japan Patent for Its Chips," Asian Wall Street Journal Weekly, Nov. 27, 1989, p. 5.

84 Toyokeizai, July 27, 1968, p. 43; and Asahi Shimbun, Apr. 27, $1 \% 7$, p. 7.

85 Interview with former MITI official Tokyo, Apr. 11, 1989.

86 Interview with former MITI official involved in the negotiations, Apr. 11, 1989.

87 Toyokeizai, Feb. 26, 1972, p. 80; and June 10, 1972, p. 81.

88 Toyokeizai, June 10, 1972, p. 81.

89 For Motorola, the partner was Alps Electric, a parts maker; for Fairchild, the partner was TDK (Tokyo Denki Kagaku), a maker of tapes and parts. Source: Toyokeizai, June 10, 1972, p. 81.

90 Toyokeizai, Oct. 22, 1966, p. 26.

91 Toyokeizai, June 10, 1972, p. 81

92 Nihon Keizai Shimbun, Sept. 26, 1971.

93 MIT Commission on Industrial Productivity, "The U.S. Semiconductor, Computer, and Copier Industries," in Working Papers of the MIT Commission on Industrial Productivity, Volume 2 (Cambridge, MA: The MIT Press, 1989), p. 14.

94 Tarui Yasuo, "Japan Seeks Its Own Route to Improve IC Techniques," Electronics, Dec. 13, 1965, pp. 90-91.

95 Michiyuki Uenohara, Takuo Sugano, John G. Linvill, and Franklin B. Weinstein, "Background" in Daniel I. Okimoto, Takuo Sugano, and Franklin B. Weinstein (eds.), Competitive Edge: The Semiconductor Industry in the U.S. and Japan (Stanford, CA: Stanford University Press, 1984), pp. 20-21.

96 Edward J. Lincoln, Japan's Industrial Policies (Washington DC: Japan Economic Institute of America, 1984), p. 35.

97 Saiyama Takuro, "A Radical Interpretation of Postwar Economic Policies," in Tessa Morris-Suzuki and Saiyama Takuro (eds.), Japanese Capitalism Since 1945 (Armonk, NY: M.E. Sharpe, Inc., 1989), p. 49.

98 Anchordoguy, Computers Inc.: Japan's Challenge to ZBM, op. cit., pp. 49-53, 125-132.

99 "Firms Curb Spending as Cost of Capital Climbs," Japan Economic Journal, Mar. 2, 1991.

100 Leslie Helm, "Big Hopes for Tiny Machines," The \&M Angeles Times, Jan. 6, 1991, p. 1.

101 Nihon Keizai Shimbun, Jan. 12, 1991, p. 10.

102 Ibid.

103 For example, MITI's report on trade and industry policy forthe 1990s states, There will be demands on Japan to continuously strive for high levels of freedom and fairness.. . Japan's efforts to attain these ideals within its own borders are becoming extremely important for the continuation and improvement of the reliability of the international free trade system." See MITI, "90 Nendai no Tsusho Sangyo Seisaku no 
Arikata," (International Trade and Industrial Policy in the 1990s), July 5, 1990.

104 Kenneth W. Neves, "Supercomputers: The Next Generation," Scientific Information Bulletin, U.S. Office of Naval Research, Far East, vol. 14, no.4, 1989, p. 77.

105 Business Week, Apr. 30, 1990, p. 83.

106 Interview with Marie Anchordoguy, Sept. 19, 1990.

107 Nihon Keizai Shimbun, Apr. 23, 1989, p. 4.

108 Interview, December 1990.

109 Kenneth Flamm, Creating the Computer: Government, Industry and High Technology (Washington, DC: The Brookings Institution 1988), p. 103.

110 Minisupercomputers refer to machines with roughly $1 / 10$ th to $1 / 2$ the performance of a supercomputer at roughly $1 / 10$ th the price; they are not a focus of this study.

111 In part, that is because the $R \& D$ intensity (R\&D expenditures as a percent of sales) is higher in the computer business than in any other. The Japanese companies may spend the same percentage (or even more) on $R \& D$ if only computer $R \& D$ and computer sales figures are counted.

112 Interview, Dec. 12, 1990.

113 Interviews of supercomputer specialists, one who recently retired from Boeing., Nov. 19, 1990; one who works at the U.S. Office of Naval Research, Sept. 27, 1990; one at Lawrence Livermore National Laboratory, Dec. 12, 1990; and one at a U.S. aerospace company, Dec. 12,1990

114 Interview of several supercomputer specialists, one formerly of Boeing, Nov. 19, 1990; one at Lawrence Livermore Lab, Dec. 12, 1990. Also James Browne, professor of computer science and physics at the University of Texas at Austin, cited in "Parallel Processing Computers Attract Crowd of Investors Despite Limited Uses," John R. Wilke, The Wall Street Journal, Oct. 5, 1990, pp. B1, B4.

115 Interview of supercomputer specialists: one formerly of Boeing, Nov. 19, 199@ three other scientists currently at or recently retired from U.S. National Labs, Nov. 30, 1990.

116 Supercomputer speeds are measured in megaflops and gigaflops, which are one million and one billion floating-point operations per second, respectively. A floating-point operation is one addition, subtraction, multiplication, or division of two numbers, where the numbers can have fractional components and can have as many digits as the computer memory accommodates. Cray's most sophisticated Y-MP machines come out on top of all Japanese supercomputers on the market (not including the one processor SX-3 of NBC, of which three have been shipped), in: 1) ONR Benchmark-LANS3D and ONR BenchmarkLANS3D-UP, Kozo Fujii and Yoshiaki Tamura, "Capability of Current Supercomputers for Computational Fluid Dynamics,' Institute of Space and Astronautical Science, Kanagawa, Japan, U.S. Office of Naval Research, Bulletin no.1, Feb. 14, 1989; 2) Perfect Benchmarks done in December 1989 by the Center for Supercomputing Research and Development at the University of Illinois; 3) LINPACK Using all Fortran 100X 100 MFLOPS Benchmark, Jack J. Dongarra, "Performance of Various Computers Using Standard Linear Equations Software," Oct. 12, 1989, Computer Science Department, University of Tennessee, and Technical Memo No. 23, Argonne National Laboratory, Feb. 9, 1990. See Cray Research, Inc., "The Japanese Public Sector: Problems and Prospects for U.S. Supercomputer Vendors," May 1990, ch. 3 .

117 David E. Sanger, "A Tough Sell for 'Made in Japan,' “ The New York Times, Nov. 30, 1990, pp. Cl, C16.

118 Hideo Yoshihara, "Performance of Japanese Supercomputers vis-a-vis Cray Computers," Scientific Information Bulletin, U.S. Department of Navy, Office of Naval Research, Far East, vol. 15, no. 3, July to September, 1990.

119 Ibid.
120 Gartner Group, Inc., High Performance Computing and Communications: Investment in American Competitiveness, report prepared for the U.S. Department of Energy and Los Alamos National Library, Mar. 15, 1991, pp. 89,205.

121 Nikkei Uotcha, IBM-Ban, May 1, 1989, p. 19.

122 Gartner Group, Inc., op. cit., pp. 210-211.

123 Gartner Group, Inc., op. cit., p. 210. Cray Research says its machines now average 2,000 to 3,000 hours MTBF. Interview of Suzanne Tichenor and David Frasch of Cray Research by OTA staff, May 1, 1991.

124 Kawabata Naohisa, Kompyuta Gyokai ga Abunai (The Computer Industry is in Danger) (Tokyo: Eiru Publishers, 1990), p. 122.

125 Nihon Keizai Shimbun, Aug. 29, 1990, p. 1.

126 David Kahanerand H.T. Kung, "Aspects of Parallel Computing Research in Japan-Hitachi, Matsushita, and Japan Electronics Show 1990," a report of the U.S. Office of Naval Research, Far East, Nov. 6, 1990, Interview of Hideo Aiso, Dean and Professor, Faculty of Environmental Information, Keio University, who heads both the fifth generation and supercomputer projects, Sept. 25, 1990.

127 Interview, Nov. 27, 1987.

128 Interviews of Takeuchi Hiroshi, Managing Director of the Long Term Credit Bank of Japan, Dec. 8, 1987; of Toda Iwao, head of NTT's Communications and Information Processing Laboratory in Yokosuka, Dec. 5, 1987; and of Okazaki Kotaro, a Director and section chief of the Operations Department, the Industrial Bank of Japan (IBJ), Dec. 4, 1987.

129 See discussion of the history of IBM's activities in Japan in Anchordoguy, ComputersInc.: Japan's Challenge to IBM, op. cit., p. 23.

130 Interview of Yoshioka Tadashi, a former MITI official involved in the promotion of the industry in the late 1950s through early 1970s and later the director of the Japan Electronics Industry Development Association (JEIDA), Nov. 27, 1987.

131 Kompyutopia, December 1973, p. 23.

132 Ibid., p. 24; "JECC Monogatari," segment 4, in Kokusan Denshikeisanki Nyusu, no. 120, Jan. 1, 1980, p. 6.

133 Ekonomisuto Editorial Board (cd.), Sengo Sangyo Shi e no Shogen (Interviews towards a history of postwar industry) (Tokyo: Mainichi Shimbunsha, 1977), vol. 1, pp.142-143.

134 Kompyutopia, October 1974, pp. 29-30.

135 Despite regulations restricting large transfers of foreign exchange, MITI allowed IBM Japan to repatriate 10 percent of sales as royalty in exchange for know-how and patents tranferred from the parent firm to the subsidiary. Kokusan Denshikeisanki Nyusu, "JECC Monogatari," segment 5, no. 121, Feb. 1, 1980, p. 3.

136 Uozumi Toru, Kompyuta Senso (The Computer War) (Tokyo: Aoya Shoten, 1979), p. 57.

137 Denshi Kogyo Nenkan, 1976, p. 683.

138 Uozumi, op. cit., pp. 78-79. Toshiba and Daiichi Bussan (today's Mitsui Bussan) made the joint venture that is today's Nikon UNIVAC.

139 Uozumi, op. cit., pp. 78-79.

140 Anchordoguy, Computers Inc.: Japan's Challenge to IBM, op. cit., pp.168-170.

141 "Foreign Computer Manufacturer Participation in the Japanese Government Sector," IDC Japan, Ltd., prepared for the American Electronics Association and the American Chamber of Commerce in Japan, March 1990.

142 Interview, Dec. 8, 1987.

143 "Nihon IBM", in Dokusen Bunseki Kenkyukai (cd.), Nihon no Dokusen Kigyo (Japan's Monopolistic Enterprises) (Tokyo: Shin Nihon Shuppansha, 1971), vol. 5, p. 275. 
144 Imai Kenichi, "Japanese Business Groups and the Structural Impediments Initiative," Japan's Economic Structure: Should It Change? Kozo Yamamura (cd.) (Seattle, WA: Society for Japanese Studies, 1990), p. 191. Fujitsu is the primary computer company in the Daiichi-Kangyo group but Hitachi has relations with this group as well as with the Sanwa and Fuyo groups. Data are not available on the percent of Daiichi Kangyo group machines that are Fujitsu or Hitachi; the only data is on the percent of both firms' machines-70 percent. $10-11$.

145 JECC Kompyuta Noto (JECC Computer Notes), 1979, pp.

146 Share of installed base, Kompyutopia, October 1989, p. 13. Foreign companies' market share in terms of sales was 25 percent as of 1988. Kompyutopia, April 1990, p. 63.

147 Interviews of Tajiri Yasushi, Deputy Section Chief, Marketing Department, Computer Systems, International Operations, Fujitsu Inc., Dec. 1, 1987; Takeuchi Hiroshi, Managing Director of the Long Term Credit Bank of Japan, Dec. 8, 1987; Inaba Masahiro, Assistant Manager, Business Coordination Department of the Industrial Bank of Japan, Dec. 4, 1987; and Ishiguro Ryuji, Director of the Japan Development Bank's Center for Research in Plant and Equipment, Nov. 12, 1984.

148 JECC IO Nenshi (Ten Year History of JECC) (Tokyo: JECC, 1973), pp. 50-51; JECC Kompyuta Noto, annual. For a detailed analysis of JECC see Chapter 3 of Anchordoguy, Computers Inc.: Japan's Challenge to IBM, op. cit., pp. 59-91; Anchordoguy, "Report on Japanese Policies for the SuperComputer Industry," op. cit., Appendix 1.

149 Aftera 15 month period, the user could return the computer at no penalty and the maker had to repurchase it from JECC at the remaining book value. This up-tint cash was thus in part returned to JECC when a machine was returned to the maker. This forced the firms to make better machines in order to encourage users to keep them longer and thereby increase the benefit of the up-front cash.

150 Anchordoguy, Computers, Inc., op. cit., p. 61.

151 Appendix, total of entries in line 10 under "subsidies." The subsidy computed is the difference between the interest JECC paid on JDB loans and the interest it would have had to pay if it had borrowed money from commercial banks at prevailing interest rates. The calculation from 1961 to 1981 is shown in Anchordoguy, Computers Inc.: Japan's Challenge to IBM, op. cit., pp. 228-230 (Appendix C).

152 Interview, Dec. 1, 1987.

153 Denshi Kogyo Nenkan, 1970-71, p. 180; JECC Kompyuta Noto, 1979, pp. 10-11.

154 Denshi Kogyo Nenkan, 1974, p. 419.

155 Anchordoguy, "Japanese Policies for the Supercomputer Industry,” op. cit., Appendix 1.

156 Sales data are from JECC Kompyuta Noto, 1979, pp. 10-11; Kompyutopia, January 1981, 1983, and other January issues; Fujitsu no Gaikyo, 1987, p. 18, and Ministry of Finance annual customs statistics for data on exports, Sales in the period from $1961-1 \% 9$ were $¥ 367.67$ billion; $¥ 1,550.50$ billion for 1970 - 1975 ; $¥ 5,441.12$ billion for 1976 1981 ; and $¥ 26.76$ trillion for $1982-1989$. This estimate of government aid as a percentage of sales is conservative in that sales data for 1982-1986 come in the form of domestic sales and exports, but export data also include exports of foreign companies, especially IBM Japan.

157 Dokusen Bunseki Kenkyukai (cd.), "Nihon Denshin Denwa Kosha" (NIT"), in Nihon no Kokigyo (Tokyo: Shin Nihon Shuppansha, 1973), pp. 134-135; also discussions with Professor Uekusa Masu of Tokyo University and Professor Nanbu Tsuruhiko of Gakushuin University.

158 Interview with Tajiri Yasushi, Deputy Section Chief of the Marketing Department, Computer Systems, International Operations, Tokyo, Dec. 1, 1987.

159 Nihon Denshin Denwa Kosha 25 Nenshi linkai (cd.), Nihon Denshin Denwa Kosha 25 Nenshi (Twenty-five year history of NTT), vol. 3 , p. 249 .

$160 ¥ 2,980.1$ billion at $¥ 220$ to the dollar. Total government procurement (including NTT) of telecom products during this period was about $\$ 17$ billion ( $¥ 3,728.7$ billion at $¥ 220$ to the dollar). Data for 1980-1984 from Denshi Kogyo Nenkan (Electronics industry yearbook) (Tokyo: Dempa Shimbun, 1986), p. 449; data for 1985-6 from Fujitsu no Gaikyo (Fujitsu's outlook) (Tokyo: Fujitsu, Ltd., 1987), p. 11.

161 Shimoda Hirotsugu, IBM to no 10 Nen Senso (The 10-year War with IBM) (Kyoto: PHP Kenkyujo, 1984), p.158; interviews of Yamamoto Kinko, Managing Director of the Japan Information Processing Development Center (JIPDEC), Feb. 28, 1986; and Kuwahara Yutaka, head of the R\&D Administration Office, Hitachi's Central Research Laboratory, Dec. 9, 1987.

162 Interview with Hitachi's Kuwaha.raYutaka. The timing of the New Series Project was of particular importance: IBM had introduced a far more advanced series of computers, the 370 series; the United States was pressuring Japan to liberalize its computer market; and two sharp devaluations of the dollar were rapidly eroding the competitiveness of Japanese products. To help the firms respond to IBM's new series of computers, the project gave subsidies to Fujitsu and Hitachi to develop large-scale computers, NEC and Toshiba to develop mediumscale machines, and Mitsubishi and Oki, small computers. No single Japanese firm had the resources to develop a full line to compete with IBM's, series which ranged from small to large-scale machines; the idea was that through the project the industry as a whole could respond as rapidly as possible.

163 Kenneth Flamm, Targeting the Computer (Washington DC: The Brookings Institution 1987), p. 134.

164 Letter in Fujitsu Nyusu, Fujitsu's internal magazine, November 1971, reprinted in Fujitsu Shashi, vol. 2, pp. 134-136.

165 Raul Mendez, "Japanese Supercomputers," in Vector Register (Tokyo: The Institute for Supercomputing Research), vol. 3, no. 1, October 1989, p. 4; Dempa Shimbun, July 1, 1987, p. 1, and Sept. 8, 1986, p. 4.

166 Interview in Bungeishunju, September 1982, p. 101.

167 Toyokeizai, July 5, 1975, p. 72.

168 JECCKompyuta Noto, 1979, p. 232 and 1981, p. 283; Denshi, vol. 19, no. 1, p. 9, January 1979, and vol. 18, no. 5, p. 37, May 1978.

169 Interview, Dec. 9, 1987.

170 Denshi (Electronics)(Tokyo: Nihon Denshi Kikai Kogyokai), July 1976, pp. 9, 14.

171 Interview, Feb. 3, 1986.

172 Shimura Yukio, IC Sangyo Daisenso (The IC Industry's Big War) (Tokyo: Daiyamondosha, 1979), p. 3..

173 Uozumi, op. cit., p. 156.

174 The Economist, Apr. 5, 1980, p. 75.

175 See, for example, Raul Mendez, "Japanese Supercomputers," op. cit., p. 4.

176 Uozumi, op. cit., pp. 128-129, 169-170; Interview of Koezuka Masahiro, Deputy Director of MITI's Electronics Policy Division, May 26, 1984; interview of Yoshioka Tadashi, former MTTI official, Nov. 27, 1987. Oki ultimately got access to the patenta of the VLSI project (though not the know-how) through NTT, to whom it had close ties on telecommunications equipment.

177 This project was part of a series of projects done under the umbrella "Large Scale Project" of MITI's Agency for Industrial Science and Technology. The umbrella project has funded research on various topics including computers, pollution problems, and energy.

178 JECC Nyusu, Feb. 1, 1981, p. 1.

179 SaisentanGijutsu noDoko (Trends in Leading-Edge Technologies), MITI's Gyosei Shiryo Chosakai, 1983, p. 748.

180 Interviews of Nishikawa Taizo, Deputy Director, Industrial 
Electronics Division, Machinery and Information Industries Bureau, MITI, and Furutani Takeshi, Deputy Director, Electronics Policy Division, Machinery and Information Industries Bureau, MITI, both on Sept. 25, 1990

181 Inter view of top Japanese computer scientist who is closely involved with several government-sponsored R\&D projects, Sept. 25, 1990.

182 Kagaku Gijutsuyo Kosoku Keisan Shisutemu no Kenkyu Kaihatsu ni kan suru Hyoka Hokokusho (The Evaluation Report of the Research and Development Done in the High Speed System for Scientific and Technological Uses), MITI's Sangyo Gijutsu Shingikai; Ogata Gijutsu Kaihatsubu Hyoka Bunkakai; and the Kosoku Keisan System Hyoka Koiinkai, August 1990, p. 8. (calculated at $¥ 150$ to the dollar).

183 Denshi Kogyo Geppo vol. 24, no. 9, pp. 42-47. JECC Kompyuta Noto, 1982, pp. 196-199.

184 Interview of Hideo Aiso, head of the project, Sept. 25, 1990.

185 NEC and Toshiba did research on gallium arsenide memory devices, Hitachi and Mitsubishi on gallium arsenide logic devices.

186 Electronics, Jan. 13, 1982, p. 71. Most of the research done in this project was done separately by the firms; there was no common lab except for the dataflow machine that MITI's Electrotechnical Laboratory (ETL) led. To make the parts compatible, the firms cooperated.

187 Koichiro Tamura, "General Remarks on the Achievements of the National R\&D Program, High Speed Computing System for Scientific and Technological Uses," Vector Register (Tokyo: Institute for Supercomputing Research), vol. 3, no. 4, fall 1990, pp. 5-6; Kahaner and Kung, op. cit.

188 The processor used was the one from Fujitsu's VP-2600 machine. David Kahaner, "Japanese Government Science Structure and Computer Related Projects," a Report of the U.S. Office of Naval Research, Far East, July 30, 1990; JECC Nyusu, Aug. 1, 1990, p. 5, no. 247. Also in Nikkei Sangyo Shimbun, Mar. 30, 1989, p. 1; Interview of a U.S. scientist who works at the Office of Naval Research, Far East, Sept. 27, 1990; Interview of Nishikawa Taizo, Deputy Director, Industrial Electronics Division, Machinery and Information Industries Bureau, MITI, Sept. 25, 1990.

189 Fujitsu' s M-380 mainframe and Hitachi's M-280Hmainfmme were used as the starting point for the development of their Fujitsu VP series of supercomputers and Hitachi S-810 supercomputers respectively; this architecture was originally developed during MITI's "New Series Project" from 1972-1976. Raul Mendez, "Japanese Supercomputers," Vector Register, vol. 3, no. 1, October 1989, p. 4; Dempa Shimbun, July 1, 1987, p. 1 and Sept. 8, 1986, p. 4.

190 JECC Nyusu, Aug. 1, 1990, p. 5, no. 247.

191 JECC Nyusu, Aug. 1, 1990, no. 247, p. 4-5. This is now being followed up with the "EM-4" project to improve the Sigma-1 machine, making it into a 1,024 processor machine. The idea is to improve upon the Sigma-1 machine by simplifying its architecture, putting several processing elements onto a single chip with a simplified network structure. [Kahaner, Report of the U.S. Office of Naval Research, Far East, July 2, 1990; Nihon Keizai Shimbun, July 16, 1988, p. 11.].

192 Kahaner and Kung, op. cit.

193 Olaf Lubeck, a researcher in the Computer Reserach and Applications Division of Los Alamos National Laboratory. Olaf Lubeck's notes in a report from the U.S. Office of Naval Research, Far East, Tokyo Office entitled "ETL Dataflow Project' written up by Dr. David Kahaner, July 2, 1990.

194 JECC Nyusu, Aug. 1, 1990, p. 5, no. 247.

195 Interview of Hideo Aiso, head of the project, Sept. 25, 1990; JECC Nyusu, Aug. 1, 1990, no. 247, p. 5; Koichiro Tamura, "General Remarks on the Achievements of the National R\&D Program, "High Speed Computing System for Scientific and Technological Uses,' “ Vector Register, fall 1990, pp. 7-8.
196 Interviews of Kitagawa Noriyoshi of NEC's Second LSI Division, Feb. 3, 1986; and discussion with Hiyaguri Toshio, Director and General Manager of Fujitsu's Computer Group after he gave a talk on Fujitsu's Supercomputer efforts at the Tokyo Foreign Correspondent's Press Club, Dec. 4, 1985; Yamamoto Kinko, Managing Director of JIPDEC, Dec. 3, 1987; Denshi Kogyo Nenkan, 1986, p. 186.

197 Koichiro Tamura, a MITT's ETL scientist, "GeneralRemarks on the Achievements of the National R\&D Program: High Speed Computing System for Scientific and Technological Uses," Vector Register, vol. 3, no. 4, fall 1990, p. 8.

198 Interview of Hideo Aiso, head of the project, Sept. 25, 1990; also, David Kahaner, "Japanese Government Science Structure and Computer Related Projects," Report of U.S. Office of Naval Research, Far East, July 30, 1990. According to an interview with Yoshio Shimamoto, a retired scientist at Brookhaven National Laboratory, Hitachi only did the programming language, while Fujitsu wrote the operating system.

199 JECC Nyusu, Aug. 1, 1990, p. 5, no. 247; Koichim Tamura, "General Remarks on the Achievements of the National R\&D Program, 'High Speed Computing System for Scientific and Technological Uses,' “Vector Register, fall 1990, pp. 3-8.

200 Nihon Keizai Shimbun, Feb. 3, 1991, evening edition, p. 1.

201 Kagaku Gijutsuyo Kosoku Keisan Shisutemu n o Kenkyu Kaihatsu ni kan suru Hyoka Hokokusho (The Evaluation Report of the Research and Development done in the High Speed System for Scientific and Technological Uses), MITT's Sangyo Gijutsu Shingikai; Ogata Gijutsu Kaihatsubu Hyoka Bunkakai; and the Kosoku Keisan System Hyoka Koiinkai, August 1990, op. cit., p. 15.

202 Interview of Fuchi Kazuhiro, project director of the 5th generation project, who is also familiar with the supercomputer project, Aug. 2, 1985, and Yamamoto Kinko, Managing Director of JPDEC, Dec. 3, 1987.

203 Interiew of Oketani Kisaburo of Fujitsu, Dec. 1, 1987.

204 Interview of Oketani Kisaburo of Fujitsu, Dec. 1, 1987.

205 The Oriental Economist, January 1980, p. 29.

206 Interview, Sept. 25, 1990.

207 The Japanese Public Sector: Problems and Prospects for U.S. Supercomputer Vendors, Cray Research, Inc., May 1990, pp. 2-3.

208 Interview with Yamamoto Kinko, Managing Director of JIPDEC, Feb. 28, 1986; Electronics, Feb. 25, 1985, p. 31.

209 Electronics, Sept. 2, 1985, p. 11 and Feb. 25, 1985, p. 31.

210 Kurita Shohei, 90 Nendai no KompyutaUoozu (Computer Wars of the 1990s) (Tokyo: Nikkan Kogyo Shimbunsha, 1988), p. 221.

211 Interview of Yamamoto Kinko, Managing Director of JPDEC, Feb. 28, 1986. Unfortunately, it is impossible to get additional information about this project.

212 Interview of Fuchi Kazuhif, director of the fifth generation computer project, Aug. 2, 1985, and Yamamoto Kinko, Managing Director of JIPDEC, Dec. 3, 1987.

213 JTECH Report on Advanced Computing in Japan, Japan Technology Evaluation Center (McLean, VA: Science Applications International Corp., December 1987).

214 Interview, Dec. 5, 1990.

215 Interview of Shimizu Sakae, Toshiba Senior Managing Director, Feb. 3, 1986.

216 Shimoda Hirotsugu, IBM to no 10 Nen Sense, pp. 60-61.

217 Interview, Feb. 28, 1986.

218 Electronics Week, June 10, 1985, p. 30.

219 Interview of Hideo Aiso, head of the project, Sept. 25, 1990.

220 Kahaner and Kung, op. cit.

221 Kahaner and Kung, op. cit.; and Report of the Research 
Committee on the New Information Processing Technology, Abstract, April 1990, MITI's Machinery and Information Industries Bureau, Industrial Electronics Division.

222 Kahaner and Kung, op. cit.

223 Kahaner and Kung, op. cit.

224 Dempa Shimbun, Apr. 22, 1989, p. 5; JECC Nyusu, July 1 , 1989, p. 7 , no. 234 .

225 JECC Nyusu, July 1, 1989, p. 7, no. 234.

226 Kahaner, op. cit

227 Interview, Dec. 9, 1987.

228 Business Tokyo, May 1990, p. 8.

229 Kawabata Naohisa, Kompyuta Gyokai gaAbunai, p. 120.

230 "Supercomputer Bout," Business Tokyo, April 1990, p. 33.

231 Kawabata, op. cit., p. 121.

232 Kawabata, op. cit., pp. 120-121.

233 Interviews of former Cray employees involve\& U.S. Embassy officials, and former USTR officials, September and October 1990. U.S. government and Cray employees also confirmed that there have been other cases in which university professors, especially those that have used Cray machines while working in the United States, have called Cray Research or the Embassy or both, with the idea of getting the United States to put pressure on Japan to give them a large enough budget for a Cray.

234 Kawabata, op. cit., p. 121; Nikkei Sangyo Shimbun, Dec. 21, 1988, p. 8 and May 1, 1989, p. 12.

235 Cited in "Supercomputer Bout," Business Tokyo, April 1990, p. 33.

236 Nikkei Sangyo Shimbun, Dec. 21, 1988, p. 8.; Nihon Keizai Shimbun, Apr. 21, 1988.

237 Dempa Shimbun, Sept. 26, 1989.

238 These include keiretsu-related purchases, auto firms' purchases of domestic machines despite Cray's clear superiority in this area, and all purchases of domestic machines by private institutiona up through 1986. (Eight are automobile companies: Nissan Diesel, 1987, Suzuki, 1986, 1989, 1989; Mazda, 1987 and 1989; Toyota, 1985 and 1988. The reruining 12 of the 20 initial purchases are by Tokai University, 1986 and 1989; Matsushita, 1985 and 1987; Fuji Electric, 1985; Sony, 1985 and 1988; Ishikawajima, Kawasaki Steel, Sharp, Shimizu, Mitsubishi, Olympus, Recruit, and Chiyoda Manufacturing, all 1986. The three upgrades are those of Tokai University, Matsushita, and Sony.)

239 This excludes the two purchases of Cray machines by NTT that were immediately sold to Recruit Co.

240 Nihon Keizai Shimbun, Dec. 4,1989, p. 5.

241 Kawabata, op. cit., p. 115.

242 Nikkei Sangyo Shimbun, Aug. 24, 1988, p. 1.

243 Nikkei Sangyo Shimbun, May 16, 1989, p. 1.

244 Asahi Shimbun, Apr. 29, 1987.

245 Utsumi Ichiro, San Nen go no Kompyuta Gyokai, Gekihen no Seiryoku Chizu (The Computer Industry in Three Years, A Map of the Rapidly Changing [Corporate] Strength) (Tokyo: Besto Bukku, 1989), p. 24 .

246 Nihon Keizai Shimbun, Mar. 11, 1989, p. 31.

247 Kompyutopia, January 1989, pp .12-19. Thia Cray was transferred to Recruit in December, 1986. Nihon Keizai Shimbun, Mar. $6,1989, p .1$.

248 “Supercomputer Bout," Business Tokyo, April 1990, p. 34. Interview of a former USTR official, Sept. 18, 1990.

249 Nihon Keizai Shimbun, Mar. 27, 1987, p. 3.
250 For example, it is discussed in: Kawabata Naohisa, Kompyuta Gyokai ga Abunai, pp. 123-128; Asahi Shimbun, Apr. 29, 1987; Nikkei Sangyo Shimbun, Sept. 8, 1989, p. 8; interview of a General Manager of Fujitsu's Marketing Department, Jan. 11, 1991.

251 Nihon Keizai Shimbun, Mar. 27, 1987, p. 3.

252 Nihon Keizai Shimbun, Mar. 2, 1989, p. 31. It was sold to Recruit in December, 1987. Recruit paid a 5 percent premium on both of these machines over what NTT had paid Cray, according to Nihon Keizai Shimbun, Nov. 2, 1988, p. 19.

253 Nihon Keizai Shimbun, Nov. 2, 1988, p. 19.

254 Ibid.

255 An emergency budget was necessary because the fiscal 1987 budget had already been set. Nihon Keizai Shimbun, Mar. 29, 1987, p. 1.

256 Ibid.

257 Interview, Sept. 18, 1990.

258 Utsumi Ichiro, San Nen go no Kompyuta Gyokai, Gekihen no Seiryoku Chizu, pp. 20-21.

259 Nikkei Computer, Mar. 26,1990, p. 98; NihonKeizai Shimbun, Mar. 8, 1988, p. 13.

260 Nikkei Sangyo Shimbun, Oct. 20, 1987, p. 3.

261 Utsumi, op. cit., p. 21.

262 NikkeiSangyoShimbun, Apr.27, 1988, p. 7 and Dec. 21, 1988, p. 8; Nikkei Computer, Mar. 26, 1990, pp. 98-99.

263 Citedin "'Supercomputer Bout," Business Tokyo, April 1990 p. 30.

264 Nikkei SangyoShimbun, Apr. 15, 1987, p. 24. For example, complaints were made that while a domestic system could be gotten for about $¥ 3$ billion a U.S. system, including peripherals, etc., would cost some $¥ 5$-6 billion

265 Nikkei Sangyo Shimbun, Apr. 15, 1987, p. 24.

266 Nikkei Sangyo Shimbun, Apr. 27, 1988, p. 7. Interview of a U.S. Department of Commerce official, Oct. 22, 1990.

267 Utsumi, op. cit., pp. 26-27.

268 Nikkei Computer, Mar. 26, 1990, p. 96.

269 Interview, Oct. 22, 1990.

270 Cited in "Supercomputer Bout," Business Tokyo, April 1990,

p. 34.

271 Nikkei Computer, Mar. 26, 1990, p. 96.

272 Business Tokyo, "Supereomputer Bcut," April 1990, p. 30.

273 This announcement was quite premature. NEC still baa not shipped any 4 processor SX-3 machines.

274 Nihon Keizai Shimbun, Apr. 23, 1989, p. 4. Also in Nikkei Sangyo Shimbun, Apr. 19, 1989, p. 3.

275 Nihon Keizai Shimbun, Apr. 28, 1989, p. 11.

276 Asahi Shimbun, June 2, 1989 and July 9, 1989; Nikkei Computer, Mar. 26, 1990, p. 98.

277 Asahi Shimbun, June 2, 1989. Nikkei Computer, Mar. 26,1990, p. 98.

278 Nihon Keizai Shimbun, Dec. 14, 1989, p. 1.

279 Nihon Keizai Shimbun, Oct. 21, 1989, p. 8.

280 Nikkei Uotcha,IBM-Ban, Oct. 2, 1989, p. 3.

281 Dempa Shimbun, Dec. 6, 1989, p. 2.

282 Nikkei Uotcha, IBM-Ban, Feb. 5, 1990, p. 4.

283 Asahi Shimbun, Dec. 5, 1989, p. 1.

284 Nihon Keizai Shimbun, Feb. 3, 1990, p. 1, and July 24, 1990, p. 11. 

1990.

285 Interview of Ministry of Foreign Affairs official, Sept. 18,

286 Interview of Ministry of Foreign Affairs official, Sept. 18, 1990. This same sentiment was strongly expressed in an article on supercomputers and the agreement in one of Japan's major computer industry magazines, Nikkei Computer, Mar. 26, 1990, p. 97.

287 Utsumi, op. cit., p. 37.

288 Citedin "Supercomputer Bout, " Business Tokyo April 1990, p. 32 .

289 In an article Fujitsu Chairman Yamamoto Takuma wrote for Nikkei Computer, Jan. 1, 1990, p. 103.

290 Utsumi, op. cit., p. 39.

291 Interview, Oct. 22, 1990.

292 Nikkei Computer, Mar. 26, p. 99. The six labs are: the Tohoku, Nagoya, and Kyushu University Large Scale Computer Labs; the Osaka University Laser Fusion Research Lab, the Fusion Science Lab, and the Meteorological Research Institute.

293 Interview, Sept. 18, 1990.

294 Interview, Sept. 18, 1990.

295 TheJapanese Public Sector: Problems and Prospectsfor U.S. Supercomputer Vendors, Cray Research, Inc., May 1990, pp. 2-3.

$2 \%$ This estimate does not include all supercomputer purchases in Japan, but all those that were made while the performance of Cray machines was unquestionably superior. The private sector companies include keiretsu-related purchases, auto firms' purchases of domestic machines despite Cray's clear superiority in this area, and all purchases of domestic machines by private institutions up through 1986. (Nissan Diesel, 1987, Suzuki, 1986, 1989, 1989; Mazda, 1987 and 1989; Tokai University, 1986; Matsushita, 1985; Toyota, 1985 and 1988; Fuji Electric, 1985; Sony, 1985; Ishikawajima; Kawasaki Steel, Sharp, Shimizu, Mitsubishi Olympus, all 1986; Recruit, 1986, Chiyoda Manufacturing, 1986.)

The govemment procurements are the 21 domestic machines procured up through 1986, after which the Japanese makers started to come out with better, though still not technologically competitive, machines.

297 In current dollars, the estimate would be even higher.

298 For more detail on some of these issues, especially Japan's way of financing long-term investments and links between firms and industries, see Making Things Better, Competing in Manufacturing, Office of Technology Assessment, Congress of the United States (Washington, DC: U.S. Government Printing Office, 1990.)

299 The most comprehensive and insightful work on the institutions of Japanese capitalism is Johnson's MITI and The Japanese Miracle, op. cit. The information in this section draws in part on Anchordoguy, "A Challenge to Free Trade? Japanese Industrial Targeting in the Computer and Semiconductor Industries," Japan's Economic Structure: Should it Change?, Kozo Yamamura (cd.) (Seattle, WA: Society for Japanese Studies, 1990), pp. 301-332.

300 Interview, Apr. 7, 1989.

301 The importance of industry and corporate structure is discussed in Charles Ferguson, "Sources and Implications of Strategic Decline: The Case of JapaneseAmericanC ompetition in Microelectronics," working paper, MIT, June 30, 1987. Also see David J. Teece, "Capturing Value from Technological Innovation: Integration, Strategic Partnering, and Licensing Decisions," in Bruce R. Guile and Harvey Brooks (eds.) Technology and Global Industry: Companies and Nations in the World Economy, National Academy of Engineering Series on Technology and Social Priorities (Washington DC: National Academy Press, 1987), pp. 65-95.

302 Interview, Nov. 30, 1990.

303 Electronics, Mar. 27, 1980, p. 122.

304 Michael Gerlach, "Keiretsu Organization in the Japanese
Economy: Analysis and Trade Implications," in Politics and Productivity, Johnson, et al. (eds.), op. cit., p. 158.

305 "Nihon IBM" (Japan IBM), Dokusen Bunseki Kenkyukai (ed.) Nihon no Dokusen Kigyo (Tokyo: Shin Nihon Shuppansha, 1971), vol. 5, p. 275.

306 As of 1984, Japan's six major industrial groups earned some 18 percent of the total net profits of all Japanese business, had nearly 17 percent of total sales, held over 14 percent of paid-up capital, and employed almost 5 percent of Japan's labor force. [Ulrike Wassmann and Kozo Yamamura, "Do Japanese Firms Behave Differently? The Effects of Keiretsu in the United States," in Kozo Yamamura (cd.) Japanese Investment in the United States: Should We Be Concerned? (Seattle, WA: Society for Japanese Studies, 1989), pp. 121-122.] These six groups are the blue chips of Japanese industry today. Though the 182 companies that make up the core of the 6 groups account for only about 10 percent of the companies on the Tokyo Stock Exchange, more than half of Japan's largest 100 companies are group members and virtually all Japan's top city banks, trust banks, insurance companies, and electronics conglomerates including all the supercomputer makers, are group members.

307 Gerlach, "Keiretsu Organization in the Japanese Economy: Analysis and Trade Implications, "in Politics and Productivity, Johnson et al. (eds.), op. cit., pp. 141-174. It should be noted that this help during hard times is frequently unpleasant; banks often send bank officers to troubled companies, replacing company managers.

308 A Research and Development Strategy for High Performance Computing, Executive Office of the President, Office of Science and Technology policy, Nov. 20, 1987, p. 26.

DARPA backing in several projects helped Intel recently come out with a custom-designed supercomputer-the Delta System-which is based on an array of 528 Intel i860 microprocessors. A consortium of 14 U.S. research institutions, led by the California Institute of Technology, recently announced a planned purchase of a Delta System. Intel has announced that the machine would have peak performance of 32 gigaflops, but this has not yet been tested. [John Markoff, "Consortium to Buy Intel Computer," The New York Times, November 13, 1990, p.C1.] For an overview of U.S. policies towards supercomputers see Supercomputers: Government Plans and Policies, Background Paper, Office of Technology Assessment, U.S. Congress, March 1986.

309 Interview, Oct. 22, 1990.

310 The Federal High Performance Computing Program, Executive Office of the President, Office of Science and Technology Policy, Sept. 8, 1989, p. 46. Sidney Fernbach, "A U.S. High-Performance computing Program," The International Journal of Supercomputer Applications, vol. 4, no. 1, spring 1990, p. 3.

311 This description of the High Performance Computing Program is taken from Executive Office of the President, Office of Science and Technology Policy, The Federal High Performance Computing Program, op. cit., passim.

312 DARPA, the National Science Foundation Department of Energy, NASA, the Department of Health and Human Services (National Library of Medicine), EPA, NIST, and the National Oceanic and Atmospheric Administration.

313 Office of Management and Budget, Budget of the United States Government, Fiscal Year 1992 (Washington, DC: U.S. GPO, 1991), Part Two, pp. 48-49.

314 Electronic Engineering Times, Jan. 21, 1991, p. 2.

315 Ruder Finn, "The Influence of U.S. Prestige on Japanese Supercomputer Makers, " Perspective, Japan Desk, vol. 1, no. 3, August 1989, p. 2.

316 Interview of a supercomputer specialist at the San Diego Supercomputer Center, Nov. 30, 1990.

317 Finn, op. cit., pp. 2-3. 


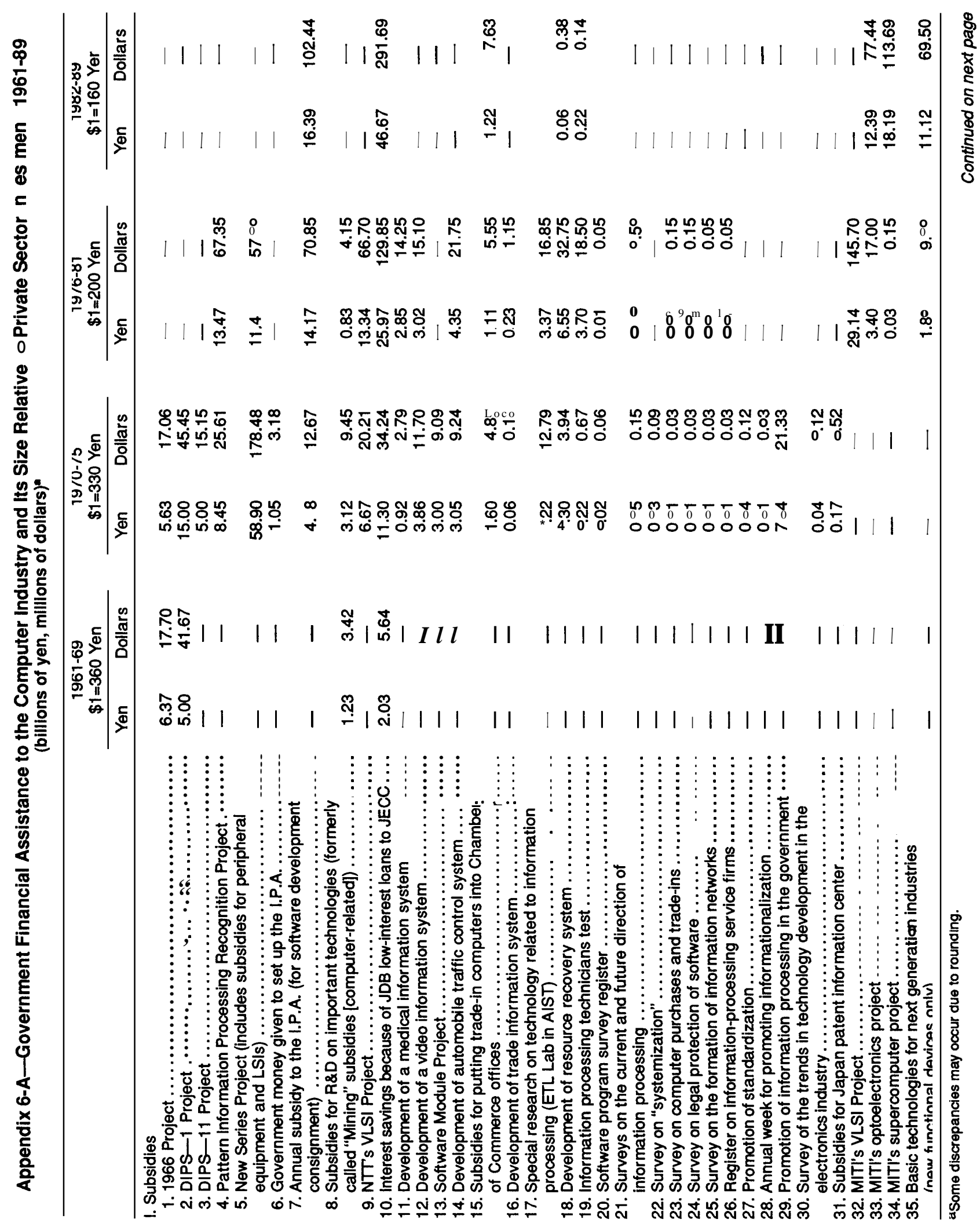




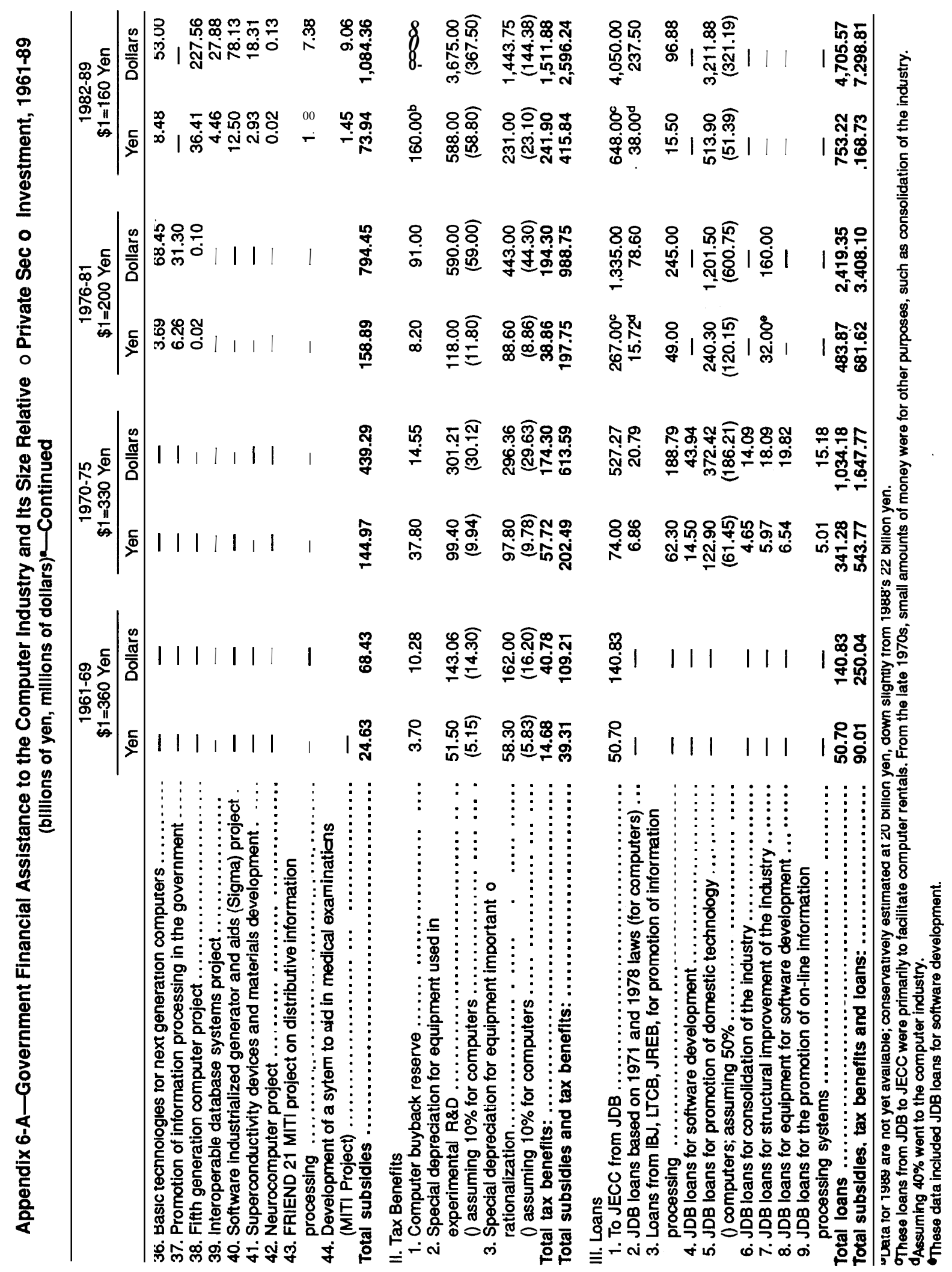


Appendix 6-A--Government Financial Assistance to the Computer Industry and Its Size Relative to Private Sector Investment, 1961-89 (billions of yen, millions of dollars)-Continued

\begin{tabular}{|c|c|c|c|c|c|c|c|c|}
\hline & \multicolumn{2}{|c|}{$\begin{array}{c}1961-69 \\
\$ 1=360 \text { Yen }\end{array}$} & \multicolumn{2}{|c|}{$\begin{array}{c}1970-75 \\
\$ 1=330 \text { Yen }\end{array}$} & \multicolumn{2}{|c|}{$\begin{array}{c}1976-81 \\
\$ 1=200 \text { Yen }\end{array}$} & \multicolumn{2}{|c|}{$\begin{array}{c}1982-89 \\
\$ 1=160 \text { Yen }\end{array}$} \\
\hline & Yen & Dollars & Yen & Dollars & Yen & Dollars & Yen & Dollars \\
\hline $\begin{array}{l}\text { IV. Private sector investment in computer-related R\&D } \\
\text { and plant and equipment } \\
\text { 1. Computer industry investment in plant and equipment } \\
\text { (private sector) } \ldots \ldots \ldots \ldots \ldots \ldots \ldots \ldots \ldots \ldots \ldots \ldots \ldots \ldots \ldots \ldots \ldots \ldots \\
\text { 2. Computer industry investment in } R \& D \text { (private sector) } \ldots \ldots \ldots \ldots \ldots \ldots \ldots \ldots \ldots\end{array}$ & $\begin{array}{r}41.78 \\
62.10 \\
103.90\end{array}$ & $\begin{array}{l}116.06 \\
172.50 \\
288.60\end{array}$ & $\begin{array}{l}129.40 \\
238.50 \\
367.90\end{array}$ & $\begin{array}{r}392.12 \\
722.73 \\
1,114.85\end{array}$ & $\begin{array}{l}153.60 \\
663.10 \\
816.70\end{array}$ & $\begin{array}{r}768.00 \\
3,315.50 \\
4,083.50\end{array}$ & $\begin{array}{l}1,338.80 \\
3,756.15 \\
5,089.95\end{array}$ & $\begin{array}{r}8,340.00 \\
23,480.00 \\
31,820.00\end{array}$ \\
\hline $\begin{array}{l}\text { V. Subsidies and tax benefits as percent of investment } \\
\text { (in percent) } \ldots \ldots \ldots \ldots \ldots \ldots \ldots \ldots \ldots \ldots \ldots \ldots \ldots \ldots \ldots \ldots \ldots \ldots\end{array}$ & \multicolumn{2}{|c|}{$37.8 \%$} & \multicolumn{2}{|c|}{$55.0 \%$} & \multicolumn{2}{|c|}{$24.2 ? !$} & \multicolumn{2}{|c|}{$8.2 \%$} \\
\hline $\begin{array}{l}\text { V1. Subsidies, tax benefits, and loans as percent of investment } \\
\text { (in percent) } \ldots \ldots \ldots \ldots \ldots \ldots \ldots \ldots \ldots \ldots \ldots \ldots \ldots \ldots \ldots \ldots \ldots \ldots \ldots \ldots\end{array}$ & \multicolumn{2}{|c|}{$86.6 \%$} & \multicolumn{2}{|c|}{$147.8 \%$} & \multicolumn{2}{|c|}{$83.5 \%$} & \multicolumn{2}{|c|}{$23.0 \%$} \\
\hline
\end{tabular}

'Data for 1989 not yet available. Estimated at $25 \%$ growth based on previous years' growth rates.

SOURCE: JECCKompyuta Noto, DenshiKogyo Nenkan; Kompyuta Hakusho; various issues of the monthly magazine Kompyutopia:Zeisei Chosa Kai, Zen Shiryo Shu, and Zeisei Chosa Kai Kankei Shiryo Shu; Internal JDB and MITI documents without titles; Nihon Kaihatsu Ginko no Genkyo; JECC 10 Nenshi, JECC annual financial reports; Shuyo Sangyo no Setsubi Toshi Keikaku, Sorifu Tokeikyoku, Kagaku Gijutsu Kenkyu Chosa Hokoku; Denshi Kogyo 30 Nenshi, p. 82; Waga Kuni Denshikeisanki Sangyo no Mondai Ten to Sono Taisaku, 1970, p. 72.

This table is taken from Appendix 1 of the contractor document prepared by Marie Anchordoguy, "Japanese Policies for the Supercomputer Industry," February 1991, pp. 117-122 (Appendix 1) (OTA Contract No. N3-4955), modified as described below.

Subsidy No. 10 and loan No. 1 in the table give the subsidy value and loan value, respectively, of low-interest loans given by the Japan Development Bank (JDB), an agency of the Japanese Government, to the Japan Electronic Computer Co. (JECC). JECC is a nonprofit joint venture of six (originally seven) Japanese computer firms; the Japanese Government has no equity in JECC. See Marie Anchordoguy, Cornputers Inc.:Japan's Challenge to I/BM(Cambridge MA: Harvard University Press, 1989), p. 61.

Professor Anchordoguy's original calculations also included subsidy and loan values based on up-front payments by JECC to computer firms for machines that JECC rented out to Professor Anchordoguy's original calculations also included subsidy and loan values based on up-front payments by JECC to computer firms for machines that JECC rented out to
users. Anchordoguy calculated that this program constituted a subsidy in the following amounts: 1961-1969, 8.10 billion yen, 22.50 million dollars; 1970-1975,6.22 billion yen, 18.85 million dollars; 1976-1981, 6,51 billion yen, 32.55 million dollars; 1982-1989, 8.6 billion yen, 53.75 million dollars. Anchordoguy also calculated that this program constituted a loan in the following amounts: 1961-1969, 97.01 billion yen, 269.47 million dollars; 1970-1975, 69.30 billion yen, 210.00 million dollars; $1976-1981$, 72.60 billion yen, 363.00 million dollars; 1982-1989, 122.13 billion yen, 763.31 million dollars. For these calculations, she noted that "JECC data on computer trade-ins is not available from 1984-1989; it was estimated at 42 percent of annual JECC purchases as the average in the seventies and early eighties was 42 percent. This trade-in data is used to calculate benefits from the JECC system." The logic behind the calculations is explained in more detail in chapter 3 of her book (cited above).

OTA does not believe that these up-front payments represent a loan and subsidy beyond the loan and subsidy already conferred by the JDB loan to JECC, and eliminated these values from the table. The only way money flowed into or out of the Japanese treasury was through loans from JDB (the governnmnt) to JECC (the pr!vate sector).

The elimination of JECC up-front payments to firms makes a difference in the total loan, tax benefit, and subsidy values, especially in the late 1960s, but the conclusion is still the same. The value of government assistance to computer firms was and is substantial. 
Chapter 7

\section{The New Competitors: Industrial Strategies of Korea and Taiwan}




\section{CONTENTS}

INTRODUCTION AND SUMMARY ................................ 295

The Role of Industrial Policies: The Debate .......................... 295

Summary of Findings ....................................... 296

KOREA AND TAIWAN: INTERNATIONAL COMPETITIVE POSITION AND

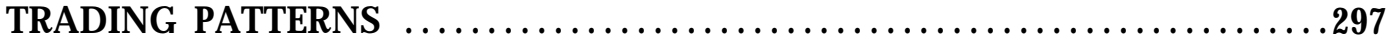

THE ROLE OF GOVERNMENT POLICY: KOREA . . ., **..* $\ldots \ldots . .{ }^{*}{ }^{*} \ldots . .{ }^{*} \ldots, \ldots, 307$

Exchange Rate and Trade Policies .................................... 307

Development Financing and Foreign Direct Investment $\ldots \ldots \ldots \ldots \ldots \ldots \ldots \ldots \ldots, 310$

Tecnology Policies ............................................ 311

Case Study: Automobiles ...................................... 314

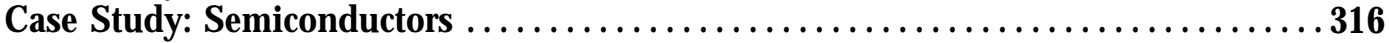

THE ROLE OF GOVERNMENT POLICY: TAIWAN ..........,.. ${ }^{*} .{ }^{*} .^{*} .^{*} \ldots . .{ }^{*} . . \quad 321$

Exchange Rate and Trade Policies ................................... 322

Development Financing and Foreign Direct Investmemt $\ldots \ldots \ldots \ldots{ }^{*}, \ldots{ }^{*} .^{*} \ldots, \ldots 323$

Technology Policies .......................................... 324

Case Study: Automobiles .................................... 327

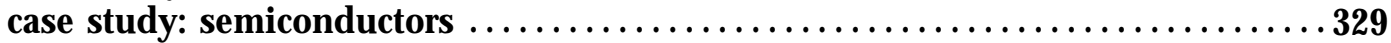

KOREA AND TAIWAN: SIMILARITIES AND DIFFERENCES …............. 332

Figure Page

7-1. Per Capita Gross Domestic Product in Korea 1960-88 .................. 297

7-2. Korean Exports and Imports as Percent of GNP, 1960-90 . . . . . . . . . .......... 297

$7^{*}$ 3. Taiwanese Exports and_as Percent of GNP, 1960-89 . . . . . . . . . . . 297

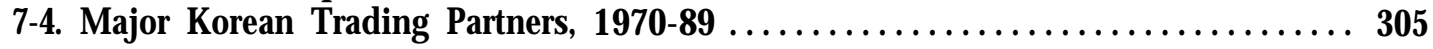

7.5. Major Taiwanese Trading Partners, $1970-89$. $\ldots \ldots \ldots \ldots \ldots \ldots{ }^{*} \ldots \ldots, .^{* * *}, .^{* * * *}, 306$

745. Korean Automobile Production . ... $\ldots \ldots \ldots \ldots \ldots \ldots{ }^{*} \ldots \ldots,{ }^{*} \ldots,^{*} .^{*}, .^{*} .^{*} .^{* *} .314$

7-7. Korean Computer Industry Exports and Production by Product .............. 319

Table

\section{Tables}

7-1. Korea and Taiwan:Basic Economic Indicators, 1956-88 ......, *.., .,... ....296

7-2. Korea and Taiwan: Changes in Industrial Structure, 1970-1988 . . . . . . . ...., 298

7-3, Korea:Revealed Comparative Advantage .......................... 299

7-4 Taiwan:Revealed Comparative Advantage. i ...+, .....* ................ . . 301

7-5. Country Destination of Korean Exports, 1970-89 Major Tradong Partners ....... 303

7-6. Country Source of Korean Imports, 1970-89 Major Trading Partners. .......... 303

7-7. Country Destination of Taiwanese Exports, 1970-89 Major Trading Partners .... 304

7-8. Country Source of Taiwanese Imports, 197(3-89 Major Trading Partners . . . . . . . 304

7-9. Shares of U.S. Majority-owned Foreign Affiliates in Total Exports? of

Manufactures, Selected Countries, 1977 and 1983 ....................... 307

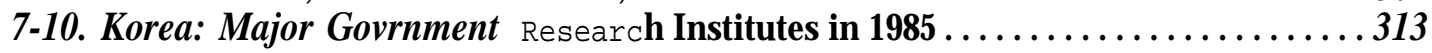

7-11. Taiwan: Major Government Research Institues in 1990 .................. 324

7-12. Taiwan Auto Industry External Sources of Capital and Technology ............. 329 


\section{INTRODUCTION AND SUMMARY}

Ten years ago, the debates about competitiveness, industrial and trade policy, and America's role in the Pacific Basin centered almost exclusively on Japan. In the last decade, other East Asian countries have also increased their exports of manufactured goods. Most prominent are the so-called 'newly industrializing countries' or NICs: the Republic of Korea, the Republic of China, Hong Kong, and Singapore. From 1980 to 1988, the four NICs increased their share of U.S. manufactured imports from 13 to 18 Percent. ${ }^{1}$

This chapter is about the two larger East Asian NICs, the Republic of Korea and the Republic of China (hereafter Korea and Taiwan). In less than 30 years they have risen far up the competitive hierarchy of nations, becoming much more important world traders overall and contending in several capital- and technology-intensive industries. Taiwan became the world's 10th biggest exporter of manufactures in 1986, up from 28th in 1965. Korea was 13th, up from 33rd. As suppliers of manufactured goods to the U.S. market, they ranked 4th and 5th in 1989 , up from 21st and 40th, respectively, in $1962 .{ }^{2}$

Korea and Taiwan remain relatively poor. Korea's per-capita income is comparable to Portugal's, and Taiwan has only recently crossed the World Bank's threshold for high-income countries. ${ }^{3}$ Their overall role in the world economy must also be kept in perspective. Their combined gross domestic product (GDP) accounts for only 1.5 percent of world GDP, excluding the socialist countries, compared to Japan's 10.3 percent; their share of manufactured exports accounts for 4.9 percent of world manufactured exports, compared to Japan's $\mathbf{1 4 . 9}$ percent and $\mathbf{1 1 . 9}$ percent for the United States.

Nonetheless, the ability of both Korea and Taiwan to move from the export of light, labor-intensive manufactures to competitive strength in higher technology industries remains impressive. For example, Korea is now the third largest producer of large capacity (VLSI) memory chips, after Japan and the United States. Taiwan is not far behind the world leaders in some kinds of semiconductor design, and has recently opened a state-of-the-art semiconductor fabrication facility for customized (ASIC) chips. Both have established important export niches in computers, peripherals, and add-ens.

Several other capital- or technology-intensive industries in both countries are competitive, including specialty steel and petrochemicals. Taiwan is the I0th largest machine tool producer in the world, with particular strength in numerically controlled machine tools at the lower precision end of the range. Korea may become the first new producer since the Japanese to break into the oligopolistic world car industry. Firms from both countries are entering alliances with multinationals from North America, Japan, and Europe to develop products for both world and Asian markets.

\section{The Role of Industrial Policies: The Debate}

Much of the literature about the economic prosperity of the East Asian NICs falls into one of several schools of thought. One argues that the main contributions of government in Japan, Korea, and Taiwan were to manage price incentives, particularly through the exchange rate and trade policy, to provide infrastructure and a favorable environment for investment, and to maintain macroeconomic stability. Writers in this school may grant that governments intervened to promote industrial development in Korea and Taiwan, but say these actions were hardly more responsible for the successes than the rooster is responsible for the dawn. They note that intervention in Korea and Taiwan was less pervasive than in most other developing countries, yet the outcomes were better. ${ }^{5}$

The second school sees government actions as more influential. In the strongest version, the state is the primary cause of rapid growth. ${ }^{6}$ An alternative line of thinking focuses on the role of government in overcoming the problems of technology acquisition and adaptation. 'Another argues that specific industrial policies can help gain entry into oligopolistic markets with high entry barriers, imperfect competition, and high returns.

A more political view examines the way particular institutional arrangements affect the efficacy of 
any state intervention. For example, some argue that public and private information-sharing in "policy networks" account for the high quality of government actions in Japan; these arguments apply to Korea and Taiwan as well. ${ }^{9}$ Others concentrate on the political conditions that made for flexible markets in the NICs, such as weak labor movements and leftist parties, and strong, authoritarian leaderships. ${ }^{10}$

\section{Summary of Findings}

Korean and Taiwanese policies for industrial promotion did influence market incentives and market outcomes in a growth-promoting direction. If the measures these countries took were not always efficient in a purely economic sense, they were highly effective in promoting private sector growth. True, their effectiveness depends on price incentives and an ample supply of well-educated workers and energetic entrepreneurs. But these policies and conditions are a matter of industrial policy and government intervention.

The industrial and trade policies of Korea and Taiwan are similar in many respects. Both share a commitment to long-term planning, constructing broad visions of the direction that economic growth ought to take and the specific industries to be encouraged. Both have tied themselves closely to world markets, forcing their firms to compete in the world arena while nurturing them at home.

But, there are significant differences in the policies of the two countries. For example, in Taiwan the economy has been more open than in Korea, industrial policy has been less directive and interventionist, and the industrial structure less concentrated; at the same time, there is a greater reliance on public enterprises. These differences show that there is more than one viable approach to industrial promotion and more than one set of conditions under which it can work.

Until recently, Korea had a relatively protected home market. But protection aimed at assisting protected industries to become internationally competitive. Protection against selected imports was often coupled with offsetting incentives for export sale. For example, exporters could get permission and needed foreign exchange to import needed inputs (raw materials, components, and machinery), as could domestic suppliers who provided intermediate inputs to exporters. In the mid-1960s the export drive became a top priority, second only to national defense, with the President himself leading monthly government/industry Export Promotion Meetings. Korean policy forced firms to set their competitive sights to the world standard, but provided a domestic safe haven from the world's premier companies.

Table 7-I-Korea and Taiwan: Basic Economic Indicators, 1956-88 (annual averages)

\begin{tabular}{|c|c|c|c|c|c|c|}
\hline $1956-60$ & $1961-65$ & $1966-70$ & 1971-75 & $1976-80$ & $1981-85$ & $1986-88$ \\
\hline \multicolumn{7}{|l|}{ Real GDP growth } \\
\hline $\begin{array}{l}\text { Korea } \ldots \ldots \ldots \ldots \ldots \ldots \ldots{ }^{3.3} \\
\text { Taiwan } \ldots \ldots \ldots \ldots \ldots \ldots \ldots \ldots \\
6.7\end{array}$ & $\begin{array}{r}6.5 \\
10.1\end{array}$ & $\begin{array}{l}12.7 \\
10.0\end{array}$ & $\begin{array}{l}9.0 \\
7.8\end{array}$ & $\begin{array}{r}7.6 \\
10.7\end{array}$ & $\begin{array}{l}7.6 \\
6.7\end{array}$ & $\begin{array}{l}10.5 \\
10.3\end{array}$ \\
\hline \multicolumn{7}{|l|}{ Export growth } \\
\hline $\begin{array}{l}\text { Korea } \ldots \ldots \ldots \ldots \ldots \ldots \ldots \ldots \\
\text { Taiwan } \ldots \ldots \ldots \ldots \ldots \ldots \ldots \\
27.9\end{array}$ & $\begin{array}{l}39.6 \\
25.8\end{array}$ & $\begin{array}{l}32.0 \\
27.2\end{array}$ & $\begin{array}{l}32.5 \\
29.2\end{array}$ & $\begin{array}{l}15.3 \\
29.3\end{array}$ & $\begin{array}{l}12.6 \\
11.6\end{array}$ & $\begin{array}{l}18.0 \\
12.6\end{array}$ \\
\hline \multicolumn{7}{|l|}{ Import growth } \\
\hline $\begin{array}{l}\text { Korea } \ldots \ldots \ldots \ldots \ldots \ldots \ldots \ldots \ldots \ldots \ldots \\
\text { Taiwan } \ldots \ldots \ldots \ldots \ldots \ldots \\
\end{array}$ & $\begin{array}{r}6.3 \\
16.2\end{array}$ & $\begin{array}{l}33.8 \\
22.7\end{array}$ & $\begin{array}{l}10.8 \\
33.8\end{array}$ & $\begin{array}{l}14.9 \\
25.9\end{array}$ & $\begin{array}{l}9.2 \\
2.7\end{array}$ & $\begin{array}{l}12.5 \\
21.2\end{array}$ \\
\hline \multicolumn{7}{|l|}{ Investment/GDP } \\
\hline $\begin{array}{l}\text { Korea } \ldots \ldots \ldots \ldots \ldots \ldots \ldots \ldots 10.5 \\
\text { Taiwan } \ldots \ldots \ldots \ldots \ldots \ldots \ldots 14.2\end{array}$ & $\begin{array}{l}13.1 \\
15,2\end{array}$ & $\begin{array}{l}23.4 \\
24.9\end{array}$ & $\begin{array}{l}23.1 \\
30.1\end{array}$ & $\begin{array}{l}28.7 \\
30.8\end{array}$ & $\begin{array}{l}28.4 \\
23.8\end{array}$ & $\begin{array}{l}28.2 \\
20.4\end{array}$ \\
\hline \multicolumn{7}{|l|}{ Exports/GDP } \\
\hline $\begin{array}{l}\text { Korea } \ldots \ldots \ldots \ldots \ldots \ldots \ldots{ }^{7.4} \\
\text { Taiwan } \ldots \ldots \ldots \ldots \ldots \ldots \ldots 10.2\end{array}$ & $\begin{array}{r}6.0 \\
16.9\end{array}$ & $\begin{array}{l}10.4 \\
25.0\end{array}$ & $\begin{array}{l}23.8 \\
41.7\end{array}$ & $\begin{array}{l}39.3 \\
50.9\end{array}$ & $\begin{array}{l}39.9 \\
53.9\end{array}$ & $\begin{array}{l}40.3 \\
59.0\end{array}$ \\
\hline \multicolumn{7}{|l|}{ Imports/GDP } \\
\hline $\begin{array}{l}\text { Korea } \ldots \ldots \ldots \ldots \ldots \ldots \ldots \ldots \ldots \ldots \ldots \\
\text { Taiwan ..... } 11.7 \\
\end{array}$ & $\begin{array}{l}13.0 \\
20.1\end{array}$ & $\begin{array}{l}25.6 \\
26.1\end{array}$ & $\begin{array}{l}34.8 \\
41.1 \\
\end{array}$ & $\begin{array}{l}48.6 \\
48.2 \\
\end{array}$ & $\begin{array}{r}41.3 \\
45.6 \\
\end{array}$ & $\begin{array}{l}32.7 \\
42.3 \\
\end{array}$ \\
\hline
\end{tabular}


Figure 7-I-Per Capita Gross Domestic Product in Korea, 1960-88

Current U.S. dollars (thousands)

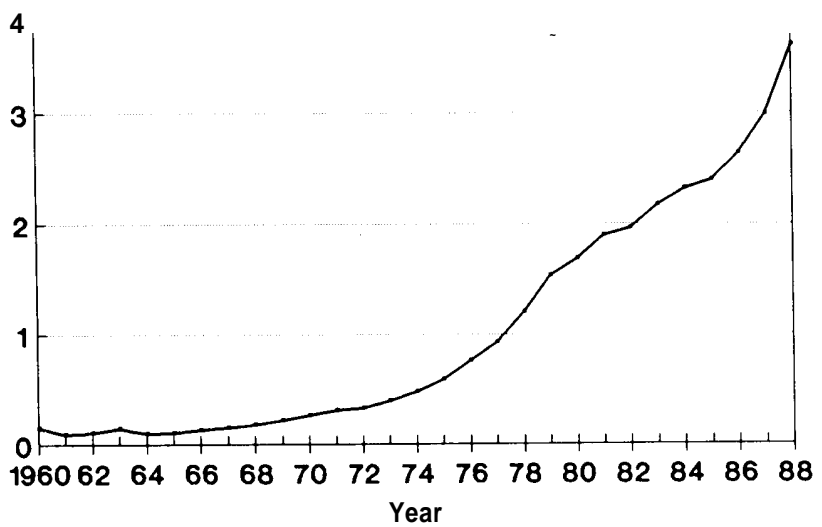

SOURCE: World Bank, World Tables, 1989-90 (Washington, DC: World Bank, 1980) and International Monetary Fund, International Financial Statistics, various issues.

In the 1980s both countries liberalized their economies, moving away from directive industrial policies. This meant not an abandonment of industrial policy, but rather closer consultation and linkages with the private sector, support for private sector initiatives, and greater emphasis on economywide policies such as manpower, infrastructure, and R\&D. Technology policies became particularly important in the $1980 \mathrm{~s}$, as both countries sought to develop an indigenous technological base.

\section{KOREA AND TAIWAN: INTERNATIONAL COMPETITIVE POSITION AND TRADING PATTERNS}

Korea and Taiwan have maintained high growth rates since their transition to an outward-oriented strategy in the early 1960s (table 7-1 and figure 7-1). This performance has been led both by high rates of export growth, particularly in the 1960s and 1970s, and by high rates of import growth (figures 7-2 and 7-3). The openness of the economy-i.e., its exposure to international trade--can be measured by the ratio of exports and imports to gross domestic product (GDP). Both Korea and Taiwan have become more open in this sense, even if their trade policies have not always been fully liberal. Both countries have had high levels of domestic investment, though Taiwan's flagged somewhat in the 1980s.
Figure 7-2-Korean Exports and Imports as Percent of GNP, $1960-90$

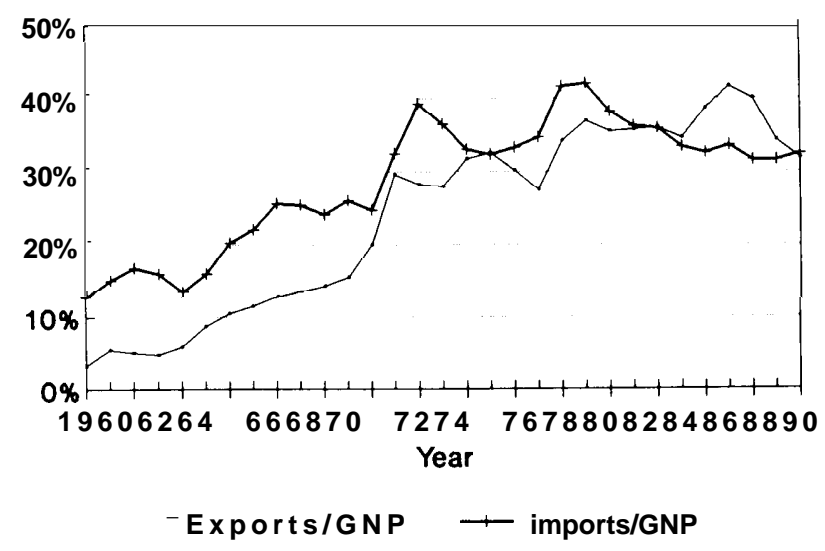

SOURCE: World Bank, World Tables, 1989-90 (Washington, DC: World Bank), July 1991; and International Monetary Fund, International Financial Statistics, (Washington, DC: International Monetary Fund, July 1991).

Figure 7-3-Taiwanese Exports and Imports as Percent of GDP, 1960-89

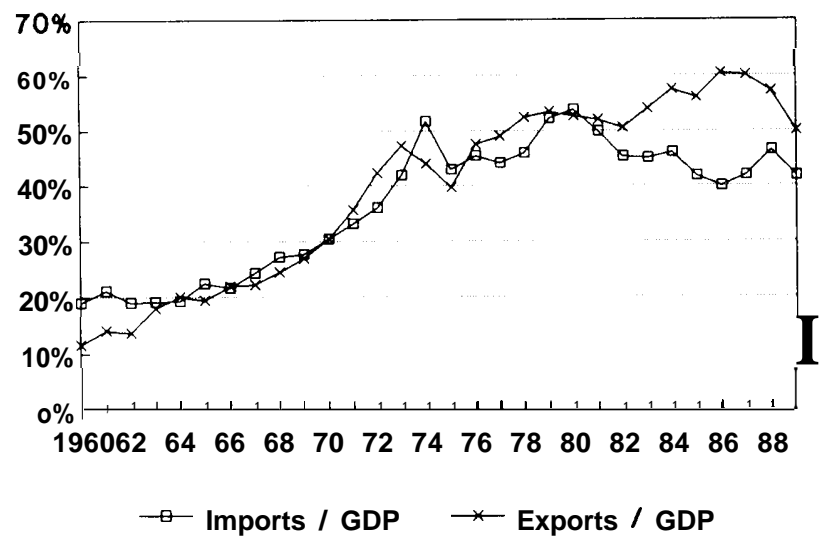

SOURCE: Republic of China, Council for Planning and Development, Taiwan Statistical Data Book, Taipei, Taiwan 1989.

Rapid growth accompanies impressive structural change (table 7-2). Taiwan had 30 percent of GDP in manufacturing by 1970; Korea took another decade to reach that level. Agriculture remained larger in Korea than in Taiwan, despite a plunge in agriculture's share of output over the 1970s and 1980s. Table 7-2 shows that finance, insurance, real estate and business services were more developed in Taiwan until 1980, when Korea's service sector took off.

$A n$ analysis of the export performance of the two countries falls under two topics: the product compo- 
Table 7-2-Korea and Taiwan: Changes in Industrial Structure, 1970-1988 (percentages of output by sector/GDP)

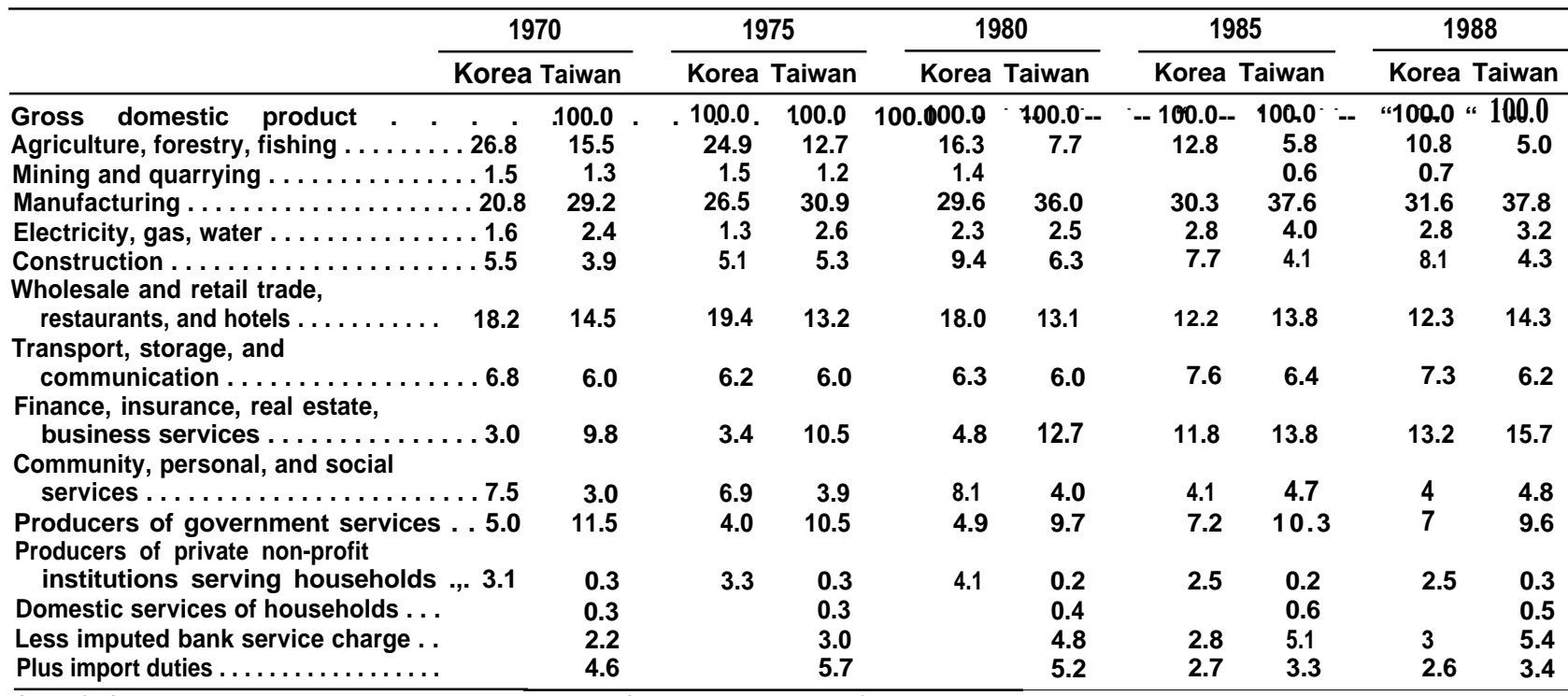

SOURCES: Directorate-General of Budget, Accounting and Statistics, Republic of China; Quarterly National Economic Trends, Taiwan Area, Republic of China; Bank of Korea, Economic Statistics Yearbook.

sition of exports, and the market or geographic composition of exports. To analyze the product composition of exports, we have calculated measures of "revealed comparative advantage" (RCA) for all export product groups from 1980 through 1986, the last year when data was available. The RCA index shows each country's share of world exports in a given product relative to that country's share of world exports of all manufactured products (making the denominator constant in all calculations). If this ratio is less than 1, the country's share in the product is less than the country's share of world trade. On the other hand, if the country has an RCA higher than 1 in a given product category, it reflects a larger market share than would be predicted on the basis of aggregate exports alone. The RCA index is a rough gauge of competitiveness; the higher the index, the larger the country's share in those markets.

Tables 7-3 and 7-4 divide the exports of the two countries into six groupings, first, on the basis of whether the RCA for the product is extremely high (over 4), high (1 to 4) or low (below 1); and, second, on the basis of whether it has risen or fallen between 1980 and 1986. We have also examined the technology intensity of these sectors, using a measure constructed on the basis of applied R\&D expenditure. Though the data on $R \& D$ expenditure is dated and does not cover all sectors, it does provide indications. We have divided the products into those with high $\left(^{* * *}\right)$, intermediate $\left(^{* *}\right)$, and low technology intensity $\left({ }^{*}\right) . "$

The tables show two other figures relevant to assessing the performance of Korea and Taiwan in the U.S. market. The first is aggregate exports in dollars. The second is an index, similar to the RCA, that measures the extent to which exports are concentrated on the U.S. market. A ranking of 1 indicates that the share of exports to the United States in the given product is equal to the share of exports to the United States in the country's total exports. A number higher than 1 indicates that Korea and Taiwan export a larger share of that product to the United States than they do of total exports, reflecting a dependence on the U.S. market and/or a competitive advantage vis-à-vis the United States.

The products with high and rising RCAs represent leading export sectors. What is surprising is the diversity of sectors represented. Korea has developed strong international competitiveness in the capital-intensive shipbuilding industry, a target of industrial policy in the late 1970s. Korea also shows strength in a range of consumer electronics products that are technology intensive, excelling in the more standardized segments. Yet Korea has also increased competitiveness in toys, games, and sporting goods, a low technology, tight-manufacturing sector that is typically labor-intensive. 
Table 7-3-Korea: Revealed Comparative Advantage (1986 exports; other figures are ratios)

\begin{tabular}{|c|c|c|c|c|c|}
\hline \multicolumn{2}{|c|}{ SITC Code and Product } & CA ratio & $\begin{array}{l}\text { Technology } \\
\text { intensity }\end{array}$ & $\begin{array}{l}\text { Exports to U.S. } \\
\text { (nearest \$million) }\end{array}$ & $\begin{array}{c}\text { Concentration } \\
\text { in U.S. }\end{array}$ \\
\hline \multicolumn{6}{|c|}{$\begin{array}{l}\text { Rising RCA ratios } \\
\text { Extremely high } R C A s \text { (extremely competitive relative } \\
\text { to other exports) }\end{array}$} \\
\hline 7528: & Offline data processing equipment...$\ldots \ldots$. & 24.5 & $\cdots$ & NA & NA \\
\hline 793: & Ships and boats ............... & 7.4 & $\bullet$ & 6 & NA \\
\hline 894: & Toys, games, and sporting goods .. & 6.3 & $\mathbf{N} \mathbf{A}^{\mathrm{C}}$ & 684 & NA \\
\hline 762: & Radios ...................... & 6.0 & $\bullet * \star$ & 214 & 0.8 \\
\hline & Preserved fish and shellfish $\ldots \ldots \ldots \ldots \ldots \ldots \ldots \ldots \ldots \ldots \ldots$ & 4.0 & NA & 41 & 0.4 \\
\hline \multicolumn{6}{|c|}{ High RCAs (advantaged relative to other exports) } \\
\hline 898: & Musical instruments, recorded discs and tapes. & 3.9 & NA & 241 & 1.0 \\
\hline 763: & Sound recorders, vCRs $\ldots \ldots \ldots \ldots \ldots \ldots \ldots \ldots \ldots \ldots$ & 3.3 & $-\star *$ & 358 & 1.2 \\
\hline 775: & Household electric appliances $\ldots \ldots \ldots \ldots \ldots \ldots \ldots \ldots \ldots$ & 3.1 & $\bullet * \star$ & 339 & 1.5 \\
\hline 7643: & 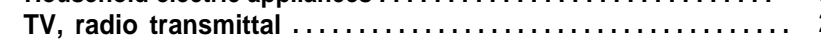 & 2.1 & $\bullet * *$ & 44 & 1.3 \\
\hline $7641:$ & Telephones $. . . \ldots \ldots .$. & 2.1 & $\bullet$ w & NA & NA \\
\hline 764: & Telecommunications $\quad \ldots \ldots \ldots \ldots \ldots \ldots \ldots \ldots \ldots \ldots \ldots$ & 1.7 & $\cdots$ & 566 & 1.7 \\
\hline $7781:$ & 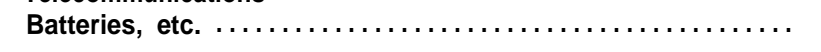 & 1.3 & $\cdot \cdot$ & 12 & 0.9 \\
\hline \multicolumn{6}{|c|}{$\begin{array}{l}\text { Low RCAs (disadvantaged relative to other exports) } \\
\text { 75: } \quad \text { Office machinery, automatic data processing equipment }\end{array}$} \\
\hline & 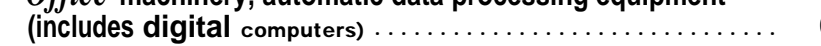 & 0.9 & $\cdots$ & 515 & 1.3 \\
\hline 655: & Knitted fabric .............. & 0.8 & $\bullet$ & 4 & NA \\
\hline 781: & Passenger oars $\ldots \ldots \ldots \ldots \ldots$ & 0.8 & $+{ }^{+}$ & 799 & 1.5 \\
\hline 334: & Refined petroleum products. & 0.7 & NA & 38 & 0.2 \\
\hline 792: & Aircraft and parts .......... & 0.6 & $\cdots$ & 15 & NA \\
\hline 582: & Plastics, condensed ...... & 0.6 & $\ddot{\cdots}$ & NA & NA \\
\hline 056: & Vegetables, preserved & 0.6 & NA & 11 & NA \\
\hline 785: & Motorcycles and bicycles ............... & 0.6 & $\cdots$ & 16 & NA \\
\hline .744: & Mechanical handling equipment and parts ... & 0.5 & NA & 57 & 1.4 \\
\hline 821: & Furniture $\ldots \ldots \ldots \ldots \ldots \ldots \ldots \ldots \ldots$ & 0.5 & NA & 54 & 1.2 \\
\hline 881: & Photo equipment & 0.5 & NA & 18 & NA \\
\hline 611: & Leather ........ & 0.3 & NA & 2 & NA \\
\hline 74: & General industrial machinery and parts $\ldots \ldots \ldots \ldots \ldots \ldots$ & 0.3 & $\bullet$ & 182 & 1.5 \\
\hline 68: & 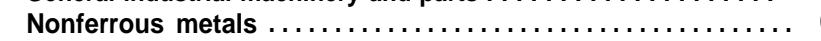 & 0.2 & $\cdot$ & 14 & NA \\
\hline 7783: & Auto electronics $\ldots \ldots \ldots \ldots \ldots \ldots \ldots \ldots$ & 0.2 & $\bullet$ & 9 & 8.2 \\
\hline 784: & Motor vehiclw parts $\ldots \ldots \ldots \ldots \ldots \ldots \ldots$ & 0.2 & $\cdot$ & 56 & 1.1 \\
\hline \multicolumn{6}{|c|}{ Falling RCA ratios } \\
\hline \multicolumn{6}{|c|}{$\begin{array}{l}\text { Extremely high RCAs (extremely competitive relative } \\
\text { to other exports) }\end{array}$} \\
\hline 831: & Travel and hand bags $\ldots \ldots \ldots \ldots \ldots \ldots$ & 12.3 & NA & 331 & 1.3 \\
\hline 85: & 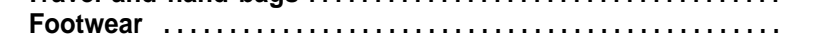 & 9.3 & NA & 1,489 & 1.8 \\
\hline 653: & Woven synthetic fabric...$\ldots \ldots \ldots \ldots \ldots \ldots \ldots \ldots \ldots \ldots \ldots \ldots \ldots \ldots$ & 8.4 & $\cdot$ & 197 & 0.3 \\
\hline 761: & Televisions $\ldots \ldots \ldots \ldots \ldots$ & 7.5 & $\bullet \cdot$ & 442 & 1.4 \\
\hline 786: & Trailers and containers ...... & 6.2 & NA & NA & NA \\
\hline 696: & Cutlery $\ldots \ldots \ldots \ldots \ldots \ldots \ldots \ldots \ldots \ldots$ & 5.9 & & 66 & 1.1 \\
\hline 84: & Wearing apparel and accessories ....... & 5.4 & NA & 2,529 & 1.2 \\
\hline 034: & 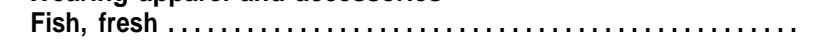 & 4.7 & NA & 73 & 0.4 \\
\hline 693 & Wire products, nonelectric .............. & 4.3 & $\bullet$ & 73 & 1.2 \\
\hline 697: & Household appliances of base metal . . . . . . . . . . . . . . . & 4.3 & NA & 95 & 1.0 \\
\hline 7642: & Microphones, loudspeakers, amplifiers . . . . . . . . . . . & 4.0 & & 45 & 2.3 \\
\hline \multicolumn{6}{|c|}{ High RCAs (advantaged relative to other exports) } \\
\hline 625: & Rubber tires and tubes $\ldots \ldots \ldots \ldots \ldots \ldots \ldots \ldots \ldots \ldots \ldots \ldots \ldots$ & 3.5 & $\begin{array}{l}\text { NA } \\
\text { NA }\end{array}$ & $\begin{array}{l}180 \\
647\end{array}$ & $\begin{array}{l}0.9 \\
1.0\end{array}$ \\
\hline \multirow[t]{2}{*}{$\begin{array}{l}\text { 776: } \\
\text { 76: }\end{array}$} & $\begin{array}{l}\text { Transistors, valves, diodes, cathode tubes, semiconductors . . } \\
\text { Telecommunications and sound recording and }\end{array}$ & 3.5 & NA & 647 & 1.0 \\
\hline & reproducing equipment $\ldots \ldots \ldots \ldots \ldots \ldots \ldots \ldots \ldots \ldots \ldots$ & 3.3 & $\star \star \star$ & 1,580 & 1.3 \\
\hline 661: & Cement, lime, building products $\ldots \ldots \ldots \ldots \ldots \ldots \ldots \ldots \ldots$ & 3.2 & $\cdot$ & 12 & NA \\
\hline 036: & 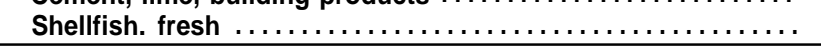 & 3.0 & NA & 24 & NA \\
\hline \multicolumn{6}{|c|}{ 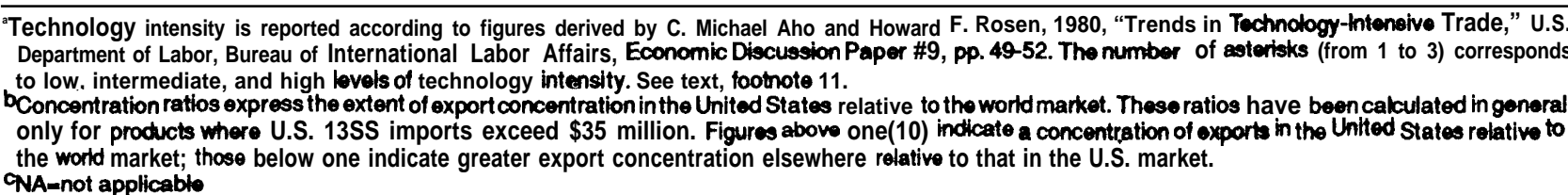 } \\
\hline
\end{tabular}


Table 7-3-Korea: Revealed Comparative Advantage (1986 exports; other figures are ratios)-Continued

\begin{tabular}{|c|c|c|c|c|c|}
\hline \multicolumn{2}{|c|}{ SITC Code and Product } & RCA ratio & $\begin{array}{l}\text { Technology } \\
\text { intensity }\end{array}$ & $\begin{array}{l}\text { Exports to U.S. } \\
\text { (nearest \$million) }\end{array}$ & $\begin{array}{c}\text { Concentration } \\
\text { in U.S. }{ }^{b}\end{array}$ \\
\hline \multicolumn{3}{|c|}{$\begin{array}{l}\text { 651,652, } \\
\text { 654,657: Variou }\end{array}$} & • & 118 & $<1$ \\
\hline 672: & iron and steeL primary forms.$\ldots \ldots \ldots \ldots \ldots \ldots \ldots \ldots \ldots$ & 2.9 & $\bullet$ & 9 & NA \\
\hline 666: & 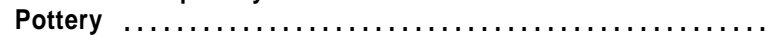 & 2.5 & $\bullet$ & 56 & 1.5 \\
\hline 694: & Nails, screws, bolts ...... & 2.5 & - & 111 & 1.9 \\
\hline 673: & iron and steeL bars, rods, and shapes. & 2.4 & * & 39 & 0.2 \\
\hline 771: & Electric power machinery $\ldots \ldots \ldots \ldots \ldots \ldots \ldots \ldots \ldots \ldots \ldots$ & 2.0 & $\cdots$ & 29 & NA \\
\hline 7782: & 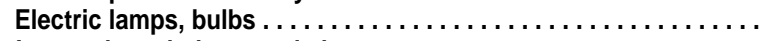 & 2.0 & $\bullet$ & 46 & 1.9 \\
\hline 674: & Iron and steel plates and sheets. & 1.8 & • & 262 & 1.1 \\
\hline 884: & Optical goods ........... & 1.8 & NA & 59 & 1,4 \\
\hline 678: & iron and steel tubes and pipe $\ldots \ldots \ldots \ldots \ldots \ldots \ldots \ldots \ldots \ldots \ldots$ & 1.6 & NA & 197 & 1.4 \\
\hline 885: & 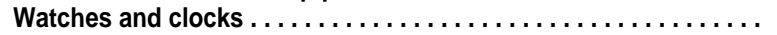 & 1.5 & & 56 & 0.7 \\
\hline 773: & Electricity distribution equipment $\ldots \ldots \ldots \ldots \ldots \ldots \ldots \ldots \ldots$ & 1.2 & $\cdots$ & 45 & 0.9 \\
\hline 897: & Jewelry, articles of precious metal . & 1.2 & NA & 92 & 1.5 \\
\hline 893: & Plastic articles, misc. $\ldots \ldots \ldots \ldots \ldots \ldots \ldots \ldots \ldots \ldots \ldots \ldots \ldots \ldots \ldots \ldots \ldots \ldots$ & 1.0 & & 100 & 1.3 \\
\hline \multicolumn{6}{|c|}{ Low RCAs (disadvantaged relative to other exports) } \\
\hline 791: & Railway vehicles .............. & 0.9 & $\bullet$ & 2 & NA \\
\hline 778: & Electrical machinery, misc. .......... & 0.8 & $\ddot{*}$ & 164 & 1.6 \\
\hline 699: & Base metal manufactures, misc. $\ldots \ldots \ldots \ldots \ldots \ldots \ldots \ldots$ & 0.8 & $\bullet$ & 101 & 1.5 \\
\hline 7512: & Calculating and accounting machines . & 0.8 & $\cdots$ & 44 & 5.4 \\
\hline 635: & Wood manufactures, misc. $\ldots \ldots \ldots \ldots \ldots \ldots \ldots \ldots \ldots \ldots$ & 0.7 & NA & 9 & NA \\
\hline 634: & Veneers, plywood $\ldots \ldots \ldots \ldots \ldots$ & 0.7 & NָA & 6 & NA \\
\hline 663: & Mineral manufactures, misc. $\ldots \ldots \ldots \ldots \ldots \ldots \ldots \ldots \ldots \ldots$ & 0.6 & *** & 8 & NA \\
\hline 759: & Parts and accessories for $752 \ldots \ldots \ldots \ldots \ldots \ldots \ldots \ldots$ & 0.5 & & 106 & 1.2 \\
\hline 812: & Plumbing, heating, and lighting equipment $\ldots \ldots \ldots \ldots \ldots \ldots$ & 0.5 & •• & 19 & NA \\
\hline 751: & Office machines..$\ldots \ldots \ldots \ldots \ldots$ & 0.4 & $\cdots$ & 46 & 2.2 \\
\hline 695: & Hand and machine tools $\ldots \ldots \ldots \ldots \ldots \ldots \ldots \ldots \ldots \ldots$ & 0.4 & $\bullet$ & 24 & NA \\
\hline 64: & 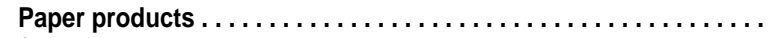 & 0.4 & NQA & 32 & 0.4 \\
\hline 772: & Switchgear, circuits, and parts $\ldots \ldots \ldots \ldots \ldots \ldots \ldots \ldots \ldots$ & 0.4 & & 73 & 1,7 \\
\hline 058: & 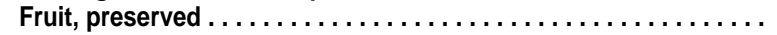 & 0.3 & NaA & 7 & NA \\
\hline 71: & Power generating machinery $\ldots \ldots \ldots \ldots \ldots \ldots \ldots \ldots \ldots \ldots$ & 0.3 & & 27 & 0.3 \\
\hline 87: & Scientific and controlling instruments $\ldots \ldots \ldots \ldots \ldots \ldots \ldots$ & 0.3 & $\cdots$ & 56 & 1.0 \\
\hline 724: & Textile and leather machines and parts . & 0.2 & •. & 6 & NA \\
\hline 73: & Metal working machinery $\ldots \ldots \ldots \ldots \ldots \ldots \ldots \ldots \ldots \ldots \ldots$ & 0.15 & $\cdot$ & 17 & NA \\
\hline 721: & Agricultural machinery and parts. $\ldots \ldots \ldots \ldots \ldots \ldots \ldots \ldots$ & 0.05 & $\bullet$ & 2 & NA \\
\hline
\end{tabular}

SOURCES: United Nations, International Trade Statistics Yearbook; National Bureau of Statistics, Economic Planning Board, Korea Statistical Yearbook.

Taiwan shows a contrasting pattern. First, the range of products in which the country improved its competitiveness in the 1980 s is greater, though with a lower average dollar value of exports in each category. This pattern reflects a' 'niche' strategy of specialization in products that are less technologyand capital-intensive than those in which Korea has excelled. For example, Taiwan improved its competitiveness in a number of apparel segments, while moving into standardized electronics products such as calculators and telephones that can be produced by small firms.

The third cluster, sectors with low but rising RCAs, represent those in which Korea and Taiwan are developing comparative advantage. In Korea, this list includes office machinery, computers, automobiles, and refined petroleum products, capitalintensive sectors targeted by the government in the last 15 years. Taiwan is competitive in steel, a sector dominated by a state-owned enterprise. Both countries show low but rising competitiveness in general industrial machinery.

The change out of light, labor-intensive manufactures is apparent in the next cluster of industries: sectors in which competitiveness was strong in the past, but is falling now. In Korea, decline in the competitiveness of steel and textile and apparel segments are noteworthy. Taiwan declined in some textile and apparel sectors, with a greater concentration of losses in light electronics, for which assembly operations were important for the country's development. The sources of this decline include rising labor costs, technological changes, and improvements in productivity that have moved production back to the advanced industrial states.

The final cell represents those sectors in which Korea and Taiwan are primarily importers rather 
Table 7-4-Taiwan: Revealed Comparative Advantage (1986 exports; other figures are ratios)

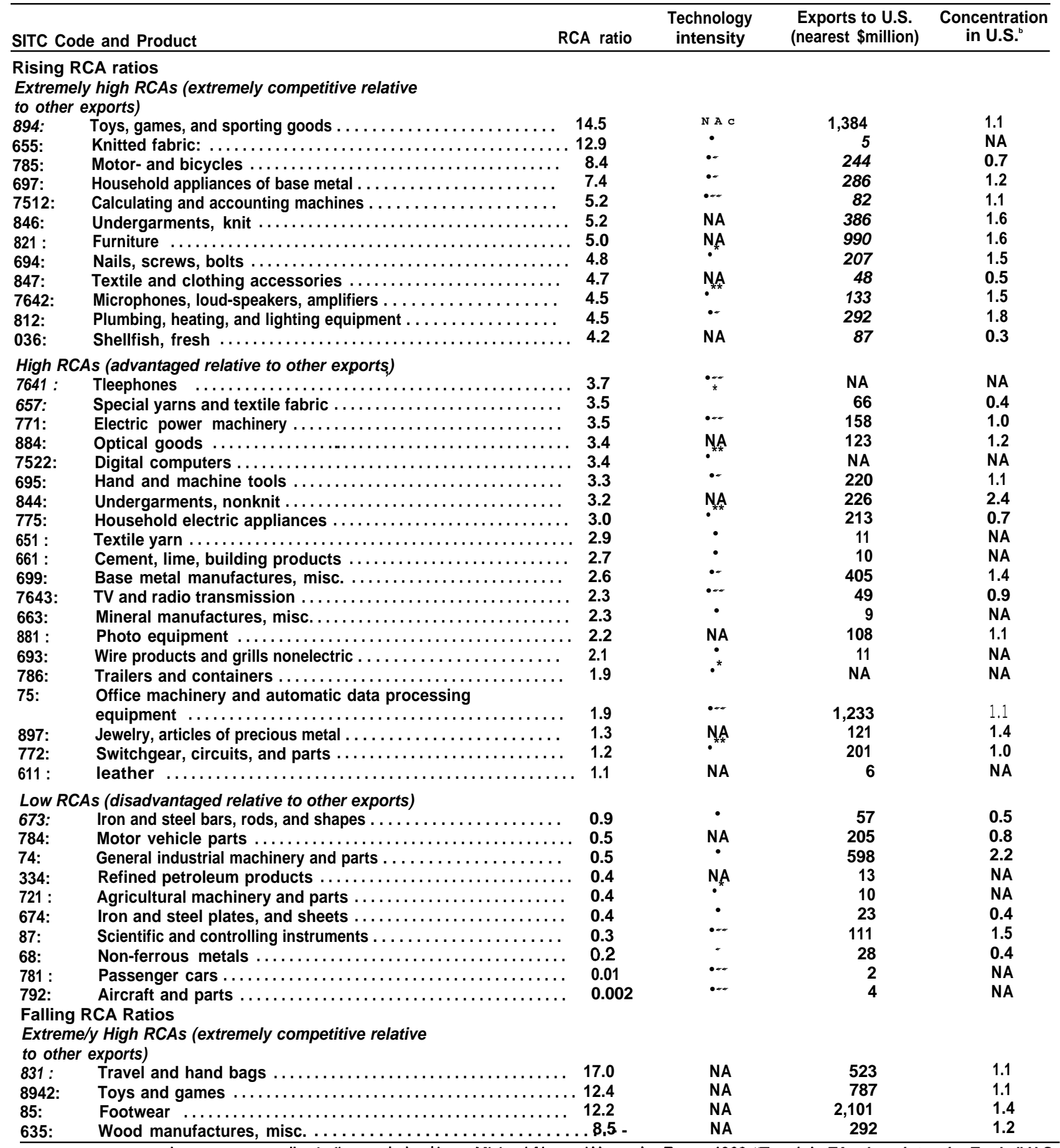

aTechnology intensity is reported according to figures derived by C. Michael Aho and Howard F. Rosen, 1980, "Trends in TAnology-intensive Trade," U.S. Department of Labor, Bureau of International Labor Affairs, Economic Discussion Paper \#9, pp. 49-52. The number of asterisks (from 1 to 3 ) corresponds to low, intermediate, and high levels of technology intensity. See text, footnote 11.

b Concentration ratios express the extent of exportconcentration in the United States relative to the worldmarket. Theseratios have been calculated in general only for products where U.S. 19S6 imports exceed \$35 million. Figures above one (1.0) indicate a concentration of exports in the United States relative to the world market; those below one indicate greater export concentration elsewhere relative to that in the U.S. market.

CNAmnot applicable 
Table 7-4-Taiwan: Revealed Comparative Advantage (1966 exports; other figures are ratios)--Continued

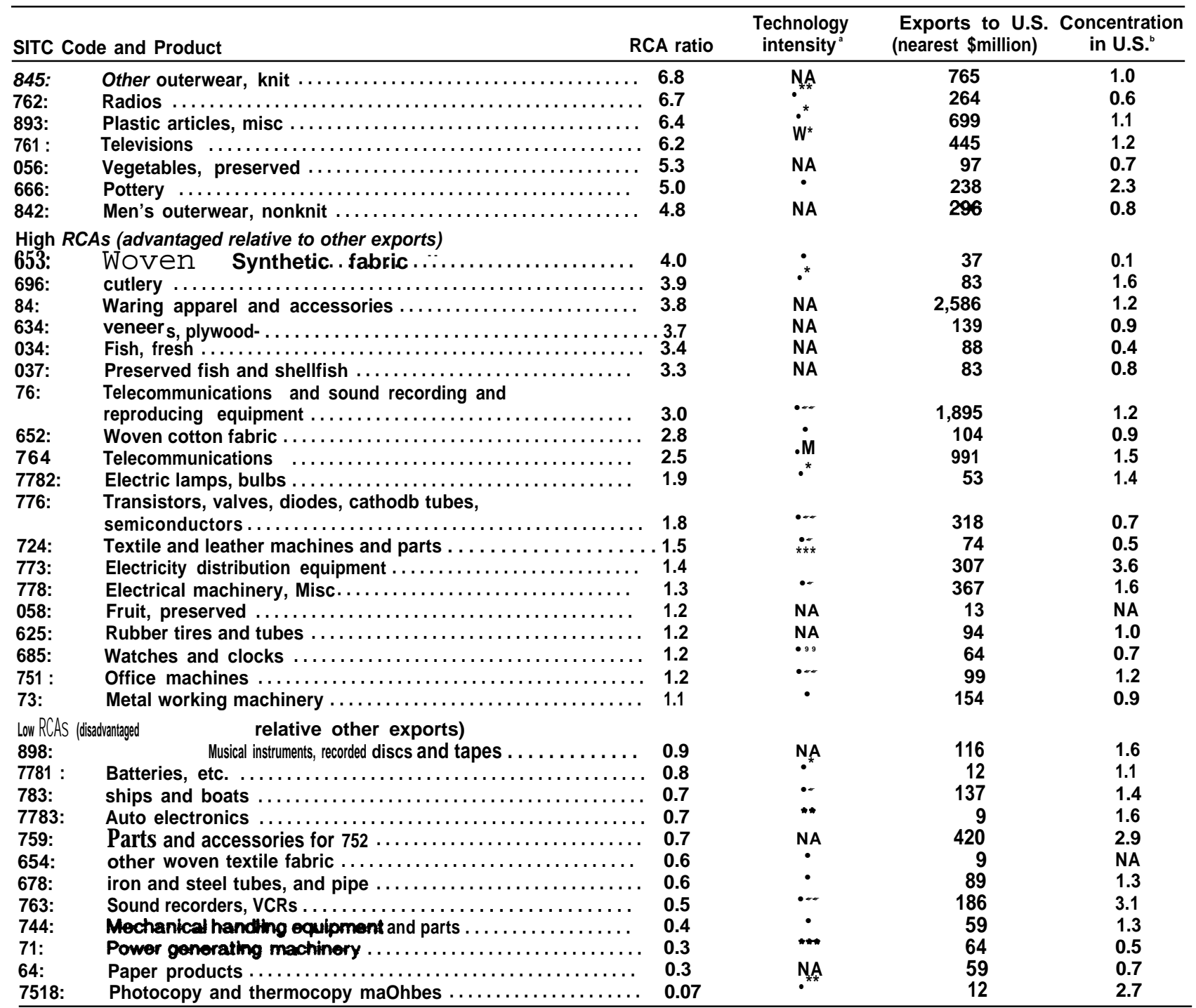

SOURCES: United Nations, International Trade Statistice Yearbook,- Statistics of Trado, Republic of Chime.

than exporters. In line with their poorh resource endowments, these sectors include a number of raw materials-based products, particularly petrochemicals, and, in Taiwan, a range of capital goods

Both countries have developed and maintained competitivess in a diverse array of products ranging from technologically simple to complex. Korea shows a greater concentration in products with higher capital and technology intensity and greater scale economies, while Taiwan Shows greater product diversity. Korea's industrial policy has led to a handful of the largest firms dominating exports. Taiwan has, on average, smaller firms.
The pace of industria l adjustment $\mathrm{o}$ u $\mathbf{t}$ of $\mathbf{d}$ e $\mathbf{c} \mathbf{l}$ i $\mathbf{n}$ i $\mathbf{n} \mathbf{g}$ sectors has been gradual; rising and falling sectors coexist over long periods Of time. In a number of product categories RCA's remain high while declining. Both countries continue to be competitive in traditional export products, such as footwear, even though comparative advantage is ending. This reflects their initial strong market positions in these sectors, and the ability of their firms to enhance productivity, increase investment, and adapt technoIogically to help offset increasing labor and other costs.

With technology transfer from industrialized nations to the NICs and the accumulation of physical 
and human capital, the skill- and capital-intensity of NIC exports has increased. This places competitive pressure on the advanced industrial states. On the other hand, the NICs remain importers of a range of capital-, skill-, and technology-intensive goods. This suggests the likelihood of extensive two-way trade in highly differentiated products, a pattern that has characterized economic relations between $\mathrm{Eu}$ rope and the United States. ${ }^{12}$

Another area of concern is the geographic concentration of the two countries' exports. Tables 7-5 to
7-8 detail their exports and imports by major markets; figures 7-4 and 7-5summarize the information graphically.

In the 1960s, Korea and Taiwan relied heavily on the U.S. market as the key to their export-oriented growth strategy. Following the first and second oil shocks, however, Korea aggressively diversified its exports. Korean construction firms pushed into the lucrative Middle East market, and exports of construction materials followed. Europe's share doubled between 1970 and 1975 .

Table 7-5-Country Destination of Korean Exports, 1970-89 Major Trading Partners (US\$ million)

\begin{tabular}{|c|c|c|c|c|c|c|c|c|c|c|}
\hline \multirow{4}{*}{$\begin{array}{l}\text { Asia: } \\
\quad \text { Australia } \ldots \ldots \ldots \ldots \ldots \ldots \ldots \ldots \\
\quad \text { Hong Kong } \ldots \ldots \ldots \ldots \ldots \ldots\end{array}$} & \multicolumn{2}{|c|}{1970} & \multicolumn{2}{|c|}{1975} & \multicolumn{2}{|c|}{1980} & \multicolumn{2}{|c|}{1985} & \multicolumn{2}{|c|}{1989} \\
\hline & & $\overline{33.9 \%}$ & & $32.7 \%$ & & $26.1 \%$ & & $23 . \overline{7} \%$ & & $\overline{3} \overline{3} . \overline{2} \%$ \\
\hline & 2.9 & $04 \%$ & 63.0 & $1.2 \%$ & 230.4 & $1.3 \%$ & 368.8 & $1.2 \%$ & $1,004.9$ & $1.6 \%$ \\
\hline & 27.5 & $3.3 \%$ & 181.9 & $3.6 \%$ & 823.3 & $4.7 \%$ & $1,565.5$ & $5.2 \%$ & $3,374.6$ & $5.4 \%$ \\
\hline Japan .... & 234.3 & $28.1 \%$ & $1,292.9$ & $25.5 \%$ & $3,039.4$ & $17,4 \%$ & $4,543.4$ & $15.0 \%$ & $13,456.8$ & $21.6 \%$ \\
\hline Singapore. . & 11.0 & $1.3 \%$ & 58.2 & $1.2 \%$ & 266.3 & 1.570 & 490.1 & $1.6 ? 40$ & $1,532.4$ & $2.5 \%$ \\
\hline Taiwan ..... . & 7.2 & $0.9 \%$ & 62.8 & $1.2 \%$ & 216.3 & $1.2 \%$ & 196.1 & $0.7 \%$ & $1,308.2$ & $2.1 \%$ \\
\hline Europe: & & $6.6 \%$ & & $12.7 \%$ & & 11.9Y0 & & $8.4 \%$ & & $9.1 \%$ \\
\hline Germany .... & 27.3 & $3.3 \%$ & 312.2 & $6.1 \%$ & 875.5 & $5.0 \%$ & 979.3 & $3.2 \%$ & $2,137.2$ & $3.4 \%$ \\
\hline Netherlands . . . . . . . . & 13.5 & $1.6 \%$ & 128.9 & $2.5 \%$ & 349.5 & $2.0 \%$ & 345.4 & $1.1 \%$ & 755.8 & $1.2 \%$ \\
\hline United Kingdom . . . . . . . . . . . . & 13.0 & $1.6 \%$ & 161.7 & $3.2 \%$ & 572.5 & $3.3 \%$ & 913.4 & $3.0 \%$ & $1,861.3$ & $3.0 \%$ \\
\hline Middle East: & & $0.2 \%$ & & $2.5 \%$ & & $6.8 \%$ & & $3.9 \%$ & & $1.6 \%$ \\
\hline Kuwait ............. & 1.5 & $0.2 \%$ & 33.9 & $0.7 \%$ & 249.1 & 1.470 & 205.6 & $0.7 \%$ & 210.1 & $0.3 \%$ \\
\hline Saudi Arabia . . . . . . . . . . . & 0.1 & $0.01 \%$ & 91.1 & $1.8 \%$ & 946.1 & $5.4 \%$ & 968.7 & $3.2 \%$ & 814.8 & 1.370 \\
\hline North America: & & $49.7 \%$ & & $34.1 \%$ & & $28.3 \%$ & & $39.6 \%$ & & $36.1 \%$ \\
\hline Canada . . . . . . . . . . . . . & 19.5 & $2.3 \%$ & 197.3 & $3.9 \%$ & 343.4 & $2.0 \%$ & $1,228.7$ & $4.1 \%$ & $1,882.3$ & $3.0 \%$ \\
\hline World; country & 835.1 & $90.3 \%$ & $5,081.0$ & $81.9 \%$ & $17,504.9$ & $73.2 \%$ & $30,283.1$ & $75.5 \%$ & $62,377.1$ & $80.0 \%$ \\
\hline $\begin{array}{l}\text { exports as } \\
\text { share of world exports }\end{array}$ & & & & & & & & & & \\
\hline
\end{tabular}

Table 7-6-Country Source of Korean Imports, 1970-89 Major Trading Partners (US\$ million)

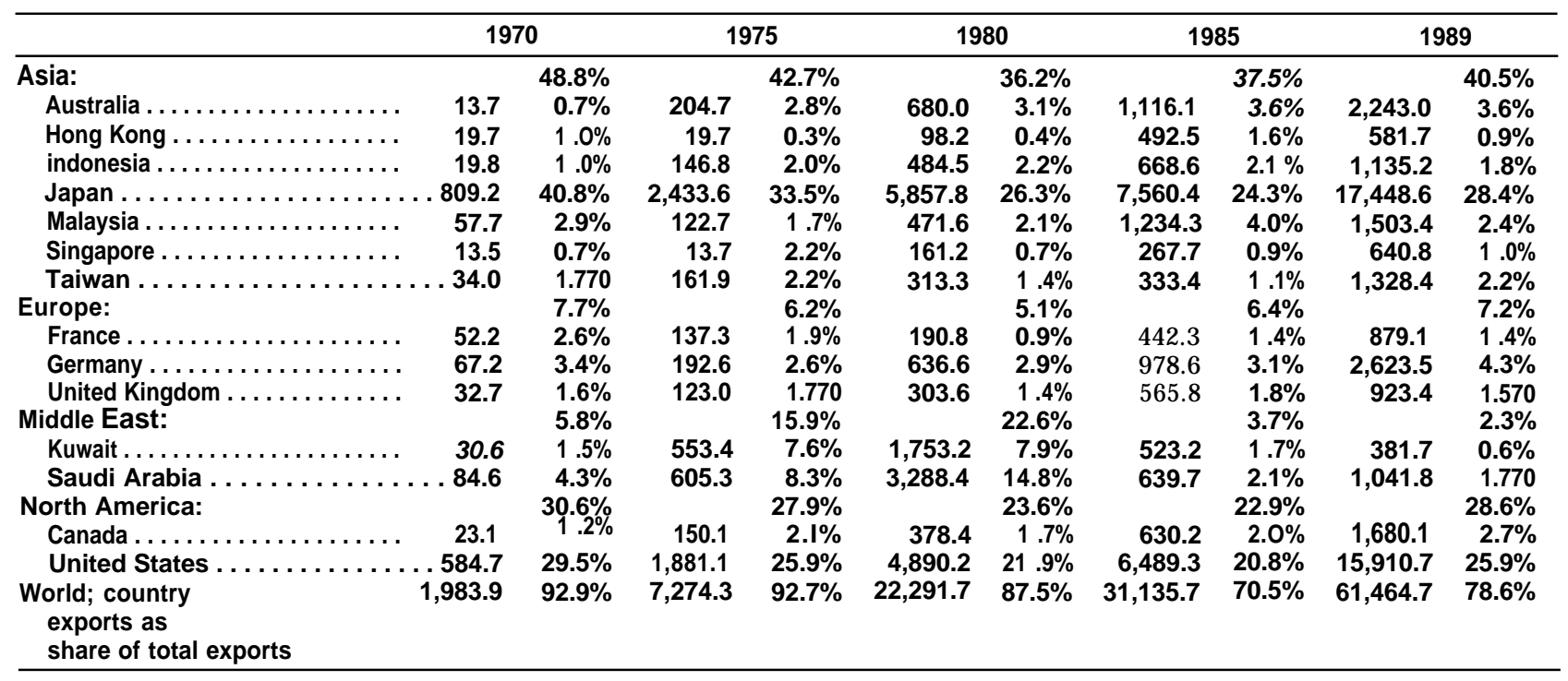

SOURCES: Bank of Korea, Economic Statistics Yearbook Bank of Kore Monthly Economic Statistics. 
Table 7-7-Country Destination of Taiwanese Exports, 1970-89 Major Trading Partners (US\$ million)

\begin{tabular}{|c|c|c|c|c|c|c|c|c|c|}
\hline & 1970 & \multicolumn{2}{|c|}{1975} & \multicolumn{2}{|c|}{1980} & \multicolumn{2}{|c|}{1985} & \multicolumn{2}{|c|}{1989} \\
\hline Asia: & $31.1 \%$ & & $28.5 \%$ & & $26.5 \%$ & & $26.4 \%$ & & $33.0 \%$ \\
\hline Australia . & $1.4 \%$ & 125.5 & $2.4 \%$ & 539.3 & $2.7 \%$ & 747.3 & $2.4 \%$ & $1,531.9$ & $2.3 \%$ \\
\hline Hong Kong . . . . . . . . . . . & $9.2 \%$ & 363.0 & $6.8 \%$ & $1,550.6$ & $7.8 \%$ & $2,539.7$ & $8.3 \%$ & $7,013.9$ & $10.6 \%$ \\
\hline Japan . . . . . . . . . . . . . . . . . . . 215.6 & $14.6 \%$ & 694.2 & $13.1 \%$ & $2,173.4$ & $11.0 \%$ & $3,460.9$ & $11.3 \%$ & $9,058.0$ & $13.7 \%$ \\
\hline Korea ............... & $1.9 \%$ & 119.5 & $2.3 \%$ & 266.5 & $1.4 \%$ & 253.8 & $0.8 \%$ & $1,131.3$ & $1.7 \%$ \\
\hline Singapore $\ldots \ldots \ldots \ldots \ldots \ldots$ & $2.4 \%$ & 140.7 & $2.7 \%$ & 545.1 & $2.8 \%$ & 885.1 & $2.9 \%$ & $1,970.0$ & $3.0 \%$ \\
\hline Thailand $\ldots \ldots \ldots \ldots \ldots \ldots$ & $1.7 \%$ & 67.8 & $1.3 \%$ & 176.2 & $0.9 \%$ & 236.2 & $0.8 \%$ & $1,103.2$ & $1.7 \%$ \\
\hline France & $0.2 \%$ & 37.5 & $0.7 \%$ & 265.6 & $1.3 \%$ & 227.6 & $0.7 \%$ & $1,084.9$ & $1.6 \%$ \\
\hline Germany . . . . . . . & $4.8 \%$ & 316.2 & $6.0 \%$ & $1,075.8$ & $5.4 \%$ & 805.4 & $2.6 \%$ & $2,558.2$ & $3.9 \%$ \\
\hline United Kingdom . . . . . . & $1.0 \%$ & 137.8 & $2.6 \%$ & 471.6 & $2.4 \%$ & 650.0 & $2.1 \%$ & $2,095.8$ & $3.2 \%$ \\
\hline North America: & $41.5 \%$ & & $37.8 \%$ & & $36.5 \%$ & & $51.2 \%$ & & $38.9 \%$ \\
\hline Canada . . . . . & $3.4 \%$ & 181.6 & $3.4 \%$ & 459.7 & $2.3 \%$ & 944.8 & $3.1 \%$ & $1,755.8$ & $2.7 \%$ \\
\hline United States . . . . . . & $38.1 \%$ & $1,822.7$ & $34.3 \%$ & $6,760.3$ & $34.1 \%$ & $14,773.3$ & $48.1 \%$ & $23,943.4$ & 36.25 \\
\hline $\begin{array}{l}\text { World;country } \\
\text { exports as } \\
\text { share of total exports }\end{array}$ & $78.6 \%$ & $5,308.7$ & $75.5 \%$ & $19,810.6$ & $72.1 \%$ & $30,725.6$ & $83.1 \%$ & $66,102.4$ & $80.6 \%$ \\
\hline
\end{tabular}

SOURCE: Council for Economic Planning and Development, Taiwan Statistical Data Book.

Table 7-8-Country Source of Taiwanese Imports, 1970-89 Major Trading Partners (US \$ million)

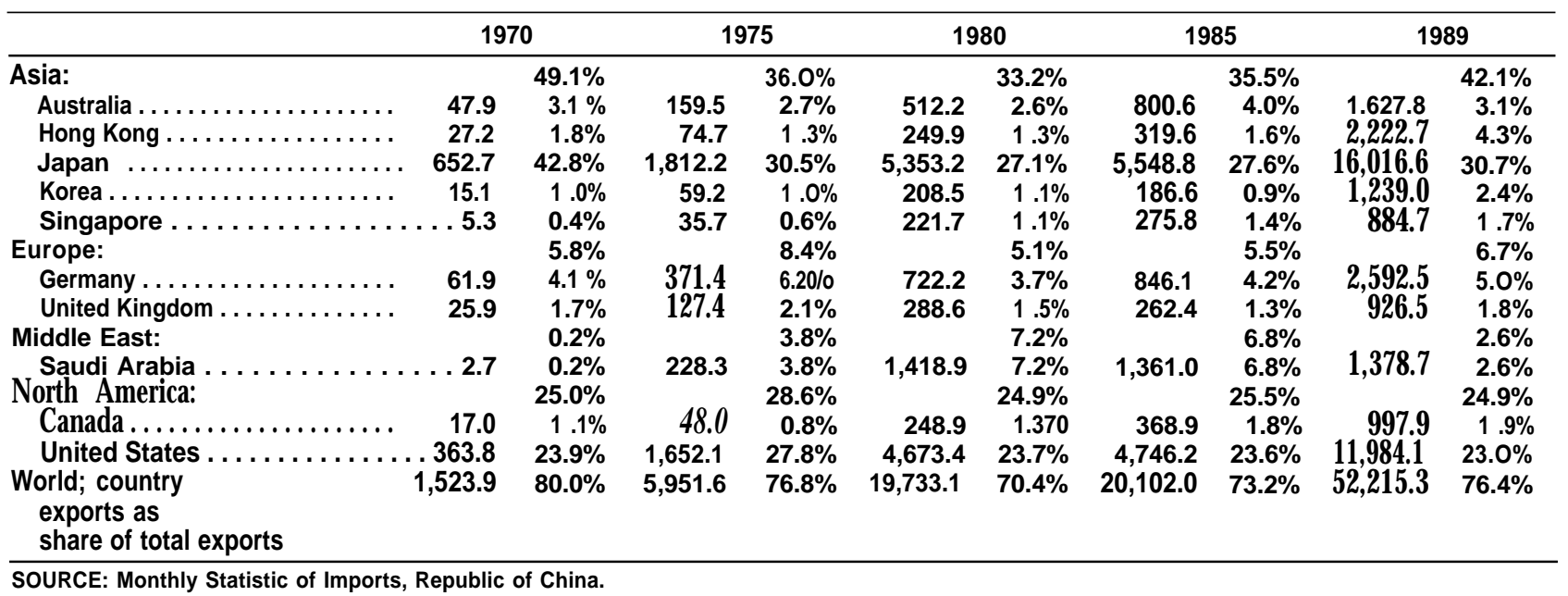

In the 1980s, the dependence on the U.S. market fluctuated with economic conditions and exchange rates. The U.S. share of Korea's exports rose after the 1982 recession, and jumped dramatically, from 35 to 40 percent, after the sharp real depreciation of the Korean won in 1985-1986. Thereafter, however, the U.S. share declined as the won rose, and has not approached its 1970 level. Korea's strategy of diversification holds true at the product level as well, though footwear and automobiles still show a marked concentration on the American market.

In Taiwan, dependence on the American market also increased over the early 1980s, but the level was much higher, approaching 50 percent in 1985 before falling to around 40 percent in 1989, roughly the same as in 1970. Imports show a similar story, with
Korea diversifying away from the United States and Taiwan's share of imports staying constant over time.

The data suggest a somewhat contradictory picture with regard to interdependence within East Asia. The NICs increased their trade with one another, though from a low base that reflects their competition in some product lines. Hong Kong's share in Taiwan's trade grew sharply over the late 1980s; an unknown portion of this trade is with the People's Republic of China. Both Korea and Taiwan increased their exports to Japan in the late 1980s, Korea more than Taiwan. Both countries have historically run deficits with Japan, their main source of imports. But Japan's share has fallen sharply since the peak in 1986 as a result of 
Figure 7-4-Major Korean Trading Partners, 1970-89

Major Korean Trading Partners, 1970

(US\$ billions)

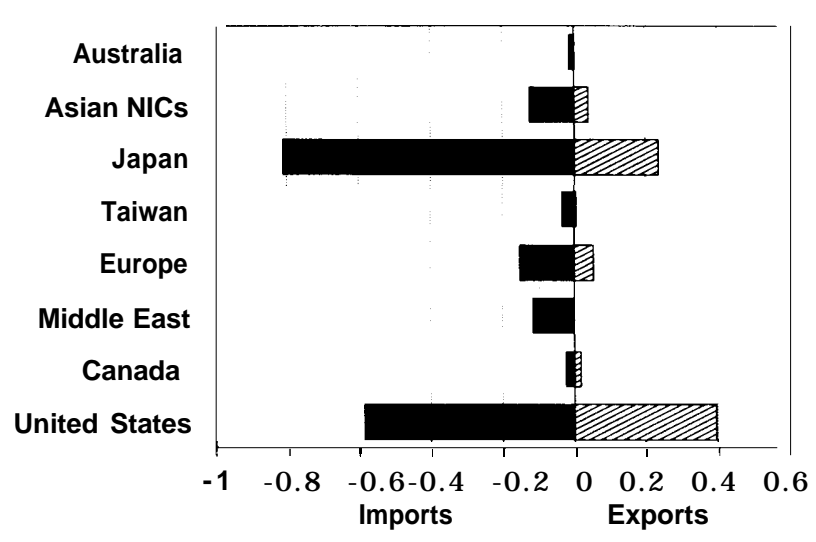

Major Korean Trading Partners, 1985 (US\$ billions)

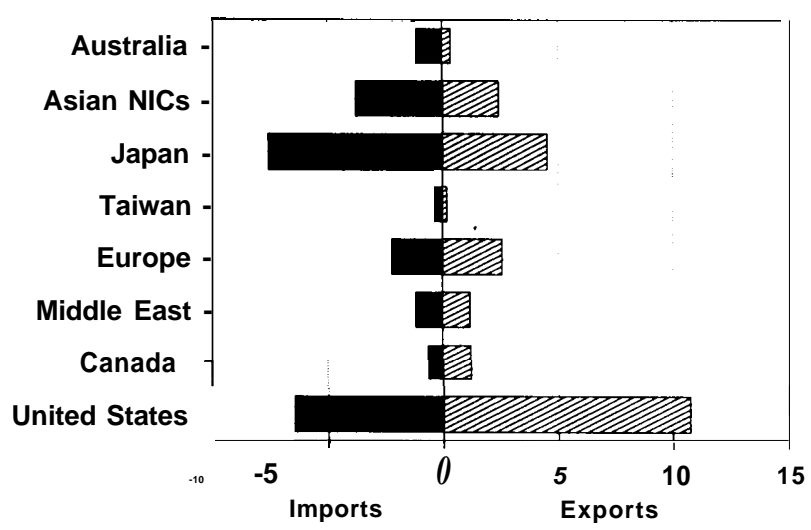

Major Korean Trading Partners, 1980 (US\$ billions)

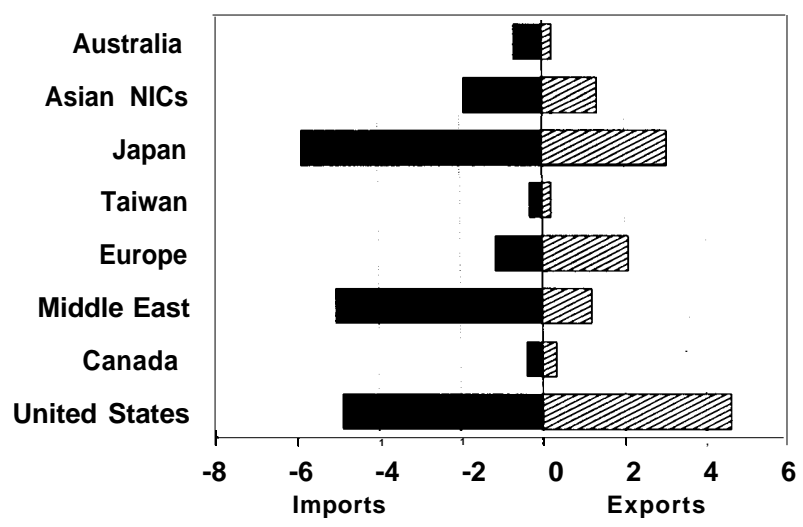

Major Korean Trading Partners, 1989 (US\$ billions)

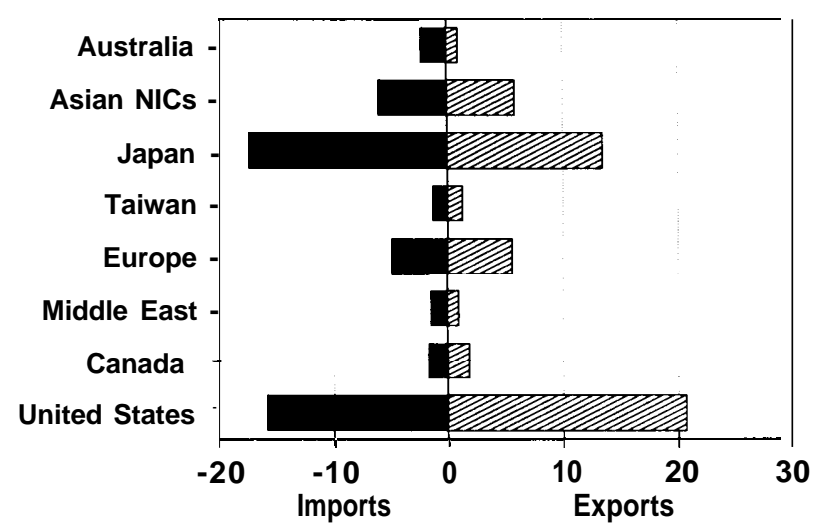

NOTE: Europe includes Germany, France, United Kingdom, and the Netherlands. Asian NICs indude Singapore, Malaysia, Thailand, and Hong Kong. Midd!e East includes Saudi Arabia and Kuwait.

SOURCE: Bank of Korea, Economic Statistics Yearbook; Bank of Korea, Monthly Economic Statistics.

exchange rate movements. Korea has been more successful in diversifying while Taiwan's trading patterns with Japan show greater constancy.

The aggregate figures for Korea's and Taiwan's trade with Asia in the last two decades do not show any striking shift in shares going to or from Asia as a whole. This suggests that while there are changes in the NICs' trading patterns within Asia, there is no long-term movement toward greater reliance on Asian markets or the creation of an intra-Asian trading bloc centered on Japan.

This picture does not take into account the growing networks of foreign investment in the region, however. Analysis of such investments goes beyond the scope of this chapter, but it is important to note how they complicate the picture. First, some share of exports from Taiwan and Korea is coming from American and Japanese subsidiaries, usually as intrafirm trade. Table 7-9 suggests that American firms have played a relatively small and declining role in the exports of the two larger NICs. Japanese foreign direct investment, by contrast, increased dramatically in the mid-1980s following the appreciation of the yen. Total foreign direct investment in 1986 through 1988 was equal to the cumulative value of Japanese foreign investment from 1951 through $1985 .{ }^{13}$ 
Figure 7-5-Major Taiwanese Trading Partners, 1970-89

Major Taiwanese Partners, 1970 (US\$ billions)

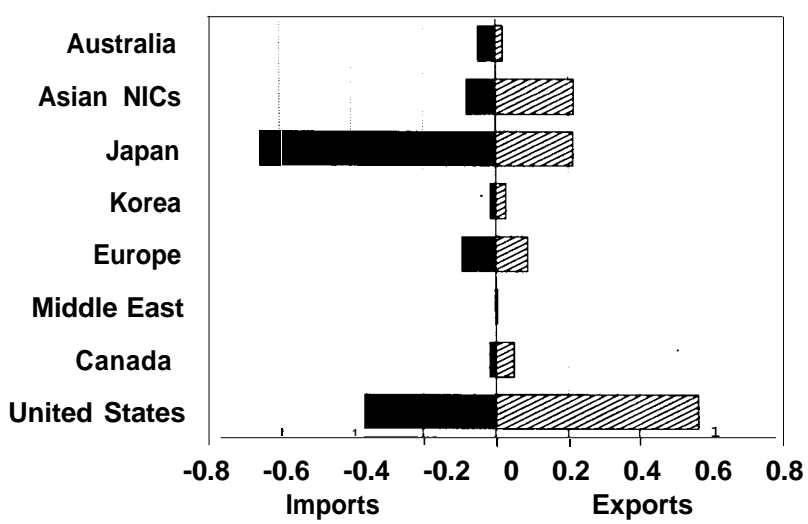

Major Taiwanese Partners, 1985 (US\$ billions)

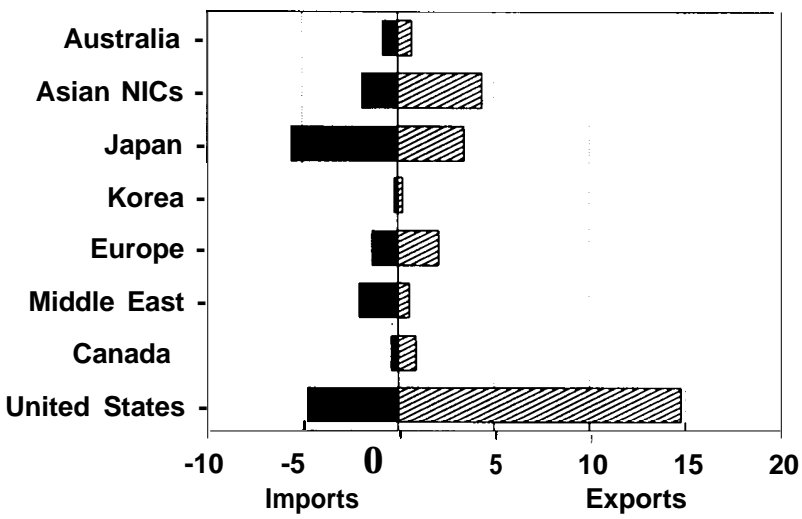

Major Taiwanese Partners, 1980 (US\$ billions)

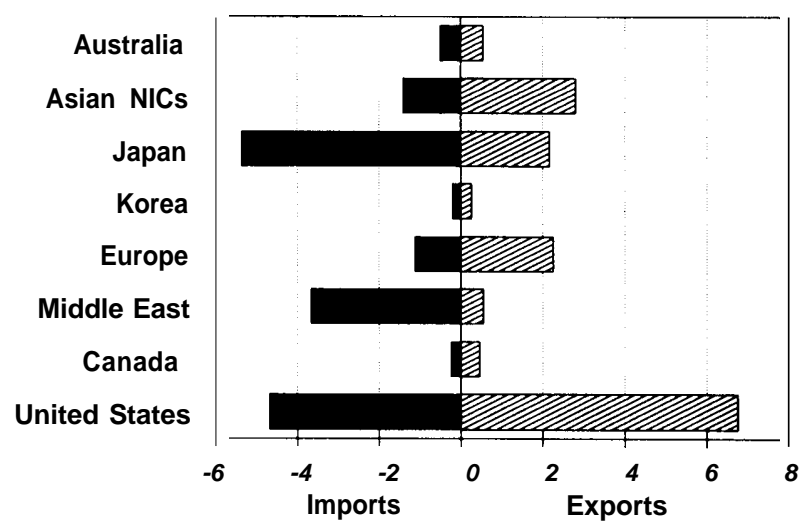

Major Taiwanese Partners, 1989 (US\$ billions)

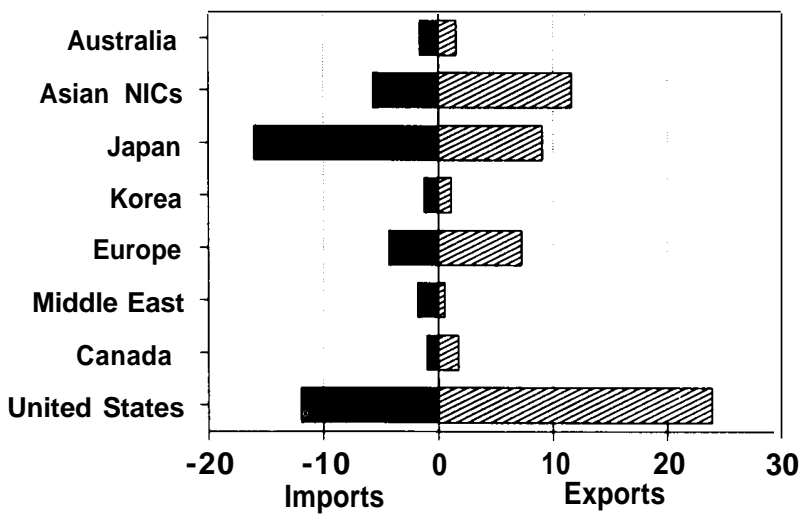

NOTE: Europe includes Germany, France, United Kingdom, and the Netherlands. Asian NICs include Singapore, Malaysia, Thailand, and Hong Kong. Middle East indudes Saudi Arabia and Kuwait.

SOURCE: Republic of China, Monthly Statistics of Imports; Council for Economic Planning and Development, Taiwan Statistical Data Book.

Data comparable to that cited for the United States are not available on the trade behavior of Japanese affiliates, but information is available on the pattern of sales of all Japanese affiliates in the four East Asian NICs. Fifty-six percent of affiliates' sales of manufactures were to the local market, 15.1 percent were to Japan, 11.2 percent were to the rest of Asia, and 9.3 percent were to the United States, with the remainder split between Europe and other areas. This suggests that the primary purpose of Japanese foreign investment in these counties is to sell in the local markets.

Another complication concerns outward investment from Korea and Taiwan, particularly to South- east Asia. Taiwanese firms have been particularly aggressive; for example, in 1986, they made three investments in Thailand with a total value of $\$ 5.8$ million and no investments in Malaysia. In 1989, Taiwanese firms initiated 214 investments valued at \$871 million in Thailand and 187 investments valued at $\$ 785$ million in Malaysia. ${ }^{14}$

Again, data are not available on the trade behavior of Korean and Taiwanese firms and their affiliates in Southeast Asia, but it is likely that some of it is export-oriented. Overseas investment is often made in order to circumvent quantitative restrictions on exports, and to compensate for rising labor costs that reduces the profitability of traditional exports. 
Table 7-9-Shares of U.S. Majority-Owned Foreign Affiliates in Total Exports of Manufactures, Selected Countries, 1977 and 1983 (percentages)

\begin{tabular}{|c|c|c|}
\hline Host country & 1977 & 1983 \\
\hline 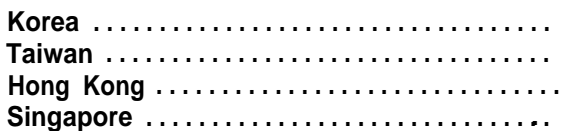 & $\begin{array}{r}1.4 \\
6.2 \\
8.1 \\
18.7\end{array}$ & $\begin{array}{r}1.3 \\
3.9 \\
5.6 \\
17.4\end{array}$ \\
\hline
\end{tabular}

SOURCE: M. Blomstrom, 1. Kravis, and R. Lipsey, "Multinational Firms' and Manufactured Reports from Developing Countries," NBER Working Paper Series No. 2493, National Bureau of Economic Research, 19SS.

\section{THE ROLE OF GOVERNMENT POLICY: KOREA}

Korea's industrial strategy has moved through several stages. From the end of the Korean War to the early 1960s, the government emphasized reconstruction. Any industrial strategy was based on import substitution in light manufacturing industries. This effort involved extensive and frequently corrupt government intervention through import controls, multiple exchange rates, sale of stateowned enterprises, and influence over the allocation of crucial U.S. aid. Nonetheless, this was a time of rapid growth for Korean manufacturing.

Following a military coup in 1961, the government began a series of dramatic economic reforms that emphasized export expansion. It collapsed the multiple exchange rates into a single rate, devalued the won, and liberalized imports for exporters. The government provided additional subsidies through the financial and tax systems, while guiding investment in priority import-substituting industries, in some cases through state-owned enterprises (as in the steel industry).

Beginningin the late 1960s and accelerating after 1973, the government emphasized the development of heavy industry, including steel and nonferrous metals, chemicals and petrochemicals, machinery, automobiles, and shipbuilding. Exports were stressed as the ultimate criterion of success in these new industries, but greater weight was placed on import substitution. During this phase, the government expanded its role in the allocation of resources and in using financial, tax, and trade instruments. The government sought to guarantee that no company dominated any product market; key industries such as automobiles, shipbuilding, computers, and semiconductors typically had four or five main producers who competed intensely. The effect of this new heavy industry push was to encourage concentration of the industrial structure. Very large business groups, called chaebol, had priority access to credit and market opportunities, and gradually came to dominate the market.

In the early 1980s, the direction of policy changed again, due to inflation, the increased sophistication of the economy, crises generated by declining industries, and direct pressure from the United States to liberalize the economy. Critical to the change was the perception among influential technocrats that the government's extensive intervention in support of heavy industrialization had been mistaken, resulting in misallocation of resources and structural problems.

The new framework emphasized economywide measures, with the aim of reducing the government's role and making markets function more effectively. Between 1980 and 1983, banks were denationalized and targeted loans were cut back. Tariffs and quantitative restrictions, once formidable impediments to imports, have diminished since 1984. Anew Industrial Development Law, approved by the National Assembly at the end of 1985, focuses on improving industrial technology and productivity and building up Korea's innovation capacity. However, as a World Bank report notes:

The legislation provides policymakers with a great deal of latitude with respect to policy implementation. ... Thus, the degree of real intervention will be determined in pragmatic fashion as circumstances warrant. $^{15}$

As this review suggests, the importance of different industrial policies has varied over time, with a period of extensive government intervention in the 1950s, followed by liberalization and more selective intervention in the 1960s. Government direction increased again during the heavy industry drive in the late 1970s. The more recent period has been one of more substantial liberalization. A stronger sense of these trends can be gotten by reviewing three major areas of policy: exchange rate, trade, and foreign investment policies; the role of the government in the provision of finance; and policies toward technology and R\&D.

\section{Exchange Rate and Trade Policies}

When comparing the export perforrnance of Korea with that of other developing countries, there is widespread agreement that exchange rate policy 
played a key role. A substantial devaluation was a key component in the transition to export-led growth in 1964-1965. Exchange rate policy thereafter was realistic, until an increase in domestic inflation led to overvaluation during the late 1970s. Following devaluation in 1980, the government returned to a stable, competitive exchange rate policy that pegged the won to a weighted average of currencies. When the dollar was rising strongly, the won depreciated relative to the dollar, as such a formula might suggest. After 1985, however, Korea experienced a period of significant real depreciation of the currency, even while the dollar was falling. ${ }^{16}$ This change was largely responsible for the emergence of large bilateral surpluses between Korea and the United States in the late 1980s. Beginning in 1987, under pressure from the United States and the International Monetary Fund (IMF), Korea began to boost the value of its currency, a factor in the reversal of Korea's trade surpluses beginning in the second half of 1989 (by 1990, Korea had current account and merchandise trade deficits).

Korea's industrialization strategy has used both export incentives and import restrictions as policy instruments. The trade regime has been outwardlooking on the export side and restrictive on the import side. Import restrictions have been aimed at directing the use of scarce foreign exchange and allowing infant industries to become internationally competitive. Although Korea ran a balance of trade deficit every year during the post war era up to 1986, ${ }^{17}$ government controlled imports, giving approvals when a national interest test was met. ${ }^{18}$

Korea's lack of raw materials and the limited supply capacity of its domestic capital goods industries have constrained its industrial growth. Government policies emphasized export promotion in order to provide the money for the imports of raw materials and capital goods needed for faster growth. Further, the government's import restrictions favored domestic industries that could convert imports into exports, so as to permit still more imports of industrial inputs. Consumer goods were targeted for import controls and high tariffs. This allowed producers to charge higher prices on the domestic market and thereby absorb thinner export profit margins. This constituted an implicit consumption tax to promote exports, and accounts for periodic charges of dumping against Korean firms. In short, up to the balance of payments surpluses in 1986, Korea exported in order to import, and vice versa.
Exports were a way to use unskilled labor in sophisticated industries. ${ }^{19}$

How protected has the Korean economy been? The economy received substantial protection over the 1960s, 1970s, and early 1980s, with protection falling markedly since then. Estimates of protection are subject to many errors, and the fact that different studies use different operational measures makes for difficulties in comparing results. The few studies available for Korea yield a sizable range of answers even for the same year. Moreover, the Korean trade system is complex; trade has been restricted in part through administrative and regulatory provisions that are neither transparent nor easily measured.

Studies suggest that patterns of protection followed the broad contours of industrial policy. ${ }^{20}$ In 1968 , the rate of effective protection for the economy as a whole was in the range of 9 to 21 percent, with the low estimate resulting from procedures that may bias the result downwards. ${ }^{21}$ Transport, consumer durables, and machinery industries received rates of over 50 percent. Effective protection increased during the heavy industry drive of the 1970s, to the range of 24 to 34 percent by 1978. For manufacturing alone, one estimate gives an average of 49 percent. ${ }^{22}$ Petrochemicals, steel, machinery, and shipbuilding received above average protection. Effective protection increased through 1982. One estimate gives a rate of 38 percent, $^{23}$ another study by the Asian Development Bank shows an overall tariff average of 33 percent for "the early 1980s." ${ }^{24}$

Although studies of effective protection rates are unavailable for the period since 1982, the liberalizing trend can be discerned in the ratio of import items that are classed as "automatically approved" (AA), as distinct from "restricted" or "prohibited." In 1981,75 percent of items were classtified as AA, accounting for 65 percent of imports by value. By 1984,85 percent of items, accounting for 72 percent of imports by value, were so classified. By 1986, the ratio had increased to 92 percent of items; the proportion by value probably exceeds 80 percent.

The liberalization of quantitative restrictions in the 1980s accompanied a phased reduction in legal tariffs, to an average of 20 percent for manufactured goods and 29 percent for agricultural goods (on an items basis) by 1986. By 1989, the average (nontradeweighted) tariff rate came down to 13 percent, and was projected to fall further, to about 8 percent by 1993, comparable to average tariffs in Europe and 
the United States. ${ }^{25}$ Tariffs remain high on many kinds of agricultural produce.

It is difficult to draw conclusions about import liberalization. For example, until recently classification of an import as AA was a necessary but incomplete condition for unimpeded importation. The government could impose short-term penalty tariffs if items on the AA list were judged to harm important domestic industries. This system was dismantled only in the last 2 years. A recent World Bank report estimated that in 1986 as many as 25 percent of the AA import items were "potentially covered by one special law or another' that allowed ministries to regulate imports. ${ }^{26}$ The report goes on to say that: "It is not known, of course, to what extent these administrative procedures lowered imports, e.g., when the relevant industry association or other body denied the importation of a commodity on the AA list. ${ }^{227}$ On the other hand, the fact that an item is classified as "restricted" does not mean that it will be difficult to import.

Historically, the government has controlled foreign exchange in Korea. Earners of foreign exchange have been required to transfer it to one of several designated agencies, which in turn transfer it to the central bank. Private companies or citizens may retain only a small amount. The government formulates an annual Foreign Exchange Demand and Supply Plan. Little is known about how the plan is compiled or how conflicting demands on foreign exchange are reconciled. It is clear, though, that the Plan has binding force. Data on projected and actual foreign exchange spending show a close correlation year after year. Banks must limit the issue of foreign exchange for any import, even an AA import, when foreign exchange use runs beyond the limits of the Plan. ${ }^{28}$ In effect, then, there have been two distinct hurdles in the import process: one to get the import license, the other to get the necessary foreign exchange. Despite a substantial import liberalization, scheduled to allow domestic industries time to adjust, a variety of administrative procedures still grant room for Korean officials to restrict imports.

Although until recently Korea had a relatively protectionist trade regime, several features differentiated it from the protective trade regimes of other developing countries. First, it was coupled with a realistic exchange rate policy so that biases in trade policy were not compounded by overvaluation. Then, protection was subordinate to a wider indus- trial strategy aimed at assisting protected industries to become internationally competitive.

Protection against selected imports dovetails with offsetting incentives for export sale. A crucial component of the transition to export-led growth in the mid-1960s was that all imports used as inputs into exports would be exempt from quantitative import restrictions. Raw material imports used for exports were also exempt from tariffs. ${ }^{29}$ Capital goods used for export production were exempt from tariffs until the early 1970s. These became subject to tariffs as the government sought to deepen (diversify) the industrial structure into these products. Exports have also been exempt from indirect taxes such as harbor charges.

Duty free import of inputs for use in exports was available to 'indirect exporters,' domestically based suppliers that provided intermediate inputs to export producers or finished goods to a trading company that then exported them. Additional incentives came through import-export links, by means of which permission to import (and therefore the ability to reap high profits on the protected domestic market), was given to those with good export performance. The import of some very popular products was linked to export performance in closely related fields. Import rights for TV receivers, for example, were granted only to exporters of radios and electronic equipment. This not only gave a direct incentive to producers of electronic equipment to export, it also allowed them to protect their domestic market share by pricing imported items in a way that did not threaten their own production. ${ }^{30}$

Free-trade export-processing zones were key in attracting export-oriented foreign direct investment (FDI). The first free trade zone opened in 1971, with another eight added by 1985 . But the zones have accounted for only around 10 percent of total FDI. They have probably been less important than the 218 "bonded' manufacturing plants (as of 1981), which can import without paying any duty but must export all their production.

Import liberalization for exporters conforms roughly to the market-oriented picture of Korea's growth. Other measures do not. Korea began giving concessional credit to exporters in the 1950s, enhancing the degree of concession and the ease of access to the credit after the transition to an export-oriented strategy in the mid- 1960s. Through the 1970s, automatic access to short-term export financing was 
available to exporters at 6 to 12 percentage points below the commercial bank loan rate, constituting a large subsidy .31 Such loans ended in 1980. Mediumand long-term loans for investment in export production were also automatically available at concessional rates until 1980. Postshipment financing, export credit insurance, and export finance guarantees still exist.

The early incentives to export did not involve industrial targeting; companies profited from the incentives regardless of the product they exported. Export incentives became more targeted in the late 1970s with the heavy and chemical industry drive. Until 1973, tax incentives included a 50-percent reduction on business income tax on profits derived from exports. Subsequently, special depreciation allowances for capital equipment used in export production have been used instead. Various studies report that these direct export incentives have been reduced since the early 1970 s, especially during the 1980s. In the early 1970s, the effective subsidy rate for exports averaged about 20 percent of the value of exports. It fell to about half that level by the end of the 1970s, and has declined further since. ${ }^{32}$

Overseas information and marketing services have helped expand Korean exports. Since 1962, the Korea Trade Promotion Corp. (KOTRA) has served as a nonprofit trade promotion arm of the Korean Government. ${ }^{33}$ It was formed after careful study of JETRO, its Japanese counterpart, which provides much technical assistance in the early years. KOTRA maintains 77 offices around the world that provide information about Korean exporters and importers, the items they buy and sell, and the services they need and provide in foreign investment and construction work. It also arranges trade fairs and is a point of first call for foreign buyers. About 70 percent of its budget comes from government grants. Another organization with overlapping functions is the Korea Traders Association (KTA), a nonprofit private organization that includes all licensed exporters and importers as its members. There are also 30 or more industry-based exporters' associations.

To complement the work of KOTRA, the government launched a scheme to build up Korean general trading companies along the lines of their Japanese counterparts. Beginning in the early 1970s, those trading companies that met the stringent performance and size criteria for "general trading compa- nies" received special privileges in terms of access to credit, retention of foreign exchange, and other assistance. They held the same leadership role on the trade side as the big conglomerates (chaebol) held in the heavy industry drive of the 1970s. By 1982, the 10 licensed general trading companies accounted for almost half of Korea's exports. ${ }^{34}$

From the mid-1960s onwards, the government elevated the export drive to the nation's number two priority, second only to national defense.

Led by the president, and supported by the top economic ministers and the heads of the biggest firms, much of the country was wrapped in the fervor and enthusiasm surrounding the drive to develop through trade. ${ }^{35}$

The priority of exports was determined through a system of export targets and high-level export meetings. These helped to unify the array of export incentives and catalyze the reciprocal relationship between government and business. From 1965 on, upwards of 100 senior political leaders, bureaucrats, and business people met each month to discuss the export drive. The meetings were chaired by the President himself as a symbol of the government's commitment to exporting.

In addition, prizes were awarded once a year on Export Day. The prizes conveyed not just prestige, but also economic rewards, such as easier bank credit for nonexport projects. ${ }^{36}$ In 1980, Export Day was renamed Trade Day, and prizes awarded for good performance in both exporting and importing. ${ }^{37}$

\section{Development Financing and Foreign Direct Investment}

Financial policy was an important component of export-promotion efforts. The Korean Government has used its control over the financial system for broader industrial policy purposes, however, discouraging business speculation and encouraging investment in "strategic" industries.

Until the early 1980s, the government owned the commercial banks. The Ministry of Finance controlled the total supply of funds and interest rates through its agent, the central bank. The commercial banks allocated private funds under the guidance of the Ministry of Finance. The Minister of Finance, and sometimes even the President himself, appointed the chairman of each bank. Interest rates 
were low for priority uses, including investment in government-designated industries and export finance. Subsidized loans, called "policy loans," constituted about half of total bank loans over the 1970s and carried nominal interest rates of around 10 to 15 percent; given inflation, real interest rates were close to or less than zero. Ordinary bank loans, on the other hand, carried nominal rates of 18 to 22 percent. These rates for ordinary loans were much less than rates on the unregulated and semi-legal curb market, which typically ranged from 30 to 40 percent a year or even higher. Estimates of the size of the curb market vary widely, from 10 to 40 percent of the financial sector. ${ }^{39}$ Since denationalization, the volume of confessional lending has been greatly reduced, but remains important for a narrower set of strategic industries, including segments of electronics and computers.

Firms depended heavily on bank loans for their investments. Corporate debt/equity ratios over the 1970s were on the order of 310 to 380 percent, as compared to 50 to 90 percent in the United States and the United Kingdom. ${ }^{40}$ This gave the government substantial leverage over individual companies. Not only could the government tempt them to enter priority fields by offering low cost or easily available credit; it could also cut off credit. This threat was serious, given the cost of alternative curb market credit and firms' inability to borrow internationally without government approval.

The government's direct influence over bank portfolios declined with the denationalization of the banks in the 1980s. The government maintains a role in financing its industrial policy objectives, however, through the Korea Development Bank and other schemes. The Korean Technology Advancement Corp. has served as a source of investment capital for the development of new products and processes generated by the Korean Advanced Institute of Science and Technology and other government research labs. The government also provides venture capital through the Korean Technology Development Corp., which makes funds available to the private sector for investment in specific R\&D, technology acquisition, and other precommercial investment projects.

With domestic savings covering only 70 to 90 percent of domestic investment, Korea has depended on sizable inflows of foreign capital. This has taken the form of foreign borrowing, while foreign direct investment (FDI) has been kept low. As a proportion of total foreign loans and investment, total FDI flows amounted to only 3.2 percent in 1980 . FDI flows have also been low as a proportion of gross fixed investment, lower than in Taiwan and much lower than in Indonesia, Malaysia, Singapore, the Philippines, and Thailand. ${ }^{41}$ This reliance on foreign capital provided the government with an important tool Of industrial policy.

In 1983, however, the government revised the Foreign Capital Inducement Law to attract more FDI. ${ }^{42}$ It anticipated that more FDI would bring more foreign technology. The new law is designed to reduce the number of restrictions on foreign investment, to accelerate the approval process, and to strengthen patent and copyright laws. Following these changes, the share of FDI in total capital inflows rose to 13.8 percent by $1988 .^{43}$ Meanwhile, the need for foreign borrowing declined as Korea moved from being a capital importing country to a capital exporter.

\section{Technology Policies}

Korea's technology policies fall into two stages of development. The frost stage covers the period from the mid-1960s to about 1980; the second stage covers the 1980s. The primary thrust of the frost stage was to obtain foreign technology and to master its use, while the secondary thrust was to develop Korea's own R\&D capacity. In the second stage, the priorities were reversed.

The Korean Government paid careful attention to the way foreign technology was obtained. It discouraged FDI while encouraging licensing both as a more effective means of transfer and as involving less dilution of national control of production. The government screened licenses. It established advisory committees with representatives from industry, universities, and state laboratories, and it bargained with technology suppliers as a sole buyer, obtaining better deals than the firms could have negotiating on their own.

Almost 80 percent of licensing agreements are with Japanese or American firms. From 1962 to 1985, Japan was the source of 55 percent of the agreements, the United States, 23 percent. But the United States received a much larger share of total royalty payments, 42 percent against Japan's 30 percent, reflecting Korea's purchase of more sophis- 
ticated and larger scale technology from the United States. ${ }^{44}$

Licensing agreements and FDI became more important in the 1980s as the government liberalized both. Efforts were made to tighten intellectual property protection, largely in response to persistent external pressure. The laws on patents and copyrights were comprehensively revised in 1987, and Korea has signed most international intellectual property rights treaties in recent years. This effort to liberalize transfers and tighten protection probably contributed to the increase in licensing agreements from 1982 to 1985. Most U.S. Government and business concerns with the laws themselves have been resolved, and the emphasis is now on enforcement, which many U.S. companies, especially in pharmaceuticals, claim is lax. ${ }^{45}$

During the first phase of technology policy, the development of Korea's own R\&D capacity was a secondary goal. Nonetheless, early on the government began a long-term effort to increase Korea's R\&D capacity. In 1966, the government created a major public industrial R\&D laboratory, the Korea Institute for Science and Technology (KIST), followed by the Ministry of Science and Technology (MOST) in 1967.

As Korea moved closer to the technological frontier, it reversed earlier priorities by emphasizing the generation of new technological capabilities. In this second stage of technology policy, begun in the 1980s, the government intensified efforts to build a "national innovation system." A much higher proportion of $R \& D$ was carried out in private firms or consortia; government research organizations focused on generic technologies and/or on providing a bridge between university research labs and businesses. Previous restrictions governing technology transfer from abroad, such as limits on royalties, were liberalized.

Korea's centralized system for planning and implementing R\&D policies is similar to those of Japan, Taiwan, France, and Germany, as opposed to the United States and the United Kingdom. The centralized system permits a clear-cut and long-term strategy for the development and commercialization of specific technologies and products. The system is dominated by MOST, which orchestrates a series of planning exercises with participation from other ministries and representatives of industries and research institutions. Science and technology plans are drawn up annually, with 5-year plans as well. In 1969 and 1986, 15-year plans attempted to determine key technologies over the long term and identify the potential for strengthening Korea's capability in them. The 1986 plan, published under the title "The Long Term Technology Forecast for the Year 2000," resulted from 2 years of discussion among some 500 experts in 8 subgroups. ${ }^{46}$

An important component of the institutional arrangements governing technology are nine government research institutes covering, among other fields, basic science, electronics, energy, and machinery (table 7-10). Over the 1980s, as private companies began to establish their own R\&D labs, the national labs moved away from applied research and commercialization toward more basic technologies, often in collaboration with private firms.

The year 1980 marked the beginning of National Technology Promotion Conferences, held quarterly and presided over by the President. The conference brings together cabinet ministers, officials, representatives of industry, and members of research institutes, perhaps 250 in all. ${ }^{47}$ This discussion forum represents a continuation of the approach applied earlier to exports through the Export Promotion Meetings, which were replaced by the National Technology Promotion Conference, indicating a shift in policy emphasis.

Based on information and opinion expressed through these networks and fora, the "Year 2000" study set 25 activities as priority areas, within which projects should be chosen by government and business. Some of the 25 were leading sectors, while others were selected because they support the growth of leading sectors. The frost set includes computers, software, semiconductors, telecommunications, bioengineering, and fine chemistry; the second set includes design engineering, spare parts and materials, machine automation, and standards and measurements.

To implement such plans, the government has used a variety of policies, including manpower development, financial and tax incentives, and technology transfer. The government has sponsored a huge expansion of science and engineering places in schools and colleges. Enrollments in third-level engineering and science courses increased from 303,202 in 1980 to 494,925 in 1986 , or 1.6 times. ${ }^{49}$ Several hundred students in public research institutes, mainly in the Korean Advanced Institute of 
Table 7-10-Korea: Major Government Research Institutes in $1985^{\mathrm{n}}$

\begin{tabular}{llcc}
\hline Name & Research fields & $\begin{array}{c}\text { Expenditure } \\
\text { (\$millions) }\end{array}$ & Staff \\
\hline $\begin{array}{l}\text { Korea Advanced Institute of Science \& } \\
\text { Technology (KAIST) }\end{array}$ & Multidisciplinary & $\$ 102$ & 1,628 \\
$\begin{array}{l}\text { Electronics and Telecommunications } \\
\text { Research Institute (ETRI) }\end{array}$ & $\begin{array}{l}\text { Semiconductors computers, } \\
\text { telecommunications }\end{array}$ & $\$ 40$ & 1,210 \\
$\begin{array}{l}\text { Korea Advanced Energy Research } \\
\text { Institute (KAERI) }\end{array}$ & Atomic energy & $\$ 31$ & 934 \\
$\begin{array}{l}\text { Korea Institute of Machinery and } \\
\text { Metals (KIMM) }\end{array}$ & Machinery, metals, shipbuilding & $\$ 21$ & 745 \\
$\begin{array}{l}\text { ailitary labs are excluded. } \\
\text { NOTE: In 1968, KAIST had 1,429 people, of whom 293 had Ph.D.s and 636 had MA.s; KETRI had 1,258 people, of } \\
\text { whom 47 had Ph.D.s and 840 had M.A.s. }\end{array}$ \\
$\begin{array}{l}\text { SOURCE: Ministry of Science and Technology, Introduction to Science and Technology, Repub/ic of Korea (Seoul: } \\
\text { Ministry of Science and Technology, 1966); Yong-chan Park, 'The National System of Innovation in Korea, } \\
\text { With an Introduction to the Semiconductor Industry" (University of Sussex, MSC thesis, 1987). }\end{array}$
\end{tabular}

Science and Technology, have scholarships provided by private companies. These students normally move to the R\&D laboratories of their sponsoring firms on graduation, providing the basis for continuing dialogue between researchers of private firms and the public institutions.

The government also sponsors an overseas study program, mostly for post-doctoral students. Between 1981 and 1985, 2,222 scientists and engineers were dispatched to the United States, Japan, and Europe for further study or work experience; the rate of dispatches scheduled to increase. ${ }^{50}$ Another program creates a network among Korean scientists and engineers working abroad. Until recently the phenomenon of foreign-educated Koreans remaining abroad was seen as a "brain drain," with negative consequences for Korea's development. Now it is seen as constituting a "brain bank" of high-level human capital. Korean companies and government research organizations can target individuals with needed skills, either inducing them to return to Korea or leaving them in situ to do work of interest to those companies or organizations.

Further, the government has undertaken more targeted financial policy actions, providing direct support for $R \& D$ in the fields of electronics, mechanical engineering, chemistry, energy, and bioengineering. In 1986, 660 projects received direct support amounting to $\$ 56$ million, with another $\$ 21$ million in cofinancing from private fins. Several earmarked funds make loans for electronics, machinery, and textiles to support R\&D investments totalling \$100 million between 1981 and 1985.
More important is the "policy" loan window, or subsidized credit facility, of the commercial banks, described earlier. The Korea Industrial Bank and the Korean Bank for Small and Medium Enterprises channel money specifically for start-ups and for investment in R\&D facilities, \$130 million in 1985. Another mechanism is venture capital. By 1986, the government had sponsored four venture capital fins, with public or mixed public/private ownership. ${ }^{51}$

Through the 1970s and more intensively since the tax reform of 1981, the government has used tax credits and deductions to stimulate R\&D. Some of the more important include: ${ }^{52}$

1. Tax deductions for technology development and manpower development; 10 percent of cost can be deducted from income tax.

2. Funds earmarked for $R \& D$ can be set aside in a reserve and deducted from taxable income, up to 1 percent of turnover or 20 percent of income. In high-technology industries, these ceilings are $\mathbf{1 . 5}$ percent of turnover or $\mathbf{3 0}$ percent of income.

3. Tax deduction or accelerated depreciation on investment cost of commercialization, either 6 percent of investment cost or 50 percent depreciation in frost year; or for locally made equipment, 10 percent of investment cost.

$R \& D$ expenditures increased rapidly, at an average annual rate of over 40 percent between 1980 and 1985 (in current won), rising from 0.58 percent of gross national product (GNP) in 1980 to 1.59 percent in 1985. A quarter of the total went to electronics in 1985. Two-thirds was spent by private industry, 
one-quarter by government research institutes, and the remainder by universities. ${ }^{53}$ The number of researchers also increased from 4.8 full-time equivalents per 10,000 population in 1980 to 9.1 in 1984 . Again, a quarter of the total worked in electronics.

The build-up of private R\&D has taken the form of business-level R\&D labs and research associations among companies. The number of private $R \& D$ institutes rose from 37 in 1980 to 183 in 1985, nearly a fivefold increase. Of the private institutes, 27 percent were in electronics and 21 percent in machinery. The 183 institutes employed a total of 9,226 staff, of which 3,864 were in electronics. Their combined R\&D expenditure came to $\$ 658$ million in 1985. Four private "super institutes" spent more than $\$ 40$ million each. ${ }^{54}$ Following the Japanese model, the government also sponsored research associations among private firms. In 1985, 23 such associations were in operation, involving 286 firms. Seventy percent of the associations were in electronics alone. Most of the associations comprised a few large firms and many small and medium-sized firms. ${ }^{55}$

The government has also looked at the restructuring of industries in which Korea has acquired a leading international position but which now face decline. In textiles and clothing, a leading export industry, the government is helping to improve production technologies and assisting firms to move upmarket by emphasizing product design and quality. The Textile Modernization Fund, established in 1981 to provide loans for modernizing textile factories, had, by mid-1985, capital of approximately $\$ 30$ million. The government has also supported $R \& D$ in textiles through the Korea Advanced Institute for Science and Technology (KANT), contributions to the Korea Federation of Textile Industries (KOFOTI), and tax exemptions for companies. ${ }^{56}$

\section{Case Study: Automobiles}

A greater sense of the interplay between government policy and industrial development is apparent through the detailed study of two industries: automobiles and semiconductors. The automobile industry is a highly concentrated, oligopolistic industry dominated by a handful of globally integrated firms. The industry is both capital- and technology-intensive, with important scale economies.
Figure 7-6-Korean Automobile Production

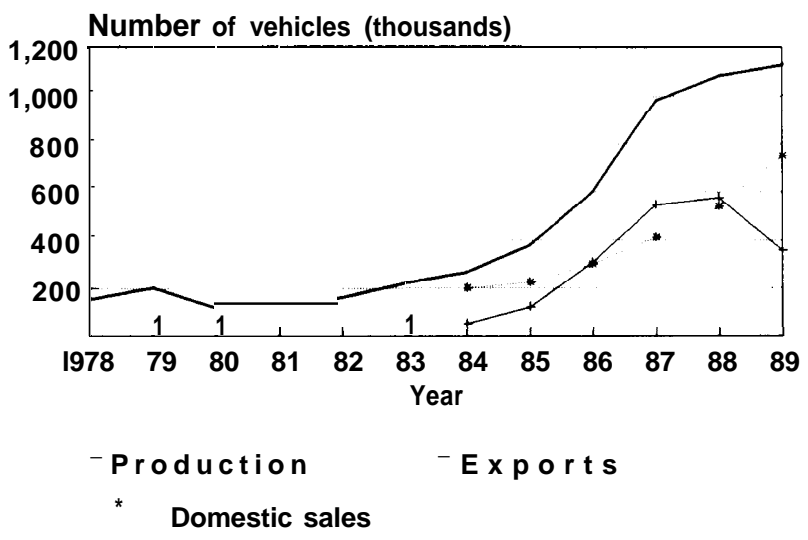

SOURCE: Automotive News Market Data Book (Detroit, MI: Automotive News, 1990).

The Korean automobile industry consists of 6 vehicle manufacturers and about 600 parts and components manufacturers. In 1988, it produced 1.1 million units, of which 577,000 (52 percent) were exported. ${ }^{57}$ The automobile industry illustrates the successful use of joint ventures and licensing agreements with foreign corporations to produce for international markets, while building on such arrangements to produce an increasingly indigenous product. This process was assisted by government policy, which designated the industry as a "strategic export industry" and provided assistance, including export incentives, access to credit facilities, and protection of the domestic market.

However, the Korean auto industry still faces difficulties. Labor demands have increased costs, and provisional figures indicate that only 31 percent of the 1.13 million autos produced in 1989 were exported ${ }^{58}$ (See figure 7-6). Some of this 40-percent decline from the previous year was due to sluggish American demand, and was offset by surging domestic demand and government prohibition of Japanese imports. ${ }^{59}$ There are also structural problems, such as continuing dependence on foreign technology, the likely focus of future policy initiatives toward the industry.

In 1962, a public enterprise established the first Korean auto assembly plant in cooperation with Nissan. When the plant went into production, the government instituted tight import controls on finished vehicles, duty-free import of components, and tax exemptions for the producer. In 1965, the government transferred the assembler to a private 
firm and approved a new technology agreement with Toyota. The government set a target of 50 percent domestic content in $\mathbf{5}$ years, rigorously enforced through control of access to foreign exchange. With heavy protection plus domestic content requirements in place, and with domestic components production growing fast, three more private firms were allowed to enter between 1965 and 1969 to fight for a market of less than 20,000 units a year.

The Heavy and Chemical Industry Plan of 1973 identified autos as a priority industry. In 1974, an industry-specific plan for automobiles was published covering the next 10 years. The objectives were to achieve a 90 percent domestic content for small passenger cars by the end of the 1970s and to turn the industry into a major exporter by the early 1980 s. ${ }^{60}$ The government stipulated the three primary producers, all chaebol, the minimum size of each producer, and the maximum size of car engines. It also required approval of all plans and precluded companies from changing their model within a set time.

Later requirements had the three producers set export targets for different markets, frost in Southeast Asia, then Latin America and the Middle East, peripheral Europe, Canada, and finally the United States. Companies were encouraged to set the export prices low, receiving various forms of compensation. The Hyundai Pony cost $\$ 3,700$ to produce in 1979 , sold domestically for $\$ 5,000$, and sold abroad (free on board) at $\$ 2,200 .{ }^{61}$ Firms received heavy export subsidies, particularly through access to credit, and were allowed to import a limited number of top-of-the-range models in kit form for lucrative domestic elite sale. The number of these imports was tied to export performance. Under these circumstances, the Korean producers invested heavily in anticipation of the export drive. ${ }^{62}$

In 1974, the government launched a complementary promotion plan for the parts and components industry. The plan required the three primary producers to meet a domestic content schedule and cooperate in the production of standardized parts and components. It further empowered the Ministry of Trade and Industry to select certain items and their assigned producers for special promotion, with a complete import ban once the item met the government's price and quality standards.

In 1980, following the second oil crisis and the rapid deterioration of domestic and world economic conditions, Chun Doo Hwan's government undertook a comprehensive rationalization of heavy and chemical industry sectors, including autos. The new regime decided that there was to be only one main auto producer, forcing one of the three "majors' to leave the business, a decision not reversed until 1984, It informed the other two that their rivalry in cars and power equipment was counterproductive, and asked them to concentrate on one line of business each. The Hyundai group got cars. The government reduced the automobile excise tax to stimulate domestic demand, halved the export targets, and greatly increased the volume of concessional credit. The investment drive resumed in 1982 as the economy recovered, with Hyundai Motor's debt to equity ratio soaring to $5: 1$. By 1986, the Hyundai Excel had become the best-selling new car import in U.S. history, following its earlier success in Canada. In 1988, Hyundai produced 650,000 cars, of which 63 percent were exported.

In 1987, Kia and Daewoo were allowed to reenter the passenger car business. ${ }^{63}$ They will soon be joined by Ssang Yong Motors, a subsidiary of the Ssangyong chaebol. ${ }^{64}$ Unlike Hyundai, which sells under its own name, Kia and Daewoo both sell their autos through foreign companies: Kia makes the Festiva for Ford Motors, and Daewoo the Lemans model for Pontiac. Similarly, Ssang Yong plans to transfer its present expertise in truck and jeep assembly to auto exports through a tie-up with Volvo. ${ }^{65}$

The automobile industry illustrates the range and multiplicity of arrangements between Korean and foreign producers. Hyundai is 10-percent owned by Mitsubishi and remains dependent on the Japanese company for its engines and designs. Its first export success, the Pony, was planned in Italy by a former designer for British Leyland. The Excel is a nearclone of the Mitsubishi Mirage, with Mitsubishimade engine and transmission. Daewoo is in a 50-50 joint venture with General Motors to make a "world-class' subcompact car. Kia Motors, after a period of assembling Fiats and Peugeots in the late 1970s, has turned to Mazda of Japan for technical guidance and through Mazda (which is 24-percent Ford-owned) to Ford Motors for overseas sales networks and brand recognition. Mazda has a minority equity stake in Kia, and has supplied Kia with designs for two mid-sized cars. However, Mazda has grown reluctant to transfer key compo- 
nent designs or grant the right to sell in Europe to its own future competitor.

Korean automakers are reaching the limits of these partnerships. Foreign automakers are more reluctant to part with proprietary technology simply for a fee, and, for their part, hope to gain entry to the Korean market through their local partners. Consequently, the Koreans are turning to in-house R\&D with the goal of bringing a wholly Korean-made car to market within the next few years. The Ministry of Trade and Industry estimates auto industry investment for 1990 alone to exceed $\$ 1.7$ billion. Hyundai has announced plans to invest over $\$ 2.5$ billion through 1992. ${ }^{67}$ Because government plans call for doubling plant capacity by $1995,{ }^{\&}$ however, the percentage of new investment funds going toward R\&D is not clear. Kia is planning to market a sub-compact model for 1992 with an engine designed in-house. Hyundai has similar plans, but has conceded that its engine designs cannot match the performance of the Mitsubishi engines. Government policy towards auto production should therefore reduce the development costs of new, indigenous products through publicly funded or collaborative research programs and continued concessional credit.

Socializing the cost of investment will not spare Korea's automakers from labor demands. Following the announcement of a liberalization of politics in 1987, Korea's auto exporters have experienced production slow-downs and higher wage settlements. Relatively smooth labor relations at Kia show in productivity statistics: its employees produced 17.4 automobiles per person in 1989, a steady growth from 13.1 per person in 1983. But while Hyundai's productivity reached a peak of 21.8 units per person in 1987, the number fell to 19.8 in 1988 and 16.7 in 1989. Daewoo marked the lowest productivity with 10.0 units per person in $1989 .{ }^{69}$ Ssang Yong has avoided most of these difficulties by offering competitive wage settlements (a 20-percent increase in 1988) and by being located away from the others' labor disputes. ${ }^{70}$ Those disputes resulted in industry average wage increases of 21.8 percent in 1988 and 23.3 percent in 1989. Increases in 1990 are more moderate: 10 percent for Hyundai, 7 percent for Daewoo, and 7.3 percent for Kia. ${ }^{71}$ Government plans to foster improved labor-management relations may include avoiding discussion above the company level, while resisting any attempts at cross-company organization.
Despite the booming domestic demand for autos, the Korean auto market is still highly protected. In response to intense U.S. pressure for general trade liberalization, the government announced an auto liberalization schedule in 1985 , which permitted small car imports to begin in 1988 for the first time in over 25 years, but with a duty of 200 percent, to be lowered to 100 percent after 2 years. Japanese compact models remain the most heavily restricted. Imports of cars above 2,000 cc were liberalized in mid-1987, but by year end only 44 had been imported. In 1988, 396 foreign cars were imported, and 501 were sold in the first half of $1989 .{ }^{2}$ These figures differ sharply from those of Taiwan, where automobile imports account for nearly 40 percent of domestic sales in a market less than half the size of Korea's. Korean dealers claim that bureaucratic delays and tariffs are not the primary deterrent to increased imports. Instead, they blame the National Tax Administration, whose investigations of foreign car buyers' finances have heightened social pressure not to flaunt wealth. ${ }^{73}$ In any case, the government's ability to restrict imports despite the trend toward liberalization is obvious.

The government's ability to limit entry of new producers at home, and thereby protect economies of scale, is a key reason for the success of the Korean automobile industry in world export markets. This was a crucial component of the 1974 auto plan, and even when some opening of the market occurred in the 1980s, there was an effort to limit the number of entrants. Because companies in Korea must seek government approval for technology imports from foreign companies, they can be easily barred from technology-intensive sectors like automobile manufacture. ${ }^{74}$ Samsung has tried to line up with Chrysler, but the government refused to allow Samsung to start an export-oriented car plant. More recently, the Ministry of Trade and Industry rejected a plan by Samsung to join with Nissan Diesel to produce large trucks, a possible prelude to Samsung's expansion into auto exports. The Taiwanese Government was much less successful in restricting entry, and partly as a result the industry remains undeveloped there.

\section{Case Study: Semiconductors}

While Korea's electronics production is geared largely to exports, the domestic market also has expanded as per capita incomes have risen. In 1988, approximately 60 percent of electronics production was exported, 40 percent sold domestically. 
Growth accompanied a shift toward production and export of more sophisticated industrial electronics, with a declining share of output in consumer electronics.

Semiconductors are an important input to consumer and industrial electronics products; an indigenous technological capability is crucial in the ability to compete in linked industries such as computers and telecommunications. Semiconductor production or "fabrication" is capital-intensive, and some market segments also have large economies of scale. This is especially true in memory chips. Ability to innovate in the fabrication of chips at the rapidly moving technological frontier demands a high level of technological competence and large R\&D expenditures. Production of more specialized custom or semi-customized chips demands ongoing design capabilities. Until recently, only firms in the United States, Japan, and Europe have had these capabilities.

Government policy toward the semiconductor industry in Korea moved through three main stages. ${ }^{77}$ In the late 1960s, government policy encouraged foreign direct investment in semiconductors and standardized consumer electronics, despite an otherwise restrictive posture toward foreign direct investment. In the 1970s, the government attempted to lead the development of an indigenous semiconductor industry. This effort, not altogether successful, resulted in the establishment of an infrastructural base that would help Korea acquire its own R\&D capabilities. But business interest was slight; the industry did not move much beyond the assembly stage.

In the 1980s, a number of the largest Korean firms became interested in acquiring semiconductor capabilities, particularly in the production of dynamic random access memories (DRAMs), the staple commodity of the semiconductor industry. At this point, government policy shifted to support the initiatives of these large national champions.

In the mid-1960s, the government encouraged foreign direct investment in semiconductors, mostly from U.S. companies such as Fairchild and Motorola. The aim was to increase Korea's exports rather than gain technology for Korean fins; there were no explicit government plans to develop the semiconductor industry. Some technology diffusion occurred, and two Korean firms subcontracted assembly of semiconductors. But the potential for technol- ogy transfer was limited because foreign firms located only labor-intensive assembly in Korea; moreover, there was little domestic demand for semiconductors.

In 1969, the government promulgated an Electronic Industry Promotion Law, designating the industry as a strategic export industry eligible for supports and incentives. ${ }^{78}$ An 'Eight Year Electronics Industry Development Plan" identified three main policy actions to achieve the goal of an indigenous semiconductor capability. The first was to create mission-oriented research institutes, both public and private. The second was to expand advanced training capacity in electronics. The third was to encourage technology imports via licensing and consultants, to guarantee greater technology transfer than had occurred through foreign direct investment.

With the launch of the Heavy and Chemical Industry drive (which included the electronics sector), the new public Korea Institute of Electronics Technology (KIET) became the vanguard of these efforts. ${ }^{79}$ Established in 1976, its charter gave it responsibility for planning and coordinating semiconductor R\&D; importing, assimilating, and disseminating foreign technologies; providing technical assistance to Korean fins; and undertaking market research. KIET consulted closely with private fins. Three working groups--covering equipment, the work program, and the training programeach included representatives from industry, the government, and KIET.

Each of KIET's three divisions-semiconductor design, processes, and systems-were headed by a Korean with academic training and industry experience in the United States. In addition, a project development division kept abreast of marketing opportunities and foreign technologies. Monitoring foreign technologies was also central to the work of KIET's liaison office in California's Silicon Wiley. Established in 1978, the liaison office helped KIET obtain equipment and technology licenses, build contacts with U.S. semiconductor firms, and create a network among Korean researchers working in U.S. semiconductor companies. Through the network, KIET was able to help Korean firms identify particular individuals with skills or access, and either enlist their help while remaining in situ or repatriate them to work in Korea. KIET mounted training programs for Korean companies and admin- 
istered a program to send Korean engineers and scientists abroad for experience in research institutes or companies. KIET took part in all technology transfer negotiations between Korean and foreign firms; in these negotiations, its Silicon Valley outpost and its project development division were especially important.

KIET opened Korea's first pilot wafer fabrication facility in a 1978 joint venture with a leading U.S. semiconductor firm, VLSI Technology. A year later it began building Korea's first full-scale commercial wafer fabrication facility to produce 16K DRAMs.

But most of the semiconductor industry in Korea was still concentrated at the assembly, packaging and testing stages, with little development of the more demanding segments of the industry. The few local firms that established fabrication facilities were dedicated to semiconductors at the commodity end of the market, mainly for use in consumer electronics. These companies were too small to undertake the huge investments needed to make standardized large-capacity chips, and lacked the design capability to produce customized chips.

Meanwhile, however, Korea's largest consumer electronics firms became interested in advanced semiconductor production because of their big in-house demand for semiconductors and a sense of vulnerability to manipulation by foreign semiconductor suppliers, particularly the Japanese. Between 1980 and 1990, five companies achieved the capability to fabricate state-of-the-art semiconductor devices, and three--samsung Electronics, Hyundai Electronic Industries, and Goldstar Electron-were involved in DRAM production. All three had links to large groups with substantial financial power, and were the national champions in the more sophisticated segments of the semiconductor industry in the 1980s.

The question was how to overcome the massive entry barriers to the more technology intensive segments of the market. The 1981 Basic Plan for Promotion of the Electronics Industry covered the period 1982-1986; in 1983, the Ministry of Commerce and Industry issued a report calling for accelerated development of semiconductors. ${ }^{80} \mathrm{De}-$ spite the general move away from targeted policies, this plan included a wide range of fiscal and financial investment incentives for the main semiconductor firms. ${ }^{81}$ The plan established an Electronics Support Fund, financed by public and private sector contributions to lend at preferential rates to firms engaged in priority activities. One of these was the establishment of R\&D subsidiaries abroad. Infant-industry protection was also used. In 1984, the import of 185 electrical and electronics products was restricted, accounting for 37 percent of all electronic product categories. While direct financial subsidies and import protection were phased out over the decades, these measures still lowered the cost of entry into an extremely risky field.

The government also sought to restructure the industry using government procurement. A goal of the plan was to integrate upstream and downstream segments, maximizing economies of scale and technological spillovers. This was a conscious imitation of Japan, where semiconductor companies were divisions of larger electronics companies, which were, in turn, parts of conglomerates.

An important step was to use the government's tight control of telecommunications to aid the big Korean firms' entry into advanced semiconductors; indeed, the Korean Telecommunication Authority was one of the sponsors of large-scale integration in the early to mid- 1980s. The restructured telecommunications industry forced out some firms, with others assigned government-selected monopoly segments. Meanwhile, the government announced a multibillion dollar expansion and modernization of the country's telecommunications infrastructure, most of which would be guaranteed to the semiconductor champions. The three industry leaders entered joint ventures with multinational firms (ITT, AT\&T, Northern Telecom), offering lucrative and risk-free telecommunications business in return for the transfer of specified telecommunications and semiconductor technology.

Computer policy also affected the development of semiconductors. The government first relied on obligatory public procurement of Korean-made machines. Then, in line with the Computer Industry Promotion Master Plan of 1984, it intensified the role of the national research labs, especially the Electronics and Telecommunications Research Institute (ETRI), in the acquisition of computer technology. It also imposed, until 1988, a complete ban on imports of microcomputers and gave software firms low interest loans for up to 90 percent of their R\&D spending. The public sector expanded its use of microcomputers, and in 1986, the government announced domestic content guidelines for all mi- 
crocomputers and peripherals, whether they were sold to the government or not. ${ }^{82}$ Figure 7-7 summarizes the growth of the Korean computer production and exports.

It appears, though, that the driving force in Korea's push into semiconductors was industry. Firms drew on both government support and their own substantial financial capabilities to jump directly into the high-volume memory market. In 1983, Samsung, the early leader in the field, acquired DRAM production technology from Micron Co. of the United States. ${ }^{83}$ The company went from greenfield sites to operating plants for $64 \mathrm{~K}$ DRAM chips in only 8 months in 1984, half the time it took in the United States and two-thirds of the time in Japan. ${ }^{84}$

This strategy had substantial risks, however, since commodity memory chips are subject to notorious price fluctuations; just as Samsung entered the 64K DRAM market, prices fell dramatically and the company was forced to absorb large losses. Nonetheless, because of its size and diversified structure, the company persevered, moving quickly from $64 \mathrm{~K}$ DRAMs to 256K DRAMs to the mass manufacturing of the 1M DRAM by the late 1980s. The company introduced engineering samples of $4 \mathrm{meg}$ abit DRAMs in late 1988, only 6 to 9 months behind the Japanese leaders. ${ }^{85}$
The investment needed for this achievement, and the attendant risk, show in the high debt/equity ratio of the firm that manages Samsung Group's semiconductor interests: nearly 7 to 1 in mid-1987. Since much of the debt was in the form of bank loans, and since the government still influenced the banking system after denationalization, this figure suggests government support for Samsung's strategy. The financing terms were generous, and Samsung crosssubsidized from other profitable parts of the group. In 1985, Samsung Semiconductor contributed 2.5 percent to the group's sales and made one-third of the group's investment. ${ }^{86}$ Samsung's in-house R\&D institute had more than 600 researchers and a budget of over $\$ 40$ million in 1986. Its Silicon Wiley outpost had a staff of 213 employees.

The strategies of the other two major producers differed from Samsung in their precise product mix. Nonetheless, the three companies' strategies had several factors in common:

- secure technology through licensing or jointventure arrangements;

- make massive investments in commodity chip production; and

- establish an American presence in Silicon Valley both for the acquisition of technology and to facilitate marketing.

Figure 7-7-Korean Computer Industry Exports and Production by Product

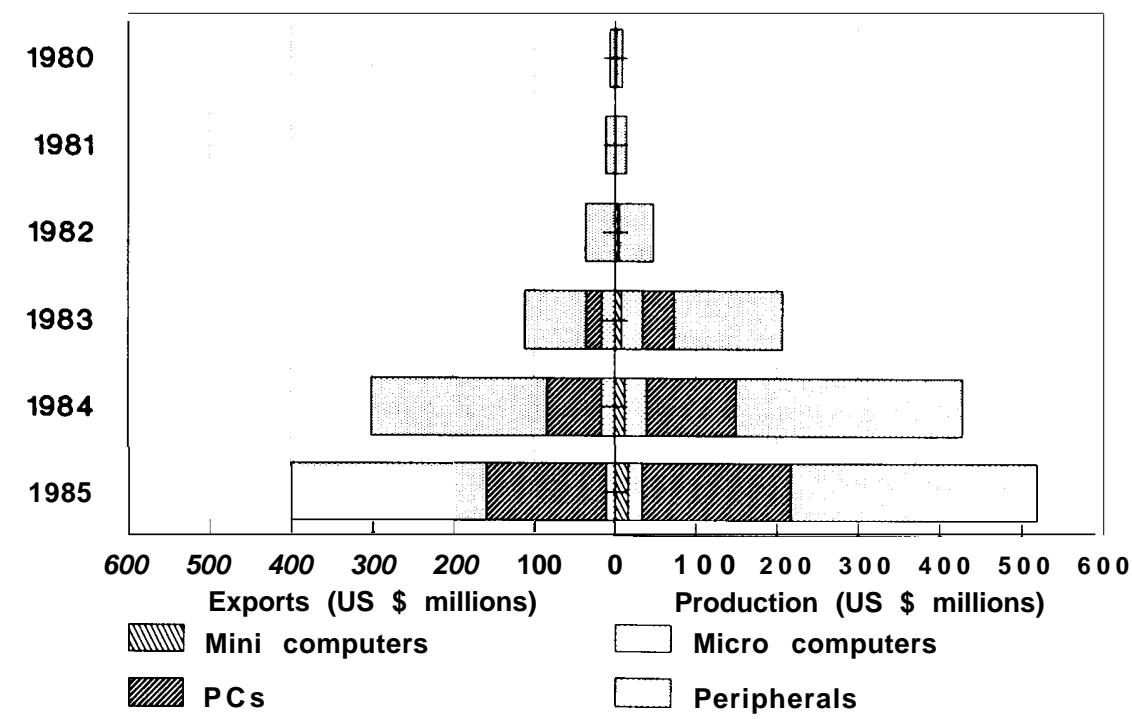

SOURCE: Stephan Haggard, David Lane, Robert Wade; and Robert Neff and Laoemi Nakarmi, "In Korea, All Circuits are Go," Business Week, No. 3168, July 9, 1990, pp. 69, 71. 
Hyundai got its initial production technology from Vitalec, an American firm. In early 1983, Hyundai announced an ambitious development plan that included a $\$ 450$ million, 5-year investment program and the establishment of a subsidiary in Silicon Valley capitalized at $\$ 5$ million. In 1985, the firm began making 256K DRAMs, bypassing production of $64 \mathrm{~K}$ DRAMs altogether. ${ }^{87}$

Goldstar had a longer-established presence in electronics and technology agreements with Western Electric and Honeywell. Goldstar devoted more attention to diversifying its production among a number of semiconductor devices. Nonetheless, it also tried to jump ahead of Samsung by securing technology for the 256K DRAM from AT\&T and in 1989 concluded a highly publicized deal with Hitachi that gave it the technology for the $1 M$ DRAM. ${ }^{88}$

The scale of South Korean investment in semiconductors was huge. The national champions committed more than $\$ 1.2$ billion to semiconductors for 1983 to 1986, five times more than the combined investment of Taiwan's four major semiconductor projects for 1984 to 1987-1988.

As business took the lead, the role of government policy changed. KIET, having pioneered mediumscale semiconductor technology, found that by 1984 the chaebol had superior fabrication facilities and were rapidly expanding their in-house $R \& D$ capacity. Rather than attempt to guide the entry into successive stages of DRAM fabrication, KIET left this to the fins. It sold most of its fabrication facilities to one of the chaebol, changed its name to the Electronics and Telecommunications Research Institute (ETRI), and initiated parallel basic research efforts in semiconductors, computers, and telecommunications. This is not to say that ETRI, as the national R\&D laboratory, has been eclipsed. Its staff numbered 1,200 in 1985 , with a budget of over $\$ 40$ million. ${ }^{89}$

By the time the 64K DRAMs were produced, the product cycle had already passed the phase of high scarcity. World demand for semiconductors slumped; aggressive pricing by the Japanese lowered the price still further. From 1985 to 1987, Korea's VLSI facilities operated at only 30 percent of capacity or less much of the time, with the price well below cost of production. Yet the government did not pour in fresh money. It was reluctant to commit itself to assisting another high-risk, capital- intensive industry in difficulty, having just finished the restructuring of the heavy and chemical industries in the 1970s. The popular impression that Korean firms have made it to the world semiconductor frontier without government help probably is due to this refusal to help the troubled fins, combined with anxiety to conceal government help for fear of retaliation from the United States and Japan on grounds of "unfair competition."

By 1986, the government decided to get more involved again. As Korea's capacity to innovate in the production of standard chips became manifest, it became increasingly difficult for companies to access foreign technologies. The government was concerned about the royalties that Korean firms were paying. Moreover, the government was planning a national computer network costing several hundreds of millions, for which most contracts would be steered to Korean companies. Joint development of advanced chips would be a giant step in that direction, especially because large-capacity memory chips are considered the "technology driver" for several kinds of advanced semiconductors integral to such a system.

In conjunction with ETRI, the government coordinated the leading firms to form a Japanese-style $R \& D$ consortium to develop the 4 megabit memory chip. A board of ETRI-sponsored experts allocated money from a joint government-business research fund to support projects proposed by research teams from member firms. Those teams whose engineering samples met govemment-specified standards had to repay much less on government loans than those whose samples failed. This performance-based cooperation resulted in increased $R \& D$ competition among member firms. By 1990, 18 collaborative research projects were underway through the consortium arrangement, with total $R \& D$ expenses estimated at $\$ 250$ million. ${ }^{90}$

When world prices of memory chips started to rise in 1988, the conglomerates, which had been prepared to wait until the 1990s, began to earn big profits on semiconductors. By 1990, Korea was the world's third largest fabricator of DRAMs after ' Japan and the United States.

Several conclusions can be drawn from this analysis of the development of the Korean semiconductor industry. Direct government efforts to lead the industry in the absence of strong private sector interest do not appear to have been effective in the 
short run, but they probably did have long-term effects.

The industry took off with the entry of the large chaebol. A variety of market forces made such a move imperative, including their own internal demand for chips. Their entry had extensive government backing and followed closely a new government plan that included both direct financial support and fiscal incentives to investment in $R \& D$ and training. The growth of the chaebol was partly an outgrowth of government policy during the heavy and chemical industry drive of the 1970s, when the electronics sector was targeted for support. The three technological leaders in the 1980s benefited from the incentive policies of the 1970s, and through their entry into consumer and industrial electronics developed their appetite for in-house production of chips.

Korea's industrial strategy and structure in semiconductors has some limitations. While the chaebol have made large investments in the production of commodity chips, policy has neglected the development of the small and medium-sized firms that played an important role in technological innovation in the United States and Taiwan. Moreover, by concentrating on standardized chip production, the Korean industry is vulnerable to price fluctuations and low profitability, though it is perhaps better able to withstand them, compared with most semiconductor firms in the United States, due to the integration of the largest Korean producers. We return to some of these issues when discussing Taiwan's strategy toward the industry.

\section{THE ROLE OF GOVERNMENT POLICY: TAIWAN}

Taiwan's industrial strategy has moved through stages similar to Korea's. ${ }^{91}$ From 1945 until the late 1950s, the emphasis was on import substitution to develop light manufacturing industries. Around 1960, some of the import-substitution controls were dismantled, and export promotion measures intensified, resulting in a rapid expansion of manufactured exports. In the early 1970s, the government intensified efforts to upgrade the industrial sector and develop heavy industries, and in the 1980s, the emphasis shifted to technological improvement.

Despite these similarities, there are important differences between the two countries in both industrial strategy and structure. First, Taiwan's state-owned enterprises spearheaded the move into heavy industries such as steel, cement, aluminum, and petrochemicals. Averaged over the 1970s, public enterprise's share of industrial production was 22.5 percent, and 30 to 35 percent of gross fixed capital formation was undertaken by public enterprises. ${ }^{92}$ (By 1988, public enterprise's share of industrial production had fallen to $\mathbf{1 8 . 1}$ percent.) These figures put Taiwan in the top decile of noncommunist countries in terms of the size of their state-owned enterprise sector. This is an interesting paradox, given that Taiwan is generally viewed as having a market-oriented economy. The Kuomintang (KNIT), arriving at the end of World War II, brought with them a strong socialist element that pervaded the Taiwanese Government for many years. The more numerous native Taiwanese are responsible for much of the country's recent business growth. The two factions have not always seen eye-to-eye.

A second difference is that the government has not explicitly promoted the concentration of the industrial structure as a component of its development strategy. Small and medium-sized firms have played a much greater role in Taiwan than in Korea. For example, in 1981 Korea had 10 firms listed in Fortune's 500 biggest industrial firms outside the United States, while Taiwan had only 2. Hyundai, Korea's largest private business group, had annual sales of $\$ 8$ billion in 1983 and employed 137,000 people; Formosa Plastics Group, Taiwan's biggest private group, had annual sales of $\$ 1.6$ billion and 31,200 employees. $^{93}$

The small size of Taiwan's firms should not be exaggerated; over time, industrial concentration has increased. Almost half of manufacturing production in 1971 and 1981 came from firma with more than 500 employees, and firms with less than 20 employees accounted for only 12 percent of manufactured output in 1971 and 9 percent in $1981 .{ }^{94}$ Nonetheless, there is a notable difference in industrial structure between the two counties that had important implications for business strategy. Small firms are more likely to seek out quick-entry niches in export markets rather than attempt to produce standardized, high-volume items with high scale economies.

The role of foreign capital was also different in Korea and Taiwan. Taiwan has been more open to foreign direct investment than Korea. Foreign direct investment has played a larger role in both capital 
formation and investment, and has been an explicit component of the country's technology strategy .95 Meanwhile, savings in Taiwan have consistently outstripped investment.

A final difference has to do with the range of instruments of industrial policy. Taiwan has had a more market-oriented strategy than Korea, with the government playing a less directive role in the economy. For example, protection has been lower and targeted credit policies have played a smaller role in Taiwan than in Korea. The government has devoted more attention to the provision of infrastructure and to arms-length incentives, such as fiscal incentives, that are less discretionary.

The government recently gave up some of the more direct techniques it employed in the past. The country is going through a period of substantial economic liberalization. Nonetheless, the government has by no means relinquished its role in guiding the evolution of the industrial structure through supportive policies, and in the 1980s accelerated its interest in enhancing the country's indigenous technological capabilities.

\section{Exchange Rate and Trade Policies}

Trade has played an even larger role in Taiwan's economy than in Korea's. Imports plus exports have been over half of GNP since 1970, and over 80 percent of GNP since 1976. Moreover, Taiwan has run balance of payments surpluses in every year since 1970, with only three exceptions-1974, 1975, and 1980-when imports surged in connection with the two oil shocks. Taiwan now has the second largest foreign exchange reserves in the world after Japan, and by far the biggest per capita.

These surpluses are largely attributable to exchange rate policy. The unification and devaluation of the exchange rate in the late 1950s was a key component of the country's export-oriented growth strategy. Unlike Korea, where macroeconomic policy has undergone several inflationary cycles, fiscal and monetary policy in Taiwan has been extremely conservative, allowing the government to hold to a fixed exchange rate policy. Because of its export success, and perhaps because of political pressure from the large export sector, the government was reluctant to allow the exchange rate to appreciate in the first half of the 1980s. Another reason for the country's pursuit of surpluses is more political. The government is preoccupied with Taiwan's vulnera- bility to pressure from mainland China, and considers large foreign exchange reserves a hedge against disruption of the island's normal trade flows.

The Central Bank intervened continually by buying foreign exchange, thus keeping the New Taiwan dollar (\$NT) undervalued. In 1986, however, the government recognized the problems associated with the strong \$NT, including inflationary pressures at home, and has slowly allowed the currency to appreciate. In 1989, the country undertook a major liberalization of its foreign exchange market, including floating the New Taiwan dollar. These actions reduced the bilateral surplus with the United States.

While less protectionist than Korea, the government has restricted imports. One reason was that tariff charges remained the single most important item of government revenue until the early 1980s. Ministry of Finance officials, worried about revenue, have resisted lowering tariffs. Even in the mid-1980s, customs duty accounted for 17 percent of tax revenue, second only to income tax at 19 percent. ${ }^{96}$ Yet industrial policy was a motivation for protection as well, suggested by the fact that these restrictions were maintained even as foreign exchange reserves ballooned in the early 1980s. Legal tariffs, which averaged over 60 percent in 1969, remained as high as 30 percent in 1986, with large differentials across sectors. ${ }^{97}$

Total tariff revenue as a percent of total imports, however, was only 9 percent in 1984, the difference being accounted for by exemptions on imports used as inputs to exports. This drawback system was one of the most power-lid export incentives at the government's disposal. Exporters enjoyed a freetrade regime; nonexporters, including consumers, paid higher prices for restrictive trade policies.

In terms of quantitative restrictions on imports, 80 percent of items on the import schedule had no restrictions as of 1984, which appeared to reflect a fairly liberal regime. However, the 20 percent of items with restrictions accounted for over half of Taiwan's imports that year. Twenty-nine percent by value had to be approved by a domestic agent, whether the producer of a domestic substitute (e.g., steel, cement), or from a government bureau, such as the Industrial Development Bureau of the Ministry of Economic Affairs. Another 21 percent were limited by who could import them; some could be imported only by publicly owned trading compa- 
nies, others only by the end-user. Only 4 percent were limited by origin in 1984; origin restrictions, especially from Japan and Korea, were much more important in the past. ${ }^{98}$

Since the mid-1980s, however, a dramatic liberalization of imports has occurred, matching an earlier run-down of export promotion assistance. The average tariff in 1986 was 28.2 percent. In August 1987, tariffs were lowered on several thousand items, reducing the average tariff level to just over 20 percent. The level dropped further in 1988 to 13 percent and in 1989 to 10.3 percent, with a target for 1992 of of only 7 percent, equivalent to or even lower than in the advanced industrial states. ${ }^{99}$ Protection of agricultural goods remains high; indeed, if it were not for higher agricultural tariffs, Taiwan's trade regime would approach complete free trade. Tariffs on agricultural products in 1989 were 24.2 percent, scheduled to decline to 20 percent by 1992. As in Korea, liberalization of agricultural imports has been a heated political issue.

Taiwan also revamped its system of nontariff controls. By March 1989, 98 percent of all product categories were freely importable, with restrictions remaining on articles related to national security and health. While tariffs have come down and quantitative restrictions have been reduced, the dutydrawback scheme, which allowed exporters to import inputs for export products at duty-free prices, is being dismantled. Other restrictive measures, such as harbor fees, have been dropped as well.

\section{Development Financing and Foreign Direct Investment}

Until the second half of the 1980s, Taiwan had an even higher investment ratio than Korea. Gross investment averaged 28.4 percent of GNP between 1965 and 1980, compared with Korea's 26.5 percent. And in contrast to Korea, Taiwan's investment has been financed with domestic savings. Between 1965 and 1980, the share of domestic savings in GNP was 28.7 percent, slightly more than the share of investment. Over the 1980s, the gap between domestic savings and investment widened; Taiwan became a net creditor.

The government controls Taiwan's formal financial markets. But whereas Korea denationalized the commercial banks between 1980 and 1983, they remain largely government-owned in Taiwan. ${ }^{100}$ The government closely regulates lending and borrowing, and appoints senior staff. The banks, in turn, have historically dominated the financial system, with nonbank financial institutions accounting for only 5 percent of the assets of Taiwan's major financial institutions in $1980 .^{101}$ The curb market has supplied some 30 percent of the total volume of loans processed through the financial system over the 1970s, at rates 50 to 100 percent higher than bank loan rates. ${ }^{102}$ Taiwan's firms depend on credit more than equity for financing. The ratio of corporate sector debt to equity was between 160 to 180 percent between 1971 and 1980, less than Korea's but in the same order of magnitude.

With companies dependent on bank loans and government controlling the banks, the government coordinated industrial investment by means of credit allocation. In the 1960s, the Ministry of Finance gave each bank lists of 6 to 12 industries for priority attention. During the 1970s, the banks themselves participated in drawing up the lists. The banks have taken pride in achieving compliance with the lists. ${ }^{103}$

Nevertheless, the government has relied on discretionary credit allocation less than the Korean Government, the difference perhaps reflecting Taiwan's greater use of public enterprises. Since the mid-1970s, government direction of commercial banks' credit allocation has declined. The government instead has relied more heavily on special industrial policy banks, notably the Bank of Communications.

The Bank of Communications was the lead bank for infrastructure financing until 1979, when it was designated a development bank. Its functions were to extend confessional loans and credit guarantees to capital-intensive industries, take equity positions in new firms in high-technology industries, and advise customers on how to improve management and innovation. Following a 1982 ruling, 40 percent of new deposits in the postal savings scheme are to be redeposited with the Bank of Communications, thus opening a major new source of funds.

Foreign direct investment accounted for only 8 percent of total investment in manufacturing during the 1970s. In electronics and machinery during the 1970s, foreign direct investment accounted for roughly 50 percent and 25 percent of investment, respectively. But over the 1970 s and 1980s, the Taiwanese Government imposed export requirements and/or domestic content requirements on most foreign investors. Local content requirements 
have helped build linkages between foreign owned and domestically' owned plants, and have aided technology transfer as Taiwanese employees of foreign firms move to locally owned firms or start their own companies.

As for outward investment, prior to the mid-1980s the government carefully screened such investment for its consistency with national development objectives. Since the mid-1980s, however, under the pressure of huge foreign exchange reserves and rising domestic wages, restraints have been cut sharply. Outflow has begun to cheaper labor sites, such as Thailand and the Chinese mainland, while outflow to North America continues. ${ }^{104}$

\section{Technology Policies}

The Government of Taiwan has taken a direct responsibility for accelerating technology development and application in industry. ${ }^{105}$ Instead of one preeminent coordinator, such as Korea's MOST, this function is dispersed among artly competing agencies in Taiwan. This may reflect the problems posed to technology policy by the country's decentralized industrial structure and the preponderance of small firms in the economy.

The nearest counterpart to Korea's MOST is the National Science Council, which reports directly to the cabinet (Executive Yuan) but does not have ministerial status. It publishes a series of National Science and Technology Development Plans. Its tasks include guiding, coordinating, and evaluating all government $R \& D$ efforts, including specific research projects and manpower development. Inside the government, the National Science Council is not preeminent in matters of science and technology, however; several other organizations vie for influence over science and technology policy, including the Council for Economic Planning and Development, the Industrial Development Bureau of the Ministry of Economic Affairs, and the Industrial Technology Research Institute (ITRI). Established in 1973, ITRI is divided into six institutes, one each for electronics, machinery, chemical engineering, energy and $\operatorname{minin}_{g}$, industrial materials, and standards and measurement. By 1990, ITRI had a budget of $\$ 270$ million and a staff of over 5,000. ITRI is concerned only with civilian technologies; another agency with a much bigger staff covers military technologies. (See also table 7-11 summarizing the four largest Taiwanese Government research institutes.)

The single most influential body on technology policy as a whole is probably the Science and Technology Advisory Group (STAG). With only a small administrative budget, it was until recently headed by K. T. Li, a man of immense personal influence resulting from several decades of experience in government. As Minister Without Portfolio with special responsibility for science and technology, he created STAG in 1979 to coordinate the various science and technology initiatives undertaken by these other organizations. ${ }^{106}$ Backed by a small secretariat, he worked with a council of about 10 foreign advisors, all of them experts in some area of science and technology and all experienced in business or administration. Almost all were American citizens. STAG assesses the relevance of world technology developments for Taiwan and evaluates proposals for technology initiatives from Taiwan.

Table 7-n-Taiwan: Major Government Research Institutes in 1990

\begin{tabular}{|c|c|c|c|}
\hline Name & Research fields & $\begin{array}{l}\text { Expenditure } \\
\text { (\$millions) }\end{array}$ & Staff \\
\hline Industrial Technology Research Institute & $\begin{array}{l}\text { Electronics, machinery, } \\
\text { Chemical engineering, stand- } \\
\text { ards \& measures, industrial } \\
\text { materials, energy \& mining, }\end{array}$ & $\$ 270$ & 5,087 \\
\hline Institute for Information Industry & $\begin{array}{l}\text { Software technology, products, } \\
\text { marketing, training }\end{array}$ & $\$ 50$ & 730 \\
\hline Development Center for Biotechnology & $\begin{array}{l}\text { Biotechnology, applied ohem- } \\
\text { istry, biochemistry, immunology }\end{array}$ & $\$ 25$ & 328 \\
\hline $\begin{array}{l}\text { Food Industry Research and } \\
\text { Development Institute }\end{array}$ & $\begin{array}{l}\text { Food technology, products, } \\
\text { processing equipment, training }\end{array}$ & $\$ 12$ & 302 \\
\hline
\end{tabular}


Taiwan lacks an equivalent of Korea's high-level National Technology Promotion Conference. Korea's "Long Term Technology Forecast for the Year $2000^{\prime \prime}$ (1986) resulted from 2 years of discussions among some 500 experts in 8 working groups. Taiwan's National Science and Technology Development Plan for 1986 to 1995 was preceded by week long conferences in 1982 and 1986, and was attended by some 400 participants, of whom only about 15 percent were from private firms. Moreover, they came as individuals rather than as representatives of industrial associations.

The government has long emphasized education. Universal primary enrollment (98 percent) was achieved in 1970 and secondary enrollment reached 80 percent of the age group in 1980 . The enrollment ratio is much lower at the tertiary level, only 14 percent for men and 12 percent for women in $1985 .{ }^{107}$ Above the junior high school level, institutions are divided into those that are academically or vocationally oriented. Since the mid-1960s a dramatic change in enrollments has occurred in favor of the vocational. Forty percent of secondary school enrollments were vocational in 1963, 66 in 1980, and 69 in 1986. This preponderance in favor of vocationally oriented institutions is exceptional compared to most other countries. At the tertiary level, 55 percent of students are in vocationally oriented colleges, 45 percent in academic universities. ${ }^{108}$

Taiwan's junior colleges (ages 18 to 20 or 21) have graduated over 20,000 engineering students a year through the 1980s, while its universities have graduated over 10,000 bachelor-level engineers a year. The figure for bachelor-level engineers is $\mathbf{7 0}$ percent more than the corresponding per capita figure for the United States, and is close to Korea's (per capita). ${ }^{109}$ The presence of a large stock of engineers has been important for allowing national control over decisions about foreign technologies and for mastering the use of those technologies. Great care is taken to ensure the practical orientation of engineering training, especially from the vocational schools, and each school has arrangements with local firms to take students as part-time workers throughout the school year.

These shifts in enrollments reflect demand, the fact that engineers are paid on average 20 percent more than arts graduates of the same age, and the fact that an engineering qualification is a fast track to management positions. ${ }^{110}$ However, these changes also reflect direct controls. From 1966 onwards, a series of Manpower Development Plans have guided Taiwan's education expansion, and the results have corresponded closely to targets in terms of expansion of different subjects, the balance between public and private schooling, and overall rates of expansion.

Some targets went strongly against social demand. For example, the government lowered the allowable rate of expansion of places in tertiary institutions from 5 percent in the Fourth Manpower Development Plan (1972-1976) to 3 percent in the Fifth (1977-198 1). The slowdown was effected both by spending controls and by reducing the pass rate in the national tertiary level entrance examination. Intended to avoid unemployment among the highly educated, the result has been to exacerbate shortages of scientific and engineering manpower. The constraint on the expansion of academic secondary schools and universities also runs against social demand, because academic secondary schools are the principal route to universities and university degrees (including engineering) that yield higher rates of return and prestige.

In 1975 , there were 2,301 students studying abroad, most under government auspices. By 1986, this number had risen to 7,016, over 90 percent of whom were in the United States. But a majority of students who study abroad do not return to Taiwan. Of the one in five of Taiwan's graduates in engineering, science, medicine and agriculture who go abroad for further study, only about 20 percent returned during 1976 to 1986 . In 1983, the government launched a program to encourage students and others with technical skills to return. The program included keeping in touch with thousands of potential recruits. Many returnees work initially at ITRI. The National Science Council also administers a program to bring Taiwanese and other Chinese engineers and scientists in the West to Taiwan for short assignments. Some 3,200 people came under this program between 1970 and 1980 .

The government has also developed a series of targeted incentives, including special funds to lend either for technologically advanced machinery or R\&D activities. The most important of these is the Strategic Industry Fund. Established in 1982, it had a capitalization of $\$ 500$ million by 1983 and could be used for: 
1. Purchase of domestically produced machinery, with an interest rate 2 points less than the average of the minimum and maximum longterm rates for commercial bank loans (this average was 10 percent in 1983).

2. Purchase of new machinery, from any source, by producers of specified products within the "strategic' industries of machinery, automobile parts, electrical machinery, and electronics and information. The list of eligible products contains $\mathbf{1 3 5}$ items. The interest rate is two points less than the minimum of the long-term rates.

3. Special cases to be decided by the planning agency, especially for the introduction of labor-saving equipment in any sector. Again, loans are at preferential rates. The existence of special cases indicates that the government retains significant discretion to decide what is strategic.

The pay-back period is a maximum of 8 years, with a 2-year grace period. The collateral is the value of the machinery itself. Compared with the normal terms of Taiwan banks, loans from the Strategic Industry Fund are highly confessional. Other specialpurpose funds include the Sine-American Fund for Economic and Social Development, established in 1965, and The Development Fund; both are available for discretionary channeling of funds into targeted sectors.

The Statute for Encouragement of Investment, first promulgated in 1960 and revised many times since, gives tax incentives for technological upgrading and R\&D activities. It combines two approaches to industrial promotion. One is to make the incentives available to many industries but stipulate stringent performance criteria so that only a few firms in each industry will be eligible. The other approach is to target the incentives on a narrow range of "strategic' industries, and make them easily available to firms within these industries. The compromise in Taiwan is to have a broad range of industries eligible, with a high proportion of items eligible from the strategic industries of machinery and electronics and information, and relatively few items eligible from such well-established industries as textiles.

The incentives include the tax holiday, accelerated depreciation, investment tax credit, duty-free import of capital goods, and reduced business tax rate. Several other schemes bolster these incentives. $R \& D$ spending is encouraged by a 20-percent tax credit for firms with yearly $R \& D$ spending above their maximum in the previous 5 years, provided this brings their spending above a certain minimum. Businesses in specified high-technology industries can defer income taxes and face a maximum income tax rate of 20 percent of annual taxable income, provided they also meet the R\&D minimum. These same firms can retain profits of up to two times their paid-in capital; they are eligible for up to 50-percent government grants for $\mathrm{R} \& \mathrm{D}$ expenditures, and also for government purchase of equity.

Companies in machinery and electronics and information are eligible for government cost sharing of up to $\mathbf{5 0}$ percent for putting in approved manufacturing or financial systems, and, since 1984, for loans at almost 3 percentage points less than the average of the minimum and maximum long-term rates. To encourage technology transfer from abroad, the government allows technical know-how or patent rights to be supplied as part of an equity share (up to 25 percent), and exempts foreign enterprises from taxes on income gained through furnishing approved patents.

A particularly innovative scheme for promoting local R\&D was the development of the Hsinchu Science-based Industry Park in 1980. Modeled on the Stanford Science Park, it attracts foreign and domestic high technology firms, mostly in informatics, precision instruments, new materials, and biotechnology. The object is to lift some of the risks faced by participating firms, and thereby induce enough companies to locate there to generate positive spillovers ("externalities") among them. Investors are allowed 5 years of tax holiday within the first 9 years, a 22-percent ceiling on corporate income tax, below-market land rents, exemptions for various import and export fees, and low-cost loans and government equity of up to 49 percent of total investment. The companies also benefit from close proximity to the ITRI institutes. One hundred firms are now operating in the Park, near its capacity.

Other technology upgrading programs include:

- an industrial extension service;

- intensive quality control efforts;

- the fostering of venture capital firms; and

- initial steps to increase the protection accorded to intellectual property rights." 
There is talk of making Taiwan the Switzerland of Asia, with high-quality products from relatively small-scale firms.

What are the effects of this system of technology policy? Compared to their Korean counterparts, Taiwan's public research and service organizations are less closely connected to private firms, which have not made nearly as large an investment in their own R\&D facilities. Critics often say that the public labs have been unsuccessful in developing new products, which is attributed to their poor communications with private firms and problems of the incentives in public sector research. But public labs carry out a major training function and encourage their younger staff to spin off their own companies to commercialize new products. This has been a major incentive for luring back Taiwanese professionals living abroad. A Taiwanese researcher at IBM, for example, may be offered the position as chief of a research team at one of the public labs, with more responsibility and command over budget than at IBM, plus the prospect of developing his own company to bring to market the products developed in the lab. The popular charge of poor communications between labs and firms presumably relates to well-established companies, rather than these spinoffs. However, this incentive mechanism disrupts the work in publicly funded technology programs when key staff leave.

Indicators of R\&D inputs must be used cautiously, for different countries use different definitions. By official figures, Taiwan spent 1.06 percent of GNP on nonmilitary R\&D in 1985, less than Korea's 1.59 percent. About half of Taiwan's spending is classed as coming from the public sector, but when government grants to certain nonprofit organizations are included, the figure rises to 60 percent. Private domestic and foreign firms account for the rest. This is perhaps three times more than the public sector's share in Korea, attributable to the presence of larger firms in Korea. In terms of numbers of researchers per 10,000 people, on ahead count rather than full-time equivalency basis, Taiwan has about 14, compared with Korea's 11 .

\section{Case Study: Automobiles}

Taiwan's automobile industry is far from breaking into the world market. ${ }^{112}$ Like Korea, Taiwan designated the automobile industry as a strategic sector, But in 1988, in contrast to Korea's output of over 1 million units, Taiwan produced only 275,725 motor vehicles. ${ }^{113} \mathrm{~A}$ case study of the industry therefore illuminates differences between Korean and Taiwanese industrial policies and structures. The Taiwanese Government was more reluctant to push into heavy, capital-intensive sectors and support the development of large national champions. This reticence was partly the result of the inability of the Taiwanese Government to restrict the entrance of new producers, policy incoherence derived from bureaucratic wrangling, and more fragmented businessgovernment relations than in Korea.

In the absence of larger firms capable of achieving the required scale economies and with a smaller domestic market, the prospects for automobile exports appeared dim. Taiwan thus turned to stateowned enterprise to promote auto exports. When this effort failed, they sought an industrial strategy that relied on trade liberalization, encouragement of foreign direct investment, and the development of an export-oriented parts industry. This strategy appears to be yielding better results.

At the end of the 1960s, the automotive industries of Taiwan and Korea looked much alike. Starting in 1958 with an assembly plant in cooperation with Nissan (the joint venture partner in Korea's first plant 4 years later), by the late 1960s Taiwan had four assemblers struggling for a share of less than 20,000 units a year. Each had Japanese participation. Industry complaints about the inadequacy of Japanese technology transfer were never quite taken to heart, however, and government promotional measures were limited to domestic content requirements and import controls. ${ }^{114}$ Over the 1970s, Taiwan's auto policy drifted. The state's organizational and financial capabilities were heavily committed to other projects aimed at boosting the competitiveness of existing export sectors. The 1974 oil crisis made matters worse by dampening expectations about the industry.

The government split on policy for the automobile industry. Some officials saw it as a future major exporter, some accorded it a central role in Taiwan's defense strategy, others doubted that domestic demand could ever be sufficient-given a population half the size of Korea's-to provide the base for an export drive. The latter group thought the emphasis should be on development of an automobile parts industry, which might later support internationally competitive assemblers. 
Another reason for policy drift was that domestic car prices above international levels did not harm the economy's overall international competitiveness as high prices on intermediate goods would have. This predisposed the government to the development of intermediate inputs. As a result of these drifting policies, auto production became less efficient. The government did nothing to stop new entrants, and in 1979 the six assemblers each produced an average of only 18,000 compacts, sedans, and light trucks. The resulting rattletraps were sold on the domestic market only.

In 1978, spurred by news of Korea's big push into automobiles, the government announced a proposal to encourage the establishment of a large-scale automobile plant with an annual capacity of 200,000 compact cars, mainly for export. The strategy was to induce a foreign car maker of world standing to enter a joint venture with a domestic enterprise, and thereby obtain technology not only for assembling but also for upgrading the capability of the auto components suppliers. Only Toyota and Nissan submitted investment applications.

To underscore that the Big Auto Plant was aimed at the world rather than the local market, the Ministry of Economic Affairs stipulated that the foreign joint venture partner could not hold more than 45 percent of the equity and would have to export 50 percent of production. Several months later, after receiving the Japanese applications, the government stated its intention to retain control over the enterprise by announcing that the state-owned China Steel Corp., rather than any existing automaker, would be the foreign partner's working counterpart. China Steel's chairman, Zhao Yaodong, was appointed head of a "Big Auto Plant preparatory committee," and Taiwan's automotive industry association played no role in the formulation of policy. Seven domestic private ths, none in automobiles, split a 30-percent equity share in the venture. Other local firms would subcontract to the plant.

In 1982, Toyota was chosen as joint-venture partner. In July 1983, however, disagreements emerged between Toyota and the Ministry of Economic Affairs (MEA). The government now insisted on a 90-percent local content, and substantial transfer of production technology, despite Toyota's protestations that these should be goals rather than fixed targets. It planned to prevent Toyota from taking profits from the venture if it failed to meet a strict timetable for achieving these conditions. Toyota argued that the conditions would be impossible to meet.

A 1984 cabinet reshuffling brought to the fore officials who had been wary of the Big Auto Plant plan. Zhao Yaodong was removed as Minister of Economic Affairs. The new government favored the development of Taiwan's auto parts industry into an integrated production system. K. H. Yu, a powerful man with easy access to the president, was inclined to retain domestic industry protection and provide greater support for private domestic and foreign firms. The new Minister of Economic Affairs first announced that the joint venture would remain contingent on Toyota's compliance with the conditions already laid down, but then the government signaled that should the joint venture fail, Taiwan would proceed with an alternate plan to develop the parts industry. In September 1984, when no convergence between Toyota and the MEA was evident, the Toyota-China Steel joint venture was canceled.

Other Japanese automakers showed an interest in Taiwan. Glad to seize at a second chance, the Taiwan Government acted to restructure the domestic industry. Chastened by the Big Auto Plant failure, the new Automobile Industry Development Plan of 1985 reversed several basic policies. It proposed to lower tariffs and domestic content requirements on finished cars, limiting import bans to small Japanese cars and quotas to Korean cars. The new plan removed the 45-percent foreign equity ceiling, allowing 100-percent foreign ownership in exportonly car and components production. It imposed export ratios and technology transfer requirements case by case. To ease pressure from Washington over Taiwan's perennial trade surplus with the United States, the plan also included gradual tariff reductions from 65 to 30 percent and the market's opening to all car imports by $1993 .{ }^{115}$ Hence, the government gave up its earlier emphasis on domestic content and national control in order to maximize an export orientation. While it favored a consolidation of the industry by means of mergers or exits, it did not try to force this consolidation.

The domestic assemblers began to show signs of life. They planned export-oriented expansion, established a joint design engineering center to develop the island's first domestically designed model, and, in the case of a joint venture with Ford, announced 
that the Taiwan subsidiary would be integrated into its global supply network. The firms chose to strengthen their links with Japanese companies and explore new relationships with other foreign producers (table 7-12). Honda, Nissan, Mitsubishi, and Toyota now have large equity stakes in Taiwanese companies. All plan to make Taiwan a major site for parts and components in the 1990s. Toyota and Nissan may export compact models, partly in hope that Taiwan will provide a fast track into the China market.

Foreign automakers also see a new market in Taiwan. Rising consumer income and the appreciation of the New Taiwan dollar since 1985 has spurred domestic demand for foreign automobiles. Growth in demand has aided domestic car makers too, but they face difficulties given the high scale economies required to be profitable and the currency appreciation. Foreign-made car sales rose to 136,000 in 1988 (38 percent of the market) from 33,000 (13 percent) in 1986. In May 1989, imports passed local car sales for the first time. ${ }^{116}$ With 9 car companies and their foreign tie-ups saturating a market of 20 million people, a major shake-out should occur in the next several years.

This case illustrates some of the difficulties in devising and applying industrial policy. Protection alone did not foster the development of a competitive industry, and in fact encouraged a proliferation of inefficient entrants. The state-led joint venture with a foreign producer also failed, but the reasons appear to have been political as well as economic; this strategy attempted to bypass domestic automakers altogether. The current strategy centers on the use of market liberalization to force a restructuring of the industry through foreign participation, with the expectation that the parts industry will provide a number of niches independent of final assembly. Two things should be noted about this strategy, however. First, no less than the state-led strategy, it rests on independence from domestic producers. Second, it is likely to result in an industry restructuring that could probably demand further government intervention.

\section{Case Study: Semiconductors}

Electronics became Taiwan's biggest export category in 1983, surpassing textiles and apparel. In 1988 , it accounted for 21.5 percent of exports. ${ }^{117}$ The industry is dominated by foreign fins, mostly from
Table 7-1 2-Taiwan Auto Industry External Sources of Capital and Technology

\begin{tabular}{|c|c|}
\hline Taiwan automaker Foreign tie-ups & Nature of linkage \\
\hline $\begin{array}{c}\text { China Auto Corp ... . Citroen } \\
\text { Mitsubishi }\end{array}$ & $\begin{array}{l}\text { Technology } \\
\text { Technology }\end{array}$ \\
\hline Ford Liu Ho $\ldots \ldots$. Ford & $\begin{array}{l}70 \% \text { equity-ownership } \\
\text { Technology }\end{array}$ \\
\hline Kuo Zui ......... Hino & $\begin{array}{l}\text { Technology } \\
22 \% \text { equity-ownership }\end{array}$ \\
\hline Prince Motor . . . . . . Suzuki & Technology \\
\hline San Yang...... Honda & $\begin{array}{l}\text { 13.5\%equity-ownership } \\
\text { Technology }\end{array}$ \\
\hline $\begin{array}{l}\ldots \text { Fuji Heavy } \\
\text { Industry (Subaru) } \\
\text { Renault }\end{array}$ & Technology \\
\hline $\begin{array}{c}\text { Ta Ching } \ldots \ldots \ldots \ldots \text {.Fuji Heavy } \\
\text { Industry (Subaru) } \\
\text { Nissan }\end{array}$ & Technology \\
\hline Yu Tian $\ldots \ldots \ldots$. Daihatsu & $\begin{array}{l}\text { Technology } \\
\text { Technology }\end{array}$ \\
\hline Yue Loong ..........Nissan & $\begin{array}{l}25 \% \text {. equity } \\
\text { Technology }\end{array}$ \\
\hline \multicolumn{2}{|c|}{$\begin{array}{l}\text { alnlate 1990, Nissan acquired a substantial share of Subaru from Fuji } \\
\text { Heavy Industries. }\end{array}$} \\
\hline $\begin{array}{l}\text { SOURCE: Jonathan Moore, "TrafficJam," Fa } \\
\text { June 21,1990, pp. 76-78; Walter A } \\
\text { State Capacity, and Taiwan's Au } \\
\text { Modem China, vol. 15, No. 2, Apri }\end{array}$ & $\begin{array}{l}\text { rEastern Economic Review, } \\
\text { nold, "Bureaucratic Politics } \\
\text { tomobile Industrial Policy," } \\
\text { I 1989, p. } 209 .\end{array}$ \\
\hline
\end{tabular}

the United States, which account for more than two-thirds of production. About two-thirds of total production is exported, primarily to the United States. Over a quarter of electronics imports come from the United States, and over half come from Japan. ${ }^{118}$ In consumer electronics, Taiwan's domestically owned firms adopted the strategy of moving into the price-sensitive low end of the consumer market left behind as the Japanese moved into more highly differentiated consumer and industrial electronics. In component production, Taiwan specialized in production of standardized components and the assembly of semiconductors. Firms began to differentiate their products and attempted to enter the more advanced end of the consumer, industrial, and component markets.

However, the small Taiwanese firms have been handicapped in reaping economies of scale. The contrast is with the Korean chaebol, whose size and diversity gives them advantages in input purchase, international marketing, and the ability to crosssubsidize. Therefore, in Taiwan, the role of the government has been more important in building up technological mastery of microelectronics. And whereas the chaebol moved into large volume 
production of standardized chips, Taiwan concentrated on small runs of specialized chips.

The original stage of Taiwan's involvement in semiconductors was based on offshore assembly operations; if anything, Taiwan was even more liberal in encouraging the entry of these fins. Yet this strategy was initially motivated by interest in exporting rather than in developing an indigenous electronics base. The foreign firms constituted a relatively insulated enclave, with many initially located in export-processing zones.

In 1974, Taiwanese Government officials made serious plans to acquire semiconductor design and production capability. ${ }^{119}$ They established the publicly owned Electronic Research and Service Organization (ERSO), under the Industrial Technology Research Institute (ITRI). ERSO was, first, to verify the possibility of "leapfrogging" directly into integrated circuit production, bypassing transistor fabrication, and, second, to be a catalyst in securing private sector interest. ERSO would then recruit a foreign partner to setup a demonstration plant, with the aim of transferring the technology to a domestic private firm and commercializing it. In 1976, ERSO opened the country's first model shop for wafer fabrication, and a year later it signed a technology transfer agreement with RCA in integrated circuit design. By the second half of 1978, ERSO was in production, with competitive costs and accelerating sales.

The aim of this venture was not simply production, however, but the development of an indigenous semiconductor industry through internal technology transfer, i.e., from ERSO to a local company. Finding no companies to take over the entire operation, in 1979 the government established a joint venture with a group of firms called United Microelectronics Corporation (UMC). UMC was a subsidiary of ERSO, with a 45-percent equity share split among five private local fins. Drawing on RCA ties and ERSO manpower and technical expertise, UMC built a state-of-the-art production facility in 1982 to fabricate customized chips. UMC made agreements with three Silicon Valley design firms owned by Chinese-Americans, which opened branches in the Hsinchu Science Park. These joint ventures soon produced advanced chip designs.

ERSO also introduced critical technologies, such as mass production capabilities. ERSO established a Common Design Service Center, which spread design technology to the private sector and provide consulting and training in computers and design tools. A number of design houses profited from the effective subsidy in ERSO's generous Iicensing agreements.

By the late 1970s, government officials envisaged an integrated information industry linking semiconductors, computers, computer software, and telecommunications. An information industry task force, headed by two senior cabinet ministers, was responsible directly to the Premier himself, thus indicating the high priority attached to the industry. The Information Industry Development Plan for 1980 to 1989 spelled out a comprehensive approach to promoting the information industry.

Industry leadership came from public research organizations and their public enterprise offshoots. ERSO was responsible for guiding the development of new core technologies and products, and for training microelectronics engineers, some of whom would then move to private industry. After demonstrating the capacity for integrated circuit (IC) production, ERSO emphasized capacity in applicationspecific integrated circuits (ASICs). Design strength in custom-tailored chips was essential, ERSO argued, both to provide a source of innovation across the information industry, from data processing to consumer electronics to telecommunications, and also to differentiate Taiwan from Korea, which was then competing against U.S. and Japanese firms in high-volume memory chips. As the private sector developed a commercial interest in semiconductors, ERSO altered its role, focusing greater attention on basic research. In 1989, it established a laboratory for developing technology to produce submicron line widths on chips; in 1990, it split its operations into two parts, one devoted to further semiconductor research, the other emphasizing systems technology. ${ }^{120}$

By 1986, however, Taiwanese firms still lacked the capacity to make VLSI chips in commercial quantities. Fearing that the time for collecting high returns on advanced chip designs would soon run out, UMC and its partners sold the designs to one Korean and two Japanese companies. This dismayed senior government policymakers, concerned that the lack of a domestic integrated circuit industry could hamper their efforts in linked industries. The government thus redoubled its efforts to find a multina- 
tional company able to fabricate VLSI chips in Taiwan.

Philips, a Dutch company with many longestablished factories in Taiwan, agreed to start a foundry in late $1986 .{ }^{121}$ The project was a joint venture of the government (48.3 percent), Philips (27.5 percent), and several domestic private firms. The government contributed almost half the $\$ 153$ million startup cost. The new company, Taiwan Semiconductor Manufacturing Corp., makes chips to order rather than designing and marketing its own, reducing the risk that it will steal proprietary knowledge.

The company claimed that its technology as of mid-1988 was only 9 months behind that of the major U.S. firms like Texas Instruments and Intel, whom it includes among its nine big U.S. customers. By mid-1988, it was making 10,000 6-inch wafers a month. U.S. industry analysts consider it state-of-theart, and its cost per wafer is estimated to be below that of the best U.S. merchant facilities. A second \$220 million plant was scheduled for completion in 1991 , with a capacity of 30,000 6-inch wafers a month and capable of 1 micron line widths.

But government leadership was not the whole story. In 1988, the country saw the emergence of the frost chip makers not funded by the government: Hualon, Winbond, and Advanced Microelectronic. ${ }^{122}$ Hualon and Winbond invested $\$ 360$ million to build two state-of-the-art fabrication facilities for DRAMs and ASICs. Market imperatives drove the larger Taiwanese end-users to form alliances in order to guarantee needed output. In 1989, Texas Instruments announced a $\$ 250$ million joint venture to make advanced semiconductors, providing its partner, the Taiwanese computer company Acer, with an assured supply of chips. During the 1988 shortage of one megabit memory chips, Acer was unable to meet demand for its computers because of the scarcity of chips, while several of its competitors were less affected because they made their own chips. The new plant came on stream in mid-1991, and makes 4 megabit DRAMs. ${ }^{123}$

In addition to the chip foundries and the Texas Instruments-Acer joint venture, Taiwan's smaller semiconductor firms design and produce large quantities of "yeoman" chips, of good quality, low price, and fast delivery, for consumer electronics products. The island has the biggest pool of chip design talent in Asia outside of Japan. Many of the design houses are staffed by ERSO-trained engineers.

The proliferation of smaller firms is visible in related segments of the electronics industry, including personal computers, peripherals and add-ens, accounting for nearly 7 percent of Taiwan's exports in 1987, up from near zero in $1980 .{ }^{12425}$ Taiwan has over 100 computer manufacturers, compared to fewer than 60 in Korea. They do everything from clone-making to add-on graphics and communication cards, Chinese-character computer systems, software packages, and the development of systems integration through multi-user workstations. The imitation lag between introduction of a new personal computer product in the United States and the launch of a machine with similar functions by Taiwan's computer makers is down to 6 to 9 months, sometimes less. ${ }^{126}$

Acer, the leading firm, had 4,800 employees as of 1987,15 percent of them in R\&D. In that year it spent $\$ 10$ million, 3 percent of revenue, on $R \& D{ }^{127}$ It ships just over 3 percent of the world's IBMcompatible personal computers, while its share of the more powerful machines based on Intel's 386 microprocessor is around 6 percent ${ }^{128}$ Its clone of IBM's PS/2 30 model appeared in mid-1988, followed in early 1989 with two more products based on models at the $P S / 2$ range but with superior performance characteristics. For the latter especially, a reputation for product reliability is crucial for market success, because a malfunction in one unit can put a whole network of users out of action. Acer and Mitac, Taiwan's second main firm, took a license under IBM's personal computer patents on a running royalties basis. IBM also obtained a substantial up-front fee plus the right to license Acer and Mitac patents on the same basis.

ERSO continues to take a leading role in computers. For example, it has provided the domestic makers with an IBM compatible basic input-output system to strengthen their hand in warding off IBM lawsuits. Over the first half of the 1980s, it dedicated major research projects to some 20 information products, including a microcomputer local area network system, a dot-matrix printer, and a 32-bit microprocessor. With the Industrial Development Bureau, it identifies firms to commercialize the products once it has mastered the technology. In 1987, ERSO had a staff of 1,700 and a budget of just under $\$ 100$ million. ${ }^{129}$ 
In the software industry the state has a large presence through both ERSO and the publicly owned Information Industry Institute (III). The III has evolved into a profit-making public enterprise, taking up nearly every major software project in the public sector instead of channeling demand to the private sector. Its competence is signaled by agreements with top U.S. computer firms to help commercialize in-house products for the Asian market. Two examples are a Chinese input-output system developed by III and licensed to IBM, and a joint venture with Hewlett Packard to develop software for the Asian market. ${ }^{130}$ Much of the other commercialization sponsored by the institute has been undertaken by its own subsidiary.

In contrast to the automobile sector, Taiwan has a successful industrial policy in semiconductors and electronics that exploits its strength in low-cost engineering capabilities. ${ }^{131}$ Initially, the government led production, and used its facilities to train personnel and transfer technology. ERSO then entered into joint ventures with local and foreign partners to develop key segments of the industry, still using it facilities for internal technology transfer with the goal of close integration among the different industry components. More recently, ERSO has concentrated its efforts in new products and more basic research. The policy aim was to move the industry towards higher technology products and to reduce dependence on foreign sources for key components and raw materials.

\section{KOREA AND TAIWAN: SIMILARITIES AND DIFFERENCES}

Many of the similarities between Korean and Taiwanese industrial policies are striking, but the differences are also significant, showing that there is more than one viable approach to industrial promotion.

Korean and Taiwanese Government leaders share a presumption that the state should promote industrial development and national prosperity. Both countries have been committed to the development of a strong private sector and have used an array of policy tools, including protection and financial incentives, to promote that goal.

Both countries issue detailed plans and quantitative targets for investment and output for particular industries. Yet this East Asian planning style has tied itself closely to world markets; in this, it is fundamentally different from the import-substituting strategy pursued by most Latin American countries and India, or the centralized planning of the Eastern European countries. The two countries' emphasis on exports forces firms to operate in environments outside government control, and acts as a check on policy.

Korea and Taiwan see no inconsistency in making a commitment both to markets and to State assistance to industry. The State helps companies become more competitive internationally, not only by infrastructure investment and macroeconomic stability, but also by intervention at sectoral and even firm levels. One of the driving themes of this intervention has been to reduce the vulnerability of their industrial sectors to cut-offs from foreign, especially Japanese, suppliers. Recent efforts in semiconductors were motivated partly by this concern, as were earlier investments in industries such as steel and petrochemicals.

Finally, both governments share a commitment to long-term planning. This planning does not mean detailed quantitative targets for investment and output for particular industries. Rather, it means broad visions of the directions that economic growth ought to take and the specific industries that ought to be encouraged. It is striking that the current successes in semiconductors and computers, for example, are the fruits of government promotional programs begun in the early to mid-1970s.

Korea and Taiwan are also distinct from each other in important ways. The Korean Government encouraged the growth of large private business groups to spearhead Korean industrialization. Particularly in the late 1970s, during the heavy and chemical industry push, it guided their investments by means of subsidized credit through the stateowned banking system, controlling their access to foreign exchange, protecting the domestic market, and offering investment tax incentives. This system was cemented by a strong government " persuasion" and durable social ties between business and government leaders. As the business groups have become more central in the economy, the government has constructed elaborate consultative mechanisms through which policy formation occurs.

Korea discouraged direct foreign investment except in electronics. Most technology came through 
either licensing or more informal means of transfere.g., returning students. Public R\&D organizations contributed to the build-up of an indigenous R\&D capability, but over the 1980 s private fins, encouraged by the government, established their own R\&D facilities.

This pattern of industrial policy accounts for both strengths and weaknesses of Korea's industrial development strategy. The development of large national champions has made the country particularly strong in the development of large-scale and capital-intensive production; this is reflected in the country's success in autos and DRAMs. Korea's weaknesses have been in flexibility and design. The policy challenge for the future, therefore, will lie in building a more flexible industrial structure, probably through the promotion of small and mediumsized firms.

The Taiwanese Government, on the other hand, has not encouraged the growth of large business groups. It has relied on public enterprises, often allied with multinational companies, to undertake big pushes into new fields. The efficiency of these investments is due to the unique nature of the political system; in contrast to other developing countries, state-owned enterprises have not enjoyed easy or unlimited access to public finance. As the semiconductor case shows, public enterprises change the distribution of profit opportunities in the downstream sectors and induce new patterns of investment. Taiwan also relies on public $R \& D$ organizations, partly because of the inability of small firms to sustain their own R\&D.

Consultative mechanisms of the Korean type are lacking, however. Relations between the government and private firms are characterized by distance and even a certain degree of mutual suspicion, perhaps reflecting the ethnic split between mainlanders, who until recently have dominated top positions in the ruling KMT, and native Taiwanese. This distance was visible in the failed effort to center an auto strategy on a state-owned enterprise and the subsequent government liberalization of the domestic market; the contrast with Korea in this regard is striking.

The government has made it easy to start a business or enter a new industry and has been more welcoming of direct foreign investment than Korea. Foreign investment is, however, under export and/or domestic content requirements to check its domina- tion of the domestic market and increase its links to domestic industries. Arms-length incentives and the ease of doing business have encouraged a dynamic small and medium-sized industry sector, not only in light, labor-intensive manufacturing, but also in dynamic, high-technology segments; this can be seen in the semiconductor case.

This combination of strategy and structure explains Taiwan's pattern of competitiveness. Less able to rely on direct government support and protection than Korean fins, and unable to finance operations of similar scale, Taiwanese firms are more likely to adopt a niche strategy, relying on indigenous design capability and flexibility to enter more specialized product lines. This shows in both the development of the custom and semi-custom end of the semiconductor market and in the rapid development of the automobile parts industry.

The differences in strategy between Korea and Taiwan also reflect the difference in industry structure. A strategy of targeting resources at a few large firms could be viable, although we have seen that this strategy also had some important costs. With Taiwan's many small and medium-sized firms, its strategy of creating opportunities for downstream entry through publicly owned upstream industries seems appropriate.

Differences in industry structure were partly the result of government policy. Taiwan's political leaders and senior officials were steeped in an official ideology that had strong socialist components. The native Taiwanese, who had been ruled by the Japanese for 50 years up to 1945 , were in a four to one majority and played a large role in the development of the private sector; they regarded the KMT Government as something of an alien force. Hence both sides, government and business, tended to view each other with suspicion. In Korea, by contrast, technocrats and political leaders shared a strong nationalism. Indeed, the sense of wounded pride induced by Korea's 45 years of Japanese rule in a previously unified kingdom with unchanged boundaries for 1,000 years helped to foster the notion of the South Korean people as a single team against the rest of the world. The perception of an underlying fusion of interests helped sustain a relatively well-developed policy network between the economic bureaucracy and private companies. Through these relations of reciprocity, the business groups emerged as Korea's national champions. 
Korea's strategy is much closer to the Japanese than is the Taiwanese. Korea's chaebol were built with the Japanese keiretsu as the prototype, although the chaebol were barred from owning banks. Korea's industrial structure resembles Japan's more than does Taiwan's. The government's instruments of industrial steerage were similar too, particularly the use of selective credit, protection, foreign direct investment controls, and export promotion. But Japan relied on public ownership less than Korea.

Industrial policy in the two countries now faces two major challenges. The first is political liberalization. In the past, strategy in both countries has been formulated with little input from interest groups other than business, and in Taiwan, even business input was limited. Democratization will now open up new channels for a host of other actors, including labor and the legislature. This will put new pressure on the coherence of industrial policy initiatives.

The second challenge is economic liberalization. In response to past failures, external pressures, and the need to be closely integrated with rapidly changing technology markets, both countries have begun to open their markets to foreign competition and reduced the government's directive role. As we have argued, however, this is not likely to mean a repositioning of the government's role rather than its demise, with greater attention focused on technology policy and collaborative ventures with the private sector.

1 U.S. Department of Commerce, International Trade Administration, Office of Trade and Investment Analysis, U.S. Foreign Trade Highlights, July 1989, table V1OB, pp. 126-128.

2 World Bank, World Development Report 1988 (New York, NY: Oxford University Press, 1988); Council for Economic Planning and Development, Taiwan Statistical Data Book 1987 (Taipei, Taiwan: Executive Yuan, 1987); United Nations Statistical Office, Department of Economic Affairs, Commodity Trade Statistics (New York, NY: United Nations, 1987); U.S. Department of Commerce, International Trade Administration ibid.

3 See World Bank, World Development Report 1990 (New York, NY: Oxford University Press, 1990), table 1, pp. 178-179.

4 Figures are for 1986, from World Bank, World Development Report 1988 (New York, NY: Oxford University Press, 1988); Council for Economicalarming and Development, op. cit. Japan's share of world gross domestic product (GDP) is for 1985, from The World in Figures (London: Hodder and Stoughton, 1987).

5 See, for example, Anne Krueger, The Development of the Foreign Sector and Aid (Cambridge, MA: Harvard University Press, 1979) and the contributions to World Development vol. 16, No. 1, 1988, a special issue on Korea.

6 See Alice Amsden, Asia's Next Giant (New York, NY: Cambridge University Press,1989).

7 The most coherent statements of the case for selective industrial policies are Howard Pack and Larry E. Westphal, "Industrial Strategy and Technological Change: Theory vs. Reality," Journal of Development Economics vol. 22, 1986, pp. 87-128; Larry Westphal, "Industrial Policy in an Export-Propelled Economy: Lessons from South Korea's Experience," Journal of Economic Perspectives vol. 4, No. 3, summer 1990, pp. 41-59.

8 See Paul Krugman, "Targeted Industrial Policies: Theory and Evidence,' in Industrial Change and Public Policy (Kansas City: Federal Reserve Bank of Kansas City, 1983).

9 Forareviewofthe debate onJapaneseindustrial policy, see Greg Noble, "The Japanese Industrial Policy Debate," in Stephan Haggard and Chung-in Moon, Pacific Dynamics: The International Politics of Industrial Change (Boulder, CO: Westview Press, 1989).

10 See Stephan Haggard, Pathways from the Periphery: The Politics of Growth in the Newly Industrializing Countries (Ithaca, NY: Cornell University Press, 1990).

11 Technology intensity is based on the ratio of applied R\&D expenditures as a share of shipments, as calculated by C. Michael Aho and Howard F. Rosen using data from the mid 1970s. This ratio ranged from 0.22 for special textile fabrics and related products to 13.4 for telecommunications apparatus, with an average of 2.19. We divided the industries into three categories. High-technology products are those that are above the sample average. Intermediate-technology products have ratios from 1 to 2; low-technology products have ratios below 1. For a full discussion of the methodology, see Aho and Rosen, Department of Labor, Bureau of International Labor Affairs, Trends in TechnologyIntensive Trade, Economic Discussion Paper 9, October 1980.

12 See H. Don, B. H. Gunasekera, "Intraindustry Specialization in Production and Trade in Newly Industrializing Countries: A Conceptual Framework and Some Empirical Evidence from East Asia,"World Development vol. 17, no. 8, 1989, pp. 1279-1287.

13 Shujiro Urata, "The Rapid Globalisation of Japanese Firms in the 1980s: An Analysis of Activities of Japanese Firms in Asia," paper prepared for OECD Meeting of Experts on Globalisation andRegionalisation of the World Economy, June 20-21, 1990. The following data on the export behavior of Japanese firms is also from Urata.

14 Jonathan Moore, "The Upstart Taipans," Far Eastern Economic ReviewVol. 148, No. 16, Apr. 19, 1990, p. 84.

15 Danny Leipziger, Korea: Managing the Industrial Transition, vol. 1 (Washington DC: World Bank, 1986), p. 106.

16 The major study of Korea's recent exchange rate policy is Bela Balassa and John Williamson Adjusting to Success: Balance of Payments Policy in the East Asian NICs, 2d ed. (Washington DC: Institute for International Economics, April 1990).

17 Bank of Korea, "Balance of Payments, Foreign Trade and Foreign Exchange," Economic Statistics Yearbook 1987 (Seoul, Korea: Bank of Korea, 1987); and Bank of Korea, "Summary of Exports and Imports," Economic Statitistics Yearbook1982 (See@ Korea: Bank of Korea, 1982).

18 Leipziger, op. cit., vol. 1, op. cit.

19 Richard Luedde-Neurath, Import Controls andExport On"ented Development: A Reassessment of the South Korean Case (Boulder, CO: Westview Press, 1986).

20 The following data is reported in "Trade Liberalization" chapter three in Leipziger, op. cit., vol. 1. See also Luedde-Neurath, ibid.; Robert Wade, "The Rise of East Asian Trading Nations-How They Managed Their Trade" (mimeo, World Bank Trade Policy Division, Country Economics Department, 1988); and Robert Wade, Governing the Market: EconomicTheory and the Role of Government in East Asian Industrialization (Lawrenceville, NJ: Princeton University Press, 1990).

21 The low estimate comes from Larry Westphal and K. S. Kim, "Industrial Policy and Development," World Bank Staff Working Paper No. 263 (Washington DC: World Bank, 1977). The high estimate comes from K. S. Kim, "Long-term Variation of Nominal and Effective 
Rates of Protection" (Seoul: Korea Development Institute, 1982). On the question of possiblecalculational bias, see Robert Wade, Governing the Market, ibid., Chapter Ten.

22 Young Soogil, "Trade Policy Reform in Korea: Background and Prospect," mimeo (Seoul Korea Development Institute, 1984).

23 Young Soogil and Yoo Jungho, "The Basic Role of Industrial Policy and a Reform Proposal for the Protection Regime in Korea," (Seoul: Korea Development Institute, 1982).

24 See Balassa and Williamson, op. cit., p. 46.

25 Office of the United States Trade Representative, National Trade Estimate Report on Foreign Trade Barriers (Washington DC: Office of the U. S.T.R., 1989), p. 115; and ibid., 1986, p. 165.

26 Leipziger, op. cit., vol. 1, p. 65.

27 Ibid., p. 65.

28 See Luedde-Neurath, op. cit.

29 Since 1975 the tariff has had to be paid and then claimed back against evidence of quantities used for exports.

30 See Luedde-Neurath, and Yung Whee Rhee, " A Framework for Export Policy and Administration: The East Asian Experience," World Bank Industry and Finance Series No. 10 (Washington DC: World Bank, no date).

31 Leroy Jones and 11 SaKong, Government, Business, and Entrepreneurship in Economic Development: The Korean Case (Cambridge, MA: Harvard University Press for Harvard University Council on East Asian Studies, 1980); David C. Cole and Yung Chul Park, FinancialDevelopment in Korea, 1945-1978 (Cambridge, MA: Harvard University Press for Harvard University Council on East Asian Studies, 1983).

32 Leipziger, vol. 1, p. 75.

cit.

33 Robert Wade, “The Rise of East Asian Trading Nations,” op.

34 Yung Whee Rhee, Bruce Ross-Larson, and Garry Pursell, Korea's Competitive Edge: Managing the Entry into World Markets (Baltimore, MD: Johns Hopkins University Press for the World Bank, 1984), table B-8.

35 Ibid., p. 16.

36 Jones and SaKong, op. cit.; R. Wade, Irrigation and Agricultural Policies in South Korea (Boulder, CO: Westview Press, 1982), pp. $86-88,112$.

37 Phone interview with Hee-Boum Lee, Korean Science Attache, Aug. 2, 1989.

38 Jones and SaKong, op. cit.

39 Tibor Scitovsky gives the high estimate in" Economic Development in Taiwan andSouth Korea," Food Research Institute Studies vol. 19, No. 3,1985, p. 253; Korea Exchange Bank, Monthly Review vol. 16, No. 7, July 1982, gives "miscellaneous" loans (which include curb market loans) as 17 percent in 1979, 23 percent in 1980, and 8 percent in 1981. See also Cole and Park, op. cit., chapter 4; and Robert Wade, "East Asian Financial Systems as a Challenge to Economics: Lessons from Taiwan," California Management Review, vol. 27, No. 4, summer 1985, pp. 106-127.

40 Scitovsky, ibid. The Korean figure is probably biased upwards by inflation and by certain features of the rules of accounting for depreciation. One estimate of the "real" Korean figure puts it at more like 160 to 180. See World Bank, Korea's Development in a Global Context (Washington, DC: World Bank, 1984), p. 238, note 8.

41 Thomas G. Parry, "The Role of Foreign Capital in East Asian Industrialization, Growth and Development" in Helen Hughes (ed.), Achieving Industrialization in East Asia (New York, NY: Cambridge University Press, 1988). Parry shows that capital flow information is statistically weak, with different statistical organizations such as the OECD and the IMF giving very different figures for the same variable.
42 Luedde-Neurath, op. cit.

43 Korean Embassy, Financial Attache, from Ministry of Finance announcement.

44 Ministry of Science and Technology, Annual Statistics on Science and Technology, Republic of Korea (Seoul: Ministry of Science and Technology, 1986).

45 R.M. Gadbow and T. Richards (eds.), Intellectual Property Rights: Global Consensus, Global Competition (Boulder, CO: Westview Press, 1988), p. 298; Far Eastern Economic Review, "Patent drugs abuse," Far Eastern Economic Review, vol. 140, No. 25, June 30, 1988, pp. 48-49. The U.S. Trade Representative announced the formation of a task force to look into Korea's patent system, explaining, "I am concerned that there is a lack of patent enforcement in Korea," International Trade Reporter, June 15, 1988, p. 883.

46 Ministry of Science and Technology, 'Umg-term Science and Technology Forecast for the Year 2000,' in Korean (Seoul: Ministry of Science and Technology, 1986).

47 Yong-chanPark, "TheNationalSystem of Innovation in Korea, with an Introduction to the Semiconductor Industry," (University of Sussex, MSC thesis, 1987).

48 Phone interview with Hee-Boum Lee, Science Attache Korean Embassy, interview with OTA staff, Aug. 2, 1989.

49 UNESCO, Statistical Yearbook (Paris: 1988), pp. 3-325. See also Ministry of Education, Statistical Yearbook of Education (Seoul: 1985).

50 Ministry of Science and Technology, Introduction to Science and Technology (Seoul: 1986).

51 Yung-chan Park, op. cit.

52 Ministry of Science and Technology, Annual Statistics on Science and Technology, op. cit.

53 Ministry of Science and Technology, Introduction to Science and Technology, op. cit.

54 Ibid.

55 Korea Industrial Research Institute, Industrial Technology White Paper, 1986, in Korean, cited in Yong-chan Park, "The National System of Innovation," op. cit.

56 Leipziger, op. cit., vol. 2, pp. 33-36.

57 Lee Byung-Jong, 'HomewardBound,' 'BusinessKorea,F ebruary 1989, p. 34.

58 Mark Clifford, "The Engine Is Straining," Far Eastern Economic Review, Jan. 18, 1990, p. 35.

59 Ibid., p. 36.

60 Nam Choong Woo, director of the Korean Ministry of Trade and Industry's transportation-machinery division claimed that though the official rate is 90 percent localization, the real rate is closer to 50 percent. The gap is ascribed to skew in the measurement of localization success. Mark Clifford, “The Engine Is Straining,” op. cit., p. 38.

61 Chu Yun-han, "Authoritarian Regimes Under Stress: The Political Economy of Adjustment in the East Asian NICS,' (University of Minnesota, PhD. thesis, 1987), p. 205.

62 Automotive News, Feb. 22, 1988.

63 Mark Clifford, "Local Anesthetic," Far Eastern Economic Review, vol. 45, No, 33, Aug. 17, 1989, p. 63.

64 “'Ssang Yong Motors Takes on (Korea's) Big Three,"Business Asia, Sept. 18, 1989, p. 308.

65 Ibid., p. 309.

66 Sohn Jie-Ae, "Letting It All Ride on the Automobile," Business Korea, July 1990, pp. 25-27; Clifford, "The Engine Is Straining," op. cit., p. 36.

67 Clifford, “The Engine Is Straining," op. cit., p. 35. 
68 Clifford, "The Engine Is Straining," op. cit.

69 Sohn Jie-Ae, op. cit., p. 28.

70 "Ssang Yong Motors Takes On (Korea's) Big Three," op. cit. p. 309.

71 Sohn Jie-Ae, op. cit., p. 28.

72 Clifford, "Local Anesthetic," op. cit., p. 63.

73 Ron McMiltan, “Still Stuck in Neutral.. .," Asian Business, July 1988, pp. 59-60.

74 Therefore, it is not clear that the plan was not rejected simply to preserve the economic rents gained by KAMA members from restricted entry. Gregory Noble (in a 1988 Harvard dissertation "Between Competition and Cooperation: Collective Action in the Industrial Policy of Japan and Taiwan,") has shown how dominant producers in Japan's steel minimill industry were able to persuade government to shutdown (unsuccessfully, as it turned out) "maverick" mills.

75 "South Korea Rejects Samsung 's Plan To Make Large Trucks with Nissan," Asian Wall Street Journal, Aug. 17-18, 1990, p. 3.

76 Electronics Industries Association of Korea, Electronic Industry of Korea 1989, table 2B.

77 For an overview of the industry, see Byung-Moon Byun and Byung-Hun Ahn, "Growth of the Korean Semiconductor Industry and Its Competitive Strategy in the World Market,' Technovation September 1989, pp. 635-656; Yong-chan Park, op. cit.

78 See Leipziger, op. cit., vol. 2; and Selected Topics and Case Studies (Washington, DC: The World Bank, 1987), pp. 202 ff.

79 Chu Yun-han, op. cit.

80 Anthony Rowley, "The Birth of a Multi-National," Far Eastern Economic Review, vol. 120, No. 14, Apr. 7, 1983, p. 56.

81 For details of this arrangement, see Leipziger, op. cit., vol. 2, pp. 203-204.

82 Chu, op. cit.

83 Fora corporate profile, see Electronic Business June 25, 1990, pp. 34-38.

84 Andrew Tanzer, "Korea Chips Away," Forbes, vol. 135, Feb. 25, 1985, p. 44.

85 Electronics Weekly, "Korea Hot on Tails of Leaders in Chip Race", June 1, 1988, p. 3.

86 Samsung Semiconductor and Telecommunication, Retrospect for the Last Ten Years of Samsung Semiconductors and Telecommunication, in Korean, 1987.

87 Electronic Business Feb. 6, 1990, pp. 25-32.

88 For corporate pro files, see Far Eastern Economic Review, Nov. 19,1987, pp. 80-82; Electronic Business Aug. 20,1990, pp. 67-9. On the tie-up with Hitachi, see "Thanks for the Memories," Far Eastern Economic Review, vol. 145 No. 34, Aug. 24, 1989, pp. 50-51.

89 Ministry of Science and Technology, Annual Statistics on Science and Technology, 1986.

90 Byun and Ahn, op. cit., p. 647.

91 For overviews of Taiwan's industrial policy, see Robert Wade, Governing the Market, op. cit.; Thomas Gold, The Taiwan Miracle (Armonk, NY: M.E.Sharpe, 1987); Walter Galenson, ed. Economic Growth and Structural Change in Taiwan (Ithaca, NY: Cornell University Press, 1979).

92 Council for Economic Planning and Development, Taiwan Statistical Data Book 1988 (Taipei, Taiwan: Executive Yuan, 1988).

93 R. Myers, 1986, "The economic development of the Republic of China on Taiwan, 1965-1981", in L. Lau, op. cit.

94 Directorate-General of Budget, Accounting and Statistics (DGBAS), Republic of China, Fourth and Sixth Censuses of Commerce and Industry.

95 Chi Schive, The Foreign Factor: The Multinational Corporation's Contribution to the Economic Modernization of the Republic of China (Stanford, CA: Hoover Institution Press, 1990).

96 Taiwan Statistical Data Book 1986, op. cit., table 8-6. Total tax revenue includes revenue from the wine and tobacco monopoly.

$97 \mathrm{Tu}, \mathrm{C}$. H. and Wang, W. T., "Trade Liberalfźzation in the Republic of China on Taiwan, and the Economic Effects of Tariff Reductions", paper to the Joint Conference on the Industrial Policies of the ROC and the ROK, (Seoul: Korea Development Institute, 1988).

98 S. C. Tsiang and Wen Lang Chen, "Developments towards Trade Liberalization in Taiwan," paper to the 1984 Joint Conference on the Industrial Policies of the ROC and the ROK (Taipei: Chung-hua Institute for Economic Research, 1985).

99 Board of Foreign Trade, "Tariff Reduction of the Republic of China on Taiwan'", (Taipei: Ministry of Economic Affairs, 1988); Balassa and Williamson, Adjusting to Success, op. cit., p. 83.

100 Of the 15 commercial banks, 4 are private. But the biggest (International Commercial Bank of China) is only nominally private, having been privatized in the wake of UN derecognition to allow Taiwan to have a bank with overseas branches while avoiding the diplomatic problems of government-owned banks. The other three private banks are tiny.

101 Ching-ing Hou Liang and Michael T. Skully, "Financial Institutions and Markets in Taiwan," in Michael T. Skully, cd., Financial Institutions and Markets in the Far East (New York, NY: St. Martin's Press, 1982), p. 174.

102 Sam P. S. Ho, "Small-scale Enterprises in Korea and Taiwan," World Bank StaffWorking Paper \#384, (Washington, DC: World Bank, 1980). The image of a street market is misleading, for most curb market credit takes the form of supplier's credits from big firms to small firms.

103 Nicholas Riegg, "TheRole of Fiscal and Monetary Policies in Taiwan's Economic Development" PhD thesis, University of Connecticut, 1978; also Taiwan's Bank of Communications, Annual Report, various years. Riegg, citing a Bank of Taiwan source, says that "up to 75 percent of loans flowed to the targeted industries" (1978:95). The Bank of Communications reporta comment proudly on the bank's success in financing its designated target industries. The 1973report, to take just one example, gives figures to show that over haJf of the bank's total loans went to its six target industries.

104 In 1988, for example, Formosa Plastics undertook a \$150 million expansion at one of its four U.S. petrochemical plants.

105 It began to do so quite early. In 1959, at a time when 76 percent of Taiwan's exports were still agricultural or processed agricultural products (mostly rice and sugar), the government promulgated the "National Guidelines for Long Range Scientific Development" and formed the "Council on Long Range Scientific Development", since renamed the National Science Council.

106 Phone interview with George Liu, North American Coordination Council Science Attache, June 30, 1989.

107 Jennie Hay Woo, "Education and Industrial Growth in Taiwan: A Case of Planning," Harvard Institute of International Development EEPA Discussion Paper \#18, 1988.

108 Specifically, theproportion of tertiary students in engineering expanded from 24.6 percent in $1955-56$ to 30.3 percent in 1975-76 to 32.8 percent in 1985-86. Natural sciences and medicine rose from 10.1 percent in 1955-56 to 14.6 percent in 1985-86. So as of 1985-86, a little less than half of Taiwan's tertiary students were studying engineering, natural sciences or medicine. Humaní'ties and fine arts fell from 15.8 percent in 1955-56 to 9.1 percent in $1985-86$. Lawfell from 6.8 percent to 1.2 percent.

109 Ministry of Science and Technology, Science and Technology Annual, 1984, p. 227. 
110 National Youth Commis sion position, cited in Woo, "Education and Industrial Growth in Taiwan," op. cit., table 8.

111 Taiwan has a reputation as a producer of pirated products. During the 1980s, however, the government committed itself to increase the level of intellectual property protection. Since 1985, the government has overhauled its intellectual property laws, creating strong domestic pressure for retrenchment. Partly as a consequence, implementation of the new laws has been lax, and pirating activity continues. There is, however, a trend towards tighter enforcement. R.M. Gadbaw and T. Richards (eds.), 1988, Intellectual Property Rights: Global Consensus, Global Conflict? (Boulder, CO: Westview Press), ch. 10.

112 For an overview, see Walter Arnold, "Bureaucratic Politics, State Capacity, and Taiwan's Automobile Industrial Policy," Modern China vol. 15, No. 2, April 1989, pp. 178-214, from which this section draws extensively.

113 Council for Economic Planning and Development, Taiwan Statistical Data Book 1989 (Taipei, Taiwan: Executive Yuan, 1989), p. 94.

114 A 1971 report on the state of the industry characterized technology transferred from several Japanese companies and General Motors as "inadequate," and proposed a more purposeful importsubstitution role for policy. The government's response was a higher auto import tariff and a superficial package of fiscal measures aimed at stimulating domestic demand. Walter Arnold, "Bureaucratic Politics, State Capacity, and Taiwan's Automobile Industrial Policy," Modern China vol. 15, No., April 1989, pp. 185-186.

115 "Taiwan's Auto Industry Faces Hard Times Amid Booming Sales," Business Asia, Jan. 30, 1989, p. 35.

116 "Foreign Automakers Capitalize on Taiwan's Relaxed Import Code," Business Asia, Sept. 11, 1989, p. 300.

117 Ministry of Economic Affairs, Taiwan Board of Foreign Trade, Foreign Trade Development of the Republic of China, 1989, p. 2.

118 "Country report: Taiwan," AEU: Journal of the Asia Electronics Union, April and May 1986.

119 Foranoverviewof tbeindustry, see Se-Hwa Wu, "TheCourse of Taiwan's Integrated Circuit Industry Development" paper presented at the conference on Taiwan Enterprises in Global Perspective, Columbia University, New York, NY, Sept. 15, 1990.

120 Far Eastern Economic Review Aug. 2, 1990, p. 54.

121 Electronic Business, Jan. 15, 1988, pp. 85-7.

122 Electronic Business, Sept. 4, 1989, p. 79.

123 Bob Johnstone, "Chipping In: Taiwan Computer Firm in Tie-up witb US Chipmaker,' Far Eastern Economic Review, May 25, 1989 , p. 82. No information is given on help tbat Acer may have gotten from the Taiwan Government.

124 Electronics Research and Service Organization\% "ROC and ROK Comparative Development of the Information Industry" (Taipei, Taiwan: Electronics Research and Service Organization 1987).

125 Note that these exports are quite import intensive; imports of inputs for personal computer components account for as much as half of the value of component exports. Chi Schive, forthcoming, "The next stage of industrialization in Taiwan and Korea," in G. Gereffi and D. Wyman, Manufactured Miracles: Patterns of Industrialization in Latin America and East Asia (Lawrenceville, NJ: Princeton University Press).

126 K. T. Li, “'Technology Development and Cooperation among NICS in the Western Paci.tic,” industry of Free China, vol. 68, No. 3, September 1987, pp. 1-12.

127 IBM official, personal communication, July 1989.

128 Johnstone, “Chipping In," op. cit., p. 82.

129 Science and Technology Advisory Group, personal communication. Eighteen percent of the staff were engaged in administrative support.

130 Chu Yun-han, "AuthontarianRegimesu nderStress," op. cit., p. 2,27 .

131 In addition to the efforts of the public research and service organizations described above, other forms of state assistance are available to makers of electronics products. Tax incentives, loans on concessionary terms, and other privileges have been targeted on electronics; protection, however, has not. 
Chapter 8

\section{Government Support of the Large Commercial Aircraft Industries of Japan, Europe, and the United States}




\section{CONTENTS}

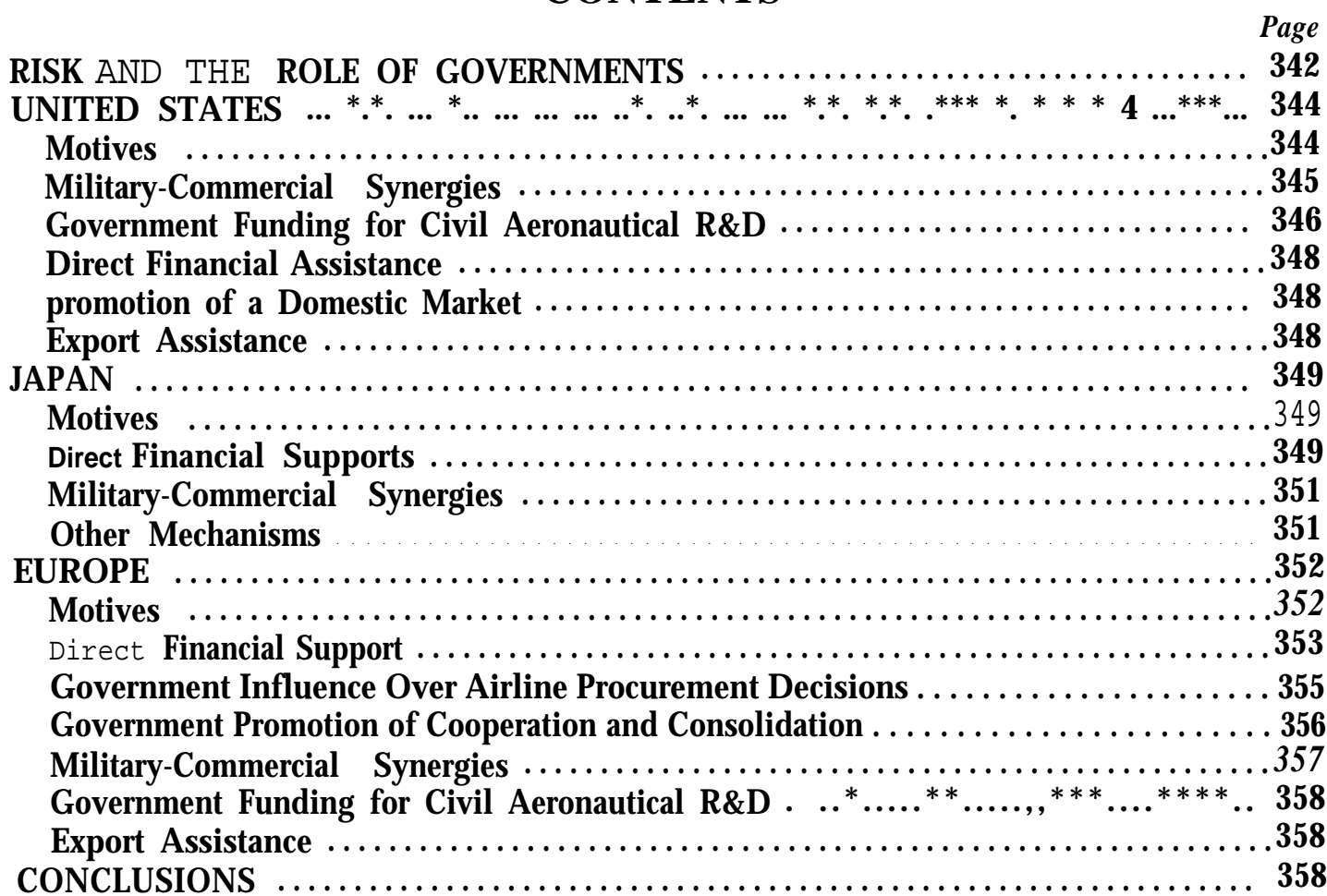

Box

Box

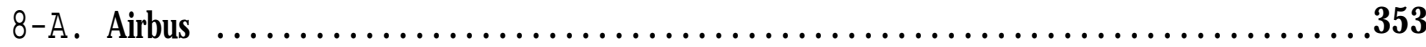

Figures

Figure $\quad$ Page

8-1. Cumulative Cash Flow for an Aircraft Project ....................... 344

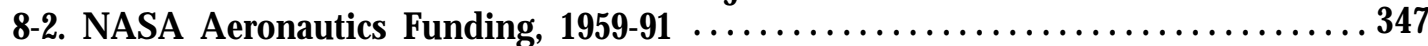

8-3. World Market Share, 1970-92 Large Commercial Transport Airplane

by Value of Deliveries ................................... 352

8-4. Aircraft Inventories by Nationality of Airlines and Aircraft Manufacture, 1989 . . 356

\section{Tables}

Table

8-1. Benefits to Commercial Aircraft and Component Manufacturers of Various

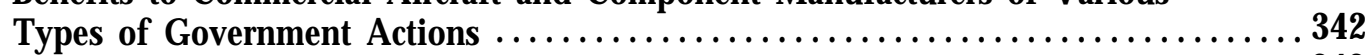

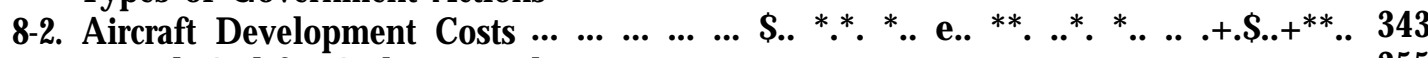

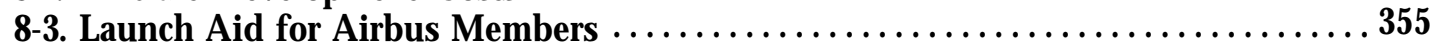

8-4. Government Ownership of Major European Airlines $\ldots \ldots \ldots \ldots \ldots \ldots \ldots \ldots \ldots \ldots \ldots$

8-5. Revenues From Military Aircraft and Related Sales, $1989 \ldots \ldots \ldots \ldots \ldots \ldots \ldots . \ldots . \ldots 37$ 


\section{Government Support of the Large Commercial Aircraft Industries of Japan, Europe, and the United States ${ }^{1}$}

The commercial aircraft industry is often characterized by superlatives. It has the largest trade surplus of any U.S. industry. There are fewer large firms dominating the world market than in perhaps any other industry. It is marked by larger economies of scale than most other industries. In every country that has a domestic commercial aircraft assembler, the hand of government is prominent in the industry's behavior and performance. Because of the industry's distinctive characteristics, it pays to be cautious in drawing broader lessons about the efficacy of government involvement in the industry's competitiveness.

Even with an appropriate dose of caution, however, some conclusions about the nature. of government/business relationships in the commercial aircraft industry sound familiar. The United States has influenced the commercial aircraft industry primarily through spinoffs from other programs, rather than directly or with the intent of improving competitiveness. Four European nations (France, Germany, Great Britain, and Spain) have played a much more decisive role in boosting the competitiveness of their aircraft consortium, Airbus Industrie. The amount and kind of support extended to Airbus from these governments has been far more effective in improving its competitiveness than the military spinoffs and basic research programs of NASA in the United States. While Japanese industrial policy has failed to produce a domestic assembler of large commercial aircraft, Japan, like Europe, has expended a great deal of money and effort aimed directly at improving competitiveness in the aircraft industry. Japanese firms have become world-class subsystems makers. In short, both Japan and Europe have directly aimed public policies and supports at competitiveness, and have gotten results. In comparison, American companies have gotten much less consistent or effective boosts from policies that were directed toward other goals.

Several advanced countries and even some developing nations have decided that the capacity to build commercial aircraft is important to their national self-interest. The preamble to the General Agree- ment on Tariffs and Trade (GATT) Agreement on Trade in Civil Aircraft acknowledges this, stating that countries have made that pact recognizing that the aircraft sector is viewed as a particularly important component of economic and industrial policy. ${ }^{3}$ The principal reasons are the industry's links to national security, the generation of technologies that may spill over to other industries, the contributions of aircraft exports to a positive balance of payments, the creation of well paying jobs, and national pride.

Government supports for the commercial aircraft industry have taken various forms: ${ }^{4}$ synergies between military and commercial work, funding of civil $R \& D$, direct financial supports for specific commercial projects, encouragement of the growth of domestic demand and efforts to steer it toward domestic suppliers, export assistance, and efforts to organize industry so it is well suited to international competition. The most important effects in the United States have come from the National Aeronautics and Space Administration (NASA) and Department of Defense (DoD) programs. While promoting competitiveness has been a goal of NASA's aeronautics program, other benefits include the side effects of actions taken for reasons unrelated to competitiveness. As a result, the benefits have consistently been smaller than if promotion of international competitiveness had been a major policy objective. In particular, the indirect benefits U.S. companies received from DoD programs were substantial in the past, but have declined as military and civil technologies have diverged and the air transport industry has matured. In contrast, the direct financial supports used heavily in Europe and Japan have been provided specifically for the purpose of improving competitiveness. While they have been costly, they have also been effective and appear likely to continue.

Table 8-1 assesses the relative importance of each of the major types of support to the success of commercial aircraft manufacturers in Europe, Japan, and the United States. 
Table 8-I-Benefits to Commercial Aircraft and Component Manufacturers of Various Types of Government Actions ${ }^{\mathrm{a}}$

\begin{tabular}{|c|c|c|}
\hline Us. & Japan & Europe \\
\hline 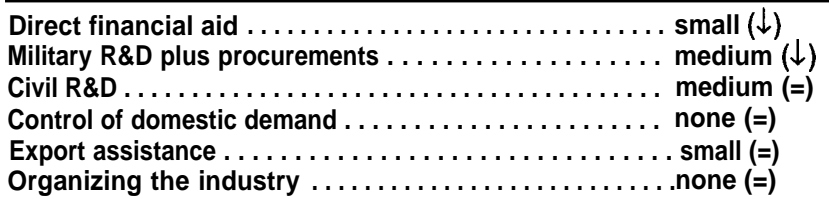 & $\begin{array}{l}\text { large }(=) \\
\text { small }(\uparrow) \\
\text { small }(=) \\
\text { small }(=) \\
\text { none }(=) \\
\text { small }(=)\end{array}$ & $\begin{array}{l}\text { very large }(=) \\
\text { medium }(\downarrow) \\
\text { small }(=) \\
\text { medium }(\downarrow) \\
\text { small }(=) \\
\text { medium }(=)\end{array}$ \\
\hline
\end{tabular}

Legend: $(\uparrow)=$ increasing in importance

$(-)=$ remaining at about the same level of importance

$(\downarrow)=$ decreasing in importance

aThistablecompares total benefits, notefficiency. That fact that two categories getthesame rating does not mean that thecosts of providing those supports are necessarily equal. Also, some types of government actions affect some parts of the industry more than others-e. g., military/civil synergies are greater for engine makers than airframes. This table represents a rough average for the whole industry.

SOURCE: Office of Technology Assessment, 1991.

\section{RISK AND THE ROLE OF GOVERNMENTS}

The principal way these supports benefit manufacturers is by reducing risk. Risk in the commercial aircraft business is higher than in most others. Both technological and market uncertainties are great, and the costs of launching a new model are enormous. This combination of uncertainties and high costs adds up to big risks. Bringing out a new airplane can mean betting the company-and more than one company has lost the bet. Government support can reduce these risks to a point where the relation between risks and expected rewards is favorable and a company can proceed to launch a new model or adopt a new technology. ${ }^{5}$

The use of state-of-the-art systems in each new generation of aircraft confronts manufacturers with significant technological risks. A project may be years and billions of dollars into its development before a technical obstacle is discovered that delays or stops the effort. Rolls Royce's effort to make all-composite fan blades for the Lockheed L-1011 engine failed, causing delay in the plane's introduction and ultimately the bankruptcy of both companies. Boeing's 747 got heavier and heavier throughout the development process, requiring more and more powerful engines and driving up costs. Pan Am, the 747's launch customer, Pratt \& Whitney, the engine makers, and Boeing were all nearly bankrupted by the effort. Even when technological uncertainty does not threaten the launch of a model, it affects the manufacturer's decision about whether to adopt advanced subsystems and components. The opportunity to develop and prove advanced technol- ogy at the expense of the government, in either military or civil $R \& D$ projects, can help give companies enough confidence in the cost and performance of the new systems to just@ incorporating them into products.

More than technological failure, failure in the market has been the source of disasters in the aircraft business. As a rule, an aircraft manufacturer needs to sell at least 500 units of a model for it to break even. Of the 26 basic airplane types introduced worldwide since the beginning of the jet age, only 6 have sold as many as 500 (another 4 are likely to do so before their production runs end). Seven sold less than 120 copies. Only four or five have been profitable. ${ }^{6} \mathrm{~A}$ report by First Boston Corp. concludes that in 1984, the jet transport aircraft programs then launched had accumulated total losses of $\$ 40$ billion on total sales of $\$ 180$ billion (in 1984 dollars). "The essential message [of these figures] is that economic failure is the norm in the civil aircraft business. '

Considering this record, no one in this business commits to building anew design before assembling a number of launch customers. These early orders not only assure the manufacturer that it will sell at least that many units, they are needed to convince the manufacturer's financial backers that the model has sufficient appeal to airlines to justify committing funds. Government influence over airlines' choice of which aircraft to buy when a launch is pending can directly affect the manufacturer's decision, as can large government orders of military aircraft that are similar or identical to commercial models. Governments naturally favor domestic suppliers for their military needs, but in the commercial business, airlines' purchase decisions frequently turn on 
narrow differences in performance and price among competing airplanes. A nudge from the airline's government--e.g., to choose a domestic company or one that buys some parts or subsystems from domestic companies--can be decisive.

In addition to technological and market uncertainties, financial risks are also high. Aircraft development costs have risen dramatically since the early days of air transport, as table 8-2 shows.

The $\$ 1.2$ billion development costs of the 747, spent between December 1965 and January 1969, were over 3 times the $\$ 372$ million capitalization of the Boeing company. The $\$ 1.1$ billion cost of developing the DC-10 was over 3 times greater than the \$364 million capitalization of the Douglas company. ${ }^{9}$ The combined launch costs of Boeing's 757 and 767 in the late 1970s again exceeded the net worth of the company. ${ }^{10}$ Coupled with these tall investment requirements are long lead times before the project reaches positive cash flow, and an even longer wait before the break-even point. Typically, it takes 4 to 5 years to develop, test, and certify a new aircraft, 2 years longer for the engines, and as much as $\mathbf{1 0}$ years from then to recover the initial investment-if that point is ever reached. "Figure 8-1 shows the cash flow of a typical aircraft program.

Unless they have government support, manufacturers finance these costs from four sources:

1. retained earnings,

2. issues of debt and equity,

3. progress payments from customers, and

4. cost-sharing with subcontractors and partners.

These sources may not be sufficient to enable a manufacturer to launch a new model, and in some instances, only if governments are willing to directly assume much of the financial risk can the project proceed. Governments can offer loan guarantees or credits with payback contingent on success; or they may pay outright some costs of developing new projects, either by providing funds at preferential rates or by contracting for development work.

Although government assistance to the large commercial aircraft industry is undeniably important overall, the effects of individual government supports vary greatly. Government support for R\&D may not advance a company's technological development. On the one hand, it may stimulate a company to increase its own funding for R\&D, or it may supplement the fro's own R\&D program. Alternatively, it may supplant R\&D the company would have done anyway. Financial assistance with the launch of new designs may enable firms to proceed with models that otherwise would never have made it past paper studies, but it may also remove market disciplines and encourage a firm to proceed without frost establishing that sufficient demand exists, leading to costly market failures. Government-provided financing to ease companies' cash flows during production may enable firms to increase production rates and improve market share, but it may diminish pressures for the firm to institute needed cost-controlling measures. The effectiveness of government support depends not only on the degree to which it is offered but also on the type given and the way in which it is delivered.

The following sections describe government policies related to the aircraft industries of the United States, Japan, and Europe, focusing on the motives, content, and results of government interactions with the industry.

Table 8-2-Aircraft Development Costs

\begin{tabular}{|c|c|c|c|c|}
\hline Aircraft & $\begin{array}{l}\text { Entered } \\
\text { service }\end{array}$ & $\begin{array}{l}\text { Development } \\
\text { cost in dollars } \\
\text { (millions) }\end{array}$ & $\begin{array}{l}\text { Development } \\
\text { cost in } 1991 \text { dollars } \\
\text { (millions) }\end{array}$ & $\begin{array}{c}\text { Development } \\
\text { cost per seat } \\
\text { in } 1991 \text { dollars } \\
\text { (millions) }\end{array}$ \\
\hline DC-3 $\ldots \ldots \ldots \ldots \ldots \ldots$ & 1936 & $\$ 0.3$ & 3 & 0.1 \\
\hline DC- $6 \ldots \ldots \ldots \ldots \ldots$ & 1947 & 14 & 90 & 1.7 \\
\hline DC- $8 \ldots \ldots \ldots \ldots \ldots$ & 1959 & 112 & 600 & 3.75 \\
\hline $747 \ldots \ldots \ldots \ldots \ldots \ldots$ & 1970 & 1,200 & 3,300 & 7.3 \\
\hline $777 \ldots \ldots \ldots \ldots \ldots \ldots$ & 1995' & 5,000 & $4,300 "$ & $14.0^{\prime}$ \\
\hline
\end{tabular}

Estimate.

SOURCE: U.S. Department of Defense, National Aeronautics and Space Administration, and Department of Transportation, R\&D Contributions to Aviation Progress (RADCAP) (Springfield, VA: National Technical Information Service, August, 1972), vol.II, app. 9, p. 21.1991 values are computed using aerospace industry price deflators for 19S5-19S9 and GNP deflators and estimates for other years. 
Figure 8-I-Cumulative Cash Flow for an Aircraft Project

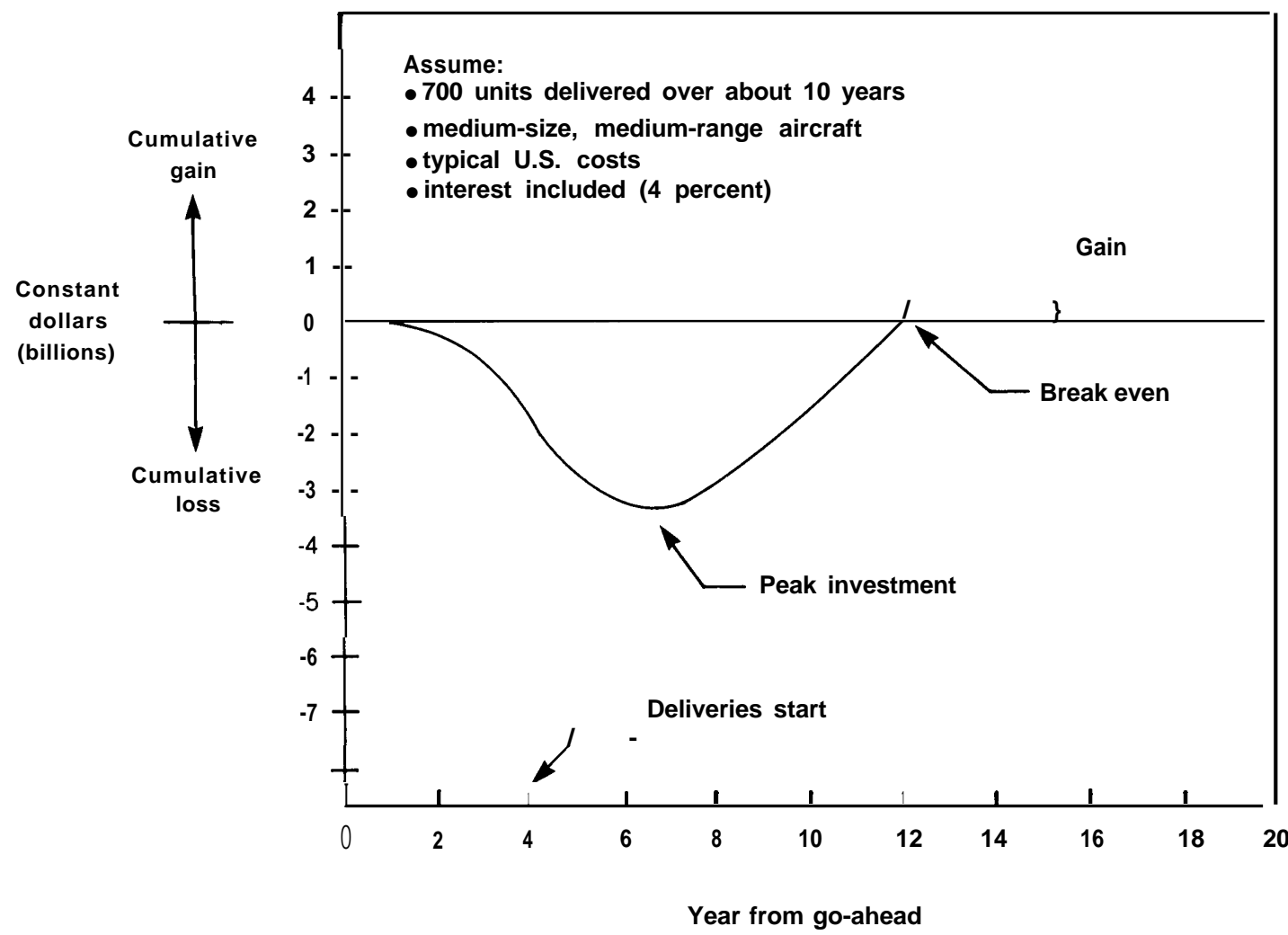

SOURCE: Boeing Commercial Airplane Co.

\section{UNITED STATES}

\section{Motives}

The U.S. Government today avoids helping any particular industry compete in world markets. However, the government does have policies related to national defense and trade, and takes actions that affect transportation and technology. The U.S. commercial aircraft industry has benefited from measures taken in these areas.

The greatest benefits for U.S. commercial aircraft manufacturers have been side effects of the government's commitment to building and maintaining a strong defense industrial and technology base. The use of advanced technology in national defense has generated both financial and technological benefits for companies that produce commercial as well as military aircraft. Several factors make the commercial aircraft industry of special interest to defense policymakers. Technological advances made for commercial aircraft show up in military hardware and concurrent production of commercial aircraft reduces military aircraft costs. The supplier base and work force skills needed for rapid military buildups are maintained by civil aircraft production, and the design teams needed for military projects are kept together by commercial work during periods of weak military demand. ${ }^{12}$ These benefits are likely to become even more important in the future as defense spending is scaled back and military hardware comes to rely more heavily on dual-use technologies. $^{13}$

Support for civil aeronautical R\&D is strong in the United States, compared with that for most other areas of the civilian economy .14 The traditional rationale for government support of NASA technology programs is that the resulting $R \& D$ compensates for the tendency of private firms to do less than the socially optimal levels of R\&D because they are unable to capture fully the returns of their investments. This is the standard economic justification for civil technology policies in general. ${ }^{15}$ Although NASA's official mission does not go father towards helping U.S. aircraft manufacturers compete, this 
alone does provide some competitiveness benefits to Us . firms.

The belief that air travel is important for U.S. transportation needs has led to measures such as airline regulation, subsidies for air mail, Federal and local subsidies for airports, safety monitoring, and the management of the air traffic environment. Though most of these measures were aimed primarily at air transportation, they fostered the early growth of a strong domestic market for commercial aircraft, which in turn benefited U.S. producers. ${ }^{16}$

As for trade policy, U.S. commitment to free trade served the country's aircraft manufacturers well for many years after World War II. During the war, the United States had become the world's greatest producer of aircraft and it emerged at war's end with the industry intact; this helped establish the industry's dominance. With the strong domestic market and continuing military-civil connections giving U.S. producers significant advantages, a liberal trade environment favored the American industry. The government also used its influence to discourage foreign support for competitors (though with limited success), maintained a tariff of 5 percent or more on aircraft imports until 1980, and provided export assistance to U.S. producers to compensate for perceived unfair practices. In the 1980s, while U.S. trade deficits reached record levels, commercial aircraft exports rose. Indeed, aircraft is the United States' largest exporting industry. The U.S. trade surplus in transport aircraft (not counting spare parts) from 1985 to 1989 (the latest year for which firm figures are available) was $\$ 35$ billion. Although sales of commercial transport aircraft represented less than 0.3 percent of U.S. gross national product (GNP) in 1989, they accounted for nearly 3.4percent of the dollar value of U.S. merchandise exports. ${ }^{17}$

Among this list of U.S. Government actions and policies, only NASA's support for civil aeronautical R\&D constitutes a deliberate effort to help the competitiveness of commercial aircraft builders. Benefits the industry has received in other areas, especially from the synergies between military and civil aircraft work, have been the results of government actions taken with goals other than competitiveness in mind.

\section{Military-Commercial Synergies}

The U.S. Government policy that has most affected the competitiveness of the commercial aircraft industry is procurement of military aircraft and funding of the related R\&D. Most important among the effects of military work are technological synergies. In a few cases, whole systems developed for the military have been spun off to commercial applications, reducing development costs and risks to the commercial users. In others, large military orders for products or technologies designed for commercial uses (or those closely related) have boosted production runs, and therefore lowered costs by allowing companies to achieve economies of scale, learn the production process, and share overhead costs. Military development programs have assumed the risks of proving advanced technologies, giving commercial users the confidence to adopt them. Often, the benefits accrue not so much to aircraft assemblers, but at the subsystem level, in materials, or in manufacturing process technology. Though synergies appear to be declining, the boost the industry was given in the past when military and civil technology were more similar accounts for a portion of the success of the industry today.

Examples of these synergies are numerous. Boeing's civil 707 and the military KC-135 tanker were both developed from a common prototype and shared 20 percent of the tooling, reducing costs to both commercial and government customers. The prototype itself drew heavily on advances made in the B- 47 and B-52 bomber programs, including the flexible swept wing and the podded engine. The core of General Electric's largest commercial engine was originally developed for the C-5 military transport, and the core of the company's medium-sized commercial engine came from the B-1 bomber. At the GE Aircraft Engines plant in Evendale, Ohio, commercial and military engines move through many of the same production stations. Both sides of the business share a common management structure, common ordering and inventory, common manufacturing processes, and common R\&D facilities. Only finance and marketing are separated. McDonnell Douglas sold 60 of its commercial DC-1OS to the Air Force for use as air refueling tankers, thus increasing the total profits of the program and helping to keep production going until the company was ready to commit to the derivative MD-11. The development of lightweight composite materials is being led by the military; commercial users have been unwilling to adopt the materials until they have acquired sufficient service experience that their safety is assured. Military users are providing that experi- 
ence. Though much of the development cost of the ring laser gyroscope for inertial reference systems was borne by companies, military funding at key moments in the development process, together with the promise of a combined military and civil market, spurred the private investment. Pratt \& Whitney's F-1 17 engine for the Air Force C-17 cargo plane was adapted from the commercial P\&W 2037 engine and bought "off the shelf" by the military, thereby increasing production runs, spreading development and overhead costs, and decreasing costs to both military and commercial users.

Military projects help train aeronautical engineers. The original 747 design team consisted of engineers who had been trained and familiarized with the tasks involved in designing wide-bodies during the C-5A military transport competition. ${ }^{18}$ One McDonnell Douglas official suggested that even if the C-17 program were canceled, it would still have had the beneficial effect of training 2,000 engineers the company could then employ on commercial work.

Until the last decade, military work was profitable. This, combined with the often alternating cycles of the commercial and military sides of the business, generated some financial benefits for companies involved in both commercial and military work. ${ }^{19}$ For example, according to a leading aircraft industry analyst, Boeing's commercial activities lost money during the first 20 years of jet production; the company was carried during that period by steady profits in its military business, especially the B-52 and Minuteman missile. ${ }^{20}$ In 1967, despite an order backlog of $\$ 2.3$ billion in commercial aircraft, the commercial Douglas Co. was forced to merge with the primarily military McDonnell Aircraft Corp. ${ }^{21}$ The cash infusion from McDonnell not only saved Douglas from bankruptcy but enabled the company to bring out the DC-10 (introduced in 1971).

However, the defense connection has not been an unqua.idled boon. Defense and commercial technologies have been gradually diverging since the beginning of the jet age, so opportunities for the commercial side to benefit from military developments are shrinking. Commercial requirements are driving high reliability, low fuel consumption, and low noise technologies, while defense needs are pushing low radar detection, high speeds, and high maneuverability. Some synergies remain, but they are smaller than they once were.
Other aspects of the defense business are negative as well. Military projects can divert limited resources (e.g., highly specialized aeronautical engineers) away from commercial projects. Export controls limit international markets, military requirements may entrench processes and mentalities ill-suited to commercial competition, and efforts to standardize military hardware with allies may have transferred commercially relevant technology to competitors. Classification of defense systems often makes advances in military technology unavailable to commercial divisions even within the same company, and much of the DoD aircraft development and procurement budget is spent with firms that have no significant commercial activity. In the late 1980s and early 1990s, defense aircraft work in the United States has become less profitable than it once was, creating a burden on profitable commercial operations.

DoD's procurement regulations often create de facto requirements for firms to separate their military and commercial development and production, reducing the potential benefits of simultaneous involvement in both sides of the business. ${ }^{22}$ The costs generated by DoD's close oversight or detailed specification of hardware and production processes cause some companies to separate military and commercial production that they might have combined if DoD provided for more latitude. ${ }^{23}$ Even when companies still find it beneficial to combine military and commercial production, the benefits are less than if DoD procurement regulations and contract specifications allowed more flexibility. ${ }^{24}$ Burdensome military requirements are unlikely to leave commercial producers less competitive than if the companies had no military business at all, but they do interfere with the ability of firms to take maximum advantage of available synergies.

The defense business has generated benefits for and imposed extra costs on firms also involved in commercial work. These benefits have been far less than they could have been if promoting commercial competitiveness were a major policy goal.

\section{Government Funding for Civil Aeronautical $R \& D$}

In addition to the often indirect and generally unintended benefits to commercial manufacturers of military aircraft, the U.S. Government has directly funded $R \& D$ for civil applications through the 
aeronautics program at NASA and its predecessor, the National Advisory Committee on Aeronautics (NACA). Figure 8-2 shows the funding history for NASA's aeronautics program. Their research projects have produced many advances that improved the performance and safety of aircraft. However, the gains for the competitiveness of U.S. aircraft manufacturers have been less clear.

One undisputed benefit has been the research and test facilities NASA provides. Since companies are relieved of the need to maintain redundant facilities of their own, the NASA facilities reduce costs for individual firms and improve the efficiency of the industry as a whole. Most used by companies are the wind tunnels. According to NASA officials, every commercial aircraft built in the United States has been tested in NASA wind tunnels. Computers, simulators, aircraft for flight testing, and other specialized equipment are also used by industry, sometimes quite heavily. Aircraft companies account for 15 to 20 percent of the use of the Numerical Aerodynamic Simulation computers, the world's most advanced facility for computational fluid dynamics (CFD). In 1984, the replacement value of all of NASA's aeronautics facilities was estimated at $\$ 10$ billion. $^{25}$

NASA's aeronautics R\&D program also benefits U.S. aircraft producers, though it does not always bestow a competitive advantage. The program helps U.S. aircraft manufactures develop and adopt new technologies by conducting research inhouse and then transferring the results to companies and by contracting with companies to perform specific research tasks, usually in cooperation with inhouse NASA research. Further, NASA researchers act as a free consulting service for industry engineers having technical problems. The availability of technologies developed and tested at NASA's expense and risk helps aircraft manufacturers incorporate new capabilities into their products at diminished cost or risk, just as military developments do.

Sometimes, these technological advances result in gains in competitiveness for the firms that use them. Examples include NASA's work in CFD, which helped Boeing find positions to locate the nacelles on the wings of the 737, 757, and 767 to minimize drag. NASA's energy efficiency projects of the late 1970s and 1980s helped U.S. engine makers decrease fuel consumption of their engines, increasing their appeal to airlines looking for ways
Figure 8-2-NASA Aeronautics Funding, 1959-91

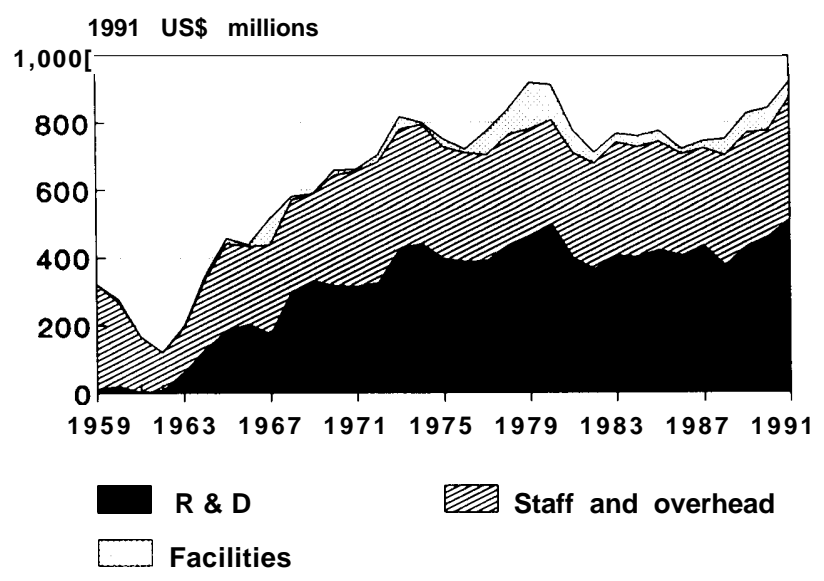

SOURCE: NASA.

to cut operating costs. NASA' $S$ noise reduction projects helped U.S. engine makers build quieter engines, which resulted in significant competitive advantages when Congress passed noise limitations in 1968 and tightened them in 1974.

However, NASA's technology advances can provide U.S. firms with a competitive advantage only if they are able to apply the technology before their foreign competitors. The record has been mixed. Cases in which foreign competitors have applied NASA research first are numerous. Winglets made their first commercial appearance on Airbus planes. The supercritical wing was frost employed on the Airbus A320. ${ }^{26}$ In Japan, the Shin-Meiwa Co., which builds some composite parts for Boeing, claims to have learned much of its carbon fiber technology from NASA publications. NASA advances in engine technology will be applied by Société Nationale d'Étude et de Construction de Moteurs d'Aviation (SNECMA), the French aircraft engine company, in its high-pressure compressor for the GE-90. ${ }^{27}$ Advances made in short take-off and landing (STOL) technology have been used more by the Canadian company DeHavilland (to the degree that they have been used at all) in its Dash-7 aircraft than by U.S. firms. ${ }^{28}$ Safety-related research, such as that on the prevention of icing, transfers quickly-as indeed it should.

NASA publishes nearly all of its research in open literature. Even when U.S. companies do get access to NASA technology first, they may transfer this technology overseas in technology licensing ar- 
rangements and through joint ventures. Foreign governments' support of their own aircraft industries in ways that reduce the risks of adopting new technologies is a major reason for foreign firms taking advantage of NASA-generated advances sooner than U.S. firms do.

U.S. firms do have some advantages in getting to NASA R\&D first. Most importantly, they often participate in the research projects, gaining valuable "hands-on" experience. NASA also tries to limit the distribution of the most valuable results, though with limited success.

It is likely that the competitiveness benefits to U.S. firms equal only a portion of the cost of NASA's aeronautical R\&D program. While the facilities and some portion of NASA's aeronautics R\&D budget may be viewed as a support to the industry, to view the whole budget as such is an overestimate of those effects. ${ }^{29}$

\section{Direct Financial Assistance}

Though synergies between military and civil work and NASA's aeronautics R\&D program are the main sources of U.S. Government benefits to commercial producers, other government actions have also helped. On three occasions, the U.S. Government has provided direct financial supports to the industry. In the late 1960s, poor sales and costs overruns of the L-1011 drove Lockheed to the brink of bankruptcy. In 1971, the Nixon administration approved a loan guarantee of $\$ 250$ million, which saved the company but failed to prevent it from exiting the commercial business within a decade. In any case, the government's main purpose was to save a defense contractor, not a commercial aircraft producer. ${ }^{\circ 0}$ Commercial interests were more directly

involved in the case of the Douglas Aircraft Co. When the company approached bankruptcy in 1967, the government eased its merger with the McDonnell Aircraft Co. by providing a loan guarantee of $\$ 75$ million, helping to save its commercial aircraft business. ${ }^{31}$ Here, the government's interest was more in the realm of the domestic economy-jobs and community economic base-than in international competitiveness. In neither situation was the guarantee called upon. In the third case, the U.S. Government spent roughly \$1 billion between 1961 and 1971 on the development of a supersonic transport (SST) to rival the Concorde. The program was canceled long before an aircraft flew but did generate some technology that appeared in later subsonic aircraft.

The Lockheed and Douglas loan guarantees and the SST program are the most significant direct financial assistance the U.S. commercial aircraft industry has received from the U.S. Government, yet they pale in comparison to the funding available in other countries. Further, these interventions were infrequent and ad hoc, not part of a coherent strategy to support the commercial aircraft manufacturing industry.

\section{Promotion of a Domestic Market}

The government has helped U.S. aircraft manufacturers indirectly through its efforts to promote the growth of domestic air travel. The size and strength of the American market is a major reason for the success of U.S. commercial aircraft manufacturers. The earliest commercial use of air transport was in carrying the mail. Deliberate government subsidies enabled carriers to use larger, faster planes better suited to carrying passengers as well. ${ }^{32}$ In 1938, the Civil Aviation Administration (CAA) was set up within the Department of Commerce to provide "direct subsidies to promote passenger travel, economic regulation of the airlines, air traffic control, and safety. ' In 1948, the CAA was divided into the Civil Aeronautics Board (CAB), with responsibility to regulate routes and fares, and the Federal Aviation Administration (FAA) to oversee safety and the air-traffic environment. ${ }^{33}$ Safety standards, efficient management of the airspace, and technical support for the construction of airports provided by the FAA all helped to make air travel a safe and desirable means of transport. Regulation, which ended in 1978 , enabled airlines to pass on the costs of more expensive, more advanced aircraft to the traveling public, $^{34}$ so airlines were quick to replace old aircraft and to introduce technological innovations. ${ }^{35}$ Though these benefits have largely disappeared in the last decade, historically they were very important to the industry.

\section{Export Assistance}

Finally, the U.S. Government has helped aircraft manufacturers export by providing credit on favorable terms through the Export Import Bank (Eximbank). Over the decade from 1967 to 1977, the Eximbank provided $\$ 5.77$ billion in loans covering the export sales of 1,185 commercial jets worth $\$ 12.8$ billion. ${ }^{36}$ In the early 1970 s, when the aircraft 
market was so weak that U.S. aircraft manufacturers faced serious threats to their survival, the Eximbank became so heavily involved in financing aircraft exports that it acquired the nickname "Boeing's bank." However, two developments have greatly undermined the importance of export financing. First, an agreement among the major aircraft exporters called the Large Aircraft Sector Understanding (LASU), concluded under the auspices of the Organization for Economic Cooperation and Development (OECD), established a minimum rate governments could offer. Second, in the mid- 1980s, the financial markets realized that aircraft retain their value well and can be held as collateral against the loans used to buy them. Bank rates for aircraft purchase loans consequently dropped very close to rates available with government guarantees, greatly diminishing the role of export financing. ${ }^{37}$ Boeing officials state the Eximbank now finances only five to seven sales of Boeing planes annually, or about 2 percent of the company's sales.

\section{JAPAN}

\section{Motives}

In contrast to the United States, the explicit goal of the Japanese Government in its support for commercial aircraft manufacturers was and still is promoting the industry's development. Japanese Government support for this industry is properly seen as another step up the technological ladder in a long succession of targeted industries.

After the U.S. occupation of Japan ended, most of the companies that had built military aircraft during WWII returned to the business. Their first significant work came from the overhaul of U.S. military aircraft used in the Korean War, followed by licensed production of U.S. military designs. In the 1960s, a project to build a twin-engine turbo-prop gave companies their first experience designing commercial transports and their first taste of the business. Following the costly failure of this domestic venture, airframe work shifted to subcontracting for Boeing and engine work focused on the multinational V2500. Military work dominates the industry today, though the proportion of commercial work is increasing rapidly. The total civil production remains less than 5 percent of that of the United States.

The legal foundation for Japanese Government support of the industry was laid with the passage of the Aircraft Industry Manufacturing Law in July,
1952, barely 2 months after the end of the occupation made aviation activities possible. The First Aircraft Industry Promotion Law of 1954 led to heavy subsidization of the industry in the 1960s. Aircraft were first designated a "targeted industry" by Japan's Ministry of International Trade and Industry (MITI) in its "vision" for the 1970s, and then again in the document for the $1980 \mathrm{~s}^{38}$ (The 1990 s vision did not name any specific industries.)

As in the United States, military work has helped Japanese companies' efforts to become major commercial suppliers, though relatively small government orders, use of licensed designs (rather than domestically developed ones), and restrictions on exports of military goods have limited the spillover benefits. Although Japanese planners may use military aircraft production to help develop their commercial aircraft industry, the overall benefits from the military connection is less than in the United States.

Promoting economic growth has been and remains the prime motivation for Japanese Government support of industry, and the nation's GNP is now the fastest growing among advanced nations. Partly as a result, Japanese firms now face an acute labor shortage. The need for growth to increase employment is not great. Instead, Japanese planners see the commercial aircraft industry as an opportunity to learn advanced new technologies that may spill over into other sectors, moving firms into more knowledge intensive and higher added-value work. ${ }^{39}$ Planners see aircraft production as an area in which recently industrialized countries are unlikely to threaten more technologically advanced nations as they have in industries like steel and ship building.

Japanese companies produced Y159 billion worth ( $\$ 1.2$ billion at 135 yen to the dollar) of commercial aircraft-related goods and services in 1989. ${ }^{40}$ Though government supports have greatly helped Japanese companies achieve such successes as they have, these supports have not been sufficient to fully overcome the obstacles the industry faced in the post-WWII period.

\section{Direct Financial Supports}

Early Japanese Government efforts to promote the development of a domestic commercial aircraft industry involved heavy government funding in the hope of rapidly catching up with the West. However, after the failure of its first effort and the high costs 
it entailed, the government switched to a more gradual approach. In the projects of the 1960s, most of the risk was borne by the government. Now much more of the risk is borne by companies, though the government funds involved are still substantial. The Japanese Government appears to have accepted that catch-up will be a decades-long process.

Government support remains very in important to the Japanese industry. Japan's post-war hiatus in aircraft manufacture, its history of licensed production of military aircraft, and limited defense budgets have left Japanese aircraft companies in a weak position from which to compete in international markets. Because commercial aircraft manufacturers in Europe, the United States, and other countries have received many benefits from their governments, the prices of aircraft made in those countries do not reflect their full cost. Without government support, Japanese aircraft manufacturers would have to be far more efficient producers and have better products to offer than their foreign competitors in order to make a profit. They have not yet achieved that. ${ }^{41}$ Each of the major Japanese aircraft companies has suffered several costly failures in commercial aircraft ventures, and they are reluctant to repeat the experience. Japan's major aircraft manufacturers are all large, highly diversified companies, and senior management is reluctant to divert too much of their technical talent to the aircraft business.

The Japanese Government has offered aircraft firms direct financial supports in various forms. Though funds involved have been far less than those provided in Europe, they have been large in relation to the size of the industry in Japan. Initially, Japan's Ministry of International Trade and Industry (MITI) used equity participation and guarantees against losses incurred during the production phase of a project. For the YS-11 airplane, a 64-passenger, twin-engine turbo-prop of the 1960s, MITI provided 54 percent of the initial capitalization and guaranteed the participating firms against production phase losses. ${ }^{42}$ By the time production was canceled in 1973 , only 182 YS-lls had been sold, two-thirds of those to domestic customers, and the project had accrued debts of Y28 billion (\$207 million), four times its initial capitalization of Y7.8 billion. ${ }^{43}$ Most of these debts were never repaid and were quietly forgiven by the government when the management organization was dissolved in $1986 .{ }^{44}$
Later, MITI used hojokin--loans offered directly from the Ministry, to be repaid only if the project is successful. The hojokin were offered only for expenses incurred during the product development phase, not during production. ${ }^{45}$ In 1977, Japan's three largest aircraft manufacturers formed a consortium to make 15 percent of Boeing's 767 (first delivered in 1982).* The Japanese partners' total costs came to Y29 billion during the official development phase, 1978 through 1983, MITIdirected funding covered Y14.7 billion. In addition, companies spent on their own an estimated VY20 billion on production facilities and tooling, for a total investment of about Y49 billion before revenues started flowing. The Japanese companies lost money on the venture for several years because of the fall of the dollar and because production was low. However, the terms of the development loans were favorable to the companies; MITI slowed the loans' early repayment because the program was so costly to the Japanese producers.

In 1986, MITI introduced a new system whereby loans for up to 50 percent of the product development costs of aircraft projects are made available by the government-owned Japan Development Bank (JDB). MITI pays the interest on these JDB loans with further loans from a new government-funded organization called the International Aircraft Development Fund (IADF). Companies begin repaying the IADF loans only when the project reaches the break-even point, so the JDB and IADF loans combined provide firms with nearly interest-free financing. Though companies are officially required to fully repay the loans' principal, if projects funded through this system ran into severe difficulty it is likely MITI would ease repayment requirements. ${ }^{47}$ The result is a system of launch aid similar to that used in Europe. Japanese companies' 20-percent participation in Boeing's 777, launched in late 1990, will probably cost $\$ 1.2$ to $\$ 1.3$ billion. Of this, $\$ 700$ million is development expense, half of which is eligible for MITI support (the remaining costs are for facilities, tooling, and operating expenses, which MITI does not cover) .48 JDB has committed to supplying Y17.4 billion (\$129 million) for the 777 for 1991, and MITI has requested Y798 million ( $\$ 6$ million) in IADF funds that "will be applied as a subsidy for 50 percent of the especially high-risk development costs and for the interest on the JDB loan.' ${ }^{49}$ 
While the Japanese Government is gradually reducing its share of the costs and risks of commercial aircraft projects, direct financial supports continue to benefit Japanese fins. MITI supports enable companies to make much larger investments in commercial aircraft projects than they would otherwise, thereby speeding the development of the industry.

\section{Military-Commercial Synergies}

Japanese aircraft companies have achieved synergies between their military and commercial businesses in many of the same ways U.S. firms have. The total benefits, however, are much lower than in the United States because Japanese procurement budgets are far smaller and the R\&D budgets smaller still. Japan's defense budget has hovered around 1 percent of the country's GNP for four decades. ${ }^{50}$ In 1988, Japan spent Y3.7 trillion (\$27.4 billion) on its military. Military aircraft procurements have ranged between 7 and 12 percent of the total defense budget (Y381 billion in 1988) for the last two decades. ${ }^{51} \mathrm{In}$ comparison, the U.S. defense budget for 1988 was $\$ 290.4$ billion, $\$ 28.2$ billion of which was for aircraft procurement. ${ }^{52}$ The contrast is even greater for R\&D. In fiscal year 1991, U.S. Department of Defense R\&D was $\$ 37.8$ billion and about 15 percent of the $\$ 285.6$ billion defense budget, ${ }^{53}$ while Japan's military R\&D spending was only Y114 billion (\$844 million) and 3 percent of the defense budget (the highest percentage it has ever been) .54

Synergies between military and civil work are reduced by Japan's propensity to license U.S. designs, rather than developing them domestically. This has denied Japanese firms the opportunity to develop valuable design and development skills. In fiscal year 1991, Japan paid the United States \$816 million in royalties for these licenses, roughly the equivalent of the entire Japanese military $R \& D$ budget. $^{55}$

On the positive side is the flexibility the Japanese Defense Agency allows its contractors, enabling Japanese aircraft manufacturers to realize some synergies much more easily than U.S. producers. For example, the JDA allows contractors to retain any intellectual property rights generated in development projects, enabling firms to use research results in commercial products at their discretion. Further, the JDA deliberately seeks out technologies with dual-use potential, increasing chances for synergies. ${ }^{56}$

\section{Other Mechanisms}

Japan has a civil aeronautical $R \& D$ program similar to NASA's, which generates some competitive benefits for Japanese firms. The mission and activities of the National Aerospace Laboratories (NAL) are much like NASA's; however funding is less than one-tenth as much. In translating its technical advances into competitive benefits for Japanese fins, NAL suffers from some of the same difficulties NASA faces. The technology development programs run by MITI's Agency of Industrial Science and Technology have been more important than NAL's efforts. The FJR-710 engine program, which was almost entirely funded by MITI through its Agency of Industrial Science and Technology (AIST) for a total of Y19.8 billion (\$147 million) between 1971 and 1981, formed the basis for Japan's current 23-percent share of the V2500 engine program. ${ }^{57}$ Officials at Ishikawajima Harima Heavy Industries state that without strong government support, they would never have attempted such a technologically risky venture. Currently, AIST is funding a research project in hypersonic propulsion systems, aimed at putting Japanese manufacturers in a position to participate in building a high-speed commercial transport that may be built early in the next century.

The Japanese Government has aided its aircraft manufacturers in two other significant ways. First, by creating a preference among domestic airlines for aircraft that have large portions built in Japan, the Japanese Government encourages foreign manufacturers to increase the amount of work they subcontract in Japan. A combination of close relationships between government officials and senior airline executives and roughly $\$ 1$ billion in preferential interest rate loans that MITI can offer for aircraft imports gives the government great influence. ${ }^{58}$ This is not to say that the government makes overt demands of foreign manufacturers. Rather, foreign companies are aware of these interactions and take into account that substantial subcontracting in Japan may help them sell to Japanese airlines.

Second, the Japanese Government has helped Japanese firms to pool their resources in consortia, decreasing the risk any one firm faces and increasing their bargaining power with potential partners. The 
main purpose of the First Aircraft Industry Promotion Law of 1954 was to create cartels within the industry. ${ }^{59}$ That law and its successors not only offer inducements for cooperation among fins; they require Japanese companies to obtain formal MITI approval before entering the aircraft business. ${ }^{60}$ Consortia in the aircraft industry are remarkable because unlike those in other Japanese industries, which handle R\&D only up to the precompetitive stage, these extend into the production stage. ${ }^{61}$ All of Japan's major international projects-the 767, the V2500, and the 777-have been handled through such consortia.

\section{EUROPE $^{62}$}

\section{Motives}

In contrast to the predominantly indirect benefits U.S. commercial aircraft manufacturers have received from the U.S. Government, European firms have benefited from government policies aimed directly at promoting their competitiveness. Several motives lie behind this direct support. European planners value aircraft manufacture explicitly for the employment it creates. An Airbus official explained that the main reason the collaboration works is that by creating jobs in an export industry, Airbus enables the member countries to capture jobs from other parts of the world. (Figure 8-3 shows the historical and expected growth in Airbus' share of the world market. For a brief description of the history and current structure of Airbus, see box 8-A.) The member governments are less concerned about global economic efficiency and rules of comparative advantage than with meeting immediate domestic needs. With government commitment to full employment, policymakers view the thousands of jobs Airbus creates in England, France, Germany, and other European countries as well worth the costs of the supports provided. ${ }^{63}$

Another reason European governments support the industry is concern that without support for their domestic manufacturers, European airlines will be forced to rely solely on two U.S. suppliers. By supporting a challenger, European governments force U.S. manufacturers to keep their prices low. As a result, some portion of every dollar European governments spend supporting Airbus is returned to their economies in lower airplane costs. Baldwin and Krugman examined the competition between the Airbus A300 and the rival Boeing 767 and con-
Figure 8-3-World Market Share, 1970-92

Large Commercial Transport Airplane by Value of Deliveries

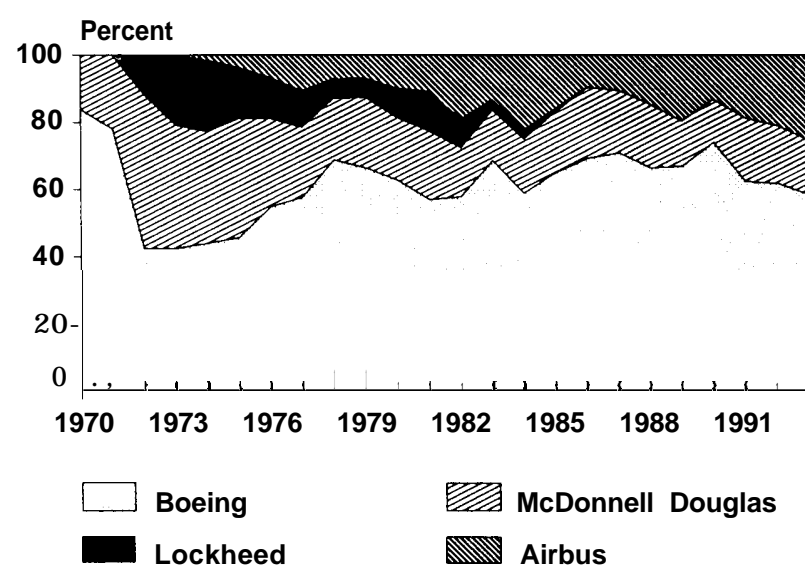

SOURCE: Boeing, World Jet Airplane Inventory, "19S9 and Bear Stearns," Aerospace Industry Review, May 9, 1991.

eluded that European consumers do benefit, but by less than what they estimate European taxpayers paid for those benefits. "Overall it seems that the A300 project constituted a beggar-thy-neighbor and beggar-thyself policy for Europe. ${ }^{\prime 64}$

National prestige plays a big role. Though the influence of pride is difficult to trace, aircraft projects have broad popular support, making them an easy cause for politicians to endorse. ${ }^{65}$ Europeans are proud of a long history of achievement in aeronautics, including the first supersonic transport, the first jet transport, the first jet engine, and even claims of the frost powered flight. Airbus Industrie (AI) executives describe an "Airbus reflex" in the French Government. Airbus does not even have to go to government offices to solicit help; the venture is so highly regarded that the relevant ministries come to Airbus on their own and ask, "How can we help?"

Just as in the United States, national defense policies aimed at maintainingg autonomous and technologically advanced military production capabilities have greatly increased the ability of firms to design, develop, and build large commercial transports. In addition, regulation and state ownership of airlines, put in place to meet air transport policy goals, provide European aircraft manufacturers with reliable domestic customers. Support for aircraft manufacture is justified on trade grounds as substituting domestic goods for imports and boosting exports. Planners perceive the products as driving 


\section{Box 8-A-Airbus}

Airbus discussions began in 1966. In 1\%7, the French, British, and German Governments agreed on a joint venture in which Britain and France would each hold shares of 37.5 percent, and Germany would hold 25 percent. France agreed to allow Britain's Rolls Royce the lead in the engine development with a 75 percent share of the new RB207, with France and Germany each getting 12.5 percent. The French, in return, would be for final assembly and design leadership. In 1\%9, the British withdrew from the project due to a combination of rising costs, lack of airline interest, BAC's reluctance to concede design leadership to the French, and Roll Royce's desire to build the RB-211 engine for the L-101 1. France and Germany then took over co-leadership of the venture, securing financial assistance from Spain and the Netherlands. Britain's Hawker-Siddeley remained as a subcontractor responsible for the design and production of the wing. In 1979, Britain rejoined Airbus and the consortium decided to pursue a strategy of offering a "family" of aircraft, committing to the long-range A300-600 and the small A310. The A300 was introduced in 1974, the A310 in 1983, the A300-600 in 1985, and the A320 in 1988. The long-range A340 and large A330 are scheduled for first flights in 1992 and 1993 respectively, followed by the derivative A321.

Airbus Industrie (AI) is now a consortium of Aerospatiale (37.9 percent), Deutsche Airbus (37.9 percent), British Aerospace (20 percent), and CASA of Spain (4.2 percent), constituted under French law as a Groupment d'Interet Economique (GIE)-a structure originally designed to let small French vineyards operate on a cooperative basis. Airbus acts only as the organizational focus of the partnership. As a GIE, it is unable to retain any earnings, and it is neither required to report financial results nor liable to pay taxes on its profits. Every 15 days, AI distributes any funds on hand to its members or calls on them for more funds if needed. The members are fully and separately liable for all $\mathrm{Al}$ activities, effectively giving $\mathrm{AI}$ a credit standing equivalent to the sum of the credit worthiness of all its members. AI's only functions are product planning, sales and marketing, some customer support, and management of the partnership.

AI owns no production facilities. All of the design, development, and production work is done by the members under contract to AI. The division of workshare among the partners roughly corresponds to the size of the partners' membership share, with the allocation of each portion decided in negotiation. This system puts the members in the strange position of being both the owners and the subcontractors. AI negotiates the contracts for each partner's share separately. The other partners do not know the terms of these contracts, and AI itself knows nothing about what the individual members' costs are, only what the "transfer prices" are. This system has been the cause of frustration in the United States and Europe; it is impossible to tell whether the whole of Airbus is operating profitably, for not even AI knows. Losses or profits incurred by AI are virtually meaningless. Members maybe making profits as subcontractors while losing money as owners, or the reverse maybe true. (Members do not disclose Airbus-related profits or losses in their individual financial reports.)

Government influence has been pervasive throughout Airbus' history. AI itself receives no financial support from governments. All of the disbursement and repayment of launch aid and other supports is handled among the members and their governments. Officially, the members do not know the terms of the support the others receive. Nevertheless, the member governments do coordinate with each other regarding the support they will give each project, and approval from an oversight committee of government officials, the Executive Agency, is required for the launch of a new model. Government-to-government negotiations were even more important than those between the companies themselves during the founding days of Airbus. Government policymakers even intruded into the design process (though this has diminished since). Government decisions were at the heart of the withdrawal and later reentry of the British, as well as the ability of the French and Germans to carry on without them.

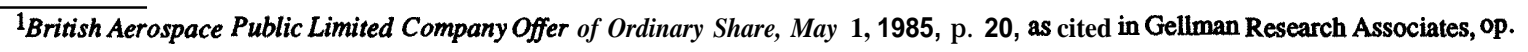
cit., p. 1-2.

technological advance and moving jobs to higher added-value and more knowledge-intensive areas.

\section{Direct Financial Support}

Direct financial supports have been the principal mechanisms used by European governments to assist their commercial aircraft manufacturers. This support has taken the form of government contracts for-the development of commercial models (in effect, grants), loans and loan guarantees on favorable terms covering both development and production costs, guarantees against losses caused by exchange rate changes, equity infusions, tax breaks, debt forgiveness, and bail outs. Without these 
supports, it is likely that no European firms would be in the large commercial aircraft manufacturing business.

Beyond simply enabling companies to operate at a loss, government financing has several benefits over commercially available financing. Governments, unlike commercial lenders, will finance specific projects. This enables manufacturers to move quickly to fill market openings with new models even when the cash flow from previous models is insufficient to convince banks to lend. This may give the manufacturers ahead start on their competitors, and because of the steep learning curve of this industry, a head start is an important advantage. Ideally, by getting into the new market first, the firm will be able to deter the entry of any competitor and so be able to establish a monopoly position. ${ }^{66}$ Also, since government funding is usually provided during the development phase and paid back as a levy on sales, the government assumes much of the risk if sales are poor. This encourages companies to shift as many costs as possible to the development phase. For example, adopting advanced manufacturing methods and higher levels of automation in the production process may increase development costs but decrease production costs. Similarly, use of more advanced product technologies may increase development costs but reduce operating costs to airlines. Since the government bears the risk for the development expenses, companies are encouraged to make the most advanced aircraft in the most advanced way possible.

Before Airbus, British, French, and German jet transport manufacturers had launched 8 different models of jet transport of which only 2 sold more than 200 (total sales of 239 and 279),2 sold between 100 and 200 (total sales of 112 and 117), and the other 4 were catastrophic failures (total sales of 14 , 11,54 , and 10). ${ }^{67}$ Judging by the experiences of Douglas (driven to bankruptcy even while its planes were selling well), Lockheed (driven to bankruptcy by the L-1011, which ultimately sold 249 units), and Convair (driven from the commercial aircraft business by the 880/990, which sold 102 units), any one of these European ventures should have forced its manufacturers into bankruptcy, or at least from the commercial aircraft business. However, not one of the firms responsible for any of these aircraft has left the field, though some have been consolidated.
The ability of these firms to launch further aircraft models after their failures with previous designs is directly attributable to government intervention. From 1945 to 1974, the British Government spent $£ 1,504$ million at 1974 prices ( $\$ 9.3$ billion inflated to 1991 values) in launch aid for civil projects, including the Concorde, and were repaid less than $£ 150$ million (\$929 million inflated to 1991 values) of that. The total cost of jet transport programs to the British Government rises to several times that amount if the cost of bailouts is included. From 1962 to 1977, the French Government spent an average of \$829 million (at 1991 values) per year on civil projects, during that period repayments averaged only about $\$ 23$ million per year. ${ }^{68}$ Costs to the German Government were lower, as they had no part in the Concorde project, but Germany had other costly failures. Not only has government funding made European prime assemblers more competitive in international markets, at the supplier level it has made companies more desirable partners for U.S. firms looking to share the burdens of launching expensive, risky projects. Government support of the European partners made European participation in ventures like the CFM-56 and V2500 much more appealing for U.S. firms.

Because of Airbus, direct financial supports have come more into the international limelight, including a formal GATT complaint from the United States in early 1991. Most of the support the British, French, and German (and Spanish) Governments have provided to their aircraft manufacturers has been in the form of launch aid, ${ }^{69}$ although the British Government has been more hesitant in this regard than the French and German Governments. ${ }^{70}$ As of the end of 1989, the governments of France, England, and Germany had disbursed a total of \$5.4 billion to the Airbus member companies in launch aid. Of this, roughly $\$ 500$ million had been repaid. ${ }^{11}$ Repayment of the remainder has been either forgiven or deferred, or was never intended. An additional \$2.3 billion had been pledged for the A330/A340, and the German Government had committed a further $\$ 3$ billion as part of the Daimler-MBB merger. ${ }^{72}$ This government financing represents almost 75 percent of the development funds required for the Airbus models developed to date. As table 8-3 shows, as of the end of 1990, the $\$ 5.6$ billion would have been $\$ 10.7$ billion if the governments had charged firms the cost of the funds at rates the government themselves have to pay for 
Table 8-3-Launch Aid for Airbus Membersa (In \$ billions)

\begin{tabular}{|c|c|c|c|c|c|c|c|c|c|}
\hline & \multicolumn{3}{|c|}{$A 300 \& A 310$} & \multicolumn{3}{|c|}{ A320 } & \multicolumn{3}{|c|}{$A 330 \& A 340$} \\
\hline & France & U.K. & FRG & France & U.K. & FRG & France & U.K. & FRG \\
\hline $\begin{array}{l}\text { Commitments } \ldots \ldots \ldots \ldots \ldots \ldots \\
\text { Disbursements } \ldots \ldots \ldots \ldots \ldots \ldots \\
\text { Value at governrnent }{ }^{\mathrm{b}} \ldots \ldots \ldots \ldots \\
\text { Value at corporation }{ }^{\circ} \ldots \ldots \ldots \ldots\end{array}$ & $\begin{array}{l}\ldots \ldots 1 \\
\ldots 1.1 \\
\cdots 3.3 \\
\cdots 7.5\end{array}$ & $\begin{array}{l}20.1 \\
0.1 \\
0.3 \\
0.3\end{array}$ & $\begin{array}{l}3.0 \\
1.5 \\
3.1 \\
5.7\end{array}$ & $\begin{array}{l}0.7 \\
0.7 \\
1.2 \\
1.8\end{array}$ & $\begin{array}{l}0.4 \\
0.4 \\
0.6 \\
0.7\end{array}$ & $\begin{array}{l}0.9 \\
1.0 \\
1.1 \\
1.2\end{array}$ & $\begin{array}{l}0.8 \\
0.3 \\
0.3 \\
0.4\end{array}$ & $\begin{array}{l}0.7 \\
0.3 \\
0.4 \\
0.4\end{array}$ & $\begin{array}{l}1.6 \\
0.3 \\
0.3 \\
0.3\end{array}$ \\
\hline \multirow{2}{*}{ Value at corporation ${ }^{\circ} . \ldots \ldots \ldots$} & \multicolumn{3}{|c|}{ Program totals ${ }^{d}$} & \multicolumn{3}{|c|}{ Country totals } & & & \\
\hline & A300 \& 31 & A320 & $30 \& 340$ & France & U.K. & FRG & \multicolumn{3}{|c|}{ All Airbus } \\
\hline $\begin{array}{l}\text { Commitments } \ldots \ldots \ldots \ldots \ldots \ldots \ldots \\
\text { Disbursements } \ldots \ldots \ldots \ldots \ldots \ldots \\
\text { Value at government } \ldots \ldots \ldots \ldots \ldots \\
\text { Value at corporation } \ldots \ldots \ldots \ldots \ldots\end{array}$ & $\begin{array}{l}\ldots 4.3 \\
\ldots 2.7 \\
\ldots 6.7 \\
\ldots 13.3\end{array}$ & $\begin{array}{l}2.0 \\
2.1 \\
2.6 \\
3.7\end{array}$ & $\begin{array}{l}3.2 \\
0.8 \\
1.1 \\
1.0\end{array}$ & $\begin{array}{l}2.7 \\
2.1 \\
4.8 \\
9.6\end{array}$ & $\begin{array}{l}1.2 \\
0.8 \\
1.3 \\
1.3\end{array}$ & $\begin{array}{l}5.5 \\
2.8 \\
4.7 \\
7.1\end{array}$ & & $\begin{array}{r}9.5 \\
5.6 \\
10.7 \\
18.0\end{array}$ & \\
\hline
\end{tabular}

a hese figures represent all launch aid and include funds alloted to non-Airbus aircraft projects such as the French ATR 42 and 72 . Officials in France, Germany, and England state that the numbers are accurate. Neither firms nor governments in Europe disclose public supports at a level more detailed than those used here, so it is impossible to tell by how much thetable overestimates the Airbus aid. Since Airbus is by far the largest aircraft venture currently receiving public financing in Europe, it is likely these figures overestimate the total Airbus launch aid by only a little.

bValue of the disbursed funds as of Dec. 31, 1988, including interest accrued assuming government rates (IO-year T-bills). The effects of staggered disbursements and loan repayments during the course of the programs have been factored in, and end-of-1988 currency exchange rates used.

CValue of the disbursed funds as of Dec. 31,1988, including interest accrued assuming corporate prime rates. The effects of staggered disbursements and loan repayments during the course of the programs have been factored in, and end-of-1988 currency exchange rates used.

dThe development costs of Airbus' most recent launch, a stretched version of the A320 designated the A321, are being financed without government assistance. The A321 was financed on commercial terms with a line of credit from the Euro Investment Bank. The financing was not project based but rather based on Al's credit standing as backed by the liability of the members under the GIE structure. TheA321 thus represents not only the first time a new or derivative Airbus model was launched without government aid, it is also the first time that Al and not the members arranged the financing.

SOURCE: U.S. Department of Commerce, unpublished data collected from publicty available data.

borrowed money, and $\$ 18.0$ billion if the firms had had to pay a corporate prime rate.

In addition to launch aid, the German Government (though not the French or British Governments) has provided its commercial aircraft manufacturers with loans to cover losses incurred during the production phase of Airbus projects. In 1988, the German Government paid off the outstanding productionphase debt its aircraft manufacturer had accumulated in the $A 300 / 310$ projects so that no more interest charges would accumulate. Accumulated capital and interest had reached $\$ 1.05$ billion. ${ }^{73}$ Further, the German Government agreed in 1988 to guarantee against losses caused by the exchange rate falling below 1.8 DM to the dollar. Analysts estimate the government's maximum liability for the guarantees through 1996 is $\$ 1.3$ billion and for the period from 1997 to 2000 is $\$ 863$ million. ${ }^{74}$ With exchange rates at levels (as low as the 1.5 DM to the dollar since the guarantee began, around 1.7 in mid-1991), the German Government is likely to have to pay nearly the full amount of the guarantee. Finally, at various times all of the Airbus members were government owned; Aerospatiale and Construziones Aeronautics S.A. (CASA) still are. Some of the equity bought by the governments constitutes a further subsidy.

\section{Government Influence Over Airline Procurement Decisions}

European governments have also created benefits for their commercial aircraft producers by influencing the procurement decisions of domestic airlines. Government ownership of airlines, close relationships between high-level officials and airline executives, and regulatory clout combine to give European governments sufficient influence to swing airlines' choice of manufacturers. (Table 8-4 shows government ownership of major European airlines.)

Examples of government intervention in procurement decisions are numerous. The British Government directed British European Airways to buy the British-made BAC 1-11 and British Overseas Airways to buy the VC-10 in the 1960s and 1970s. All of British Airways' current fleet uses Rolls Royce engines. The French Government pressured French airlines to buy the French-made Caravelle, and Air Inter, France's domestic airline, was the only airline ever to buy the short-lived Mercure. The French Government tried to force Air France to buy DC-9s instead of Boeing's 737s in order to help negotiations between McDonnell Douglas and Dassault over the proposed Mercure 200. The French Government succeeded in forcing the airline to buy GE engines instead of Pratt \& Whitney engines for the 
Table 8-4--Government Ownership of Major European Airlines

\begin{tabular}{|c|c|c|}
\hline Airline & Country & Government ownership \\
\hline British Airways & Great Britain & O\% (100\% until 1987) \\
\hline Air France & France & $\begin{array}{l}\text { Almost } 100 \% \text { (previously } \\
\text { private UTA bought in } \\
1990 \text { ) }\end{array}$ \\
\hline Lufthansa & Germany & $528(72 \%$ in 1987$)$ \\
\hline Iberia & Spain & Almost $100 \%$ \\
\hline Sabena & Belgium & $\begin{array}{l}\text { Almost } 100 \% \text { (trying to } \\
\text { privatize parts) }\end{array}$ \\
\hline KLM & Netherlands & $\begin{array}{l}34 \% \text { (declining from over } \\
70 \% \text { in early } 80 \mathrm{~s} \text { ) }\end{array}$ \\
\hline Alitalia & Italy & $100 \%$ \\
\hline Swiss Air & Switzerland & NA \\
\hline SAS & Scandinavian & $\begin{array}{l}100 \% \text { (Sweden, Norway, } \\
\text { and Denmark) }\end{array}$ \\
\hline
\end{tabular}

NA-not applicable.

SOURCE: County NatWest Bank.

A310 because of GE's close ties to the French engine-maker SNECMA. Overall, the preference of European airlines for Airbus planes is pronounced, as figure 8-4 shows. In the categories where U. S.made and Airbus aircraft compete directly, both Air France and Lufthansa have only Airbus planes in their inventories. ${ }^{75}$ In fact, the willingness of national airlines to buy Airbus planes was an essential part of the original agreement by which Airbus was established. ${ }^{7}$

The significance of government-steered procurements has come less from the total volume of these orders than from their timing. French, British, and German airlines have provided the key launch orders, without which few of Europe's commercial aircraft programs would ever have proceeded. Without these orders, no Airbus models would likely have been launched.

The preference the Airbus members have shown for sourcing domestically has also been effective at promoting the development of a European supplier industry and at convincing U.S. manufacturers to transfer workshare and technology to European suppliers in return for access to Airbus contracts. During the selection of engines for the A300, Pratt \& Whitney offered European firms subcontracts, but GE offered SNECMA and MTU a full partnership, giving them 16 and 10 percent respectively of the workshare of GE's CF-6-50 engine, and a say in the program's management. This offer was sufficient to convince the French and German Governments to
Figure 8-4-Aircraft Inventories by Nationality of 'Airlines and Aircraft Manufacture, 1989

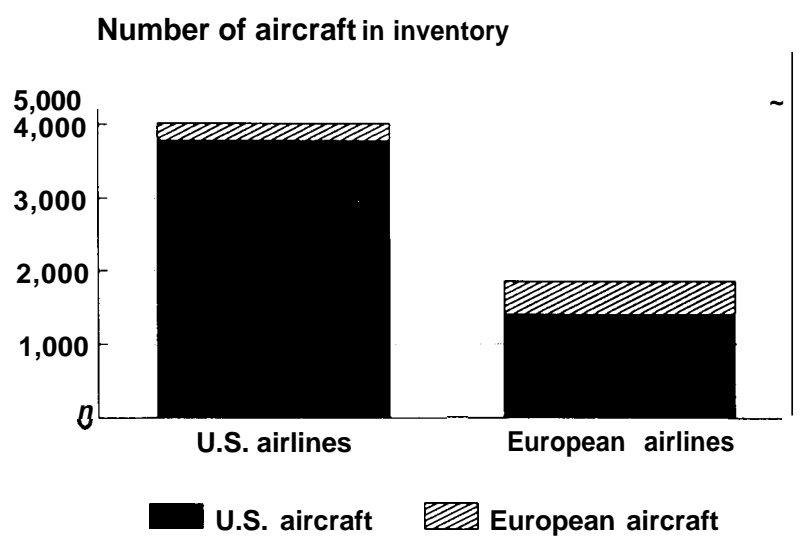

SOURCE: Boeing, World Jet Airplane Inventory, 1989 year end, 1990.

specify the GE engine for the launch of the A300. Again, in the A31O engine competition, the GE partnership with SNECMA convinced the French Government to override Air France's preference for Pratt \& Whitney engines. ${ }^{77}$ This selection led to GE's and SNECMA's 50/50 venture to build the CFM-56 engine, which is now used on the A320. Needless to say, Air France has specified the CFM-56 for all of its A320s.

\section{Government Promotion of Cooperation and Consolidation}

European governments have also tried to improve the competitiveness of their aircraft manufacturers by promoting domestic consolidation and intraEuropean cooperation. European planners believe that to compete internationally in this industry, bigger companies are better. Domestic competition is seen as inefficient and has been sacrificed willingly to form larger firms better able to compete with American rivals. In England, France, and Germany, the dozens of aircraft companies that emerged from WWII were gradually consolidated into one commercial airframer and one commercial engine maker in each country. Consolidation at the supplier level followed. Competition within Europe has been discouraged in favor of cooperation, leading to a string of multinational ventures.

The rise of intra-European cooperation is an extension of the desire to achieve economies of scale that motivated consolidation within countries. The Concorde was the frost major collaborative civil 
project, followed by the ill-fated VFW-614 project between MBB and Fokker. Civilian collaboration really took off, however, with Airbus. Collaboration in military aircraft ventures is even more common than in civil projects. The Transall and the Tornado have been the biggest to date. Currently over $\mathbf{7 0}$ percent of Deutsche Aerospace's turnover is derived from collaborative projects, a proportion that is likely to rise to 80 percent by the end of the decade. ${ }^{78}$ Though it is impossible to know exactly what the competitive benefits of all this consolidation and cooperation have been, European policymakers seem well satisfied by the results.

\section{Military-Commercial Synergies}

In addition to all the benefits described above, European manufacturers have profited from synergies between their military and commercial businesses, from funding of civil aeronautical $R \& D$, and from export assistance much as U.S. companies have.

Examples of military/civil synergies in Europe are numerous. Rolls Royce's early engines, the Avon, the Olympus, and the Spey, all began as military engines. Among Rolls' current commercial engines, none has a direct lineage in a military predecessor, but strong military R\&D programs and sales, especially to the Middle East, contributed to Rolls Royce's recent recovery in the commercial engine business. SNECMA has benefited from combined civil and military sales of the CFM-56 just as GE has. ${ }^{80}$ GEC of the United Kindom is developing a heads-up-display (HUD) combined with an infrared sensor to create a so-called "'synthetic vision system" for use on commercial aircraft. The needed technologies came out of military developments for night flying. ${ }^{81}$ The Transall military transport collaboration between France and Germany ran from the late 1950s until the early 1970s and provided both specific technical synergies and broader business synergies with the commercial sides of the companies involved.

Some differences between the European and U.S. defense businesses affect the ability of commercial aircraft manufacturers to realize benefits from their military work. On the negative side, European governments have spent less on military aircraft than the U.S. Government, and military R\&D has been a lower percentage of procurement, creating fewer opportunities for spillovers to the commercial side of the business. Duplication of R\&D among various countries, each wanting to maintain autonomous defense production capabilities, has led to inefficient use of total European military R\&D funds, resulting in fewer opportunities for commercial spin-offs than if the countries' $R \& D$ programs had been coordinated. European governments have spent less on the development of bombers, tankers, and military transports, which generate the most benefits for commercial aircraft.

On the positive side, European military exports are a greater percentage of total military production, partly compensating for lower domestic sales. Further, a higher proportion of the funds spent on military aircraft in Europe go to the same companies that build commercial planes than in the United States, which has many dedicated military contractors. As table 8-5 shows, total military production of all the Airbus members (excluding the rest of Daimler-Benz) is comparable to that of Boeing and McDonnell Douglas, and the reliance of these firms on military sales is higher than Boeing's, though not quite as high as McDonnell Douglas'.

European governments have mostly paid to develop military aircraft domestically rather than licensing from the United States. This practice has generated more commercially useful design and development capabilities than licensed production. The generally close relationships among European governments and their aircraft manufacturers create an atmosphere of trust in which companies are given substantial flexibility in the organization of their military work, leaving them more free than U.S. companies to achieve possible commercial-military synergies. ${ }^{82}$ Consolidation has left most countries with only one manufacturer in each product category, which increases the bargaining power companies have in concluding contracts with their govern-

Table 8-5-Revenues From Military Aircraft and Related Sales, 1989

\begin{tabular}{|c|c|c|}
\hline Company & $\begin{array}{c}\text { Military } \\
\text { sales }^{\mathrm{a}}\end{array}$ & $\begin{array}{l}\text { Percent } \\
\text { of total }\end{array}$ \\
\hline 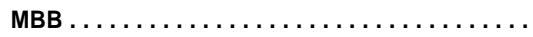 & 783 & 47.0 \\
\hline Aerospatiale $^{\mathrm{b}} \ldots \ldots \ldots \ldots \ldots \ldots \ldots$ & $\ldots 1,335$ & 33.5 \\
\hline British Aerospace $\ldots \ldots \ldots \ldots \ldots \ldots$ & $\ldots 3,470$ & 53.6 \\
\hline All Airbus $\ldots \ldots \ldots \ldots \ldots \ldots \ldots \ldots$ & $.5,588$ & 46.1 \\
\hline Boeing $\ldots \ldots \ldots \ldots \ldots \ldots \ldots \ldots \ldots$ & . 4,361 & 23.4 \\
\hline McDonnell Douglas . . . . . . . . . . . & $\ldots 5,919$ & 55.5 \\
\hline
\end{tabular}


ments. This may enable firms to achieve higher profits on military work, and those funds may then be used to finance commercial programs.$^{83}$ Finally, most of the European companies interviewed for this study appear to do as well or better than U.S. firms at combining military and civil overhead functions, reducing costs.

\section{Government Funding for Civil Aeronautical $R \& D$}

Civil aeronautical R\&D in Europe is similar to that in the United States. The Deutsche Forschungsund Versuchsanstalt für Luft- und Raumfahrt (previously DFVLR, now DLR) in Germany, Britain's Royal Aircraft Establishment (RAE) and the Office National d'Etude et de Recherches Aerospatiale (ONERA) in France all perform functions similar to NASA's aeronautics program. They supply some of Europe's largest, most expensive research and test facilities and conduct research in areas in which firms would otherwise underinvest. These activities generate some competitive benefits for European firms, but the benefits are limited by the same difficulties NASA faces. Also, their combined aeronautics budget is smaller than NASA's, and redundancy among the three organizations reduces their effectiveness. The prospects for increased cooperation are good. While the benefits to European manufacturers of government-funded technology programs are unlikely to equal those for U.S. manufacturers, at least they are likely to increase from the level they are at now.

\section{Export Assistance}

Finally, European governments have helped their aircraft manufacturers export. In Europe, as in the United States, export financing has become much less important in the last decade than it once was. However, before the Large Aircraft Sector Understanding (LASU) agreement and the improvement of commercially available export financing, European governments helped aggressively. Until the late 1970s, Airbus sold so few planes that each sale was critically important. One order could represent a year's production. These circumstances drove Airbus to offer extreme deals to win orders. Even now, U.S. companies claim Airbus can offer better deals than they can because of the government support the members receive. European governments are also involved in providing offsets as sales incentives, whereas the U.S. Government refuses to become involved in such practices. Desirable landing rights for purchasing countries' airlines and development assistance to poorer countries are the most commonly cited examples.

Overall, Airbus deserves credit for the technical excellence of its aircraft and its improvements in production efficiency and product support. However, the importance of direct financial supports, other direct supports, and indirect benefits such as civil/military synergies are so great that it is fair to say that Europe has bought itself an aircraft industry.

\section{CONCLUSIONS}

The principal lesson of this study is that, for governments that believe some industries are more important to national welfare than others, many tools are available to speed the development of those industries. Some of the means of promoting development described here are expensive, and the task of weighing the cost of acquiring the desired industry against the benefits derived must be done carefully. In many cases, government supports have undesired side effects that undermine the intended positive effects. However, others cost little and all that is required of a government is the will to employ them. Sometimes, actions the government would take anyway naturally help the competitiveness of a desired industry, and all that is needed is that the government not prevent the benefits from accruing. Without doubt, effectively supporting an industry is difficult. However, as the world's aircraft industries show, it is possible.

1 This report discusses only England, France, Germany, Japan, and the United States. Brazil, Canada, Indonesia, Sweden, the Netherlands, Italy, Spain, and Belgium all support their commercial aircraft industries, not to mention the Soviet Union and China.

2 In this chapter, the term "commercial aircraft industry" is applied only to the part of the industry that produces large (over 100-seat) commercial jet aircraft.

3 Some of the foreign government actions described in this chapter could be deemed to violate the basic GATT treaty, one or more of the GATT codes (including Subsidies, Procurement and Aircraft), and/or other treaties related to international trade. This chapter does not address these issues.

4 The government actions included in this discussion are not intended to be a comprehensive list of all the many government actions that affect the competitiveness of commercial aircraft manufacture. Environmental regulation, education, labor policies, and macroeconomic policies, to name just a few, affect firms' competitiveness. This study focuses on actions that are mostspecific to the aircraft industry.

5 The launch decision is of special interest because it is at this point that government intervention can have the greatest impact. Inability to muster the resources to launch new models will ultimately force a manufacturer to exit the market. Further, at the time of the launch decision, many smaller technical and financial decisions are made that 
will bind the manufacturer for decades.

6 Companies do not provide program-based financial data, but most industry analysts agree four programs have passed break-even, one is currently around that point, one is getting near, and the rest are not even close. The figures count derivatives as part of the same program. Some of the planes have been introduced only recently and may yet be profitable before their production is terminated.

7 Wolfgang Demisch, Christopher Demisch, and Theresa Concert, The JetlinerBusiness, First Boston Corp., Oct. 5, 1984, p. 4.

8 Unlike most products, where a belief in the presence of a market is sufficient to justify a product launch, commercial aircraft manufacturers require commitments from the customers before development begins. As a Boeing official pointed out, "one of the strangest features of this industry is that the manufacturers don't launch new products, the customers do."

9 Office of Science and Technology Policy, Aeronautical Research and Technology Policy, Vol. 11: Final Report, November 1982, p. C-49.

10 Irene L. Sinrich, "AirbusversusB oeing (A): Turbulent Skies," Harvard Business School case 9-386-193, in David B. Yoffie (cd.), International Trade and Competition: Cases and Notes in Strategy and Management (New York, NY: McGraw-Hill Publishing Co., 1990), p. 334.

11 Artemis March "TheUS Commercial Aircraft Industry and Its Foreign Competitors," Working Papers of the MIT Commission on Industrial Productivity, vol. 1 (Cambridge, MA: The MIT Press, 1989), pp. 11-12.

12 National Research Council, The Competitive Status of the U.S. Civilian Aviation Manufacturing Industry: A Study of the Influences of Technology in Determining Industrial Competitive Advantage (Washington, DC: National Academy Press, 1985), p. 25.

13 OSTP, op. cit., p. 1-11,

14 Among civilian manufacturing industries, the aircraft industry is by far the greatest beneficiary of government technology policy. Outside manufacturing, agriculture and health are also major beneficiaries of government $R \& D$.

15 OSTP, op. cit.

16 From 1928-34 the airline industry was supported by subsidy payments for carrying the U.S. airmail (e.g., the Kelly Act of 1928 and the Watres act of 1930). At that time, the aircraft manufacturers and the airlines that bought their products were parts of the same companies, enabling the parent corporations to channel benefits of the government subsidies from the air carriers to the manufacturers. In 1934, the subsidy system was ended, with the airmail contracts put out for bid at much lower prices. OSTP, op. cit., pp. I-22-23.

17 Calculated from figures presented in Aerospace Industries Association, Aerospace Facts and Figures, 1990-1991 (Washington, DC: 1989), pp. 19, 121, 123, and 127.

18 John Newhouse, The Sporty Game (New York, NY: Alfred A. Knopf, 1982), p. 113.

19 The fact that military work does not operate on the same cycles as the rest of the economy has not resulted from a conscious effort of government planners, but has nonetheless been important when it was coincidental. Most recently, the slowdown in commercial orders of the early 1980s coincided with the Reagan defense buildup. However, in the early 1970s, when down-turns in both sides of the business coincided, the industry was devastated.

20 Wolfgang Demisch, Managing Director, UBS Securities, personal communication, Sept. 11, 1990.

21 David C. Mowery, Alliance Politics and Economics: Multinational Joint Ventures in Commercial Aircraft (Cambridge, MA: Ballinger Publishing Co. 1987) p. 39.

22 DoD's regulations were adopted in response to a number of public needs that have often been at odds with the needs of increasing competitiveness and reducing costs. Among these are control of defense contractors by the government, maintaining fairness and competition in contract awards, ensuring against fraud or excessive profits at taxpayer expense, and protecting the interests of minorities, small business, and constituent groups. See U.S. Congress, Office of Technology Assessment, Holding the Edge: Maintaining the Defense Technology Base, OTA-ISC-420 (Washington, DC: U.S. Government Printing Office, April 1989), p. 10.

23 "In order to conduct (the billions in DoD procurement each year) the government has its own set of procurement rules, the Federal Acquisition Regulations, or FARs. Defense firms organize themselves structurally and especially administratively, to conform to these regulations, which often in-es costs relative to commercial projects. Compliance with the FAR is one of the factors that splits U.S. industry into two sectors." U.S. Congress, Office of Technology Assessment, Arming Our Allies: Cooperation and Competition in Defense Technology, OTA-ISC-449 (Washington DC: U.S. Government Printing Office, May 1990), p. 81.

24 This report does not analyze Pentagon procurement practices. Other OTA reports, includingHolding the Edge and Arming Our Allies, op. cit., provide information on this topic. Briefly, Pentagon rules may require quality inspections so detailed and so frequent that they interfere with the ability of firms to produce efficiently. DoD specifications may demand exotic features or extreme performance that radically increase costs (the last few percent of improved performance often increases the total cost by a much larger percent). Finally, DoD specifications often detail not only the performance of the finished product, but also the processes that must be used in its manufacture, preventing the contractor from taking innovative steps to improve quality and reduce costs.

25 NRC, op. cit., pp. 117-118.

26 Though NASA claims credit for the development of the supercritical wing, earlier airfoil work that contributed to the breakthrough was conducted in the United Kingdom. OSTP, op. cit., pp. VII-81-82.

27 The technology was transferred by GE as part of the partnership agreement.

28 John S. Langford, The NASA Experience in Aeronautical R\&D: Three Case Studies With Analysis, IDA Report R-319 (Alexandria, VA: Institute for Defense Analysis, March 1989), p. 79.

29 European observations of NASA's impact on competitiveness bear out this point. An official in the aircraft industry division at Britain's Department of Trade and Industry feels that their system of direct financial supports is a "poor man's support" compared to R\&D support. He thinks that governments (for whom promoting competitiveness is a priority) get far more bang-for-the-buck from direct subsidies than from R\&D support.

30 Daniel Todd, Jamie Simpson, and Ronald Humble, Aerospace and Development: A Survey (Winnipeg, Canada: Department of Geography of the University of Manitoba, 1985), p. 14.

31 Mowery, Alliance Politics and Economics, op. cit., p. 39.

32 Postmaster General Harold Brown exploited his powers to "develop a small number of financially strong, transcontinental carriers who would provide a strong market for larger, more comfortable passenger transports." David Mowery and Nathan Rosenberg, "The Commercial Aircraft Industry,' in Richard R. Nelson (cd.), Government and Technical Progress (New York, NY: Pergamon Press, 1982), p. 141.

33 NRC, op. cit., p. 27.

34 Mowery and Rosenberg, op. cit., pp. 141-143.

35 A 1970 study comparing adoption of technical innovations between California's nonregulated airlines and the regulated "trunk" carriers showed that all but 2 of 40 aircraft types operated between 1946 and 1965 were first introduced by the regulated airlines. W.A. Jordan, Airline Regulation in America (Baltimore, MD: Johns Hopkins University Press, 1970), p. 55. 
36 Standard and Poor's, "Aerospace Basic Analysis," p. A26 as cited in Barry Bluestone, Peter Jordan, and Mark Sullivan, Aircraft Industry Dynamics: An Analysis of Competition, Capital, and Labor (Boston, MA: Auburn House Publishing Co., 1981), p. 88.

37 These low bank rates may not persist. If the air travel market weakens and airlinesfind themselves with a glut ofaircraft, the residual value of used planes may drop dramatically.

38 This document stated: "It seems realistic that the private sector should bear the ultimate risks involved in an aircraft development project, but for the time being, the government will subsidize projects on the condition that a percentage of the profits be contributed to the government, contingent on success. . . Development of aircraft engineering must be conducted on the initiative and assistance of the government as it involves highly sophisticated and complex technology." Ministry of International Trade and Industry, "The Vision of MITI Policies in the1980s," pp. 291-292 as quoted in David C.Mowery and Nathan Rosenberg, The Japanese Commercial Aircrafi Industry Since 1945: Government Policy, Technical Development, and Industrial Structure (Stanford, CA: The International Strategic Institute at Stanford, 1985), pp. 16-17.

39 Ministry of International Trade and Industry, "The Vision of MITI Policies in the 1980s," pp. 291-292 as quoted in Mowery and Rosenberg, ibid., pp. 16-17.

40 Aerospace Japan Weekly, June 11, 1990, This figure is likely to increase steadily with the growth of sales of recently introduced commercial aircraft and engines in which Japanese manufacturers are major participants. The commercial aircraft industry has failed to live up to MITI's early ambitions and has failed to keep pace with the rates of growth seen in other targeted industries.

41 Some Japanese manufacturers of components and subsystems, especially electronics and advanced materials, appear to have become competitive with their best foreign rivals.

42 David C. Mowery, "The Japanese Commercial Aircraft Industry: Deja Vu All Over Again?" paper presented at the meetings of the International Studies Association, London, Mar. 29-30, 1988, p. 7. Reports differ on the extent to which the Japanese Government assumed financial responsibility for the YS-11, though all agree that the government's share was substantial. See Richard W. Moxon, Thomas P. Roehl, and Frederick Truitt, Emerging Sources of Foreign Competition in the Commercial Aircraft Manufacturing Industry (Washington, DC: U.S. Department of Transportation, 1985), p. 122; Japan Economic Institute, "Japanese Industrial Policy with a Twist: Commercial Aircraft," report No. 39A (Washington, DC: 1983), p. 2

43 Masao Kuno and Paul J. Rubin, "Japanese Aerospace-Aiming for the 21st Century, "Aerospace Japan, November 1984, p. 64. Another source states debts accumulated as of March 1980 were only $¥ 7.1$ billion. Koku Kikai Kogyo Shingikai (The Aerospace Advisory Committee), Konkai no Kokuki Kogyo Seisaku ni Tsuite: Daini Chukan Hokoku (Second Preliminary Report on the Future of the Aircraft Industry), Aug. 18, 1980, p. 16, as cited in Richard W.Moxon, Thomas P. Roehl, and Frederick Truitt, Emerging Sources of Foreign Competition in the Commercial Aircraft Manufacturing Industry (Washington DC: U.S. Department of Transportation, 1985), p. 122.

44 Richard J. Samuels and Benjamin C. Whipple, "Defense Production and Industrial Development: The Case of Japanese Aircraft," Chalmers Johnson, Laura D'Andrea Tyson, and John Zysman (eds.), Politics and Productivity: The Real Story of Why Japan Works, a research project of the Berkeley Roundtable on the International Economy (BRIE) (Cambridge, MA: Ballinger Publishing, 1989), pp. 309-310, note 6 .

45 One MITI official stated that MITI has also made loans to aircraft manufacture to pay for tooling and that companies have to reimburse MITI for the depreciation.

46 Italy's national aircraft manufacturer, Aeritalia, also shared 15 percent of the development and manufacturing work on the 767 . The 15 percent refers only to the value of the airframe and drops to about
7 percent of the total cost of producing the plane if components such as avionics and engines are included. JEI, op. cit., p. 5.

47 This system is also designed to insulate MITI politically by providing the financial assistance through intermediate organizations rather than directly from MITI coffers. Even so, MITI officials worry that the IADF may create dangers related to the General Agreement on Tariffs and Trade (GATT) negotiations currently underway between the United States and Europe, especially if the United States and Europe come to any substantive agreements over acceptable and unacceptable practices.

48 Officials of the Japan Aircraft Manufacturing Co., personal communication July 4, 1990 .

49 Umezama Kyoji, "Nichi/Bei Kyodo Jigyo Taisei Naru” (The Japan-U.S. Cooperative Development Effort Forms),Aerospace Japan, January 1991, p. 31.

50 If calculated by the NATO standard method, which includes some expenses, excluded in the Japanese accounting method, such as pension commitments, the defense budget has ranged between 1.2 and 1.5 percent of Japan's GNP. Michael W. Chinworth, "Financing Japan's Defense Buildup," working paper of the MIT-Japan Program, December 1989, p. 8.

51 Yasuichi Arao (cd.), “Aerospace Industry in Japan, 1989. 1990" (Tokyo: The Society of Japanese Aerospace Companies, 1989), pp. 30-31.

52 AIA, 1989-1990, op. cit., p. 21,

53 This does not include R\&D conducted at the U.S. Department of Energy, most of which relates to nuclear weapons.

54 Aerospace Japan Weekly, Mar. 25, 1991, p.4. and Budget of the United States Government: Fiscal Year 1992 (Washington, DC: U.S. Government Printing Office, 1991), Part I, p. 11, and Part II, p. 183. The official figures for Japanese military R\&D appears to be substantially understated because some $R \& D$ expenses the firms undertake are later compensated in (and counted as) procurement. However, there is no doubt that R\&D is a much bigger share of the U.S. defense budget than it is of the Japanese defense budget.

55 "Important Import," Aviation Week and Space Technology, Apr. 15, 1991, p. 11.

56 Michael Chinworth explains that "as a matter of policy TRDI emphasizes utilizing private sector resources to the greatest degree possible in order to minimize governm ent expenditures and hasten the development of new technologies and products." See Chinworth, op. cit., p. 37.

57 Ministry of International Trade and Industry, Agency of Industrial Science and Technology, "National Research and Development Program (Large-Scale Project), 1989," brochure, March 1989, p. 5.

58 In 1990 , MITI had available $¥ 133.5$ billion to loan to Japanese aircraft manufacturers to purchase foreign aircraft, $¥ 72.7$ billion from the JDB and $¥ 61.8$ billion from the Japan Export-Import Bank. Aerospace Japan Weekly, Jan. 15, 1990, p. 8.

59 Samuels and Whipple, op. cit.; Johnson et al., op. cit., pp. 289-290.

60 For example, a recent article reports, "MITI does not want Toyota to enter the military aircraft market for the time being. But it is positive about Toyota's entry into the commercial aircraft market. Toyota itself seems to be well aware of MITT's intention. Toyota will concentrate its efforts in the commercial aircraft market for a while." Aerospace Japan Weekly, Aug. 6, 1990, pp. 8-9.

61 Mowery, "The Japanese Commercial Aircraft Industry," op cit., p. 19.

62 This section looks only at the governments and companies of England, France, and Germany. Within Europe, Holland, Italy, Spain, and Belgium also have substantial capabilities in commercial aircraft and component production, and the governments in these countries have 
also been active in promoting the growth of their aircraft industries. The three countries dealt with here were chosen because they account for the bulk of Europe's aerospace production ( 88 percent of the total in 1988) and because they are the principal manufacturers of planes of the size dealt with in this study. Policy measures and the motivations behind them in France, England, and Germany are similar but not identical. This section will treat the government policies of all three countries together with differences pointed out as they arise, rather than presenting separate discussions for each. Commission of the European Communities, "The European Aerospace Industry, Trading Position and Figures, 1990," Directorate-General Internal Market and Industrial Affairs, Brussels, February 1990, p. 180.

63 Support for the aircraft industry also is a tool of regional development. Keith Hayward argues that this was the intent of French policy makers when they located substantial subcontracting work for commercial aircraft in Saint Naziere, then a depressed area of the country. France's main aircraftcenter, Toulouse, was a locus of aircraft construction before WWI, but the decision to concentrate aircraft production there after the war is also viewed as regional policy.

64 Richard Baldwin and Paul Krugman, "Industrial Policy and International Competition in WideBodied Jet Aircraft," Robert E. Baldwin (cd.), Trade Policy Issues and Empirical Analysis (Chicago, IL: The University of Chicago Press, 1988), pp. 68-69. Another study looks at the competition between all of Airbus' and Boeing's current products and concludes that an estimated \$20 billion in Airbus subsidies buys a net welfare gain in Europe of $\$ 7.7$ billion (including the cost of those subsidies) compared to a hypothetical U.S. monopoly but a net welfare deficit of $\$ 3.7$ billion compared to a U.S duopoly. Gemot Klepper, "Industrial Policy in the Transport Aircraft Industry," paper presented at the Center for Economic Policy Research workshop on Strategic Trade Policy, Cambridge, MA, Oct. 13 and 14, 1989, p. 24.

65 A recent EC report on the aviation industry cited this reason (among others) why the aircraft industry is a valuable asset: "A strong aeronautics industry should be recognized at the highest levels as an essential element in the promotion of a European identity ... [T] existence of a European aeronautics industry in world markets. . . helps to spread the economic and cultural influence of Europe." Euromart Study Report: Executive Summary, a joint study of the European Commission and nine major European aircraft manufacturers, April 1988, p. 33.

66 Boeing accomplished this with the 747; for 20 years no company has challenged Boeing's position in this category. The early Airbus launch of the A320 was a major factor deterring Boeing from launching a direct competitor. Boeing's 2-year lead hinging out the 727 before Douglas' DC-9 was important in the eventual success of the 727, as was Boeing's l-year lead bringing out the 707 before the DC-8. Airbus' deliveryoftheA3008 years before Boeing's 767 was a principal reason Airbus was able to get a foothold in the commercial aircraft business at all.

67 Fokker of the Netherlands also launched a jet transport, the F-28 (which sold 241 copies and continues to sell as the updated F-10O) and had a share of the VFW-614, a 50-seat short range jet that was canceled before any deliveries were made.

68 Keith Hayward, International Collaboration in Civil Aerospace (New York, NY: St Martł̌n's Press, 1986), p. 162. Converted using data from IMF, International Financial Statistics Yearbook, 1989 and BEA's GNP deflators.

69 Launch aid generally covers only development costs. Plants and equipment that might be reused for future models are not usually included in development, but aircraft-specific hardware such as jigs and tooling usually are. For example, the $\$ 725$ million British Aerospace got from the British Government to develop the A330/A340 wing will be used to fund not only the hardware development but also the flight testing and the cost of most of the tooling. March, op. cit., p. 18. Since development costs are the highest-risk portion of the total startup costs, government assumption of these costs is more valuable than government assumption of other costs. Nevertheless, launch aid covers only a portion of the investment needed to begin production of a new model. For example, the total financing needs for Aerospatiale's portion of the A330-340, is 7-8 billion French francs (\$1.4-1.6 billion). Of this, the French Government financed 60 percent of the development costs, amounting to 30-35 percent of the total capital required. The rest was borrowed. Representatives of Aerospatiale, personal communication, Oct. 16, 1990.

70 Withthenationalization of BACand Hawker-Siddeleyin 1977, the British Government discontinued the practice of providing launch aid. Equity investment was used instead. However, when the newly formed BAe was privatized in 1982, it once again became eligible for launch aid under the provisions of the 1949 Civil Aviation Act.To give launch aid, the government must be convinced that a project would not go ahead without the government's support, that there is a reasonable chance that the government will recoup its funds, and that the project is in the national interest. It is worth noting that these criteria are nearly identical to those the Japanese Government usein deciding whether or not to provide hojokin. Keith Hayward, Government and British Civil Aerospace (Manchester, U.K.: Manchester University Press, 1983), pp. 196-197 and representatives of the Department of Trade and Industry, personal communication Oct. 8, 1990.

71 This is the Gellman Research associates estimate. Keith Hayward estimates that roughly $\$ 1$ billion had been repaid by 1986 . The Economist reports that, "Every time an Airbus A31O flies off to join an airline. . $\$ 10 \mathrm{~m}$ is paid back to the governments." Gellman Research Associates, "An Economic and Financial Overview of Airbus Industries," Sept. 4, 1990, prepared for the International Trade Administration, U.S. Department of Commerce, pp. 2-3, Hayward, 1986, op. cit., p. 52, and 'Dissecting Airbus," The Economist, Feb. 16, 1991, p. 51.

72 Gellman Research Associates, op. cit., p. 2-2.

73 Keith Hayward, “European Civil Aerospace," contractor report for the Office of Technology Assessment, November 1990, p. 69.

74 Gellman Research Associates, op. cit., pp. 2-11.

75 Air France has A300s, A 310s, and A320s, but no 757s or 767s. Air France does have some 737s and 747s, but Airbus makes no planes of comparable sizes to compete with these. Air France also has some old $727 \mathrm{~s}$, but these were bought before the equivalent Airbus aircraft had entered production.

76 Hayward, International Collaboration in Civil Aerospace, op. cit., p. 53.

77 To help compensate for the French Government's pressure on Air France to buy the GE/SNECMA engines for their A31OS, Pratt offered the following package: rebuilding the Pratt and Whitney engines on Air France's 747s at a value of \$25 million, setting up anew engine maintenance shop at Charles de Gaulle airport, and providing direct offsets to French subcontractors of 30 percent of the value of the A310 engines (including those sold to other airlines) including turbine disc forgings, machine tools, and bearings. It was not enough. "Inside the Airbus Engine War," The Economist, Oct. 13, 1979, p. 81.

78 Hayward, “European Civil Aerospace,” op. cit., pp. 23-24.

79 The Avon was developed for the Hunter military jet and was also used in the Valiant bomber. Commercially, the engine was used in later Comet models and the French Caravelle. The Olympus was developed for the Vulcan bomber and then was upgraded for supersonic use and adapted on parallel tracks for the TSR-2 bomber and the Concorde (though its adaptation for civil use proved more difficult than initially expected). The Spey was first developed for a number of “ military aircraft, which were canceled in 1957. Rolls privatelyfinanced a civil version, which was used in the Trident, and the original military version was ultimately used in the British F-4s bought in the early 1960s. Keith Hayward, letter to OTA staff, Feb. 11, 1990, p. 7.

80 Since the CFM-56 program began, the U.S. Govemment has sometimes been a bigger SNECMA customer than the French Government.

81 “UK'S GEC Develops Airliner HUD,” Flight International, 
Oct. 31-Nov. 6, 1990, p. 17.

82 In contrast to the United States, where military aircraft manufacturers often state that DoD procurement rules hinder or prevent them from achieving synergies between their military and commercial products, all the European contractors interviewed for this study stated that they faced no such barriers. The government-ownedfirms pointed out that since any increased profits would only return to the government, the government would be silly to prevent firms from achieving synergies where possible. This close relationship between government and industry is more pronounced inGermany and France than in Britain.

83 For example, the British Ministry of Defense (MoD) has difficulty exercising cost control over Rolls Royce since there is no domestic alternative source of supply. Rolls Royce officials state that MoD has threatened to shift procurement contracts to U.S. suppliers but has never actually done so (though one small service contract was shifted to a U.S. competitor). Representatives of Rolls Royce, personal communication Oct. 10, 1990. The inability of the MoD to wield a credible threat of removing work from Rolls Royce plants may enable Rolls to generate higher profit margins on MoD contracts than U.S. companies can. These higher profitsfrom military production could be used to hold down commercial prices or to fund higher levels of $R \& D$.

84 The RAE and ONERA are funded from defense budgets while DLR is funded from civil sources. 


\section{Index}


Academic research, 50,219,273,274,275

Acer, 331

Advanced Display Manufacturers of America Research Consortium, 66

Advanced Manufacturing Initiative, 19

Advanced Technology Program, 13, 14, 24, 43, 62-63, 66-67, 74-75

foreign interests, 26,28, 110

Advertising, 136, 163

Advisory bodies, 15-16,25,72,73

Agency for International Development, 167

Agricultural Extension Service, 48

Agriculture, 48,58, 124

protectionism, 122,250

Airbus Industrie, 13,34,35,68, 192, 197, 225, 229-230, 341 , $352,353,355,356,357,358$

Aircraft industry, 34-35, 120-121, 154,341-358

capital investments, general, 217,343

cost factors, general, 343,345-346,350

European, 13, 34, 35, 68, 192, 197-198, 202, 217, 225, $229-230,341,352-358$

funding, 9-10,23-24,34,35,197-198, 217,343,345-348,350

GATT, 341,354

Germany, 354,355,358

historical perspectives, 345,348-350,353,355, 356

international agreements, 349, 358

Japanese, 35,251,341,349-352

joint ventures, 13, 34, 35,68, 192, 197, 225, 229-230, 341, $347-348,352,353,354,355,356-357,358$

military procurement, $158,159,341,344,345-347, \quad 351,352$, 357-358

R\&D, 9-10,23-24,34,64,74, 217,279,280,281,341, 342, $343-348,350-358$

U.S., 9-10,23-24,34,35,64, 74,120-121,217,230,251, 341, 342,344-349,355-356

see also National Aeronautics and Space Admini'stration

Aircraft Industry Manufacturing Law (Japan), 349

Aircraft Industry Promotion Law (Japan), 352

Air France, 356

Aluminum, 136

Antitrust law, 19,50,99,226-230

Europe, 192,209,226-228

foreign direct investment and, 98-99, 109-110

Japanese, 7-8,219,243,248,251，252,264

see also Business acquisitions and mergers

Apprenticeships, 46,47

Ardent Computer, 94

Argentina, 133

Arrangement on Guidelines for Officially Supported Export credits, 166

AT\&T, $67,73,320$

Australia 99, 100, 122,253

Automobile industry, 26,47,57,208

bilateral agreements, 205-207

dumping, 148

electric, 26, 70-71

European, 9,30,57,58,95, 122,202,203,205-208, 242

foreign direct investment, 91-93, 101-103, 107, 108

government procumbent, 26, 70-71, 159

Japanese，28,57,58,91-93,94,101-103，107,122,148，156,
205-208,242,246-248, 250,251,271-272,315-316, 327, 328,329

joint ventures, $86,206,314,327,328$

Korean, 314-316,333

Taiwanese, 327-329

U.S., 86, 102-103,242,246,315, 316,328

Awards, medals, and prizes, 19,50-52

Basic Guide to Exporting, 164

Bilateral agreements, 121, 122, 124, 127-128, 137-138

automobiles, 205-207

development assistance, 167

Free Trade Agreements, 122, 124, 127, 159

government procurement, 157, 159, 160-162, 274-275, 276277

with Japanese, 205-207, 274-275, 276-277

Boeing, 35, 120,217,230,251,342, 343,345

Brazil, 132, 133, 134

BRITE， 209,217,218,219,220， 221-222,223,225

Bureau of Apprenticeship and Training, 46

Bureau of Economic Analysis, 104

Bureau of Export Admini"stration, 60, 168, 171, 172-173, 174, 175

Bush Administration, 13,43,73,75, 137, 170-171

Business acquisitions and mergers, 19,94,98-99, 103,216

European, 191，192,226-227,354

Japanese, 245

see also Foreign direct investment

Buy American Act, 159, 160, 162

Buy American preferences, 157, 159, 160, 199

Canada

automobiles, exports to, 107

foreign direct investment, 27,89,90,93,95, 100

Free Trade Agreement, 122, 124, 159

Capital investments, $15,10,18-19,20,41,68,123$

aircraft, general, 217,343

depreciation, 17,25,44,74,245,313

Europe, 193,216

financing, government policies, 8, 17,44-45, 243, 245-246

foreign affiliates in U.S., 86,93-94,97, 100

Japanese， 8， 17,68，100,243,245-246,252， 279

Korean, 8, 17,68, 100,311,316,317,319, 320

Taiwanese, 325-326,327

see also Taxation, tax incentives

Cartels, 118

Japanese, 12,244-245,250-251,262

Celanese, 94

Chaebol, 310,315,320,321,329-330, 334

Chemicals industry, 197,210,250,315

China, 62,304

China Steel Corp., 328

Chrysler, 316

Civil Aviation Administration, 348

Civilian Technology Agency, proposed, 16,24,63-64,74,75

Commis sion of the European Communities, 30, 58, 191, 192 , 193,194-195,196,199, 205,207,217,218,221, 222,224, 225

antitrust, $227-228$

national subsidies, 228-230 
Cormmis sion on Industrial Competitiveness, 3

Committee on Foreign Investment in the United States, 109-110

Common Market Motor Vehicle Constructors, 208

Communications Intelligence Corp., 67

Communist countries, 170

see also China; Eastern Europe; Soviet Union

Competitiveness Policy Council, 15-16,72

Computer-integrated manufacturing, 219,254,271-272

machine tool industry, 18-19,48,49,67, 150,295

Computers and computer science

ESPRIT (EC), 31,209,215,217,218-219， 220-221,222,224, 226

Europe, general, 198,202-203,208,209, 225

export controls, 23,59, 168, 170, 171, 172-173

funding for technology, 32,65,66,67,254,263, 264,267-270, 277-278,279,280,318-319, 331,332

international cooperation, 217

Japanese， 32,123-124,127-128,152， 157,205,209,251,252, 256-279,280-281

Korean, 318-319

R\&D，general，32，65，66，67，251，252-264，265-270, 277-278,279-281,318-319, 331,332

supercomputers, 26, 32, 64, 70, 128, 131, 134, 157, 158, 253-281

Taiwanese, 331,332

tariffs on, 198

telematics, 209

training assisted by, 18

see also Semiconductors

Concorde, 354,356

Confidentiality, 151

Control Data Corp., 254-255,270,272,274, 275

Coordinating Committee for Multilateral Export Controls, 60 , $62,168,170-174$

\section{cost factors}

aircraft development, 343, 345-346,350

containment, 22

labor costs, 147,314,315

overhead, 147

see also Dumping

Council of Ministers of the European Communities, 194

Countervailing duties, 118,139-140, 141, 143-146,148-154 defined, 138

Court cases, see Litigation

Cray Research Co.,'158, 254, 255, 256, 262, 264, 271-272, 273-275,277-278,280-281

Cultural factors, 9

Canada/U.S. relations, 90

European, 219

Japenese, 31,219,250,252,270-272

patriotism 17, 157, 159, 160, 195,333

see also Social factors

Currency, 6-7,41,45,86, 108,118,127, 146,295

European, 355

Japanese，241,242,246,247,260，295,304-305

Korean, 307-310,315

Taiwanese, 322,324

Customs procedures, 20, 163

export licenses, 59, 60-61, 168-175

import licenses, 200-202

Daewoo, 315
Defense Advanced Research Projects Agency, 24,43,63,64,65, 279,280

Defense Appropriations Act, 160

Defense Technology Security Adminti tration, 173, 175

Denmark, 199

Department of Agriculture, 58,124,163

Department of Commerce, 16,19,24-25,50,55,58, 59,74,75, 77, 124

dumping and subsidies, 143,144,146,148,149, 150,152,154 export controls, 60-61, 168-175

export promotion, 163-165

R\&D funding standards, 65

semiconductors, 73

see also National Institute of Standards and Technology

Department of Defense, 25,34,60,75, 124, 172, 173,341

DARPA, 25,43,63,64,65,279,280

procurement, 69-70,71,109, 158,159,279,345,346

semiconductors, 69, 73

Department of Education, 47

Department of Energy, 19,49,73, 158,280

Department of Industry and Technology, proposed, 24,77

Department of International Commercial Policy, proposed, 77

Department of International Trade and Investment, proposed, 77

Department of Justice, 19,50, 109-110

Department of Labor, 46

Department of State, 23,60, 124

Depreciation, $17,25,44,74,245,313$

Developing countries, 9,332, 333

aid, 22, 59, 166-167

currency exchange, 307-308

export financing assistance by, 58

foreign direct investment in, 85,99,305-306

see also Korea; Taiwan

Domestic content requirements, 57-58, 65,95, 199, 204, 207, 315,323-324

Drug trafficking, 7

Dumping, 20,21,55, 117, 124, 138-140, 141-154

automobiles, 148

defined, 42, 138, 139

Department of Commerce, 143,144,146,148,149, 150,152, 154

electronics, Japanese, 57, 203,248

European antidumping actions, 192, 199-200,203-205

GATT, 138-143，149，152，153,204

International Trade Commission, 143，144，145，148，149, 150, 154

Japanese，11-12,57，139，146-148，199,203-205,248

Korean, 308

Eastern Europe, 7,60

EC and, 192,200

exports to, controls on, 168, 173, 174

Economic cycles

industrial targeting, 10

Japan, 10，12,244,247,250

Korea, 315

oil crises, 241, 245, 250, 315

Economies of scale, 15, 120, 121,204,327,329

Education and training, 9,13,16,17-18,44,4547, 50,137,280 computer assisted, 18

engineers, $18,47,325,346$

Japanese，31,50,240,247-248,252，273,274,275 
Korean, 312-313,317-318

Taiwanese, 325

see also Job training and aiding; Universities and colleges

E.I. du Pent de Nemours \& Co., 67

Electronic Research and Service Organization, 330,331

Electronics and Telecommunications Research Institute, 320

Electronics industry, 35,66,69, 135, 156,279

European, 9, 57, 196-197, 200, 202-205, 208, 216, 224, $225-226,228$

French, 194

international cooperation, 217

Japanese, 42,57,74,90, 150,203,228,243,248, 252

Korean, 314, 316-321

Taiwanese, 329-332

textile industry and, 12

U.S., 13,74, 135, 156

see also Computers and computer science; Semiconductors; Television

Electronics Industry Promotion Law (Korea), 317

Employee benefits, 123

Employment and unemployment

EC, free movement of workers, 194

foreign affiliates in U.S., 27, 86, 87, 88,89-90,95,99-100, 101-104

government procurement, set asides, 159

Japanese, 250-251

labor costs, $147,314,315$

labor-management relations, 102, 103,247,316

minorities, 46

trade policy and, 118, 122-123, 157

see also Job training and aiding; Wages and salaries

Energy sources

DOE, $19,49,73,158,280$

European, 199,213

Oil, 241,245, 250, 315

utilities, 162, 199

Engineers and engineering

education, 18,47, 325, 346

salaries, 174

Enhanced Proliferation Control Initiative, 62, 170, 175

Environmental issues, 121

Environmental Protection Agency, 43

ES2, 225

ESPRIT， 31,209,215,217,218-219， 220-221,222,224,226

ETA, 254-255,274,278

EURAM, 209

EUREKA，9,31,209-210,211-212，214-215,217,222,223-226 see also specific programs

Europe, see Eastern Europe; Western Europe; specific countries

European Community, 3, 191-230

aircraft industry, 13,34,35,68, 192, 197-198,202,217, 225, 229-230,341,352-358

antidumping actions, 192, 199-200, 203-205

antitrust (competition) policy, 192,209,226-228

automobile industry, $9,30,57,58,95,122,202,203,205-208$, 242

business acquisitions and mergers, 191, 192,226-227,354 computers, 198, 202-203, 208, 209, 225; see also ESPRIT cultural factors, 219

currency, 355

domestic content standards and, 57,58,95, 199,204,207

Eastern Europe, relations with, 192,200 electronics, general, 9,57, 196-197,200,202-205, 208,216, $224,225-226,228$

energy, 199, 213

export promotion and control, 164, 166,205,206, 357,358

exports by EC countries, general, 205, 206, 357

exports to EC countries, general, 193, 196-209

financing assistance, 191, 193

foreign direct investment, 24-25, 26, 30, 88, 90, 92, 95, 104-108,122, 192, 195-196,205-208

GATT, 191，198-199,204,354

government procurement, 70, 162，163，196，197，198-199, $222,353,355-356$

historical perspectives, 191,193,203-204,205-206, 208,209

industrial targeting, 7, 9, 13, 191, 202-203, 219, 228-230

institutions of, described, 194

Japan and, 191-192, 200，201-202，203-208，209，210, 216-219,222

licenses and permits, 200-202 200-202

national aids to competition, $7,13,191,202-203,219$, 228-230,354-355

nationalize industries, $162,230,352,358$

politics, 195,215-217,224,228

protectionism, 195, 196-197,203,205-208, 209

R\&D funding, 24-25,26,31,88,209-210, 214

Single Market, 30-31,41,95, 122, 191, 193-195,224

telecommunications, 9,209,216,218, 221,223-224, 230

Treaty of Rome, 191, 194,230

trade policy, general, 134, 137-138, 191-192

U.S. vis-á-vis，192-193，196-209,210

see also Commis sion of the European Communities; Framework Program; EUREKA; specific member countries

European Court of Justice, 195,229

European Free Trade Association, 212,222

Executive branch

advisory bodies, $15-16,25,72,73$

Bush Administration, 13,43,73,75, 137, 170-171

critical industries office, 76-77

Office of Science and Technology Policy, 73,77,280

Reagan Administration, 127, 274

trade barrier removal, general, 54, 155

see also U.S. Trade Representative

Export Administration Act, 59, 168-169, 170

Export Enhancement Act, 60,61, 170, 171

Export-Import Bank Act, 166

Export-Import Bank of the United States, 58,59,118,124,163, 165-166, 167,348-349

War Chest, 22,59, 167

Export promotion and controls, 22-23,58-62, 163-175

Asian countries, 9

CoCom, 60,62, 168, 170-174

computers, 23,59, 168, 170, 171, 172-173

Department of Commerce, 60-61, 163-165, 168-175

to Eastern Europe, 168, 173, 174

European, 164, 166,205,206,357,358

Eximbank financial assistance, 22, 58, 59, 118, 124, 163, 165-166, 167

financing, other government assistance, 22,58,59,77, 118, $154,163,166,309-310,311,348-349$

funding of, 164, 167-168

insurance, 58, 165-166

Japanese, 58,59, 166

Korean, 308,309-310,315,316 
licenses, 59,60-61, 168-175

loans, 58, 165-166,310,311

military technology, 23,29,60,61-62, 122, 175,281

standards, $170-171$

subsidies, 14, 21, 42, 52, 55, 117, 124, 138-154; see also

Countervailing duties; Dumping

Taiwanese, 323

telecommunications, $170,171,173-174$

U.S., general, 60, 168, 171, 172-173, 174, 175,348-349

Exports

automobiles, to Canada, 107

barriers to foreign markets, general, 4, 5, 20-21, 52, 53-55,

$117,118,125-138,155-157$

by EC countries, 205,206,357

to EC countries, 193, 196-209

foreign direct investment and, 86, 108,305-306

Korea, 33,297-300,301-305,308, 309-310,316-317

semiconductors, $59,127-128$

Taiwan, 33,297-300,301-305,322, 328,329

in trade theory, 119-120

Federal High Performance Computing program, 280

Financial factors, 16, 17,44-45

European, 191, 193

Eximbank, 22,58,59, 118,124, 163,165-166,167,348-349

exports, general government assistance, 22, 58, 59, 77, 118, $154,163,166,309-310,311,348-349$

governme nt risk sharing, 23-24, 25, 64, 65, 68-69, 74, $342-344,348,349-351,353-354$

Japanese, general, 243-245, 247-248, 261-262, 265, 279, 289-291

Korean, 309-311,313,314

Taiwan, 322,323

see also Capital investments; Currency; Interest rates; Investments; Loans; Savings

Ford, 246,315,328

Foreign aid, 22

loans, 59, 167

tied aid, 59, 166-168

Trade and Development Program, 23,59, 167-168

Foreign and Commercial Service, 58

Foreign Capital Inducement Law (Korea), 311

Foreign direct investment, general, 85-111

antitrust law, 98-99, 109-110

automobile industry, 91-93, 101-103, 107, 108

Asia and Pacific Rim countries, 8

developing countries, 85,99,305-306

domestic content standards and, 57-58,65,315,323-324

Europe, 24-25, 26, 30, 88,95, 104-108, 122, 192, 195-196, 205-208

exports and, 86, 108, 305-306

historical perspectives, $26,85,88-93,96,100,102,104,108$, 305

by Japan, 32,242,305-306,315-316, 327,328,329

in Japan, 12, 58,86, 100, 108,242, 246,247, 249,260-261

Korea，305-306,310-311,312，317,319,320,332-333

reinvestment of profits, 104-106

Taiwan, 305-306,321-322,323-324, 327,328,329,331

by U.S., $87-88,104$

see also Multinational companies

Foreign direct investment in U.S., 26,85-111

by Canada, 27,89,90,93,95, 100 employment and, 27,86,87, 88,89-90,95,99-100, 101-104 European countries, 90,92, 104-108

by Japanese, 86,87,89,90,91-95,97-101, 102-103,104-107, 108,111

military technology, restrictions, $87,109-110$

politics of, 95,99, 109

R\&D, 24-25,26,28,65, 87,88,93-94,95-96,98, 101，108, 110

reinvestment of profits, 104-106

State and local government promotion of, 87

Foreign exchange, see Currency

Foreign Exchange Control Law (Japan), 242

Foreign Investment Law (Japan), 242,261

Foreign Investment and Loan program, 243

Foreign policy

military export controls, 23,29,60-62, 122, 175,281

technology export controls, 23,29,60,61-62, 122, 175,281

Foreign trade, general

balances of, $4,11,108,121,136,197,241,308,322,341$

free market approaches, 3,5,7-9,41,42, 118-119, 121

market shares, 3,6, 298

see also Customs procedures; Dumping; Export promotion and controls; Exports; Imports; International agreements; Protectionism

Framework Program (EC), 9,28, 31, 209, 210-211, 212, 217, 222,223-226

specific programs, summarized, 213

see also specific programs

France, 194, 197,210-211,212,227, 229,230,352,354, $355-356,358$

Free market economies, 3,5,7-9,41,42, 118-119, 121

Europe v. U.S., 7, 191

Japanese, 240

Free Trade Agreements, 122, 124, 127, 159

Fringe benefits, 123

Funding

aircraft industry, 9-10, 23-24, 34, 35, 197-198, 217, 343, 345-348,350

computer technology, 32,65,66,67,254,263, 264,267-270, $277-278,279,280,318-319, \quad 331,332$

European R\&D, 24-25,26,31,88,209-210, 214

export promotion, 164, 167-168

foreign aid, 22,59, 167-168

R\&D， 24,32,34,49,63,64,65， 66,67,95-96,252,254，263， $264,267-270,277-278$, 279,280,298,313,314, 318,320, 325-326,327,346-348

State-level technology extension, 18,46,47-48

trade development, 23, 167-168

Fujitsu, 222,254,270,275-276, 278,279,281

General Accounting Office, 145, 161, 164,281

General Agreement on Tariffs and Trade, 20,21,22,28-29,53, $54,55-56,118,121-122,128,156-157$

aircraft, 341, 354

dispute resolution, 129-131

dumping, 138-143, 149, 152, 153,204

escape clause, 155

Europe and, 191, 198-199,204,354

foreign investments, 85

governme nt procurement, 26, 70-71, 157, 159-162, 198-199, 277,281 
history, 28-29, 128, 129, 131

Japanese and, 243,277

quotas and tariffs, 127, 128

Uruguay Round, 55,56, 128,129, 153, 191, 199

General Electric, 162, 199,263,355-356,357

General Motors, 86, 102-103,246,315

Generic technologies, 63, 110, 192

Georgia, 47-48

Germany, Federal Republic

aircraft, 354, 355, 358; see also Airbus Industrie

apprenticeships, 47

auto industry, 206

balance of trade, 11

capital investments, financing, 8, 17

foreign direct investment, 90

national aids to industry, 228, 354, 355

patents, 210

prices and exchange rates, 45

R\&D, 212,214

Government contracts and procurement, 25-26,31, 32, 34, 59, 69-71, 131, 135, 157-163

aircraft industry, 158, 159, 341, 344, 345-347, 351, 352, 355-356,357-358

automobiles, 26,70-71, 159

bilateral agreements, 157, 159, 160-162,274-275,276-277

capital investment financing, general, 8, 17, 44-45, 243, 245-246

DoD, 69-70,71, 109, 158, 159,279,345,346

DOE, 158

employment-related set asides, 159

European, 70,162,163,196,197,198 -199, 222,353,355-356

foreign aid, tied, 59, 166-168

GATT, 26,70-71, 157, 159-162, 198-199,277,281

GNT and, 159

Japanese, 32,70, 131, 134, 157,270,272-278,351

Korean, 318,320

military technology, general, 69-70, 157-160,279,280,281

minority set asides, 157

R\&D and, 70,71,324,345,346

small business set asides, 159, 160, 199, 221

standards, 71,85, 109, 195, 199

State and local governments, 71, 158-159, 160, 162

supercomputers, $70,158,270,272-278$

Government role, general, 14,41-43,62-78

advisory bodies, $15-16,25,72,73$

aircraft industry, 341-358

education, support for, 17-18, 31, 46-47, 50, 240, 247-248, $252,273,274,275,312-313,317-318,325$

financial risk sharing, 23-24,25,64,65,68-69, 342-344,348, 349-351,353-354

joint ventures with industry, general, $14,24,26,41,42,49,53$, 62-67,71-78

laboratories, 19,49,273,279

national aids to competition, $7,13,191,202-203,219$, 228-230

see European Community; Export promotion and control; Funding; Industrial targeting; Laws; Local government; Nationalized industries; State government; Taxation; specific departments, agencies, and programs

Gross domestic product

European, 196

foreign trade indicators and, 11
German, 11

Japanese, 5,68,295

Korea and Taiwan, 295,297

Gross national product

European, 31, 164,208

export promotion and, 164

foreign direct investment and, 26

foreign trade indicators and, 4,6

government procurement and, 159

Japanese, 243,349

Korean, 313

Taiwanese, 322,323

Hampshire Instruments, Inc., 67

High Speed Computing System for Scientific and Technological Uses Project, 32,265-268

Historical perspectives

aircraft industry, 345, 348-350, 353, 355, 356

currency values, 6,45

Europe, 191, 193,203-204,205-206, 208,209

Federal aid to industries, direct, 25,69

Federal organization, 77

foreign direct investment, $26,85,88-93,96,100,102,104$, 108,305

GATT, 28-29, 128, 129, 131

Japanese, competition controls, 7-8,219,240

Japanese, post-War, 5, 10, 31, 32, 33, 123-124, 205-206, 239-252,260-270,279, 349

Japanese, pre-War, 239-240,242,246

Korea, 295-321

supercomputers, 254-255, 260-264

Taiwan, 321-334

U.S. trade policy, 52,54, 117, 119-120, 121, 167-168,345

U.S. trade deficit, 136,241

U.S. wages, 3-4

Hitachi, 254,272,278,279,281, 320

Honda, 329

Human resources, 13, 17-18,45-47

see also Education and training; Job training and aiding

Hyundai, 315,320,321

IBM, $88,222,253,254,260-261 ， 262,263,268-269,272,281$ 327,331

ICL, 222

Imports, 155-157

domestic content requirements, 57-58, 65, 95, 199, 204, 323-324

import dependence, 11-13

Korea and Taiwan, 300,302,303,304,308, 316

licenses, 200-202

multinational firms, affiliates and, 27,32,86,90,97-98, 101, 106-108

quotas and tariffs, $4,20,30,117,118,121,127,128,146,193$, 198,206-208,243,244, 277,308-309,316,322-323

see also Countervailing duties; Dumping; Protectionism

Income, 3-4

poverty, 46

profits of direct foreign investors, 104-106

see also Wages and salaries

Industrial capacity and utilization, 11-12,245

Industrial Development Law (Korea), 307

Industrial Research and Development Advisory Committee, 220 
Industrial targeting, 9-11,29,32,53,72-76, 117, 197-198 European, 7, 13, 191,202-203,219,228-230, 341,352-358 French, 194,228,230

Japanese, 9, 10,29,32,53,239,244-252, 264-281,349-352 Korean, 307,314-321,332,333

Taiwanese, 327-332,333

Informatics, see Computers and computer science

Information Promotion Agency, 251

Institute for New Generation Computer Technology, 268

Insurance

employee health, 123

export assistance, 58, 165-166

Intellectual property, 19,50

Korea, 131,312

Taiwan, 326,330

see also Patents

Interest rates, $17,45,68,243,252,262,310-311,354-355$

International agreements

aircraft industry, 349, 358

CoCom, 60,62, 168, 170-174

computers, 217

EFTA, 212,222

foreign aid, 22,59

OECD, 28,85,196,243,349

semiconductors 11,12

technology, 216-217,222

see also Bilateral agreements; European Community; General Agreement on Tariffs and Trade

International Aircraft Development Funds, 350

International Monetary Fund, 308

International TradeAdmin'fí tration, 11,99, 146, 163, 164

International Trade Commission, 56, 124, 155-156 antidumping, 143, 144, 145, 148, 149, 150, 154

antitrust, 226-230

European actions, 199

International Trade Organization, 54, 128

Investments

domestic, 86,326

industrial targeting and, 10

see also Capital investments; Foreign direct investment

Israel, 122, 159

\section{Japan, 3,5-7,31-33,43,239-281}

aircraft industry, 35, 251,341, 349-352

automobiles, 28, 57, 58, 91-93, 94, 101-103, 107, 122, 148, 156,205-208,242,246-248, 250,251,271-272,315-316, $327,328,329$

bilateral agreements with, 205-207,274-275,276-277

capital investments, financing, 8, 17,68, 100,243, 245-246, 252,279

cartels, 12,244-245,250-251,262

competition controls, 7-8, 219,243, 248,251,252,264

computers, 32, 123-124, 127-128, 152, 157, 205, 209, 251, 252,256-279,280-281

cultural factors, $31,219,250,252,270-272$

currency, 241,242,246,247, 260,295, 304-305

dumping, 11-12,57, 139, 146-148, 199,203-205,248

economic cycles, effect on, 10, 12,244,247,250

educational system, 31,50,240,247-248,252, 273,274,275

electronics general, 42, 57,74, 90, 150, 203, 228, 243, 248, 252

employment issues, $250-251$
Europe Vis-á-Vis, 191-192,200,201-202, 203-208,209,210, 216-219,222

export promotion by, 58,59, 166

exports to, promotion of, 165

financial factors, general, 243-245, 247-248, 261-262, 265, 279,289-291

foreign aid, 167

foreign direct investment by, general, 32, 242, 305-306, $315-316,327,328,329$

foreign direct investment by, in U.S., 86,87, 89,90,91-95, 97-101, 102-103, 104-107, 108, 111

foreign direct investment in Japan, 12,58,86,100,108,242, $246,247,249,260-261$

GATT, 243,277

government procurement, $32,70,131,134,157,270$, 272-278,351

history, competition controls, 7-8,219,240

history, post-War, 5, 10, 31, 32, 33, 123-124, 205-206, 239-252,260-270,279, 349

history, pre-War, 239-240,242,246

industrial targeting, 9, 10,29,32,53,239,244-252, 264-281, 349-352

keiretsu, 12-13,32,95,226,243, 261,270-271,272,279, 334

Korea and Taiwan, relations with, 304-305, 311, 314-316, $328,329,333$

loans, 241-242,243,244,245, 262,279,350

politics, 250,278

price controls, 7, 11-12,45,99,203-204, 240,244-245,262, 264,275-277,278,295

protectionism, general, 13, 54-55, 136-138, 240, 242, 244, $245,247,249,253,260,261$

$R \& D$, general, 8, 123,251,252-264,265-270

savings, 240, 243

semiconductors, 11, 12,25,54-55,68,69,99, 127-128, 132, $136,137,139,152-153,205,209,218,219,219-250,252$, 263-264,275,278

standards, 247, 269

steel, 103, 244-246

supply industries, 222,242, 247

tax incentives, 8,32,243,244,245,247, 262

technology, diffusion of, general, 18,28,47,48-49,98,244

technology, general, $7,8,98,242,247$

telecommunications, 32, 137, 262, 263-264, 268, 273-274, 278

television, $28,248,122,124,248$

trade balance with U.S., 136

universities, 31, 50, 240, 247-248, 252, 273,274, 275

wages, 5,32

see also Ministry of International Trade and Industry

Japan Development Bank, 241-242,245,262,350

Japan Electronic Computer Co., 261-262,270

Japan Information Processing Development Center, 269

Japan Telegraph and Telephone Co. (NTT), 262,263-264,268, 273-274,278

JESSI, 214-215,218,220,222, 225,226

Job training and aiding, 17-18,46-47, 137

apprenticeships, 46,47

foreign affiliates, 102, 108

Joint ventures, 330

aircraft industry, 13,34,35,68, 192, 197,225,229-230,341, $347-348,352,353,354,355,356-357,358$

automobile industry, 86, 206, 314, 327, 328 
governme nt/industry, $14,24,26,41,42,49,53,62-67,71-78$ legal issues, general, 19

multinational and domestic firms, 86-87, 98, 108, 110, 136, $216,261,315-316,319,327,328,331$

Sematech, 14,24,26,42,54,64-65, 74,99, 109, 154

small businesses, 108

see also Advanced Technology Program

Keiretsu, 12-13,32,95,226,243, 261,270-271,272,279, 334

Kia, 315

Korean, South, 3,8,29,33-34,57, 123,295-321,332-334

automobiles, 314-316, 333

capital investment, 8, 17,68, 100, 311,316, 317,319, 320

chaebol, 310,315, 320,321, 329-330,334

computers, $318-319$

currency, 307-310,315

dumping, 308

educational system, 312-313,317-318

electronics, 314, 316-321

export promotion and control, 58, 165-166

financial factors, 309-311,313,314

foreign direct investment, 305-306,310-311, 312,317,319, 320,332-333

government procurement, 318,320

industrial targeting, 307, 314-321, 332, 333

intellectual property, 131, 133

Japan, relations with, 304-305,311,314-316, 328,329,333

loans, 307,310,311,314

nationalized industries, 318, 321, 334

politics, 295-296,307-321,334

prices and price controls, 295,315,319

productivity, $314,315,316$

protectionism, 296,308-309,316,334

R\&D, 298,312-314,317,318-319, 320,333

semiconductors, 295, 316-321, 333

small business, 314

suppliers, 308, 315

taxes, $313,314,316$

technological innovation, general, 297,311-314,332-333

technology transfer and diffusion, 302-303, 311-312, 314, $316,318,319,333$

telecommunications, 318,320

wages, 316

Korean Institute of Electronics Technology, 317-318,320

Korean Trade Promotion Corp., 310

Korean Traders Association, 310

Kubota Ltd., 94

Labeling, 163, 165

Labor costs, 147,314,315

Labor-management relations, 102, 103,247,316

Law on Temporary Measures for Promoting the Machinery Industries (Japan), 247

Laws, specific Federal, 124-125, 126

Buy American Act, 159, 160, 162

Defense Appropriations Act, 160

Export Adml'hl's tration Act, 59, 168-169, 170

Export Enhancement Act, 60,61, 170, 171

Export-Import Bank Act, 166

National Cooperative Research and Development Act, 76

Omnibus Trade and Competitiveness Act, 70, 73, 109, $161-162,275$
Technology Transfer Act, 49

Trade Act, 21,22,54,62, 124-126, 130-136, 154, 155-156

Trade Agreements Act, 160

Laws, specific foreign

Aircraft Industry Manufacturing Law (Japan), 349

Aircraft Industry Promotion Law (Japan), 352

Electronics Industry Promotion Law (Korea), 317

Foreign Capital Inducement Law (Korea), 311

Foreign Exchange Control Law (Japan), 242

Foreign Investment Law (Japan), 242,261

Industrial Development Law (Korea), 307

Law on Temporary Measures for Promoting the Machinery Industries (Japan), 247

Single European Act, 193,224

Legal issues

confidentiality, 151

technology transfer, 19

see also Antitrust laws; Intellectual property; Litigation

Licenses and permits

Europe, 200-202

import/export, 59,60-62, 134, 168-175

multinational corporations, 216, 314

of patents, 19,49,50,260, 268-269, 311-312, 316,333,351

Light Age, Inc., 67

Litigation, 140-154, 193, 195

European Court of Justice, 195,229

foreign direct investors, 94,98-99, 109-110

supercomputers, 268-269

Loans

European, 191, 193,354-355

export assistance, 58, 165-166,310,311

foreign aid, 59, 167

governme nt risk-sharing, 68-69, 241-242, 350

interest rates, 17,45, 68, 243, 252, 262, 310-311, 354-355

Japanese, 241-242,243,244,245，262,279,350

Korean, 307,310,311,314

Taiwanese, 323,325-326

U.S., 58,59, 118, 124, 163,165-166,348

Local government

foreign investment promotion, 87

procurement, 71, 158-159, 160, 162

Lockheed, 342,348,354

Lufthansa, 356

Machine tool industry, 18-19,48,49,67, 150,228,295

Making Things Better: Competing in Manufacturing, 16,17,44, 68,117

Malcolm Baldrige National Quality Award, 19,50-52

Management and managers, 99-100, 102-103, 108

Materials sciences

European, 209,213,217,218,219, 220,223

superconductors, 53,124

see also semiconductors

Matsushita Communication Industrial Co. Ltd., 98

Mazda, 315

McDonnell Douglas, 35,217,230,343,354,355

McDonnell Douglas Electronic Systems Co., 67

Mega project, 214,215

Mergers, see Business acquisitions and mergers

Microelectronics \& Computer Technology Corp., 66

Middle East, 87

Military technology, 122,279 
aircraft, 158, 159,341, 344,345-347, 351, 352, 357-358 commercial synergies, 69-70, 154, 341, 344, 345-346, 351, 352,357-358

export controls, military, 23, 29, 60-62, 168, 172, 173, 175, 323,346

foreign direct investment, restrictions, $87,109-110$

Japanese automobile industry, 246

procurement, 69-70, 157-160,279,280,281

see also Department of Defense

Military training, 46-47

Ministry of International Trade and Industry, 11-12, 16,31,33, $35,43,127-128,136,177,219,228,240-253$ (passim), 260-261,263,265-278, 350-352

foreign direct investment, 87,97,99-100, 101,242,243

Minorities

education, 18

employment, 46

governme nt procumbent, set asides, 157

Mitsubishi, 315-316,329

Models, trade, 119, 121, 122-123, 150

Most-favored-nation status, 122

Motor vehicles, see Automobile industry

Multinational companies, 26-27,216

foreign affiliates, import practices, 27,32,86,90,97-98,101, 106-108

foreign affiliates in U.S., 26-28, 106-108

joint ventures involving, 86-87,98, 108, 110, 136,216,261, $315-316,319,327,328,331$

see also Foreign direct investment

Mutec, 151

National Academy of Sciences, 168, 174-175

National Advisory Committee on Semiconductors, 15, 25, 72, 73

National Aeronautics and Space Administration, 9-10, 23-24, $34,64,74,279,280,281, \quad 341,344,345,347-348$

National Aerospace Laboratories, 351

National Center for Manufacturing sciences, 19,66

National Committee on Semiconductors, 69

National Cooperative Research and Development Act, 76

National Institute of Standards and Technology, 24, 51, 52, 74-75

see also Advanced Technology Program

National Intergroup, Inc., 103

Nationalism, 199,261

Buy American preferences, 157, 159, 160, 199

domestic content requirements, 57-58,65,95,199,204, 207, 315,323-324

patiotism, 17,157, 159, 160, 195,333

Nationalized industries

European, general, 162,230,352,358

Korean and Taiwan, 318,321,328,330,334

U.S., 70, 162

utilities, 162, 199

National Label Co., 151

National Science Foundation, 47,50,63,73,279,280

National Steel Corp., 103

National Storage Industry Consortium, 66

NEC, 254,255,258,270,272, 273,275,278,279,281

Netherlands, 214,229

New Information Technology Project, 269

New United Motor Manufacturing, Inc., 86, 102-103
New Zealand, 122

Nicolet Instruments Corp, 98

Nippon Sanso, 98-99, 109-110

Nissan, 314,316,327,329

NKK, 103

Nonvolatile Electronics, Inc., 67

Norway, 135

Office of Science and Technology Policy, 73,77,280

Oil shocks, 241,245,250,315

Omnibus Trade and Competitiveness Act, 70,73,109,161-162, 275

Organizational factors, $15-16,71-73,76-78$

business consortia, 46,65, 66,87, 192,209,224,225,320, 351-352

chaebol, 310,315, 320,321, 329-330,334

EUREKA， 9,31,211-212,214-215， 217,222,223-226

European, general, 217

government bureaucracy, 240, 241

job training, 46

keiretsu, 12-13,32,95,226,243, 261,270-271,272,279, 334

management and managers, 99-100, 102-103, 108

trade associations, 46

vertical integration, $68,217,218,255,278-279$

see also Joint ventures

Organization for Economic Cooperation and Development, 28, $85,196,243,349$

Overhead, 147

Parts, see Suppliers

Patents, 210-211,240,249

licensing, 19,49,50,260,268-269, 311-312,347-348,351

Patriotism, 17, 157, 159, 160, 195,333

Philips, 214-215,331

Planning, economic, 16,4243,44,62-65,71-78

advisory bodies, $15-16,25,72,73$

Korea and Taiwan, 8,9,312-313,324,325

Politics, 41,45, 123, 168

European, 195,215-217,224,228

foreign investors, 95,99, 109

Japanese, 250,278

Korea, 295-296,307-321,334

Taiwan, 295-296,322,333,334

Pontiac, 315

Postal Service, 26,70-71,243

Poverty, 46

Pratt \& Whitney, 217,344,346,355-356

Prices and price controls, 45, 118,350

Buy American preferences, 157, 159, 160, 199

cartels, 12, 118, 244-245, 250-251,262

customs value, 127

European telecoms, 216

foreign direct investors, 106

Japanese, 7, 11-12,45,99,203-204, 240,244-245,262,264 $275-277,278,295$

Korea and Taiwan, 295,315,319,328

subsidies, 14,21,42,52,55, 117, 124, 138-143

supercomputers, 258-259,262,264,275-278

see also Dumping

Procurement

private sector, $270-272,280-281$

see also Government contracts and procurement 
Production and productivity, 11-12,22

costs and trade, 120

domestic content requirements and, 57,315

industrial capacity and utilization, 11-12, 245

Korean, 314, 315,316

Profits

dumping and, 152

foreign direct investment, reinvestment, 104-106

Protectionism, 8,21-22,29,55-57, 117-118, 121, 122

agricultural products, 122, 250

developing countries, 9

European, 195, 196-197,203,205-208, 209

industrial targeting and, 10

infant industry, general, 123-124

Japanese, 13,54-55, 136-138,240,242,244，245,247,249, $253,260,261$

Korean, 296,308-309,316,334

steel industry, 122-123

Taiwanese, 296,322-323,328-329, 334

textiles, 122-123

U.S., general, 14,41

Public opinion

Japanese, 43

patriotism, 17,157, 159, 160, 195,333

Quality and quality control, 42

awards, 19, 50-52

see also Standards

\section{RACE, 209,218,221,223}

RCA, 263,330

Reagan Admíhi'stration, 127, 274

Recession, see Economic cycles

Reconstruction Finance Corp., 25,69

Regionalism 122, 192

Regulations

antidumping/countervailing charges, 140-154

nontariff barriers, general, 163

see also Licenses and permits; Standards

Research and development

academic, 50,219,273,274, 275

aircraft, 9-10,23-24,34,64,74, 217,279,280,281,341, 342, 343-348,350-358

computers, 32,65, 66, 67, 251, 252-264, 265-270, 277-278, 279-281,318-319,331, 332

consortia, 46, 65, 66, 87, 192, 205, 209, 224, 225, 320, 351-352

DARPA, $25,43,63,64,65,279,280$

electronics, general, 66-67

European, 8,24-25,26,31,88, 192,209-226,228

Federal role, U.S., 9-10, 13,20,23-25,53,62-65

foreign direct investors, 24-25, 26, 28, 65, 87, 88, 93-94, 95-96,98, 101, 108, 110

free market economies, 8

funding, $24,32,34,49,63,64,65,66,67,95-96,252,254$, $263,264,267-270,277-278,279,280,298,313,314,318$, $320,325-326,327,346-348$

generic technologies, 63, 110, 192

Germany, 212,214

government procurement, general, $70,71,324,345,346$

Japanese, general, 8, 123,251,252-264,265-270

Korean, 298,312-314,317,318-319, 320,333
NASA, $9-10,23-24,34,64$

semiconductors, 14, 24, 26,42, 54,64-65, 74, 99, 109, 154, $205,209,214-215,217-218,219,220,222,225-226$, 317-319,330-332

small businesses, 18-19,47,48, 117, 209, 220-222

standards, 24-25, 26, 65

subsidies and trade, 149, 152-153, 154

Taiwanese, 298,324-327,330-332, 333

as trade externality, 121

U.S., general, 13,14,24,26,28,43,62-63, 66-67,74-75,110, 118

see also Advanced Technology Program; Framework Program; ESPRIT; EUREKA; Technology transfer and diffusion

Research and Development in Advanced Communications in Europe Program, 71

Rolls Royce, 342

Saginaw Machine Systems, Inc., 67

Salaries, see Wages and salaries

Samsung, 316

Savings

American, 17,44,45,86, 136, 137

Japanese, 240,243

Korean, 322

Taiwanese, 323

Science and Technology Advisory Group, 324-325

Sematech, 14,24,26,42,54,64-65, 74,99,109, 154

Semiconductor Industry Association, 127

Semiconductors, $11-12,15,25,68,69,249-250$

DoD, 69,73

European, 30,95,192,198,199,203， 204,205,209,214-215 $218,220,222,225-226$

exports, $59,127-128$

Japan, 11, 12,25,54-55,68,69,99, 127-128, 132, 136, 137, 139,152-153,205,209, 218,219,249-250,252, 263-264, 275,278

Korea, 295,316-321,333

National Advisory Committee, 15,25,72,73

patents, 249

R\&D, general, 14,24,26,42,54,64-65, 74,99,109,154,205, 209,214-215,217-218, 219,220,222,225-226, 317-319, 330-332

Sematech, 14,24,26,42,54,64-65, 74,99,109, 154

Taiwanese, 329-332

U.S., 69,73,99, 109, 127-128, 152-153, 154

Semiconductor Trade Agreement, 11, 12

Semi-Gas System, 98-99, 109-110

Siemens, 214

Single European Act, 193,224

Small and medium-sized businesses awards, 51

European actions, 209,220-222,228

foreign trade, assistance, 145, 157

government procurement, set asides, 159, 160, 199,221

joint ventures, foreign partners, 108

Korean, 314

Taiwanese, 321,324,326-327,329-330, 331

technology development and diffusion, 18-19, 47, 48, 117, 209,220-222

Small Business Admithis tration, 209

Smith Corona Corp., 148-149 
SNECMA, 356,357

Social factors, $14,118,157,250,325$

mergers, 227

see also Cultural factors

Soviet Union, 60,62, 168

Special Drawing Rights, 159

Sperry Rand, 261

SPRINT, 221

Ssang Yong Motors, 315

standards

domestic content requirements, 57-58,65,95,199,204, 207, 315,323-324

European, 57-58,95, 195, 199,200-202,204,207, 223-224

export controls, $170-171$

foreign direct investment and, 57-58,65,85,95, 109-111

government procurement, 71, 85, 109, 195, 199

Japanese, 247,269

labeling, 163, 165

R\&D funding, government, 24-25,26,65

as trade barriers, general, 20, 136, 137-138, 163

U.S., 348

Standards of living, 3-4,42, 108, 120, 121

European, 210,213

German, 11

Japanese, 32

State government

foreign investment promotion, 87

procurement, 71, 158-159,160, 162

technology extension, $18,46,4748$

Steel industry

Japanese, 103,244-246

protectionism, 122-123

Stellar Computer, 94

Stocks and shares, 279

Supercomputers, 26,32,64, 128, 131, 134, 157,253-281

government procurement, $70,158,270,272-278$

Superconductors, 53, 124

Suppliers, general

education of suppliers by manufacturers, 47

Japanese, 222,242,247

Korean, 308,315

vertical integration, $68,217,218,255,278-279$

Sweden, 47

Taiwan, 3,8,33-34, 127, 133,295-306,321-334

automobiles, 327-329

capital investments, 325-326, 327

computers, 331, 332

currency, 322, 324

exports, 33,297-300,301-305,322, 328,329

financial factors, 322,323

foreign direct investment, 305-306, 321-322, 323-324, 327, $328,329,331$

industrial targeting, 327-332, 333

intellectual property, 326, 330

Japan, relations with, 304-305,328,329,333

loans, 323,325-326

nationalized industries, 328, 330, 334

politics, 295-296,322,333,334

prices and price controls, 295,328

protectionism, 296,322-323,328-329, 334

R\&D, 298,324-327,330-332, 333 small businesses, 321,324,326-327,329-330, 331

technology diffusion, 302-303,324,330

Taxation, general, 44

European, 193,353

foreign direct investors, 106

Korean, 316

tax incentives, 326

Taxation, incentives, 10, 17, 19,20,25,41,44-45,68

capital gains, 45

depreciation, $17,25,44,74,245,31-3$

high-technology investments, 49, 118

Japanese, 8,32,243,244,245,247, 262

Korean, 313,314,316

Taiwanese, 326

Technical assistance

government extension services, 18, 46,4748

to suppliers from manufacturers, 47

training linked with, 18,46

Technological innovation, 8, 14, 16-20,44

European, 195,209-226

export controls to protect, 23, 29,60, 61-62, 122, 175, 281

foreign direct investment, restrictions, 87, 109-110

funding, 32,65,66,67,254,263, 264,267-270,277-278, 279, 280,318-319,331,332

generic technologies, 63, 110, 192

industrial targeting, 9-11

international agreements, 216-217,222

Japanese, 7,8,98,242,247

Korean, 297,311-314,332-333

knowledge intensity, 120-121

Taiwanese, 297,324-327

tax incentives for investment, 49, 118

see also Military technology; Research and development

Technology Transfer Act, 49

Technology transfer and diffusion, 13,14, 18-20,29,44,47-52, 120-121

awards affecting, 19,50-51

education and, 46

generic technologies, 63, 110, 192

industrial targeting and, 10

Japanese, 18,28,47,48-49,98,244

Korean, 302-303,311-312,314, 316,318,319,333

military technology, restrictions, $23,29,60-62,87,109-110$, $168,172,173,175,323,346$

patent licensing, 19,49,50,260,268-269, 311-312,316,333, 347-348,351

small and medium-sized businesses, 18-19,47,48, 117,209, 220-222

State-level technology extension, 18,46,4748

supercomputers, 260

Taiwanese, 302-303,324,330

see also Intellectual property

Technology Transfer Project Group, 19,49

Telecommunications, 159

European, 9,209,216,218,221,223-224, 230

export controls, 170, 171, 173-174

international cooperation, 217

Japanese, 32, 137,262,263-264,268, 273-274,278

Korean, 318,320

U.S., $67,70,73,320$

Telematics, 209

Television 
high-definition, 74, 122, 124,229

Japanese, 28, 122, 124,248

Texas Instruments, 249,331

Textiles, 12,216,218,314

protectionism, 122-123

Thatcher, Margaret, 195,228,229

Tokyo Institute of Technology, 274

Torrington Co., 143-145, 150

Toyota, $86,314,328,329$

Trade Act, 21,22,54,64, 124-126, 130-136, 154, 155-156

Trade Agreements Act, 160

Trade and Development Program, 23,59, 167-168

Trade associations, 46

Trade Promotion Coordinating Committee, 163

Trade Remedy Assistance Office, 145

Treaty of Rome, 191, 194,230

United Kingdom, 57,90,195,205,207,208, 222,228,229,230, $311,354,355$

United States of America, 85-175

aircraft industry, 9-10, 23-24, 34, 35,64, 74, 120, 217, 230, $251,341,342,344-349, \quad 355-356$

automobiles, 86, 102-103,242,246,315, 316,328

EC relations with, 192-193, 196-209,210

electronics, general, 13,74, 135, 156

employment, 27,86, 87,88,89-90,95,99-100, 101-104

Europe Vis-à-Vis, 192-193, 196-209,210

export controls, military, 23,29, 60-62, 168, 172, 173, 175, 323,346

Export-Import Bank of the United States, 58, 59, 118, 124, $163,165-166,348$

export promotion and control, general, 60,168, 171,172-173, 174, 175,348-349

foreign direct investment by, 87-88, 104

Free Trade Agreements, 122, 124, 127, 159

government procurement, 25-26, 34, 59, 69-71, 131, 135, $157-163,279,281$

historical perspectives, 34,52,54, 117, 119-120, 121, 136, 241, 167-168,345

loans, 58,59, 118, 124, 163, 165-166,348

nationalized industries, 70,162

protectionism, general, 14,41

R\&D, Federal role, U.S., 9-10, 13,20,23-25,53,62-65

R\&D, general, 13,14,24,26,28,43,62-63,66-67,74-75, 110, 118

savings, $17,44,45,86,136,137$

semiconductors, 69,73,99, 109, 127-128, 152-153, 154

standards, 348

telecommunications, $67,70,73,320$

trade policy, general, 7, 14,20-23,28-29,52-62, 117-175 wages and salaries, 3-4, 86, 95, 103-104, 108

see also Foreign direct investment in U. S.; specific govern-

ment departments, agencies, and programs of the Federal Government

Universities and colleges

academic research, 50,219,273,274, 275

engineers, $18,47,325,346$

European, 219

Japanese, 31,50,240,247-248,252, 273,274,275

Korean, 312-313,317-318

Taiwanese, 325

Uruguay Round (GATT, 55,56, 128, 129, 153, 191, 199

U.S. and Foreign Commercial Service, 163, 164-165

U.S. Trade Administration, proposed, 16

U.S. Trade Representative, 16, 20-21, 53, 55, 70, 77, 124, 130-132, 136, 137, 162-163,275,276

Utilities, 162, 199

Vertical integration, 68,217,218,255,278-279

Vitalec, 320

Vocational education, see Job training and aiding

Voluntary restraint agreements, 121

Wages and salaries, 123

Bureau of Export Admithistration, 174

foreign affiliates in U. S., 86,95, 103-104, 108

Japanese, 5,32

Korean, 316

U.S., general, 3-4

War Chest, 22,59, 167

Western Europe

aircraft industry, 13,34,35,68, 192, 197-198,202,217,225, 229-230,341,352-358

export promotion and controls, 164, 166, 205,206,357,358

foreign direct investment, 27,87,90,95, 100, 101,104

government procurement, 70

Korea and Taiwan, exports to, 303

national aids to competition, 7, 13, 191

politics, $195,215-217,224,228$

telecoms, 9,209,216,218,221,223-224, 230

trade policy, general, 117, 118

see also European Community; specific countries

Westinghouse, 162

Women

education, 18

World Bank, 244,307

Zaibatsu, 243

Zweckform, 151 


\section{Other Related OTA Reports}

-Making Things Better: Competing in Manufacturing

Free summary available from OTA

OTA-ITE-443, February 1990; 244p.

GPO stock \#052-003-01178-6; \$11.00 per copy

NTIS order \#PB90-205469

- Paying the Bill: Manufacturing and America's Trade Deficit

OTA-ITE-390, June 1988; $92 \mathrm{p}$.

NTIS order \#PB88-229539

. Trade Adjustment Assistance: New Ideas for an Old Program

OTA-ITE-346, June 1987; 80p.

NTIS order \#PB87-203741

NOTE: Reports are available from the U.S. Government Printing Office, Superintendent of Documents, Dept. 33; Washington, DC 20402-9325, (202) 783-3238; and/or the National Technical Information Service, 5285 Port Royal Road, Springfield, VA 22161-0001, (703) 487-4650. 